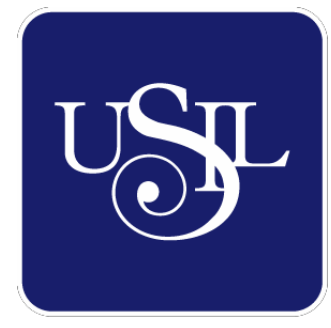

UNIVERSIDAD

SAN IGNACIO

DE LOYOLA

ESCUELA DE POSTGRADO

\title{
PLAN DE NEGOCIOS PARA LA PRODUCCIÓN DE MACERADOS DE FRUTAS EN PISCO EN LIMA METROPOLITANA PARA EL 2018
}

Trabajo de Investigación para optar el grado de:

CARLOS ALBERTO BRICEÑO DÍAZ

Maestro en Ciencias Empresariales con Mención en Gestión de Proyectos

GUISELLE RUTH JIMÉNEZ ESCALANTE

Maestro en Ciencias Empresariales con Mención en Gestión del

Capital Humano

\section{JOSELYN DELIA TELLO SIERRA}

Maestro en Ciencias Empresariales con Mención en Gestión del Capital Humano

Asesor:

Nidia Ruth Vílchez Yucra

$$
\text { Lima - Perú }
$$

2018 


\section{Tabla de contenido}

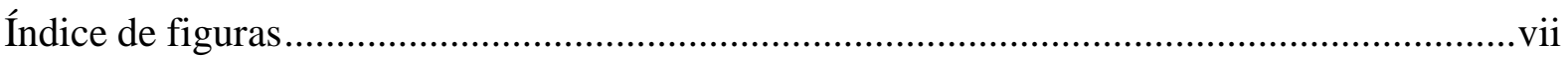

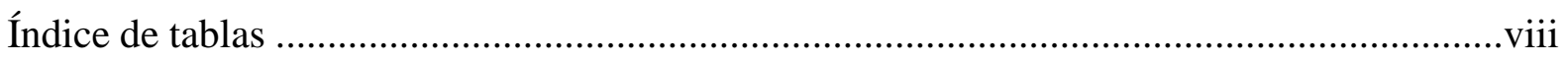

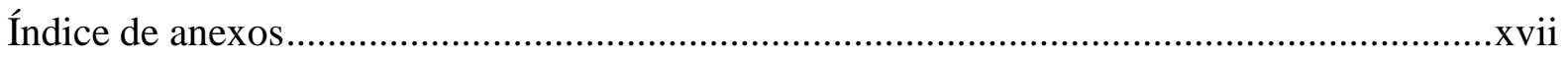

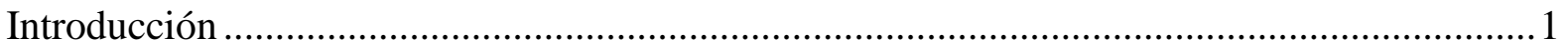

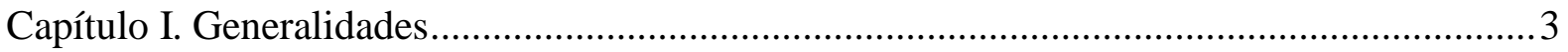

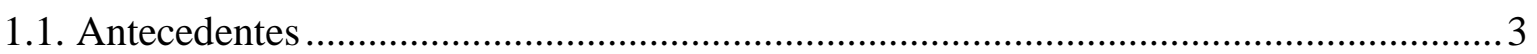

1.2. Determinación de la oportunidad ......................................................................... 7

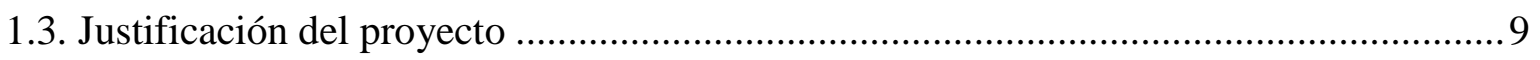

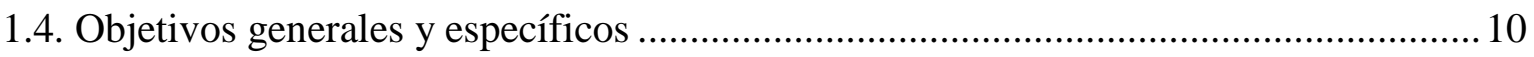

1.5. Alcances y limitaciones de la investigación ............................................................. 11

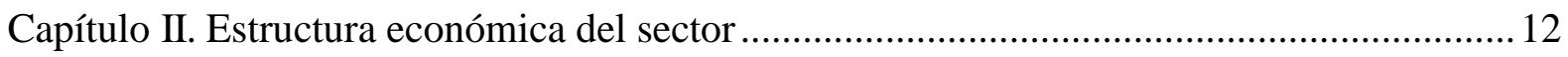

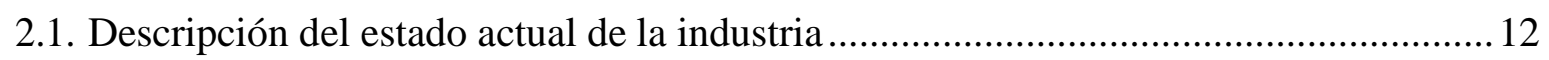

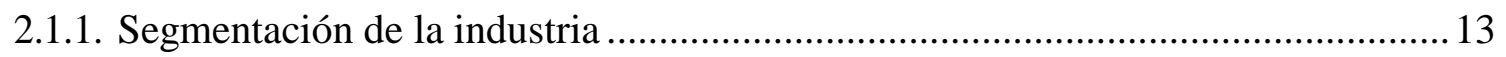

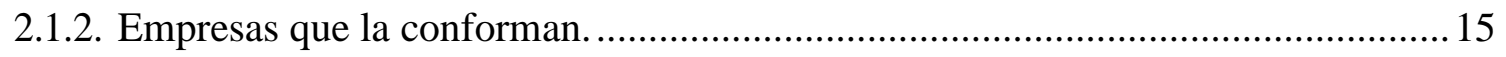

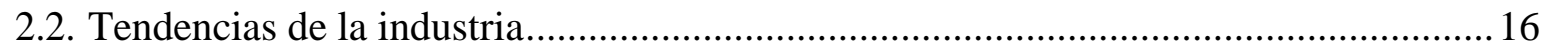

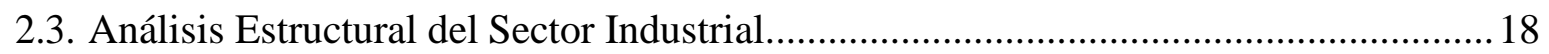

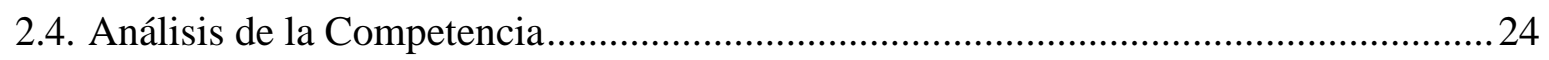

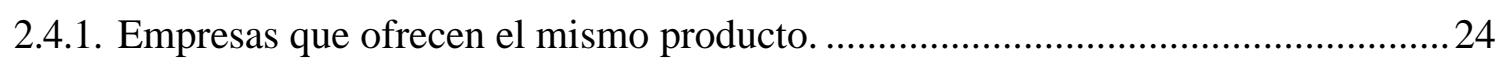

2.4.2. Participación de mercado de cada uno de ellos. .................................................. 27

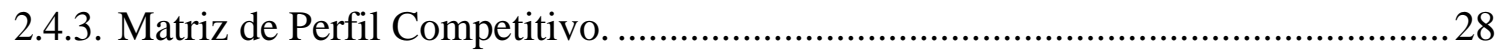

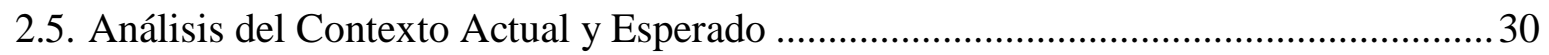

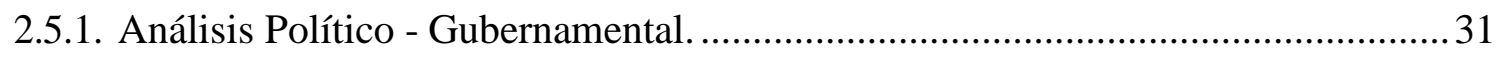

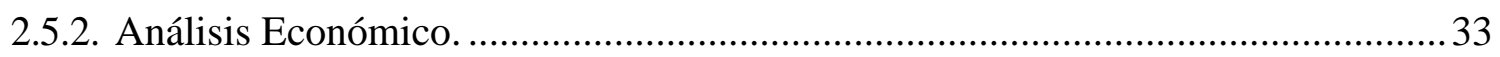




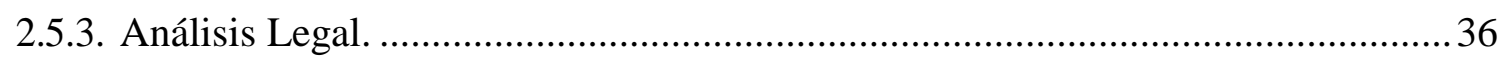

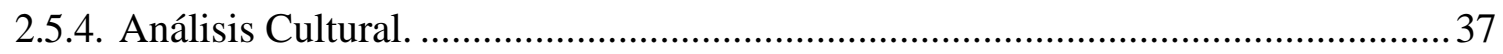

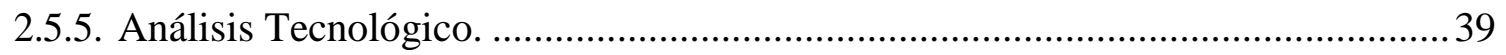

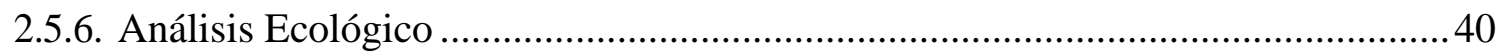

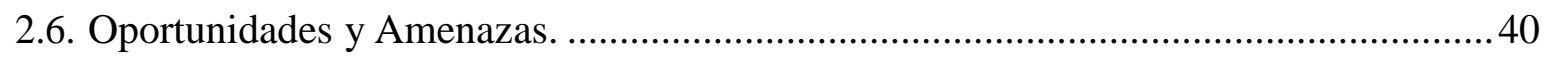

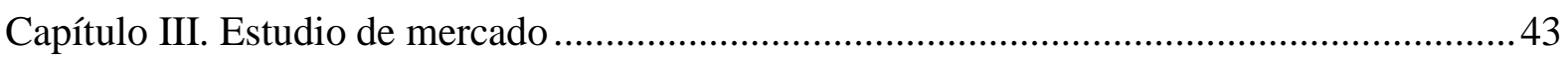

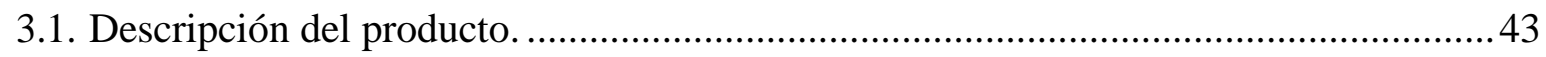

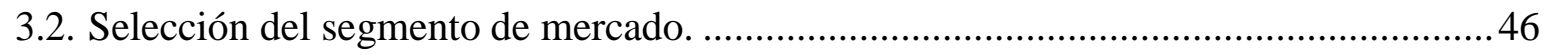

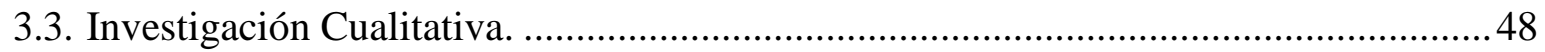

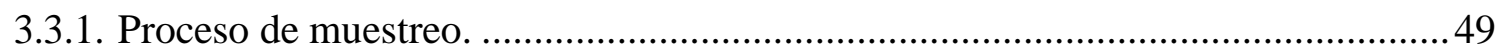

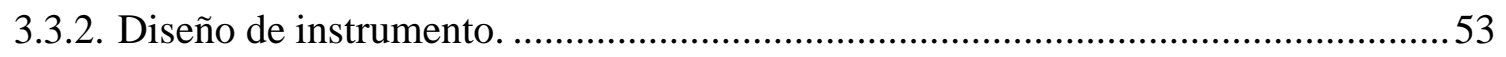

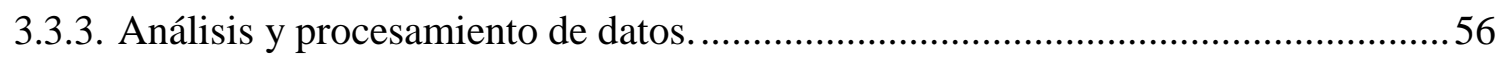

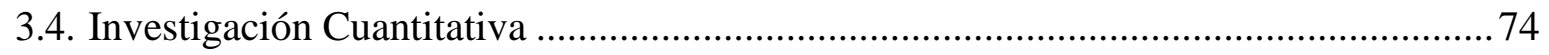

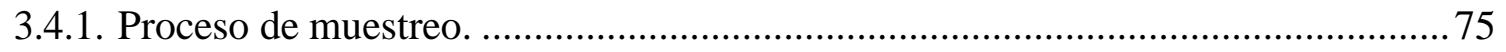

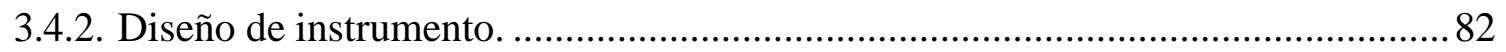

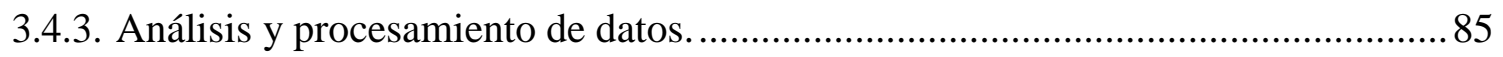

3.5. Conclusiones y recomendaciones del Estudio Cualitativo y Cuantitativo.....................93

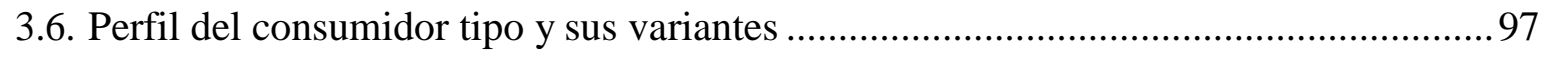

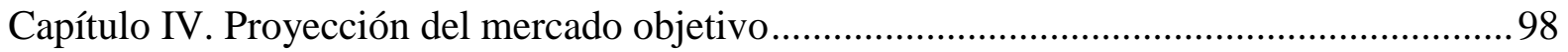

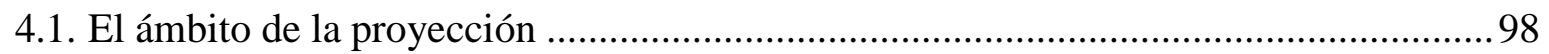

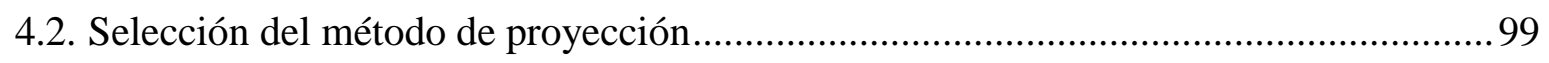

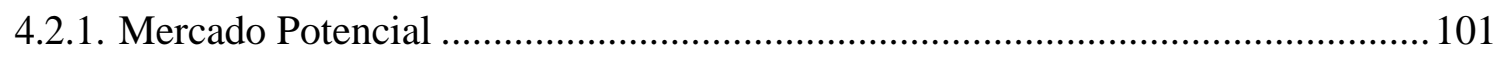

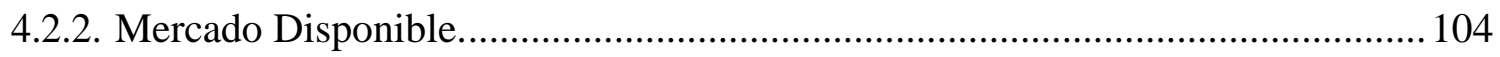

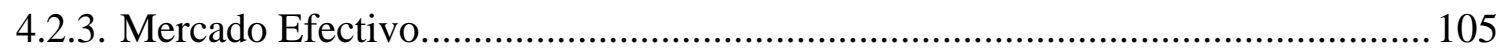

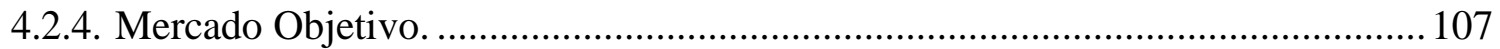


4.3. Pronóstico de Ventas....................................................................................................111

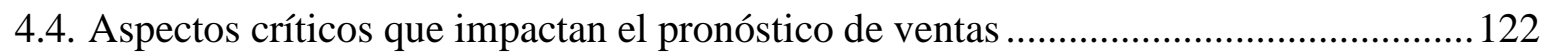

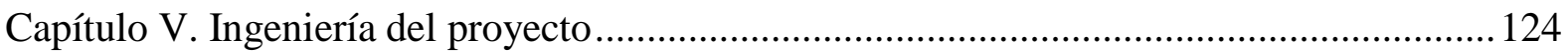

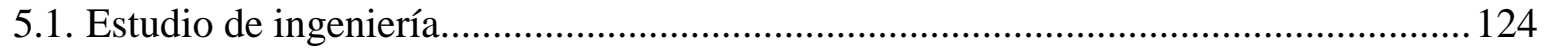

5.1.1. Modelamiento y selección e procesos productivos........................................... 125

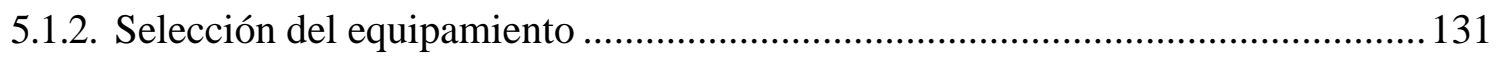

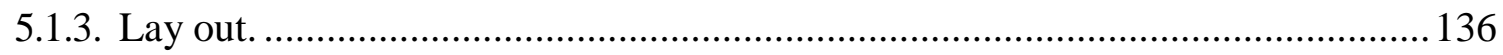

5.1.4. Distribución de equipos y maquinarias.............................................................. 138

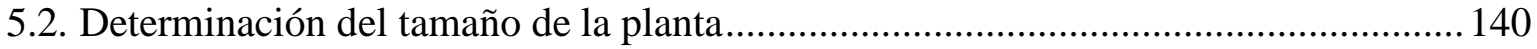

5.2.1. Proyección de crecimiento.............................................................................. 140

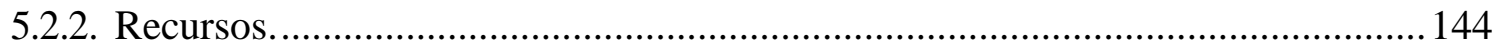

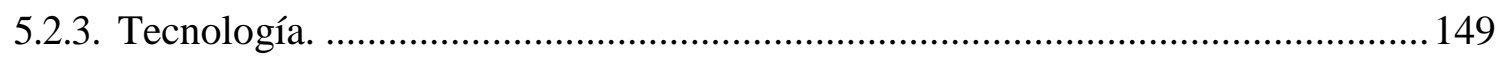

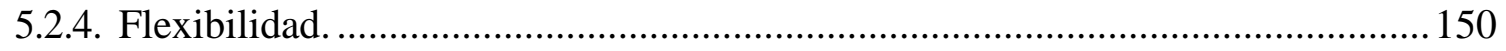

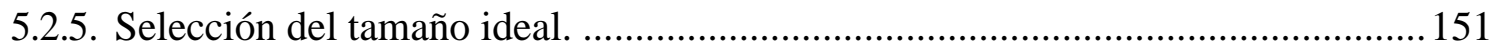

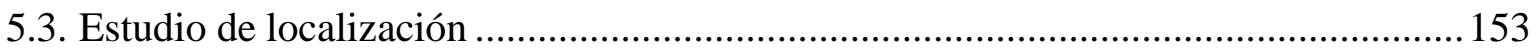

5.3.1. Definición de factores locacionales. ................................................................. 159

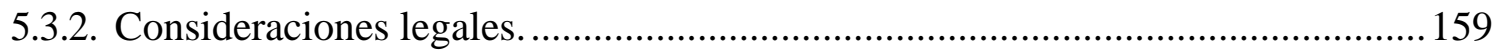

5.3.2.1. Identificación del marco legal........................................................................ 159

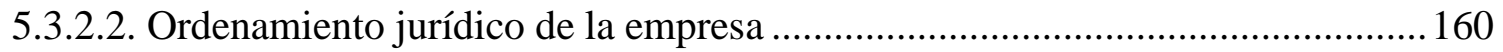

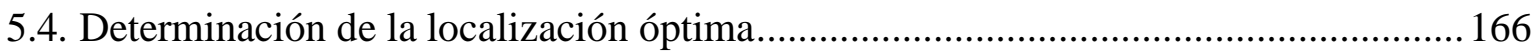

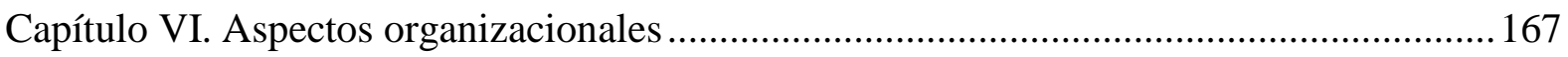

6.1. Caracterización de la cultura organizacional deseada........................................... 167

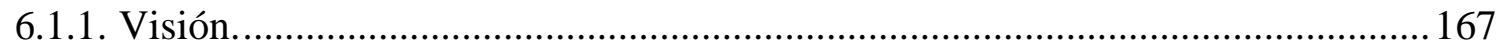

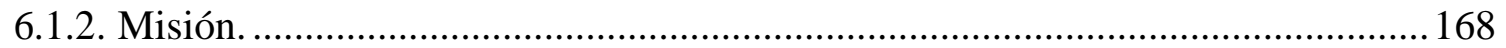

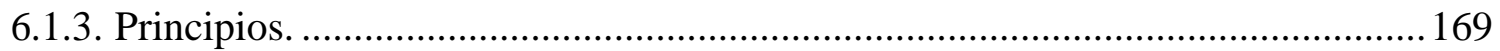


6.2. Formulación de Estrategias del Negocio ................................................................ 170

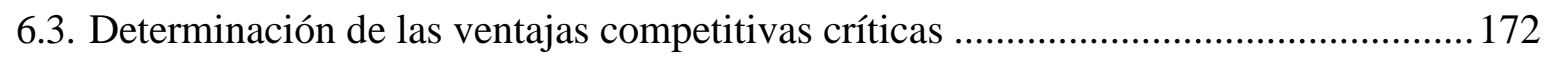

6.4. Diseño de la estructura organizacional deseada................................................... 173

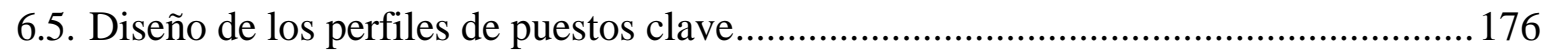

6.6. Remuneraciones, compensaciones e incentivos ................................................... 188

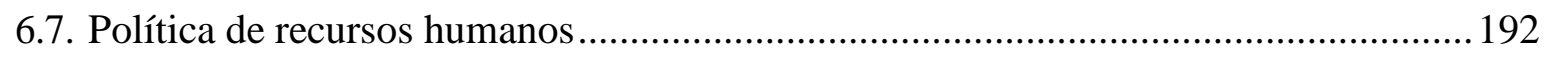

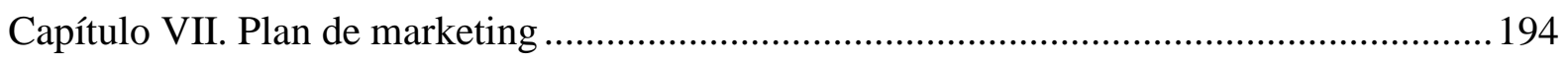

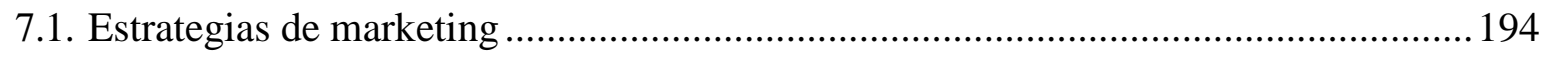

7.1.1. Estrategia de Producto. ................................................................................... 194

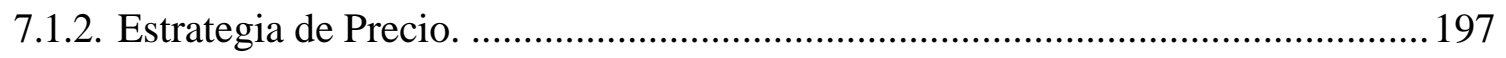

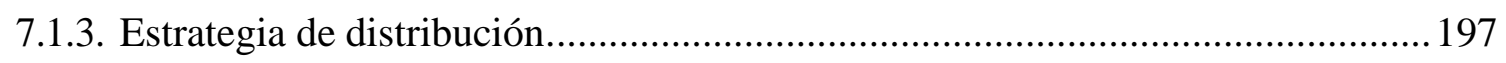

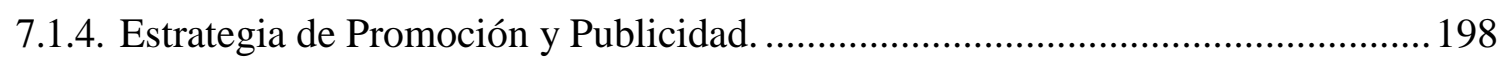

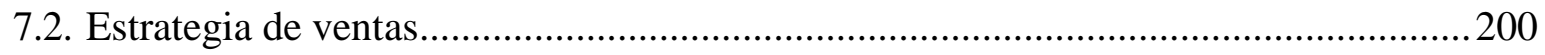

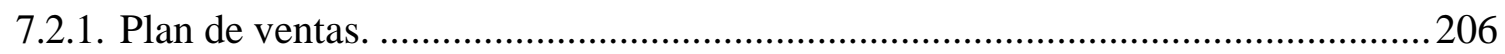

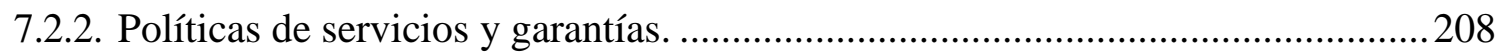

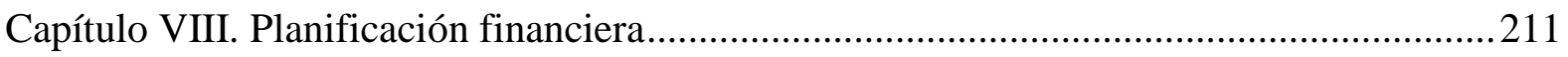

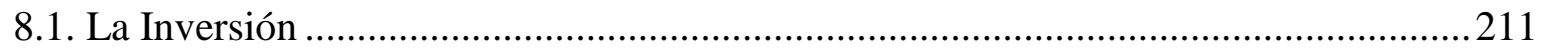

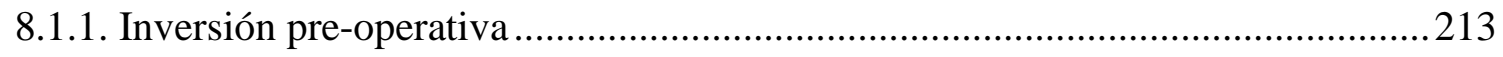

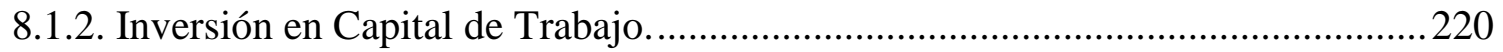

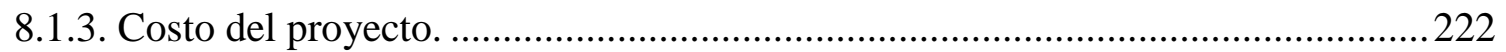

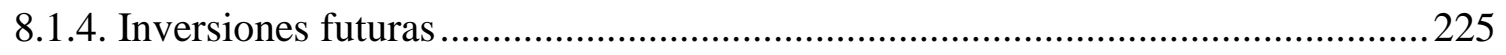

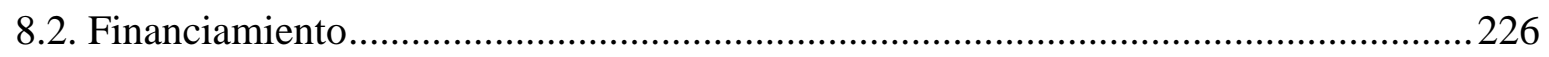

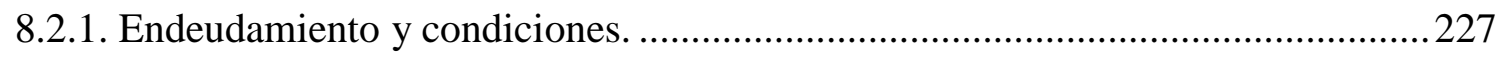

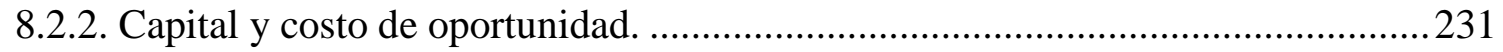

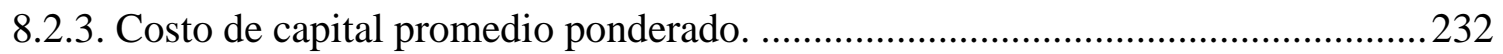




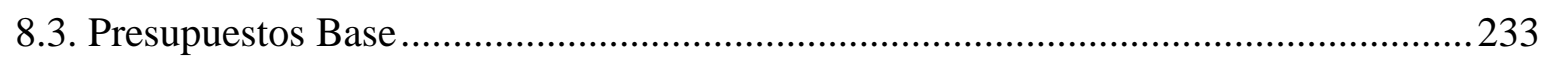

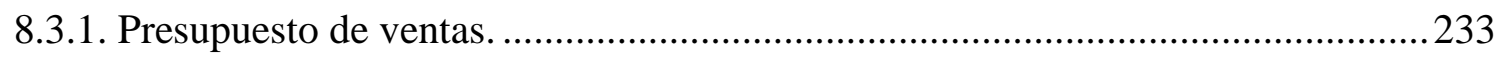

8.3.2. Presupuesto de costo de producción. ..................................................................2. 235

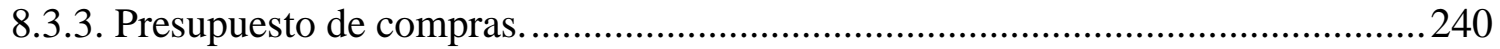

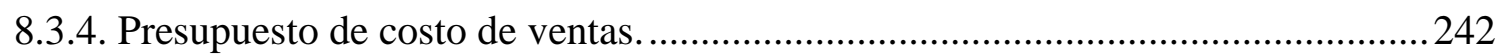

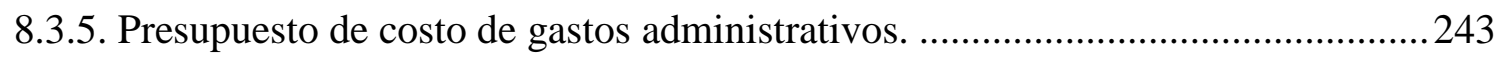

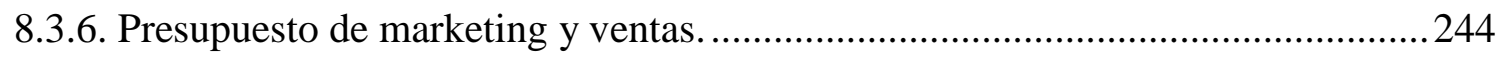

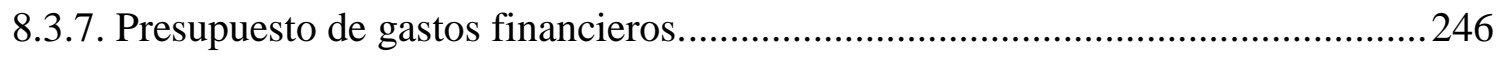

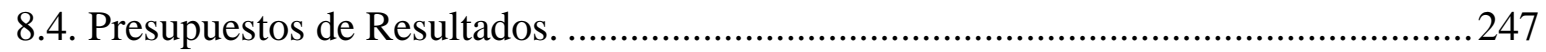

8.4.1. Estado de ganancias y pérdidas proyectado....................................................2 247

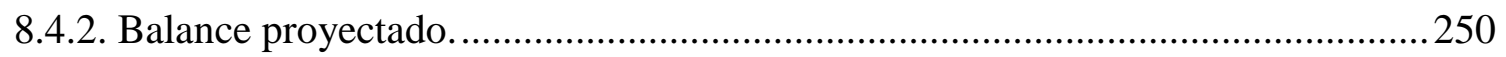

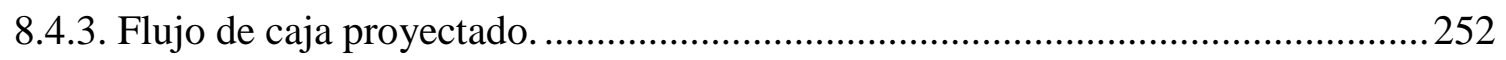

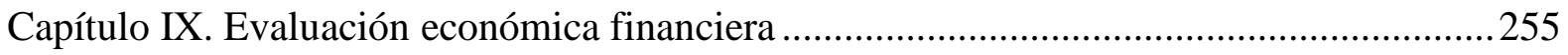

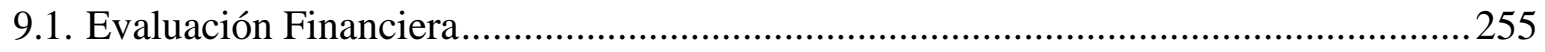

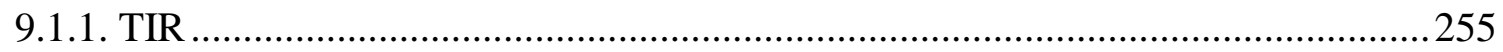

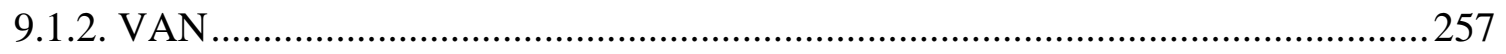

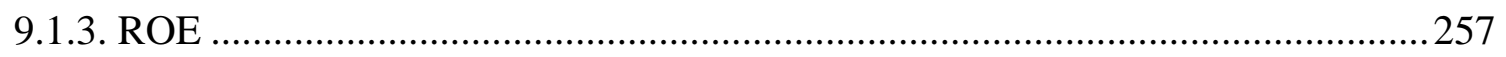

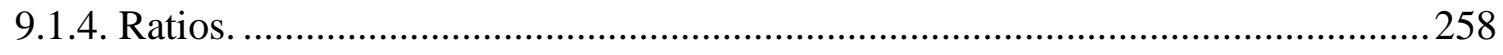

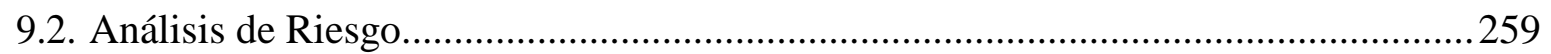

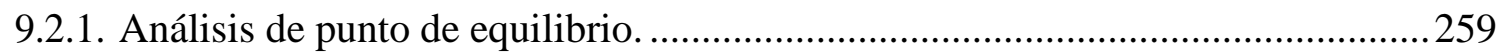

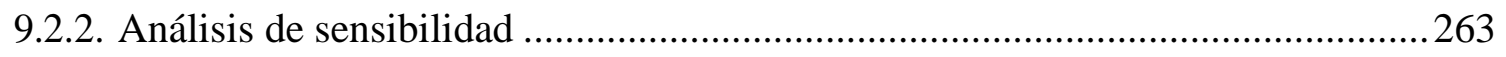

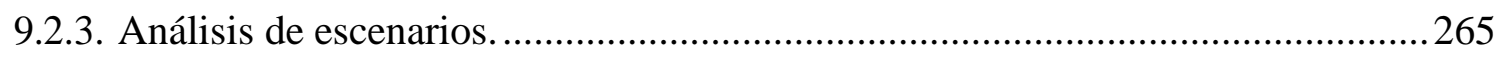

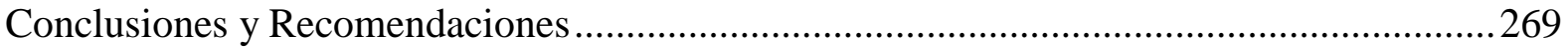

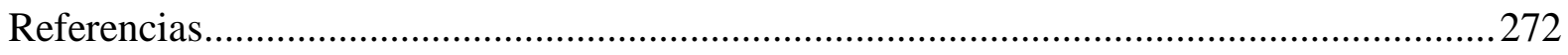

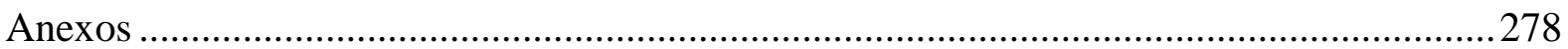




\section{Índice de figuras}

Figura 1. Porcentaje de exportación año 2017 ........................................................................ 4

Figura 2. Producción de pisco en litros............................................................................... 4

Figura 3. Porcentaje de exportación por bodega................................................................ 15

Figura 4. Participación de empresas formales e informales en Macerados de frutas en pisco 27

Figura 5. Consumo per Cápita de Bebidas alcohólicas en América Latina según país ........... 31

Figura 6. Producto Bruto Interno - Variación \% ……............................................................. 34

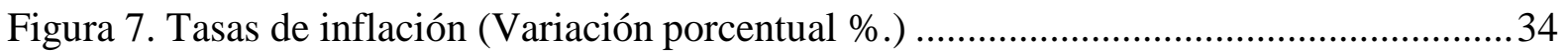

Figura 8. Consumo interno de pisco estimado del 2012 al 2016 ....................................... 108

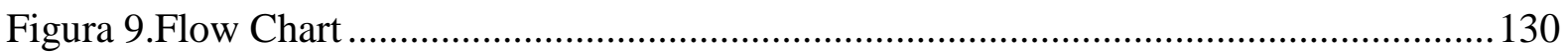

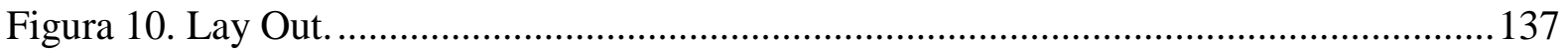

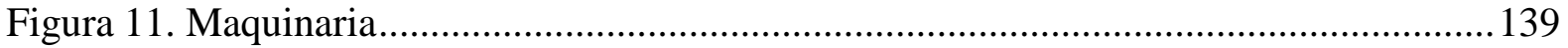

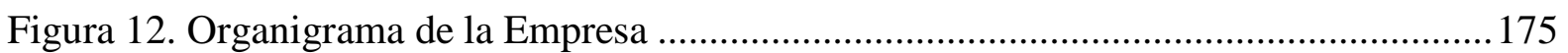

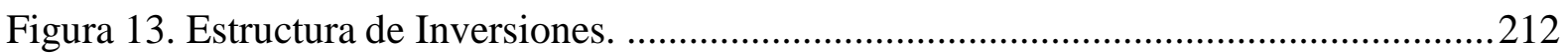




\section{Índice de tablas}

Tabla 1 Crecimiento de Empresas Productoras de Pisco por Provincias................................. 14

Tabla 2 Distribución de Empresas por tipo de Pisco Producido.............................................. 14

Tabla 3 Consumo de bebidas alcohólicas en Perú (por litros)...............................................22

Tabla 4 Resumen de las Cinco Fuerzas de Porter...................................................................23

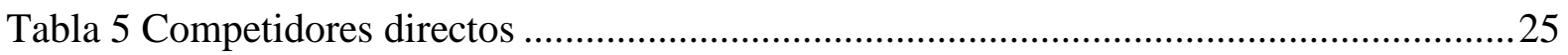

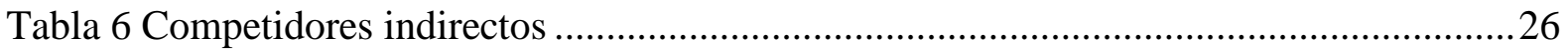

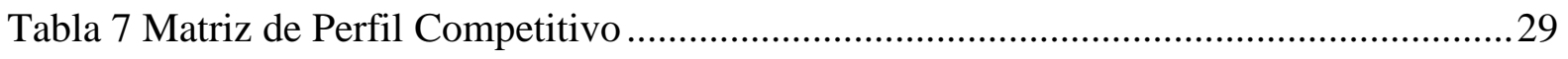

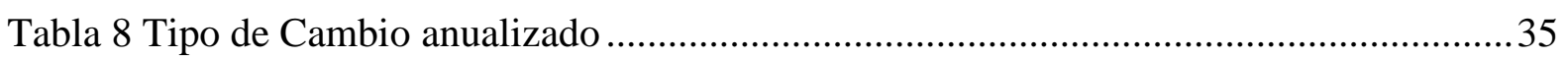

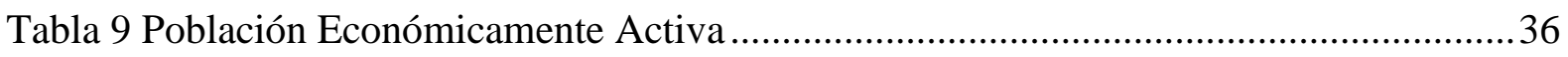

Tabla 10 Matriz de Evaluación de los Factores Externos.................................................... 41

Tabla 11 Producto: Macerados de frutas en pisco. ........................................................... 45

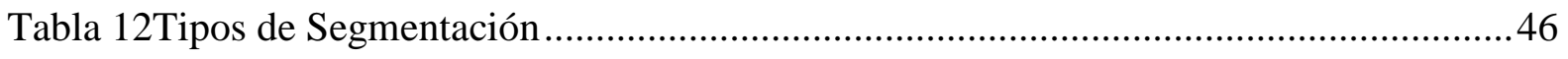

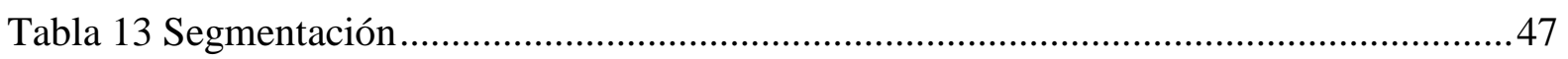

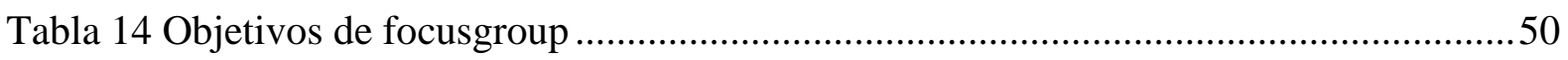

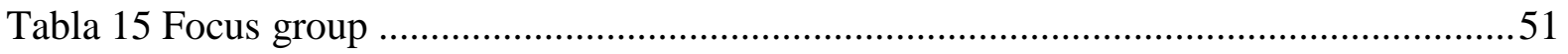

Tabla 16 Objetivos de las entrevistas a profundidad ........................................................52

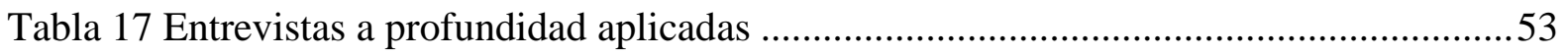

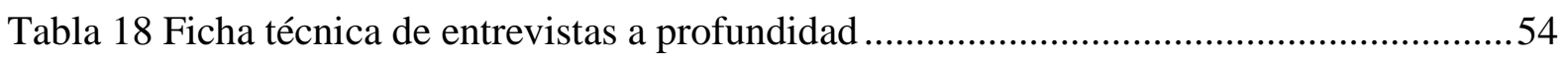

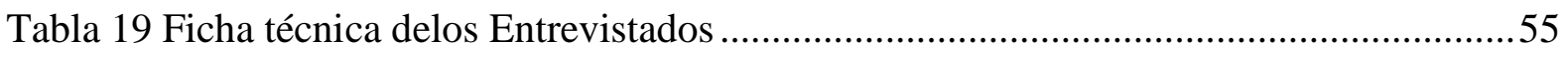

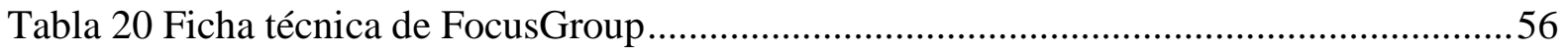

Tabla 21 Entrevistas a profundidad Conocimiento del mercado ........................................67

Tabla 22 Entrevistas a profundidad Estratégico y Comercial..............................................69

Tabla 23 Entrevistas a profundidad Administrativo, Operativo, Comercial y Logístico ........70

Tabla 24 Entrevistas a profundidad Operativo, Comercial y Logístico.................................. 72 


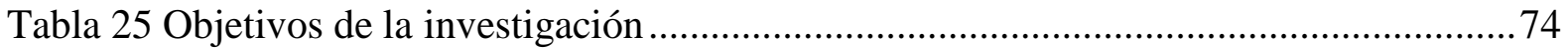

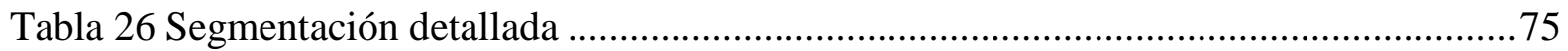

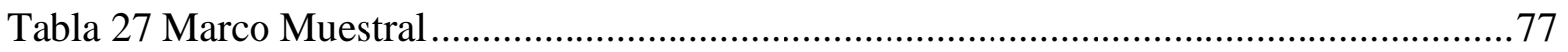

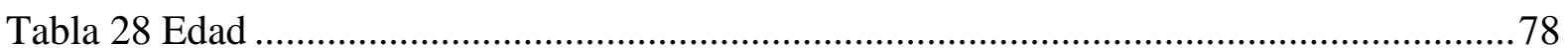

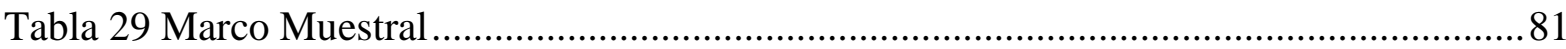

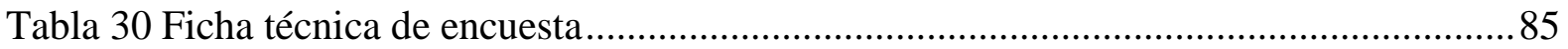

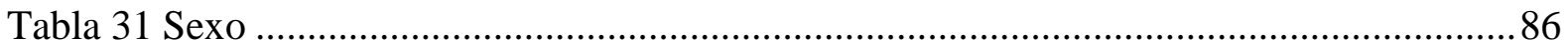

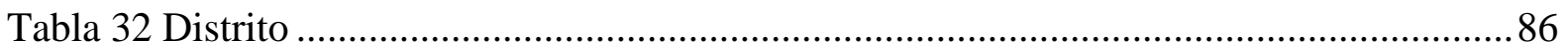

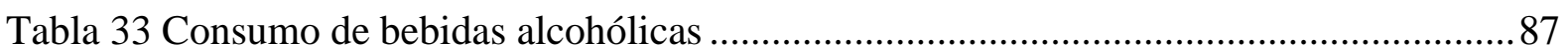

Tabla 34 Frecuencia de consumo de bebidas alcohólicas...................................................... 87

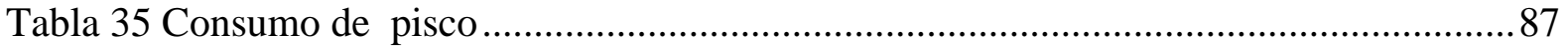

Tabla 36 Experiencia con macerados de frutas en pisco .................................................. 88

Tabla 37 Conocimiento de marcas de macerados de frutas en pisco...................................... 88

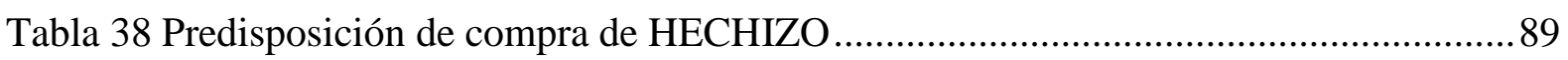

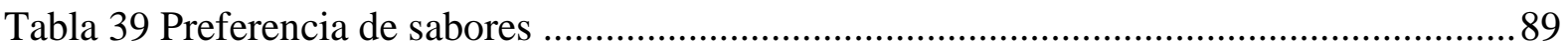

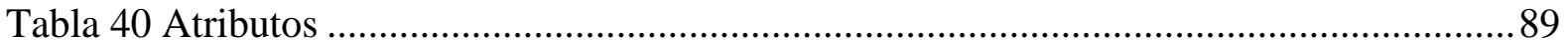

Tabla 41 Frecuencia de compra de HECHIZO .................................................................... 90

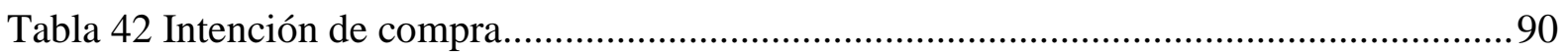

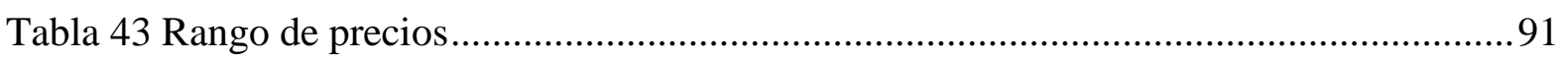

Tabla 44 Preferencia de consumo de HECHIZO ...............................................................92

Tabla 45 Estacionalidad de consumo de HECHIZO ........................................................... 92

Tabla 46 Preferencia de lugar de compra de HECHIZO ......................................................93

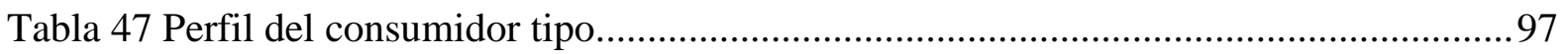

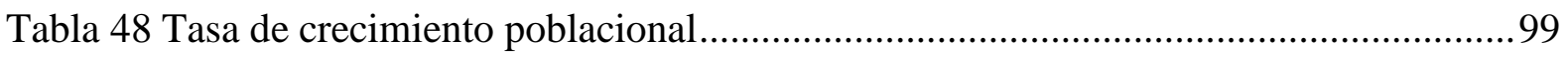

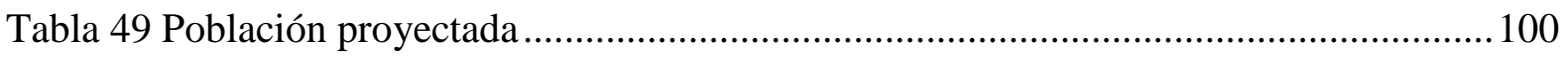


Tabla 50 Mercado Potencial (Porcentaje de personas del total de la población). 102

Tabla 51 Mercado Potencial (personas) 103

Tabla 52 Consumo de bebidas alcohólicas 104

Tabla 53 Consumo de pisco 104

Tabla 54 Mercado Disponible (Número de personas) 105

Tabla 55 Predisposición de compra de HECHIZO. 106

Tabla 56 Rango de precios. 106

Tabla 57 Mercado Efectivo en personas 107

Tabla 58 Producción y Consumo interno estimado de Pisco en Perú 107

Tabla 59 Demanda estimada 108

Tabla 60 Variación de crecimiento de tasa promedio 108

Tabla 61 Proyección del crecimiento del mercado 109

Tabla 62 Potenciales competidores 109

Tabla 63 Participación y crecimiento de mercado 109

Tabla 64 Mercado objetivo (Personas) 110

Tabla 65 Mercado Objetivo resumen 110

Tabla 66 Demanda vs Capacidad de producción (unidades) 110

Tabla 67 Frecuencia de compra de HECHIZO? .

Tabla 68 Intención de compra

Tabla 69 Adquisición de botella

Tabla 70 Demanda Anual (unidades)

Tabla 71 Preferencia de lugar de compra de HECHIZO

Tabla 72 Preferencia de canal

Tabla 73 Preferencia de sabor.

Tabla 74 Demanda anual (Unidades) 


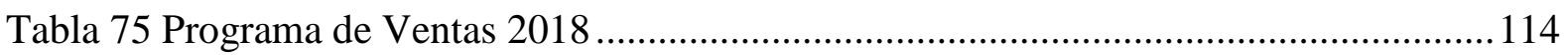

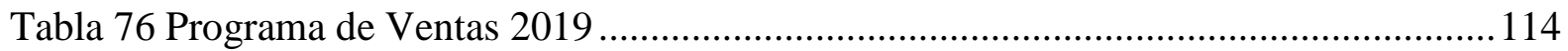

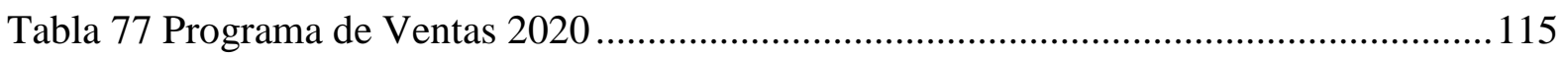

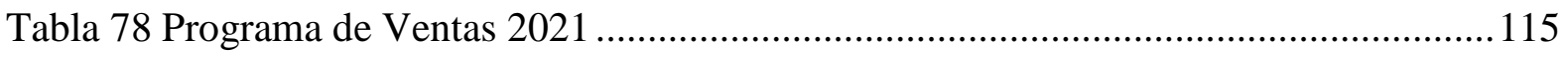

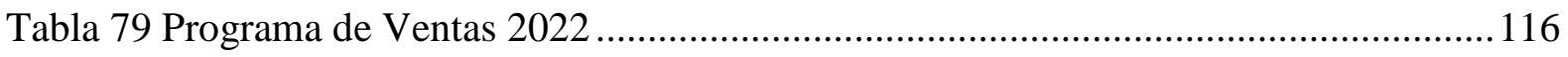

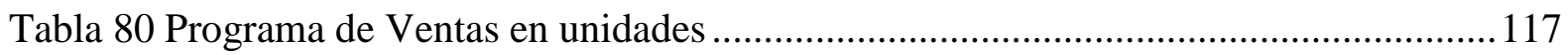

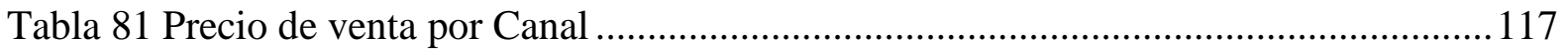

Tabla 82 Programa de Ventas anual 2018 Soles.............................................................. 119

Tabla 83 Programa de Ventas anual 2019 Soles............................................................... 119

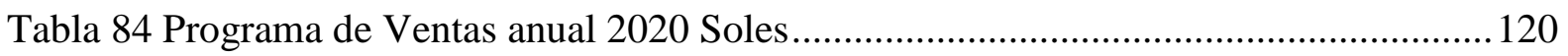

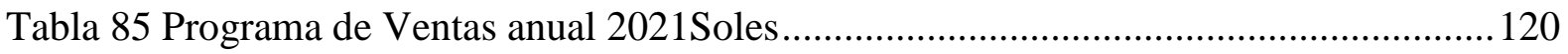

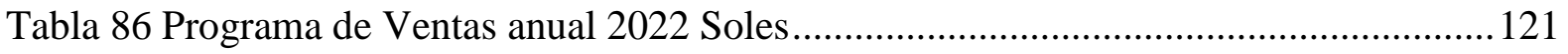

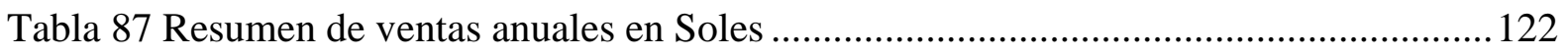

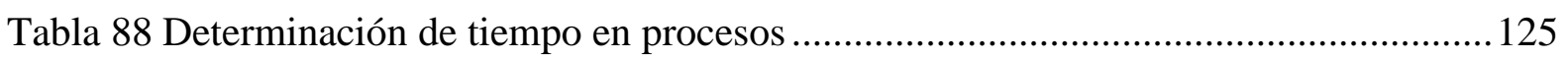

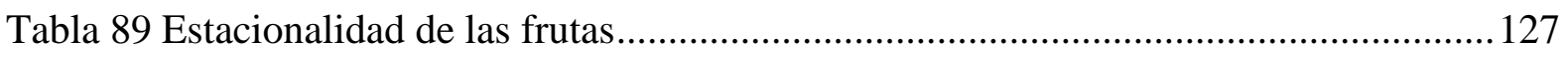

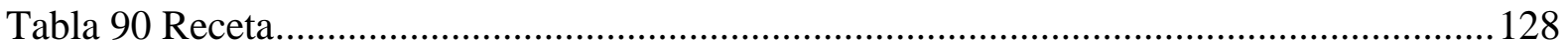

Tabla 91 Abastecimientos de insumos y Almacenamiento de equipos ...............................132

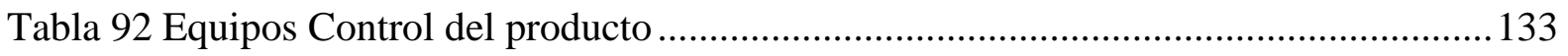

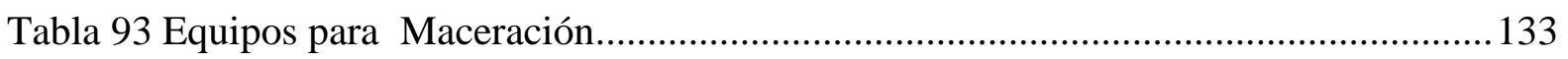

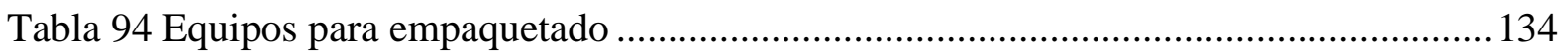

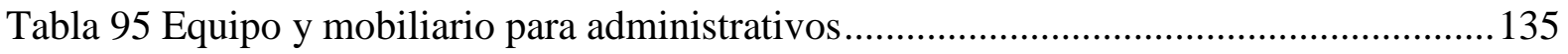

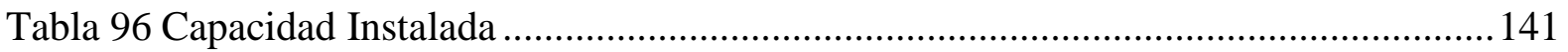

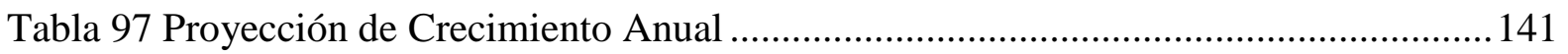

Tabla 98 Programa de Producción Proyectado .................................................................. 143

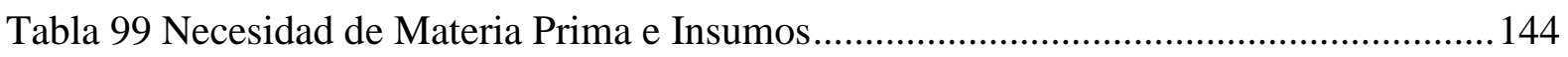


Tabla 100 Requerimiento de Personal 145

Tabla 101 Demanda Estimada de Mercado 146

Tabla 102 Precio de Pisco Utilizado 147

Tabla 103 Producción de Frutas por Región en el Perú (2015) en Toneladas 147

Tabla 104 Precios de Frutas por Kilogramo 148

Tabla 105 Precios de Insumos 149

Tabla 106 Precios de Botellas y Tapones

Tabla 107 Escenario Ideal de Producción. 151

Tabla 108 EscenarioÓptimo de Producción 152

Tabla 109 Escenario Real de Producción 152

Tabla 110 Requerimiento anual de tanques de maceración en función a la producción 153

Tabla 111 Porcentaje de Utilización en botellas.

Tabla 112 Macrolocalización 155

Tabla 113 Microlocalización 158

Tabla 114 División de las acciones. 161

Tabla 115 Visión 168

Tabla 116 Misión 168

Tabla 117 Estrategias de Negocio. 170

Tabla 118 Palancas de acción 172

Tabla 119 Matriz de evaluación de factores internos

Tabla 120 Requerimiento de personal 176

Tabla 121 Estructura Salarial por Puesto...

Tabla 122 Kit de bienvenida

Tabla 123 Política de mejora de clima laboral 193

Tabla 124 Clima laboral. 193 
Tabla 125 Macerados de frutas en pisco 196

Tabla 126 Proceso de toma de decisión 201

Tabla 127 Acciones para la estrategia 1 .202

Tabla 128 Acciones para la estratega 2 .202

Tabla 129 Acciones para el logro de objetivos de estrategia 1. .203

Tabla 130 Acciones para el logro de objtivos de estrategia 2 .203

Tabla 131 Acciones para resolución de temores de estrategia 1 203

Tabla 132 Acciones de resolución de temores de estrategia 2 204

Tabla 133 Decisión de compra estrategia 1 204

Tabla 134 Decisión de compra estrategia 2 205

Tabla 135 Implementaciòn estrategia 1 205

Tabla 136 Implementaciòn estrategia 2 206

Tabla 137 Plan de ventas estrategia 1 206

Tabla 138 Estacionalidad 206

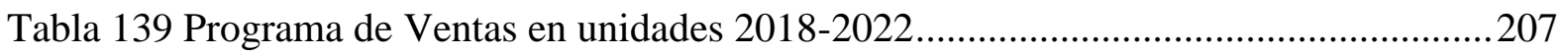

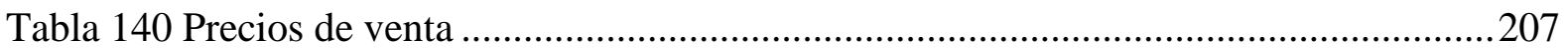

Tabla 141 Resumen de Ventas en Soles 2018-2022 .......................................................208

Tabla 142 Distribución de la Inversión 212

Tabla 143 Distribución de la Inversión en porcentaje

Tabla 144 Inversión en Pre-Operativos (Nov-Dic). 215

Tabla 145 InversiónPre Operativa - Bienes no Depreciables 216

Tabla 146 InversiónActivos fijos - Año Cero 217

Tabla 147 InversiónIntangibles 218

Tabla 148 Inversiónen Otros Intangibles..... 219

Tabla 149 Inversión en Capital de Trabajo Anual 221 
Tabla 150 Costos de Producción Unitarios .223

Tabla 151 Margen Unitario .224

Tabla 152 Costos Fijos y Variables .224

Tabla 153 Costos Fijos y Variables - Margen de contribución .225

Tabla 154 Inversiones Futuras 226

Tabla 155 Estructura de Inversión 227

Tabla 156 Estructura de Financiamiento 227

Tabla 157 Aporte de cada socio .227

Tabla 158 Porcentaje Tasas de interés anuales 228

Tabla 159 Cronograma de pagos préstamo de Activos Fijos 228

Tabla 160 Resumen de amortización para Activo fijo. 229

Tabla 161 Tasas de interés anual 229

Tabla 162 Cronograma de pagos préstamo Capital de Trabajo 230

Tabla 163 Resumen de pago de Capital de Trabajo. 230

Tabla 164 COK - Modelo CAPM .231

Tabla 165 Costo de la deuda .232

Tabla 166 Costo Promedio Ponderado de Capital (WACC) 233

Tabla 167 Programa de venta de botellas 234

Tabla 168 Precio por canal 234

Tabla 169 Programa de ventas en Soles 235

Tabla 170 Proyección de producción en botellas 235

Tabla 171 Variables para la proyección. 236

Tabla 172 Presupuesto de compra de Materia prima por año 236

Tabla 173 Presupuesto de compra de Materia prima por año (Unidades) 237

Tabla 174 Costo de Materia Prima (Soles) por Producto 238 
Tabla 175 Costo de Producción Promedio..... .239

Tabla 176 Mano de obra .240

Tabla 177 Resumen de compras ...... .241

Tabla 178 Costo de materia prima (Soles) 242

Tabla 179 Costo de mano de obra directa 242

Tabla 180 Resumen de gastos administrativos

Tabla 181 Resumen de marketing y ventas 245

Tabla 182 Cronograma de financiamiento Prestamos Activos..... 246

Tabla 183 Cronograma de financiamiento Capital de trabajo 246

Tabla 184 Cronograma de financiamiento Deuda Total 247

Tabla 185 Estado de Resultados Integrados 248

Tabla 186 Cálculo de impuesto a la renta 248

Tabla 187 Estado de Resultados Integrados- Incluye gastos Financieros 249

Tabla 188 Cálculo del impuesto a la renta..... 249

Tabla 189 Balance de Situación Financiera Proyectado 251

Tabla 190 Flujo de Caja Proyectado .253

Tabla 191 Módulo de IGV 254

Tabla 192 TIR Económico 256

Tabla 193 TIR Financiero 256

Tabla 194 Van Económico. 257

Tabla 195 Van Financiero. 257

Tabla 196 Resultados ROE 258

Tabla 197 Ratios de Rentabilidad. 259

Tabla 198 Ratios de Endeudamiento 259

Tabla 199 Distribución por sabor 260 
Tabla 200 Punto de Equilibrio .261

Tabla 201 Estado de Resultados (Punto de Equilibrio) .........................................................262

Tabla 202 Análisis de Sensibilidad Unidimensional - Precios ............................................263

Tabla 203 Análisis de Sensibilidad Unidimensional - Cantidad ...........................................263

Tabla 204 Análisis de Sensibilidad Unidimensional - Materia Prima ...................................264

Tabla 205 Análisis de Sensibilidad Unidimensional - Costos de personal ...........................265

Tabla 206 Análisis de sensibilidad multidimensional .........................................................266

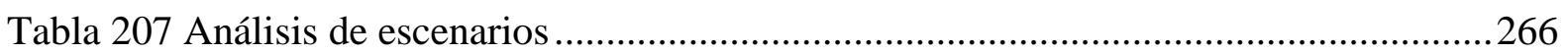

Tabla 208 Matriz de probabilidad e impacto para riesgos negativos o amenazas .................267

Tabla 209 Matriz de probabilidad e impacto para riesgos positivos u oportunidades ...........268 


\section{Índice de anexos}

Anexo 1 - Presentación HECHIZO (macerados de frutas en pisco) .....................................2278

Anexo 2 - Cuestionario de Entrevista a Profundidad - Sarcay y Bailetti .............................2279

Anexo 3 - Cuestionario de Entrevista a profundidad -Juan Carlos Mathews ........................280

Anexo 4 - Cuestionario de Entrevista a profundidad - Productores artesanales ...................281

Anexo 5 - Cuestionario de Entrevista a profundidad - Sommelier ......................................282

Anexo 6 - Transcripción de Entrevista a profundidad a Sarcay ..........................................283

Anexo 7 - Transcripción de Entrevista a profundidad a Gerente de Bodega Bailetti ............285

Anexo 8 - Transcripción de Entrevista a profundidad a Ex Viceministro de Mype ...............287

Anexo 9 - Transcripción de Entrevista a profundidad a Productor de Macerados ................289

Anexo 10 - Transcripción de Entrevista a profundidad a Productor de Macerados ..............291

Anexo 11 - Transcripción de Entrevista a profundidad a Sommelier....................................293

Anexo 12 - Guía de pautas para Focus Group .....................................................................2 295

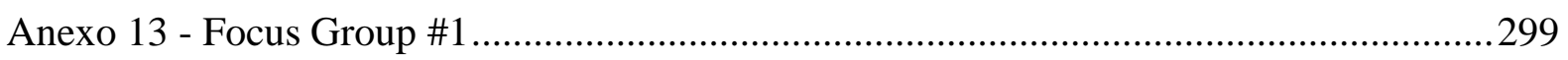

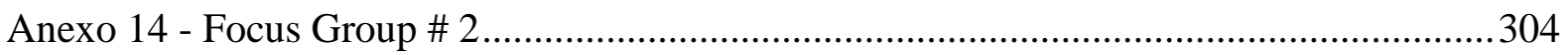

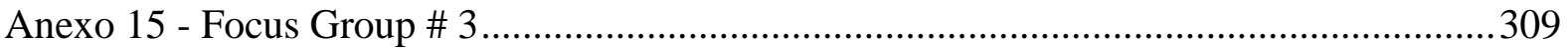

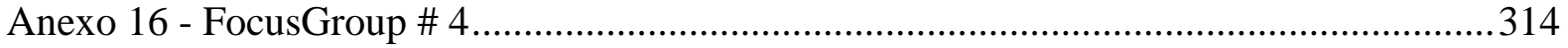

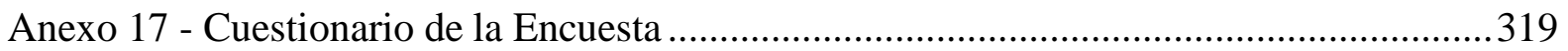

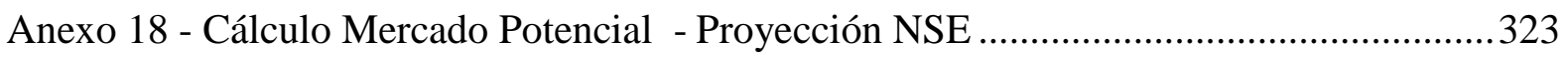

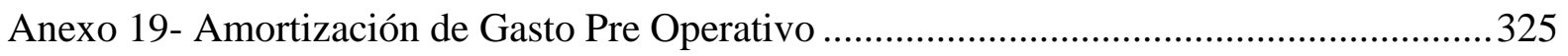

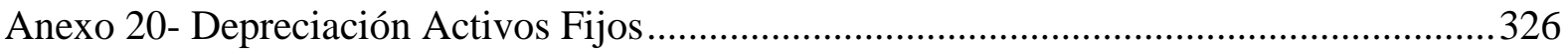

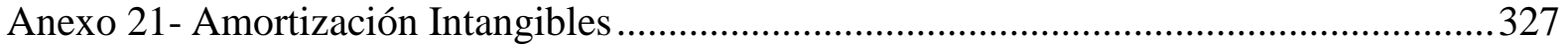

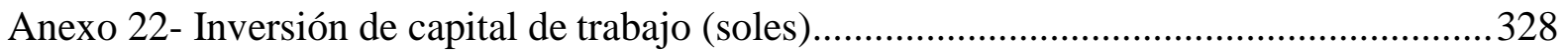

Anexo 23- Inversión en Capital de Trabajo Egresos en Materiales y Personal......................329

Anexo 24 - Capital de Trabajo: Egresos en Servicios ...................................................... 330 
Anexo 25 - Capital de Trabajo: Egresos en Impuestos y Préstamo

Anexo 26 - Costos: Costo variable y fijos

Anexo 27 - Detalle de Gastos Administrativos.

Anexo 28 - Detalle de Gastos Ventas 338

Anexo 29 - Costos de Producción: Maracuyá y frambuesa. 340

Anexo 30 - Costos de Producción: Fresa y Guinda 341

Anexo 31 - Costos de Producción: Chicha 342

Anexo 32 - Cotizaciones 


\section{Introducción}

La producción de pisco a nivel nacional se ha visto incrementada en promedio en $8 \%$ anualmente (Estadísticas, CONAPISCO, 2015). Además, ser declarado como producto bandera, la controversia con Chile, la creación del día del pisco sour, del día del chilcano y toda esta promoción,hace que los peruanos aprecien más el pisco y apuestan por lo nacional, debido a que el patriotismo en esta época se ha incrementado (¡Salud! El consumo interno, ElComercio.pe, 2014). Aprovechando esta coyuntura es que este estudio buscó proponer una nueva alternativa de consumo de pisco a través de un derivado. Se observó que en la industria de macerados de frutas en pisco hay muy pocos competidores industrializados y que la mayoría son productores artesanales.

A continuación se detalla el contenido de cada capítulo del presente plan de negocios. En el capítulo I y II se trató generalidades, análisis de la industria, segmentación, competidores, objetivos generales y específicos que se querían lograr con la investigación y análisis PESTEL de la industria.

En el capítulo III, IV y V, se desarrolló la propuesta del producto: macerados de frutas en pisco. También ayudó a medir la aceptación de los macerados de frutas en pisco. A través del estudio de mercado, se buscó información sobre buenas prácticas en la producción y las preferencias de los consumidores. Con los resultados obtenidos se definió la demanda y con ello se proyectaron las ventas, el tamaño ideal del proyecto, la localización, la maquinaria a usar, el requerimiento en recursos humanos y de materia prima.

En cuanto a los aspectos organizacionales explicados en el capítulo VI, se enfocó en plantear la estrategia para ser sostenible en el tiempo. En el capítulo VII, se enfocó en plan de marketing, en cuanto a productola estrategia escogida fue de enfoque por diferenciación, con relación a precio la estrategia fue de descreme, la estrategia de distribución elegida fue directa para los compradores por web y tercerizada para los puntos de venta y la de 
promoción below the line. La estrategia de ventas se basó en el ciclo de la decisión de compra del cliente aprovechando la estacionalidad en épocas festivas.

La información de los capítulos VIII y IX, se analizaron los aspectos financieros y el estudio arrojó como resultado la rentabilidad del proyecto. Se simularon distintos escenarios que dieron como resultado el éxito del negocio ya que la probabilidad de fracaso era de $15.72 \%$. Se sustentó estos resultados ya que el VAN obtenido fue positivo (S/.235,972) y el TIRE tuvo un resultado de $48.34 \%$ y el WACC el $28.90 \%$. 


\section{Capítulo I. Generalidades}

En este capítulo se explican los antecedentes, problemas, objetivos generales y específicos del Plan de Negocios. Asimismo, expresan los alcances y limitaciones para la producción de macerados de frutas en pisco en Lima Metropolitana para el 2018.

En este capítulo se utilizó la información sobre el mercado, proveedores, en donde conseguir información y leyes que obtuvimos de la entrevista a profunidad realizada al Sr Juan Carlos Mathews (Ver tabla 22 y Anexo \# 8).

\subsection{Antecedentes}

En Perú, el pisco es reconocido y consumido por la mayoría de los ciudadanos, además de ser conocido y denominado como producto bandera. Su nombre es de origen quechua y se obtiene de la destilación de uvas fermentadas. Para poder denominarse Pisco, este debe ser producido con uvas de las ciudades de Lima, Ica, Arequipa, Moquegua y Tacna (Valles de Locumba y Caplina) (Harrell, 2009). Existen 400 bodegas de pisco que producen más de 3,5 millones de litros de pisco anual, de las cuales solo cinco cuentan con una mayor producción industrial como Santiago Queirolo, Tabernero y Ocucaje, aumentando así el consumo interno en un 15\% anual (;Salud! El consumo interno, ElComercio.pe, 2014). En la producción total, aproximadamente entre un $40 \%$ y $50 \%$ es destinado a la exportación, es decir que 1,5 millones de litros mueven un aproximado de US\$ 5 millones en envíos de la bebida bandera. Actualmente, como se aprecia en la figura 1, los principales destinos de exportación son Estados Unidos, Chile, Alemania, Ecuador y Japón. Por tal motivo, se sabe que en el mercado de los licores existe una gran demanda de pisco (MINCETUR: Exportaciones de pisco,Gestión.pe, 2015). 


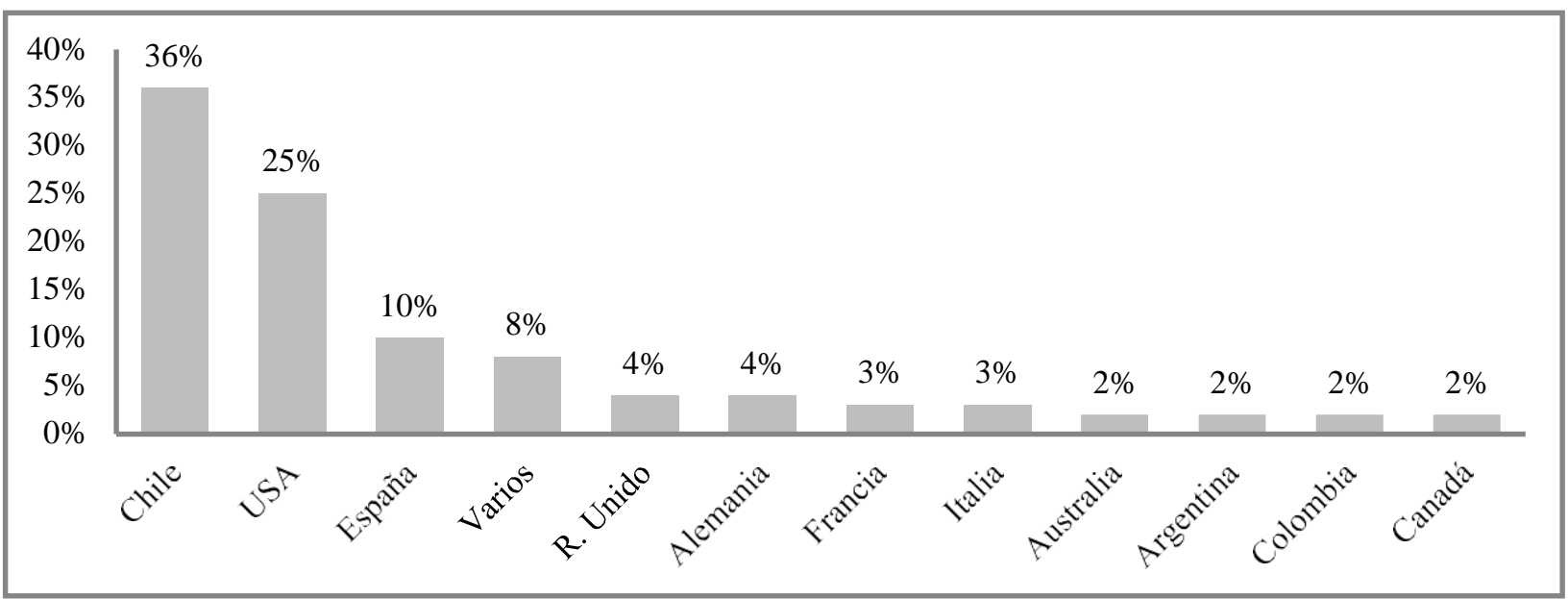

Figura 1. Porcentaje de exportación año 2017. Adaptado de "Exportación de pisco 2017" por Paan C., El Comercio.pe,junio 2016. Recuperado de http://elcomercio.pe/economia/negocios/situacion-real-pisco-peru-analisis-428825

Según informó el Ministerio de la Producción (PRODUCE), como se observa en la figura 2para el cierre del 2017 se estima finalizar con una producción total de 10.5 millones de litros de pisco, reflejando de esta manera un aumento del 4\% en comparación al año 2016. El incremento en la producción del pisco data desde el 2012. Esto ha servido de sustento para que el pisco ingrese a nuevos mercados a nivel mundial, entre los que destacan Bélgica, India, Emiratos Árabes Unidos y Australia.

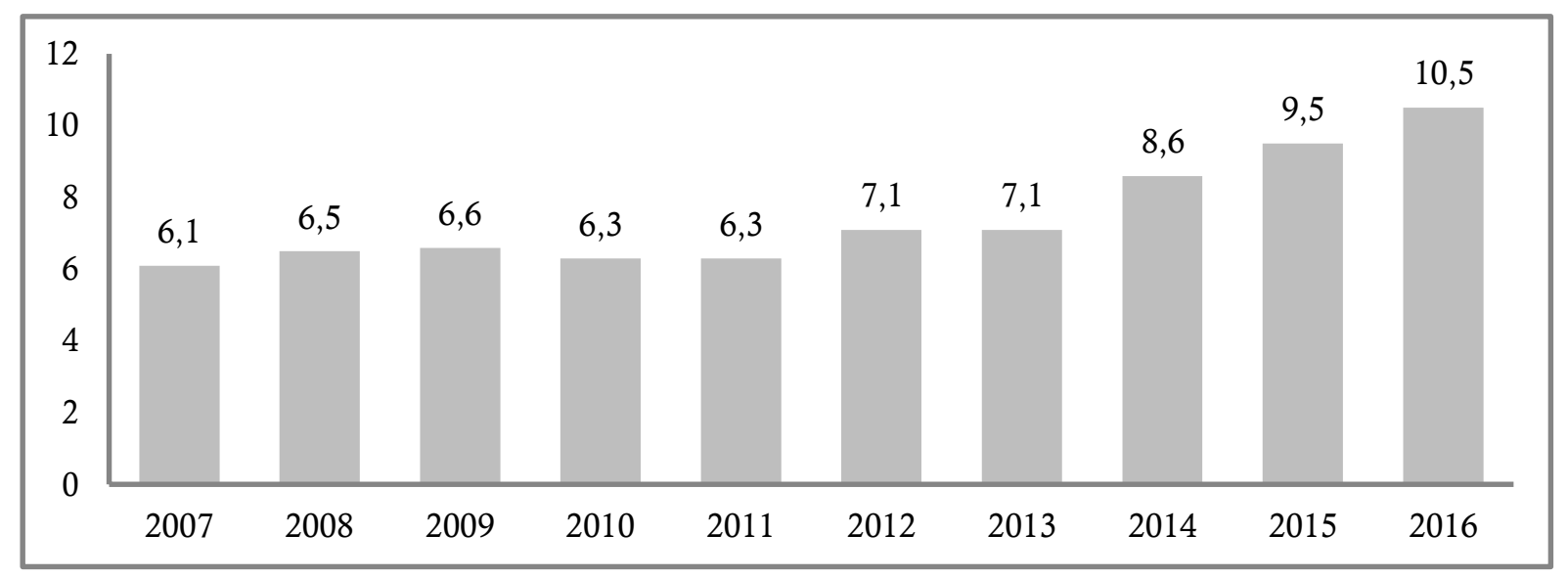

Figura 2. Producción de pisco en litros. Adaptado de "Producción de pisco registró record". Semanaeconomica.com, Febrero 2017. Recuperado de http://semanaeconomica.com/article/sectores-y-empresas/industria/213151-produccion-depisco-registro-record-en-el-2016/

Durante el 2016 fueron registradas un total de 523 empresas formales, representando un incremento del $15.5 \%$ en relación al 2015. La mayoría de las empresas registradas tienen 
sede en Lima, liderando el ranking con $48.8 \%$, seguido de Ica con un $34.6 \%$ y Tacna representada con un 14.6\% (Produce: Producción del Pisco, Semanaeconómica.pe, 2017).

Por otro lado, el país cuenta con variedades de frutas, hierbas y especies que gozan de un gran sabor y aroma, que combinadas con el pisco logran ser irresistibles para los paladares más exigentes.

De tal forma, luego de haber analizado e identificado que el pisco posee una alta demanda tanto en el mercado local, como en el extranjero, se considera importante tomar ventaja de esto y ofrecer un derivado, haciendo uso de los recursos.

Se ha identificado que el pisco no presenta muchos productos derivados, perdiendo una gran oportunidad de expansión y de negocio, para que este pueda tener mayor participación en el mercado local y extranjero mediante un producto de calidad y $100 \%$ natural.

La gran calidad y sabor del pisco peruano es reconocido por todo el mundo y como muestra de ello, el pisco Demonio de los Andes ha sido galardonado con la medalla de oro tanto en el concurso SpiritsChallenge de Londres como en el Citadelle du Vin desarrollado en Francia (Economía: Pisco peruano gana concurso en Europa, LaRepublica.pe, 2017).

Para continuar con la promoción del pisco a nivel mundial, el Sr. William Urbina, presidente del Comité del pisco del gremio exportador, indicó que los exportadores seguirán participando en ferias y asistiendo a misiones en el exterior con el objetivo de reforzar la presencia en los mercados e incursionar en nuevos países (Economía: El piso peruano llegó a 44 países, Correo.pe, 2017).

Además, se sabe que existe una controversia por el Pisco entre Perú y Chile. Hace algunos meses, se realizó el concurso "SpiritsSelectionbyConcoursMondial de Bruxelles" del 22 al 24 de agosto en La Serena, en el valle de Pisco Elqui, Chile. En donde, no se permitió la participación del producto bandera peruano, con su nombre "Pisco", ya que existe una ley 
chilena que impide que ingresen a su territorio un producto con el mismo nombre, a pesar de que Perú tiene la denominación de origen basada en su historia, desde hace más de 400 años. Para cumplir con dicha ley chilena, los piscos provenientes de Perú, debían registrarse con el nombre de “Aguardiente de Perú".Muchos de los participantes desistieron, sin embargo, el Instituto Nacional de Defensa de la Competencia y de la Protección de la Propiedad Intelectual (INDECOPI), se pronunció y advirtió que quitaría la denominación de Pisco a todos aquellos productores que concursen en Chile (La controversia por origen,LaRepública.pe, 2010).

Dada esta controversia el canal HistoryChannel ha lanzado una encuesta en su portal web para que las personas puedan emitir su voto sobre el origen del pisco, cabe resaltar que a la fecha el Perú se muestra como ganador con un $96 \%$ de la votación total. Además, en este portal se presenta información histórica de ambos países donde dan a conocer el origen de la bebida bajo cada punto de vista. (Las rutas del pisco, Tuhistory.com.pe, 2017).

Con este estudio, se quiere aprovechar el crecimiento del consumo de pisco y sus derivados, como el macerado de frutas en pisco.

Cojal M. y Rojas K. (2016), en su tesis Asociatividad de pequeños productores de aguardiente para la elaboración y comercialización de un licor macerado con frutas exóticas a Baltimore - EE.UU., se enfocaron en la elaboración de macerados con diversas frutas, mediante la asociación de diversos productores para lograr cubrir la demanda existente y poder exportar su producto a los EE.UU. Este estudio servirá para revisar la elaboración y técnicas de los macerados de frutas.

Mendoza, W. (2011) en su proyecto Asociatividad como estrategia para desarrollar las exportaciones de pisco del valle de Cañete, se basó en analizar la problemática de los productores en una zona específica del país para poder lograr una producción en conjunto que los pueda ayudar a posicionarse en nuevos mercados en el exterior. 
INDECOPI (2016), en su Observatorio de mercados, realizó un estudio de la producción y análisis de la demanda del pisco, además de hacer referencia al proceso productivo, la cantidad de productores, tipos de pisco y mencionan una estructura de costos ligados a la comercialización de los derivados del pisco.

Sin embargo, no se ha hallado, el estudio para la producción de macerados de pisco en Lima Metropolitana. Los estudios mencionados anteriormente, servirán como guía y complemento para la investigación.

Por esta razón, para aprovechar el crecimiento del consumo de pisco y el aumento de la demanda se propone realizar un Plan de Negocios para la Producción de Macerados de frutas en pisco en Lima Metropolitana para el 2018.

\subsection{Determinación de la oportunidad}

Según PRODUCE, en 2017, la producción nacional de pisco llegó a 10.9 millones de litros, lo cual significaría un avance del 4\% a comparación del 2016. Debido a las campañas internas y el ingreso a nuevos mercados, el sector continúa creciendo y las cifras son altamente positivas. Además, el pisco ha ingresado a nuevos mercados como la India, Israel, Noruega, Bélgica, República Dominicana, Australia, Emiratos Árabes, entre otros. Sin embargo, Estados Unidos y Chile siguen siendo los destinos con mayor número de pedidos (Produce: reconocimiento de pisco, Semanaeconomica.com, 2017).

Actualmente, el presidente del Perú, Pedro Pablo Kuczynski, ha llamado la atención sobre la necesidad de unir esfuerzos para promocionar mejor el pisco, que es conocido a nivel mundial como uno de los mejores. En efecto, desde el año 1999, se celebra el Día Nacional del Pisco, cada cuarto domingo de julio (Rojas, 2017). Donde se busca incrementar el consumo del producto bandera y realzar el sabor de este destilado de uvas para que los peruanos y extranjeros puedan disfrutarlo. 
Por otra parte, no sólo existe el Día del Pisco, también el Día del Pisco Sour, la bebida bandera hecha a base de pisco, jugo de limón y diversos agregados. Por Resolución Ministerial - PRODUCE decretó el Día del Pisco Sour, el primer sábado de febrero de cada año (Redacción EC, 2015). Con el objetivo de difundir el cóctel típico del Perú y a la vez, realizar diversas actividades en donde se busca encontrar quiénes son los que elaboran el mejor pisco sour, se realiza concursos para buscar una nueva figura de la coctelería nacional y que los asistentes degusten y consuman. También se ofrece variedades del emblemático cóctel, en las que destacan el pisco sour hecho con maracuyá, camucamu, mango, aguaymanto chicha morada, entre otros frutos oriundos del Perú para todos los gustos.

Dado que el pisco cuenta con distintas formas de presentación en cocteles, una opción refrescante y reconstituyente, que a los peruanos y extranjeros les encanta, es el Chilcano. Que busca denominarse como un cóctel clásico de Perú, a base del emblemático licor peruano, gaseosa ginger ale y sutil toque de limón. Por la gran demanda y aceptación de este coctel hoy en día, se celebra la Semana del Chilcano, del 9 al 18 de enero de cada año, en donde los establecimientos se afilian y aprovechan esta oportunidad para promover su cata a todo el público (El chilcano reclama su carácter, Lainformacion.com, 2015).

Por consiguiente, al incrementar la demanda del pisco anualmente, se identificó la necesidad de más allá de consumir el producto final, las personas puedan vivir la experiencia de cómo se realiza este delicioso licor, ofreciendo un tour llamado "La Ruta del Pisco", que son rutas que trascienden las visitas a las bodegas, donde los especialistas recomiendan recorridos para Lima, Moquegua, Ica, Arequipa y Tacna. Existen dos rutas en Lima: norte y sur. En el norte, se puede hacer la ruta que va desde la provincia de Huaral, en la bodega de Alvanor, hasta Pativilca, pasando por Huacho.

Por otro lado, la ruta del sur se puede iniciar en la planta de Queirolo, situado en Pachacamac, concluyendo en Azpitia. Se puede realizar otro recorrido por el valle del río 
Cañete. Es enriquecedor visitar las bodegas, ya que los asistentes pueden participar en la vendimia y presenciar la destilación y fermentación del producto (Las rutas del pisco, Gestion.pe, 2017).

Por esas razones, además de que el consumo del pisco aumente año tras año, ya que las personas están consumiendo y prefiriendo el producto nacional, se detecta la necesidad de ofrecer un derivado con un valor agregado, que es un producto $100 \%$ natural y de alta calidad, con ausencia de insumos químicos, sintéticos y sustancias tóxicas que afecten el medio ambiente.

Este estudio se enfocará en el público insatisfecho y que busca otra alternativa, que cubra la demanda para eventos especiales, fiestas particulares, corporativas, ferias, restaurantes, entre otros.

Por lo tanto, se analizará el consumo del macerado de pisco ofreciendo distintos sabores para todos los gustos y lograr que los peruanos, tanto jóvenes como adultos, reemplacen el consumo de ron, vodka, entre otros, por el licor nacional. Que conserven la cultura y tradiciones mediante estos macerados, ya que se utilizarán insumos oriundos del Perú. El producto lo pueden consumir de distintas formas: puro, con ginger ale o utilizarlo para la preparación de chilcanos, inclusive al darle estos macerados de pisco a un chef o pastelero, sería como un reto de innovación para poder deleitar los paladares con nuevas creaciones tanto en la cocina como en la pastelería.

\subsection{Justificación del proyecto}

Para la realización del proyecto propuesto, se toma en consideración el por qué se va hacer, la razón y el origen del mismo. Se explicará la necesidad y cómo satisfacerla y por qué la solución que se propone es la más conveniente (Arias, 2012).

Se encontró la oportunidad en las iniciativas que tiene el gobierno hacia el consumo y producción pisco. Aprovechando la Ley N 30460, en la que se promueve la promoción y 
desarrollo del Pisco y Vino peruano como Bebida nacional. Esta Ley busca la difusión de la producción, elaboración y consumo del vino y pisco juntamente con sus tradiciones. Promueve la celebración del día del Pisco Sour, la semana del Chilcano, entre otros $\left(\mathrm{N}^{\circ}\right.$ 30460, El Peruano.pe, 2016). Bajo esa perspectiva, la idea de este estudio es demostrar que el consumo de Macerados es una opción que debe ser explotada ofreciendo un producto beneficiándose de la ventaja de ser un derivado de un producto bandera. Con visión a que el macerado de frutas en pisco se pueda comercializar en los anaqueles de los supermercados llegando a nuevos mercados (Pisco ya se vende en supermercados, Perú Retail.com, 2017).

El desarrollo e implementación del proyecto tendrá repercusiones sociales, al ofrecer un derivado del pisco, la comunidad se verá beneficiada ya que es un producto atractivo para los consumidores.

\subsection{Objetivos generales y específicos}

a) Objetivo General

- Desarrollar un plan de negocio para la producción de macerados de frutas en pisco en Lima para el 2018.

b) Objetivos Específicos

- Analizar la industria del pisco.

- Elaborar el estudio de mercado para determinar el mercado objetivo.

- Realizar el plan de Recursos Humanos para la planificación del personal necesaria.

- Ejecutar el plan de Marketing para lograr identificar la mejor forma de comunicar el producto.

- Realizar el plan de Operaciones para lograr la eficacia en el proceso interno.

- $\quad$ Elaborar el plan Financiero para evaluar y demostrar la viabilidad del proyecto. 


\subsection{Alcances y limitaciones de la investigación}

a) Alcances

El presente estudio buscará la aceptación de la producción de macerados de frutas en pisco de distintos sabores dentro de Lima Metropolitana.

Dependiendo de las ventas, la aceptación y el resultado de la investigación en los primeros dos años, se evaluará la posibilidad de ingresar a nuevos mercados en el exterior.

b) Limitaciones

Escaso acceso a información actualizada del sector, al no ser un commodity, la información que se encuentra publicada no está actualizada de manera constante, lo que dificulta que se encuentren datos representativos.

Limitado acceso a información de la competencia, ya que las empresas no comparten su información, son muy pocas las que lo hacen. Existe gran cantidad de empresas que no son formales y esto dificulta el acceso a la información verídica.

La estacionalidad de la fruta afecta la producción en alguno de los sabores que se eligieron para la elaboración del proyecto. 


\section{Capítulo II. Estructura económica del sector}

En este capítulo se presenta la investigación y análisis sobre el estado actual de la industria, tendencias y tamaño de macerados de pisco. También se analiza la competencia, la participación del mercado y las razones por las cuales sería atractivo invertir en este negocio.

Al ser un derivado de un producto bandera, se ha investigado y recopilado información necesaria para así poder conocer a la competencia y orientar el Plan de Negocios.

En este capítulo se utilizó la información sobre el mercado, proveedores, en donde conseguir información y leyes que obtuvimos de la entrevista a profunidad realizada al Sr Juan Carlos Mathews (Ver tabla 22 y Anexo \# 8).

\subsection{Descripción del estado actual de la industria}

El sector de bebidas alcohólicas en el Perú está conformado por todas las bebidas producidas dentro del territorio nacional y además por las que provienen de la importación. En el transcurso del 2014 el sector sufrió una caída de hasta 8\% debido al cambio en la Ley del Impuesto Selectivo al Consumo (ISC). En cambio, en el 2015 el sector evidenció una mejora del 10\% resultado de mejores estrategias comerciales. En el año 2016 se produjo un crecimiento solo del 6\%, debido a una mejor situación macroeconómica, que favoreció el incremento en las ventas, según declaraciones del presidente del gremio de vinos y licores de la Cámara de Comercio de Lima, Salvador López Cano. (Negocios. Sector licores crecerá 6\% durante el 2016. El Comercio.pe, 2016).

En febrero de 2017, el vice ministro de la producción de aquella época, Juan Calos Matthews, se refirió al pisco indicando que el consumo dentro del país viene creciendo debido a la coyuntura que viene atravesando la bebida nacional en relación a la polémica suscitada con Chile y a nivel mundial, además señaló que el pisco ocupa el tercer lugar en la preferencia del peruano, en segundo lugar figura el vino un consumo de 1.5 litros por persona 
y lidera la lista la cerveza con un total de 47 litros por persona. (Villa, P. Produce: el pisco es la tercera bebida de mayor consumo. El Comercio.pe, 2017).

\subsubsection{Segmentación de la industria.}

La industria del pisco se distribuye entre las ciudades de Lima, Ica, Arequipa, Moquegua y Tacna como se puede observar en la Tabla 1. Solo los destilados producidos en estas zonas pueden adquirir la Denominación de Origen: pisco.

Terminado el año 2016, el PRODUCE, indicó que son en total 523 empresas productoras de pisco las que cuentan con autorizaciones y Denominación de Origen para poder operar en el país. Por otra parte, el presidente del comité del Pisco de Asociación de Exportadores (ADEX), William Urbina indicó que es muy difícil saber el número exacto de productores de pisco en todo el país, esto en referencia a la gran cantidad de informales dentro de la industria y por lo tanto no se puede tener una cifra en litros del total de la producción nacional. Además, añadió que el no contar con un número exacto de productores dificulta que la asesoría técnica se pueda extender a todos. Además, el presidente del gremio de importadores y comerciantes de bebidas alcohólicas de la Cámara de Comercio de Lima, Salvador López Cano, indicó que son muy pocas las bodegas que cuentan con capacidad financiera para poder invertir en programas de marketing que les sirvan para ganar participación en el mercado y de esta manera puedan competir con otras bebidas alcohólicas. (Paan, C. Esta es la situación real del pisco. El Comercio.pe, 2017).

Entre los productos que se presentan en la industria se encuentran muchas variedades de pisco dependiendo de las mezclas de uvas que se encuentra en la Tabla 2, tales como quebranta, mosto verde, acholado, torontel y otras mezclas de uvas propias de cada bodega. El nombre de estos tipos derivan de los tipos de uvas que se utilizan para destilar el pisco. 
Tabla 1

Crecimiento de Empresas Productoras de Pisco por Provincias

\begin{tabular}{lccc}
\hline \multicolumn{1}{c}{ Provincias } & 2014 & $\begin{array}{c}2015 \\
\mathrm{~N}^{\circ} \text { de Empresas }\end{array}$ & 2016 \\
\hline Lima & 205 & 201 & 255 \\
Ica & 178 & 174 & 181 \\
Arequipa & 46 & 46 & 51 \\
Moquegua & 18 & 18 & 20 \\
Tacna & 12 & 14 & 16 \\
\hline Total & 459 & 453 & 523 \\
\hline Nota. Porcentaje de exportación. Adaptado de "Exportación de pisco 2017"
\end{tabular}

Nota. Porcentaje de exportación. Adaptado de "Exportación de pisco 2017" por Paan C., El Comercio.pe,junio 2016. Recuperado de http://elcomercio.pe/economia/negocios/situacionreal-pisco-peru-analisis-428825

La Denominación de Origen es muy importante para los productores de pisco porque mediante esta distinción se pueden obtener diversos beneficios además de garantizar la calidad del pisco, certificando que fue elaborado con las mejores uvas. Entre otros beneficios se pueden mencionar: la protección del producto, la facilidad con la que pueden ser comercializados en el mercado local e internacional y el fomento para los gremios de productores. (INDECOPI, 2016).

Tabla 2

Distribución de Empresas por tipo de Pisco Producido

\begin{tabular}{lcccc}
\hline \multicolumn{1}{c}{ Provincias } & $\begin{array}{c}\text { Uvas } \\
\text { aromáticas }\end{array}$ & $\begin{array}{c}\text { Uvas no } \\
\text { aromáticas } \\
N^{\circ} \text { de Empresas }\end{array}$ & $\begin{array}{c}\text { Acholado } \\
\text { Mosto verde }\end{array}$ \\
\hline Lima & 84 & 144 & 63 & 10 \\
Ica & 54 & 130 & 60 & 7 \\
Arequipa & 25 & 23 & 38 & 2 \\
Moquegua & 13 & 11 & 7 & 1 \\
Tacna & 13 & 10 & 7 & 20 \\
\hline Total & 189 & 318 & 175 & \\
\hline
\end{tabular}

Nota. Adaptado de "Observatorio de Mercados" por Gerencia de Estudios Económicos, INDECOPI, Año 10, No 33, septiembre 2016, p. 19. Recuperado de https://www.INDECOPI.gob.pe/documents/474320/633971/N\%C2\%B0+33++Setiembre+2016+Pisco.pdf/c61 abd40-6d20-4e57-9ef6-7b916fbee86d?version=1.0

Entre las entidades públicas del país que están relacionadas en la producción del pisco se destacan los siguientes: 
- Ministerio de la Producción (PRODUCE).

- Ministerio de Comercio Exterior y Turismo (MINCETUR).

- Instituto Tecnológico de la Producción (CITE Agroindustrial).

- Instituto Nacional de Defensa de la Competencia y de la Protección de la Propiedad Intelectual (INDECOPI).

- Instituto Nacional de la Calidad (INCAL).

- Dirección General de la Salud Ambiental e Inocuidad Alimentaria (DIGESA).

(INDECOPI, 2016).

\subsubsection{Empresas que la conforman.}

Entre las principales empresas que conforman la industria del pisco, como señala la figura 3 se encuentran bodegas como Tabernero, Santiago Queirolo, Tacama, entre otros. Entre estas grandes bodegas se reparten gran parte de la producción nacional, además tienen la capacidad de exportación.

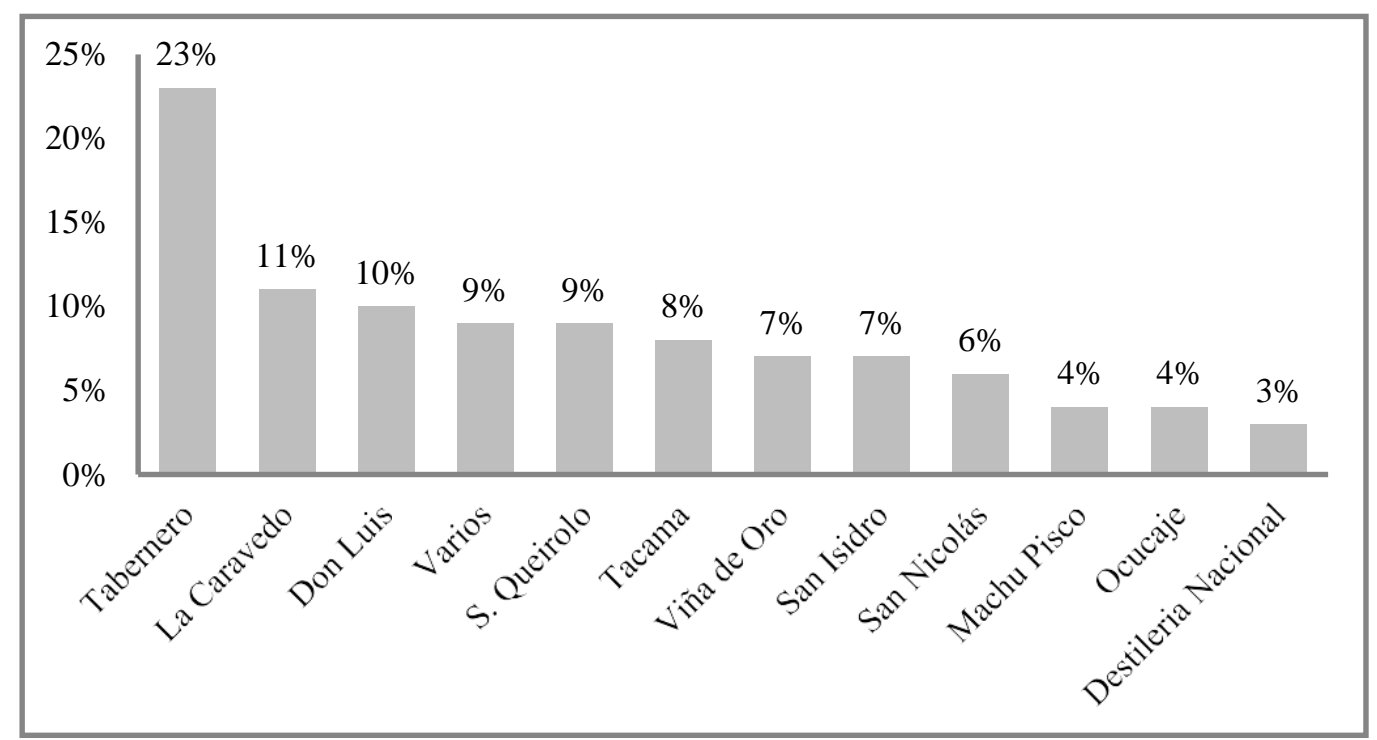

Figura 3. Porcentaje de exportación por bodega. Adaptado de "Exportación de pisco 2017" por Paan C., El Comercio.pe, junio 2016. Recuperado de http://elcomercio.pe/economia/negocios/situacion-real-pisco-peru-analisis-428825

La suma de estos factures dificulta el acceso a información vital para el estudio, como son el volumen de ventas, cantidad de empleados, etc. La industria de macerados recién inicia 
su camino a la fama y gracias a los esfuerzos del Gobierno y de sus entidades estos productos pueden aprovechar los beneficios y el terreno ganado por el pisco al presentar una bebida alcohólica a base de nuestra bebida nacional pero con un excelente valor agregado como son la gran variedad de frutas que se pueden encontrar en el país.

\subsection{Tendencias de la industria}

La industria del pisco viene creciendo a grandes proporciones durante los últimos años. Esta tendencia se viene fortaleciendo gracias a las iniciativas del gobierno en promover y apoyar el consumo tanto en el mercado interno como en el externo, esto lo está logando gracias al envío de delegaciones a diversos países y además ayudando a los productores para que puedan presentar sus productos en concursos internacionales muy importantes. (INDECOPI, 2016).

Según informó el PRODUCE, para el cierre del 2017 se estima finalizar con una producción total de 10.9 millones de litros de pisco, reflejando de esta manera un aumento del 4\% en comparación al año 2016.

Durante el 2016 fueron registradas un total de 523 empresas formales, representando un incremento del $15.5 \%$ en relación al 2015. La mayoría de las empresas registradas tienen sede en Lima liderando el ranking con $48.8 \%$, seguido de Ica con un $34.6 \%$ y Tacna representada con un 14.6\% (Produce: Producción del Pisco, Semanaeconómica.pe, 2017).

En la actualidad la producción conjunta entrega Lima e Ica suman alrededor del 90\% del total nacional, lo que significa que la gran cantidad de empresas pertenecen a dichas zonas del país. (Tendencia: Congreso eleva a rango de ley declaración al pisco. Gestion.pe, 2017).

En febrero de 2017, el Vice Ministro de MYPE e Industria del PRODUCE, Juan Carlos Matthews, quien se desempeñaba en el cargo en aquella época, señaló que el incremento en el consumo del pisco lo ha posicionado en el tercer lugar en la preferencia del 
público peruano detrás de la cerveza y el vino que se mantienen como las líderes. Este aumento considera al pisco puro, chilcano y sour. El crecimiento de la producción de pisco se ha evidenciado de un manera sustancial reflejando un promedio del 10.8\% anual, además indicó que el 90\% de la producción nacional fue destinada al abastecimiento del mercado local mientras que el 10\% fue destinado a la exportación. (Economía: Producción de pisco alcanzó record. Gestión.pe, 2017).

La evolución del pisco ha generado una serie de eventos en el Perú, tal es el caso de la semana del chilcano la cual se celebró este año 2017 entre los días 12 y 19 de enero y para realzar este evento los organizadores programaron un cronograma por el sur del país en el cual se podía degustar esta refrescante bebida en las ciudades en las que se produce el pisco, combinándolo con deliciosos potajes de cada zona que incluso han sido creados para acompañar el chilcano. Para el caso de Lima se ha preparó una agenda especial en donde se recomiendan conocidos bares en los cuales la preparación del chilcano ofrece algo especial como hierbas, frutas y demás agregados. (Semana del chilcano: actividades para celebrar. El comercio.pe. 2017).

Otro de los eventos que tiene al pisco como principal atracción es la tradicional celebración del día del pisco sour, evento que se inició en el año 2004 y que se desarrolla cada año presentando nuevos sabores para todos los gustos. Según los investigadores esta bebida tan querida por los peruanos fue creada en el año 1916 en un conocido bar de aquel entonces ubicado en el Jirón de la Unión y desde esa época no ha dejado de deleitar a todas las generaciones. Debido a este especial motivo no solo la Municipalidad de Lima prepara eventos y degustaciones sino que muchos distritos de la capital ofrecen eventos donde el pisco sour es la principal atracción. (Día del pisco sour. El Comercio.pe, 2017).

Al igual que en otros países en el mundo en los cuales acompañan su gastronomía con una bebida alcohólica típica de la zona, el pisco no es ajeno a esta situación. Por ejemplo en 
la cocina francesa es muy común que las personas utilicen el vino u otras bebidas para acompañar las comidas o cenas, en el Perú, el pisco busca posicionarse como un aperitivo que pueda ser consumido antes de una comida. No solo se puede consumir puro sino en sus diferentes variedades como sours, chilcanos y demás presentaciones que los expertos ofrecen. (¿Se imagina la comida peruana sin pisco? El Comercio.pe, 2017).

Para el caso de este estudio, se detectó una nueva tendencia en la presentación de pisco es la de macerados a base de frutas, los cuales han ido ganando presencia en el segmento gourmet, como por ejemplo ingresando a tiendas especialidas, restaurantes gourmet e incluso en principales hoteles cinco estrellas. Se define segmento gourmet debio a la especialización realizada en estos locales, pueden ser desde platos de comida hasta debidas elaboradas para un segmento con gustos muy exigentes. Se puede macerar todo tipo de frutas o hierbas pero todo dependerá del tiempo que necesite cada fruta o hierba. El tiempo de maceración definirá el color, sabor y aroma que adquiera el pisco luego del reposo con las frutas o hierbas. (Empresas. Macerados de pisco. Gestion.pe, 2016).

El mercado de macerados se presenta muy atractivo, debido a la gran versatilidad de nuestra bebida nacional, el uso de frutas, hierbas o especias es excelente para lograr un producto de calidad, que sea innovador y que a su vez pueda agragad al público en general ofreciendo una nueva opción a la hora de disfrutas con amigos o en familia.

\subsection{Análisis Estructural del Sector Industrial}

Para David (2013), las fuerzas externas tienen una influencia importante y es necesario identificarlas para ser competitivos. Haciendo un estudio de todo lo que rodea el sector es como se espera tener la base para hacerse sostenible y tener una ventaja sobre los demás competidores. De acuerdo a lo que sostiene el modelo de las 5 fuerzas de Porter, determina que las empresas logran desarrollarse por las fuerzas de la industria. Entonces se podría decir que estas fuerzas externas son más importantes que las internas, pues tienen que 
ver con la forma cómo las empresas se desarrollan y se posicionan a través de su ventaja competitiva. Entonces estas fuerzas tienen un alto impacto con el comportamiento del consumidor, con los precios, las tendencias, con la demanda, con la variedad de productos, con la variedad de servicios que se ofrezcan, a qué mercado se quiere llegar y todo lo que relacione a la industria. Así poder estudiar el mercado, tener claro el contexto hará que las organizaciones puedan tener habilidad para crear estrategias que les permitan ser competitivos. Como resultado de este análisis de podrá identificar si la industria de los macerados es atractiva o no y con ello empezar un proyecto que permita ser rentable en el tiempo.

\section{Poder de negociación de los proveedores del sector.}

Según David (2013), el poder de negociación de los proveedores impacta de manera directa fuerza de los competidores y esto se intensifica aún más cuando existe un gran número de competidores en la industria y también cuando el cambiar de materia prima incurre en un costo elevado. Por lo general los proveedores realizan esfuerzos como ofrecer precios justos, mantener un buen nivel de inventario, realizar entregas a tiempo. Todo en beneficio de mejorar la rentabilidad a futuro. Por lo general las compañías prefieren el uso de proveedores externos para bajar sus costos y centrarse netamente en su negocio.

El principal insumo para la elaboración de macerados es el pisco puro y como se ha mencionado en los puntos anteriores y de acuerdo a las indagaciones que se hicieron el tipo de pisco quebranta el que mejor se adecua para estas mezclas. Se identificó que en la actualidad la oferta de pisco es muy amplia debido al crecimiento en el número de productores y a la promoción impulsada por el Gobierno. Además de estos factores se consideró el gran número de productores informales, que intervienen de manera directa en los precios del pisco, limitando mucho el poder de negociación ante los consumidores. 
Para poder ofrecer un producto de calidad se debe trabajar con productos que cuenten con Denominación de Origen, lo cual permitiría a los proveedores mantener un precio que los beneficie, pero considerando que la oferta es muy grande esto le permite al consumidor tener mayores opciones para elegir.

En el caso de los demás insumos que serían las frutas, la estacionalidad de estás hace que los proveedores tengan un poder medio de negociación. Para el caso de los demás proveedores (botellas, etiquetas, etc) el mercado es más amplio aun, lo que le permite a los consumidores tener el poder de negociación. (INDECOPI, 2016).

\section{Poder de negociación de los consumidores}

Para David (2013), el poder de negociación de los consumidores es elevado cuando representan un número grande dentro de la industria y a su vez realizan comprar por grandes volúmenes. Entre otros factores que incrementan el poder de negociación de los consumidores se puede mencionar la estandarización de los productos debido a que los consumidores tienen el control para negociar los precios.

Según lo que observó, la demanda de pisco en el mercado local viene atravesando uno de sus mejores momentos por lo tanto, los precios son generados por el mercado y varían según la calidad de pisco ofertada por las bodegas. Esto genera como consecuencia que el poder de negociación de los consumidores sea bajo, es decir que ellos serían precioaceptantes. En el caso de los macerados, se pudo observar que no existía una industria desarrollada ya que la mayoría de productores era artesanales y utilizaban las redes sociales como canales de ventas. Mediante el análisis de mercado se identificará el tamaño del mercado y a los principales competidores para poder estimar una demanda a satisfacer.

Debido a que no existe mucho desarrollo en el mercado de los macerados de fruta en pisco, son los productores los que tienen el poder de negociación fijando los precios según el tipo de mezcla que utilicen para realizar sus productos. (INDECOPI, 2016). 


\section{Amenaza de nuevos competidores.}

Según David (2013), el ingreso de nuevos competidores siempre está latente en las industrias y esto puede generar que la competencia entre los jugadores sea más fuerte. Entre las diversas barreras de ingreso a la industria se pueden considerar la adquisición de economías de escala, barreras arancelarias, tecnología, gran soporte de capital, etc. Incluso habiendo mencionado estas barreras de ingreso se puede presentar el caso de ingreso de nuevos competidores que traen su experiencia, precios bajos y productos de calidad. Ante esto las empresas afianzadas deben estar siempre alerta a las nuevas estrategias contra las que deben lidiar.

De acuerdo a lo que se investigó, se observó que en la actualidad existían pocas barreras de entrada para la industria del pisco, muchos de los nuevos participantes no producen la bebida alcohólica, ellos aprovechan la experiencia y técnicas de las bodegas ya establecidas en el mercado y encargan la producción del pisco a estas bodegas con lo cual ahorran en costos, tecnología y tiempo, lo que les permite basarse en sus estrategias de mercado.

En relación a los macerados de fruta en pisco se observó la misma tendencia ya que muchos de los nuevos competidores pueden replicar el método de los actuales jugadores en el mercado y adquirir el insumo pisco ya elaborado para ahorrar en temas de producción y abocarse en estrategias de marketing y ventas que le permitan posicionar sus productos. Mediante estos factores se puede indicar que la amenaza de nuevos competidores era alta, y solo queda la diferenciación en los productos para poder aumentar la participación en el mercado. (INDECOPI, 2016).

\section{Amenaza de productos sustitutos.}

Como indica David (2013), la presencia de productos sustitutos hace que la rivalidad dentro de la industria sea más dura. Esta competencia genera que los precios tengan límites 
con lo cual se generan topes en las ganancias de las empresas. La intensidad por los productos sustitutos genera que los precios de estos bajen de manera gradual debido al costo que deben afrontar los consumidores en su búsqueda de estos productos sustitutos.

Los productos sustitutos lo representan todas las bebidas alcohólicas que integran el mercado, como se observa en la tabla 3, es decir cerveza, ron, whisky, gin, entre otras. La gama de bebidas es muy amplia y los proveedores tienen en frente muchas opciones a escoger y esto ligado a la variedad de precios que tienen todas las bebidas en el mercado nacional. (INDECOPI, 2016).

Tabla 3

Consumo de bebidas alcohólicas en Perú (por litros)

\begin{tabular}{lrrrrr}
\hline Nombre de Bebida & $\mathbf{2 0 1 1}$ & $\mathbf{2 0 1 2}$ & $\mathbf{2 0 1 3}$ & $\mathbf{2 0 1 4}$ & $\mathbf{2 0 1 5}$ \\
\hline Ron & $7,672,500$ & $8,239,500$ & $8,662,500$ & $9,002,700$ & $9,310,500$ \\
Pisco & $8,108,500$ & $8,858,250$ & $8,939,250$ & $9,258,750$ & $9,074,250$ \\
Whisky & $3,332,100$ & $3,908,250$ & $4,506,750$ & $4,763,250$ & $5,870,250$ \\
Vodka & 920,250 & $1,084,500$ & $1,233,000$ & $1,570,500$ & $1,656,000$ \\
Tequila & 139,500 & 157,500 & 148,500 & 182,250 & 168,750 \\
Aguardiente de caña & 67,500 & 81,000 & 99,000 & 110,250 & 119,250 \\
\hline
\end{tabular}

Nota .Medida Litros. Adaptado de "Observatorio de Mercados" por Gerencia de Estudios Económicos, INDECOPI, Año 10, $N^{o} 33$, Septiembre 2016, p. 20. Recuperado de https://www.INDECOPI.gob.pe/documents/474320/633971/N\%C2\%B0+33++Setiembre+2016+Pisco.pdf/c61 abd40-6d20-4e57-9ef6-7b916fbee86d?version=1.0

Entre los sustitutos directos de los macerados se pudo encontrar otros licores preparados con el pisco puro como los sours, chilcanos, algarrobinas y coctelería. Por lo tanto se pudo observar que la amenaza de sustitutos para el macerado de fruta en pisco era alta dentro del mercado peruano.

\section{Rivalidad entre los competidores.}

Para David (2013), la rivalidad entre los competidores es la principal fuerza entre las cinco de Porter. Las empresas solo pueden lograr el éxito si sus estrategias están sustentadas en una ventaja competitiva que les permita hacer la diferencia por sobre los demás competidores. Entre otros factores que incrementan el nivel de rivalidad se puede mencionar el gran número de competidores, costos fijos elevados y poca fidelidad de los consumidores. 
Cuando la rivalidad aumenta significativamente las utilidades en esa industria disminuyen mucho al punto de que se pierde todo tipo de atractivo.

La rivalidad entre los productores de pisco es marcada, el mercado está distribuido entre las grandes bodegas y los pequeños productores que pugnan por acceder a ganar espacio dentro del mercado. En el caso de las grandes bodegas que están ya establecidas en el mercado local, otra opción para ellos es llevar sus productos al exterior y competir a otro nivel, además de aprovechar las ventajas establecida por el Gobierno para ayudar que la bebida sea protegida dentro del territorio y fuera de él.

Si analizamos a los competidores de macerados de frutas en pisco se encuentra que no son muchas las empresas formales que cuentan con inscripción en SUNAT, muchos de los competidores elaboran sus productos de manera artesanal y venden haciendo uso de redes sociales lo cual elimina muchos costos durante sus procesos. Se puede decir que la rivalidad es intermedia porque cualquier persona puede macerar inclusive en la comodidad de su hogar, solo quedaría establecer nuevas y sólidas estrategias y aprovechar la diferenciación para obtener participación en el mercado y lograr la satisfacción de los clientes. (INDECOPI, 2016). En la tabla 4, se aprecia el resumen de las Cinco Fuerzas de Porter.

Tabla 4

Resumen de las Cinco Fuerzas de Porter

\begin{tabular}{llcc}
\hline \multicolumn{1}{c}{ Fuerzas de Porter } & Alta & Media & Baja \\
\hline $\begin{array}{l}\text { 1. Poder de negociación de los proveedores del } \\
\text { sector }\end{array}$ & $\mathrm{X}$ & & \\
2. Poder de negociación de los clientes & & & $\mathrm{X}$ \\
3. Amenaza de nuevos competidores & $\mathrm{X}$ & & \\
4. Amenaza de productos sustitutos & $\mathrm{X}$ & & \\
5. Rivalidad entre los competidores & & $\mathrm{x}$ & \\
\hline
\end{tabular}

Nota. Se muestra el resultado del análisis previo desarrollado en el capítulo. Cada marca representa a la valoración producto del estudio. Tomado de Administración Estratégica (p, 76), por F. David, 2013, México, D.F., México: Prentice Hall. Copyrigth 2013 por Pearson Education 


\subsection{Análisis de la Competencia}

Según David (2013), una parte importante es identificar a los rivales y determinar sus fortalezas, debilidades, capacidades, oportunidades, amenazas, objetivos y estrategias. Por ello, recopilar y evaluar la información de los competidores es esencial para la formulación exitosa de estrategias. Identificar a los competidores no es fácil, ya que muchas empresas tienen divisiones que compiten en diferentes industrias, además, estas no proporcionan información sobre ventas y ganancias, ni publican su información financiera ni de marketing.

De acuerdo a lo indagado se detectó que los macerados de fruta en pisco era un producto que existía en el mercado, sin embargo, la mayoría provenía de empresas o productores informales y sólo una reducida cantidad de ellos eran formales. Por lo que la información que se pudo obtener de la competencia era escasa. Si bien es cierto, el pisco es un producto bandera del mercado peruano, el producto ofrecido es un derivado, por lo que tiene una ventaja competitiva y un valor diferencial, al ofrecer macerados de fruta en pisco utilizando frutas oriundas del Perú y sabores innovadores que actualmente no existen en el mercado.

\subsubsection{Empresas que ofrecen el mismo producto.}

a) Competidores directos

Para el caso de este estudio se detectó que existían comercializadores y algunas pocas empresas que se dedicaban a la preparación de macerados de frutas en pisco, pero que no cubrían la demanda y en algunos casos no contaban con el registro sanitario respectivo, ni Registro Unico de Contribueynte (RUC). Por ello, se consideró a las empresas que ofrecían el mismo producto: macerados de frutas en pisco. En la tabla 5 se presentó los cuatro competidores y se describió cada uno de ellos. 
Tabla 5

Competidores directos

\begin{tabular}{cl}
\hline Empresa & \multicolumn{1}{c}{ Descripción } \\
\hline & $\begin{array}{l}\text { Realizan macerados elaborados con Pisco } \\
\text { Quebranta. El proceso de elaboración es artesanal, } \\
\text { los productos con licores gourmet de alta gama, no } \\
\text { utilizan químicos, colorantes, saborizantes o } \\
\text { esencia, sólo productos naturales de alta calidad. } \\
\text { Los macerados cuentan con registro sanitario. } \\
\text { Cuenta con 5 sabores de macerados de pisco: } \\
\text { canela, limón - naranja, cramberry (arándano } \\
\text { rojo), uva borgoña y kion al precio de S/. 60 en } \\
\text { botella de 500ml. }\end{array}$ \\
\hline
\end{tabular}

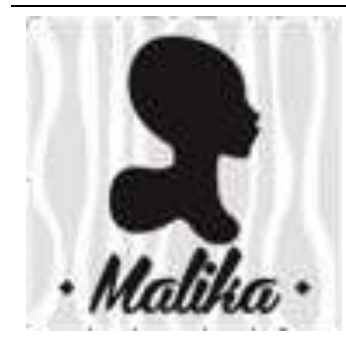

Preparan macerados de pisco utilizando distintos frutos y hierbas con intensos sabores y aromasUtiliza Pisco Quebranta Premium peruano, con frutos exóticos y finas hierbas, embotellados en envases de $500 \mathrm{ml}$. No contiene preservantes, saborizantes ni colorantes. Tienen 7 presentaciones diferentes de sabores cítricos y picantes que contienen $40 \%$ de alcohol. El pisco preserva los insumos en perfectas condiciones por un periodo de un año. Los sabores son: rocoto, maracuyá,

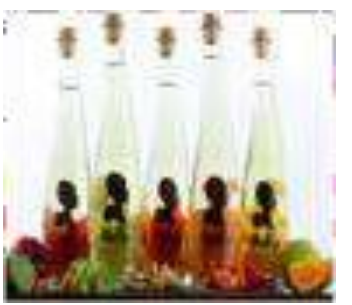
toronja y canela, ají amarillo, lima, ají limo y naranja y aguaymanto.

Se dedica a la producción y comercialización de
macerados de pisco quebranta con frutas peruanas.
Ofrecen 4 variedades como el de maracuyá, el de
naranja, mandarina, limón y kion, el de canela y
clavo y por último el de aguaymanto. Tienen dos
presentaciones una botella tradicional de 500ml y
una botella pequeña de 187ml. Utilizan productos
$100 \%$ naturales y peruanos.

Nota. Tomado de las páginas web de cada empresa. Recuperado https://www.socialtools.me/index.php?action=accessApps\&app_id=330011\&section=product os \& https://www.facebook.com/malika.macerados/ \& http://badega.com/pisco-macerado-deaguaymanto-500-ml/\#.VXtunsvv7qA \& http://sinkaperu.com/ 
b) Competencia indirecta

Se consideró como competencia indirecta a las marcas de pisco que venden en el mercado actual, ya que al ser grandes empresas podrían ofrecer derivados del pisco.

En la tabla 6 se puede apreciar la descripción de los competidores indirectos.

Tabla 6

Competidores indirectos

\begin{tabular}{cl}
\hline Empresa & \multicolumn{1}{c}{ Descripción } \\
\hline 9 & $\begin{array}{l}\text { Además de que tiene botellas en formas de huacos, es uno de } \\
\text { los piscos más agradables. Ofrece pisco moscatel, Pisco Puro, } \\
\text { Italia o Acholado. }\end{array}$ \\
\hline
\end{tabular}

Es un pisco elaborado en Ica, se jactan de tener la destilería
más antigua de toda América Latina.

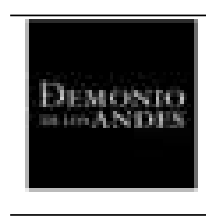

Es de la bodega de Tacama, elaborado con uvas quebranta y

Pisco puro.

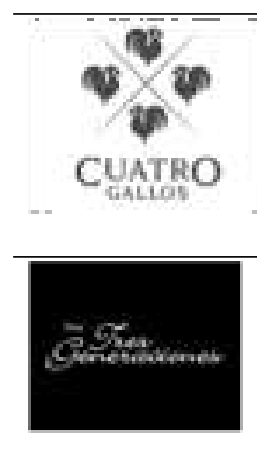

Produce un pisco único y marcando la diferencia. Se inspiran en la tradición y modernidad para el preparado de su pisco.

Es la única empresa liderada por una mujer, la maestra pisquera Juanita Martínez de Gonzáles, reconocida como "La dama del pisco". Ofrecen pisco de alta calidad producto de su selección de uvas.

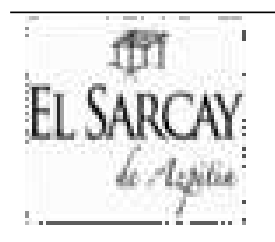

Ocho amigos residentes en Azpitia compartieron la misma idea, producir un pisco de altísima calidad, el mejor entre todos. Una tradición de más de 400 años, resguardada por familias y maestros pisqueros que han sabido mantener la caldiad del pisco, reconocida mundialmente.

Nota. Tomado de las páginas web de cada empresa. Recuperado de https://botilleria365.com/592-pisco-biondi-italia.html \&https://www.piscoporton.com/ \& https://www.piscotresgeneraciones.com/ \& http://www.cuatrogallos.com.pe/ \& http://www.elsarcay.pe/ 


\subsubsection{Participación de mercado de cada uno de ellos.}

Según David (2013), es importante conocer la proporción de productos o servicios que un negocio vende, comercializa en un determinado lugar. Así se podrá conocer cuál es la participación de una empresa y la posición que ocupa dentro de la competencia.

Debido a que eran pocas empresas que ofrecían este producto, macerados de frutas en pisco y no eran tan conocidas, no existía un estudio o información que ayude al estudio a tener la participación de cada competidor. Sin embargo, como se ha mencionado anteriormente el consumo de pisco aumentó en un 4\% en comparación con el 2016.

Además, dentro de sus competidores directos, RR Macerados, era el que tenía más presencia en el mercado, ya que incluso ellos vendían y estaban presentes en el Boulevard de Asia. En cambio, otras marcas, para poder vender solo contaban con su página web y redes sociales. En la figura 4 se muestra los porcentajes de las empresas de macerados.

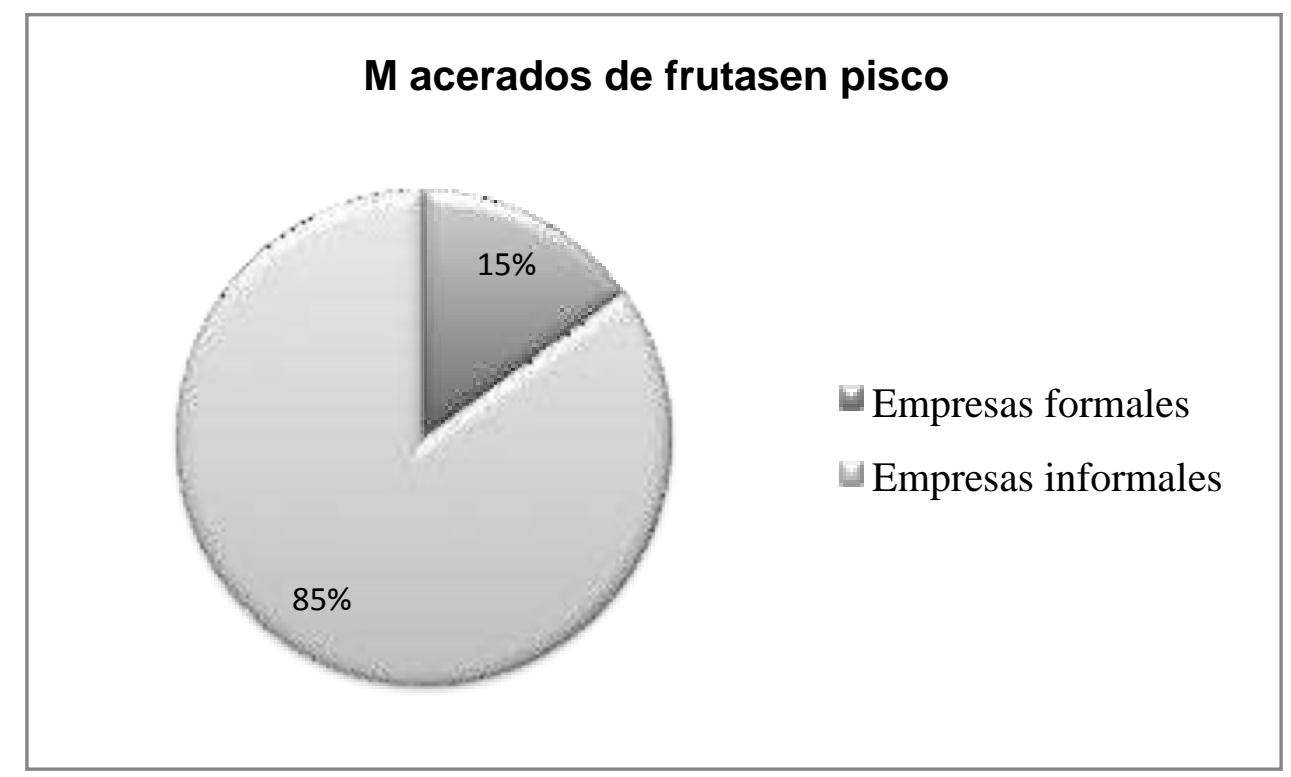

Figura 4. Participación de empresas formales e informales en Macerados de frutas en pisco. Adaptado de "Macerados de pisco: una alternativa que gana presencia en el segmento gourmet", Gestion.pe, febrero 2016. Recuperado de https://gestion.pe/empresas/maceradospisco-alternativa-que-gana-presencia-segmento-gourmet- 2154860 


\subsubsection{Matriz de Perfil Competitivo.}

La Matriz de Perfil Competitivo (MCP) es una herramienta que identifica y compara a los principales competidores y resalta sus fortalezas y debilidades (David, 2013).

La MCP cuenta con siete factores de éxito que se obtuvo de los expertos luego de realizar las entrevistas a profundidad tomando en cuenta los criterios más importantes (Ver anexos de \# 2 al \# 11). El primero fue el reconocimiento de marca, la que obtuvo una calificación de uno, siendo la debilidad principal, debido a que será un negocio nuevo. (David, 2013).

El segundo factor es el respaldo financiero, el cual es necesario para afrontar cualquier imprevisto o inconveniente y poder desarrollar el proyecto, obtuvo una calificación de tres ya que es considerada una fortaleza menor, ya que se cuenta con un capital inicial y el préstamo no es una cantidad muy elevada.

El tercer factor es la calidad del producto, esta obtuvo una puntuación de 4, es una fortaleza principal de HECHIZO, ya que se usa insumos de calidad y los procesos son supervisados por un experto.

El cuarto factor es el experto en la elaboración del producto, obtuvo una puntuación de cuatro siendo una fortaleza principal porque se necesita una persona especialista en la preparación que lleve a cabo todos los procesos para que el resultado sea un producto uniforme y se pueda repetir todas las veces necesarias.

El quinto factor es el plan de marketing, obtuvo una calificación de dos, siendo un debilidad menor, esto se debe a que al ser nuevos se necesita una estrategia fuerte para ser reconocidos en el mercado.

El sexto factor de éxito es la presentación innovadora que obtuvo una calificación de cuatro, siendo una fortaleza principal, ya que se ofrece un diseño distinto al tradicional y donde la forma de la botella transmite el signficado del nombre del producto: HECHIZO. 
Finalmente el séptimo factor, fue la distribución, obtuvo la califcación de uno, siendo la debilidad principal, debido a que se vende por internet y en licorerías, lo cual es limitado, sin embargo el ingreso a los retails es muy costoso.

Se estableció un mayor puntaje de ponderación (0.20) a los siguientes factores de éxito: respaldo financiero y experto en la elaboración del producto. Con respecto a la calidad del producto y el plan de marketing se estableció una ponderación de $(0.15)$ y en caso de el reconocimiento de marca, presentación innovadora y distribución se estableció una ponderación de (0.10).

En la tabla 7, se muestra el análisis que se realizó a los competidores directos con respecto a los macerados de frutas en pisco.

El número uno indica la debilidad principal, el número dos indica la debilidad menor, el número tres indica la fortaleza menor y el número cuatro indica la fortaleza principal.

Tabla 7

Matriz de Perfil Competitivo

\begin{tabular}{|c|c|c|c|c|c|c|c|}
\hline \multirow{2}{*}{$\begin{array}{l}\text { Factor Clave } \\
\text { de Éxito }\end{array}$} & \multirow{2}{*}{ Pond. } & \multicolumn{2}{|c|}{ HECHIZO } & \multicolumn{2}{|c|}{ RR Macerados } & \multicolumn{2}{|c|}{ Malika } \\
\hline & & Cal. & Punt. & Cal. & Punt. & Cal. & Punt. \\
\hline $\begin{array}{l}\text { 1. Reconocimiento de } \\
\text { marca }\end{array}$ & 0.1 & 1 & 0.1 & 2 & 0.2 & 1 & 0.1 \\
\hline 2. Respaldo financiero & 0.2 & 3 & 0.6 & 3 & 0.6 & 3 & 0.6 \\
\hline 3. Calidad del producto & 0.15 & 4 & 0.6 & 4 & 0.6 & 3 & 0.45 \\
\hline $\begin{array}{l}\text { 4. Experto en la } \\
\text { elaboración del producto }\end{array}$ & 0.2 & 4 & 0.8 & 4 & 0.8 & 3 & 0.6 \\
\hline 5.Plan Marketing & 0.15 & 2 & 0.3 & 3 & 0.45 & 1 & 0.15 \\
\hline $\begin{array}{l}\text { 6. Presentación } \\
\text { innovadora }\end{array}$ & 0.1 & 4 & 0.4 & 2 & 0.2 & 1 & 0.1 \\
\hline 7. Distribución & 0.1 & 1 & 0.1 & 3 & 0.3 & 1 & 0.1 \\
\hline Resultado & 1 & & 2.9 & & 3.15 & & 2.1 \\
\hline
\end{tabular}

Nota. Tomado de Conceptos de Administración Estratégica, por David, F. R., 2013, México: Pearson Editorial. Recuperada de http://www.academia.edu/16434996/Conceptos-deadministracion-estrategica-14edi-david_1_ 
Según el resultado de factores de éxito, HECHIZO obtuvo una puntuación de 2.9, colocándose en el medio, ya que RR Macerados obtuvo 3.15 debido a que lleva más tiempo en el mercado y Malika obtuvo 2.1, a pesar de que lleva algunos años en el mercado no ha logrado tener presencia.

\subsection{Análisis del Contexto Actual y Esperado}

El macerado de frutas en pisco, pertenece al sector de "Bebidas Alcohólicas". Sector compuesto no solo por el pisco y sus derivados, sino también por toda clase de licores, destilados, cervezas y todo tipo de bebidas alcohólicas que se producen, importan y comercializan en Perú. El comportamiento de este sector demostró un crecimiento sostenido los últimos años. Desde que en el 2005 se declaró como producto bandera, esto ha favorecido su posicionamiento, consumo y entrada a nuevos mercados considerado como un producto de calidad, según lo informado por INDECOPI. En la figura 5 se mostró el consumo per cápita de bebidas alcohólicas en países de Lationamerica y el Perú consume 8.1 litros.

De acuerdo a lo comunicado por PRODUCE la producción de Pisco en el 2017 fue de 10.7 millones de litros, se dice que el crecimiento alcanzó 14.3\% (Ministerio de la Producción), en comparación con la del 2016 fue de 10.5 millones de litros, con un crecimiento del $10.2 \%$, gracias a que se ha ingresó a nuevos mercados y a las campañas e iniciativas del gobierno por alentar el consumo de pisco convirtiéndolo en la tercera bebida de mayor consumo. En este mismo artículo mencionan que las exportaciones de pisco crecieron en $12.6 \%$ y que la producción de este tuvo un crecimiento anual del 10.8\%. Existen 523 empresas productoras de pisco en todo el Perú. (Pisco: Producción alcanzó, Gestión.pe, 2017).

De acuerdo a lo informado por INDECOPI, el Pisco es la segunda bebida alcohólica más consumida por los peruanos con 9. 074.250 litros, precedida por el ron con 9.310.500 
litros. Según la Organización Panamericana de la Salud (OPS), Perú es un país con un consumo alto per cápita de alcohol en toda la región (Ver figura 5).

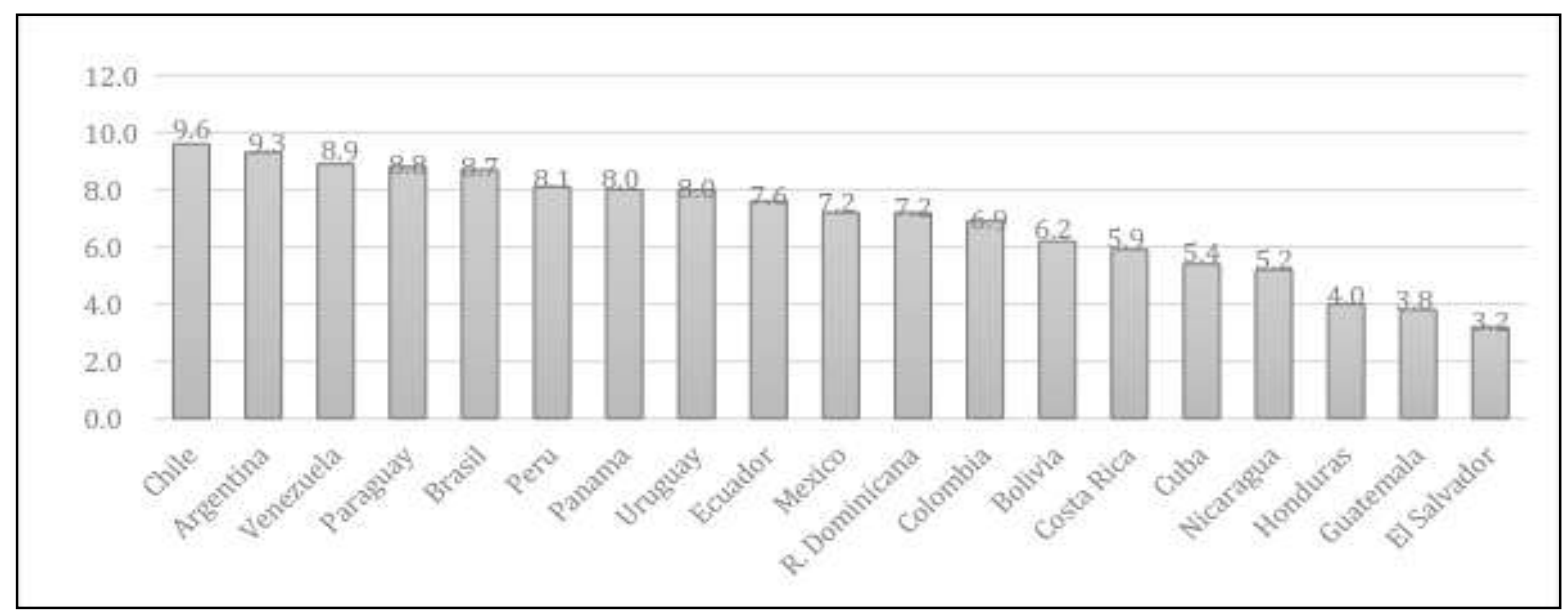

Figura 5. Consumo per Cápita de Bebidas alcohólicas en América Latina según país. Medida Litros. Adaptado de "Observatorio de Mercados" por Gerencia de Estudios Económicos, INDECOPI, Año 10, No 33, Septiembre 2016, p. 20. Recuperado de https://www.INDECOPI.gob.pe/documents/474320/633971/N\%C2\%B0+33++Setiembre+2016+Pisco.pdf/c61 abd40-6d20-4e57-9ef6-7b916fbee86d?version=1.0

Se puede concluir entonces, que el consumo de Pisco y el mercado de "Bebidas Alcohólicas" en el Perú, sigue en crecimiento. Entonces dada esta coyuntura de promoción e incentivo de consumo y producción de pisco se quiere probar a través de este estudio la aceptación de los macerados de fruta en pisco.

\subsubsection{Análisis Político - Gubernamental.}

Según David (2013), el entorno político gubernamental, son entes quienes vigilan y controlan las organizaciones. Por lo tanto pueden representar oportunidades o amenazas para las organizaciones. Porque la estabilidad o subvenciones que dan los gobiernos permiten que estas puedan operar con tranquilidad, estas son algunas de las variables que se deben tener en cuenta.

De acuerdo a lo mencionado anteriormente, el Pisco fue declarado como "producto bandera“ en el 2005. Esta denominación fue promovida por el Ministerio de Comercio Exterior y Turismo (MINCETUR), con el objetivo de que las exportaciones crecieran (Los productos bandera de Perú, Gestión.pe, 2015). 
El Gobierno orientado a la promoción del Pisco a través de las entidades del estado como PRODUCE, que apoya el proceso de la producción y la promoción interna y fuera del país. El MINCETUR, quien está a cargo de las negociaciones internacionales y se encarga de impulsarlo, negociar facilidades para el ingreso del pisco a otros mercados. INDECOPI, quien otorga la Denominación de Origen. Instituto Nacional de la Calidad (INACAL), que se preocupa por que la calidad ofrecida cumpla con los estándares de nivel internacional. La Dirección General de Salud Ambiental e Inocuidad Alimentaria (DIGESA), quien vigila, fiscaliza y establece normas sobre inocuidad en la producción (INDECOPI, 2016).

La estabilidad económica y jurídica para las inversiones. La actual coyuntura política, tiene la economía retraída, hasta el momento el gobierno ha asegurado su apoyo al desarrollo de nuevos negocios, se espera llegar a la estabilidad para seguir con el crecimiento que se ha tenido hasta el momento y que esto no afecte al proyecto.

El Presidente Pedro Pablo Kuczynski en su mensaje del 28 de Julio del 2017, confirmó que se ha diseñado un plan con acceso a crédito para la pequeña y mediana empresa, esto permitirá tener un régimen tributario y que la carga impositiva sea menor, se pueda acceder a crédito, formalizar trabajadores, ser sostenible y permita el crecimiento y desarrollo para este sector, estas medidas tendrían un impacto positivo para el estudio del proyecto. Con las medidas que el gobierno está tomando como combatir la corrupción, lo destinado para la Reconstrucción con cambios, por los daños ocasionados por el Niño Costero, orden fiscal, baja inflación, reducción de la deuda pública, Inversión en infraestructura, reactivación de la economía dándole tranquilidad a los inversores en el sector minero, crecimiento de las exportaciones, reforma del sistema judicial, desarrollo de la industria, la implementación de un programa de acceso a viviendas. Con todas estas medidas el gobierno espera que se active la economía (Mensaje a la Nación, La República.pe, 2017) 


\subsubsection{Análisis Económico.}

Las variables económicas como por ejemplo políticas monetarias, fiscales, tasas de impuestos, desempleo, tasas de interés, de inflación, nivel de ingresos disponibles, entre otras se deben tomar en cuenta pues constituyen oportunidades y amenazas para las organizaciones (David, 2013).

Según el Banco Mundial (2017), el Perú ha sido una economía con un crecimiento promedio de $5.9 \%$ en la última década. Esto debido a las políticas aplicadas que generaron un ambiente de crecimiento y han dado como resultado que la inflación sea baja. La tasa de pobreza ha bajado, tanto la moderada como la extrema, reporta que entre el 2004 y el 2015 , un total de 9 millones de peruanos dejaron de ser pobres. Gracias a la minería es que la economía creció en 3.9\% en el 2016. Se estima que para este año 2017, el crecimiento tenga una desaceleración, por la estabilidad del sector minero, la baja Inversión privada y por los escándalos de corrupción. El detenimiento del crecimiento de la economía de China, la política monetaria de Estados Unidos, volatilidad de los mercados de capital. Sumado a eso lo que ha afectado en el Norte del Perú, el fenómeno de El Niño.

El crecimiento sostenido del PBI, de acuerdo a la figura 6, de información obtenida del Instituto Nacional de Estadística e informática, la economía peruana está pasando por una fase de desaceleración y las proyecciones estarán supeditadas a la evolución de las expectativas de las empresas y consumidores. Vemos que el 2016 el PBI ha comenzado a crecer en 3.9\% en comparación del 2015 en que tuvo una ligera mejora en comparación con el año 2014, este crecimiento sostenido se dio gracias a las actividades primarias como la pesca y minería. Toda esta desaceleración fue resultado de la baja Inversión privada y pública, menor productividad y competitividad del país (Ver figura 6). 


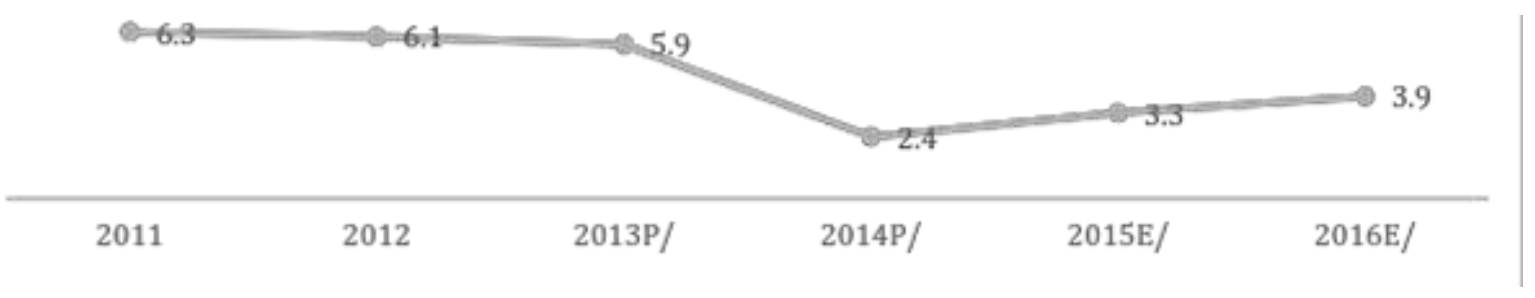

Figura 6. Producto Bruto Interno - Variación \%. Tomado de "Producto Bruto Interno según Actividad Económica (Nivel 14) 1994 - 2016 (Valores a precios constantes de 2007) “, por Instituto Nacional de Estadísticas e Informática (INEI), 2017. Recuperado de https://www.inei.gob.pe/media/MenuRecursivo/indices_tematicos/pbi_act_econ_n14_kte_19 94-2016.xlsx

Se observa que en el año 2016 la inflación se ubicó en un nivel superior al comportamiento que tuvo los años anteriores, en la figura 7 se observa que en el 2015 la tasa fue de $4.40 \%$, y en los años 2013 y 2014 con una variación del $2.86 \%$ y $2.65 \%$ respectivamente. Se prevé que la inflación baje, de hecho Perú tiene la inflación anualizada menor en América Latina.

Una inflación baja es una condición necesaria para promover la Inversiónprivada. En caso de que la inflación tenga una alza impactaría en los precios de producción y perjudicaría las ventas, ya que las personas disminuirían el consumo al no ser un producto de primera necesidad. Sin embargo, es una cadena porque no solo afectaría a la empresa, sino a los proveedores ya que disminuirían las compras de insumos.

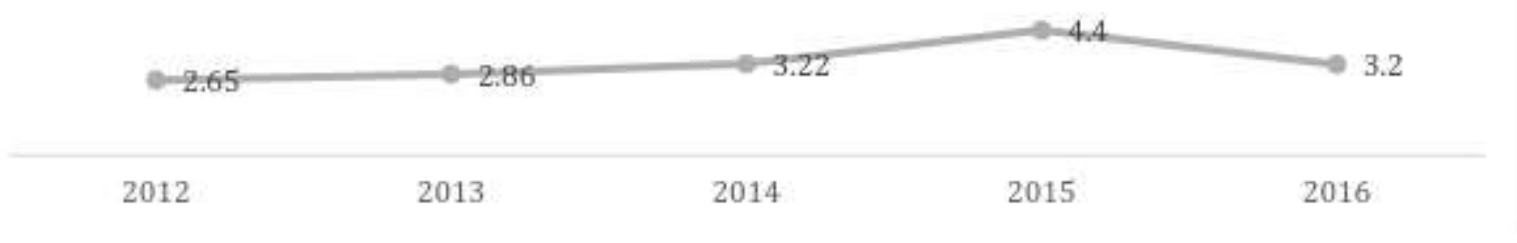

Figura 7. Tasas de inflación (Variación porcentual \%.). Tomado de “ Boletín de Producción Manufacturera: Reporte de Producción Manufacturera“, Oficina de Estudios Económicos, por PRODUCE, Mayo 2017. p.19. Recuperado de http://demi.produce.gob.pe/images/publicaciones/publieb494f7047e46459c_11.pdf

Según el Banco Central de Reserva ajustaría si fuera necesario la política monetaria para garantizar que los niveles de inflación se mantengan entre un rango de $1 \%$ y $3 \%$.

El tipo de cambio, de acuerdo a lo que se observa en la tabla 8 está propenso al alza. 
La coyuntura política actual, la incertidumbre lleva a los inversores extranjeros a demandar dólares. A lo que va del año el dólar registró un alza de 3.28\%. Sin embargo, esta situación no nos afecta ya que todas las ventas, deudas y compras son en soles (Ver tabla 8).

Tabla 8

Tipo de Cambio anualizado

\begin{tabular}{ccccccc}
\hline Año & 2011 & 2012 & 2013 & 2014 & 2015 & 2016 \\
& & & & & & \\
\hline Promedio de tipo de cambio & 2.75 & 2.64 & 2.70 & 2.84 & 3.19 & 3.40 \\
\hline
\end{tabular}

Nota. Adaptado de “ Boletín de Producción Manufacturera: Reporte de Producción Manufacturera”, Oficina de Estudios Económicos, por PRODUCE, Mayo 2017. p.19. Recuperado de http://demi.produce.gob.pe/images/publicaciones/publieb494f7047e46459c_11.pdf

Según la Comisión Económica para América Latina y el Caribe (CEPAL), proyectó que para el 2017, la economía en Perú tendrá un crecimiento del 2.5\%. Lo que es positivo para el desarrollo de la viabilidad del estudio.

Lo que favorecerá al estudio es el incremento del gasto general del Gobierno que busca el incentivo para el crecimiento de la pequeña empresa, el panorama internacional favorable, hace que se proyecte una tasa de crecimiento superior al 4\% para el 2018 lo que significa una reactivación económica para el país.

El crecimiento de la población en Perú ha desacelerado, se ha dado cuando en los 90 comenzó la migración, las tasas de fecundidad son menores, las tasas de nacimiento también, por lo tanto, las tasas de crecimiento de la población. Se prevé que para el año 2025-2030 la fuerza de trabajo que hoy está subiendo, dejará de crecer. El promedio de hijos que tienen las mujeres en Lima es de 1.8. La mayoría de población en edad de trabajar se encuentra en Lima y Callao. En el Perú la población aporta un tercio del PBI, si no hay crecimiento solo queda el ingreso per cápita que es $1 \%$ anual (Taipe, 2017).

Impulsados por el crecimiento de la economía, el porcentaje de la Población Económicamente Activa (PEA) con empleo aumentó y los ingresos también, como se aprecia en la tabla 9. Según lo informado por INEI el desempleo entre 2004 y 2014 bajó de 5.1\% a 
3.7\%. En Perú el problema principal es el subempleo. Por lo que $40 \%$ de la PEA trabaja en una actividad que no es la que estudió (Ver tabla 9).

Tabla 9

Población Económicamente Activa

\begin{tabular}{lrrrrr}
\hline & \multicolumn{1}{c}{2012} & \multicolumn{1}{c}{2013} & \multicolumn{1}{c}{2014} & \multicolumn{1}{c}{2015} & \multicolumn{1}{c}{2016} \\
\hline PEA & 16142.1 & 16328.8 & 16396.4 & 16498.1 & 16500.0 \\
Población Inactiva & 5797.7 & 5974.5 & 6272.2 & 6536.1 & 6600.0 \\
\hline \multicolumn{1}{c}{ Total } & 21939.9 & 22303.4 & 22668.6 & 23034.2 & 23100.0
\end{tabular}

Nota. Adaptado de "Boletín de Producción Manufacturera: Reporte de Producción Manufacturera“, Oficina de Estudios Económicos, por PRODUCE, mayo 2017. p.19. Recuperado de http://demi.produce.gob.pe/images/publicaciones/publieb494f7047e46459c_11.pdf INEI https://www.inei.gob.pe/estadisticas/indice-tematico/economically-active-population/

\subsubsection{Análisis Legal.}

Para David (2013), el análisis legal también tiene repercusión en el funcionamiento de las organizaciones pues un cambio en las leyes, en regulaciones gubernamentales, en ley de la política fiscal, en las políticas sobre el trabajador, concesiones, legislación antimonopolio tienen de hecho un efecto para bien o para mal.

En este sentido en el contexto de este sector hay varias leyes y regulaciones que se deben tener en cuenta y aprovechar para el desarrollo del estudio:

- Ley No. 30460, Ley que declara de interés nacional la promoción y difusión del Vino Peruano y del Pisco como bebidas Nacionales, en la que promociona la imagen, marca, producción, comercialización y consumo del Pisco Peruano. En ese sentido estas actividades facilitarán el estudio pues se aprovechará de este incentivo de promoción que darán oportunidades para aceptación de los macerados de pisco (Ley No. 30460).

- Decreto Supremo No. 001-91-ICTI/IND, del 16 de enero de 1991, y su reglamento Resolución No. 002378-2011/DSD-INDECOPI, en donde el Pisco Peruano es reconocido con Denominación de Origen, esta denominación es solo para los que 
hayan sido producidos con uvas de Lima, Ica, Arequipa, Moquegua, y Valles de Locumba, Sama y Caplina en Tacna. Denominación de Origen, es el nombre que se le da a un producto que es originario de alguna región específica y sus particularidades son únicamente del lugar originario, las denominaciones de origen (DdO) no se crean se declaran. En 2011 se creó el Consejo Regulador de la Denominación de Origen Pisco, quienes son los encargados de dar orientación, vigilar y controlar que la producción y comercialización cumpla con el Reglamento (Consejo Regulador del Pisco).

- Normas para la producción de bebidas alcohólicas, NTP 212.033:2007 y la 212.034.2007 Pisco. Buenas prácticas, en donde se protege la inocuidad para ofrecer un producto de calidad.

- Ley de protección al consumidor

- Ley No. 28681 : Ley que regula la comercialización,consumo y publicidad de bebidas alcohólicas, con la que se busca poner en autos a los consumidores sobre los daños, riesgos, en busca de proteger a menores de edad.

- Ley 30460, que se encarga de promover el consumo y producción del pisco y difundir las características culturales y tradiciones que tienen implicancia en la producción, elaboración y consumo de pisco y vino (El Peruano, 2016).

\subsubsection{Análisis Cultural.}

Los aspectos sociales y culturales deben ser tomados en cuenta, pues las variaciones que se dan impactan en las organizaciones. Por ejemplo David (2013), menciona que actualmente en Estados Unidos hay más personas adultas que jóvenes, lo que generaría un impacto directo si se retiraran en antes de la edad calculada. Las propensiones sociales y culturales dan como resultado formas de vivir y necesidad de productos y demandas 
insatisfechas, lo que aumenta oportunidades y ganancias para las organizaciones. Es decir una oportunidad para aplicar nuevas y exitosas estrategias.

Se consideran como variables culturales las tradiciones y costumbres, que tienen implicancia al momento de decidir la compra del producto. Por eso se consideró que al declarar el pisco con producto de bandera por costumbre el consumo iba aumentar.

En el 2003, el Pisco fue declarado como producto bandera, por tener características únicas que hacen que se les identifique con el Perú, resaltando la imagen peruana, esta declaración se dio con el afán de potenciar las exportaciones, el plan se llamó Plan Nacional Exportador 2003-2013, promovido por MINCETUR (Productos bandera, El Comercio.pe, 2015). La idea se dio para aumentar el consumo y poder posicionar el pisco en mercados internacionales. Por lo tanto, esto ayuda a que HECHIZO tenga oportunidad en el mercado al ser un derivado del producto bandera y los consumidores lo reconozcan como tal y esto incentive su consumo.

El Concurso Bruselas, se lleva a cabo anualmente. En el año 2017, hubo un problema con la denominación de origen, pues el evento se realizó en Chile. Como ya se ha mencionado antes, hay una controversia entre Perú y Chile por la denominación de origen. El reclamo y el retiro de los participantes peruanos se daría porque no los dejaban usar la denominación: Pisco Peruano. INDECOPI, acordó sancionar a los productores de pisco peruano que participaran en este evento. Este tipo de situaciones pone al Pisco en el tapete y muy de moda y crece la identificación de los consumidores peruanos por su producto bandera. Esto ayuda a HECHIZO, ya que al encontrarse esta controversia, tiende a consumir más el producto por patriotismo e identificación.

Otro factor es que por tradición el pisco era percibido como un licor barato y no estaba en la mente del consumidor regalar u ofrecer, sin embargo, en los últimos años, el pisco se ha posicionado y esto ayuda a la preferencia y consumo del producto. Otra variables 
que se identificó que impactarían las decisiones de compra son: la tendencia que tienen los clientes hacia las compras impulsivas, ya que en su mayoría esto sucede cuando van a un retail y ven una oferta atractiva, no valoran el producto solo el precio.

\subsubsection{Análisis Tecnológico.}

David (2013), sostiene que la tecnología es un elemento clave para las organizaciones. El no estar a la vanguardia o alerta a los cambios tecnológicos podría ser desfavorable para la toma de decisiones. La tecnología podría ser una ventaja competitiva que las organizaciones podrían aprovechar. Ya que la tendencia de esta cambia los periodos de vida de productos, haciéndolos más cortos, facilitar la distribución, acercar a mercados y sobre todo ayudar a estandarizar productos. Presenta una nueva forma de plaza, para los consumidores, por lo tanto presenta un abanico de oportunidades y amenazas que se deben tener en cuenta al implementar las estrategias.

De acuerdo a lo informado por el INEI, la facilidad que tienen los peruanos a tener acceso a la tecnología va en aumento, de cada 100 hogares, en 93 hay por lo menos alguna herramienta de tecnología, de acuerdo su boletín informativo del primer trimestre del 2017 (Estadísticas de la Tecnología, 2017).

El uso de tecnología en Perú, va en aumento y es una herramienta que se debe tener en cuenta al realizar el estudio, pues se encontrará información relevante del comportamiento.

Por eso, es importante estar al tanto en los avances en la industria. Tener en cuenta el ciclo de vida y velocidad de la tecnológica. Acceso a nuevas inversiones y desarrollo. Aprovechar de la facilidad de acceso a internet y explotarlo como red para exponer los productos. Aplicar políticas de difusión efectiva de la información a través de redes sociales. Por lo tanto, esto ayuda al proyecto, ya que las ventas se realizan por internet, sin embargo como la tecnología avanza, si aparece otro mecanismo más técnologico nos afecta ya que se debe hacer una nueva Inversión. 


\subsubsection{Análisis Ecológico.}

Las tendencias alrededor del mundo han variado, ahora los mercados exigen productos con certificaciones en Responsabilidad Social, la organizacion cuenta con procesos y funciona de manera amigable con el medio ambiente. Aplica buenas prácticas en la producción de los productos y no contribuye a la contaminación. Tiene un manejo eficiente en desechos. Hace uso eficiente de la energía y tiene en cuenta los costos. Aplica procesos para tener un cuidado responsable del agua, que es un recurso que al Sur del Perú es escaso.

Los factores ambientales como los fenómenos naturales afectarían directamente a la producción del producto ya que se trabaja con frutas y en caso exista escacez de alguna de las frutas, limita a la empresa a ofrecer sus variedades.

\subsection{Oportunidades y Amenazas.}

Se realizó una Matriz de Evaluación de los factores Externos (EFE) donde se resumió y evaluó la información del macro entorno. Se asignó una ponderación a cada factor. El rango es entre 0.0 (no es importante) hasta 1.0 (muy importante). La suma de todos los pesos de los factores asignados deben sumar $100 \%$.

Además, en la tabla 10 se calificó en una escala del uno al cuatro a los factores determinantes para el éxito, con el fin de determinar si las estrategias están respondiendo con eficacia al factor. 
Tabla 10

Matriz de Evaluación de los Factores Externos

\begin{tabular}{|c|c|c|c|}
\hline Factores externos clave & Ponderación & Calificación & $\begin{array}{l}\text { Puntuación } \\
\text { ponderada }\end{array}$ \\
\hline Oportunidades & & & \\
\hline $\begin{array}{l}\text { La aceptación positiva del pisco } \\
\text { en el mercado nacional e } \\
\text { internacional. }\end{array}$ & 0.15 & 4 & 0.6 \\
\hline $\begin{array}{l}\text { El apoyo de los Organismos } \\
\text { gubernamentales. }\end{array}$ & 0.08 & 3 & 0.24 \\
\hline $\begin{array}{l}\text { Leyes que favorecen la producción } \\
\text { del pisco. }\end{array}$ & 0.05 & 3 & 0.15 \\
\hline $\begin{array}{l}\text { Mayor ingreso promedio del } \\
\text { consumidor peruano. }\end{array}$ & 0.08 & 4 & 0.32 \\
\hline Fácil acceso al cliente por internet. & 0.05 & 3 & 0.15 \\
\hline $\begin{array}{l}\text { Apoyo del gobierno en la } \\
\text { promoción del consumo del pisco. }\end{array}$ & 0.05 & 4 & 0.2 \\
\hline $\begin{array}{l}\text { Apoyo del gobierno a las MYPES. } \\
\text { Amenazas }\end{array}$ & 0.08 & 3 & 0.24 \\
\hline Nuevas tecnologías. & 0.10 & 4 & 0.4 \\
\hline $\begin{array}{l}\text { Crisis económica del Perú y del } \\
\text { mundo. }\end{array}$ & 0.06 & 4 & 0.24 \\
\hline Crisis política actual. & 0.09 & 4 & 0.36 \\
\hline $\begin{array}{l}\text { Fenómenos naturales que afectan } \\
\text { el abastecimiento de los insumos. }\end{array}$ & 0.10 & 4 & 0.4 \\
\hline Inflación. & 0.06 & 3 & 0.18 \\
\hline $\begin{array}{l}\text { Gran cantidad de normas } \\
\text { sanitarias y reglamentos por } \\
\text { cumplir. }\end{array}$ & 0.05 & 3 & 0.15 \\
\hline Resultado & 1.00 & & 3.39 \\
\hline
\end{tabular}

Nota.El número 1 significa una respuesta mala, el número 2 una respuesta media, el número 3 una respuesta superior a la media y el número 4 una respuesta superior. Adaptado de "Conceptos de Administración Estratégica" por David, F. R., 2013, México: Editorial Pearson Educación.

El total ponderado de 3.36, que se obtuvo como resultado de la Matriz de Factores externos (EFE), indica que la producción de macerados de frutas en pisco estaba por encima de la media en su esfuerzo para seguir con las estrategias que incrementen las oportunidades externas y así evitar las amenazas. El peso ponderado total de oportunidades fue de 1.9 y las amenazas de 1.7 , lo cual establece que el entorno era favorable para el negocio.

Los pesos fueron determinados según la importancia que cada factor tiene para la industria en la que se encuentra, mientras que la calificación se basó en los macerados de 
frutas en pisco. Por esta razón, se consideraron como principales oportunidades como la aceptación del pisco en mercado nacional e internacional con un peso de 0.15 y una calificación de cuatro.

De igual manera, se identificaron como principales amenazas las nuevas tecnologías y los fenómenos naturales que afectan el abastecmiento de insumos ya que sin la materia prima, no se podrían realizar los macerados, por lo tanto se les asignó un peso de 0.10 y una calificación de cuatro. 


\section{Capítulo III. Estudio de mercado}

Según Malhotra (2008), el estudio de mercado es la identificación, recopilación, análisis, difusión y uso sistemático y objetivo de la información, con el fin de ayudar a la administración y a la toma de decisiones relacionadas con la solución de problemas.

En este capítulo se dio a conocer el producto, sus características y se determinó el segmento al cual está dirigido. Se pretendió conocer el comportamiento del público objetivo, a través de estudios de mercado cualitativos mediante focusgroup y entrevistas a profundidad, y estudios cuantitativos mediante la encuesta. Gracias a este estudio se identificó las necesidades de consumo, preferencias y hábitos.

\subsection{Descripción del producto.}

El pisco peruano es conocido como una bebida espirituosa en Perú, se produce con 7 $\mathrm{kg}$ de uva por litro y se destila una vez en alambique tradicional. Obtiene sus sabores y aromas de la propia destilación como una bebida transparente.

El plan de negocios se basa en la producción de Macerados de frutas en pisco en distintos sabores. El macerado de frutas en pisco es una bebida alcohólica que se consigue mediante un proceso de macerado de distintos frutos en pisco de uva (quebranta) que mantiene las condiciones sensoriales de la materia prima, brindando la mejor calidad y ofreciendo productos sin impurezas.

Para la producción de macerados, se utilizó pisco quebranta que fue comprado en la bodega Bailetti, ubicada en Chincha y que cuenta con denominación de origen. Luego se incorporaron las frutas y especies en el pisco, para iniciar el proceso de maceración. Se pusieron las frutas y especies en un contenedor lleno de pisco, y se dejó macerar por dos meses. Después, se filtró el producto para que vaya limpio, se envasó en botellas de vidrio de tapa ancha, se colocó la fruta deshidratada para que la presentación sea atractiva para el cliente. 
Se contó con un establecimiento para la producción. Sin embargo, el producto planea venderse en licorerías, ferias y otros establecimientos. También se cuenta con la opción de compras online para entregas a domicilio.

Además, posee una presentación distinta al pisco tradicional, que es una botella larga. En este caso, se ofrece una botella redonda Rosettade $750 \mathrm{ml}$ en donde se aprecia la fruta. La etiqueta es transparente y tiene un distintivo peruano. Además, cuenta con un tapón negro y una soga para no perder el toque artesanal. Al ofrecer esta presentación en botella redonda, hace que el producto se disitngade la competencia y rompe esquemas.

La vida útil es de un año y una vez abierto el producto debe mantenerse en un lugar fresco, a temperatura ambiente y debiendo serconsumido antes de los 30 días.

Este producto se puede disfrutar en casa, en eventos familiares o corporativos. En cualquier momento que se le antoje un delicioso cóctel natural, ya que posee el perfecto equilibrio y sabor.

El nombre del producto es Hechizo, el cual significa una atracción misteriosa e irresistible sobre alguien, por lo que al tomar el macerado cautivará al consumidor y no podrá dejar de tomarlo.

Los macerados de frutas en pisco son espirituosos y aromáticos cocteles peruanos que expresan el mejor sabor y variedad del producto bandera. El pisco permite combinar con diferentes ingredientes y abre el abanico de posibilidades de degustarlo e innovar, dándole distintos sabores y aromas. Si lo que el consumidor busca es placer, no puede dejar de probarlo.

En la tabla 11,se apreció la descripción de los tres sabores y presentación del macerado de frutas en pisco. 
Tabla 11

Producto: Macerados de frutas en pisco.

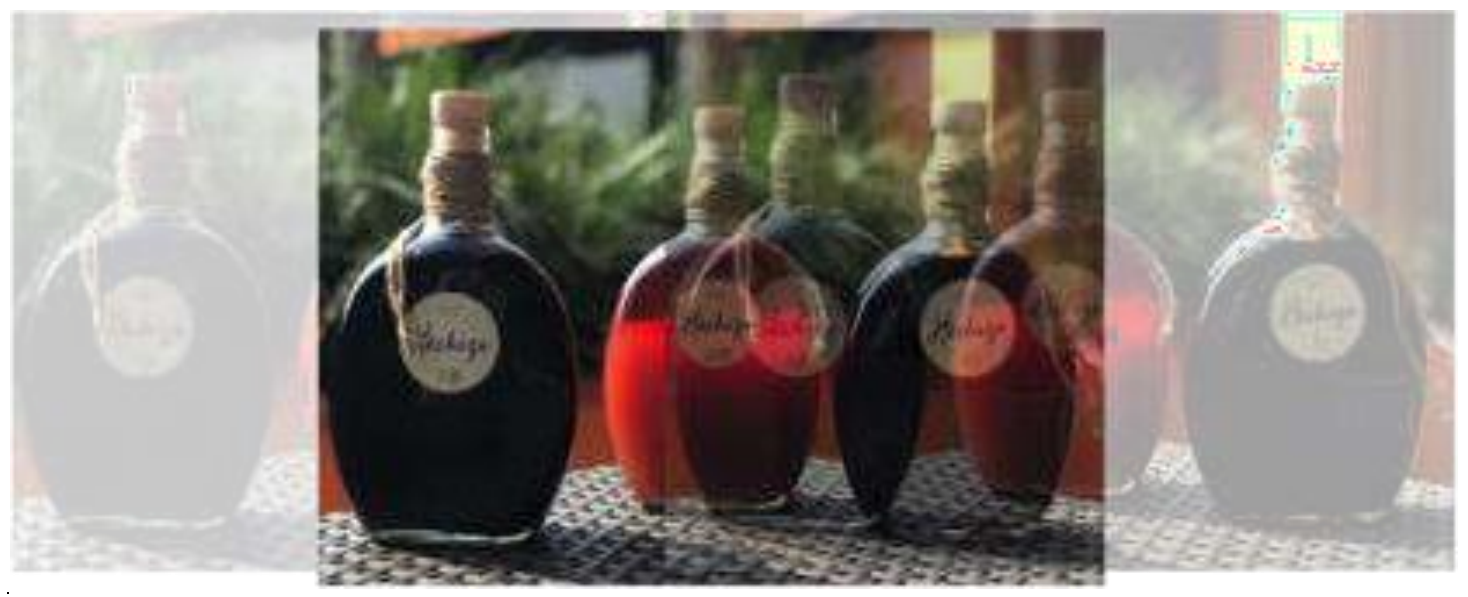

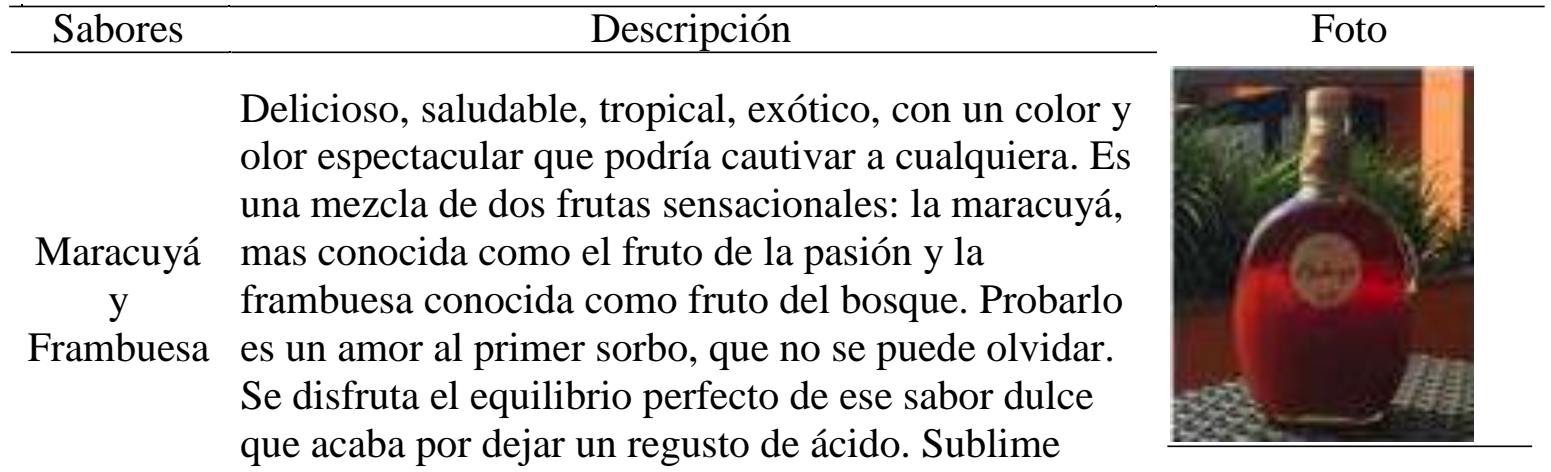
sensación para el paladar.

Unir generaciones y revivir las tradiciones mediante esta mezcla de dos frutos dulces, de aroma intenso y contundente color rojo. La guinda, que dejó un

Fresa y importantísimo legado en la historia y que se quiere

Guinda preservar este emblemático fruto y la fresa, esta delicia que destaca por su dulce sabor y sus propiedades nutricionales. Es un manjar de los dioses, con el toque perfecto de dulzor para disfrutarlo en

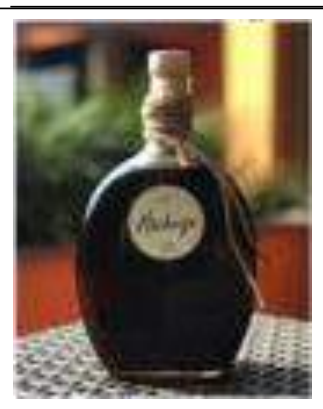
cualquier ocasión.

\section{Chicha} (maíz morado, membrillo y canela)
Refrescante, aroma intenso, color predominante y sabor exquisito. Es una bebida tradicional de la gastronomía peruana, que no podía faltar. Con propiedades medicinales y antioxidante. Esta maravillosa mezcla de sabores logra el extracto natural y así poder disfrutar cada sorbo de este elixir.

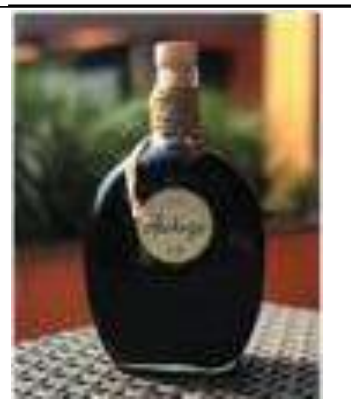




\subsection{Selección del segmento de mercado.}

Para Kotler y Keller (2012), segmentar significa fraccionar los mercados en grupos con características iguales o grupos que tienen distintos gustospara identificar cuál se puede cubrir. Dicho proceso permite enfocar el segmento que mayor aceptación se tendrá. Primero se definió a quién se quiere llegar, elegir cómo se va a dar a conocer los beneficios de la propuesta y la diferenciación con los demás como se observa en la tabla 12.

\section{Tabla 12}

Tipos de Segmentación

\begin{tabular}{ll}
\hline Peográficas & $\begin{array}{l}\text { Por zona específica (Ej. Boomers suburbanos, viejas ciudades } \\
\text { industriales) }\end{array}$
\end{tabular}

Demográficas

Fácil de medir. Clase Social, nacionalidad, nivel, educativo, tamaño de familia, ciclo de Vida, Genero, ingresos.

Nota. Adaptado de "Identificación de Segmentos de Mercado y Mercado Meta, Dirección de Marketing (Cap. 8) México. Pearson Educación.

Para definir el mercado al cual se quiere llegar, se debe tomar en cuenta que el segmento sea medible, accesible, diferenciable, accionable y sustanciable y hacer un análisis de las 5 fuerzas de Porter (Kotler\&Keller, 2012).

En la Tabla 13, se mostró el estudio que se realizó en Lima Metropolitana,donde se concentra el mayor consumo de productos de pisco y derivados como el macerado. Se observó la segmentación geográfica y demográfica en donde se especifica la población por distintas zonas, edades, nivel socioeconómico y género. 
Tabla 13

Segmentación

\begin{tabular}{llr}
\hline Geográfica & Lima Metropolitana & $1,168,953$ \\
& Zona 6 & 386,948 \\
& Zona 7 & 782,005 \\
\hline Demográfica & Nivel socioeconómico A y B & \\
\hline Zona 6 & A & $14.90 \%$ \\
& B & $59.30 \%$ \\
Zona 7 & A & $34.90 \%$ \\
& B & $46.00 \%$ \\
& Hombres & 277,786 \\
Entre 21 años y 65 años & Mujeres & 292,616 \\
\hline
\end{tabular}

Nota. Adaptado de APEIM 2017.

Se eligió este segmento considerando los siguientes factores:

- Las personas del nivel socio-económico A y B representan el 29.4\% del total de la población de Lima Metropolitana y se encuentran concentradas en los distritos que comprenden la Zona 6 y 7 (APEIM, 2017).

- De acuerdo a lo informado por APEIM (2017) el gasto promedio en esparcimiento, diversión, servicios culturales y de enseñanza es de S/.1 321,00 en el NSE A y de S/.800,00 en el NSE B.

- Se ha escogido ese segmento de personas porque son las que estarían dispuestas a consumir los macerados de fruta con pisco, porque les gusta probar propuestas diferentes, les gusta entretenerse y compartir el tiempo con sus pares, familiares.

- La PEA, que la población en edad de trabajar está concentrada en Lima y Callao. 


\subsection{Investigación Cualitativa.}

La investigación cualitativa recopila información a través de la observación en entrevistas, narraciones, notas de campo, grabaciones, transcripciones de audios, de registros de todo tipo. La investigación cualitativa sirve para poder recopilar información de datos primarios y secundarios. Los datos secundarios sirven para obtener información sobre comportamiento de los clientes meta, cuotas de mercado, competidores o reacciones de consumidores y poder ajustar la información a las necesidades de lo que se quiere cubrir. Por eso esta información debe ser actual, relevante, precisa, actualizada y, sobre todo, objetiva.La investigación cualitativa y la cuantitativa son compatibles entre las dos, pues de la información que se obtiene se hace un mix para poder tomar decisiones en cuanto a los resultados obtenidos (Olabuénaga, 2012).

Siguiendo con lo que Olabuénaga (2012) propone, se han considerado los siguientes objetivos para realizar este estudio:

Objetivos generales

- Estudiar el mercado para conocer el precio de los macerados en el mercado y estimar la demanda insatisfecha.

- Identificar las frecuencias y volúmenes según la modalidad de la compra, para poder determinar la viabilidad del proyecto.

Objetivos específicos

- Identificar el precio en el mercado.

- Conocer el flujo y cadena de distribución.

- Identificar procesos de producción y la cadena de abastecimiento.

- Conocer gustos y preferencias de potenciales consumidores.

- Identificar qué los motivaría a comprar los macerados de frutas en pisco. 
Para poder levantar toda la información necesaria se usó las técnicas de investigación como: entrevistas a profundidad y focusgroup. Las entrevistas a profundidad se realizaron a expertos y los focusgroup se conformaron con personas de acuerdo a la segmentación establecida.

Según Gonzáles (2007), el focusgroup es una técnica cualitativa que tiene una duración entre 60 y 120 minutos con un grupo limitado de personas que reúnen características comunes para su selección y que son guiadas por un moderador, quien es encargado de conducir la sesión en base a una guía. Mediante esta técnica se puede conocer las opiniones de los participantes con respecto a un asunto o tema determinado.

Para Robles (2011), las entrevistas a profundidad sirven para recabar información detallada sobre las prácticas o experiencias de otros. La describe como una herramienta que sirve para poder investigar, observar, analizar a través de consultas, información que será importante para el investigador. También indica que no se deben hacer juicios de valor y debe desarrollarse en ambientes y situaciones en donde se pueda obtener la mayor cantidad de información.

\subsubsection{Proceso de muestreo.}

Hernández, Fernández, y Baptista (2010), indicaron que el proceso de muestreo cualitativo se fundamenta en la metodología de recopilación de datos que no son determinados ni con un estándar definido por lo tanto la forma de medición no es cuantitativa, lo que no refleja una investigación detallada. Para dar forma a este proceso es clave obtener información de los participantes. Para desarrollar este proceso se desea saber las opiniones y apreciaciones tales como emociones, conocimientos y experiencias de personas o grupos de personas dentro de un contexto o realidad.

Hernández et al. (2010), mencionan que uno de los métodos de muestreo cualitativo es el de "bola de nieve" o por redes. Este método tiene la particularidad de ayudar a la 
selección de participantes que se ajusten al tema planteado en la investigación y estos a su vez pueden contactar a otras personas que aportaron conocimientos sobre el tema.

Este fue el método que se utilizó para captar a los participantes para los focus group, con la finalidad de asegurar la calidad de la información y también ampliar los conocimientos y experiencias sobre el tema planteado.

En este método el investigador recopila los datos al interactuar de manera directa con los participantes, creando un escenario para conocer sus opiniones, manera de actuar y como se desenvuelven. Se planteó la realización de cuatro focusgroup para los cuales participaran entre 6 a 12 personas por cada uno. Los participantes fueron seleccionados tomando como principal característica la preferencia por el consumo de bebidas alcohólicas, teniendo como preferencia al pisco en algunas de sus presentaciones. Se elaboraron preguntas exploratorias para que los participantes puedan brindar sus ideas, comentarios, sugerencias, experiencias y además puedan intercambiar opiniones entre ellos sobre el tema planteado.

La información que se obtuvo al utilizar esta técnica es conocer la aceptación de los macerados de frutas en pisco por lo que los siguientes objetivos en la tabla 14 .

Tabla 14

Objetivos de focusgroup

\begin{tabular}{ll}
\hline Objetivos & \multicolumn{1}{c}{ Descripción } \\
\hline General & $\begin{array}{l}\text { Identificar el nivel de aceptación de los macerados de fruta en pisco de } \\
\text { varios sabores. }\end{array}$ \\
& Determinar las características del producto que el cliente espera. \\
& Conocer la frecuencia de consumo \\
& Identificar las variables determinantes al momento de la compra. \\
& Conocer si la presentación tiene mayor aceptación. \\
& Determinar el nombre más adecuado para el producto. \\
& Conocer si los sabores son los adecuados
\end{tabular}


Se realizaron cuatro focusgroup, los cuales fueron segmentados en la tabla 15:

Tabla 15

Focusgroup

\begin{tabular}{|c|c|c|}
\hline Grupos & \multicolumn{2}{|l|}{ Descripción } \\
\hline Grupo 1 & \multicolumn{2}{|c|}{5 hombres y 2 mujeres, 21 a 65 años, Zona 6 y 7 , NSE A y B } \\
\hline \multirow{5}{*}{ Detalle } & \multicolumn{2}{|c|}{ Zona 6} \\
\hline & \multicolumn{2}{|c|}{ Mujer, 27 años, Pueblo Libre Hombre, 29 años, Lince } \\
\hline & \multicolumn{2}{|c|}{ Zona 7} \\
\hline & Mujer, 30 años, San Borja & Hombre, 28 años, La Molina Hombre, 25 años, San Isidro \\
\hline & Hombre, 29 años, San Borja & Hombre, 27 años, Surco \\
\hline Grupo 2 & \multicolumn{2}{|c|}{4 hombres y 3 mujeres, 21 a 65 años, Zona 6 y 7 , NSE A y B } \\
\hline \multirow{5}{*}{ Detalle } & \multicolumn{2}{|c|}{ Zona 6} \\
\hline & Mujer, 62 años, Lince & Hombre, 36 años, Lince \\
\hline & \multicolumn{2}{|l|}{ Zona 7} \\
\hline & Mujer, 38 años, Miraflores & Hombre, 55 años, La Molina \\
\hline & \multicolumn{2}{|c|}{ Hombre, 42 años, Miraflores Hombre, 59 años, Surco } \\
\hline Grupo 3 & \multicolumn{2}{|c|}{4 mujeres y 3 hombres, 21 a 65 años, Zona 6 y 7 , NSE A y B } \\
\hline \multirow{5}{*}{ Detalle } & \multicolumn{2}{|c|}{ Zona 7} \\
\hline & Mujer, 24 años, Surco & Hombre, 60 años, Surco \\
\hline & Mujer, 21 años, Surco & Hombre, 43 años, San Borja \\
\hline & Mujer, 63 años, Surco & Hombre, 60 años, La Molina \\
\hline & Mujer, 58 años, Surco & \\
\hline Grupo 4 & \multicolumn{2}{|c|}{4 mujeres y 3 hombres, 21 a 65 años, Zona 6 y 7 , NSE A y B } \\
\hline \multirow{5}{*}{ Detalle } & Mujer, 36 años, San Borja & Mujer, 28 años, Surco \\
\hline & Mujer, 34 años, San Borja & Mujer, 35 años, Surco \\
\hline & Hombre, 24 años, San Borja & \\
\hline & Hombre, 33 años, San Borja & \\
\hline & Hombre, 34 años, San Borja & \\
\hline
\end{tabular}

Otros de los métodos seleccionados fueron las entrevistas a profundidad a expertos en el tema planteado, para conocer los procesos de producción, medios de distribución y costos en la elaboración de macerados de frutas. Para la selección de las seis personas se consideraron algunas características relacionadas con la investigación planteada. Se entrevistaron a dos gerentes de reconocidas bodegas de pisco a nivel nacional para recopilar información sobre los procesos de producción y costos de utilidad para la investigación. Se realizaron entrevistas a dos productores artesanales de macerados para conocer los procesos aplicados en la elaboración del producto. También se entrevistó al ex vice ministro de la 
producción. Esto con la finalidad de obtener información sobre cómo se desarrolla el sector, los costos y las políticas que impulsan a la promoción de los productos. Para terminar con las entrevistas a profundidad se estableció contactar a un sommelier para que pueda exponer sus conocimientos sobre los macerados de frutas en pisco, expresar comentarios sobre los sabores, mezclas y presentaciones de productos y preferencias del consumidor.

Los puntos que se tocaron en las entrevistas a profundidad son lo que se detallan continuación en la tabla 16.

Tabla 16

Objetivos de las entrevistas a profundidad

\begin{tabular}{|c|c|c|}
\hline Objetivos & & Descripción \\
\hline General & $\begin{array}{l}\text { El objetivo de } 1 \\
\text { competidores, } \mathrm{b} \\
\text { entre otros que } \\
\text { empresas que c } \\
\text { macerados de fl }\end{array}$ & $\begin{array}{l}\text { a entrevista a profundidad es obtener la mayor información sobre } \\
\text { uenas practicas, demanda actual, procesos operativos, temas legales, } \\
\text { sean de utilidad para el desarrollo del estudio del proyecto basada } \\
\text { uentan con la experiencia en producción y comercialización de piscos y } \\
\text { utas. }\end{array}$ \\
\hline \multirow{4}{*}{ Específicos } & $\begin{array}{l}\text { Area } \\
\text { Administrativa }\end{array}$ & $\begin{array}{l}\text { Identificar perfil del especialista y determinar cantidad de personal } \\
\text { necesario. } \\
\text { Identificar el marco legal. }\end{array}$ \\
\hline & $\begin{array}{l}\text { Area de } \\
\text { Operaciones }\end{array}$ & $\begin{array}{l}\text { Averiguar el tipo de maquinaria y equipos que emplean. } \\
\text { Identificar materiales e insumos que se utilizan. } \\
\text { Conocer el layout óptimo de la planta. } \\
\text { Identificar los controles de calidad. } \\
\text { Identificar la capacidad y proceso de producción de la planta. }\end{array}$ \\
\hline & $\begin{array}{l}\text { Area } \\
\text { Comercial }\end{array}$ & $\begin{array}{l}\text { Describir las funciones y objetivos del departamento comercial y su } \\
\text { relación con la actividad productiva. } \\
\text { Determinar la forma de negociar. } \\
\text { Identificar problemas recurrentes con los clientes. } \\
\text { Calcular el precio de venta de los productos. }\end{array}$ \\
\hline & $\begin{array}{c}\text { Area } \\
\text { Logística }\end{array}$ & $\begin{array}{l}\text { Identificar el almacenamiento del producto. } \\
\text { Identificar el traslado de la mercancía. } \\
\text { Determinar cómo se preparan los pedidos. } \\
\text { Determinar la optimización de costos. } \\
\text { Identificar la forma de distribución del producto }\end{array}$ \\
\hline
\end{tabular}

Para la investigación exploratoria se realizaron seis entrevistas a profundidad a especialistas en la preparación de piscos y macerados de frutas, como Gerentes y Jefes de 
empresas productoras de pisco y macerados de frutas en pisco. Las entrevistas se realizaron a las siguientes personas en la tabla 17.

Tabla 17

Entrevistas a profundidad aplicadas

\begin{tabular}{|c|c|c|}
\hline $\begin{array}{c}\text { Cantidad } \\
\text { Entrevistados }\end{array}$ & Objetivos & Perfil de los Entrevistados \\
\hline 1 & $\begin{array}{l}\text { Conocimiento del } \\
\text { mercado }\end{array}$ & $\begin{array}{l}\text { Gerentes de bodegas, que tengan experiencia en } \\
\text { producción industrial, a los que se pidió } \\
\text { información en cuanto a segmentación, penetración } \\
\text { de mercado, procesos, momentos, críticos, leyes a } \\
\text { cumplir, buenas prácticas, proveedores de insumos } \\
\text { directos e indirectos. }\end{array}$ \\
\hline 1 & Estratégico y Comercial & $\begin{array}{l}\text { Ex Ministro de Producción para poder acceder a } \\
\text { información exacta de mercado, competidores, } \\
\text { acceso a financiamiento, facilidades para MYPES. }\end{array}$ \\
\hline 2 & $\begin{array}{l}\text { Administrativo, } \\
\text { Operativo, } \\
\text { Comercial y Logístico }\end{array}$ & $\begin{array}{l}\text { Gerentes de empresas que preparan macerados de } \\
\text { frutas en pisco en forma artesanal, para procesos, } \\
\text { tiempos de maceración, recetas, Know how. }\end{array}$ \\
\hline 1 & $\begin{array}{l}\text { Operativo, Comercial } \\
\text { y Logístico }\end{array}$ & $\begin{array}{l}\text { Bartender, Sommelier y Catador de pisco durante } 8 \\
\text { años en el mercado, especialista en pisco hace } 3 \\
\text { años. Gestiona el movimiento pisquero de Lima } \\
\text { hasta Tacna. }\end{array}$ \\
\hline
\end{tabular}

\subsubsection{Diseño de instrumento.}

En el anexo2se encuentra la guía de pautas del focusgroup, en donde se aprecia la distribución de los temas generales y los específicos, para poder determinar la aceptación del producto.

Además, en los anexos 7, 8, 9, 10, 11 y 12 se encuentrael cuestionario de las preguntas de las entrevistas a profundidad, cuya finalidad fue obtener la mayor información de buenas prácticas, para poder entender el knowhow, aclarar dudas de procesos, entender en cuales son los que tienen mayor dificultad y así poder obtener datos que serán importantes para el estudio.

En la tabla 18 se puede apreciar la ficha técnica de las entrevistas y en la tabla 19 se muestra la información de cada uno de los entrevistados. detalle.

En la tabla 20 se mostró la ficha técnica del focus group indicando la información al 
Tabla 18

Ficha técnica de entrevistas a profundidad

\begin{tabular}{ll}
\hline Método & Cualitativo \\
\hline $\begin{array}{l}\text { Técnica de recolección de } \\
\text { Número de entrevistados }\end{array}$ & Entrevistas a Profundidad \\
Participantes & Seis personas \\
& \\
Reclutamiento & $\begin{array}{l}\text { Se convocó a Gerentes de bodegas de pisco, a personas } \\
\text { que preparan macerados de frutas en pisco artesanalmente, } \\
\text { a un experto en información de mercado y a un sommelier. }\end{array}$
\end{tabular}

Duración 1 hora aproximadamente por entrevista

Fecha de levantamiento Del 16 al 26 de octubre de 2017

Equipo de Trabajo Entrevistador, cuestionario de entrevista y equipo audiovisual. 
Tabla 19

Ficha técnica delos Entrevistados

\begin{tabular}{|c|c|c|c|c|}
\hline Nombre & Cargo & Especialista & Empresa & Objetivo \\
\hline 1. Juan Carlos Matthews & $\begin{array}{l}\text { Director General de la } \\
\text { Escuela de Postgrado }\end{array}$ & $\begin{array}{l}\text { Ex Vice Ministro de } \\
\text { MyPE e Industria, } \\
\text { Director de } \\
\text { Exportaciones, Director } \\
\text { Ejecutivo de } \\
\text { PROMPEX, Director } \\
\text { Nacional de Comercio } \\
\text { Exterior. Economista }\end{array}$ & $\begin{array}{l}\text { Universidad San Ignacio de } \\
\text { Loyola }\end{array}$ & Información del Mercado \\
\hline 2. Jaime Marimon Pizarro & $\begin{array}{l}\text { Director - } \\
\text { Gerente General }\end{array}$ & $\begin{array}{l}\text { Pisco - Empresario. } \\
\text { Ex Presidente de } \\
\text { CONAPISCO. }\end{array}$ & $\begin{array}{l}\text { El Alambique de Azpitia SAC } \\
\text { (Pisco: Sarcay de Azpitia). }\end{array}$ & $\begin{array}{l}\text { Administrativo, Operativo, } \\
\text { Comercial y Logístico }\end{array}$ \\
\hline 3. Piero Bailetti & Gerente de Operaciones & $\begin{array}{l}\text { Pisco - Empresario. } \\
\text { Control de producción, } \\
\text { distribución, venta y } \\
\text { maquilado pisco Don } \\
\text { Salvattore. }\end{array}$ & Bodega Bailetti & $\begin{array}{l}\text { Administrativo, Operativo, } \\
\text { Comercial y Logístico }\end{array}$ \\
\hline 4. Manuel Pardo Figueroa & Gerente Comercial & $\begin{array}{l}\text { Comercialización y } \\
\text { Fabricación artesanal de } \\
\text { Macerados de fruta en } \\
\text { pisco entre otras } \\
\text { actividades. }\end{array}$ & Foodies & $\begin{array}{l}\text { Operativo, Comercial y } \\
\text { Logístico. }\end{array}$ \\
\hline 5. Eduardo Correa & Gerente Comercial & $\begin{array}{l}\text { Comercialización y } \\
\text { Fabricación artesanal de } \\
\text { Macerados de fruta en } \\
\text { pisco entre otras } \\
\text { actividades. }\end{array}$ & Eddu's & $\begin{array}{l}\text { Operativo, Comercial y } \\
\text { Logístico. }\end{array}$ \\
\hline 4. Hector Tuesta & Sommelier & $\begin{array}{l}\text { Cata Privada, Bartender. } \\
\text { Gestiona el moviento } \\
\text { pisquer de Lima a Tacna. }\end{array}$ & Bodega Santiago Queirolo & Operativo \\
\hline
\end{tabular}


Tabla 20

Ficha técnica de FocusGroup

\begin{tabular}{ll}
\hline Método & Cualitativo \\
\hline \multirow{2}{*}{ Sesiones } & $\begin{array}{l}\text { Se efectuaron cuatro sesiones conformadas por } \\
\text { siete participantes por sesión pertenecientes a la } \\
\text { zona 6 (Jesús María, Lince, Pueblo Libre, Magdalena y San } \\
\text { Miguel) y zona 7 (La Molina, Miraflores, San Borja, San Isidro } \\
\text { y Santiago de Surco), siendo en total 28 participantes. }\end{array}$ \\
\hline Participantes & $\begin{array}{l}\text { Estuvo conformado por hombres y mujeres de } \\
21 \text { a } 65 \text { años que consuman bebidas alcohólicas. }\end{array}$ \\
\hline Reclutamiento & $\begin{array}{l}\text { Se convocó a participantes que cumplan con el } \\
\text { perfil del público objetivo en base a edad } \\
\text { (21 a 65 años), NSE (A\&B), distrito (Zona 6 y Zona 7). }\end{array}$ \\
\hline Duración & $\begin{array}{l}\text { Cada sesión duró aproximadamente una hora, } \\
\text { efectuadas del 10 al 28 de octubre. }\end{array}$ \\
\hline Equipo de trabajo & $\begin{array}{l}\text { En cada sesión se contó con un moderador, } \\
\text { un transcriptor, y un asistente para el apoyo } \\
\text { del audio. }\end{array}$ \\
\hline
\end{tabular}

\subsubsection{Análisis y procesamiento de datos.}

\section{Conclusiones entrevistas a profundidad}

Área Administrativa

Se determinó que un punto importante era tener un especialista en preparación de macerados de pisco en frutas para poder mantener en el tiempo la receta adecuada y el sabor esperado en todas las producciones.

Se pudo observar que los productores de pisco pertenecían a CONAPISCO y buscaban asociarse entre ellos, buscando negociar en bloque y que el costo de distribución en retails sea menor al 60\%, que es lo que les cobraban en ese momento.

Área de Operaciones

En cuanto a maquinaria lo que se pudo obtener de las entrevistas fue que usaban tanques de maceración que cumplan con todos los estándares de calidad la mayoría aplicaban procesos HACCP que a pesar de encarecer la producción aseguraban un producto que 
cumplían con estándares de calidad que permitiría que el producto en un largo plazo también pueda ser exportado.

Se determinó que el pisco más apropiado a usar era el quebranta ya que era el que mejor quedaba con la fruta. Se determinó que usar fruta seca era la mejor opción. Se estableció que el proceso de producción el tiempo de maceración ideal era de 30 días. El mejor control era aplicar HACCP, para evitar la contaminación cruzada. Para iniciar las operaciones se decidió que se iniciarán unos meses antes para poder tener producto macerado y tener producto para ofrecer. De acuerdo a lo que se indagó se pudo determinar la distribución ideal de la planta y poder ser eficientes en la producción.

Área Comercial

Se determinó que debía contratarse un especialista en Marketing para poder aplicar una estrategia que sea eficiente para poder tener participación en el mercado. Se estableció que se debía tomar en cuenta un presupuesto para sampling, promoción. No se determinaron problemas recurrentes. En cuanto al precio se determinó de acuerdo al tamaño y la percepción de calidad que se quiere dar al producto sería de S/.55.00.

Área Logística

En el área logística, se determinó la ubicación era en Lince por la cercanía a los proveedores. En cuanto al traslado de la mercadería para la venta por web se haría a través de un motorizado (tercerizado) y para la venta en licorería y bodegas también sería servicio tercerizado. Se estableció que el producto será envasado en una botella de 750ML diferente a las que actualmente hay en el mercado. En cuanto a la optimización de costos se decidió iniciar en el mercado con sabores que balanceen los costos.

En las tablas 21 al 24 se observan al detalle y el comparativo de las entrevistas a profundidad. 
Conclusiones focus groups

Focus \# 1

- Participaron 5 hombres y 2 mujeres, de los distritos de San Borja, La Molina, Surco, Pueblo Libre, San Isidro y Lince.

- El 100\% de los participantes confirmaron que consumían bebidas alcohólicas, cinco de ellos lo hacían una vez por semana y el resto dos veces por semana. Mencionaron tomar cerveza y pisco.

- Tres de ellos dijeron que habían probado macerados de frutas de canela, damasco, macerado casero, de coco y raíces. El resto no había probado ninguno. Confirmar haber probado macerados de un solo sabor.

- Las expectativas que dijeron tener del producto era buena, les agradaba la presencia de frutas y les llamaba la atención los nuevos sabores y mezclas.

- Todos estuvieron de acuerdo que tomaban macerados de frutas en eventos sociales, familiares y corporativos, y que podrían reemplazar el macerado por otros tragos.

- Cuatro de los participantes dijeron que consideraban que el mayor atractivo del producto era el color, los demás consideraron que fue la presentación artesanal y el macerado en sí.

- Tres de los participantes confirmaron que estarían dispuestos a pagar entre S/.50 y S/. 60 Soles por botella, mientras que el resto dijo que podrían pagar entre S/. 70 y S/.100 Soles.

- A todos les gustó la idea de encontrarlo en establecimientos como retails, mientras que también a algunos dijeron que les gustaba la idea de poder comprar por redes y licorerías. 
- Tres de los participantes opinaron que la combinación de sabores era la característica principal, el resto que era el envase, les gustaba la propuesta porque se veía hecho con productos naturales.

- Cuatros de los participantes consideraron que la presentación de Maracuyá y frambuesa era mejor. En segundo lugar les parecía el de fresa y guinda. Sin embargo tres de ellos consideraron que el mejor era el de fresa con guinda y en segundo lugar maracuyá y frambuesa, fueron los dos sabores más aceptados. Las presentaciones que menos aceptaron fuero piña y hierba luisa y arándanos y canela.

- Todos coincidieron que el balance entre frutas y pisco era la característica que debía que ser considerada como importante, para otros el tiempo de maceración y

- Tres de los participantes dijeron que les gustaría encontrar nuevos sabores como frutos rojos, el resto dijeron que les gustaría sabores ácidos, como carambola, de repente más opciones con guinda, frutas exóticas.

- Todos coincidieron que el nombre de Nuna es de fácil recordación, sin embargo no les gustó, ni lo vincularon con un macerado de pisco en fruta, uno de ellos prefirió el nombre Kimsa, pero tampoco lo relacionaba con macerados.

Focus group \# 2

- Participaron 4 hombres y 3 mujeres de los distritos de Lince, Miraflores, Surco y La Molina.

- Todos confirmaron que tomaban bebidas alcohólicas y la mayoría prefería el whisky, vino, ron y pisco.

- Uno de los participantes dijo que consumía pisco dos veces por semana, cuatro de dos veces al mes, el resto una vez al mes. 
- Seis de los participantes confirmaron que habían probado macerados de fruta en pisco y que la experiencia fue buena. Dijeron haber consumido con frutos secos, eucalipto, damasco y otros sabores.

- Dijeron que la diferencia que encontraron con otros macerados era el color y sabor del producto.

- Todos dijeron que tenían una expectativa positiva cuando probaron los macerados de fruta en pisco.

- Confirmaron todos que tomaban pisco y macerados de fruta en pisco en eventos sociales, familiares y corporativos y lo reemplazaría por otros tragos.

- Confirmaron que el principal atractivo del producto era la botella, la mezcla de sabores, color y frutas.

- Todos estuvieron de acuerdo que y afirmaron que estarían dispuestos a pagar S/.50 como máximo. De hecho comentaron que les gustaba la idea de poder encontrar lo en establecimientos.

- La mayoría opinó que se debería aprovechar la forma de la botella, color y sabor del producto.

- Para la mayoría los mejores sabores fueron el fresa y guinda, luego el de frambuesa y maracuyá. Mientras que los menos aceptados fueron el de piña y hierba luisa y por último el de arándanos y canela.

- Todos coincidieron en que debería mejorar en el proceso de maceración. También que les gustaría encontrar otros sabores cómo damasco, eucalipto, canela, kión y tuna.

- La mayoría votó por el nombre de Nuna y consideraron que era de fácil recordación. Sin embargo, no les gustó ni lo vinculan con el macerado. 
Focus group \# 3

- Participaron 4 mujeres y 3 hombres. Las mujeres dos de ellas entre 21 y 30 años, dos de ellas entre 51 y 60 años. En cuanto a los hombres uno de ellos entre 41 y 50 años, y los otros dos entre 51 y 60 años. Cinco de ellos vivían en Surco, uno el San Borja y uno en La Molina.

- El 100\% de los participantes consumen bebidas alcohólicas fines de semana más de una vez por semana. Mencionaron tomar cerveza, vino y pisco.

- Indicaron haber consumido el macerado de fruta en pisco en bares, bares de restaurantes campestres, confirmaron que si tenían conocimiento de la existencia . Les gustó la variedad. Dijeron que el dulce de la fruta les agradaba. Solo una persona dijo no haber probado.

- Sobre los macerados de frutas en pisco, más del 50\% de los participantes si tenía algún conocimiento sobre esta tipo de bebida. Dijeron que era agradable, dulce, que debería poder tomarse puro tipo frapé, o en chilcano.

- Opinaron que se vea la fruta en la presentación de la botella. Creían que daba credibilidad al producto. Les gustó la idea que era artesanal. Que no fuera turbio. Mencionaron que se debería usa fruta seca y entera. Dieron cómo idea que se hagan pruebas con otros ingredientes como el jengibre.

- Los hombres lo prefirieron puro, las mujeres más dulce y con evervess.

- Dieron sus apreciaciones en cuanto a los sabores y aroma

- La presentación de Hierba Luisa con piña, no lo aceptaron, creen que debió ser más dulce.

- La presentación Arándano con canela, dijeron que era agradable, sintieron el arándano, a la mayoría le gustó más que el primer sabor. 
- La presentación Maíz morado, membrillo y canela, les gustó el aroma, predominó el sabor del pisco. No les pareció agradable.

- La presentación Maracuyá con frambuesa, mencionaron que el aroma a maracuyá predominó, que se debería poner la fruta pero la frambuesa.

- La presentación Guinda con fresa, dijeron que les encantó aroma de fruta, sintieron los dos sabores, toque dulce, que era la combinación perfecta.

- Les gustó la propuesta de probar los macerados de fruta en pisco, el aroma, la mezcla, que era una nueva opción y cubrió sus expectativas.

- El sabor preferido fue el guinda con fresa, como segundo el de maracuyá, arándanos con canela. Siempre que haya equilibrio en los sabores.

- Todos los participantes mencionaron que un buen momento para consumir sería en almuerzo, reuniones familiares, al llegar a casa para el frío. Concluyeron que en cualquier momento eras bueno. Cuando se les apetecía, toda ocasión.

- Confirmaron que estarían dispuestos a reemplazar lo que toman por macerados de frutas en pisco. Les pareció bien cambiar los macerados de fruta. Lo importante dijeron era que la receta fuera siempre la misma con las cantidades adecuadas, un producto de calidad, de buen sabor.

- El atractivo dijeron mayor transparencia en el producto. Mencionaron que todo entraba por los ojos, la botella les gustó. La idea de que tuviera la fruta era atractivo Dijeron que la botella con nombre se vería bien pero que sea transparente.

- En cuanto a nombre coincidieron que el nombre sea KIMSA.

- En cuanto al precio estaban dispuesto a pagar un rango entre 50 a 60 Soles.

- Todos los participantes coincidieron que prefieren encontrar el producto en licorerías o estaciones de servicio, en donde se pueda exponer el producto para que puedan probarlo y hacer promociones. 
- Les pareció una buena opción la venta por Facebook.

- No les pareció que se promocione como artesanal, porque no estarían dispuesto a pagar.

- También indicaron que si estarían de acuerdo en encontrar información y promociones mediante redes sociales, como principal medio mencionaron Facebook. Focus group \# 4

- Participaron 4 mujeres y 3 hombres. Las mujeres dos de ellas entre 31 y 40 años, una de ellas entre 41 y 50 años. En cuanto a los hombres uno de ellos entre 21 y 30 años, y los otros dos entre 31 y 40 años. Cinco de ellos vivían en San Borja, dos de ellos en Surco.

- El 100\% de los participantes confirmaron que consumían bebidas alcohólicas de una a dos veces por semana.

- Sobre los macerados de frutas en pisco, más del 50\% de los participantes si tenía algún conocimiento sobre esta tipo de bebida.

- Las bebidas que era de mayor preferencia entre los encuestados mencionaron la cerveza, vino y pisco, este último en sus diversas presentaciones, puro, en sour, chilcano, etc.

- Los participantes que si habían consumido macerados de frutas en pisco indicaron que era una buena alternativa con relación al pisco en sus otras presentaciones e incluso para las demás bebidas alcohólicas típicas.

- Con relación a la experiencia al tomar macerados de frutas en pisco, los participantes señalaron que la experiencia fue agradable y si lo volverían a tomar, en algunos casos puro y en otros con ginger ale al estilo chilcano. 
- La principal diferencia que encontraron los participantes, fue la combinación de dos o más ingredientes (frutas, especias y/o hierbas). Esto no lo habían encontrado en otras bebidas.

- Los participantes señalaron que la principal expectativa que ellos consideraban antes de probar estas bebidas, era que pudieran sentir el olor y sobre todo el sabor de los ingredientes. Es decir que estos sabores prevalezcan sobre el clásico sabor del pisco.

- Todos los participantes mencionaron que no tenían un momento en particular para disfrutar esta bebida y estarían dispuestos a consumirla en cualquier tipo de evento y sobre todo en cualquier época del año.

- En cuanto a reemplazar alguna debida que los participantes consumen con regularidad, todos coincidieron que si la podían reemplazar para probar nuevos sabores pero señalaron que sobre todo estarían dispuestos a agregar los macerados de frutas en pisco dentro de su habitual lista de bebidas.

- El principal atractivo en el cual coincidieron todos los participantes fue que están de acuerdo en que se presenten frutas en el interior de las botellas porque esto ofrecería confianza y veracidad al producto.

- Mencionaron en cuanto al precio estimado que estaban dispuesto a pagar oscilaba entre un rango entre 40 y 60 soles, dependiendo del tipo de presentación y detalles en la botella.

- Todos los participantes coincidieron que prefieren encontrar el producto en licorerías porque les generaba confianza poder observar el contenido y los colores particulares de cada sabor porque esto es uno de los atributos que señalaron.

- También indicaron que si estarían de acuerdo en encontrar información y promociones mediante redes sociales, como principal medio mencionaron Facebook. 
- Mencionaron que la principal característica que se debería aprovechar en el producto era la combinación de los ingredientes, logrando sabores y colores únicos.

- Respecto a los 5 sabores, las opiniones estuvieron divididas en 3 grupos muy marcados, todos los participantes coincidieron que el macerado de guinda con fresas fue el mejor seguido del sabor maracuyá y frambuesa. El segundo grupo lo conformaron los sabores de piña con hierba luisa y arándano con canela, mientras que el sabor de chicha morada tuvo poca aceptación entre todos.

- Los participantes coincidieron en indicar que el tiempo de maceración era importante para este tipo de bebida y en alguno de los sabores se debería invertir más tiempo en reposar la fruta para que poder apreciar los sabores.

- Entre los sabores que les gustaría encontrar, se mencionaron algunos como: granadilla, kion; también cítricos como: lima, toronja, naranja, etc.

- De las tres opciones que se plantearon de nombres, indicaron que el nombre de mayor recordación fue Nuna, porque era el más corto y de fácil pronunciación. En cuanto a los otros, indicaron que no serían apropiados.

Conclusiones de focus group por objetivos

- Determinar las características del producto que el cliente espera

Para cumplir con las expectativas que esperaría el cliente los macerados de fruta en pisco deberían ser de calidad. Se entiende por calidad: cumplir con el tiempo de maceración exacto, la combinación de sabores ideal (la receta en la que los ingredientes estén balanceados para que los sabores y aromas estén en armonía), lo puedan comprar en redes sociales y establecimientos.

- Conocer la frecuencia de consumo

Se pudo identificar que el pisco por lo general, se consume en cualquier ocasión, y que el macerado de frutas en pisco tiene la misma aceptación. Lo que quiere decir que la 
estacionalidad no sólo sería en fechas especiales, sino también para todo tipo de reuniones sociales (almuerzos, cenas, fiestas) y en todo tipo de lugares.

- Identificar las variables determinantes al momento de la compra

La presentación de 750 Ml, el color del producto, el tema siguiendo la onda artesanal y natural, la combinación de los sabores, el precio justo para que la percepción de que es de baja calidad son variables que toman en cuenta al momento de comprar.

Según lo que se observó la botella y presentación de producto fue aceptado. Se apreció que a todos les gustó ya que no habían visto una presentación similar. Incluso la cantidad que ofrece la botella de $750 \mathrm{Ml}$ les pareció conveniente.

- Determinar el nombre más adecuado para el producto

Se concluyó en los tres focus que se realizaron que los nombres que se propusieron no causaron ninguna reacción, ni recordación. Se decidió cambiar por eso a HECHIZO, porque era un nombre que tenía mayor relación con el producto y generaba mayor expectativa.

A continuación en la tabla 21, se puede ver el resumen y comparativo de las Entrevistas a profunidad hechas a Eduardo Correa de Eddus y Manuel Pardo Figueroa. En la tabla 22 el resumen de la entrevista a profundidad a Juan Carlos Mathews. En la tabla 23 se puede ver el resumen y el comparativo de las entrevistas hechas a Jaime Marimon Pizarro de Sarcay de Aspitia y Piero Bailetti de Bodega Don Salvattore. Por último en la tabla 24 está el resumen de la entrevista al Sommelier Hector Tuesta. 
Tabla 21

Entrevistas a profundidad Conocimiento del mercado

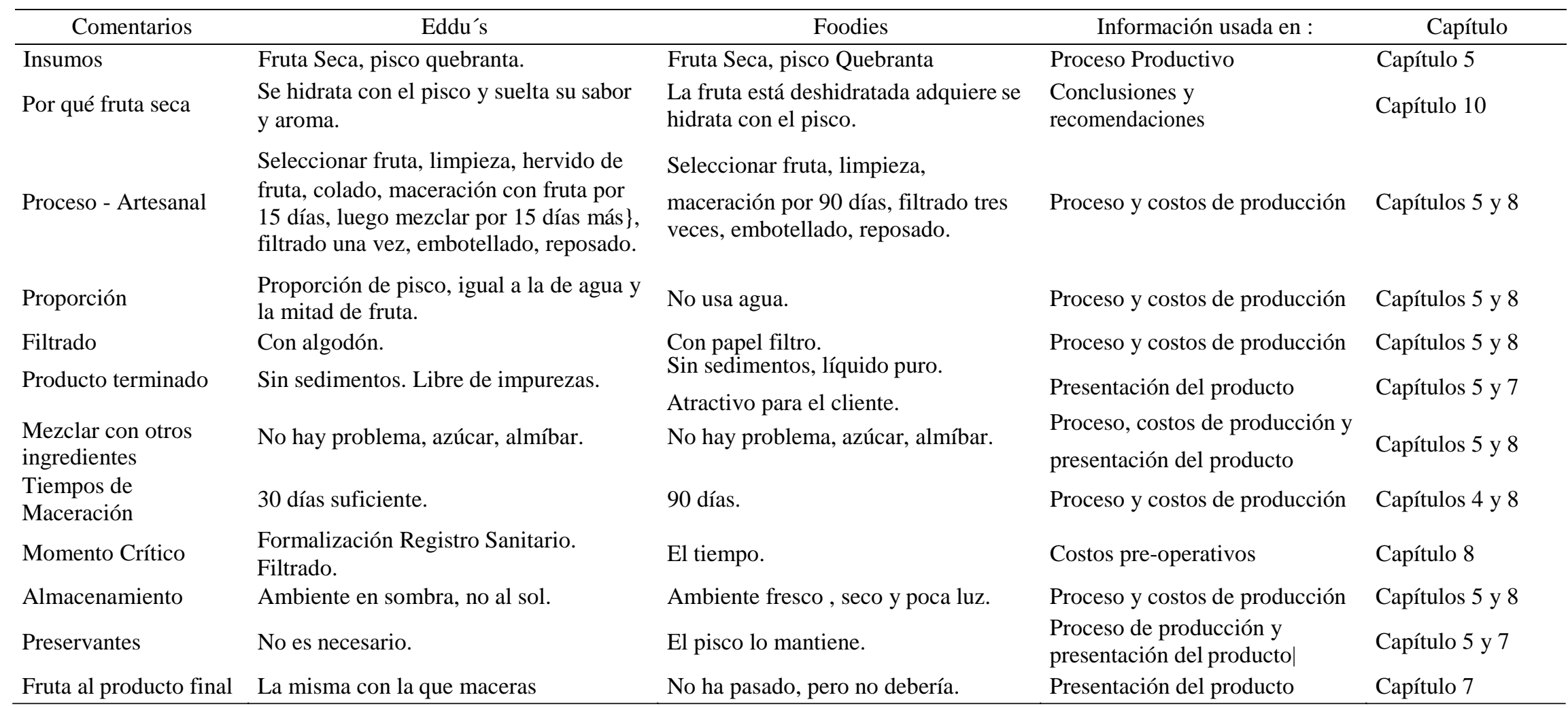




\begin{tabular}{|c|c|c|c|c|}
\hline Comentarios & Eddu's & Foodies & Información usada en : & Capítulo \\
\hline Proceso de ventas & $\begin{array}{l}\text { Ofrecer a conocidos, amigos, face book, por } \\
\text { pedidos. }\end{array}$ & Ofrecer a conocidos, por pedido. & $\begin{array}{l}\text { Presentación del producto, el } \\
\text { precio, forma de distribución, } \\
\text { estrategia de ventas y } \\
\text { promoción. }\end{array}$ & Capítulo 7 \\
\hline Canal & Licorerias, bares, restaurantes, amistades & Licorerías bares & Estrategia de distribución & Capítulo 7 \\
\hline Retail es el canal & $\begin{array}{l}\text { Dificil entrar. Analizar la capacidad } \\
\text { financiera. }\end{array}$ & $\begin{array}{l}\text { Analizar la capacidad de produccion y } \\
\text { financiera. Estructura de precios que incluya } \\
\text { todos los márgenes. }\end{array}$ & Costos del producto & Capítulo 8 \\
\hline Términos de venta & Contra entrega. & $\begin{array}{l}\text { Analizar el precio que incluya todos los } \\
\text { gastos. }\end{array}$ & Costos del producto & Capítulo 8 \\
\hline $\begin{array}{l}\text { Vida del producto } \\
\text { recolocación }\end{array}$ & Si soporta el pisco lo mantiene. & Si soporta el pisco lo mantiene. & Proceso de producción & Capítulo 5 \\
\hline Rango de precios & $\mathrm{S} / .35 .00$ & S/.50.00 & $\begin{array}{l}\text { Costo del producto y estrategia } \\
\text { de precios }\end{array}$ & Capítulo 7 y 8 \\
\hline Presentación & $500 \mathrm{ML}$ en pomo o botella & 500 ML en pomo o botella & Presentación del producto & Capítulo 7 \\
\hline Reclamos & No tienen reclamos & $\begin{array}{l}\text { Producto de calidad, por eso lo filtra tres } \\
\text { veces. }\end{array}$ & $\begin{array}{l}\text { Proceso de producción y } \\
\text { presentación del productol }\end{array}$ & Capítulos 5 y 7 \\
\hline Promoción & El mismo producto. & $\begin{array}{l}\text { En el precio incluir lo que se va a gastar en } \\
\text { rebates, promoción, activaciones, pruebas. }\end{array}$ & Estrategia de promoción & Capítulo 7 \\
\hline Diferencia con el competidor & Sabor. La receta. & Calidad, filtrado, & Estategia de producto & Capítulo 7 \\
\hline Distribución & Licorerias, bares, restaurantes, amistades & Licorerías, bares. & $\begin{array}{l}\text { Estategia de distribución y } \\
\text { costos del producto }\end{array}$ & Capítulo 7 y 8 \\
\hline Política de Abastecimiento & Mercado de Lince. & Mercado de Surquillo. & Costos de producción & Capítulo 8 \\
\hline Comentarios & $\begin{array}{l}\text { No ha trabajado con Maracuyá, va } \\
\text { probar. La receta es importante. Tener } \\
\text { control y cuidado con los ingredientes a } \\
\text { usar. }\end{array}$ & $\begin{array}{l}\text { Trabajar con sabores que hay en le } \\
\text { mercado. Realizar pareto, para } \\
\text { determinar cuál sería el } 80 \% \text { de las } \\
\text { ventas en cuanto al sabor aceptado. Tener } \\
\text { en cuenta el programa de producción, } \\
\text { hacerlo semanalmente. }\end{array}$ & $\begin{array}{l}\text { Conclusiones y } \\
\text { recomendaciones }\end{array}$ & Capítulo 10 \\
\hline
\end{tabular}


Tabla 22

Entrevistas a profundidad Estratégico y Comercial

\begin{tabular}{|c|c|c|c|}
\hline Comentarios & Juan Carlos Mathews & Información usada en : & Capítulo \\
\hline Información sobre pisco & Mincetur & Estudio de mercado & Capítulo 5 \\
\hline Demanda de pisco & En aumento, en el mercado nacional e internacional & Determinar la demanda del producto & Capítulo3 \\
\hline Derivados del pisco & Son una nueva opción & Competidores & Capítulo 2 \\
\hline La demanda actual esta cubierta & $\begin{array}{l}\text { No del todo, ya que la producción informal no esta } \\
\text { contemplada }\end{array}$ & Porcentaje de participación & Capítulo3 \\
\hline Desarrollo de la pequeña empresa & Las grandes bodegas dominan el mercado & Inversión del proyecto & Capítulo 8 \\
\hline Formalización de productores & Evaluación de proveedores & Selección de proveedores & Capítulo 5 \\
\hline Política de promoción & Produce, trabaja en proyectos como Innovate Perú & Estrategia de promoción & Capítulo 7 \\
\hline Apoyo a los productores & Ruta exportadora & Estudio de mercado & Capítulo 1 \\
\hline Información sobre empresas & Prompex, Produce & Estudio de mercado & Capítulo3 \\
\hline Exportación & Testear el producto en el exterior & Estudio de mercado & Capítulo3 \\
\hline Mercado internacional & Tamaño, barreras de acceso y rentabilidad & Tamaño del mercado & Capítulo 3 \\
\hline Estrategia de introducción & Cadenas especializadas, branding & Estrategia de marketing & Capítulo 7 \\
\hline Promoción en el exterior & Iniciar por promocionar en comunidades peruanas & Estudio de mercado & Capítulo3 \\
\hline Requisitos para exportar & Importante el certificado de calidad & Desarrollo del producto & Capítulo 5 \\
\hline Certificaciones & Requisito muy importante & Desarrollo del producto & Capítulo 5 \\
\hline Alianzas estratégicas & $\begin{array}{l}\text { Aprovechar el posicionamiento de empresas establecidas en el } \\
\text { exterior }\end{array}$ & Estrategias de Marketing & Capítulo 7 \\
\hline Producto perecible & Lo perecibles van como consignación & Estrategias de Marketing & Capítulo 7 \\
\hline Brockers & Conocen el mercado y manejan grandes volumenes & Estudio de mercado & Capítulo3 \\
\hline Comentarios & $\begin{array}{l}\text { Veo con buenos ojos el proyecto y luego de un estudio creo que } \\
\text { pueden dirigirse al mercado imternacional }\end{array}$ & Conclusiones y recomendaciones & Capítulo 10 \\
\hline
\end{tabular}


Tabla 23

Entrevistas a profundidad Administrativo, Operativo, Comercial y Logístico

\begin{tabular}{|c|c|c|c|c|}
\hline Comentarios & Sarcay de Azpitia & Bailetti & Información usada en : & Capítulo \\
\hline Insumos & Fruta, especias, endulzante & Frutas frescas, preservante natural & Proceso productivo & Capítulo 5 \\
\hline Conocimiento del producto & $\mathrm{Si}$, vienen haciendo pruebas & $\begin{array}{l}\text { Han hecho pruebas de macerados } \\
\text { de frutas en piscco }\end{array}$ & Proceso productivo & Capítulo 5 \\
\hline $\begin{array}{l}\text { Nombre correcto del } \\
\text { producto }\end{array}$ & Macerados de fruta en pisco & Macerados de frutas en pisco & $\begin{array}{l}\text { Nombre formal del } \\
\text { producto }\end{array}$ & $\begin{array}{l}\text { En todos los } \\
\text { capítulos }\end{array}$ \\
\hline Receta & Propia, no revelada & $\begin{array}{l}\text { Cuentan con un experto en } \\
\text { maceración }\end{array}$ & Proceso productivo & Capítulo 5 \\
\hline Filtrado & Equipos diseñados a medida & Lo han hecho artesanalmente & Proceso productivo & Capítulo 5 \\
\hline Producto terminado & Sin sedimentos. Libre de impurezas. & Con frutas en las botellas. & $\begin{array}{l}\text { Presentación del } \\
\text { producto }\end{array}$ & Capítulo 5 \\
\hline $\begin{array}{l}\text { Mezclar con otros } \\
\text { ingredientes }\end{array}$ & No hay problema, azúcar, almíbar. & & Proceso productivo & Capítulo 5 \\
\hline Tiempos de Maceración & Depende de cada sabor & $\begin{array}{l}\text { Mínimo } 30 \text { días, depende del } \\
\text { insumo }\end{array}$ & $\begin{array}{l}\text { Proceso y costos de } \\
\text { producción }\end{array}$ & Capítulo 5 y 8 \\
\hline Momento Crítico & $\begin{array}{l}\text { Formalización Registro Sanitario. } \\
\text { Filtrado. }\end{array}$ & Filtrado & Proceso productivo & Capítulo 5 \\
\hline Almacenamiento & En lugar fresco y oscuro & En un lugar fresco y oscuro & Proceso productivo & Capítulo 5 \\
\hline Preservantes & Sin preservantes el alcohól lo mantiene & Preservante natural & $\begin{array}{l}\text { Proceso y costos de } \\
\text { producción }\end{array}$ & Capítulo 5 y 8 \\
\hline Fruta al producto final & Sin frutas porque daña la presentación & $\begin{array}{l}\text { Con frutas, producto más artesanal } \\
\text { y atractivo }\end{array}$ & $\begin{array}{l}\text { Presentación del } \\
\text { producto }\end{array}$ & Capítulo 5 \\
\hline Proceso de ventas & Web, mayoristas y minoristas & $\begin{array}{l}\text { En bodega Bailetti en Chincha, } \\
\text { pedidos por mayor a Lima }\end{array}$ & Canales de distribución & Capítulo 7 \\
\hline Canal & Tiendas especializadas y retails & Bodega Bailetti & $\begin{array}{l}\text { Estrategia de } \\
\text { distribución }\end{array}$ & Capítulo 7 \\
\hline Retail es el canal & Ya estan posicionados & No, es muy caro & $\begin{array}{l}\text { Estrategia de } \\
\text { distribución }\end{array}$ & Capítulo 7 \\
\hline Términos de venta & $\begin{array}{l}\text { De } 60 \text { a } 90 \text { días dependiendo el } \\
\text { comprador }\end{array}$ & $\begin{array}{l}\text { Ventas directas con el consumidor } \\
\text { en bodegas }\end{array}$ & $\begin{array}{l}\text { Estrategia de } \\
\text { distribución }\end{array}$ & Capítulo 7 \\
\hline Vida del producto & Apróximandamente 1 año & 1 año & Proceso productivo & Capítulo 5 \\
\hline
\end{tabular}




\begin{tabular}{|c|c|c|c|c|}
\hline Comentarios & Sarcay de Azpitia & Bailetti & Información usada en : & Capítulo \\
\hline Rango de precios & No especificado & $\begin{array}{l}\text { Depende de la fruta y del pisco } \\
\text { utilizado }\end{array}$ & \multirow{2}{*}{$\begin{array}{l}\text { Estrategia de precios } \\
\text { Presentación del } \\
\text { producto }\end{array}$} & Capítulo 7 \\
\hline Presentación & Botella de $500 \mathrm{ML}$ & Botella de $500 \mathrm{ml}-1000 \mathrm{ml}$ & & Capítulo 4 \\
\hline Reclamos & Aun no lanzado al mercado & $\begin{array}{l}\text { Es un proyecto, aun no ha sido } \\
\text { lanzado }\end{array}$ & Marketing & Capítulo 7 \\
\hline Promoción & $\begin{array}{l}\text { La nueva línea será reforzada por el } \\
\text { mombre de la marca }\end{array}$ & $\begin{array}{l}\text { Boca a boca y participación en } \\
\text { concursos }\end{array}$ & Estrategia de promoción & Capítulo 7 \\
\hline $\begin{array}{l}\text { Diferencia con el } \\
\text { competidor }\end{array}$ & Marca registrada y soporte financiero & Sabor del pisco & Estrategia de producto & Capítulo 7 \\
\hline Distribución & Tiendas especializadas y retails & $\begin{array}{l}\text { Bodega Bailetti. Planes de } \\
\text { posicionarse en Lima }\end{array}$ & $\begin{array}{l}\text { Estrategia de } \\
\text { distribución }\end{array}$ & Capítulo 7 \\
\hline Política de Abastecimiento & Proveedores homologados & Proveedores homologados & Proceso productivo & Capítulo 5 \\
\hline Comentarios & $\begin{array}{l}\text { Se encuentran haciendo pruebas con } \\
\text { diversos sabores, algunos de ellos son } \\
\text { aguaymanto y lima. }\end{array}$ & $\begin{array}{l}\text { Se refresca la fruta y hierbas. La } \\
\text { distribución debe ser rápida y } \\
\text { especificar que tiene un tiempo de } \\
\text { vida limitado. La distribución es } \\
\text { importante y el boca a boca para } \\
\text { posicionarse. }\end{array}$ & $\begin{array}{l}\text { Estrategia de } \\
\text { distribución }\end{array}$ & Capítulo 7 \\
\hline
\end{tabular}


Tabla 24

Entrevistas a profundidad Operativo, Comercial y Logístico

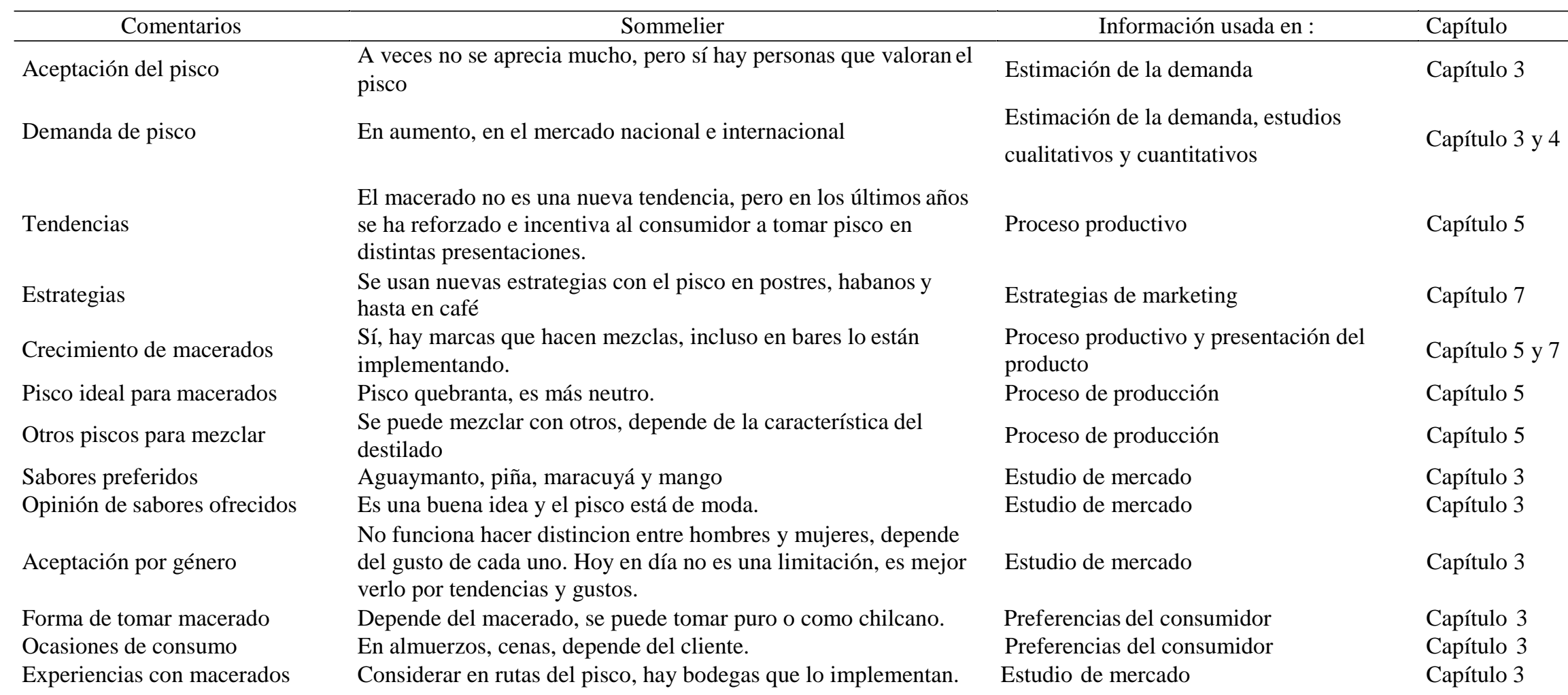




\begin{tabular}{|c|c|c|c|}
\hline Comentarios & Sommelier & Información usada en & Capítulo \\
\hline Nombre del producto & Un nombre que sea de fácil recordación y tenga significado. & Estudio de mercado & Capítulo 3 \\
\hline Certificaciones & Requisito muy importante & Costos pre-operativos & Capítulo 8 \\
\hline \multirow[t]{3}{*}{ Comentarios } & $\begin{array}{l}\text { Poner la misma cantidad de frutas en la presentación final, para } \\
\text { mantener la estandarización del sabor del producto. El alcohol es un } \\
\text { preservante natural, el dulce también es un preservante, dura } \\
\text { aproximadamente dos años. La fruta expuesta llama la atención. } \\
\text { Estandarizar el precio. Deshidratar la fruta para botar el agua de la fruta } \\
\text { y que tenga mayor sabor y se realice el proceso de maceración en menor } \\
\text { tiempo. }\end{array}$ & Conclusiones y recomendaciones & Capítulo 10 \\
\hline & $\begin{array}{l}\text { Necesitas estar en Sunat y en Indecopi. Registro sanitario por sabor. La } \\
\text { ley va a cambiar porque ya no se necesitará registro sanitario, sino } \\
\text { HACCP. }\end{array}$ & Costos pre-operativos & Capítulo 8 \\
\hline & Mantener en un lugar fresco, oscuro, para que no se malogren. & Proceso de producción & Capítulo 5 \\
\hline
\end{tabular}




\subsection{Investigación Cuantitativa}

Se realizó la investigación cuantitativa con el fin de verificar si los supuestos planteados para este trabajo se confirmaban o rechazaban en base a la información de datos numéricos.

Los objetivos de la investigación son:

- Identificar el mercado disponible.

- Identificar el mercado efectivo.

- Conocer la intención de compra.

- Conocer la frecuencia de compra y preferencia del consumidor.

- Determinar la estacionalidad de compra.

- Identificar los competidores.

En la tabla 25 se muestra los objetivos de la investigación y se indica los detalles.

Tabla 25

Objetivos de la investigación

\begin{tabular}{cl}
\hline Objetivos & \multicolumn{1}{c}{ Descripción } \\
\hline \multirow{3}{*}{ General } & $\begin{array}{l}\text { Determinar el mercado potencial, efectivo y disponible, así como algunas } \\
\text { tendencias de consumo y caracterización del producto que podrían } \\
\text { enriquecer la estrategia comercial del producto. }\end{array}$
\end{tabular}

Obtener información sobre las costumbres de compra del Plaza consumidor, identificando lugares, medios y sobre todo la frecuencia.

\begin{tabular}{lll}
\cline { 2 - 3 } Específicos & Precio & $\begin{array}{l}\text { Obtener información sobre el precio y además establecer } \\
\text { cual es precio base que el consumidor está dispuesto a } \\
\text { pagar. }\end{array}$ \\
\cline { 2 - 3 } & Producto $\quad \begin{array}{l}\text { Identificar si los sabores y la presentación del producto son } \\
\text { de la elección del público. }\end{array}$
\end{tabular}

Promoción Identificar si el nombre y los medios para dar a conocer el producto son de la preferencia del público. 


\subsubsection{Proceso de muestreo.}

Hernández et al. (2010), indican que el primer paso para elegir la muestra es definir el elemento de la investigación que pueden ser comunidades, grupos sociales, eventos, entre otros. Dentro del proceso de muestreo cuantitativo, la definición de la muestra se indica como un subgrupo, el cual es extraído de la población que interesa al investigador y es sobre esta muestra que se recolectarán datos. La muestra tiene que ser precisada o determinada con la debida anticipación y precisión. En resumen, la muestra deberá representar a la población sobre la cual se realizará la investigación. El principal objetivo es que la muestra sea particular de una manera estadística.

El alcance se definió considerando hombres y mujeres entre 21 a 65 años pertenecientes a los niveles socioeconómicos A y B que vivan en Lima Metropolitana dentro de la zona seis y siete según la segmentación mostrada en la tabla 26 y tabla 27.

Según Malhotra (2008), el marco muestral es muy útil porque da la posibilidad de reconocer de manera óptica los componentes de la población. De esta forma se pueden marcar y seleccionar los elementos de la muestra.

Tabla 26

Segmentación detallada

\begin{tabular}{|c|c|c|c|c|c|c|}
\hline ZONA & DISTRITO & $\begin{array}{l}\text { Población } \\
\text { Tntal ग017 }\end{array}$ & $\begin{array}{l}\text { Edad } \\
21-65 \\
\text { AÑOS }\end{array}$ & $\begin{array}{l}\text { Población } \\
\text { entre } 21 \text { y } 65 \\
\text { años }\end{array}$ & NSE A & NSE B \\
\hline \multirow{5}{*}{ ZONA 6} & Jesus Maria & 71,740 & $61.70 \%$ & 44,266 & $14.90 \%$ & $59.30 \%$ \\
\hline & Lince & 48,556 & $62.11 \%$ & 30,156 & $14.90 \%$ & $59.30 \%$ \\
\hline & Pueblo Libre & 75,483 & $60.52 \%$ & 45,685 & $14.90 \%$ & $59.30 \%$ \\
\hline & Magdalena & 54,838 & $61.52 \%$ & 33,734 & $14.90 \%$ & $59.30 \%$ \\
\hline & San Miguel & 136,332 & $61.57 \%$ & 83,939 & $14.90 \%$ & $59.30 \%$ \\
\hline \multirow{5}{*}{ ZONA 7} & La Molina & 180,264 & $62.54 \%$ & 112,741 & $34.90 \%$ & $46.00 \%$ \\
\hline & Miraflores & 80,228 & $64.23 \%$ & 51,532 & $34.90 \%$ & $46.00 \%$ \\
\hline & San Borja & 112,185 & $62.41 \%$ & 70,018 & $34.90 \%$ & $46.00 \%$ \\
\hline & San Isidro & 52,868 & $62.31 \%$ & 32,941 & $34.90 \%$ & $46.00 \%$ \\
\hline & Santiago de Surco & 356,461 & $61.65 \%$ & 219,750 & $34.90 \%$ & $46.00 \%$ \\
\hline
\end{tabular}

Nota. Niveles socioeconómicos 2017. Por Asociación Peruana de Empresas de Investigación de Mercados (Apeim, 2017). Recuperado de http://www.apeim.com.pe/wpcontent/themes/apeim/docs/nse/APEIM-NSE-2017.pd 
Para obtener la muestra se utilizó información del reporte de Asociación Peruana de Empresas de Investigación de Mercados 2017 (APEIM), en el cual se encuentran datos relacionados con los niveles socioeconómicos en el Perú y sobre todo Lima, incluidos todos sus distritos. En cuanto a la cantidad de personas por distrito, esta información se obtuvo del reporte del Instituto Nacional de Estadística e Informática (INEI) de 2015. Con esta información se planteó la segmentación considerando los siguientes puntos:

La investigación será orientada a hombres y mujeres.

- $\quad$ Los rangos de edades van desde los 21 a 65 años.

- Los niveles socioeconómicos elegidos son el A y B.

- La investigación será desarrollada dentro del de Lima Metropolitana.

- Se consideran la zona 6 que comprende los distritos de Jesús María, Pueblo Libre, Magdalena, San Miguel y Lince, y la zona 7 que integra los distritos de La Molina, San Isidro, San Borja, Miraflores y Santiago de Surco. 
Tabla 27

Marco Muestral

\begin{tabular}{|c|c|c|c|c|c|c|c|c|c|c|c|c|c|c|}
\hline ZONA & DISTRITO & $\begin{array}{c}\text { Población } \\
\text { Total } \\
2017\end{array}$ & $\begin{array}{l}\text { Edad } \\
21-65 \\
\text { AÑOS }\end{array}$ & $\begin{array}{l}\text { Población } \\
\text { entre } 21 \text { y } \\
65 \text { años }\end{array}$ & NSE A & NSE B & $\begin{array}{l}\text { NSE A } \\
\text { y B }\end{array}$ & $\begin{array}{c}\text { Segmento } \\
\text { mercado }\end{array}$ & Hombres & Mujeres & $\begin{array}{c}\% \\
\text { Cuota }\end{array}$ & $\begin{array}{c}\# \\
\text { Encuestas }\end{array}$ & $\begin{array}{c}\# \\
\text { Encuestas } \\
\text { hombres }\end{array}$ & $\begin{array}{c}\# \\
\text { Encuestas } \\
\text { mujeres }\end{array}$ \\
\hline \multirow{5}{*}{$\begin{array}{c}\text { ZONA } \\
6\end{array}$} & Jesus Maria & 71,740 & $61.70 \%$ & 44,266 & $14.90 \%$ & $59.30 \%$ & $74.20 \%$ & 32,846 & 15,996 & 16,850 & $6 \%$ & 22 & 11 & 11 \\
\hline & Lince & 48,556 & $62.11 \%$ & 30,156 & $14.90 \%$ & $59.30 \%$ & $74.20 \%$ & 22,376 & 10,897 & 11,479 & $4 \%$ & 15 & 7 & 8 \\
\hline & Pueblo Libre & 75,483 & $60.52 \%$ & 45,685 & $14.90 \%$ & $59.30 \%$ & $74.20 \%$ & 33,898 & 16,509 & 17,390 & $6 \%$ & 23 & 11 & 12 \\
\hline & Magdalena & 54,838 & $61.52 \%$ & 33,734 & $14.90 \%$ & $59.30 \%$ & $74.20 \%$ & 25,031 & 12,190 & 12,841 & $4 \%$ & 17 & 8 & 9 \\
\hline & San Miguel & 136,332 & $61.57 \%$ & 83,939 & $14.90 \%$ & $59.30 \%$ & $74.20 \%$ & 62,283 & 30,332 & 31,951 & $11 \%$ & 42 & 20 & 22 \\
\hline \multirow{5}{*}{$\begin{array}{c}\text { ZONA } \\
7\end{array}$} & La Molina & 180,264 & $62.54 \%$ & 112,741 & $34.90 \%$ & $46.00 \%$ & $80.90 \%$ & 91,207 & 44,418 & 46,789 & $16 \%$ & 61 & 30 & 31 \\
\hline & Miraflores & 80,228 & $64.23 \%$ & 51,532 & $34.90 \%$ & $46.00 \%$ & $80.90 \%$ & 41,689 & 20,303 & 21,387 & $7 \%$ & 28 & 14 & 14 \\
\hline & San Borja & 112,185 & $62.41 \%$ & 70,018 & $34.90 \%$ & $46.00 \%$ & $80.90 \%$ & 56,644 & 27,586 & 29,059 & $10 \%$ & 38 & 19 & 20 \\
\hline & San Isidro & 52,868 & $62.31 \%$ & 32,941 & $34.90 \%$ & $46.00 \%$ & $80.90 \%$ & 26,649 & 12,978 & 13,671 & $5 \%$ & 18 & 9 & 9 \\
\hline & $\begin{array}{l}\text { Santiago de } \\
\text { Surco }\end{array}$ & 356,461 & $61.65 \%$ & 219,750 & $34.90 \%$ & $46.00 \%$ & $80.90 \%$ & 177,778 & 86,578 & 91,200 & $31 \%$ & 120 & 57 & 63 \\
\hline & & $1,168,953$ & & 724,763 & & & & 570,402 & 277,786 & 292,616 & $100 \%$ & 384 & 186 & 198 \\
\hline
\end{tabular}

Nota. Adaptado de Niveles Socioeconómicos 2017. APEIM. Recuperado de http://www.apeim.com.pe/wp-

content/themes/apeim/docs/nse/APEIM-NSE-2017.pdf 
La cantidad de personas y porcentajes por cada distrito fueron obtenidos del informe de perfiles socioeconómicos publicado por APEIM en el año 2017, dando como resultado el total de población del mismo año. Según lo indicado, el mercado estaría segmentado de la siguiente manera:

- País: Perú

- Provincia: Lima Metropolitana

- Nivel socioeconómico: A y B

- Zonas 6 y 7

- Rango de edades: 21 a 65 años

- Hombres y mujeres en el rango de edades: 21 a 65 años

Según la segmentación seleccionada, en la tabla 30, Hechizo se dirige a personas entre los 21 años a 65 años, teniendo como resultado que el 34\% que respondieron las encuestas fueron de 21 a 29 años, mientras que el $26 \%$ fueron de 30 a 39 años, seguido de un $25 \%$ de 40 a 49 años. Mientras que sólo el $11 \%$ tenían de 50 a 59 años, un 3\% de 60 a 65 años y finalmente sólo el 1\% tenía más de 66 años. Esto permite conocer las preferencias, aceptación y gustos para cada uno de los rangos de edades seleccionados.

Tabla 28

Edad

\begin{tabular}{lc}
\hline Respuesta & Porcentaje \\
\hline De 21 años a 29 años & $34 \%$ \\
De 30 años a 39 años & $26 \%$ \\
De 40 años a 49 años & $25 \%$ \\
De 50 años a 59 años & $11 \%$ \\
De 60 años a 65 años & $3 \%$ \\
De 66 años a más & $1 \%$ \\
\hline Total & $100 \%$ \\
\hline
\end{tabular}


La población total de Lima Metropolitana es de 10’190,922 personas, por lo tanto la cantidad de personas seleccionadas $\left(1^{\prime} 168,953\right)$ dentro de las zonas 6 y 7 representa el 11.46\% de la población total en Lima Metropolitana. El 28.9\% de la población de Lima Metropolitana pertenece al nivel socioeconómico A y B. Todas las cifras corresponden a datos del año 2017.

Luego, los porcentaje de personas dentro de las edades de 21 a 65 años fueron obtenidos multiplicando este porcentaje por el número de personas por distrito logramos obtener el número de personas dentro del rango de edad establecido para este estudio. Los porcentajes de NSE A y B se obtuvieron del informe y se procedió a sumarlos, debido a que son los dos segmentos que nos interesan para el estudio. Para obtener el segmento de mercado, se multiplico la suma de los porcentajes de NSE A y B por el número de población dentro del rango de edades.

Una vez planteada la segmentación se procedió a trabajar con la información encontrada, obteniendo los siguientes datos (ver tabla 29):

- Se halló que la población que representa los niveles socioeconómicos A y B en las zonas 6 y 7 equivale a 1'168,953habitantes en total.

- La cantidad de habitantes que están dentro del rango de edades entre 21 a 65 años es de 724,763 personas.

- Luego se ponderó esta cantidad de habitantes para cada distrito dentro de las zonas 6 y 7 , y se determinó la cantidad de hombres y mujeres y cuántas encuestas por cada uno.

- La técnica utilizada en el muestreo fue no probabilístico, por conveniencia. Sin embargo, con fines académicos se asumió que la población con muestra no probabilística, fue una probabilística para lograr obtener la información necesario para posterior cálculo de los mercados. 
- Para llegar al número óptimo de encuestados (384 personas) se utilizó la fórmula de población infinita (asumiendo que es una población con muestra probabilística).

Según Estadística y Muestreo, la fórmula es n=z^2xpxq/e^2 (2012).

- Los componentes de la fórmula son los siguientes:

○ $\mathrm{N}$, equivale al tamaño de la muestra.

- Z, que representa el nivel de confianza.

○ P, porcentaje de la población el cual presenta el atributo deseado.

○ Q, porcentaje de la población que no presenta el atributo deseado.

○ E, máximo error de estimación que se acepta.

Según Ciro Martínez, la población infinita está compuesta por un número indeterminado de individuos seleccionados en un sector. Si determinamos el tamaño de una muestra dentro de una población finita demasiado grande, el resultado no sufre mayor variación al determinado para una población infinita.

Se establecen las diferencias entre las poblaciones finitas e infinitas para un mayor sustento.

- Población Infinita, es igual a $\mathrm{n} / \mathrm{N} \leq 5 \%$

- Población Finita, es igual a $\mathrm{n} / \mathrm{N} \geq 5 \%$

- Por lo tanto si aplicamos la fórmula de la población infinita tenemos que 384/570,402 es igual a 0.0006732094, con lo que se demuestra que el rango está dentro de una población infinita. 
Tabla 29

Marco Muestral

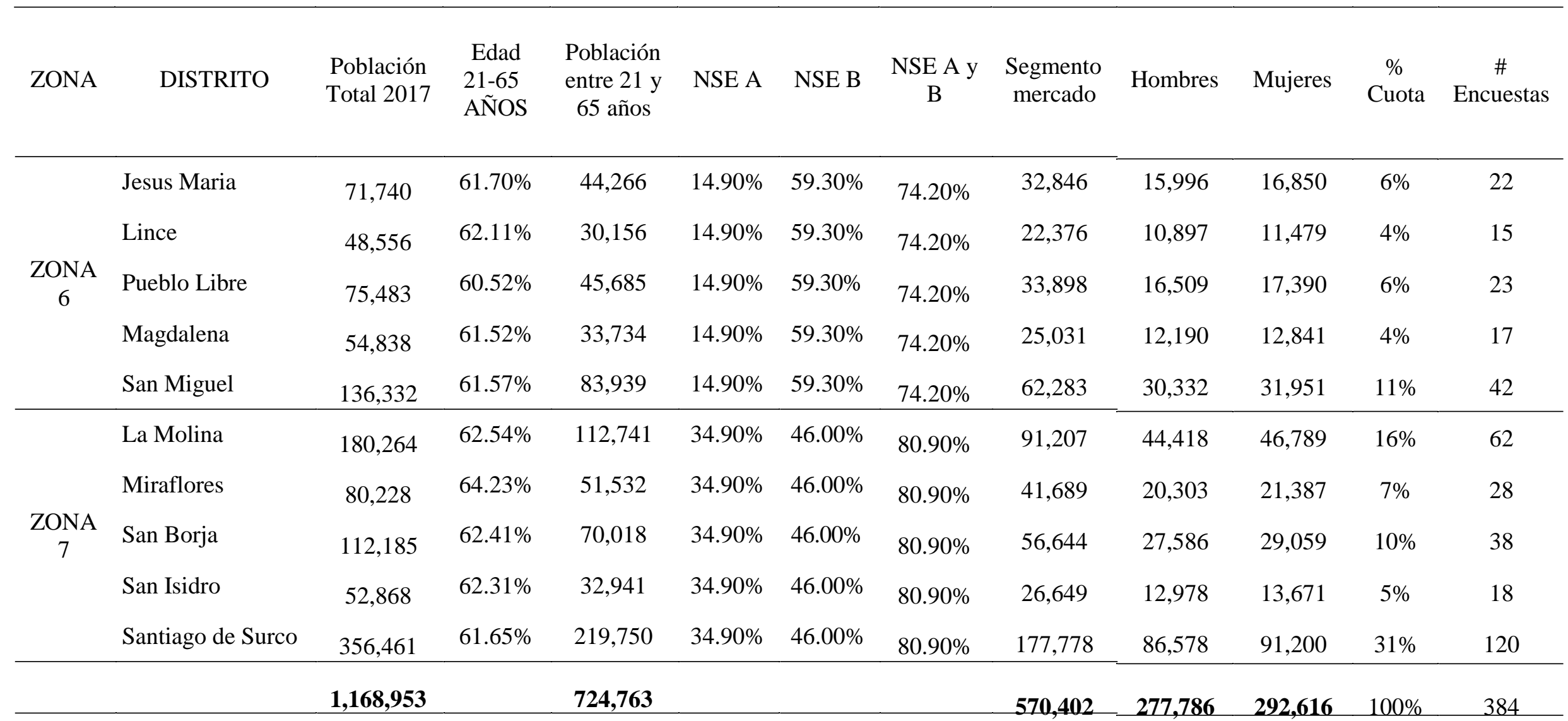

Fuente: INEI (Población)

Fuente: APEIM (NSE) 


\subsubsection{Diseño de instrumento.}

Según Malhotra (2008), los cuestionarios representan una técnica con una estructura establecida para la recopilación de información que como principal instrumento contempla el uso de preguntas, ya sean escritas u orales, las cuales tienen que ser contestadas por los encuestados. Además, propone que los objetivos del cuestionario son tres. Primero, la información que se desea obtener se debe expresar en preguntas específicas que sean fáciles de entender para los encuestados. Segundo, el cuestionario debe contener preguntas bien elaboradas que permitan al encuestado mantener el interés en resolver el formato de manera completa y respondiendo de manera veraz, evitando así la fatiga y la falta de interés. Tercero, el cuestionario debe ser elaborado para minimizar el margen de error en las respuestas de los encuestados.

Entre los tipos de preguntas se pueden identificar las dicotómicas, las cuales presentan sólo dos respuestas, sí o no. Con este tipo de pregunta se busca información sobre si el encuestado está de acuerdo o en desacuerdo con lo consultado. Otro tipo de preguntas son las estructuradas, que representan un grupo de posibles alternativas bajo un formato establecido y pueden presentarse preguntas dicotómicas, de escala o de opción múltiple, para el caso de estas preguntas, se presentan varias opciones de respuesta para que el encuestado pueda elegir una de ellas.

La técnica utilizada para el proceso cuantitativo fue la elaboración de una encuesta, que fue un cuestionario estructurado como medio para obtener información de las personas a las cuales se les entregó dicho cuestionario de manera directa (ver anexo 17).

El cuestionario presenta 17 preguntas las cuales están íntegramente relacionadas con los objetivos de la investigación. El encuestado respondió de acuerdo a sus preferencias y experiencias. 
Para el diseño del cuestionario se consideraron algunos tópicos importantes para obtener información valiosa sobre los mercados y los posibles clientes, ver anexo 17.

- La primera parte del cuestionario está orientado a obtener información sobre las personas encuestadas, es decir considera presuntas sobre edad, sexo y distrito (preguntas 1,2 y 3 ).

- La segunda parte del cuestionario está orientado a recabar información sobre el mercado disponible al considerar preguntas como el consumo de bebidas alcohólicas sobre todo pisco (preguntas 4, 5,6 y 7).

- Parte tres, las de preguntas están orientadas a obtener información sobre el consumo de macerados y la competencia (preguntas 8 y 9).

- El siguiente conjunto de preguntas está basado en extraer información sobre el mercado objetivo al contemplar preguntas de intensión y frecuencia de compra (preguntas 9, 10, 11, 12, 13 y 14).

Cabe mencionar que la pregunta 9 está totalmente diseñada para obtener información importante sobre la intención de compra de los consumidores.

El cuestionario final reflejó en total 17 preguntas de las cuales algunas se muestran como cerradas y abiertas y fueron distribuidas de manera lógica para ayudar a identificar los objetivos de la investigación.

- Entre las preguntas filtro utilizadas se consideró si el encuestado consumía bebidas alcohólicas, esta pregunta es vital para asegurar la validez del cuestionario y continuar con el mismo, las personas que no lo consuman automáticamente que dan fuera de la recopilación de datos.

- El tiempo estimado para el desarrollo de cada cuestionario es de cinco minutos por persona. 
- Solo se aplicará el cuestionario según el segmento seleccionado, considerando las zonas y NSE determinados.

La técnica de muestreo utilizada fue no probabilística, por conveniencia porque se buscó obtener muestras representativas incluyendo grupos supuestamente típicos. Se seleccionaron directa e indivualmente a los individuos de la población de los que se tiene fácil acceso. Se obtuvo los datos de todas las personas que representan la muestra seleccionada, luego se filtró tomando en cuenta el nivel socioeconómico, distrito, edad y sexo. Se utilizó este tipo de muestreo por la facilidad operativa y los bajos costos, además de la falta de tiempo para realizar un trabajo de campo extenso, se optó por filtrar los datos según los segmentos seleccionados para poder reemplazar el proceso de trabajo de campo. La falta de tiempo, lo complicado de los horarios, la poca predisposición de las personas ligado aún más a la inseguridad ciudadana obligó a utilizar el método no probabilístico por conveniencia con el objetivo de obtener una muestra representativa de la población necesaria para la investigación.

Sin embargo, la manera correcta para obtener la muestra seria contar con todos los datos completos de las personas que representan el total de la muestra seleccionada, luego de filtrar según los segmentos seleccionados, rangos de edad y sexo. Estos datos ingresarían a un software con el cual de manera aleatoria se podrían seleccionar las muestras necesarias. Se recuerda que según este muestreo todas las muestras tienen las mismas probabilidades de ser elegidas.

En la tabla 30 se puede observar la ficha técnica que fue utilizada para la encuesta. 
Tabla 30

Ficha técnica de encuesta

\begin{tabular}{|c|c|}
\hline Naturaleza Metodológica & Cuantitativa \\
\hline \multirow{2}{*}{ Técnica metodológica } & Encuesta personal por internet (Google formularios) \\
\hline & Cuestionario Estructurado de 17 preguntas cerradas y de opción \\
\hline Instrumento & múltiple. \\
\hline Universo & $\begin{array}{l}\text { Peruanos o residentes en Perú que vivan en Lima Metro } \\
\text { politana en las zonas } 6 \text { y } 7 \text { entre los } 21 \text { y } 65 \text { años }\end{array}$ \\
\hline \multirow{2}{*}{ Ámbito Geográfico } & $\begin{array}{l}\text { Zona } 6 \text { (Magdalena, Lince, Pueblo Libre, Jesús María, San } \\
\text { Miguel) }\end{array}$ \\
\hline & Zona 7 (San Borja, La Molina, San Isidro, Surco, Miraflores) \\
\hline \multirow{2}{*}{$\begin{array}{l}\text { Tipo de Preguntas } \\
\text { Fecha de Recolección de } \\
\text { datos }\end{array}$} & Dicotómicas, de opción múltiple y escala de importancia \\
\hline & Del 25 al 31 de octubre de 2017 \\
\hline
\end{tabular}

\subsubsection{Análisis y procesamiento de datos.}

Para Hernández et al. (2010), el procesamiento de la información obtenida del análisis cuantitativo se realizó con la ayuda de la tecnología, es decir, mediante el soporte de programas estadísticos en los ordenadores virtuales. El primer paso consiste en elegir un programa estadístico que permita colocar las variables deseadas, se usó Google formularios. Como siguente pasose analizó la exploración de los datos, esta etapa no debería mostrar inconvenientes siempre y cuando los datos seleccionados anteriormente sean los correctos. Cómo último paso, luego de obtener los resultados finales, se elaboraron los reportes respectivos para presentar los resultados.

Luego de realizar la encuesta los resultados obtenidos fueron los siguientes:

En tabla 31, la pregunta uno fue diseñada para conocer la cantidad de hombres y mujeres que pertenecen al mercado objetivo y que responderán la encuesta. Arrojando un total de $53 \%$ de hombres y $47 \%$ de mujeres, que emitieron su respuesta de manera libre y sincera. 
Tabla 31

Sexo

Respuesta

Porcentaje

Femenino

$47 \%$

Masculino

$53 \%$

Total $100 \%$

Hechizo se dirige a la zona 6 y zona 7, que conforman 10 distritos de Lima, de los cuáles el 31\% son de Santiago de Surco, el 16\% de La Molina, el 11\% de San Miguel, el 10\% de San Borja, el 7\% de Miraflores, el 6\% de Jesús María, el 6\% de Pueblo Libre, el 5\% de Magdalena, 5\% de San Isidro y el 4\% de Lince, ver tabla 32. Se obtiene el punto intermedio entre los distritos para colocar la planta y la distribución sea en un lugar céntrico entre los 10 distritos.

Tabla 32

Distrito

\begin{tabular}{lc}
\hline Respuesta & Porcentaje \\
\hline Santiago de Surco & $31 \%$ \\
San Miguel & $11 \%$ \\
San Isidro & $5 \%$ \\
San Borja & $10 \%$ \\
Pueblo Libre & $6 \%$ \\
Miraflores & $7 \%$ \\
Magdalena & $5 \%$ \\
Lince & $4 \%$ \\
La Molina & $16 \%$ \\
Jesús María & $6 \%$ \\
\hline Total & $100 \%$ \\
\hline
\end{tabular}

En la tabla 33, se observó el 89\% de personas respondió que consume bebidas alcohólicas, mientras que sólo el 7\% indicó que consume a veces y el 4\% de personas, respondió que no consume. Por lo que se puede identificar que existe un público amplio que podría interesarle el producto al consumir este tipo de bebidas. 
Tabla 33

Consumo de bebidas alcohólicas

\begin{tabular}{lcc}
\hline & Respuesta & Porcentaje \\
\hline Sí & $89 \%$ \\
A veces & $7 \%$ \\
No & $4 \%$ \\
\hline Total & $100 \%$ \\
\hline
\end{tabular}

El mayor porcentaje de personas, con un $66.9 \%$, consume bebidas alcohólicas de vez en cuando, mientras que el $20.6 \%$ consume siempre, el $8.6 \%$ rara vez, el $3.4 \%$ casi nunca y solo el $0.5 \%$ respondió que nunca consume, por lo que hay un consumo periódico de las personas con estas bebidas, ver tabla 34 .

Tabla 34

Frecuencia de consumo de bebidas alcohólicas

\begin{tabular}{lcc}
\hline & Respuesta & $\%$ \\
\hline Siempre & & $20.6 \%$ \\
De vez en cuando & $66.9 \%$ \\
Rara vez & & $8.6 \%$ \\
Casi nunca & & $3.4 \%$ \\
Nunca & $0.5 \%$ \\
\hline & Total general & $100.0 \%$ \\
\hline
\end{tabular}

En la tabla 35, se puede concluir que el $56.3 \%$ de encuestados consume pisco de vez en cuando, mientras que el $26.8 \%$ siempre, el $8.9 \%$ rara vez, el $6.8 \%$ casi nunca y solo el $1.3 \%$ nunca consume pisco, por lo que existe una preferencia y gusto por el pisco, que es la base de Hechizo.

Tabla 35

Consumo de pisco

\begin{tabular}{lcc}
\hline & Respuesta & $\%$ \\
\hline Siempre & & $26.8 \%$ \\
De vez en cuando & & $56.3 \%$ \\
Rara vez & & $8.9 \%$ \\
Casi nunca & & $6.8 \%$ \\
Nunca & & $1.3 \%$ \\
\hline & Total general & $100.0 \%$ \\
\hline
\end{tabular}


En la tabla 36, el 66\% ha probado macerados de frutas en pisco, mientras que el $34 \%$ no ha probado. Esto indica que el producto aún no es consumido habitualmente, sin embargo, la mayor parte conoce el producto.

Tabla 36

Experiencia con macerados de frutas en pisco

\begin{tabular}{lc}
\hline Respuesta & Porcentaje \\
\hline Sí & $66 \%$ \\
No & $34 \%$ \\
\hline Total & $100 \%$ \\
\hline
\end{tabular}

En la tabla 37, se introdujo con el objetivo de conocer si el público tenía alguna marca de su preferencia o para saber si conocían los macerados de frutas en pisco. Como resultado se obtuvo que el $78 \%$ de los encuestados no conocía ninguna marca. La segunda opción elegida fue "otros" con el 8\%, en de esta opción el público señaló que conocían el producto debido a que ellos mismos los elaboraban en casa, lo consumieron en bares, restaurantes o en casa de familiares, todos elaborados de manera artesanal.

Tabla 37

Conocimiento de marcas de macerados de frutas en pisco

\begin{tabular}{lc}
\hline Respuestas & Porcentaje \\
\hline RR Macerados & $4 \%$ \\
Malika & $3 \%$ \\
Sanka Macerados & $3 \%$ \\
Olaya Macerados & $2 \%$ \\
Golden Fruit Macerados & $2 \%$ \\
Ninguna & $78 \%$ \\
Otros & $8 \%$ \\
\hline Total & $100 \%$ \\
\hline
\end{tabular}

La pregunta 9, en la tabla 38,está completamente enfocada en conocer si el público está dispuesto a comprar los macerados de frutas en pisco, obteniendo como respuesta más 
votada el sí con un 48\% sobre el total, luego tal vez con 31\% y definitivamente sí con 19\% del total.

Tabla 38

Predisposición de compra de HECHIZO

\begin{tabular}{lc}
\hline Respuestas & Porcentaje \\
\hline Definitivamente sí & $19 \%$ \\
Si & $48 \%$ \\
Tal vez & $31 \%$ \\
No & $2 \%$ \\
Definitivamente no & $0 \%$ \\
Total & $100 \%$ \\
\hline
\end{tabular}

Para la pregunta 10, ver tabla 39, se presentaron los tres sabores de macerados de frutas en pisco que se ofrecieron al público. El resultado fue una igualdad entre dos sabores con $36 \%$ cada uno y un $28 \%$ para el sabor de chicha morada. Estos resultados demuestran que ambos sabores tienen la misma aceptación por el público.

Tabla 39

Preferencia de sabores

\begin{tabular}{lc}
\hline Sabores & Porcentaje \\
\hline Maracuyá y frambuesa & $36 \%$ \\
Fresa y guinda & $36 \%$ \\
Chicha morada & $28 \%$ \\
Total & $100 \%$ \\
\hline
\end{tabular}

Con esta pregunta se buscó saber cuáles eran los principales atributos que el público estaba dispuesto a encontrar al momento de adquirir los macerados de frutas en pisco. Entre la primera opción para el público figuran la calidad y el sabor con el mismo porcentaje de $38 \%$ sobre el total, seguido por el precio con $21 \%$ de elección, ver tabla 40.

Tabla 40

Atributos

\begin{tabular}{lc}
\hline Opción & Porcentaje \\
\hline Calidad & $38 \%$ \\
Sabor & $38 \%$ \\
Precio & $21 \%$ \\
Versatilidad & $2 \%$ \\
Tradición & $1 \%$ \\
Total & $100 \%$ \\
\hline
\end{tabular}


Con la formulación de la pregunta 12 en la tabla 40 se buscó conocer la frecuencia de compra del público, luego de haber manifestado de manera positiva la adquisición del producto, en consecuencia, los resultados reflejaron que el 38\% del total comprarían de manera semanal, seguido de trimestral con el $26 \%$, bimensual con $22 \%$ y quincenal con el $10 \%$ del total.

Tabla 41

Frecuencia de compra de HECHIZO

\begin{tabular}{lc}
\hline Opción & Porcentaje \\
\hline Semanal & $4 \%$ \\
Mensual & $38 \%$ \\
Quincenal & $10 \%$ \\
Bimensual & $22 \%$ \\
Trimestral & $26 \%$ \\
Total & $100 \%$ \\
\hline
\end{tabular}

Para poder cuantificar la demanda, se preguntó a los encuestados la cantidad de botellas que estarían dispuestos a comprar: comprarían una botella 206 personas que corresponde al 53.5\%, comprarían dos botellas 156 personas que corresponde al $40.52 \%$, comprarían tres botellas 17 personas que corresponde al $4.42 \%$, comprarían cuatro botellas tres personas que corresponde al $0.8 \%$ y comprarían cinco botellas solo 2 personas también que corresponde al $0.52 \%$, ver tabla 42 .

Así se pudo determinar las cantidad de botellas por compra a : 1.5 botellas.

Tabla 42

Intención de compra

\begin{tabular}{lc}
\hline Una & $53.5 \%$ \\
Dos & $40.5 \%$ \\
Tres & $4.4 \%$ \\
Cuatro & $0.8 \%$ \\
Cinco o mas & $0.5 \%$ \\
\hline & $100.0 \%$ \\
\hline
\end{tabular}

Para poder determinar el mercado efectivo se hizo esta pregunta, tabla 43 y se obtuvo el siguiente resultado: las personas que estarían dispuestas a pagar entre 45 y 49 Soles fueron 132 que representan el 32\%, las que estaban dispuestas a pagar entre 50 y 54 Soles fueron 
112 personas que representan el $29.2 \%$, las que estuvieron dispuestas a pagar entre 55 y 59 Soles fueron 114 personas que representan el 29.7\%, las que estuvieron dispuestas a pagar entre 60 y 64 Soles fueron 28 personas y por último las que estuvieron dispuestas a pagar entre 65 Soles a más fueron 7 personas que corresponde al $7 \%$.

Se usó las respuestas desde las que estaban dispuestas a pagar entre 50 y 54 Soles hasta 65 Soles a más dando un total de $68 \%$, para conjuntamente con otras poder determinar el mercado objetivo (Ver tabla 42).

Tabla 43

Rango de precios

\begin{tabular}{lc}
\hline Respuesta & $\%$ \\
\hline Entre 45 y 49 Soles & $32.0 \%$ \\
Entre 50 y 54 Soles & $29.2 \%$ \\
Entre 55 y 59 Soles & $29.7 \%$ \\
Entre 60 a 64 Soles & $7.3 \%$ \\
De 65 Soles a más & $1.8 \%$ \\
\hline Total general & $100.0 \%$ \\
\hline
\end{tabular}

Para determinar la estacionalidad y cuando consumirían el producto, en la tabla 44 se consideró hacer la pregunta de en cuando consumirían y las respuestas fueron: 70 personas dijeron que consumirían los macerados en fiestas representando un $18.2 \%$, otras 55 personas respondieron que consumirían los macerados en Eventos representando un 14.3\%, las que estarían dispuestas a consumirá los macerados en reuniones fueron 100 personas que representan un $26 \%$, las que consumirían en almuerzos fueron 18 personas que representan un $4.7 \%$, en cenas 4 personas que representan un $1 \%$ y en cualquier ocasión respondieron 138 personas que corresponden al $35.8 \%$. 
Tabla 44

Preferencia de consumo de HECHIZO

\begin{tabular}{lc}
\hline Respuesta & $\%$ \\
\hline Fiestas & $18.2 \%$ \\
Eventos & $14.3 \%$ \\
Reuniones & $26.0 \%$ \\
Almuerzos & $4.7 \%$ \\
Cenas & $1.0 \%$ \\
En cualquier Ocasión & $35.8 \%$ \\
\hline
\end{tabular}

Para poder determinar la estacionalidad se hizo la pregunta demostrada en la tabla 45, sobre en que época del años estarían dispuestos a comprar HECHIZO obteniéndose que : el 3\% de las personas consumirían en Primavera, el 10\% de las personas la consumirían en Verano, el 1\% de las personas la consumirían en Otoño, el 6\% de las personas en Invierno y el $80 \%$ de las personas la consumirían todo el año.

Tabla 45

Estacionalidad de consumo de HECHIZO

\begin{tabular}{lc}
\hline Respuestas & $\%$ \\
\hline Primavera & $3 \%$ \\
Verano & $10 \%$ \\
Otoño & $1 \%$ \\
Invierno & $6 \%$ \\
Todo el año & $80 \%$ \\
\hline
\end{tabular}

Para poder determinar el mercado efectivo se utilizó esta pregunta, en la tabla 46, dando como resultado que el $20.1 \%$ de ellas estaban dispuestas a comprar vía web, el $19.6 \%$ estaban dispuestas a comprar en estaciones de servicio, el $45.5 \%$ estaban dispuestas a comprar en Licorerías, el 14\% estaban dispuestas a comprar en supermercados y el $0.8 \%$ en otros.

De esa manera se utilizó los resultados de compras por web, estaciones de servicio, licorerías y supermercados dando un total del $85.2 \%$. 
Tabla 46

Preferencia de lugar de compra de HECHIZO

\begin{tabular}{lc}
\hline Respuesta múltiple & $\%$ \\
\hline Web (Delivery) & $20.1 \%$ \\
Estaciones de servicio & $19.6 \%$ \\
Licorerías & $45.5 \%$ \\
Supermercados & $14.0 \%$ \\
Otros & $0.8 \%$ \\
\hline Total general & $100.0 \%$ \\
\hline
\end{tabular}

\subsection{Conclusiones y recomendaciones del Estudio Cualitativo y Cuantitativo}

Estudio Cualitativo

Conclusiones del estudio cualitativo - Entrevistas

Area administrativa

Se identificó los permisos necesarios para poner en marcha el negocio.

Area de Operaciones

Se identificó lo más importante, pues de ahí se tomó las decisiones para el proceso productivo, calidad de productos, proveedores, ingredientes a usar, controles de calidad, equipos a usar.

Area Comercial

Se identificó cómo se realizarían las ventas, canales a usar, publicidad, métodos de cobranza, precio de venta ideal. Además de cómo realizar el marketing y el nombre comercial.

Area Logística

Se identificó cómo llegar al cliente, optimización de costos. 


\section{Recomendaciones}

- El experto en la preparación, debe mantener la receta original de cada uno de los sabores para garantizar la calidad del producto en cada uno de los lotes

- El experto en Marketing, para realizar la estrategia de ventas y poder competir en el mercado.

- Tener en cuenta los gastos de publicidad que sean necesarios para que el producto sea aceptado y reconocido.

- Realizar samplings del producto para darlo a conocer y los clientes puedan apreciar el producto.

Conclusiones del estudio cualitativo - Focus Group

Identificar el nivel de aceptación de los macerados de frutas en pisco

- Se identificó la calidad era un punto importante para la aceptación del producto.. Se entiendió por calidad: cumplir con el tiempo de maceración exacto, la combinación de sabores ideal (la receta en la que los ingredientes estén balanceados para que los sabores y aromas estén en armonía).

Frecuencia de consumo

- Se identificó que el pisco por lo general, se consume en cualquier ocasión, y que el macerado de frutas en pisco tiene la misma aceptación. Lo que quiere decir que la estacionalidad no sólo sería en fechas especiales, sino también para todo tipo de reuniones sociales (almuerzos, cenas, fiestas) y en todo tipo de lugares.

\section{Variables determinantes para la compra}

- Se identificó la presentación de 750 Ml, el color del producto, el tema siguiendo la onda artesanal y natural, la combinación de los sabores, el precio justo para que la percepción de que es de calidad son variables que toman en cuenta al momento de comprar. 
Presentación del producto

- Según lo que se observó la botella y presentación de producto fue aceptado. Se apreció que a todos les gustó ya que no habían visto una presentación similar. Incluso la cantidad que ofrece la botella de $750 \mathrm{Ml}$ les pareció conveniente.

Determinación del nombre

- Se concluyó en los tres focus que se realizaron que los nombres que se propusieron no causaron ninguna reacción, ni recordación. Se decidió cambiar por eso a HECHIZO, porque era un nombre que tenía mayor relación con el producto y generaba mayor expectativa.

Sabores adecuados

- En cuanto a los sabores se concluyó que la mejor opción era trabajar con tres sabores para desarrollar bien la marca y el mercado. Los sabores de mayor aceptación y fueron maracuyá y frambuesa, guinda y fresa y por último chicha morada. Estos fueron los sabores que se produjeron y se usaron en todo el plan de Negocios.

Recomendaciones del estudio Cualitativo

- Se debe tener en cuenta que el experto en la maceración es una persona importante en el proceso de producción, igualmente el tiempo de maceración es determinante para obtener un producto de calidad.

- Ingresar al mercado con tres sabores inicialmente era lo más apropiado.

- Los ingredientes a utilizar deben ser seleccionados con mucho cuidado y buscar proveedores que ofrezcan productos de calidad.

Estudio Cuantitativo

Conclusiones del estudio cuantitativo

- En relación al objetivo general del estudio cuantitativo, se pudo concluir que el consumo de pisco ha aumentado entre personas jóvenes (entre 21 y 30 años) mientras 
que el consumo se ha visto fortalecido en las personas de 31 años a más. El consumo del pisco ha dado un giro total en cuanto a la forma de consumo tradicional, es decir, no solo se consume puro, en sour o chilcano, hemos evidenciado que un gran número de personas prefieren nuevas formas de consumir esta bebida, ya sea en cocteles o mezclado con frutas y especies.

- En cuanto a los objetivos específicos, se obtuvieron los siguientes resultados:

Plaza

- Se puedo verificar que las personas menores de 30 años estarían dispuestas a comprar los macerados de frutas en pisco por internet, al ser una generación muy ligada a la tecnología, indicaron que no tendrían inconvenientes en adquirir el producto por esta vía, mientras que las personas mayores preferían la manera tradicional para adquirir el producto, es decir en licorerías, estaciones de servicios y tiendas especializadas.

Precio

- En relación al precio no se encontraron grandes desviaciones al momento de recoger información sobre este punto, cerca del total de encuestados sugirieron que estarían dispuestos a pagar un precio entre los rangos de 55 y 60 nuevos soles por una botella de $750 \mathrm{ml}$.

Producto

- El resultado final mostrado en estas encuestas mostraron que los principales sabores preferidos por los encuestados fueron guinda y fresa, y maracuyá y frambuesa, seguidos por chica morada el cual mostró un menor porcentaje. Estos tres sabores fueron los de mayor predilección para los encuestados.

Promoción

- Los nombres seleccionados para la encuesta no resultaron ser de fácil recordación para los encuestados y sugirieron establecer otros con mayor o fácil recordación. 
Recomendaciones del estudio cuantitativo

- La gran mayoría de encuestados indicaron que se debería ofrecer una degustación del producto antes de lanzarlo para la venta, esto debido a que la principal característica que resalta el producto es su sabor.

- Sugirieron degustaciones y campañas de promoción vía internet.

- Mencionaron que el nombre no lo recordaban con facilidad y tampoco lo relacionaban con el producto por lo tanto debería cambiarse.

\subsection{Perfil del consumidor tipo y sus variantes}

Se estableció un Perfil del consumidor tipo según las características del público que consume bebidas alcohólicas, en especial pisco y sus derivados. Sin embargo, las personas que consumen bebidas alcohólicas, no son siempre las mismas, por lo que se debe reflejar ciertas variaciones de segmentación utilizadas para poder atender al cliente correctamente, ver tabla 47.

Tabla 47

Perfil del consumidor tipo

\begin{tabular}{llc}
\hline & Edad & $21-65$ años \\
\cline { 2 - 3 } demogriables & Sexo & M y F \\
\cline { 2 - 3 } & $\begin{array}{l}\text { Nivel } \\
\text { Socioeconómico }\end{array}$ & A y B \\
\hline
\end{tabular}

\begin{tabular}{|c|c|c|c|}
\hline \multirow{3}{*}{$\begin{array}{l}\text { Variables } \\
\text { geográficas }\end{array}$} & & Zona 6 & $\begin{array}{l}\text { Lince } \\
\text { Pueblo Libre } \\
\text { Magdalena } \\
\text { Jesús María } \\
\text { San Miguel }\end{array}$ \\
\hline & $\begin{array}{l}\text { Distrito de } \\
\text { pertenencia }\end{array}$ & & \\
\hline & & Zona 7 & $\begin{array}{l}\text { La Molina } \\
\text { San Borja } \\
\text { Santiago de Surco } \\
\text { Miraflores } \\
\text { San Isidro }\end{array}$ \\
\hline
\end{tabular}




\section{Capítulo IV. Proyección del mercado objetivo}

En este capítulo, con la información recabada de la encuesta y la segmentación, se proyectó el mercado y con ello se elaboró el pronóstico de las ventas. Con esta indagación también se pudo ver la problemática que se presentó para el pronóstico de ventas. Cabe señalar que, con la problemática actual, el crecimiento en las ventas se ve afectado por la pasividad de crecimiento de la economía actual.

Cabe mencionar que en este capítulo, se trabajó con información de una muestra no probabilística, asumiendo que era una muestra probabilística. Teniendo en consideración que según la teoría de Malhotra, esto no es correcto para poder obtener proyecciones desde este capítulo en adelante. Sin embargo, debido a factores como la falta de tiempo, no tener datos disponibles y altos costos para acceder a la información se hizo difícil implementar la muestra probabilísitca, es así que con fines académicos se trabajó de esta manera.

Esta proyección del mercado objetivo se realizó con la información real de la población de la zona 6 y zona 7 de la ciudad de Lima. Se utilizará el método de proyección lineal.

Para la proyección del mercado objetivo se utilizó la información recabada de las entrevistas de profundidad hechas a los dueños y Gerentes de bodegas de Pisco Sarcay y Bailetti (Ver tabla 23), productores artesanales de macerados de pisco en fruta Eddu's y Foodies (Ver tabla 21), sommelier para la mezcla de sabores (Ver tabla 24), de esa manera se logró tomar las decisiones que más convenían para la realización del proyecto. Para mayor información ver transcripciones de las entrevistas a profunidad en los Anexos \# 6, 7, 9, 10 y 11.

\subsection{El ámbito de la proyección}

En este estudio, el ámbito de la proyección fue dirigido a la ciudad de Lima Metropolitana, que según INEI (2017), cuenta con una población de 9 millones 111 mil 
habitantes. Del cual, según INEI (2017), el 68\% representa a la Población Económicamente Activa (PEA), siendo este un buen signo económico y demuestra que es un mercado con potencial para colocar un negocio.

\subsection{Selección del método de proyección}

Para el método de proyección se utilizó la regresión lineal, ya que permite proyectar la población de los distritos que fueron seleccionados en base a una tendencia lineal que se obtuvo según los datos históricos que se tienen de la población.

La proyección de la población se realizó a partir del año 2017 (año 0 para efectos del estudio) y se prolongó hasta el año 2022, teniendo así que el proyecto se evalúa por un periodo de cinco años.

Para efectos de la proyección se utilizó data histórica de la población a partir del año 2005 hasta el 2015.

A continuación, se muestra la fórmula utilizada en la proyección de cada distrito seleccionado, así como la población proyectada de la tabla 48 a la tabla 49.

Tabla 48

Tasa de crecimiento poblacional

\begin{tabular}{clcccc}
\hline $\mathrm{N}^{\circ}$ & $\begin{array}{c}\text { Distritos de Lima } \\
\text { seleccionados }\end{array}$ & $\begin{array}{c}\text { Total } \\
\text { Población al } \\
2005 \\
\text { (personas) }\end{array}$ & $\begin{array}{c}\text { Total } \\
\text { Población al } \\
2015 \\
\text { (personas) }\end{array}$ & $\begin{array}{c}\text { Tasa } \\
\text { crecimiento } \\
\text { del periodo } \\
(2005-2015)\end{array}$ & $\begin{array}{c}\text { Tasa } \\
\text { crecimiento } \\
\text { anual } \\
\text { promedio } \\
\text { poblacion } \\
(2005-2015)\end{array}$ \\
\hline 1 & Jesus Maria & 70,839 & 71,589 & $1.06 \%$ & $0.11 \%$ \\
2 & Lince & 59,495 & 50,228 & $-15.58 \%$ & $-1.68 \%$ \\
3 & Pueblo Libre & 78,930 & 76,046 & $-3.65 \%$ & $-0.37 \%$ \\
4 & Magdalena del Mar & 53,756 & 54,656 & $1.67 \%$ & $0.17 \%$ \\
5 & San Miguel & 134,081 & 135,954 & $1.40 \%$ & $0.14 \%$ \\
6 & La Molina & 128,306 & 170,333 & $32.75 \%$ & $2.87 \%$ \\
7 & Miraflores & 90,049 & 81,787 & $-9.17 \%$ & $-0.96 \%$ \\
8 & San Borja & 110,728 & 111,940 & $1.09 \%$ & $0.11 \%$ \\
9 & San Isidro & 62,037 & 54,296 & $-12.48 \%$ & $-1.32 \%$ \\
10 & Santiago de Surco & 287,788 & 343,971 & $19.52 \%$ & $1.80 \%$ \\
\hline & TOTAL & $1,112,347$ & $1,150,801$ & $3.46 \%$ & $0.34 \%$ \\
\hline
\end{tabular}


Tabla 49

Población proyectada

\begin{tabular}{|c|c|c|c|c|c|c|c|c|c|}
\hline 2 & Lince & 50,228 & 49,385 & 48,556 & 47,740 & 46,939 & 46,151 & 45,376 & 44,614 \\
\hline 4 & Magdalena del Mar & 54,656 & 54,747 & 54,838 & 54,929 & 55,020 & 55,112 & 55,203 & 55,295 \\
\hline 5 & San Miguel & 135,954 & 136,143 & 136,332 & 136,521 & 136,711 & 136,901 & 137,091 & 137,281 \\
\hline 6 & La Molina & 170,333 & 175,228 & 180,264 & 185,444 & 190,774 & 196,256 & 201,896 & 207,698 \\
\hline 9 & San Isidro & 54,296 & 53,577 & 52,868 & 52,168 & 51,477 & 50,795 & 50,123 & 49,459 \\
\hline \multirow[t]{2}{*}{10} & Santiago de Surco & 343,971 & 350,161 & 356,461 & 362,875 & 369,404 & 376,051 & 382,818 & 389,706 \\
\hline & $\begin{array}{l}\text { TOTAL Numero de } \\
\text { personas }\end{array}$ & $1,150,801$ & $1,159,734$ & $1,168,953$ & $1,178,461$ & $1,188,266$ & $1,198,374$ & $1,208,789$ & $1,219,519$ \\
\hline
\end{tabular}




\subsubsection{Mercado Potencial.}

Según Kotler y Keller (2012), el mercado potencial es el conjunto de consumidores que presentan un nivel de interés suficientemente alto por la oferta de mercado. Este interés no alcanza para poder definir el mercado, salvo que poder adquisitivo de los consumidores se incremente y con ello pueda llegar a tener el sustento económico para obtener el producto.

El mercado potencial se obtuvo en base a la segmentación seleccionada y considerando los distritos que integran las zonas 6 y 7 . Se trabajó en base al rango de edad elegido, el cual considera las edades entre 21 y 65 años de edad, luego fueron consideras las personas que pertenecían a los estratos A y B. Para proyectar el crecimiento de la población al año 2022, se realizó un análisis de la siguiente manera : se tomaron los crecimientos de dos años como referencia 2013 y 2017 con lo cual se obtuvo una tendencia de crecimiento entre dicho años, luego esto se proyectó para cada uno de los años posteriores considerando las variables de : niveles socio-económicos, rango de edad y distritos de las zonas 6 y 7 de Lima Metropolitana. El resultado final fue una suma de ambos sectores lo cual arrojo en porcentaje final del mercado meta. Esto se muestra en la tabla 50 y tabla 51.En la tabla 51, se muestran los resultados por número de personas. En el anexo \# 18 se puede observar el detalle de la proyección. 
Tabla 50

Mercado Potencial (Porcentaje de personas del total de la población)

\section{CRITERIOS SEGMENTACION}

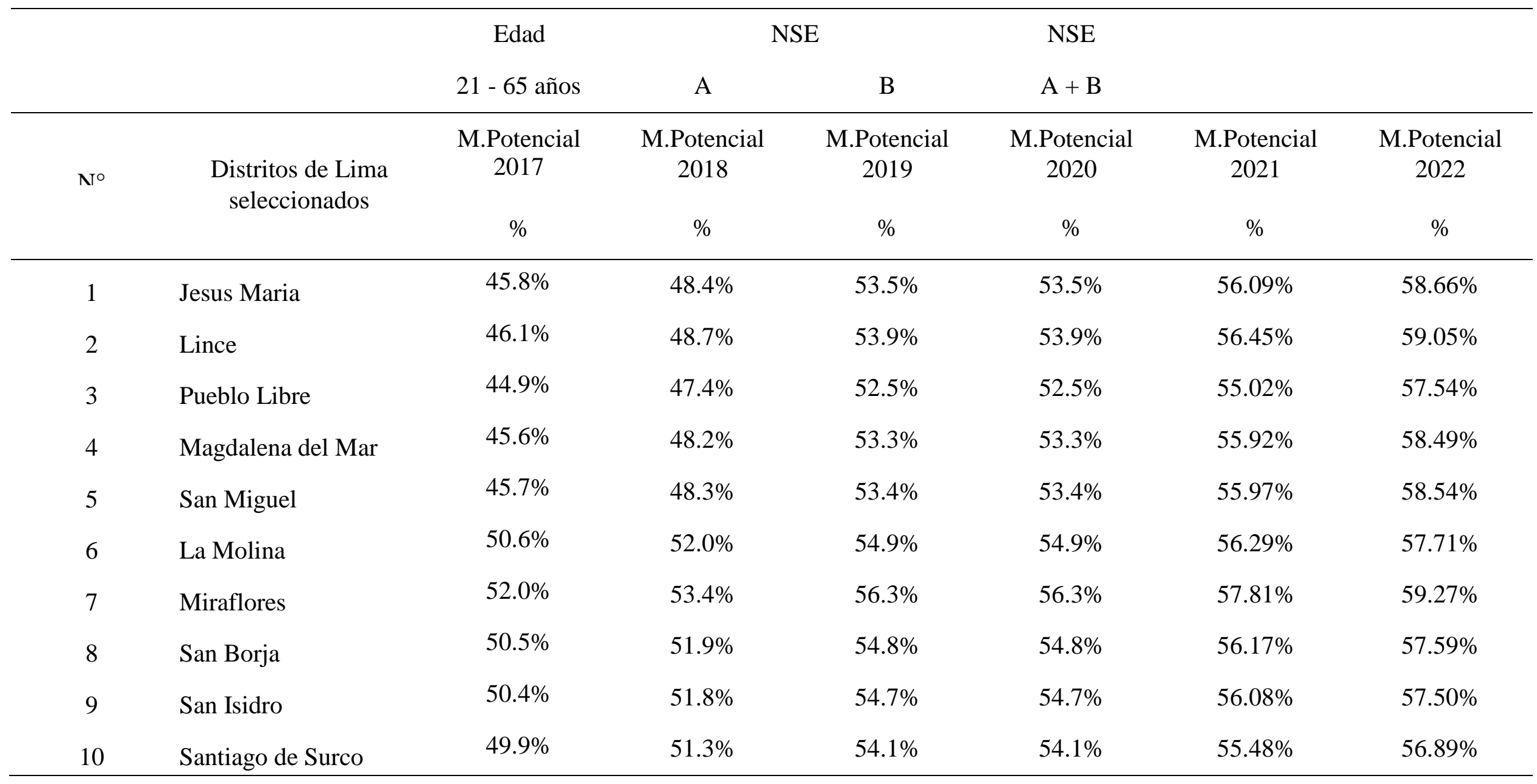


Tabla 51

Mercado Potencial (personas)

\begin{tabular}{llrrrrrr}
\hline $\mathrm{N}^{\circ}$ & \multicolumn{1}{c}{$\begin{array}{c}\text { Distritos de Lima } \\
\text { seleccionados }\end{array}$} & 2017 & 2018 & 2019 & 2020 & 2021 & 2022 \\
\hline 1 & Jesus Maria & 32,846 & 34,730 & 36,619 & 38,511 & 40,408 \\
2 & Lince & 22,376 & 23,238 & 24,065 & 24,858 & 25,617 & 26,344 \\
3 & Pueblo Libre & 33,898 & 35,673 & 37,433 & 39,181 & 40,914 & 42,634 \\
4 & Magdalena del Mar & 25,031 & 26,483 & 27,940 & 29,402 & 30,868 & 32,340 \\
5 & San Miguel & 62,283 & 65,879 & 69,484 & 73,100 & 76,725 \\
6 & La Molina & 91,207 & 96,467 & 101,954 & 107,676 & 113,644 \\
7 & Miraflores & 41,689 & 42,451 & 43,195 & 43,920 & 44,627 \\
8 & San Borja & 56,644 & 58,301 & 59,961 & 61,624 & 63,291 \\
9 & San Isidro & 26,649 & 27,036 & 27,408 & 27,765 & 28,108 \\
10 & Santiago de Surco & 177,778 & 186,066 & 194,594 & 203,370 & 212,398 \\
\hline
\end{tabular}




\subsubsection{Mercado Disponible.}

Según Kotler y Keller (2012), el mercado disponible es el conjunto de consumidores que tienen interés, ingresos y acceso a una oferta en particular. Este interés no alcanza para poder definir el mercado, salvo que el poder adquisitivo de los consumidores se incremente y con ello pueda llegar a tener el sustento económico para obtener el producto.

Para hallar el mercado disponible se cruzó la información de las siguientes preguntas, estas sirvieron como filtro para determinarlo en la tabla 52.

Tabla 52

Consumo de bebidas alcohólicas

\begin{tabular}{lcc}
\hline & Respuesta & $\%$ \\
\hline $\mathrm{Si}$ & $89.1 \%$ \\
$\mathrm{~A}$ veces & $6.8 \%$ \\
No & $4.2 \%$ \\
\hline Total general & $100.0 \%$ \\
\hline
\end{tabular}

El 89.1\% de personas respondió que consume bebidas alcohólicas, mientras que sólo el $6.8 \%$ indicó que consume a veces y el $4.2 \%$ de personas, respondió que no consume. Por lo que se puede identificar que existe un público amplio que podría interesarle el producto al consumir este tipo de bebidas.

Se utilizó la pregunta 6, la cual es ¿Consume pisco?, en donde se consideró las respuestas de los encuestados que contestaron que "siempre" con un $26.8 \%$ y "de vez en cuando" con un 56.3\%, que consumen pisco, obteniendo como resultado un total $83.1 \%$. (Ver tabla 53).

Tabla 53

Consumo de pisco

\begin{tabular}{lc}
\hline \multicolumn{1}{c}{ Respuesta } & $\%$ \\
\hline Siempre & $26.8 \%$ \\
De vez en cuando & $56.3 \%$ \\
Rara vez & $8.9 \%$ \\
Casi nunca & $6.8 \%$ \\
Nunca & $1.3 \%$ \\
\hline \multicolumn{2}{r}{ Total general } \\
\hline
\end{tabular}


Para hallar el mercado disponible, se multiplicó el resultado del mercado potencial por distrito sobre el porcentaje de cada una de las respuestas que se usaron como filtro. De acuerdo a ese resultado el mercado disponible de personas por distritos en la tabla 54.

Tabla 54

Mercado Disponible (Número de personas)

\begin{tabular}{|c|c|c|c|c|c|c|c|}
\hline $\mathrm{N}^{\circ}$ & $\begin{array}{l}\text { Distritos de Lima } \\
\text { seleccionados }\end{array}$ & 2017 & 2018 & 2019 & 2020 & 2021 & 2022 \\
\hline 1 & Jesus Maria & 24,300 & 25,694 & 27,091 & 28,492 & 29,895 & 31,301 \\
\hline 2 & Lince & 16,554 & 17,192 & 17,804 & 18,390 & 18,952 & 19,490 \\
\hline 3 & Pueblo Libre & 25,079 & 26,391 & 27,694 & 28,987 & 30,269 & 31,542 \\
\hline 4 & Magdalena del Mar & 18,518 & 19,593 & 20,671 & 21,752 & 22,837 & 23,926 \\
\hline 5 & San Miguel & 46,078 & 48,739 & 51,406 & 54,081 & 56,763 & 59,453 \\
\hline 6 & La Molina & 67,477 & 71,369 & 75,428 & 79,661 & 84,076 & 88,678 \\
\hline 7 & Miraflores & 30,843 & 31,406 & 31,956 & 32,493 & 33,016 & 33,527 \\
\hline 8 & San Borja & 41,907 & 43,132 & 44,360 & 45,591 & 46,824 & 48,060 \\
\hline 9 & San Isidro & 19,716 & 20,002 & 20,277 & 20,541 & 20,795 & 21,038 \\
\hline \multirow[t]{2}{*}{10} & Santiago de Surco & 131,524 & 137,655 & 143,965 & 150,457 & 157,137 & 164,008 \\
\hline & Numero de personas & 421,995 & 441,173 & 460,652 & 480,445 & 500,564 & 521,022 \\
\hline
\end{tabular}

Para el calculo del mercado disponible, se consideraron algunas preguntas del cuestionario.

La pregunta 6, que tiene la finalidad de obtener información sobre el consumo de pisco, es decir que la intención fue determinar que porcentaje de personas que consumen bebidas alcohólicas prefieren como primera opción el pisco y el resultado arrojo un $26.8 \%$ para "siempre" y 56.3\% para "de vez en cuando".

En la muestra seleccionada y en la pregunta nueve, un total del $67.7 \%$ indicaron que, si estarían dispuestos a comprar los macerados de frutas en pisco, lo que refleja de manera clara que más de la mitad de los 384 encuestados demuestran intención ce compra.

\subsubsection{Mercado Efectivo.}

Según Kotler y Keller (2012), el mercado efectivo es la parte del mercado calificado a la que la empresa opta por atender. Para determinar el mercado efectivo se cruzó la 
información de las preguntas 9 y 14 de la encuesta para poder analizar las preferencias y cuánto estarían dispuestos a pagar.

Filtro 1

Tabla 55

Predisposición de compra de HECHIZO

\begin{tabular}{lc}
\hline \multicolumn{1}{c}{ Respuesta } & $\%$ \\
\hline Definitivamente si & $19.3 \%$ \\
$\mathrm{Si}$ & $48.4 \%$ \\
Tal vez & $30.5 \%$ \\
No & $1.6 \%$ \\
Definitivamente no lo compraría & $0.3 \%$ \\
\hline Total general & $100.0 \%$ \\
\hline
\end{tabular}

Para esta pregunta solo se usará la suma de las personas que definitivamente sí comprarían y las que sí, dando un total de $67.7 \%$, ver tabla 55.

Filtro 2

Tabla 56

Rango de precios

\begin{tabular}{lc}
\hline Respuesta & $\%$ \\
\hline Entre 45 y 49 & $32.0 \%$ \\
Entre 50 y 54 & $29.2 \%$ \\
Entre 55 y 59 & $29.7 \%$ \\
Entre 60 a 64 & $7.3 \%$ \\
De 65 a más & $1.8 \%$ \\
\hline Total general & $100.0 \%$ \\
\hline
\end{tabular}

$38.8 \%$

En esta pregunta el mayor porcentaje y muy parejo se presentó entre las opciones que estarían dispuestos a pagar entre S/ 55 y S/ 59 Soles, dando un total de 38.8\%, ver tabla 56.

Con el cruce de todas estas respuestas tenemos el mercado efectivo en personas, se puede ver la tabla 57 con el detalle. 
Tabla 57

Mercado Efectivo en personas

\begin{tabular}{|c|c|c|c|c|c|c|c|}
\hline $\mathrm{N}^{\circ}$ & $\begin{array}{l}\text { Distritos de Lima } \\
\text { seleccionados }\end{array}$ & 2017 & 2018 & 2019 & 2020 & 2021 & 2022 \\
\hline 1 & Jesus Maria & 6,383 & 6,749 & 7,116 & 7,484 & 7,853 & 8,222 \\
\hline 2 & Lince & 4,348 & 4,516 & 4,677 & 4,831 & 4,978 & 5,119 \\
\hline 3 & Pueblo Libre & 6,588 & 6,932 & 7,275 & 7,614 & 7,951 & 8,285 \\
\hline 4 & Magdalena del Mar & 4,864 & 5,146 & 5,430 & 5,714 & 5,999 & 6,285 \\
\hline 5 & San Miguel & 12,104 & 12,802 & 13,503 & 14,206 & 14,910 & 15,617 \\
\hline 6 & La Molina & 17,725 & 18,747 & 19,813 & 20,925 & 22,085 & 23,294 \\
\hline 7 & Miraflores & 8,102 & 8,250 & 8,394 & 8,535 & 8,673 & 8,807 \\
\hline 8 & San Borja & 11,008 & 11,330 & 11,652 & 11,976 & 12,300 & 12,624 \\
\hline 9 & San Isidro & 5,179 & 5,254 & 5,326 & 5,396 & 5,462 & 5,526 \\
\hline \multicolumn{2}{|c|}{10 Santiago de Surco } & 34,548 & 36,159 & 37,816 & 39,522 & 41,276 & 43,081 \\
\hline & Numero de personas & 110,848 & 115,886 & 121,002 & 126,201 & 131,486 & 136,860 \\
\hline
\end{tabular}

\subsubsection{Mercado Objetivo.}

Según Kotler y Keller (2012), el mercado objetivo es el conjunto de consumidores que adquieren el producto que ofrece la empresa.

Se necesitó determinar la producción de pisco, para poder hallar el crecimiento promedio y proyectar la demanda y la variación del crecimiento del mercado.

En la tabla 58 se muesta el consumo interno de pisco en litros desde el año 2011 al 2016.

Tabla 58

Producción y Consumo interno estimado de Pisco en Perú

\begin{tabular}{lccrrr}
\hline & Período & $\begin{array}{c}\text { Producción } \\
\text { (Millones } \\
\text { Litros) }\end{array}$ & Variación \% & $\begin{array}{c}\text { Exportaciones } \\
\text { (Miles litros) }\end{array}$ & $\begin{array}{c}\text { Consumo } \\
\text { Interno } \\
\text { (Litros) }\end{array}$ \\
\hline 2011 & 1 & 6.30 & -0.40 & 0.46 & 5.84 \\
2012 & 2 & 7.10 & 12.80 & 0.56 & 6.54 \\
2013 & 3 & 7.10 & -0.10 & 0.64 & 6.47 \\
2014 & 4 & 8.60 & 21.50 & 0.74 & 7.86 \\
2015 & 5 & 9.50 & 10.10 & 0.94 & 8.56 \\
2016 & 6 & 10.50 & & 1.06 & 9.44 \\
\hline
\end{tabular}


Con el resultado del consumo interno de pisco se hizo una proyección para poder sacar la tasa de crecimiento promedio,usando datos desde el 2012 al 2016 (Ver figura 8).

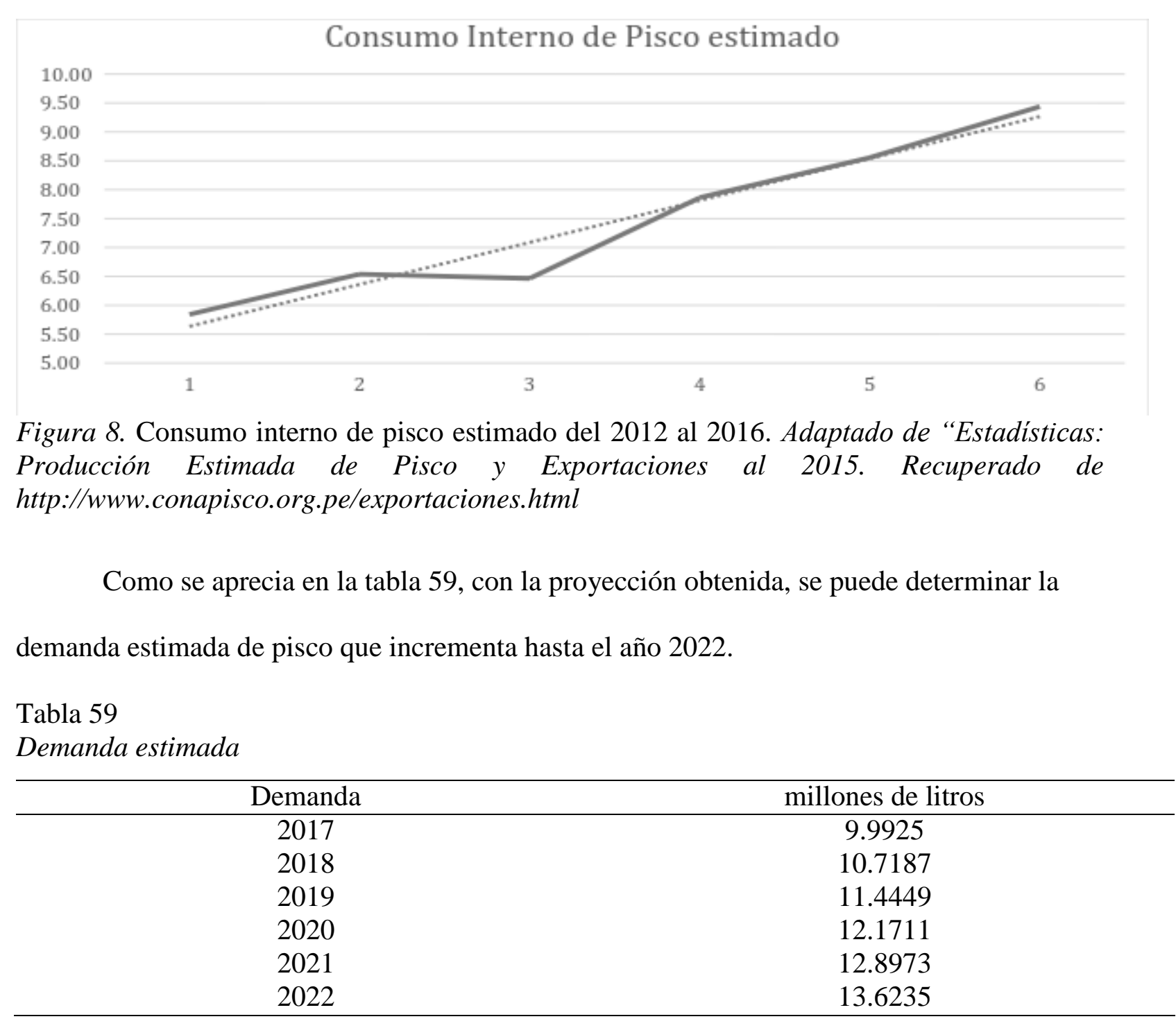

De igual manera, en la tabla 60 se puede observar la obtención de la variación de crecimiento de la tasa promedio.

Tabla 60

Variación de crecimiento de tasa promedio

\begin{tabular}{cccc}
\hline $\begin{array}{c}\text { Total de litros al } \\
2012 \text { (Pisco) }\end{array}$ & $\begin{array}{c}\text { Total de litros al } \\
2016 \text { (Pisco) }\end{array}$ & $\begin{array}{c}\text { Tasa crecimiento del } \\
\text { periodo } \\
(2012-2016)\end{array}$ & $\begin{array}{c}\text { Tasa crecimiento } \\
\text { anual promedio } \\
(2012-2016)\end{array}$ \\
\hline 6.54 & 9.44 & $44 \%$ & $7.61 \%$ \\
\hline
\end{tabular}

Para hallar el mercado objetivo se hizo un cuadro analizando la participación de los competidores en el mercado, ver tabla 61. 
Tabla 61

Proyección del crecimiento del mercado

\begin{tabular}{ccccccc}
\hline 2016 & 2017 & 2018 & 2019 & 2020 & 2021 & 2022 \\
\hline $7.61 \%$ & $8.19 \%$ & $8.81 \%$ & $9.48 \%$ & $10.20 \%$ & $10.98 \%$ & $11.82 \%$ \\
\hline
\end{tabular}

En la tabla 62 se muestran los competidores y su participación en el mercado, información obtenida de la encuesta.

Tabla 62

Potenciales competidores

\begin{tabular}{lc}
\hline Participación de mercado & Porcentaje \\
\hline RR Macerados & $4.16 \%$ \\
Malika & $2.86 \%$ \\
Sanka Macerados & $3.12 \%$ \\
Olaya Macerados & $1.56 \%$ \\
Golden Fruit Macerados & $2.08 \%$ \\
Gotas de oro & $0.26 \%$ \\
InKanto & $0.26 \%$ \\
Queirolo & $0.78 \%$ \\
Rayito de Sol & $0.26 \%$ \\
Waska & $0.26 \%$ \\
Yayo's pisco & $0.26 \%$ \\
Tentazione & $0.26 \%$ \\
Bares / Restaurantes & $1.30 \%$ \\
Artesanal & $4.68 \%$ \\
Ninguno & $77.92 \%$ \\
\hline
\end{tabular}

Nota. Datos obtenidas mediante la encuesta.

Para obtener la participación del mercado, en la tabla 63 se consideró tener una participación inicial de $1.80 \%$, siendo conservadores, ya que el mercado se prevé que va a tener un crecimiento del $8 \%$ y al no ser una marca nueva debe posicionarse en el mercado.

Tabla 63

Participación y crecimiento de mercado

\begin{tabular}{lccccc}
\hline Participación de Mercado & $1.80 \%$ & & & & \\
\hline Crecimiento de Mercado & $8.0 \%$ & & & & \\
\hline & 2018 & 2019 & 2020 & 2021 & 2022 \\
\hline Participación de mercado & $1.80 \%$ & $1.94 \%$ & $2.10 \%$ & $2.27 \%$ & $2.45 \%$ \\
\hline
\end{tabular}


En las tablas 64 se aprecia el mercado objetivo por distritos y en la tabla 65 el resumen anual.

Tabla 64

Mercado objetivo (Personas)

\begin{tabular}{|c|c|c|c|c|c|c|}
\hline $\mathrm{N}^{\circ}$ & $\begin{array}{l}\text { Distritos de Lima } \\
\text { seleccionados }\end{array}$ & 2018 & 2019 & 2020 & 2021 & 2022 \\
\hline 1 & Jesus Maria & 121 & 138 & 157 & 178 & 201 \\
\hline 2 & Lince & 81 & 91 & 101 & 113 & 125 \\
\hline 3 & Pueblo Libre & 125 & 141 & 160 & 180 & 203 \\
\hline 4 & $\begin{array}{l}\text { iviagaaiena deı } \\
\text { Mar }\end{array}$ & 93 & 106 & 120 & 136 & 154 \\
\hline 5 & San Miguel & 230 & 263 & 298 & 338 & 382 \\
\hline 6 & La Molina & 337 & 385 & 439 & 501 & 570 \\
\hline 7 & Miraflores & 148 & 163 & 179 & 197 & 216 \\
\hline 8 & San Borja & 204 & 227 & 251 & 279 & 309 \\
\hline 9 & San Isidro & 95 & 104 & 113 & 124 & 135 \\
\hline 10 & Santiago de Surco & 651 & 735 & 830 & 936 & 1,055 \\
\hline & $\begin{array}{l}\text { Número de } \\
\text { personas }\end{array}$ & 2,086 & 2,352 & 2,650 & 2,981 & 3,352 \\
\hline
\end{tabular}

Tabla 65

Mercado Objetivo resumen

\begin{tabular}{lccrrr}
\hline & 2018 & 2019 & 2020 & 2021 & 2022 \\
\hline Personas & 2,086 & 2,352 & 2,650 & 2,981 & 3,352 \\
MERCADO OBJETIVO TOTAL & 2,086 & 2,352 & 2,650 & 2,981 & 3,352 \\
\hline
\end{tabular}

La capacidad instalada de la planta puede atender la demanda estimada del proyecto

(Ver tabla 66).

Tabla 66

Demanda vs Capacidad de producción (unidades)

\begin{tabular}{lrrrrr}
\hline Año & 2018 & 2019 & 2020 & 2021 & 2022 \\
\hline Demanda & 35,228 & 39,726 & 44,748 & 50,351 & 56,602 \\
Capacidad producción botellas & 41,652 & 43,788 & 49,128 & 54,468 & 54,468 \\
\hline \multicolumn{1}{c}{$\%$ de utilización } & $85 \%$ & $91 \%$ & $91 \%$ & $92 \%$ & $104 \%$
\end{tabular}




\subsection{Pronóstico de Ventas}

Para determinar la demanda, se consideraron las siguientes preguntas mostradas en la tabla 67 y tabla 68 .

Tabla 67

Frecuencia de compra de HECHIZO?

\begin{tabular}{lccr}
\hline Respuesta & $\%$ & Cantidad al año & Promedio \\
\hline Semanal 15 días & $4 \%$ & 52 & 2.16 \\
Mensual 30 días & $38 \%$ & 12 & 4.58 \\
Quincenal 15 días & $10 \%$ & 24 & 2.37 \\
Bimensual 60 días & $22 \%$ & 6 & 1.31 \\
Trimestral 90 días & $26 \%$ & 4 & 1.03 \\
\hline Total general & $100 \%$ & & 11.00 \\
\hline
\end{tabular}

Tabla 68

Intención de compra

\begin{tabular}{lc}
\hline Respuesta & \\
\hline Una & $53.5 \%$ \\
Dos & $40.5 \%$ \\
Tres & $4.4 \%$ \\
Cuatro & $0.8 \%$ \\
cinco o más & $0.5 \%$ \\
\hline & $100 \%$ \\
\hline
\end{tabular}

Con el cruce de estas preguntas se obtuvo el consumo promedio de una persona anual y arrojó el siguiente resultado en la tabla 69 , tabla 70 y tabla 71.

Tabla 69

Adquisición de botella

Una persona en promedio adquiere

$\begin{array}{cl}16.9 & \text { Botella de } 750 \mathrm{ml} \text { al año } \\ 1.4 & \text { Botella de } 750 \mathrm{ml} \text { al mes } \\ 0.3 & \text { Botella de } 750 \mathrm{ml} \text { a la semana }\end{array}$

Tabla 70

Demanda Anual (unidades)

\begin{tabular}{lrrrrr}
\hline Presentación & 2018 & 2019 & 2020 & 2021 & 2022 \\
\hline Botella 750ML & 35,228 & 39,726 & 44,748 & 50,351 & 56,602 \\
\hline Total unidades & 35,228 & 39,726 & 44,748 & 50,351 & 56,602 \\
\hline
\end{tabular}


Tabla 71

Preferencia de lugar de compra de HECHIZO

\begin{tabular}{lcc}
\hline Respuesta & $\%$ & $\%$ \\
\hline Web & $20.1 \%$ & $23.6 \%$ \\
Otros canales & $65.1 \%$ & $76.4 \%$ \\
\hline Total general & $85.2 \%$ & $100.0 \%$ \\
\hline
\end{tabular}

Se puede apreciar que los encuestados prefieren que el producto lo puedan encontrar en licorerías, ver tabla 72.

Tabla 72

Preferencia de canal

\begin{tabular}{lc}
\hline Respuesta & $\%$ \\
\hline Supermercado & $14.0 \%$ \\
Web & $20.1 \%$ \\
Otros canales & $65.9 \%$ \\
\hline Total general & $100.0 \%$ \\
\hline
\end{tabular}

La distribución por sabores, que preferían los encuestados fue la siguiente, ver tabla

73.

Tabla 73

Preferencia de sabor

\begin{tabular}{lc}
\hline Respuesta & $\%$ \\
\hline Maracuyá y frambuesa & $36.0 \%$ \\
Fresa y guinda & $36.0 \%$ \\
Chicha & $28.0 \%$ \\
\hline Total general & $100.0 \%$ \\
\hline
\end{tabular}

En resumen, de acuerdo al análisis, en la tabla 74 se puede apreciar la demanda anual en unidades. 
Tabla 74

Demanda anual (Unidades)

\begin{tabular}{lrrrrr}
\hline PRESENTACION & 2018 & 2019 & 2020 & 2021 & 2022 \\
\hline WEB & 8,309 & 9,370 & 10,554 & 11,876 & 13,350 \\
Maracuyá y frambuesa & 2,991 & 3,373 & 3,800 & 4,275 & 4,806 \\
Fresa y guinda & 2,991 & 3,373 & 3,800 & 4,275 & 4,806 \\
Chicha & 2,326 & 2,624 & 2,955 & 3,325 & 3,738 \\
\hline OTROS CANALES & 26,919 & 30,356 & 34,193 & 38,475 & 43,252 \\
Maracuyá y frambuesa & 9,691 & 10,928 & 12,310 & 13,851 & 15,571 \\
Fresa y guinda & 9,691 & 10,928 & 12,310 & 13,851 & 15,571 \\
Chicha & 7,537 & 8,500 & 9,574 & 10,773 & 12,110 \\
\hline Total unidades & 35,228 & 39,726 & 44,748 & 50,351 & 56,602 \\
\hline
\end{tabular}

Tomando como referencia la tabla 74, en donde se muestra la demanda anual en botellas (unidades), para el año 2018 se consideran 35,228 botellas, la relación fue obtenida al multiplicar esta cantidad por el porcentaje obtenido para cada canal de distribución, en el caso de web, equivale al 24\% y otros canales es igual al 76\%. Luego de esta operación se obtiene que para el año 2018 para el canal web se tendría el total de 8,309 botellas, mientras que para otros canales el total para el 2018 sería de 26,919 botellas de macerados de frutas en pisco.

En la tabla 75 muestra al detalle las cantidades de botellas para ambos canales durante los doce meses del año 2018, arrojando un total de 35,228 botellas según el programa de ventas de este año. En la tabla 76 se evidencia el programa de ventas para el año 2019, donde el total de botellas al cierre del año equivale a 39,726. La tabla 77 exhibe el programa de ventas al detalle para todo el año 2020, mostrando un total de 44,748 botellas. En relación al programa de ventas para el año 2021, la tabla 78 nuestra al detalle dicha proyección donde en total de botellas es de 50,351 unidades. Por último, en la tabla 79 se muestra el programa de ventas para el año 2022, donde el total de botellas proyectadas es de 56,612 unidades. Todas las proyecciones de ventas fueron elaboradas en relación a la estacionalidad del producto . 
Tabla 75

Programa de Ventas 2018

\begin{tabular}{|c|c|c|c|c|c|c|c|c|c|c|c|c|c|}
\hline & ENE & FEB & MAR & $\mathrm{ABR}$ & MAY & JUN & JUL & AUG & SEP & OCT & NOV & $\mathrm{DEC}$ & TOTAL \\
\hline Estacionalidad & $5.00 \%$ & $6.00 \%$ & $7.00 \%$ & $8.00 \%$ & $8.00 \%$ & $9.00 \%$ & $9.00 \%$ & $9.00 \%$ & $9.00 \%$ & $10.00 \%$ & $10.00 \%$ & $10.00 \%$ & $100.00 \%$ \\
\hline WEB & 415 & 499 & 582 & 665 & 665 & 748 & 748 & 748 & 748 & 831 & 831 & 831 & 8,309 \\
\hline Maracuyá y frambuesa & 150 & 179 & 209 & 239 & 239 & 269 & 269 & 269 & 269 & 299 & 299 & 299 & 2,991 \\
\hline Fresa y guinda & 150 & 179 & 209 & 239 & 239 & 269 & 269 & 269 & 269 & 299 & 299 & 299 & 2,991 \\
\hline Chicha & 116 & 140 & 163 & 186 & 186 & 209 & 209 & 209 & 209 & 233 & 233 & 233 & 2,326 \\
\hline OTROS CANALES & 1,346 & 1,615 & 1,884 & 2,154 & 2,154 & 2,423 & 2,423 & 2,423 & 2,423 & 2,692 & 2,692 & 2,692 & 26,919 \\
\hline Maracuyá y frambuesa & 485 & 581 & 678 & 775 & 775 & 872 & 872 & 872 & 872 & 969 & 969 & 969 & 9,691 \\
\hline Fresa y guinda & 485 & 581 & 678 & 775 & 775 & 872 & 872 & 872 & 872 & 969 & 969 & 969 & 9,691 \\
\hline Chicha & 377 & 452 & 528 & 603 & 603 & 678 & 678 & 678 & 678 & 754 & 754 & 754 & 7,537 \\
\hline Total unidades & 1,761 & 2,114 & 2,466 & 2,818 & 2,818 & 3,171 & 3,171 & 3,171 & 3,171 & 3,523 & 3,523 & 3,523 & 35,228 \\
\hline
\end{tabular}

Tabla 76

Programa de Ventas 2019

\begin{tabular}{|c|c|c|c|c|c|c|c|c|c|c|c|c|c|}
\hline & ENE & FEB & MAR & $\mathrm{ABR}$ & MAY & JUN & JUL & AUG & SEP & OCT & NOV & DEC & TOTAL \\
\hline Estacionalidad & $8.82 \%$ & $8.82 \%$ & $8.82 \%$ & $7.94 \%$ & $7.94 \%$ & $7.94 \%$ & $8.43 \%$ & $8.43 \%$ & $8.43 \%$ & $8.14 \%$ & $8.14 \%$ & $8.14 \%$ & $100.00 \%$ \\
\hline WEB & 827 & 827 & 827 & 744 & 744 & 744 & 790 & 790 & 790 & 762 & 762 & 762 & 9,370 \\
\hline Maracuyá y frambuesa & 298 & 298 & 298 & 268 & 268 & 268 & 284 & 284 & 284 & 274 & 274 & 274 & 3,373 \\
\hline Fresa y guinda & 298 & 298 & 298 & 268 & 268 & 268 & 284 & 284 & 284 & 274 & 274 & 274 & 3,373 \\
\hline Chicha & 231 & 231 & 231 & 208 & 208 & 208 & 221 & 221 & 221 & 213 & 213 & 213 & 2,624 \\
\hline OTROS CANALES & 2,678 & 2,678 & 2,678 & 2,411 & 2,411 & 2,411 & 2,559 & 2,559 & 2,559 & 2,470 & 2,470 & 2,470 & 30,356 \\
\hline Maracuyá y frambuesa & 964 & 964 & 964 & 868 & 868 & 868 & 921 & 921 & 921 & 889 & 889 & 889 & 10,928 \\
\hline Fresa y guinda & 964 & 964 & 964 & 868 & 868 & 868 & 921 & 921 & 921 & 889 & 889 & 889 & 10,928 \\
\hline Chicha & 750 & 750 & 750 & 675 & 675 & 675 & 717 & 717 & 717 & 692 & 692 & 692 & 8,500 \\
\hline Total unidades & 3,505 & 3,505 & 3,505 & 3,155 & 3,155 & 3,155 & 3,349 & 3,349 & 3,349 & 3,233 & 3,233 & 3,233 & 39,726 \\
\hline
\end{tabular}


Tabla 77

Programa de Ventas 2020

\begin{tabular}{|c|c|c|c|c|c|c|c|c|c|c|c|c|c|}
\hline & ENE & FEB & MAR & $\mathrm{ABR}$ & MAY & JUN & JUL & AUG & SEP & OCT & NOV & DEC & TOTAL \\
\hline Estacionalidad & $8.82 \%$ & $8.82 \%$ & $8.82 \%$ & $7.94 \%$ & $7.94 \%$ & $7.94 \%$ & $8.43 \%$ & $8.43 \%$ & $8.43 \%$ & $8.14 \%$ & $8.14 \%$ & $8.14 \%$ & $100.00 \%$ \\
\hline WEB & 931 & 931 & 931 & 838 & 838 & 838 & 890 & 890 & 890 & 859 & 859 & 859 & 10,554 \\
\hline Maracuyá y frambuesa & 335 & 335 & 335 & 302 & 302 & 302 & 320 & 320 & 320 & 309 & 309 & 309 & 3,800 \\
\hline Fresa y guinda & 335 & 335 & 335 & 302 & 302 & 302 & 320 & 320 & 320 & 309 & 309 & 309 & 3,800 \\
\hline Chicha & 261 & 261 & 261 & 235 & 235 & 235 & 249 & 249 & 249 & 240 & 240 & 240 & 2,955 \\
\hline OTROS CANALES & 3,017 & 3,017 & 3,017 & 2,715 & 2,715 & 2,715 & 2,883 & 2,883 & 2,883 & 2,782 & 2,782 & 2,782 & 34,193 \\
\hline Maracuyá y frambuesa & 1,086 & 1,086 & 1,086 & 978 & 978 & 978 & 1,038 & 1,038 & 1,038 & 1,002 & 1,002 & 1,002 & 12,310 \\
\hline Fresa y guinda & 1,086 & 1,086 & 1,086 & 978 & 978 & 978 & 1,038 & 1,038 & 1,038 & 1,002 & 1,002 & 1,002 & 12,310 \\
\hline Chicha & 845 & 845 & 845 & 760 & 760 & 760 & 807 & 807 & 807 & 779 & 779 & 779 & 9,574 \\
\hline Total unidades & 3,948 & 3,948 & 3,948 & 3,553 & 3,553 & 3,553 & 3,773 & 3,773 & 3,773 & 3,641 & 3,641 & 3,641 & 44,748 \\
\hline
\end{tabular}

Tabla 78

Programa de Ventas 2021

\begin{tabular}{|c|c|c|c|c|c|c|c|c|c|c|c|c|c|}
\hline & ENE & FEB & MAR & $\mathrm{ABR}$ & MAY & JUN & JUL & AUG & SEP & OCT & NOV & $\mathrm{DEC}$ & TOTAL \\
\hline Estacionalidad & $8.82 \%$ & $8.82 \%$ & $8.82 \%$ & $7.94 \%$ & $7.94 \%$ & $7.94 \%$ & $8.43 \%$ & $8.43 \%$ & $8.43 \%$ & $8.14 \%$ & $8.14 \%$ & $8.14 \%$ & $100.00 \%$ \\
\hline WEB & 1,048 & 1,048 & 1,048 & 943 & 943 & 943 & 1,001 & 1,001 & 1,001 & 966 & 966 & 966 & 11,876 \\
\hline Maracuyá y frambuesa & 377 & 377 & 377 & 340 & 340 & 340 & 360 & 360 & 360 & 348 & 348 & 348 & 4,275 \\
\hline Fresa y guinda & 377 & 377 & 377 & 340 & 340 & 340 & 360 & 360 & 360 & 348 & 348 & 348 & 4,275 \\
\hline Chicha & 293 & 293 & 293 & 264 & 264 & 264 & 280 & 280 & 280 & 271 & 271 & 271 & 3,325 \\
\hline OTROS CANALES & 3,395 & 3,395 & 3,395 & 3,055 & 3,055 & 3,055 & 3,244 & 3,244 & 3,244 & 3,131 & 3,131 & 3,131 & 38,475 \\
\hline Maracuyá y frambuesa & 1,222 & 1,222 & 1,222 & 1,100 & 1,100 & 1,100 & 1,168 & 1,168 & 1,168 & 1,127 & 1,127 & 1,127 & 13,851 \\
\hline Fresa y guinda & 1,222 & 1,222 & 1,222 & 1,100 & 1,100 & 1,100 & 1,168 & 1,168 & 1,168 & 1,127 & 1,127 & 1,127 & 13,851 \\
\hline Chicha & 951 & 951 & 951 & 856 & 856 & 856 & 908 & 908 & 908 & 877 & 877 & 877 & 10,773 \\
\hline Total unidades & 4,443 & 4,443 & 4,443 & 3,998 & 3,998 & 3,998 & 4,245 & 4,245 & 4,245 & 4,097 & 4,097 & 4,097 & 50,351 \\
\hline
\end{tabular}


Tabla 79

Programa de Ventas 2022

\begin{tabular}{|c|c|c|c|c|c|c|c|c|c|c|c|c|c|}
\hline & ENE & FEB & MAR & $\mathrm{ABR}$ & MAY & JUN & JUL & AUG & SEP & OCT & NOV & DEC & TOTAL \\
\hline Estacionalidad & $8.82 \%$ & $8.82 \%$ & $8.82 \%$ & $7.94 \%$ & $7.94 \%$ & $7.94 \%$ & $8.43 \%$ & $8.43 \%$ & $8.43 \%$ & $8.14 \%$ & $8.14 \%$ & $8.14 \%$ & $100.00 \%$ \\
\hline WEB & 1,178 & 1,178 & 1,178 & 1,060 & 1,060 & 1,060 & 1,126 & 1,126 & 1,126 & 1,086 & 1,086 & 1,086 & 13,350 \\
\hline Maracuyá y frambuesa & 424 & 424 & 424 & 382 & 382 & 382 & 405 & 405 & 405 & 391 & 391 & 391 & 4,806 \\
\hline Fresa y guinda & 424 & 424 & 424 & 382 & 382 & 382 & 405 & 405 & 405 & 391 & 391 & 391 & 4,806 \\
\hline Chicha & 330 & 330 & 330 & 297 & 297 & 297 & 315 & 315 & 315 & 304 & 304 & 304 & 3,738 \\
\hline OTROS CANALES & 3,816 & 3,816 & 3,816 & 3,435 & 3,435 & 3,435 & 3,647 & 3,647 & 3,647 & 3,519 & 3,519 & 3,519 & 43,252 \\
\hline Maracuyá y frambuesa & 1,374 & 1,374 & 1,374 & 1,236 & 1,236 & 1,236 & 1,313 & 1,313 & 1,313 & 1,267 & 1,267 & 1,267 & 15,571 \\
\hline Fresa y guinda & 1,374 & 1,374 & 1,374 & 1,236 & 1,236 & 1,236 & 1,313 & 1,313 & 1,313 & 1,267 & 1,267 & 1,267 & 15,571 \\
\hline Chicha & 1,069 & 1,069 & 1,069 & 962 & 962 & 962 & 1,021 & 1,021 & 1,021 & 985 & 985 & 985 & 12,110 \\
\hline Total unidades & 4,994 & 4,994 & 4,994 & 4,495 & 4,495 & 4,495 & 4,772 & 4,772 & 4,772 & 4,606 & 4,606 & 4,606 & 56,602 \\
\hline
\end{tabular}


En la tabla 80 se puede ver el resumen del programa de ventas por los cinco años del proyecto reflejado en unidades.

Tabla 80

Programa de Ventas en unidades

\begin{tabular}{ccccccc}
\hline Programa ventas botellas & 2018 & 2019 & 2020 & 2021 & 2022 & \\
\hline WEB & 8,309 & 9,370 & 10,554 & 11,876 & 13,350 & \\
Maracuyá y frambuesa & 2,991 & 3,373 & 3,800 & 4,275 & 4,806 & $24 \%$ \\
Fresa y guinda & 2,991 & 3,373 & 3,800 & 4,275 & 4,806 & \\
Chicha & 2,326 & 2,624 & 2,955 & 3,325 & 3,738 & \\
\hline OTROS CANALES & 26,919 & 30,356 & 34,193 & 38,475 & 43,252 & \\
Maracuyá y frambuesa & 9,691 & 10,928 & 12,310 & 13,851 & 15,571 & $76 \%$ \\
Fresa y guinda & 9,691 & 10,928 & 12,310 & 13,851 & 15,571 & \\
Chicha & 7,537 & 8,500 & 9,574 & 10,773 & 12,110 & \\
\hline Total unidades & 35,228 & 39,726 & 44,748 & 50,351 & 56,602 & \\
\hline
\end{tabular}

De acuerdo al estudio del mercado y con los cálculos de costos, se decidió trabajar con los siguientes precios por canal (Ver tabla 81).

Tabla 81

Precio de venta por Canal

$\begin{array}{cccccc} & \text { Precio de } & & & \\ \text { venta } & \text { Margen } & \text { Precio de } \\ \text { venta al } & \text { IGV } & \text { Valor venta } \\ \text { sugerido } & \text { canal } & & & \\ \text { al público } & & & & \end{array}$

\begin{tabular}{|c|c|c|c|c|c|c|c|c|}
\hline \multicolumn{9}{|l|}{ WEB } \\
\hline $\begin{array}{l}\text { Maracuyá y } \\
\text { frambuesa }\end{array}$ & 55.00 & $0 \%$ & S/. & 55.00 & $\mathrm{~S} /$. & 8.39 & $\mathrm{~S} /$. & 46.61 \\
\hline Fresa y guinda & 55.00 & $0 \%$ & $\mathrm{~S} /$. & 55.00 & $\mathrm{~S} /$. & 8.39 & $\mathrm{~S} /$. & 46.61 \\
\hline Chicha & 55.00 & $0 \%$ & S/. & 55.00 & $\mathrm{~S} /$. & 8.39 & $\mathrm{~S} /$. & 46.61 \\
\hline \multicolumn{9}{|l|}{ OTROS CANALES } \\
\hline $\begin{array}{l}\text { Maracuyá y } \\
\text { frambuesa }\end{array}$ & 55.00 & $25 \%$ & $\mathrm{~S} /$. & 41.25 & S/. & 6.29 & $\mathrm{~S} /$. & 34.96 \\
\hline Fresa y guinda & 55.00 & $25 \%$ & $\mathrm{~S} /$. & 41.25 & $\mathrm{~S} /$. & 6.29 & $\mathrm{~S} /$. & 34.96 \\
\hline Chicha & 55.00 & $25 \%$ & S/. & 41.25 & S/. & 6.29 & $\mathrm{~S} /$. & 34.96 \\
\hline
\end{tabular}


En la tabla 82 se muestra al detalle de los montos de las ventas en Soles para ambos canales durante los doce meses del año 2018, arrojando un total de S/1,328,306 según el programa de ventas de este año. En la tabla 83 se evidencia el programa de ventas para el año 2019, donde el monto total en Soles al cierre del año equivale a S/1,497,912. En la tabla 84 se exhibe el programa de ventas al detalle para todo el año 2020, mostrando un monto total de S/1,687,254. En relación al programa de ventas para el año 2021, la tabla 85 nuestra al detalle dicha proyección donde en el monto total en Soles es de S/1,898,541. Por último, en la tabla 86 se muestra el programa de ventas para el año 2022, donde el monto total en Soles es de S/2,134,224. Todos los montos mencionados no incluyen IGV. 
Tabla 82

Programa de Ventas anual 2018 Soles

\begin{tabular}{|c|c|c|c|c|c|c|c|c|c|c|c|c|c|}
\hline PRODUCTOS & ENE & FEB & MAR & $\mathrm{ABR}$ & MAY & JUN & JUL & AGO & SEP & OCT & NOV & DIC & TOTAL \\
\hline WEB & $.19,364$ & S/. 23,237 & $.27,109$ & 30082 & . 30,982 & S/. 34,855 & S/. 34,855 & S/. 34,855 & S/. 34,855 & S/. 38,728 & S/. 38,728 & S/. 38,728 & S/. 387,278 \\
\hline Maracuyá y frambuesa & S/. 6,971 & S/. 8,365 & S/. 9,759 & & & S/. 12,548 & S/. 12,548 & S/. 12,548 & S/. 12,548 & S/. 13,942 & S/. 13,942 & S/. 13,942 & \\
\hline Fresa y guinda & 71 & S/. 8 & 59 & 54 & $\mathrm{~S} / .11$ & S/. 12,548 & S/. 12,548 & S/. 12,548 & S/. 12,548 & S/. 13, & S/. 13,9 & 942 & 20 \\
\hline Chicha & +22 & /. 6,506 & 591 & $.8,675$ & S/. 8,675 & S/. 9,759 & S/. 9,759 & S/. 9,759 & S/. 9,759 & S/. 10,844 & S/. 10,844 & S/. 10,844 & 438 \\
\hline OTROS CAN & 47,051 & 56,462 & /. 65,872 & $.75,282$ & S/. 75,282 & /. 84,693 & S/. 84,693 & S/. 84,693 & S/. 84, & & $\mathrm{S} / .9$ & & \\
\hline & & & & & & & & & & & & & \\
\hline Fresa y guinda & S/. 16,939 & S/. 20,326 & $\mathrm{S} / .2$ & & & $\mathrm{~S} / .30$ & & & & & $\mathrm{~S} / .3$ & & \\
\hline Chicha & S/. 13,174 & S/. 15,809 & S/. 18,444 & S/. 21,079 & S/. 21,079 & S/. 23,714 & S/. 23,714 & S/. 23,714 & S/. 23,714 & S/. 26,349 & S/. 26,349 & S/. 26,349 & S/. 263,488 \\
\hline Ventas (sin IGV) & S/. 66,415 & S/. 79,698 & S/. 92,981 & S/. 106,264 & S/. 106,264 & S/. 119,548 & S/. 119,548 & S/. 119,548 & S/. 119,548 & S/. 132,831 & S/. 132,831 & S/. 132,831 & S/. 1,328,306 \\
\hline IGV & & S/. 14,346 & S/. 16,737 & & & S/. 21,519 & S/. 21,519 & & S/. 21,519 & & S/. 23,910 & S/. 23,910 & S/. 239,095 \\
\hline Ventas (con IGV) & S/. 78,370 & S/. 94,044 & S/. 109,718 & S/. 125,392 & S/. 125,392 & S/. 141,066 & S/. 141,066 & S/. 141,066 & S/. 141,066 & S/. 156,740 & S/. 156,740 & S/. 156,740 & S/. 1,567,401 \\
\hline
\end{tabular}

Tabla 83

Programa de Ventas anual 2019 Soles

\begin{tabular}{|c|c|c|c|c|c|c|c|c|c|c|c|c|c|}
\hline PRO & ENE & FEB & MAR & ABR & MAY & JUN & JUL & AGO & SEP & OCT & NOV & DIC & TOTAL \\
\hline & S/. 38,535 & S/. 38,53 & S/. 38,535 & S/. 34,681 & S/. 34,681 & S/. 34,681 & S/. 36,822 & S/. 36,822 & S/. 36,822 & S/. 35,538 & S/. 35,538 & S/. 35,538 & S/. 436,728 \\
\hline $\begin{array}{l}\text { Maracuyá y } \\
\text { mbuesa }\end{array}$ & S/. 13,873 & S/. 13,873 & S/. 13,873 & S/. 12,485 & S/. 12,485 & S/. 12,485 & S/. 13,256 & S/. 13,256 & S/. 13,256 & S/. 12,794 & S/. 12,794 & S/. 12,794 & S/. 157,222 \\
\hline Fresa y guinda &, 873 & S/. 13 & S/. 13 & S/. 12 & S/. 12,485 & S/. 12,485 & S/. 13, & & S/. 13 & & S/. 12,794 & S/. 12,794 & S/. 157,222 \\
\hline Chicha & /. 10,790 & S/. 10,790 & S/. 10,790 & S/. 9,711 & S/. 9,711 & S/. 9,711 & S/. 10,310 & S/. 10,310 & S/. 10,310 & S/. 9,951 & S/. 9,951 & S/. 9,951 & S/. 122,284 \\
\hline OTROS CAN & S/. 93,634 & S/. 93,634 & S/. 93,634 & S/. 84,270 & S/. 84,270 & S/. 84,270 & S/. 89,472 & S/. 89,472 & S/. 89,472 & S/. 86,351 & S/. 86,351 & S/. 86,351 & S/. 1,061,184 \\
\hline $\begin{array}{l}\text { Maracuyá y } \\
\text { frambuesa }\end{array}$ & S/. 33,708 & S/. 33,708 & S/. 33,708 & S/. 30,337 & S/. 30,337 & S/. 30,337 & S/. 32,210 & S/. 32,210 & S/. 32,210 & S/. 31,086 & S/. 31,086 & S/. 31,086 & S/. 382,026 \\
\hline Fresa y & & & & & & S/. 30,337 & & & & & & S/. 31,086 & \\
\hline Chicha & & S/. 26,217 & S/. 26,217 & S/. 23,596 & S/. 23,596 & S/. 23,596 & S/. 25,052 & S/. 25,052 & S/. 25,052 & S/. 24,178 & S/. 24,178 & S/. 24,178 & S/. 297,131 \\
\hline Ventas $(\sin I C$ & 132,169 & /. 132,169 & S/. 132,169 & S/. 118,952 & S/. 118,952 & S/. 118,952 & S/. 126,295 & S/. 126,295 & S/. 126,295 & S/. 121,889 & S/. 121,889 & S/. 121,889 & S/. 1,497,912 \\
\hline IGV & 23,790 & S/. 23,790 & S/. 23,790 & S/. 21,411 & S/. 21,411 & S/. 21,411 & S/. 22,733 & S/. 22,733 & S/. 22,733 & S/. 21,940 & S/. 21,940 & S/. 21,940 & S/. 269,624 \\
\hline Ventas (con IGV) & S/. 155,959 & S/. 155,959 & S/. 155,959 & S/. 140,363 & S/. 140,363 & S/. 140,363 & S/. 149,028 & S/. 149,028 & S/. 149,028 & S/. 143,829 & S/. 143,829 & S/. 143,829 & S/. 1,767,536 \\
\hline
\end{tabular}


Tabla 84

Programa de Ventas anual 2020 Soles

\begin{tabular}{|c|c|c|c|c|c|c|c|c|c|c|c|c|c|}
\hline PRODUCTOS & ENE & FEB & MAR & ABR & MAY & JUN & JUL & AGO & SEP & OCT & NOV & DIC & TOTAL \\
\hline WEB & S/. 43,406 & S/. 43,406 & S/. 43,406 & S/. 39,065 & S/. 39,065 & S/. 39,065 & S/. 41,477 & S/. 41,477 & S/. 41,477 & S/. 40,030 & S/. 40,030 & S/. 40,030 & S/. 491,932 \\
\hline $\begin{array}{l}\text { Maracuyá y } \\
\text { frambuesa }\end{array}$ & S/. 15,626 & S/. 15,626 & S/. 15,626 & S/. 14,063 & S/. 14,063 & S/. 14,063 & S/. 14,932 & S/. 14,932 & S/. 14,932 & S/. 14,411 & S/. 14,411 & S/. 14,411 & S/. 177,096 \\
\hline Fresa y guinda & S/. 15,626 & S/. 15,626 & S/. 15,626 & S/. 14,063 & S/. 14,063 & S/. 14,063 & S/. 14,932 & S/. 14,932 & S/. 14,932 & S/. 14,411 & S/. 14,411 & S/. 14,411 & S/. 177,096 \\
\hline Chicha & S/. 12,154 & S/. 12,154 & S/. 12,154 & S/. 10,938 & S/. 10,938 & S/. 10,938 & S/. 11,613 & S/. 11,613 & S/. 11,613 & S/. 11,208 & S/. 11,208 & S/. 11,208 & S/. 137,741 \\
\hline OTROS CANALES & S/. 105,470 & S/. 105,470 & S/. 105,470 & S/. 94,923 & S/. 94,923 & S/. 94,923 & S/. 100,782 & S/. 100,782 & S/. 100,782 & S/. 97,266 & S/. 97,266 & \multicolumn{2}{|c|}{ S/. 97,266 S/. 1,195,322 } \\
\hline $\begin{array}{l}\text { Maracuyá y } \\
\text { frambuesa }\end{array}$ & S/. 37,969 & S/. 37,969 & S/. 37,969 & S/. 34,172 & S/. 34,172 & S/. 34,172 & S/. 36,282 & S/. 36,282 & S/. 36,282 & S/. 35,016 & S/. 35,016 & S/. 35,016 & S/. 430,316 \\
\hline Fresa y guinda & S/. 37,969 & S/. 37,969 & S/. 37,969 & S/. 34,172 & S/. 34,172 & S/. 34,172 & S/. 36,282 & S/. 36,282 & S/. 36,282 & S/. 35,016 & S/. 35,016 & S/. 35,016 & S/. 430,316 \\
\hline Chicha & S/. 29,531 & S/. 29,531 & S/. 29,531 & S/. 26,578 & S/. 26,578 & S/. 26,578 & S/. 28,219 & S/. 28,219 & S/. 28,219 & S/. 27,235 & S/. 27,235 & S/. 27,235 & S/. 334,690 \\
\hline Ventas ( $\sin$ IGV) & S/. 148,875 & S/. 148,875 & S/. 148,875 & S/. 133,988 & S/. 133,988 & S/. 133,988 & S/. 142,259 & S/. 142,259 & S/. 142,259 & S/. 137,296 & S/. 137,296 & S/. 137,296 & S/. 1,687,254 \\
\hline IGV & S/. 26,798 & S/. 26,798 & S/. 26,798 & S/. 24,118 & S/. 24,118 & S/. 24,118 & S/. 25,607 & S/. 25,607 & S/. 25,607 & S/. 24,713 & S/. 24,713 & S/. 24,713 & S/. 303,706 \\
\hline Ventas (con IGV) & S/. 175,673 & S/. 175,673 & S/. 175,673 & S/. 158,106 & S/. 158,106 & S/. 158,106 & S/. 167,865 & S/. 167,865 & S/. 167,865 & S/. 162,009 & S/. 162,009 & S/. 162,009 & S/. $1,990,960$ \\
\hline
\end{tabular}

\section{Tabla 85}

Programa de Ventas anual 2021Soles

\begin{tabular}{|c|c|c|c|c|c|c|c|c|c|c|c|c|c|}
\hline PRODUCTOS & ENE & FEB & MAR & ABR & MAY & JUN & JUL & AGO & SEP & OCT & NOV & DIC & TOTAL \\
\hline WEB & S/. 48,841 & S/. 48,841 & S/. 48,841 & S/. 43,957 & S/. 43,957 & S/. 43,957 & S/. 46,671 & S/. 46,671 & S/. 46,671 & S/. 45,043 & S/. 45,043 & S/. 45,043 & S/. 553,535 \\
\hline $\begin{array}{l}\text { Maracuyá y } \\
\text { frambuesa }\end{array}$ & S/. 17,583 & S/. 17,583 & S/. 17,583 & S/. 15,825 & S/. 15,825 & S/. 15,825 & S/. 16,801 & S/. 16,801 & S/. 16,801 & S/. 16,215 & S/. 16,215 & S/. 16,215 & S/. 199,272 \\
\hline Fresa y guinda & S/. 17,583 & S/. 17,583 & S/. 17,583 & S/. 15,825 & S/. 15,825 & S/. 15,825 & S/. 16,801 & S/. 16,801 & S/. 16,801 & S/. 16,215 & S/. 16,215 & S/. 16,215 & S/. 199,272 \\
\hline Chicha & S/. 13,676 & S/. 13,676 & S/. 13,676 & S/. 12,308 & S/. 12,308 & S/. 12,308 & S/. 13,068 & S/. 13,068 & S/. 13,068 & S/. 12,612 & S/. 12,612 & S/. 12,612 & S/. 154,990 \\
\hline OTROS CAN & S/. 118,677 & S/. 118,677 & S/. 118,677 & S/. 106,809 & S/. 106,809 & S/. 106,809 & S/. 113,403 & S/. 113,403 & S/. 113,403 & S/. 109,447 & S/. 109,447 & S/. 109,447 & S/. 1,345,007 \\
\hline $\begin{array}{l}\text { Maracuyá y } \\
\text { frambuesa }\end{array}$ & S/. 42,724 & S/. 42,724 & S/. 42,724 & S/. 38,451 & S/. 38,451 & S/. 38,451 & S/. 40,825 & S/. 40,825 & S/. 40,825 & S/. 39,401 & S/. 39,401 & S/. 39,401 & S/. 484,202 \\
\hline Fresa y guinda & S/. 42,724 & S/. 42,724 & S/. 42,724 & S/. 38,451 & S/. 38,451 & S/. 38,451 & S/. 40,825 & S/. 40,825 & S/. 40,825 & S/. 39,401 & S/. 39,401 & S/. 39,401 & S/. 484,202 \\
\hline Chicha & S/. 33,230 & S/. 33,230 & S/. 33,230 & S/. 29,907 & S/. 29,907 & S/. 29,907 & S/. 31,753 & S/. 31,753 & S/. 31,753 & S/. 30,645 & S/. 30,645 & S/. 30,645 & S/. 376,602 \\
\hline Ventas (sin IGV) & S/. 167,518 & S/. 167,518 & S/. 167,518 & S/. 150,767 & S/. 150,767 & S/. 150,767 & S/. 160,073 & S/. 160,073 & S/. 160,073 & S/. 154,489 & S/. 154,489 & S/. 154,489 & S/. 1,898,541 \\
\hline IGV & S/. 30,153 & S/. 30,153 & S/. 30,153 & S/. 27,138 & S/. 27,138 & S/. 27,138 & S/. 28,813 & S/. 28,813 & S/. 28,813 & S/. 27,808 & S/. 27,808 & S/. 27,808 & S/. 341,737 \\
\hline Ventas (con IGV) & S/. 197,672 & S/. 197,672 & S/. 197,672 & S/. 177,904 & S/. 177,904 & S/. 177,904 & S/. 188,886 & S/. 188,886 & S/. 188,886 & S/. 182,297 & S/. 182,297 & S/. 182,297 & S/. 2,240,279 \\
\hline
\end{tabular}


Tabla 86

Programa de Ventas anual 2022 Soles

\begin{tabular}{|c|c|c|c|c|c|c|c|c|c|c|c|c|c|}
\hline PRODU & ENE & FEB & MAR & $\mathrm{ABR}$ & MAY & JUN & JUL & $\mathrm{AGO}$ & SEP & OCT & NOV & DIC & TOTAL \\
\hline WEB & S/. 54,904 & S/. 54,904 & S/. 54,904 & S/. 49,41 & S/. 49,414 & S/. 49,41 & S/. 52,464 & S/. 52,464 & S/. 52,46 & S/. 50,634 & S/. 50,634 & S/. 50,634 & S/. 622,250 \\
\hline $\begin{array}{l}\text { Maracuyá y } \\
\text { frambuesa }\end{array}$ & S/. 19,766 & S/. 19,766 & S/. 19,766 & S/. 17,789 & S/. 17,789 & S/. 17,789 & S/. 18,887 & S/. 18,887 & S/. 18,887 & S/. 18,228 & S/. 18,228 & S/. 18,228 & S/. 224,010 \\
\hline Fresa y guinda & S/. 19,766 & S/. 19,766 & S/. 19,766 & S/. 17,789 & S/. 17,789 & S/. 17,789 & S/. 18,887 & S/. 18,887 & S/. 18,887 & S/. 18,228 & S/. 18,228 & S/. 18,228 & S/. 224,010 \\
\hline Chicha & S/. 15,373 & S/. 15,373 & S/. 15,373 & S/. 13,836 & S/. 13,836 & S/. 13,836 & S/. 14,690 & S/. 14,690 & S/. 14,690 & S/. 14,178 & S/. 14,178 & S/. 14,178 & S/. 174,230 \\
\hline OTROS & \multicolumn{13}{|c|}{ S/. 133,409 S/. 133,409 S/. 133,409 S/. 120,069 S/. 120,069 S/. 120,069 S/. 127,480 S/. 127,480 S/. 127,480 S/. 123,033 S/. 123,033 S/. 123,033 S/. 1,511,974 } \\
\hline $\begin{array}{l}\text { Maracuya y } \\
\text { frambuesa }\end{array}$ & S/. 48,027 & & & S/. 43,225 & S/. 43,225 & S/. 43,225 & & & & & & S/. 44,292 & S/. 544,311 \\
\hline Fresa y guinda & S/. 48,027 & S/. 48,027 & S/. 48,027 & & S/. 43,225 & S/. 43,225 & S/. 45,893 & S/. 45,893 & S/. 45,893 & & S/. 44,292 & S/. 44,292 & S/. 544,311 \\
\hline Chicha & S/. 37,355 & S/. 37,355 & S/. 37,355 & S/. 33,619 & S/. 33,619 & S/. 33,619 & S/. 35,694 & S/. 35,694 & S/. 35,694 & S/. 34,449 & S/. 34,449 & S/. 34,449 & S/. 423,353 \\
\hline Ventas (sin & S/. 188,314 & S/. 188,314 & S/. 188,314 & S/. 169,482 & S/. 169,482 & S/. 169,482 & S/. 179,944 & S/. 179,944 & S/. 179,944 & S/. 173,667 & S/. 173,667 & S/. 173,667 & S/. $2,134,224$ \\
\hline IGV & S/. 33,896 & S/. 33,896 & S/. 33,896 & S/. 30,507 & S/. 30,507 & S/. 30,507 & S/. 32,390 & S/. 32,390 & S/. 32,390 & S/. 31,260 & S/. 31,260 & S/. 31,260 & S/. 384,160 \\
\hline Ventas (con IGV) & S/. 222,210 & S/. 222,210 & S/. 222,210 & S/. 199,989 & S/. 199,989 & S/. 199,989 & S/. 212,334 & S/. 212,334 & S/. 212,334 & S/. 204,927 & S/. 204,927 & S/. 204,927 & S/. 2,518,384 \\
\hline
\end{tabular}


La tabla 87 muestra el resumen de ventas anuales en Soles, divididos por canales, mostrando el porcentaje por cada uno de ellos.

Tabla 87

Resumen de ventas anuales en Soles

\begin{tabular}{|c|c|c|c|c|c|c|}
\hline Programa ventas (soles) & 2018 & 2019 & 2020 & 2021 & 2022 & Porcentaje \\
\hline WEB & S/. 387,278 & S/. 436,728 & S/. 491,932 & S/. 553,535 & S/. 622,250 & \multirow{4}{*}{$24 \%$} \\
\hline Maracuyá y frambuesa & S/. 139,420 & S/. 157,222 & S/. 177,096 & S/. 199,272 & S/. 224,010 & \\
\hline Fresa y guinda & S/. 139,420 & S/. 157,222 & S/. 177,096 & S/. 199,272 & S/. 224,010 & \\
\hline Chicha & S/. 108,438 & S/. 122,284 & S/. 137,741 & S/. 154,990 & S/. 174,230 & \\
\hline OTROS CANALES & S/. 941,028 & $\begin{array}{r}\mathrm{S} / . \\
1,061,184\end{array}$ & $\begin{array}{r}\mathrm{S} / . \\
1,195,322\end{array}$ & $\begin{array}{r}\mathrm{S} / \\
1,345,007\end{array}$ & $\begin{array}{r}\mathrm{S} / \mathrm{.} \\
1,511,974\end{array}$ & \multirow{4}{*}{$76 \%$} \\
\hline Maracuyá y frambuesa & S/. 338,770 & S/. 382,026 & S/. 430,316 & S/. 484,202 & S/. 544,311 & \\
\hline Fresa y guinda & S/. 338,770 & S/. 382,026 & S/. 430,316 & S/. 484,202 & S/. 544,311 & \\
\hline Chicha & S/. 263,488 & S/. 297,131 & S/. 334,690 & S/. 376,602 & S/. 423,353 & \\
\hline Ventas (sin IGV) & $\begin{array}{r}\mathrm{S} / . \\
1,328,306\end{array}$ & $\begin{array}{r}\mathrm{S} / . \\
1,497,912\end{array}$ & $\begin{array}{r}\mathrm{S} / . \\
1,687,254\end{array}$ & $\begin{array}{r}\mathrm{S} / . \\
1,898,541\end{array}$ & $\begin{array}{r}\mathrm{S} / . \\
2,134,224\end{array}$ & \\
\hline $\begin{array}{l}\text { IGV } \\
\text { Ventas (con IGV) }\end{array}$ & $\begin{array}{r}\text { S/. } 239,095 \\
\text { S } / \\
1,567,401\end{array}$ & $\begin{array}{r}\text { S/. 269,624 } \\
\text { S/. } \\
1,767,536 \\
\end{array}$ & $\begin{array}{r}\text { S/. 303,706 } \\
\text { S/. } \\
1,990,960\end{array}$ & $\begin{array}{r}\text { S/. } 341,737 \\
\text { S/. } \\
2,240,279 \\
\end{array}$ & $\begin{array}{r}\text { S/. 384,160 } \\
\text { S/. } \\
2,518,384 \\
\end{array}$ & \\
\hline
\end{tabular}

\subsection{Aspectos críticos que impactan el pronóstico de ventas}

En la actualidad, se sabe que el pronóstico de ventas puede verse afectado por factores externos e internos provocando un alza o una disminución en las ventas. Una disminución en las ventas afecta la rentabilidad del negocio, por ende, su viabilidad.

Algunos de los factores que impactan son:

- Situación económica general: la desaceleración económica influye en el nivel de consumo, al igual que la inflación hace que la población concentre sus ingresos en las necesidades básicas como alimentación básica, salud, educación y vivienda.

- Nuevos competidores: Si más empresas se formalizan y lanzan productos con los mismos sabores o parecidos, las personas tendrán más opciones para escoger y la demanda se repartirá por lo que afectaría a la venta directamente.

- Nivel de novedad del producto: los productos nuevos son los más difíciles de pronosticar dado que no se ha establecido una tendencia clara acerca del consumo, 
además muchas empresas que realizan este producto son informales, por lo que no hay estudios ni información formal.

- Variaciones en el comportamiento del consumidor: hoy en día, el pisco está de moda, se ha vuelto popular en Perú, por lo que esto afecta positivamente al producto, ya que existe una demanda para satisfacer.

- Promociones de ventas: el fin es aumentar las ventas, en especial en temporadas bajas, para que haya un equilibrio y el producto no se quede en stock. 


\section{Capítulo V. Ingeniería del proyecto}

En este capítulo se va a determinar la tecnología a usar, la ubicación de la planta, el sistema de producción, los recursos necesarios y el cómo se producirá. Y por último, la factibilidad de la industrialización para la optimización de los costos.

Para el proceso de producción se utilizó la información recabada de las entrevistas de profundidad hechas a los dueños y Gerentes de bodegas de Pisco Sarcay y Bailetti (Ver tabla 23), productores artesanales de macerados de pisco en fruta Eddu's y Foodies (Ver tabla 21), sommelier para la mezcla de sabores (Ver tabla 24), de esa manera se logró tomar las decisiones que más convenían para la realización del proyecto.

\subsection{Estudio de ingeniería}

Para desarrollar este capítulo se consideró los recursos y equipos necesarios para poder hacer la producción de los macerados, determinar la producción óptima, los costos, el layout, utilización eficiente de los recursos disponibles, costos, maquinaria, incluso requerimiento de personal.

En este sentido, para Sapag y Sapag (2008), este estudio debe tener información importante que sea útil para que pueda hacerse un análisis económico como resultado del estudio técnico.

Además, se tomó en cuenta las consideraciones legales y jurídicas que implican el poner en funcionamiento la planta de producción de macerados de frutas en pisco, y así poder:

- Definir los procesos y estándares de producción y establecer operaciones requeridas.

- Determinar cuáles serán los recursos necesarios en lo que se refiere a insumos, equipos, local. 


\subsubsection{Modelamiento y selección e procesos productivos.}

Sapag y Sapag (2008), definen el proceso de producción como la transformación de insumos en productos, en donde se combina mano de obra, maquinaria, procedimientos operativos, etc., es decir usar determinada tecnología. Este proceso es en serie y tiene efecto en el flujo de caja del proyecto.

Para definir el proceso, se tomó en cuenta que se van a producir macerados de frutas en pisco de tres sabores: Maracuyá con frambuesa, fresa con guinda y chicha.

El pisco es definido en la norma técnica peruana No. 211.001 - 2006 como aguardiente, que debe tener un grado de alcohol entre 38 y 43 grados. Por lo tanto el producto a ofrecer es la combinación del pisco de uva quebranta y fruta seca o deshidratada.

En la tabla 88, se muestra los tiempos estimados de cada actividad en los procesos de elaboración.

Tabla 88

Determinación de tiempo en procesos

\begin{tabular}{|c|c|}
\hline Proceso & $\begin{array}{c}\text { Tiempo minutos por } \\
\text { lote }\end{array}$ \\
\hline Recepción de MP & 60 \\
\hline Selección de fruta & 60 \\
\hline Lavado de fruta & 60 \\
\hline Troceado de fruta & 240 \\
\hline Envío a producción & 40 \\
\hline Tanque de maceración (llenado) & 60 \\
\hline Lavado botellas & 110 \\
\hline Filtrado y embotellado & 220 \\
\hline Tapado & 30 \\
\hline Encapsulado & 400 \\
\hline Etiquetado & 10 \\
\hline Control de calidad & 40 \\
\hline Embalaje final & 120 \\
\hline Almacenamiento de PT & 40 \\
\hline Total de tiempo en minutos & 1490 \\
\hline Total de tiempo en horas & 24.83 \\
\hline
\end{tabular}


Para este estudio se consideró un proceso productivo con los siguientes pasos :

1. Abastecimiento de insumos y almacenamiento

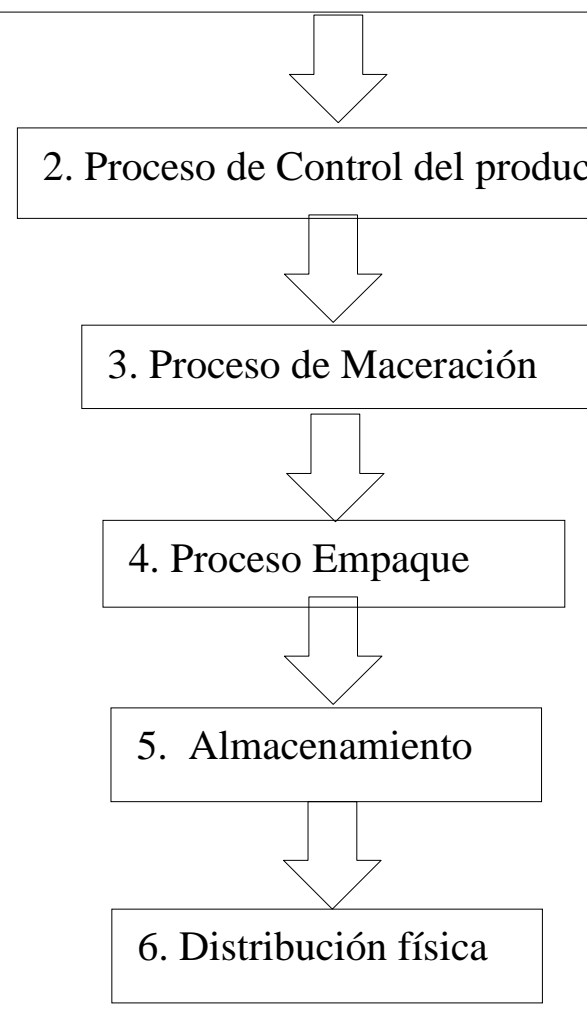

1. Abastecimiento de insumos y almacenamiento

El pisco a utilizar es tipo uva quebranta, con denominación de origen, según lo mencionado líneas arriba con un nivel de alcohol de entre 38 a 43 grados. El proveedor es la Bodega Bailetti, con su pisco Don Salvattore. Quién lo hará llegar de Chincha a la planta en Lima. El pisco llega a la planta en damajuanas de 4 litros de capacidad.

Con relación a los proveedores de fruta fresca se comprará a diversos proveedores mayoristas de frutas, que aseguraran productos de calidad (Ver en anexos \# 33 para encontrar las cotizaciones de los proveedores). Es importante tener en cuenta el requerimiento de insumos, ya que hay algunas frutas que son estacionales y no tienen presencia todo el año. Para eso es necesario tener claro la estacionalidad de estas frutas. La estacionalidad la podemos apreciar en la tabla 89que se muestra a continuación. 
Tabla 89

Estacionalidad de las frutas

\begin{tabular}{lllllllllllll}
\hline & Ene & Feb & Mar & Abr & May & Jun & Jul & Ago & Set & Oct & Nov & Dic \\
\hline Frambuesa & & & & & & & & & & & & \\
Maracuyá & & & & & & & & & & & & \\
Fresa & & & & & & & & & & & & \\
Guinda & & & & & & & & & & & & \\
Arándano & & & & & & & & & & & & \\
Membrillo & & & & & & & & & & & \\
Piña & & & & & & & & & & & & \\
\hline
\end{tabular}

Nota. Amarillo mayor producción, rojo menor producción, blanco no hay producción.

Adaptado de Calendario de estacionalidad de frutas a nivel nacional, Arándano azul, frambuesa (Sierra exportadora) Recuperado de http://1.bp.blogspot.com/-

NWRYWPghF0E/UDgCCk02vVI/AAAAAAAADZo/uLgTPQLyG1M/s1600/30_apega_coc ina_peruana.jpg, https://www.sierraexportadora.gob.pe/frambuesa-2/

Las frutas secas se almacenarán en envases de cristal bien sellados y en lugar fresco, seco y protegido de luz e insectos. Su tiempo de vida máximo será de 2 meses. La maracuyá se debe mantener a temperatura ambiente por máximo 2 días. Estos insumos se guardarán en el almacén de insumos al ingreso a la planta para luego iniciar el proceso de producción.

2. Proceso de control del producto

En este proceso los insumos, son revisados, pesados y analizados para poder garantizar que cumplan con los estándares de calidad requeridos para la producción. Se utilizarán balanzas industriales para poder controlar el peso sobre mesas. En el caso del pisco, se analizará que cumpla con la denominación de origen, con el grado de alcohol deseado y que no tengo impurezas.

En este proceso se hará el lavado de los insumos, se selecciona la fruta, luego se procede con el lavado y pesaje. Las botellas se lavan usando una máquina especial de lavado a presión con agua purificada. Se revisan las tapas y que las etiquetas se encuentren en excelente estado.

\section{Proceso de Maceración}

Este es el proceso más importante y se lleva a cabo dentro de los tanques de maceración. Se pondrá el pisco quebranta junto con la fruta seca dentro de los tanques de maceración 
(200 litros), ver tabla 90, se tomará en cuenta la temperatura y el tiempo de maceración que será de 2 meses.

Tabla 90

Receta

\begin{tabular}{lrlrl}
\hline Cantidad necesaria & & & Pisco \\
\hline Maracuyá & $75 \mathrm{Kgs}$ & Frambuesa & $50 \mathrm{Kgs}$ & $100 \mathrm{Ltrs}$ \\
Fresa & $120 \mathrm{Kgs}$ & Guinda & $30 \mathrm{Kgs}$ & $100 \mathrm{Ltrs}$ \\
Maíz morado & $120 \mathrm{Kgs}$ & Canela & $4 \mathrm{Kgs}$ & $100 \mathrm{Ltrs}$ \\
Membrillo & $60 \mathrm{Kgs}$ & Piña Golden & $60 \mathrm{Kgs}$ & \\
Clavo de Olor & $3 \mathrm{Kgs}$ & & & \\
\hline
\end{tabular}

Durante este proceso el pisco tomará el sabor y el aroma de las frutas, el nivel del alcohol bajará un poco sin perder sus propiedades.

\section{Proceso de Empaque}

Luego de la maceración, se separa las materias sólidas del producto, para esto se realizará un proceso de filtrado, en donde se utiliza un filtro prensa. Este filtro está en la máquina embotelladora, con este proceso se eliminan las impurezas del producto, es a presión y usa placas, marcos y tela filtrante en donde se retienen partículas. Este proceso dará un producto en el que no haya sedimentos. Se tiene como resultado el macerado de fruta en pisco con el aroma y sabor esperado.

Como paso siguiente se usará la máquina tapadora semi-automática en donde las botellas serán selladas en forma hermética y luego se hará el encapsulado con la pistola encapsuladora colocando el capuchón.

Durante este proceso también se hará el etiquetado y embalado. Al estar el producto en las botellas se procederá a etiquetar, este proceso se hará con una máquina de etiquetado automática, que aplicará la etiqueta y contra etiqueta, luego pasarán por un control y serán embaladas. En cajas de 6 botellas cada una. 
5. Proceso de almacenamiento

Luego de todo el proceso el producto embalado listo para ser comercializado se pondrá en el almacén de productos terminados listo para la venta.

6. Distribución física

La distribución física de los productos se llevará a cabo de dos formas. En el caso de Licorerías y otros lugares se tercerizará el servicio de distribución a través de una empresa que se encargará de esta actividad. En cuanto a la distribución de la mercadería de las compras hechas vía la web, esta se realizará via un motorizado. Este motorizado también será free lance contratado quien con su propia moto se encargará hacer la distribución y percibirá por honorarios.

Diagrama de Proceso

De acuerdo a D’Alessio (2012), es un gráfico en donde se puede apreciar todas las actividades de un proceso, por pasos. Para poder hacer el cuadro de proceso, primero se identificó los procesos que agregan valor y los que pueden causar problemas con que diagrama de actividades como soporte. Ahí se definió que el proceso de filtrado y embotellado es el más importante y en donde habría que poner mayor atención, ver figura 9. 


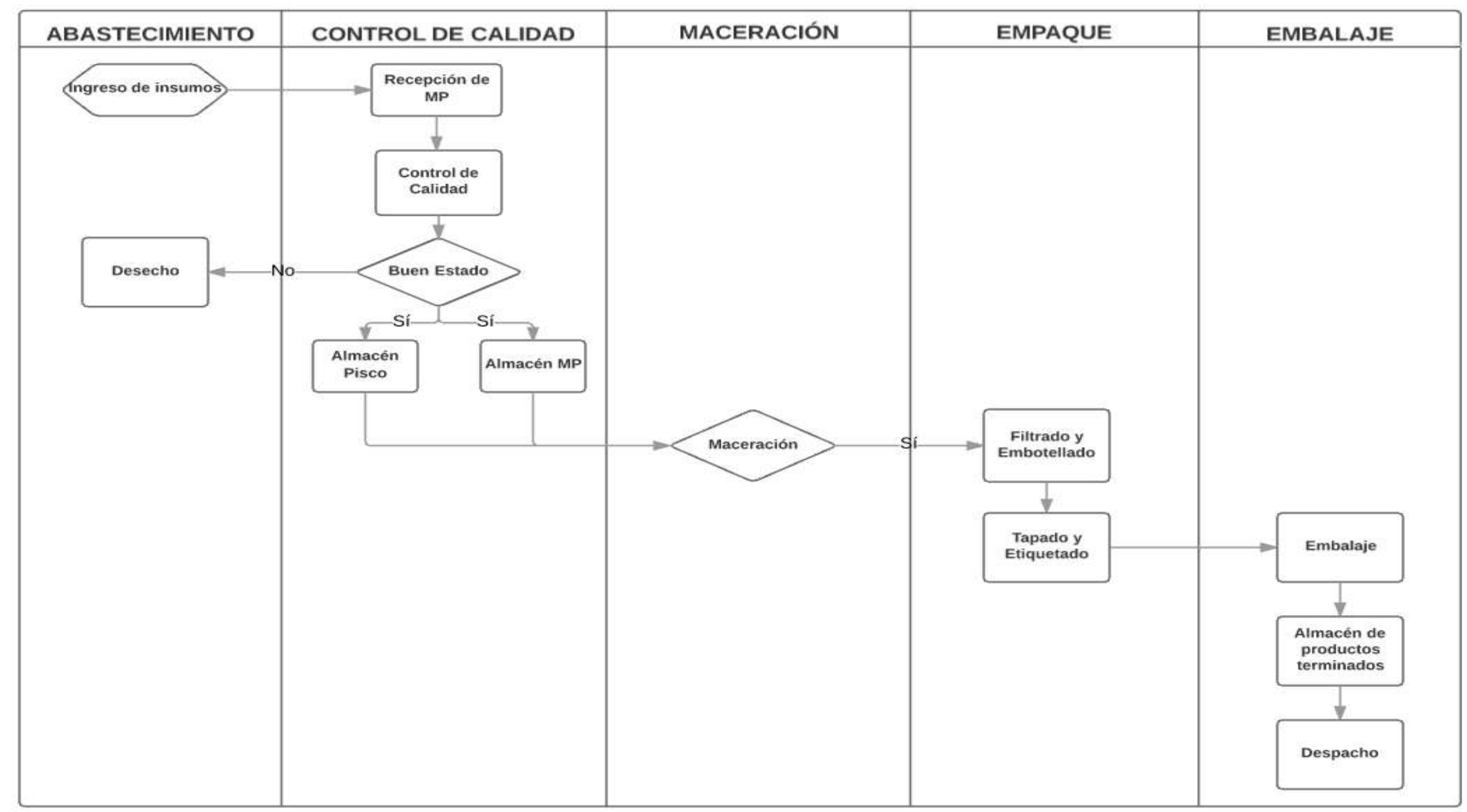

Figura 9.Flow Chart 


\subsubsection{Selección del equipamiento}

La selección del equipamiento, dependerá del proceso productivo en donde se determina qué tipo de maquinaria se usará, de qué calidad, equipos, herramientas, mobiliario y sobre todo la tecnología a usar, de esa manera se podrá calcular la Inversión, y los costos del proyecto (Sapag \& Sapag, 2008).

Se determinaron los equipos necesarios de acuerdo a cada una de las etapas de producción.

Proceso de abastecimiento de insumos y almacenamiento

Para este proceso se consideró las herramientas y maquinarias para el manejo del ingreso de insumos como anaqueles para el almacenaje, una congeladora para mantener la fruta por unos días hasta que termine el proceso (Ver tabla 91). 
Tabla 91

Abastecimientos de insumos y Almacenamiento de equipos

\begin{tabular}{|c|c|c|c|c|c|}
\hline Equipos & Cantidad & Características & Marca & Imagen & Precio \\
\hline $\begin{array}{l}\text { Balanzas } \\
\text { industriales }\end{array}$ & 1 & $\begin{array}{l}\text { Para el pesado de la fruta } \\
\text { y botellas de pisco. } \\
\text { Balanza electrónica de } \\
300 \mathrm{~kg} \text {. Doble } \\
\text { pantalla.*Estructura de } \\
\text { metal estrellado o Acero } \\
\text { y resistencia con soporte } \\
\text { *Precisión programable } \\
\text { 50gramos *Alarma de } \\
\text { sonido exceso de peso }\end{array}$ & $\begin{array}{l}\text { Hekrotex } \\
\text { Mod. TCS-B }\end{array}$ & & $\mathrm{S} / 411.82$ \\
\hline $\begin{array}{l}\text { Mesas con } \\
\text { iluminación } \\
\text { fluorescente }\end{array}$ & 3 & $\begin{array}{l}\text { Para el preparado de la } \\
\text { fruta. } \\
2 \text { mesas de trabajo de } \\
\text { acero inoxidable con } \\
\text { lavadero de } 2 \text { pozas. }\end{array}$ & Inoxbellsa & & $\mathrm{S} / 720.00$ \\
\hline $\begin{array}{l}\text { Herramientas } \\
\text { de medición } \\
\text { (vernier) }\end{array}$ & 2 & $\begin{array}{l}\text { Vernier Pie De Rey } \\
\text { Calibrador Digital }\end{array}$ & $\begin{array}{l}\text { ER } \\
\text { Industrial } \\
\text { Tools Perú }\end{array}$ & & S/103.84 \\
\hline Congeladora & 1 & $\begin{array}{l}\text { Doble sistema de } \\
\text { enfriamiento. De acero. }\end{array}$ & Frigosur & & $\mathrm{S} / 2,900.00$ \\
\hline $\begin{array}{l}\text { Estantes para } \\
\text { almacenamiento }\end{array}$ & 2 & $\begin{array}{l}4 \text { Estantes, acabado en } \\
\text { cromo }\end{array}$ & Inoxbellsa & & S/1,079.98 \\
\hline
\end{tabular}

Proceso de control del producto

Para este proceso se consideró las cuchillas para cortar la fruta si fuera necesario, lupas para poder determinar en la selección de la fruta la de mejor calidad y una máquina automática lavadora de botellas. Todo para poder ofrecer un producto que cumpla con estándares de calidad, ver tabla 92. 
Tabla 92

Equipos Control del producto

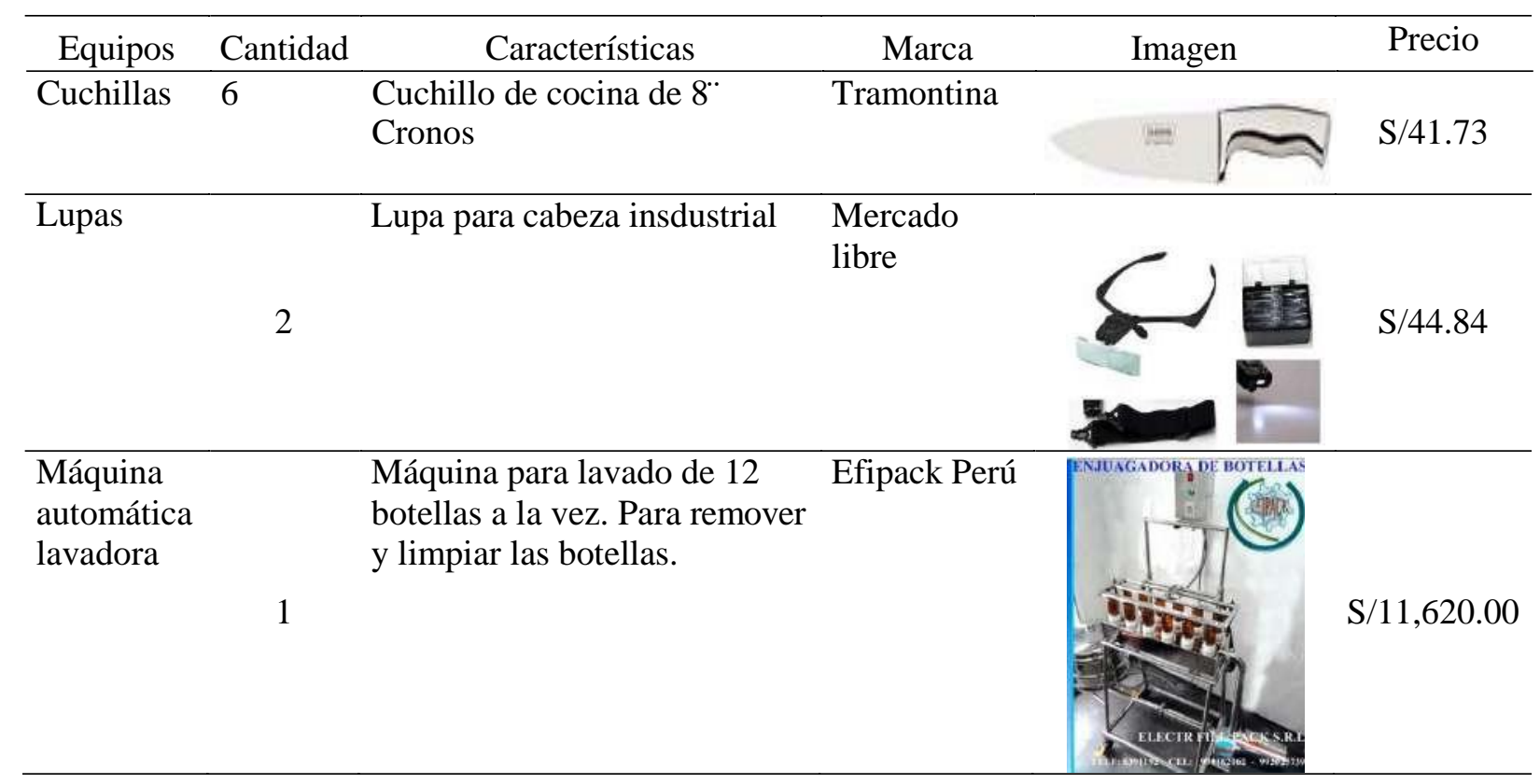

Proceso de Maceración

Para este proceso se ha consideró los tanques de maceración necesarios para maceración de 2 meses, y tener un programa de producción continuo, ver tabla 93.

Tabla 93

Equipos para Maceración

\begin{tabular}{ccllll}
\hline Equipos & Cantidad & \multicolumn{1}{c}{ Características } & \multicolumn{1}{c}{ Marca } & Imagen & Precio \\
\hline $\begin{array}{l}\text { Tanques de } \\
\text { maceración }\end{array}$ & $\begin{array}{l}\text { Depósito tipo cántaro de } \\
\text { acero inoxidable A 304 }\end{array}$ & $\begin{array}{l}\text { Cork Peru } \\
\text { Marcas } \\
\text { Marchisio }\end{array}$ & $\begin{array}{l}\text { Capacidad 100 litros. } \\
\text { Con caño y tapa de acero } \\
\text { inox A3 30 }\end{array}$ & & S/780.00 \\
\hline
\end{tabular}


Proceso de Empaquetado

Para este proceso se decidió enviar a fabricar una máquina que satisfaga las características necesarias para poder obtener una producción que tome un tiempo estimado no muy alto. Esta máquina semi-automática llena 6 botellas al mismo tiempo antes de llenarse se realizará el filtrado. Para el sellado, se decidió importar de China la máquina para sellado de corchos y la encapsuladora. Para el etiquetado se consideró comprar una máquina etiquetadora manual, ver tabla 94.

Tabla 94

Equipos para empaquetado

\begin{tabular}{|c|c|c|c|c|c|}
\hline Equipos & Cantidad & Características & Marca & Imagen & Precio \\
\hline $\begin{array}{l}\text { Máquina } \\
\text { llenadora } \\
\text { semi } \\
\text { automática }\end{array}$ & 1 & $\begin{array}{l}\text { De } 6 \text { válvulas para envasar el } \\
\text { macerado. } \\
\text { Con filtro prensa incluído. } \\
\text { Dimens } 1.70 \times 1.80 \text { x } 0.80 \mathrm{Mt} \\
\text { Cap. } 72 \text { botellas/h }\end{array}$ & Efipack Perú & & $\mathrm{S} / 28,220.00$ \\
\hline $\begin{array}{l}\text { Máquina semi } \\
\text { automática de } \\
\text { tapado }\end{array}$ & 1 & $\begin{array}{l}\text { ngo de embotellado de } 20 \text { a } 335 \\
\text { m. } \\
\text { so } 80 \mathrm{Kgs} \\
\text { po de embotellado vertical. } \\
\mathrm{cm} \times 24 \mathrm{~cm} \times 1.50 \mathrm{Mt} \\
\text { éctirica } 220 \text { Voltios }\end{array}$ & $\begin{array}{l}\text { Importada de } \\
\text { China }\end{array}$ & & $S / 1,557.74$ \\
\hline $\begin{array}{l}\text { Máquina de } \\
\text { encapsulado } \\
\text { (Sellado) }\end{array}$ & 2 & $\begin{array}{l}\text { Para encapsular el corcho } \\
72 \text { botellas /h }\end{array}$ & $\begin{array}{l}\text { Importada de } \\
\text { China }\end{array}$ & & $\mathrm{S} / 268.92$ \\
\hline $\begin{array}{l}\text { Etiquetadora } \\
\text { Manual }\end{array}$ & 1 & $\begin{array}{l}\text { Para etiquetar y contra } \\
\text { etiquetar en el mismo rollo } \\
30 \text { pcs por min }\end{array}$ & $\begin{array}{l}\text { Technical } \\
\text { Automation } \\
\text { Service S.A. }\end{array}$ & & S/1,657.34 \\
\hline
\end{tabular}


Equipo y mobiliario para administrativos

Dentro del requerimiento de maquinarias y equipos también se ha consideró los requeridos para el área administrativa, como mobiliario y equipos para que los trabajadores puedan realizar sus funciones, ver tabla 95.

Tabla 95

Equipo y mobiliario para administrativos

\begin{tabular}{|c|c|c|c|c|c|}
\hline Equipos & Cantidad & Características & Marca & Imagen & Precio \\
\hline Laptop & 1 & Intel Core I5 & Toshiba & 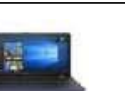 & $\mathrm{S} / 2,483.36$ \\
\hline $\begin{array}{l}\text { Computadoras } \\
\text { Escritorio }\end{array}$ & 6 & & & & $\mathrm{~S} / 1,942.20$ \\
\hline $\begin{array}{l}\text { Impresora- } \\
\text { Fotocopiadora }\end{array}$ & 1 & $\begin{array}{l}\text { Imprime, escanea y saca } \\
\text { copias }\end{array}$ & HP & $\stackrel{=}{=1}$ & S/836.64 \\
\hline
\end{tabular}

\begin{tabular}{|c|c|c|c|c|c|}
\hline Equipos & Cantidad & Características & Marca & Imagen & \\
\hline Silla de Gerente & 1 & Piaza & Office Decor & & $\mathrm{S} / 599.00$ \\
\hline Sillas oficina & 5 & Con brazos plegables & Office Decor & & \\
\hline Mesa Sala de reuniones & 1 & Con 6 sillas $\mathrm{p}$ & Office Decor & & \\
\hline Escritorio Gerente & 1 & Modelo Imperial & Office Decor & & \\
\hline Escritorios & -5 & Modelo Nud & Office Decor & & \\
\hline
\end{tabular}




\subsubsection{Lay out.}

Para D’Alessio (2012), tanto la planificación como la distribución de planta son factores determinantes para la eficiencia y que se mantenga en el tiempo una organización. La distribución óptima de la planta reduce costos operativos, mejora la productividad y las condiciones laborales. En la figura 10se puede apreciar el plano de cómo está distribuida la planta de la manera más eficiente para que los proceso de producción sean exitosos y todos el funcionamiento de la planta sea el adecuado. 


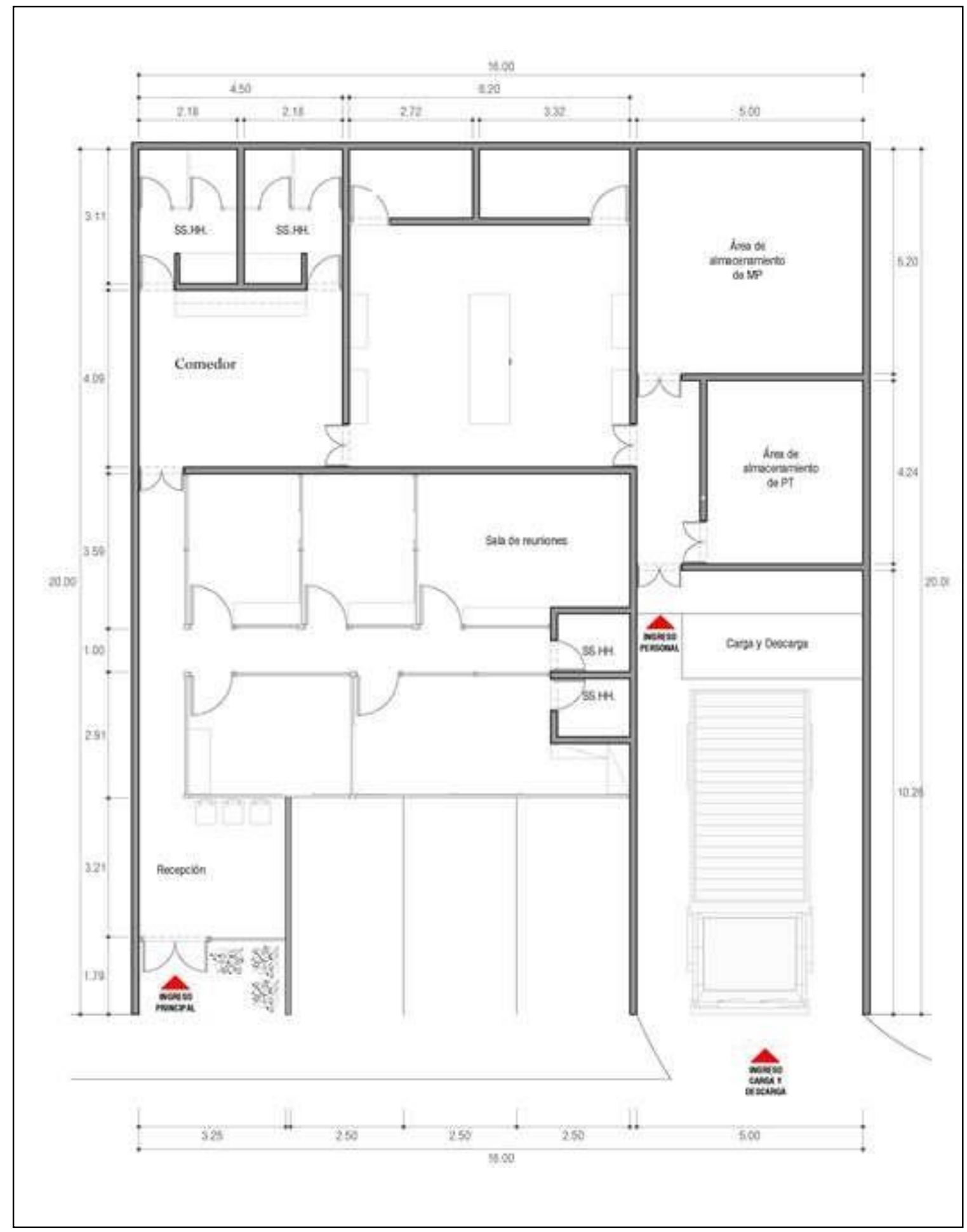

Figura 10. Lay Out. 


\subsubsection{Distribución de equipos y maquinarias.}

Siguiendo con lo que dice D’Alessio (2012), la distribución óptima reduciría riesgos de salud, haría que el proceso de producción sea más corto, la productividad y producción aumentaría, el uso de espacio necesario, la maquinaria estaría utilizada eficientemente, la manipulación de materiales sería menor y se facilitaría la supervisión. Existen tres tipos de distribución: por producto, por proceso y celular.

En el caso de la planta, se usó la distribución por proceso para obtener una mayor eficiencia. Como se puede apreciar en el plano líneas abajo, el proceso se inicia en el área de almacenamiento de Materia Prima. Este almacén conecta con el ambiente en donde se inicia el proceso de calidad, lavado, maceración, filtrado y llenado, luego el tapado y etiquetado siguiendo finalmente el encajado y embalado. Para luego se enviado al Almacén de producto terminado, Que conecta con la rampa de carga y descarga. El área del terreno es de 320m2. También se ha considerado las oficinas para la parte administrativa, el comedor y los servicios higiénicos, ver figura 11. 


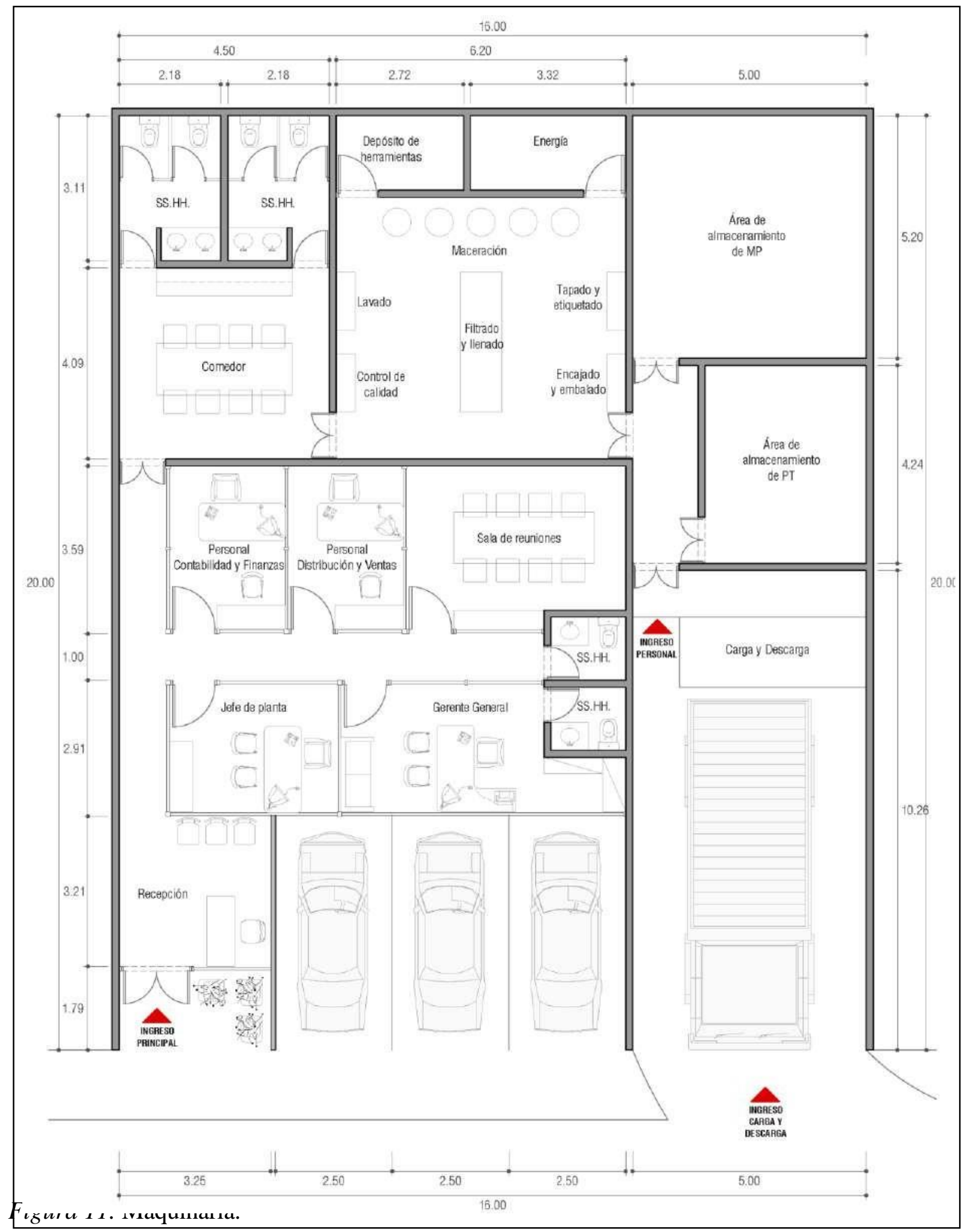




\subsection{Determinación del tamaño de la planta}

Según Baca (2010), para poder establecer el tamaño óptimo de la planta se debe tener una mayor comprensión y exactitud sobre los tiempos determinados para cada proceso o de lo contrario moldearlos hasta obtener un diseño haciendo uso de ingenio y técnicas establecidas.

\subsubsection{Proyección de crecimiento.}

Como menciona Baca (2010), en el estudio de mercado se determinarán algunas variables relacionadas a las particularidades del producto, la proyección de la demanda a través del tiempo, la estacionalidad, el aprovisionamiento de materias primas y los canales de distribución óptimos. Esta investigación deberá ser tomada en cuenta al momento de optar por el proceso productivo del cual darán resultado los requerimientos de maquinarias y equipos, la selección y disposición en planta (layout) y la necesidad de mano de obra que participe en la operación. Luego de todo el estudio se pueden definir las necesidades de espacio y obras físicas.

Para la proyección de crecimiento se consideraron algunos factores como el incremento de la demanda y se tomó como base la capacidad instalada de las maquinas que se utilizaran para la elaboración de los macerados de frutas en pisco. En la tabla 96 se puede observar la cantidad de máquinas requeridas durante la operación. 
Tabla 96

Capacidad Instalada

\begin{tabular}{|c|c|c|c|c|c|c|c|c|c|}
\hline Máquina / Equipo & Unidad & $\begin{array}{l}\text { Capacidad } \\
\text { del equipo }\end{array}$ & $\begin{array}{c}\text { Tiempo en } \\
\text { minutos del } \\
\text { proceso en } \\
\text { maquina }\end{array}$ & $\begin{array}{c}\text { Capacidad } \\
\text { por hora } \\
\text { en } \\
\text { botellas }\end{array}$ & $\begin{array}{l}\text { Capacidad } \\
\text { por día en }\end{array}$ & $\begin{array}{c}\text { Capacidad } \\
\text { por mes } \\
\text { en } \\
\text { botellas }\end{array}$ & $\begin{array}{c}\text { Capacidad } \\
\text { por año en } \\
\text { botellas } \\
\text { equipo } \\
\text { equipo }\end{array}$ & $\begin{array}{l}\text { Número } \\
\text { de } \\
\text { equipos } \\
\text { requeridos }\end{array}$ & $\begin{array}{c}\text { Capacidad } \\
\text { total en }\end{array}$ \\
\hline Máquina lavadora de botellas & Bot & 12 & 5 & 144 & 1,152 & 27,648 & 331,776 & 1 & 331,776 \\
\hline Tanques de maceración & Bot & 178 & & & & & 1,068 & 31 & 33,108 \\
\hline Máquina selladora semiautomática & Bot & 6 & 5 & 72 & 576 & 13,824 & 165,888 & 1 & 165,888 \\
\hline Máquina manual de tapado & Bot & 500 & 60 & 500 & 4,000 & 96,000 & $1,152,000$ & 1 & $1,152,000$ \\
\hline Máquina de encapsulado & Bot & 1 & 2 & 40 & 320 & 7,680 & 92,160 & 1 & 92,160 \\
\hline Etiquetadora manual & Bot & 30 & 1 & 1,800 & 14,400 & 345,600 & $4,147,200$ & 1 & $4,147,200$ \\
\hline
\end{tabular}

Tabla 97

Proyección de Crecimiento Anual

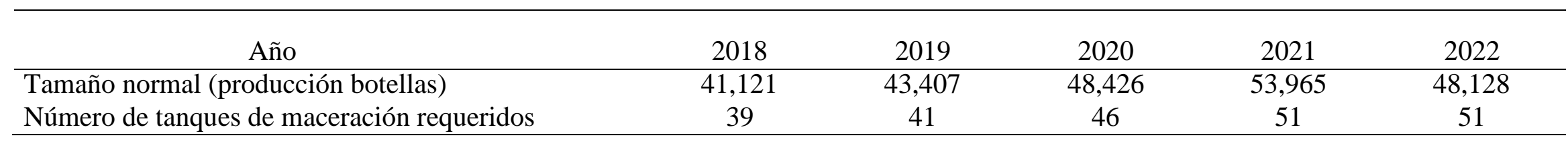


En la tabla 97 se muestra el crecimiento anual en relación al número de botellas producidas y la cantidad de tanques de maceración, los cuales definieran la capacidad de producción del proyecto. En el año uno se inicia con 39 tanques de maceración y al cierre del año cinco se termina el proyecto con 51 tanques que permiten alcanzar una producción total de 48,128 botellas de macerados de frutas en pisco.

a. Programa de producción

Programa de producción toma como referencia las ventas proyectadas, además considera la capacidad instalada, la cantidad de equipos y el área total destinada a la producción. Como base también se consideró los resultados arrojados en el estudio cuantitativo teniendo en cuenta los gustos y preferencias de los consumidores.

Como resultado de la encuesta se consideraron las preferencias de los consumidores en la:

- $\quad$ Elección de los sabores que son de su mayor agrado.

- Frecuencia de compra ya sea por semana, mensual, bimensual o trimestral.

- Cantidad de botellas que serían adquiridas en cada compra.

El trabajar con fruta siempre presenta un porcentaje de merma, esto representa una reducción en el total de materia prima utilizada, este porcentaje fue considerado en la elaboración de los macerados.

En la siguiente tabla 98 se aprecia el programa de producción proyectado por los cinco años. 
Tabla 98

Programa de Producción Proyectado

\begin{tabular}{lccccccc}
\hline $\begin{array}{l}\text { PRODUCCIÓN } \\
\text { botellas) }\end{array}$ & nov-17 & dic-17 & 2018 & 2019 & 2020 & 2021 & 2022 \\
\hline $\begin{array}{l}\text { Maracuyá y } \\
\text { Frambuesa }\end{array}$ & 764 & 823 & 14,804 & 15,626 & 17,433 & 19,428 & 17,326 \\
Fresa y Guinda & 764 & 823 & 14,804 & 15,626 & 17,433 & 19,428 & 17,326 \\
Chicha & 594 & 640 & 11,514 & 12,154 & 13,560 & 15,110 & 13,476 \\
\hline Total botellas al año & 2,123 & 2,287 & 41,121 & 43,407 & 48,426 & 53,965 & 48,128 \\
\hline Total botellas al mes & 2,123 & 2,287 & 3,427 & 3,617 & 4,035 & 4,497 & 4,011 \\
\hline Total botellas al dia & & & 143 & 151 & 168 & 187 & 167 \\
\hline Total botellas por hora & & & 18 & 19 & 21 & 23 & 21 \\
\hline
\end{tabular}

b. Programa de compras

Posterior a obtener el programa de ventas totales por botellas para cada uno de los tres sabores, se procedió hacer el cálculo de la cantidad de fruta por kilogramo para poder elaborar los macerados de frutas en pisco con el fin de proyectar las compras.

Para obtener la cantidad exacta de kilogramos por fruta se tomó como referencia la elaboración de una botella por cada sabor para luego establecerlo como un estándar y poder proyectar la cantidad de compra futura, ver tabla 99. 
Tabla 99

Necesidad de Materia Prima e Insumos

\begin{tabular}{lrrrrrrrr}
\hline & Unidad & nov-17 & dic-17 & 2018 & 2019 & 2020 & 2021 & 2022 \\
\hline Pisco & $\mathrm{Lt}$ & 1,083 & 868 & 20,981 & 22,148 & 24,709 & 27,535 & 24,557 \\
Maracuyá & $\mathrm{Kg}$ & 358 & 386 & 6,939 & 7,325 & 8,172 & 9,107 & 8,122 \\
Frambuesa & $\mathrm{Kg}$ & 195 & 210 & 3,776 & 3,986 & 4,447 & 4,956 & 4,420 \\
Fresa & $\mathrm{Kg}$ & 484 & 521 & 9,369 & 9,890 & 11,034 & 12,296 & 10,966 \\
Guinda & $\mathrm{Kg}$ & 117 & 126 & 2,271 & 2,398 & 2,675 & 2,981 & 2,658 \\
Maíz morado & $\mathrm{Kg}$ & 387 & 39 & 7,499 & 7,916 & 8,832 & 9,841 & 8,777 \\
Membrillo & $\mathrm{Kg}$ & 202 & 20 & 3,916 & 4,134 & 4,612 & 5,139 & 4,584 \\
Piña golden & $\mathrm{Kg}$ & 214 & 21 & 4,147 & 4,377 & 4,883 & 5,442 & 4,853 \\
Canela & $\mathrm{Kg}$ & 12 & 1 & 237 & 251 & 280 & 311 & 278 \\
Clavo & $\mathrm{Kg}$ & 9 & 1 & 178 & 188 & 210 & 234 & 208 \\
Botella & $\mathrm{Und}$ & 2,144 & 1,723 & 41,536 & 43,846 & 48,915 & 54,510 & 48,614 \\
Soguilla & $\mathrm{M}$ & 2,144 & 1,723 & 41,536 & 43,846 & 48,915 & 54,510 & 48,614 \\
Tapon & $\mathrm{Und}$ & 2,144 & 1,723 & 41,536 & 43,846 & 48,915 & 54,510 & 48,614 \\
\hline
\end{tabular}

5.2.2. Recursos.

Según Baca (2010), para estimar el tamaño de la planta, se debe tener presente la existencia de factores que están relacionados entre sí, tales como disponibilidad de insumos, tamaño de la demanda, recursos humanos y el financiamiento para el proyecto.

1. Recursos financieros

Como menciona Baca (2010), el global del financiamiento con recursos propios o externos debe permitir la viabilidad del proyecto, permitiendo menores costos de producción y mayor rentabilidad.

Este recurso se desarrollará al detalle en el transcurso del capítulo VIII. 
2. Recursos humanos

Como establece Baca (2010), es luego del estudio técnico para determinar el tamaño de la planta que se debe asegurar la cantidad y calidad de personas que formaran parte de la organización en cada uno de los puestos establecidos a fin de asegurar el buen funcionamiento de la misma, ver tabla 100 .

Tabla 100

Requerimiento de Personal

\begin{tabular}{lll}
\hline \multicolumn{1}{c}{ Cargo } & \multicolumn{1}{c}{ Área } & Tipo de costo y gasto \\
\hline Gerente General & Administrativa & G. Administración \\
Asistente Administrativo & Administrativa & G. Administración \\
Gerente de Marketing & Ventas & G. Ventas \\
Ejecutivo de Ventas & Ventas & G. Ventas \\
Community Manager & Ventas & G. Ventas \\
Jefe de Producción y Logística & Producción & MOI \\
Operario & Producción & MOD \\
\hline
\end{tabular}

Se solicitará el servicio outsourcing para algunas áreas que no representan el corebusiness de la empresa, entre los servicios considerados figuran: estudio contable, estudio de abogados y servicio de limpieza.

\section{La demanda}

Para Baca (2010), la demanda es un factor muy importante para estimar el tamaño de la planta ya que esta siempre debe ser superior al tamaño estimado. Cuando la demanda es mayor al tamaño de la planta, este tamaño solo debe cubrir el 10\% de la demanda de mercado, ver tabla 101. 
Tabla 101

Demanda Estimada de Mercado

\begin{tabular}{lrrrrr}
\hline PRESENTACION & 2018 & 2019 & 2020 & 2021 & 2022 \\
\hline WEB & 8,309 & 9,370 & 10,554 & 11,876 & 13,350 \\
Maracuyá y frambuesa & 2,991 & 3,373 & 3,800 & 4,275 & 4,806 \\
Fresa y guinda & 2,991 & 3,373 & 3,800 & 4,275 & 4,806 \\
Chicha & 2,326 & 2,624 & 2,955 & 3,325 & 3,738 \\
\hline OTROS CANALES & 26,919 & 30,356 & 34,193 & 38,475 & 43,252 \\
Maracuyá y frambuesa & 9,691 & 10,928 & 12,310 & 13,851 & 15,571 \\
Fresa y guinda & 9,691 & 10,928 & 12,310 & 13,851 & 15,571 \\
Chicha & 7,537 & 8,500 & 9,574 & 10,773 & 12,110 \\
\hline Total unidades & 35,228 & 39,726 & 44,748 & 50,351 & 56,602 \\
\hline
\end{tabular}

\section{Disponibilidad de insumos}

Según Baca (2010), se debe asegurar el adecuado abastecimiento y calidad de las materias primas e insumos ya que es de suma importancia para el desarrollo del proyecto. Se debe realizar un registro de todos los proveedores y asignarles un almacén específico para mantener un riguroso control sobre la materia prima e insumos para que no se conviertan en limitantes para el buen desarrollo de la organización.

\section{a. Pisco}

El pisco es de origen peruano y es considerada nuestra bebida alcohólica bandera lo que ha generado un mayor interés y consumo en las preferencias de todos los peruanos.

Entre los muchos productores de pisco que existen en el mercado se decidió elegir a la Bodega Bailetti como el principal proveedor de pisco Quebranta, principal insumo para la elaboración de los macerados de frutas, esto debido a que es un producto que este año 2017 fue galardonado con la Gran Medalla de Oro Nacional otorgada por CONAPISCO. La compra es en envases de cuatro litros (damajuana) a un precio de S/ 40.00 nuevos soles, ver tabla 102. 
Tabla 102

Precio de Pisco Utilizado

\begin{tabular}{lllll}
\hline Proveedor & Tipo de pisco & Cantidad & Precio unitario \\
\hline Bodega Bailetti & Quebranta & $41 \mathrm{t}$ & S/. 40.00 \\
\hline
\end{tabular}

b. Frutas

El Perú es un país que presenta una gran variedad de especies comestibles y el caso de las frutas no es ajeno a ello. Se producen alrededor de 56 especies de frutas entre oriundas del Perú y otras variedades que fueran traídas en el pasado y que se adaptaron con mucha facilidad al suelo y climas del país, ver tabla 103.

Tabla 103

Producción de Frutas por Región en el Perú (2015) en Toneladas

\begin{tabular}{|c|c|c|c|c|c|c|}
\hline Región & Maracuyá & Membrillo & Guinda & Fresa & Piña & Maíz Morado \\
\hline Nacional & 59,580 & 6,958 & 1,214 & 25,256 & 450,635 & 21,160 \\
\hline Amazonas & 0 & 0 & 0 & 0 & 8,407 & 0 \\
\hline Ancash & 12,039 & 150 & 0 & 0 & 0 & 2,048 \\
\hline Apurímac & 0 & 93 & 0 & 67 & 0 & 113 \\
\hline Arequipa & 0 & 102 & 0 & 55 & 0 & 1,533 \\
\hline Ayacucho & 47 & 68 & 754 & 0 & 1,756 & 1,303 \\
\hline Cajamarca & 73 & 0 & 0 & 0 & 3,821 & 389 \\
\hline Callao & 0 & 0 & 0 & 0 & 0 & 0 \\
\hline Cusco & 0 & 0 & 0 & 0 & 9,756 & 0 \\
\hline Huancavelica & 0 & 45 & 26 & 0 & 0 & 0 \\
\hline Huánuco & 254 & 0 & 0 & 58 & 10,267 & 2,130 \\
\hline Ica & 16 & 176 & 0 & 0 & 0 & 792 \\
\hline Junín & 1,112 & 0 & 433 & 0 & 331,858 & 0 \\
\hline La Libertad & 4,327 & 659 & 0 & 480 & 23,846 & 1,889 \\
\hline Lambayeque & 13,520 & 0 & 0 & 0 & 0 & 0 \\
\hline Lima & 19,488 & 5,321 & 0 & 23,632 & 0 & 10,762 \\
\hline \multicolumn{7}{|l|}{ Lima } \\
\hline Metropolitana & 0 & 163 & 0 & 535 & 0 & 0 \\
\hline Loreto & 326 & 0 & 0 & 0 & 15,965 & 0 \\
\hline Madre de Dios & 0 & 0 & 0 & 0 & 3,204 & 0 \\
\hline Moquegua & 11 & 121 & 0 & 0 & 0 & 202 \\
\hline Pasco & 0 & 0 & 0 & 430 & 586 & 0 \\
\hline Piura & 7,816 & 0 & 0 & 0 & 0 & 0 \\
\hline
\end{tabular}




\begin{tabular}{lrrrrrr}
\hline \multicolumn{1}{c}{ Región } & Maracuyá & Membrillo & Guinda & Fresa & Piña & Maíz Morado \\
\hline \multicolumn{1}{c}{ Nacional } & 0 & 0 & 0 & 0 & 19,017 & 0 \\
\hline Puno & 19 & 0 & 0 & 0 & 12,237 & 0 \\
San Martín & 0 & 60 & 0 & 0 & 0 & 0 \\
Tacna & 171 & 0 & 0 & 0 & 0 & 0 \\
Tumbes & 362 & 0 & 0 & 0 & 9,915 & 0 \\
Ucayali & & & & & & \\
\hline
\end{tabular}

Nota. Adaptado de producción hortofrutícula, por Sistema Integrado de Estadísticas Agrarias (SIEA). Recuperado de http://siea.minag.gob.pe/siea/?q=produccion-agricolay-ganadera-2015.

Los precios de las frutas fueron obtenidos del portal web que está a disponibilidad de todos por el Ministerio de Agricultura y Riego. En la tabla 106 se presentan los precios máximos de las frutas en lo que va del 2017 en el Mercado mayorista de frutas, ver tabla 104.

Tabla 104

Precios de Frutas por Kilogramo

\begin{tabular}{|c|c|c|c|}
\hline Producto & Cantidad & \multicolumn{2}{|c|}{ Precio unitario } \\
\hline Fresa & $\mathrm{Kg}$ & $\mathrm{S} /$ & 2.50 \\
\hline Membrillo Serranito & $\mathrm{Kg}$ & $\mathrm{S} /$. & 4.00 \\
\hline Maíz Morado & $\mathrm{Kg}$ & S/. & 1.40 \\
\hline Piña Golden & $\mathrm{Kg}$ & S/. & 2.50 \\
\hline Maracuyá & $\mathrm{Kg}$ & S/. & 3.50 \\
\hline Guinda & $\mathrm{Kg}$ & S/. & 20.00 \\
\hline Frambuesa & $\mathrm{Kg}$ & S/. & 40.00 \\
\hline
\end{tabular}

Nota. Adaptado de sistema de abastecimiento de precios, por Ministerio de Agricultura y Riego (MINAGRI). Recuperado de http://sistemas.minag.gob.pe/sisap/portal2/mayorista/

c. Insumos

Entre otros insumos considerados para la producción se encuentra la canela, como se sabe esta especia no es originaria del Perú por lo que no existen datos de producción, por el contrario, su ingreso al país se da por medio de la importación, ver tabla 105. El 98\% de la canela entera que importa el Perú proviene de Sri Lanka, esto 
refleja un total de 565 mil kilos lo que asciende a una suma de US\$ 5.9 millones.

(Ramos E. Perú importa el 98\% de canela de Sri Lanka. Agraria.pe, 2017).

Tabla 105

Precios de Insumos

\begin{tabular}{lccc}
\hline Insumo & Cantidad & & Precio unitario \\
\hline Canela entera & $100 \mathrm{gr}$ & $\mathrm{S} /$. & 8.00 \\
Clavo de olor & $100 \mathrm{gr}$ & $\mathrm{S} /$. & 6.00 \\
\hline
\end{tabular}

d. Otros

Para la presentación final del producto se consideraron las botellas y tapas, las cuales fueron cotizadas a diversos proveedores siendo seleccionado Cork Perú, quien ofrecía el tipo de botella que se buscaba para presentar el producto. El resultado de estas cotizaciones se muestra a continuación en la tabla 106.

Tabla 106

Precios de Botellas y Tapones

\begin{tabular}{clll}
\hline Producto & Cantidad & Precio unitario & Imagen \\
\hline $\begin{array}{c}\text { Botella Rosetta transparente de } 750 \\
\mathrm{ml}\end{array}$ & 20 und & $\mathrm{S} /$. & 2.60
\end{tabular}

Tapón sintético

50 und $\mathrm{S} /$.

0.40

\subsubsection{Tecnología.}

Como establece Baca (2010), en conclusión se puede decir que la tecnología y los equipos son determinantes en la limitación del tamaño del proyecto mostrando el mínimo de producción deseado para que sea viable. 


\section{Proceso de macerado}

Para el proceso de macerado se utilizaran tanques de maceración de 200 litros en material de aluminio para que la fruta pueda reposar en el pisco quebranta y de esta manera se pueda lograr el sabor deseado. El tiempo de macerado estándar es de 60 días según las pruebas establecidas en el tiempo de experimentación. Se tomaron como referencias las distintas entrevistas a profundidad en las cuales los expertos indicaron que el tiempo de maceración es vital para logra un excelente sabor que se convierta a futuro en un estándar de calidad.

2. Proceso de filtrado

Este proceso es posterior al de macerado, luego de que la fruta cumpla en tiempo deseado para fusionarse con el pisco el siguiente paso es el filtrado. En este proceso se obtiene solo el líquido proveniente de la maceración lograda en los tanques de maceración de 200 litros, eliminando residuos provenientes de las mismas frutas o especias utilizadas.

3. Proceso de embotellado y sellado

Una vez obtenido el producto final (macerado de frutas en pisco) se procede con el embotellado y sellado. Este proceso es realizado bajo estándares de calidad que aseguren que el producto final sea el deseado.

\subsubsection{Flexibilidad.}

Como menciona Baca (2010), se debe logar una distribución de planta que sea fácil de adaptarse a los cambios que se presentaran en el medio, con el fin poder realizar cambios dentro del proceso de la manera más económica posible.

Se consideró un solo tipo de producto, macerado de frutas en pisco, pero se decidión que se presentaran 3 sabores al púbico objetivo. La producción de los tres sabores corresponderá netamente a la demanda proyectada para casa sabor que se 
obtuvo de la encuesta realizada. Se consideró trabajar sobre un proceso estandarizado, el cual será el resultado de la receta ideal para cada uno de los sabores ofertados. El uso de solo un tipo de pisco (quebranta) representa una ventaja y a la vez una facilidad en cuando costos y estandarización de producto.

Los cambios en la demanda afectan de manera directa a la producción de los macerados. La producción debe mostrar flexibilidad para adaptarse a la estacionalidad de la materia prima o a los cambios en la demanda. El uso de tecnología debe estar preparado para estos cambios, pudiendo moverse cuando estos fenómenos se presenten y de esta manera aprovechar los beneficios de los cambios o reducir el impacto de un cambio negativo.

\subsubsection{Selección del tamaño ideal.}

Se realizó la estimación en base a la capacidad de producción de la maquina embotelladora, la cual realiza el embotellado de 72 botellas en el lapso de una hora. En la tabla 107 se presenta el escenario óptimo trabajando al 100\% de su capacidad y las 24 horas del día.

Tabla 107

Escenario Ideal de Producción

\begin{tabular}{lll}
\hline Tiempo & Cantidad & Unidad \\
\hline 1 hora & 72 & Botellas \\
24 horas & 1,728 & Botellas \\
Semanal & 10,368 & Botellas \\
Mensual & 311,040 & Botellas \\
Anual & $3,732,480$ & Botellas \\
\hline
\end{tabular}

En el lapso de 24 horas la máquina llegaría a producir 1,728 botellas por lo tanto en el periodo de un año se tendría una producción total de 3’732,480 botellas.

Para el escenario óptimo de producción se consideró que la máquina trabajaría por un lapso de 10 horas sin interrupción. Logrando una producción anual total de 207,360 botellas (Ver tabla 108). 
Tabla 108

EscenarioÓptimo de Producción

\begin{tabular}{lll}
\hline Tiempo & Cantidad & Unidad \\
\hline 1 hora & 72 & Botellas \\
10 horas & 720 & Botellas \\
Semanal & 4,320 & Botellas \\
Mensual & 17,280 & Botellas \\
Anual & 207,360 & Botellas \\
\hline
\end{tabular}

Para el escenario real, se consideró que la máquina realice el trabajo durante un lapso de 8 horas laborales, siendo esto ajustado a la realidad. Esta capacidad instalada se hizo en función a la capacidad de producción de los equipos y por tanque de maceración de 200 litros. Para poder hacer ese cálculo se hizo el resumen de la tabla 109.

Tabla 109

Escenario Real de Producción

\begin{tabular}{|c|c|c|c|c|c|c|c|c|c|}
\hline $\begin{array}{c}\text { Máquina / } \\
\text { Equipo }\end{array}$ & & $\begin{array}{l}\text { Cap del } \\
\text { equipo } \\
\text { en } \\
\text { botellas }\end{array}$ & $\begin{array}{l}\text { Tiempo } \\
\text { en } \\
\text { minutos } \\
\text { del } \\
\text { proceso } \\
\text { en } \\
\text { máquina }\end{array}$ & $\begin{array}{l}\text { Capacidad } \\
\text { por hora } \\
\text { en botellas }\end{array}$ & $\begin{array}{l}\text { Capacidad } \\
\text { por dia en } \\
\text { botellas }\end{array}$ & $\begin{array}{c}\text { Capacidad } \\
\text { por mes en } \\
\text { botellas }\end{array}$ & $\begin{array}{c}\text { Capacidad } \\
\text { por año en } \\
\text { botellas } \\
\text { por equipo }\end{array}$ & $\begin{array}{l}\text { Número } \\
\text { de } \\
\text { equipos } \\
\text { requerid } \\
\text { os }\end{array}$ & $\begin{array}{c}\text { Cap total } \\
\text { en } \\
\text { botellas }\end{array}$ \\
\hline $\begin{array}{l}\text { Maquina } \\
\text { lavadora de } \\
\text { botellas }\end{array}$ & BOT & 12 & 5 & 144 & 1,152 & 27,648 & 331,776 & 1 & 331,776 \\
\hline $\begin{array}{l}\text { Tanques de } \\
\text { Maceración } \\
\text { Máquina }\end{array}$ & BOT & 178 & & & & & 1,068 & 31 & 33,108 \\
\hline $\begin{array}{l}\text { llenadora } \\
\text { Semiautomá } \\
\text { tica. }\end{array}$ & BOT & 6 & 5 & 72 & 576 & 13,824 & 165,888 & 1 & 165,888 \\
\hline $\begin{array}{l}\text { Máquina } \\
\text { Manual de } \\
\text { Tapado }\end{array}$ & BOT & 500 & 60 & 500 & 4,000 & 96,000 & $1,152,000$ & 1 & $1,152,000$ \\
\hline $\begin{array}{l}\text { Máquina de } \\
\text { Encapsulado }\end{array}$ & BOT & 1 & 2 & 40 & 320 & 7,680 & 92,160 & 1 & 92,160 \\
\hline $\begin{array}{l}\text { Etiquetadora } \\
\text { Manual }\end{array}$ & BOT & 30 & 1 & 1,800 & 14,400 & 345,600 & $4,147,200$ & 1 & $4,147,200$ \\
\hline
\end{tabular}

Con este resultado se pudo calcular la cantidad de tanques de maceración de 200 litros requeridos, tabla 110 . 


\begin{tabular}{cccccc} 
Año & 2018 & 2019 & 2020 & 2021 & 2022 \\
\hline & & & & & \\
Tamaño normal (producción botellas) & 41,121 & 43,407 & 48,426 & 53,965 & 48,128 \\
$\begin{array}{l}\text { Número de tanques de maceración } \\
\text { requeridos }\end{array}$ & 39 & 41 & 46 & 51 & 51 \\
\hline
\end{tabular}

Entonces la capacidad de utilización de la maquinaria por año se calculó de acuerdo a la tabla 111

Tabla 111

Porcentaje de Utilización en botellas

\begin{tabular}{lrrrrr}
\multicolumn{1}{c}{ Año } & 2018 & 2019 & 2020 & 2021 & 2022 \\
\hline $\begin{array}{l}\text { Tamaño normal (producción } \\
\text { botellas) }\end{array}$ & 41,121 & 43,407 & 48,426 & 53,965 & 48,128 \\
$\begin{array}{l}\text { Capacidad instalada (producción } \\
\text { botellas) }\end{array}$ & 41,652 & 43,788 & 49,128 & 54,468 & 54,468 \\
\hline & & & & & \\
\hline & $98.7 \%$ & $99.1 \%$ & $98.6 \%$ & $99.1 \%$ & $88.4 \%$
\end{tabular}

\subsection{Estudio de localización}

Según Baca (2001), el método cualitativo por puntos consiste en asignar factores cuantitativos a elementos que se consideren importantes para la localización. Esto tiene como resultado una comparación cuantitativa de diferentes sitios. Este método permite ponderar factores de preferencia por el investigador para tomar la decisión más adecuada. 
Por lo que se realizó un estudio de Macro localización considerando las zonas 6 y 7 para determinar el distrito en el cual se ubicó el local, utilizando 7 factores considerados los más importantes.

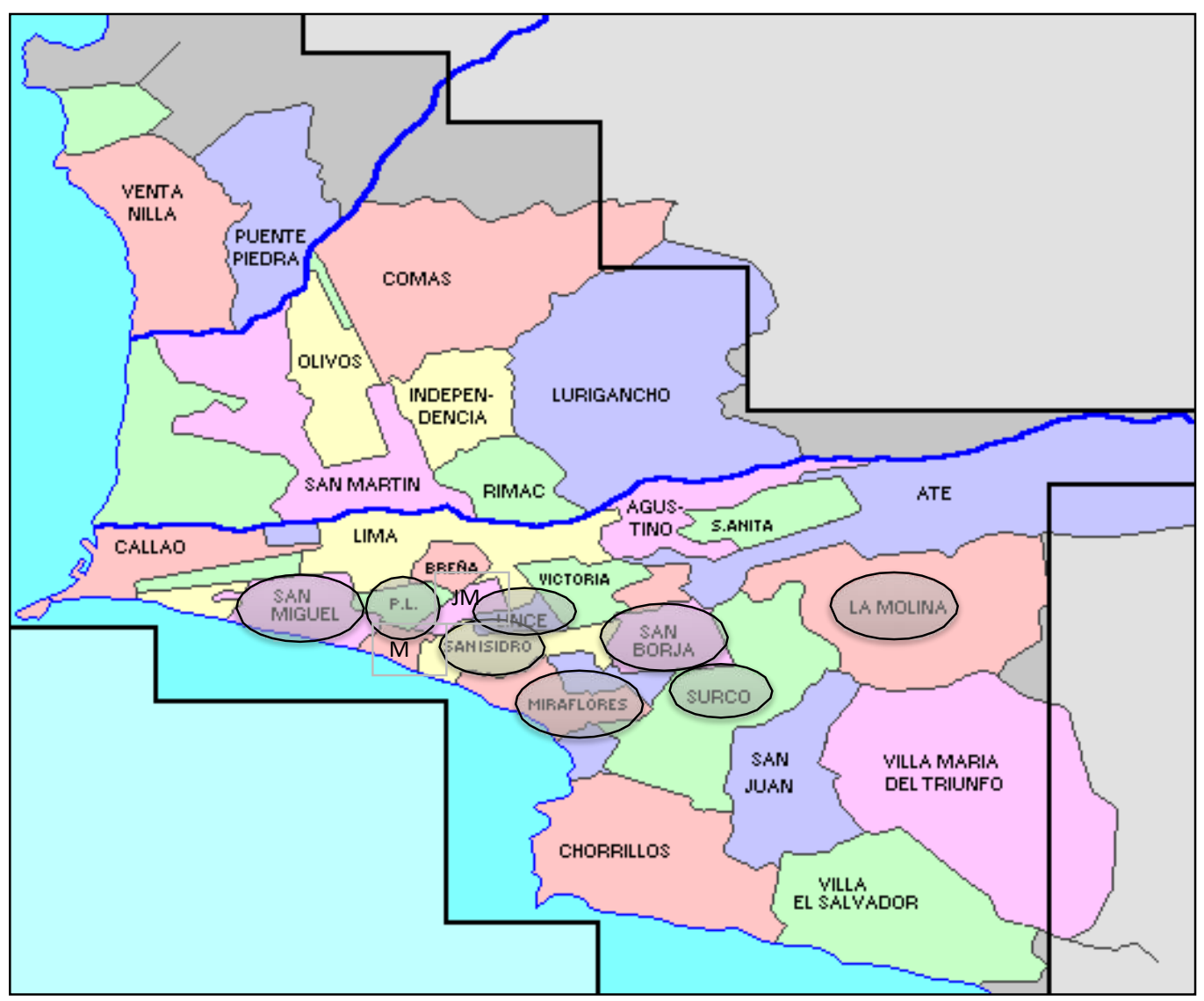


Tabla 112

Macrolocalización

\begin{tabular}{|c|c|c|c|c|c|c|c|c|c|c|c|c|c|c|c|c|c|c|c|c|c|c|}
\hline & & \multicolumn{11}{|c|}{ Zona 6} & \multicolumn{10}{|c|}{ Zona 7} \\
\hline & & \multicolumn{3}{|c|}{ Magdalena } & \multicolumn{2}{|c|}{ San Miguel } & \multicolumn{2}{|c|}{ Jesús María } & \multicolumn{2}{|c|}{ Pueblo Libre } & \multicolumn{2}{|c|}{ Lince } & \multicolumn{2}{|c|}{ La Molina } & \multicolumn{2}{|c|}{ Santiago de Surco } & \multicolumn{2}{|c|}{ San Borja } & \multicolumn{2}{|c|}{ San Isidro } & \multicolumn{2}{|c|}{ Miraflores } \\
\hline $\begin{array}{l}\text { Ite } \\
\mathrm{m}\end{array}$ & Descripción & $\begin{array}{c}\text { Pes } \\
\text { o }\end{array}$ & $\begin{array}{l}\text { Puntaje } \\
\text { de } \\
(0-10)\end{array}$ & $\begin{array}{c}\text { Resultad } \\
\quad\end{array}$ & $\begin{array}{l}\text { Puntaje } \\
\text { de } \\
(0-10)\end{array}$ & $\begin{array}{l}\text { Result } \\
\text { ado }\end{array}$ & $\begin{array}{l}\text { Puntaj } \\
\text { e de } \\
(0- \\
10)\end{array}$ & $\begin{array}{c}\text { Resultad } \\
\mathrm{o}\end{array}$ & $\begin{array}{l}\text { Puntaj } \\
\text { e de } \\
(0- \\
10)\end{array}$ & $\begin{array}{c}\text { Resulta } \\
\text { do }\end{array}$ & $\begin{array}{l}\text { Puntaj } \\
\text { e de } \\
(0- \\
10)\end{array}$ & $\begin{array}{c}\text { Resultad } \\
\mathrm{o}\end{array}$ & $\begin{array}{l}\text { Puntaj } \\
\text { e de } \\
(0- \\
10)\end{array}$ & $\begin{array}{c}\text { Resultad } \\
\mathrm{o}\end{array}$ & $\begin{array}{l}\text { Puntaj } \\
\text { e de } \\
(0- \\
10)\end{array}$ & $\begin{array}{l}\text { Resultad } \\
\mathrm{o}\end{array}$ & $\begin{array}{c}\text { Puntaje } \\
\text { de } \\
(0-10)\end{array}$ & $\begin{array}{c}\text { Resultad } \\
\quad\end{array}$ & $\begin{array}{l}\text { Puntaje } \\
\text { de } \\
(0-10)\end{array}$ & $\begin{array}{c}\text { Resultad } \\
\quad\end{array}$ & $\begin{array}{l}\text { Puntaje } \\
\text { de } \\
(0-10)\end{array}$ & Resultado \\
\hline 1 & $\begin{array}{l}\text { Disponibilida } \\
\text { d de materia } \\
\text { prima }\end{array}$ & 0.3 & 8 & 2.40 & 8 & 2.40 & 8 & 2.40 & 8 & 2.40 & 9 & 2.70 & 8 & 2.40 & 7 & 2.10 & 7 & 2.10 & 5 & 1.50 & 5 & 1.50 \\
\hline 2 & $\begin{array}{l}\text { Disponibilida } \\
\text { d de mano de } \\
\text { obra }\end{array}$ & 0.2 & 7 & 1.40 & 7 & 1.40 & 7 & 1.40 & 7 & 1.40 & 8 & 1.60 & 6 & 1.20 & 5 & 1.00 & 6 & 1.20 & 6 & 1.20 & 6 & 1.20 \\
\hline 3 & $\begin{array}{l}\text { Costo de los } \\
\text { insumos }\end{array}$ & 0.15 & 7 & 1.05 & 7 & 1.05 & 8 & 1.20 & 5 & 0.75 & 8 & 1.20 & 8 & 1.20 & 6 & 0.90 & 7 & 1.05 & 5 & 0.75 & 5 & 0.75 \\
\hline 4 & Costo de M2 & 0.15 & 5 & 0.75 & 6 & 0.90 & 6 & 0.90 & 5 & 0.75 & 8 & 1.20 & 6 & 0.90 & 6 & 0.90 & 6 & 0.90 & 4 & 0.60 & 4 & 0.60 \\
\hline 5 & $\begin{array}{l}\text { Fácil acceso } \\
\text { del mercado }\end{array}$ & 0.1 & 7 & 0.70 & 8 & 0.80 & 8 & 0.80 & 7 & 0.70 & 7 & 0.70 & 6 & 0.60 & 6 & 0.60 & 7 & 0.70 & 7 & 0.70 & 6 & 0.60 \\
\hline 6 & $\begin{array}{l}\text { Facilidad para } \\
\text { obtención de } \\
\text { permisos y } \\
\text { licencias }\end{array}$ & 0.05 & 8 & 0.40 & 8 & 0.40 & 8 & 0.40 & 8 & 0.40 & 8 & 0.40 & 8 & 0.40 & 8 & 0.40 & 8 & 0.40 & 8 & 0.40 & 8 & 0.40 \\
\hline 7 & Tipo de clima & 0.05 & 6 & 0.30 & 7 & 0.35 & 6 & 0.30 & 6 & 0.30 & 7 & 0.35 & 7 & 0.35 & 6 & 0.30 & 6 & 0.30 & 6 & 0.30 & 5 & 0.25 \\
\hline & Total & 1.00 & & 6.30 & & 6.55 & & 6.70 & & 6.00 & & 7.40 & & 7.05 & & 6.20 & & 6.65 & & 5.45 & & 5.30 \\
\hline
\end{tabular}


Luego de seleccionar la ubicación de de mayor puntaje, dio como resultado el distrito de Lince con 7.40, teniendo el puntaje más alto dentro de los 10 distritos pertenecientes a la zona 6 y 7 , ver tabla 112 .

Se buscó locales dentro del distrito de Lince, seleccionando tres de los cuales se realizó el estudio de Microlocalización.

Local 1

Ubicación: Av. Arenales

Precio: S/ 18,826

Datos principales:

- Local Comercial

- Área total: $514 \mathrm{~m} 2$

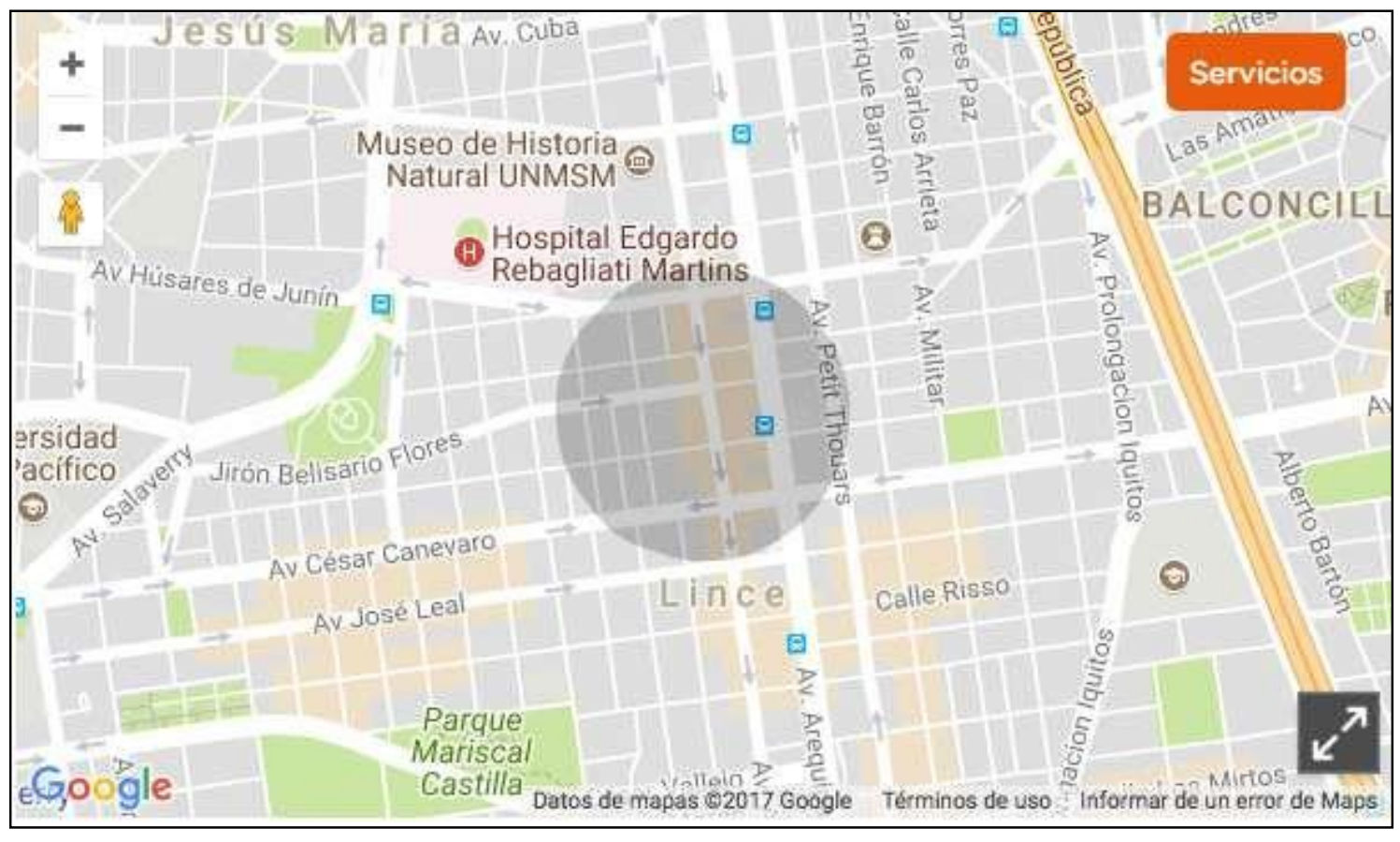


Local 2

Ubicación: Teodoro Cárdenas

Entre la Av. Arequipa y Petit Thouars

Precio: S/ 16,500

Datos principales:

- Local Comercial

- Área total: 400 m2

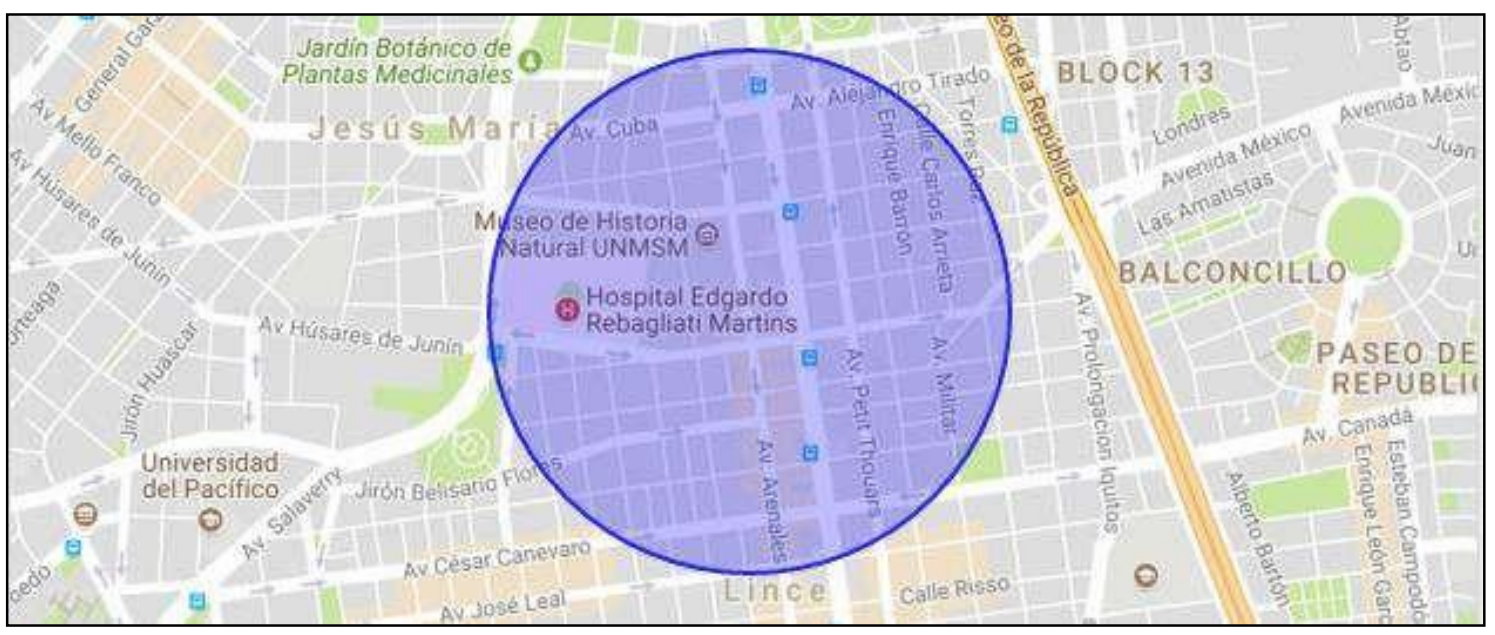

Local 3

Ubicación: Av. PetitThouars

Cuadra 15

Precio: S/ 12,882

Datos principales:

- Local Comercial

- Área total: 400 m2 


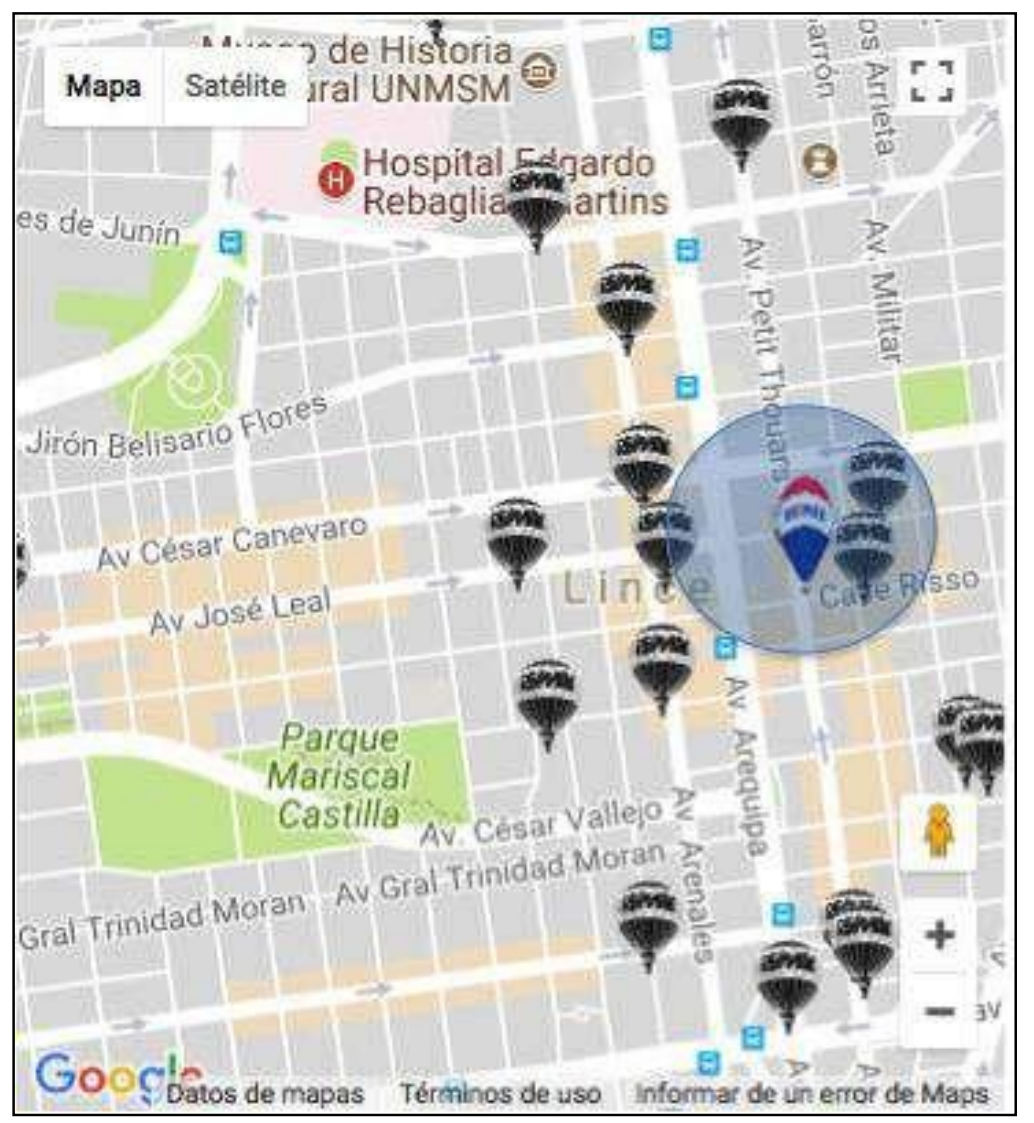

Ver detalle de microlocalización en la tabla 113.

Tabla 113

Microlocalización

Local 1 - $\quad$ Local 2 Local 3 -

Av. Arenales Teodoro Cardenas Av. Petit Thouars

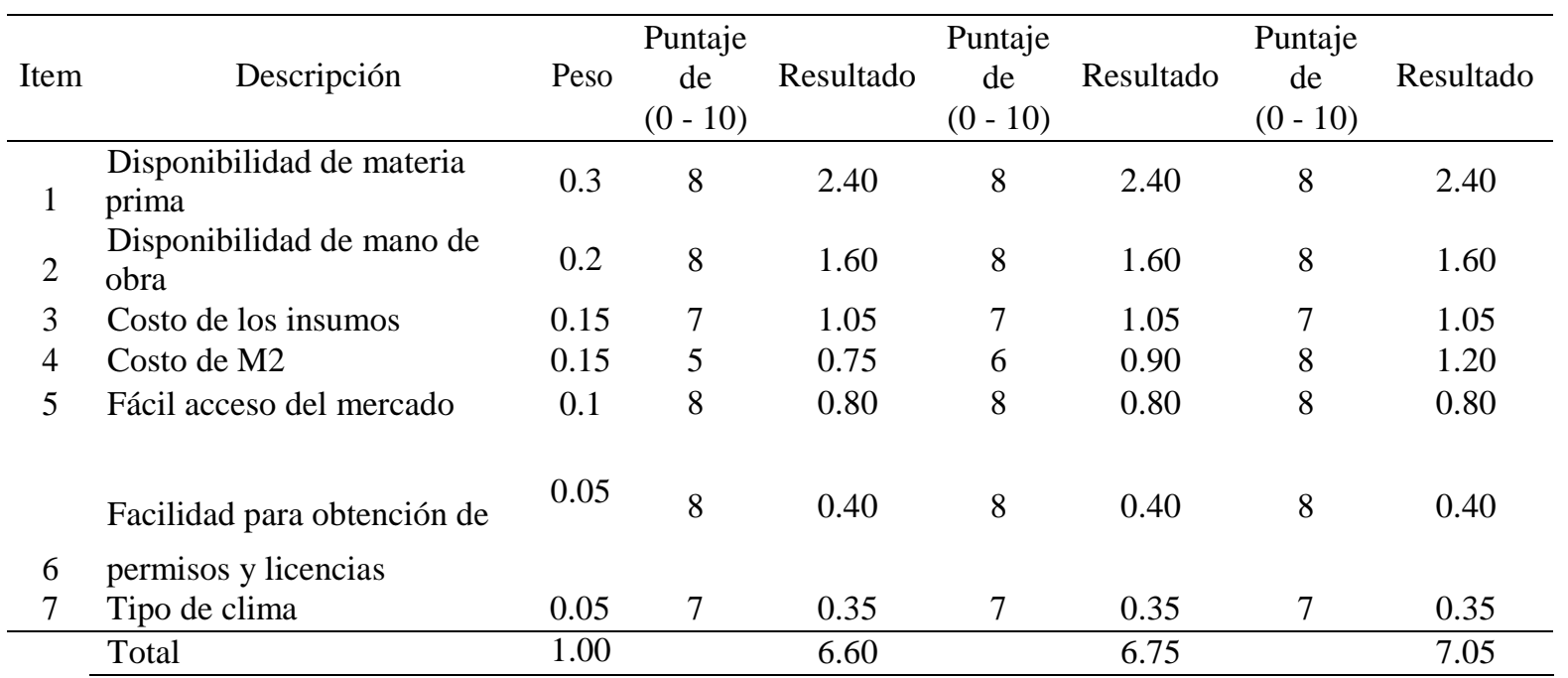




\subsubsection{Definición de factores locacionales.}

- Concentración de la población objetivo: La planta de producción deberá ubicarse en un punto medio entre la zona 6 y zona 7 para que facilite su distribución a los establecimientos.

- Cercanía con insumos: Se decidió que la ubicación deberá ser cerca de los lugares de venta de insumos, ya que al tratarse de frutas, estas deben conservarse lo mejor posible para el traslado a la planta, a su vez ahorrar tiempo y mermas debido a los golpes o movimientos bruscos sufridos en la movilización.

- Tamaño de local: Se consideró un local pequeño, ya que al ser una empresa MYPE, inicialmente la producción no será masiva ni las maquinarias serán muy grandes, a fin de que las maquinas tengan espacio suficiente como para trabajar.

- Seguridad: Se tomó en cuenta la zona de localización de la planta, con la finalidad de encontrar un lugar seguro interna y externamente para realizar el despacho y la producción de manera segura, para así evitar cualquier tipo de robos y asaltos.

\subsubsection{Consideraciones legales.}

\subsubsection{Identificación del marco legal.}

Para el funcionamiento de la planta de producción de macerados de frutas en pisco, se averiguó que se debería proceder con los siguientes trámites administrativos.

- Empresa legal de Responsabilidad Limitada.

- Licencia de la Municipalidad Distrital de Lince para el funcionamiento, se debe obtener la autorización de la Municipalidad con el fin de desarrollar una actividad comercial. El área encargada del trámite es la Sub Gerencia de Registro, Licencia y Orientación Tributaria.

- Se debe tomar en cuenta que la licencia de funcionamiento se encuentra ligada al cumplimiento de las condiciones técnicas de seguridad establecidas por INDECI 
(Instituto Nacional de Defensa Civil), la cual tiene una vigencia de certificación de Defensa Civil por un periodo de dos años.

- Se deberá registrar la marca ante INDECOPI.

- El producto deberá contar conr un Registro Sanitario del producto (DIGESA) por cada sabor que se produzca. Se deberá aprobar la "Norma Sanitaria para la Fabricación de Alimentos a base de granos y otros, destinados a Programas Sociales de Alimentación".

La Autoridad Sanitaria Municipal, realiza una verificación del cumplimiento de la norma sanitaria, con el fin de:

- Verificar que el establecimiento cuente con la calidad sanitaria e inocuidad correcta para los alimentos para el consumo.

- Verificar los requisitos sanitarios operativos y las buenas prácticas de manipulación con los productos al laborar con estos insumos.

- Verificar las condiciones higiénicas sanitarias y de infraestructura mínima que debe cumplir el establecimiento.

\subsubsection{Ordenamiento jurídico de la empresa.}

\section{Forma Societaria}

Nombre de la empresa: "Hechizo"

La razón social escogida para la empresa fue : Hechizo S.A.C., se ha decidió trabajar con este tipo de sociedad por las principales características de una Sociedad Anónima Cerrada, la cual se encuentra regulada por la Ley General de Sociedades 26887 y de acuerdo al artículo 234 .

Las razones por las que se eligió la constitución bajo los parámetros de Sociedad Anomia Cerrada son las siguientes:

- $\quad$ No tiene más de 20 accionistas 
- $\quad$ No tiene acciones inscritas en el Registro Público del mercado de valores

- $\quad$ No se puede solicitar la inscripción en dicho registro de las acciones de una sociedad anónima cerrada

- $\quad$ Que una SAC tenga como máximo 20 accionistas no implica que se vea afectada la posibilidad de manejar grandes capitales.

De acuerdo a lo citado por el artículo 234, la constitución de la empresa sería realizada por los 3 socios fundadores, quienes suscribirán y pagarán íntegramente las acciones al momento de otorgar la escritura pública, de acuerdo al siguiente detalle en tabla 114.

Tabla 114

División de las acciones

\begin{tabular}{lcc} 
& Accionistas & Participación \\
\hline Carlos Briceño & $33.33 \%$ \\
Guiselle Jiménez & $33.33 \%$ \\
Joselyn Tello & $33.34 \%$ \\
\hline
\end{tabular}

Procedimiento de la Constitución:

Para constituir Hechizo S.A.C. básicamente se requirió:

1. Tramitar el Certificado de Búsqueda Mercantil en la Oficina de Registros Públicos de Lima y Callao a fin de verificar si existe o no otra empresa con la misma denominación.

2. Elaborar la Minuta (2 juegos) de acuerdo al modelo proporcionado y presentarla a la Oficina de Asesoramiento, adjuntando el Certificado de Búsqueda Mercantil y copia simple del DNI de los socios y/o accionistas titulares y cónyuges en el caso de ser casados.

3. Si el aporte de capital es en bienes, los cónyuges de los socios y/o accionistas deberán firmar el proyecto de Minuta. 
4. Si el aporte de capital o parte del mismo es en efectivo, depositar dicho monto en una Cuenta Corriente a nombre de la empresa, en el Banco de su preferencia. Entregar el comprobante de depósito en la Oficina de Asesoramiento a fin de adjuntarla. Luego la Minuta será remitida al Notario público, esta se encargada de elevar la Minuta a Escritura Pública y derivarla a la Oficina de Registros Públicos, previo pago de los derechos Notariales y Regístrales correspondientes.

5. Obtener el número de Ruc de la empresa; se deberá llevar la escritura, copia simple del DNI del representante legal y recibo de luz y agua del local donde va a funcionar la empresa a la SUNAT. Nuestra empresa se acogerá será al REGIMEN ESPECIAL DEL IMPUESTO A LA RENTA.

6. Solicitar a la Municipalidad la autorización de funcionamiento o apertura de establecimiento bajo la denominación de Licencia de Funcionamiento ya sea permanente o provisional.

Registro de marcas y patentes.

Marcas

La marca "Hechizo" debe ser tramitada en la Dirección de Signos Distintivos del Instituto Nacional de Defensa al Consumidor y a la Propiedad Intelectual (INDECOPI). Para realizar estos los registros se debe solicitar la siguiente búsqueda:

- Servicio de búsqueda de antecedentes fonéticos.

- Servicio de búsqueda de antecedentes figurativos.

El registro tiene una vigencia de 10 años, renovables por períodos iguales. La duración del trámite de registro es de 120 días aproximadamente que abarca desde la presentación de la solicitud en INDECOPI hasta la expedición del Certificado o Título de Propiedad), siempre y cuando no existan oposiciones por parte de terceros. La solicitud de 
registro o depósito en INDECOPI se obtiene el derecho de prioridad, la expedición de este documento demora 24 horas.

Los requisitos para la inscripción de la marca son los siguientes:

1. Presentar tres ejemplares del formato de la solicitud correspondiente (uno de los cuales servirá de cargo). Se debe indicar los datos de identificación del solicitante (incluyendo su domicilio para que se le remitan las notificaciones).

2. En caso de contar con un representante, se deberá indicar sus datos de identificación y su domicilio será considerado para efecto de las notificaciones. Consecuentemente, será obligatorio adjuntar los poderes* correspondientes.

3. Indicar cuál es el signo que se pretende registrar. Si éste posee elementos gráficos, se deberá adjuntar su reproducción (tres copias de aproximadamente $5 \mathrm{~cm}$ de largo y $5 \mathrm{~cm}$ de ancho y a colores, si se desea proteger los colores).

4. Determinar expresamente cuáles son los productos, servicios o actividades económicas que se desea registrar, así como la clase o clases a la que pertenecen (Clasificación de Niza).

5. En caso de tratarse de una solicitud multiclase, los productos o servicios se deben indicar agrupados por clase, precedidos por el número de clase correspondiente y en el orden estipulado por la Clasificación de Niza.

6. De ser necesario, se deberá manifestar la prioridad que se reivindica. En esta situación particular, se adjuntará la copia de la solicitud cuya prioridad se invoca, certificada por la autoridad que la expidió, de ser el caso, traducida al español.

7. Adjuntar la constancia de pago del derecho de trámite, cuyo costo es equivalente al $14.46 \%$ de la Unidad Impositiva Tributaria (UIT) por una clase solicitada. El monto (S/. 534.99 nuevos soles) se cancelará en la Caja del INDECOPI. Por cada 
clase adicional, el pago del derecho de trámite será de S/. 533.30, cuyo costo es equivalente al $14.46 \%$ de la Unidad Impositiva Tributaria (UIT).

Patentes

La empresa HECHIZO S.A.C no registrará la patente del producto debido a que es un producto ya existente en el mercado.

Licencias y autorizaciones.

Las licencias que Hechizo S.A.C. deberá obtener para el funcionamiento de la planta son los siguientes:

1. Licencia SUNARP

2. Licencia SUNAT

3. Licencia de Funcionamiento de la Municipalidad de Lince.

4. Licencia Ministerio de Trabajo y Promoción del Empleo - MINTRA

5. Autorización Municipal de apertura de establecimiento.

6. Autorización de libro de planillas en el Ministerio de Trabajo y Promoción del Empleado (MTPE).

7. Certificado de seguridad en Defensa Civil.

8. Registro patronal (ESSALUD).

9. Registro de empleador.

10. Legalización de libros contables.

Legislación Laboral

Hechizo S.A.C. se encuentra dentro del Régimen de la Ley General de Sociedades. Dentro de las características que establece este régimen :

- La modalidad de contratación de los empleados: contrato de necesidades de mercado que da como máximo la contratación hasta de 5 años del trabajador. 
- $\quad$ El trabajador está sujeto a 3 meses de prueba pudiendo el empleador rescindir el contrato durante estos meses. En esta modalidad de contrato esta versado el decreto legislativo No 728 aprobado por D.S N 003-97-TR-ley de la productividad y la competitividad laboral. Dicho contrato será por un periodo de 6 meses, será renovado si la empresa lo desea o en caso contrario prescindir de los servicios del trabajador .

- $\quad$ Legislación laboral vigente: los trabajadores que percibirán adicionalmente a la remuneración mensual establecida por contrato las siguientes partidas:

De la empresa

Aportes:

- Gratificaciones legales: Julio y Diciembre

- $\quad$ Compensación por tiempo de servicios (CTS)

- $\quad$ Seguro Social de Salud

- Descanso vacacional de 30 días calendario por año de servicio.

- $\quad$ Seguro Complementario de trabajo de riesgo.

Del Trabajador

Aportes:

AFP (Administradora de Fondo de Pensiones), aportará lo siguiente:

- $\quad 10.00 \%$ aporte obligatorio

- $\quad 1.33 \%$ prima de seguro (promedio entre las AFPs)

- $\quad 1.55 \%$ comisión variable (promedio entre las AFPs)

- $\quad$ SNP (Sistema Nacional de Pensiones) - Si los empleados optan por el SNP tendrán que hacer una aportación del 13\% de su remuneración asegurable.

- $\quad$ Pago de utilidades a los trabajadores. El pago de utilidades a los trabajadores. 
Legislación Tributaria

Hechizo S. A.C. se acogerá a las siguientes legislaciones tributarias:

Impuesto a la Renta: Regimen MYPE Tributario.

Reglamentado bajo el Decreto Legislativo 1261 Artículo 5, en el que define la tasa, que determinará aplicando a la renta neta anual en una escala progresiva acumulativa de acuerdo al siguiente detalle :

Renta neta Anual Tasas

Hasta 15 UIT $\quad 10 \%$

Más de 15 UIT $\quad 29,50 \%$

Impuesto General a las Ventas (IGV) .

El impuesto a pagar se determina mensualmente deduciendo el impuesto calculado sobre las ventas del periodo menos el total del impuesto pagado en las compras.

La tasa del impuesto es del $16 \%$ adicionalmente se aplica el $2 \%$ que corresponde al impuesto de promoción municipal, lo que hace un total del $18 \%$.

El impuesto debe estar en forma discriminada para que permita la utilización del crédito fiscal. (Base Legal: D.S. No055-99-EF).

\subsection{Determinación de la localización óptima}

Luego de haber realizado el análisis de Macrolocalización y Microlocalización, se determinó que el local se ubicaría en el distrito de Lince, ubicado en Av. PetitThouars, el cual es un lugar comercial de fácil acceso y céntrico. 


\section{Capítulo VI. Aspectos organizacionales}

El contenido de este capítulo muestrael desarrollo de la organización de manera interna. Para evidenciar esto se detalló la jerarquía, el requerimiento de personal y los principales aspectos que debieron cumplir todos los empleadores de la empresa y se mostró el organigrama.

Para los aspectos organizacionales se utilizó la información recabada de las entrevistas de profundidad hechas a los dueños y Gerentes de bodegas de Pisco Sarcay y Bailetti (Ver tabla 23), productores artesanales de macerados de pisco en fruta Eddu’s y Foodies (Ver tabla 21), sommelier para la mezcla de sabores (Ver tabla 24), de esa manera se logró tomar las decisiones que más convenían para la realización del proyecto (Ver anexos \# $6,7,9,10$ y 11).

\subsection{Caracterización de la cultura organizacional deseada}

Según David (2013), la cultura organizacional es un proceso establecido de comportamiento por parte de las organizaciones, que ha sido desarrollado a medida que ha superado problemas externos e internos. Estos procesos son registrados y transmitidos cada vez que ingresa un nuevo miembro a la organización. Esta cultura organizacional es muy fuerte en cuanto al cambio se trata y es el principal factor para las fortalezas y debilidades de la organización.

\subsubsection{Visión.}

Para David (2013), la visión se define como una expresión que busca responder ¿en qué se quiere convertir la empresa? En un largo plazo. 
Tabla 115

Visión

\begin{tabular}{ll}
\hline \multicolumn{1}{c}{ Preguntas Clave } & \multicolumn{1}{c}{ Propuesta } \\
\hline $\begin{array}{l}\text { 1.- ¿Hacia dónde nos dirigimos? } \\
\text { 2.- ¿Qué cosas nuevas pretendemos buscar? }\end{array}$ & Público que consume pisco \\
& Innovación en nuevos sabores \\
$\begin{array}{l}\text { 3.- ¿Cuál será nuestro modelo de negocio } \\
\text { en los próximos cinco años? }\end{array}$ & Enfocado al cliente \\
$\begin{array}{l}\text { 4.- ¿En qué clase de organización } \\
\text { queremos convertirnos? }\end{array}$ & Enfocado a diferenciación \\
$\begin{array}{l}\text { 5.- ¿Cuál es la posición que pretendemos } \\
\text { lograr dentro de cinco años? }\end{array}$ & $\begin{array}{l}\text { Aumentar la participación de mercado y } \\
\text { como resultado posicionar la marca }\end{array}$ \\
\hline
\end{tabular}

Al 2022, ser reconocidos en el mercado peruano como una empresa líder en la producción y venta de macerados de frutas en pisco, ver tabla 115.

\subsubsection{Misión.}

Según David (2013), la misión representa una filosofía perpetua en el tiempo que expresa la razón de ser la organización y que a la vez la distingue de otras similares en la industria, tabla 116.

Tabla 116

Misión

\begin{tabular}{lc}
\hline \multicolumn{1}{c}{ Componentes } & $\begin{array}{c}\text { ¿Se identifica el } \\
\text { componente en la misión? }\end{array}$ \\
\hline 1.- Clientes & $\mathrm{Si}$ \\
2.- Producto o servicio & $\mathrm{Si}$ \\
3.- Mercado & $\mathrm{Si}$ \\
4.-Tecnología & $\mathrm{No}$ \\
5.-Filosofía & $\mathrm{Si}$ \\
6.- Preocupación por la supervivencia, crecimiento y & $\mathrm{Si}$ \\
$\quad$ rentabilidad & $\mathrm{Si}$ \\
7.- Auto concepto (ventaja competitiva) & $\mathrm{No}$ \\
8.- Preocupación por la imagen pública & $\mathrm{Si}$ \\
9.- Preocupación por los empleados & \\
\hline
\end{tabular}

Ser la empresa líder en la producción de macerados de frutas en pisco, ofreciendo productos de alta calidad y sabores innovadores para lograr el equilibrio perfecto en los macerados. 


\subsubsection{Principios.}

Este punto es considerado de importancia para el buen gobierno corporativo, por tal motivo se consideran estos como los más importantes:

- Compromiso

Difundir la visión y misión de la empresa para lograr que todos los colaboradores se integren a la filosofía plantada y con ello seguir el camino para poder lograr los objetivos y metas.

- Calidad.

Crear, difundir y aplicar la filosofía para lograr y mantener la calidad en toda la cadena de suministro. La calidad debe aplicarse a todos los implicados en la cadena de suministro, desde proveedores, distribuidores, proceso de producción hasta el servicio postventa.

- Mejora continua.

Nada es eterno, por lo tanto la mejora continua debe aplicar a cada proceso y aspecto de la empresa para seguir optimizando el mejor funcionamiento de la misma.

- Orientado al cliente (Buscar siempre la satisfacción del cliente, como eje del negocio).

Buscar siempre la satisfacción del cliente, como eje del negocio. Todos los esfuerzos y procesos que realice la empresa deben tener como objetivo principal la satisfacción del cliente porque es quien definirá si el producto tendrá éxito o no.

- Integridad

Todas las personas en la empresa deben realizar sus actividades con mucha integridad, desde la compra de insumos hasta la venta y atención al cliente, se debe aplicar el criterio de transparencia para crear un ambiente de confianza en la empresa. 
- Trabajo en equipo

El motor de la empresa es su gente y esto debe estar presente en cada uno de los miembros. Se deben realizar todos los esfuerzos para incentivar y lograr el trabajo en equipo porque un grupo consolidado es una fuerza que puede alcanzar los objetivos.

\subsection{Formulación de Estrategias del Negocio}

Según David (2013), la estrategia de enfoque consiste en presentar productos y servicios que satisfagan las necesidades de un grupo de pequeños consumidores. Dentro de esta estrategia, existen 2 alternativas de enfoque: el tipo cuatro y cinco. En el caso de la estrategia de tipo cinco, esta hace referencia a un enfoque en el mejor valor, es decir, ofrecer productos y servicios a nichos de clientes al mejor precio existente en el mercado. Esta estrategia es mejor conocida como diferenciación enfocada. En la tabla 117 se muestra la distribución de las estrategias de Michael Porter.

Tabla 117

Estrategias de Negocio

\begin{tabular}{|c|c|c|c|}
\hline 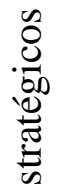 & $\begin{array}{l}\cdot \stackrel{\Xi}{\Xi} \\
\stackrel{\Xi}{\Xi} \\
\stackrel{\Xi}{\Xi}\end{array}$ & Diferenciación & Liderazgo en costos \\
\hline$\frac{0_{0}^{\infty}}{\frac{0}{0}}$ & 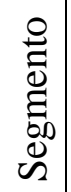 & $\begin{array}{c}\text { Segmentación enfocada a un } \\
\text { segmento }\end{array}$ & $\begin{array}{l}\text { Segmentación con enfoque en costos } \\
\text { bajos }\end{array}$ \\
\hline & & \multicolumn{2}{|c|}{ Ventaja Estratégica } \\
\hline
\end{tabular}

La elección de esta estrategia se sustenta en el mercado seleccionado para ofrecer el producto. La industria de macerados de frutas en pisco es por el momento muy artesanal y son muy pocas las empresas formales que están en el mercado y que a su vez no muestran grandes volúmenes de producción y ventas. Luego de realizar los estudios de mercado se obtuvo información sobre los consumidores de macerados de frutas en pisco y se concluyó 
que estos tienen poder adquisitivo, acceso a la oferta y privilegian la calidad antes que el precio.

Como objetivos estratégicos para los siguientes cinco años 2018- 2022, se propone:

- Incrementar la participación en el mercado en un 4\% anual, logrando que los clientes reconozcan la marca HECHIZO, macerados de frutas en pisco.

- Lograr la excelencia en la gestión operativa.

Para lograr estos objetivos, se planea implementar las siguientes estrategias.Si el objetivo es ser líderes en el mercado de macerados de fruta en pisco, definiendo valores y atributos que diferencien a HECHIZO, pero alineados a los principios estratégicos, como son:

1. Innovación y agregación de valor (Negocio)

2. Flexibilidad y calidad (Procesos)

3. Liderazgo, motivación y respeto (Personas)

Para poder lograr la estrategia de incrementar la participación en el mercado, es necesario que en el proceso de producción este guiado por estándares de calidad y especialmente, el soporte del capital humano como socio estratégico para el logro.

- Negocios

Incrementar la aceptación del producto a través del posicionamiento en clientes, productos y proveedores.

- Procesos

Gestionar de manera eficiente para lograr los más altos estándares de calidad.

- Personas

Considerando que son socios de la organización, motivar aplicando buenas prácticas sociales en recursos humanos, ver tabla 118. 
Tabla 118

Palancas de acción

\begin{tabular}{lll}
\hline \multicolumn{1}{c}{ Negocio } & \multicolumn{1}{c}{ Procesos } & \multicolumn{1}{c}{ Personas } \\
\hline Posicionar la marca. & $\begin{array}{l}\text { Obtener y mantener } \\
\text { certificaciones de calidad. }\end{array}$ & $\begin{array}{l}\text { Implementar la gestión de } \\
\text { indicadores }\end{array}$ \\
$\begin{array}{l}\text { Establecer alianzas estratégicas } \\
\text { con los canales de distribución. }\end{array}$ & $\begin{array}{l}\text { Mantener el factor } \\
\text { diferenciador que es la } \\
\text { producción industrial del } \\
\text { producto, pero sin perder el } \\
\text { cetalle de artesanal. }\end{array}$ & $\begin{array}{l}\text { Gestionarador la responsabilidad } \\
\text { social interna a través del }\end{array}$ \\
$\begin{array}{ll}\text { Incrementar las ventas. } \\
\begin{array}{l}\text { Establecer alianzas estratégicas } \\
\text { con la cadena de suministros. }\end{array}\end{array}$ & ejemplo \\
\hline
\end{tabular}

\subsection{Determinación de las ventajas competitivas críticas}

Como determina David (2013), la ventaja competitiva está representada como algo que la empresa hace muy bien en comparación con las otras empresas del rubro. Esto que la empresa hace bien puede ser representado como optimización en costos, producción a escala o respaldo financiero.

Para Alonso (2010), los factores claves de éxito están determinados por eventos en donde el éxito da como resultado un rendimiento competitivo. Afirma que estos factores se relacionan con la relación logro de la visión, misión y de los objetivos que tiene la organización a largo plazo. Estos componentes claves dice que pueden ser internos (habilidades, recursos, atributos) y también otros que tienen que ver con el entorno externo.

Por lo tanto, estas ventajas como tales pueden ser medidas y evaluadas, según su rendimiento.

Tomando en cuenta que los FCE de la industria son la promoción, producción a escalaa menores costos y la distribución. Para poder competir con empresas que están posicionadas en el mercado por ejemplo del tamaño de Cartavio. Seconsideró contratar a un Gerente de Marketing para aplique una estrategia de promoción y distribución del producto de manera que se pueda ser competitivo y lograr ser sostenible en el mercado. La estrategia 
de promoción está planteada como debajo de la línea. Pero la idea fue aplicarla de manera que los consumidores nos identifiquen. Se analizó entrar en co-branding con alguna empresa productora de pisco que ya esté posicionada y así poder ingresar y la Inversión en promoción y distribución compartirla con los asociados.

De todas formas se ha hecho una evaluación de factores internos, una simulación de cómo se encontraría HECHIZO, para poder enfrentar a la industria, ver tabla 119.

Tabla 119

Matriz de evaluación de factores internos

Factores Clave

\section{Fortalezas}

1 Flexibilidad y adaptabilidad a los requerimientos de los clientes Optimo uso de recursos mediante la adaptación de la

2 metodología Lean

3 Alto nivel de rotación de inventario

4 On Time Delivery (OTD) por encima del 90\%

5 Elevado poder de negociación

Debilidades

6 Baja Inversión en publicidad

7 Demora en pago a proveedores

8 Falta de planificación por parte de ventas

9 Demora en la recepción de mercadería

10 Proceso para obtener aprobaciones muy lento

Ponderación Clasificación Puntuación

0.10

3

0.30

0.07

0.10

0.20

0.18

4

0.28

0.30

0.80

0.18

0.05

0.10

0.09

0.18

0.08

0.08

0.06

0.12

0.07

1.00

0.07

2.41

El promedio es bajo, sugiere debilidad, esto debido a que como el estudio demuestra el ingresar a esta industria requiere de mucha promoción para poder competir como empresas más grandes.

\subsection{Diseño de la estructura organizacional deseada.}

Según Franklin (2009), todas las empresas además de su naturaleza o industria necesitan de un ámbito de acción. Este ámbito lo representa la estructura organizacional, que en resumen es la segmentación ordenada de las unidades de trabajo de la empresa con sustento en las estrategias planteadas. 
Al ser una pequeña empresa se optó por implementar un organigrama funcional para expresar de manera gráfica la estructura de la organización, los niveles de jerarquía y de coordinación, ver figura 12 .

De esa manera los cargos serán ocupados por el personal idóneo, capaz de desarrollarse en el área que maneja. Se muestran las principales funciones de cada persona y las interrelaciones que puedan tener. Se determinó que la comunicación será directa, al no tener una línea grande de intermediarios, se pretende que no se encuentre ruidos en esta de manera que sea eficiente. 


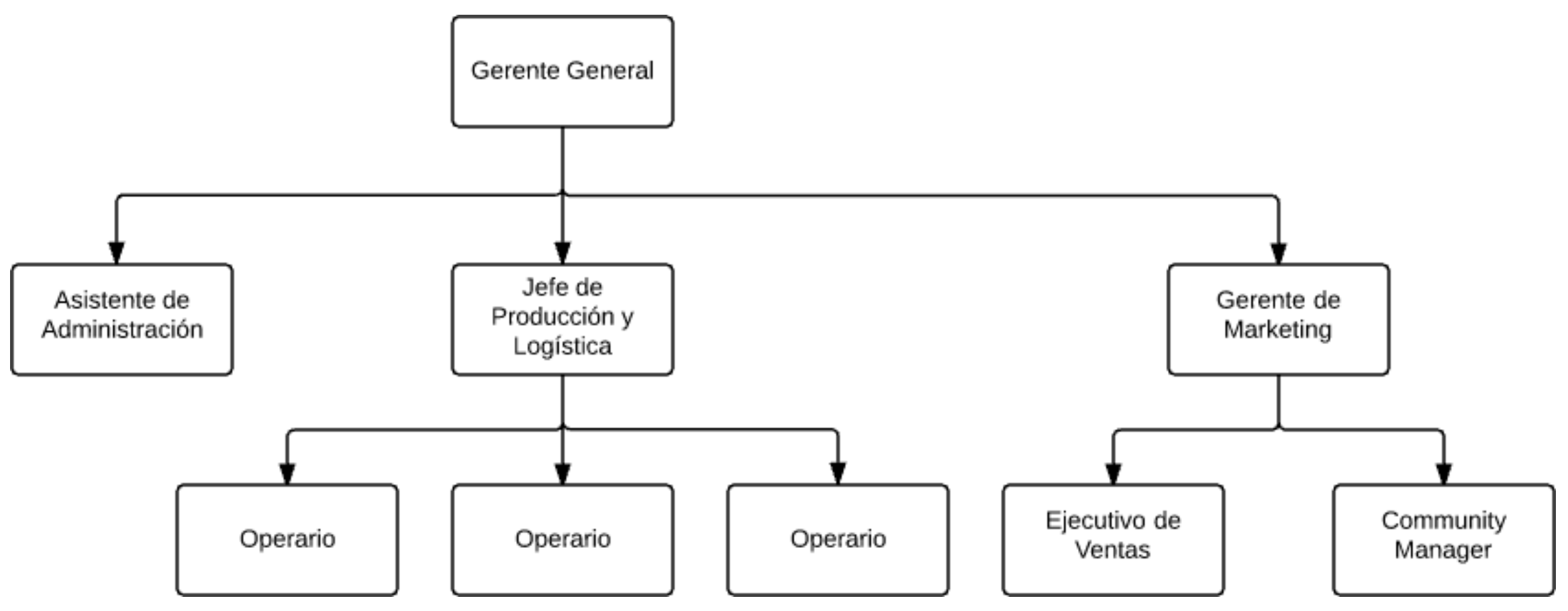

Figura 12. Organigrama de la Empresa 


\subsection{Diseño de los perfiles de puestos clave}

Como indica Chiavenato (2011), el diseñar el perfil de puesto considera cuatro requisitos fundamentales, el contenido del puesto, que está integrado por todas las tareas y obligaciones que desempeñará el trabajador. Los procedimientos de trabajo, que explica el cómo realizar las tareas y obligaciones. La responsabilidad, en donde se indica a quien reporta el trabajador, jefe directo y por último la autoridad, que indica si el trabajador supervisa a otra persona en la empresa, estos pueden ser subordinados, ver tabla 120.

Tabla 120

Requerimiento de personal

\begin{tabular}{|c|c|c|c|}
\hline \multirow{4}{*}{$\begin{array}{l}\text { Operarios de } \\
\text { Producción }\end{array}$} & Puesto & Req. & Proceso \\
\hline & Jefe de Producción y Logística & 1 & Producción \\
\hline & Operarios de producción & 2 & Lavado - Secado - Macerado - Embalaje \\
\hline & Operarios de maquinaria & 1 & Filtrado Embotellado \\
\hline \multicolumn{2}{|c|}{ Total Requerimiento personal } & 4 & \\
\hline \multirow{7}{*}{$\begin{array}{l}\text { Personal } \\
\text { Administrativo }\end{array}$} & Puesto & Req. & Proceso \\
\hline & Gerente General & 1 & Control de la Planta \\
\hline & Gerente de Marketing & 1 & Promoción y Ventas \\
\hline & Asistente Administrativo & 1 & Tareas varias \\
\hline & Jefe de Ventas & 1 & Logística y Administración \\
\hline & Community Manager & 1 & Ventas web \\
\hline & Ejecutivo de Ventas & 1 & Ventas otros canales \\
\hline \multicolumn{2}{|c|}{ Total Requerimiento personal } & 6 & \\
\hline
\end{tabular}


Fecha : 2/11/17

\begin{tabular}{ll}
\hline \multicolumn{2}{c}{ PERFIL DE PUESTO } \\
\hline 1. IDENTIFICACION DEL PUESTO & \\
\hline Nombre del Puesto & Gerente General \\
Unidad & Administración \\
Gerencia & Gerencia General \\
Reporta & \\
Supervisa a & Gerente de Finanzas y Administracion, Gerente Comercial \\
\hline 2. OBJETO GENERAL DEL CARGO & \\
\hline
\end{tabular}

Garantizar que la empresa funcione de forma operativa y de la adecuada gestión administrativa, así como velar por los recursos humanos.

3. FUNCIONES PRINCIPALES

Plantear y determinar el rumbo del negocio.

Dirigir la empresa hacia los objetivos planteados.

Realizar propuestas a la junta de socios sobre políticas

adecuadas.

Controlar y analizar los estados financieros de la empresa.

Establecer relaciones de la empresa con los clientes.

Controlar y supervisar la acción de todas las áreas de la empresa.

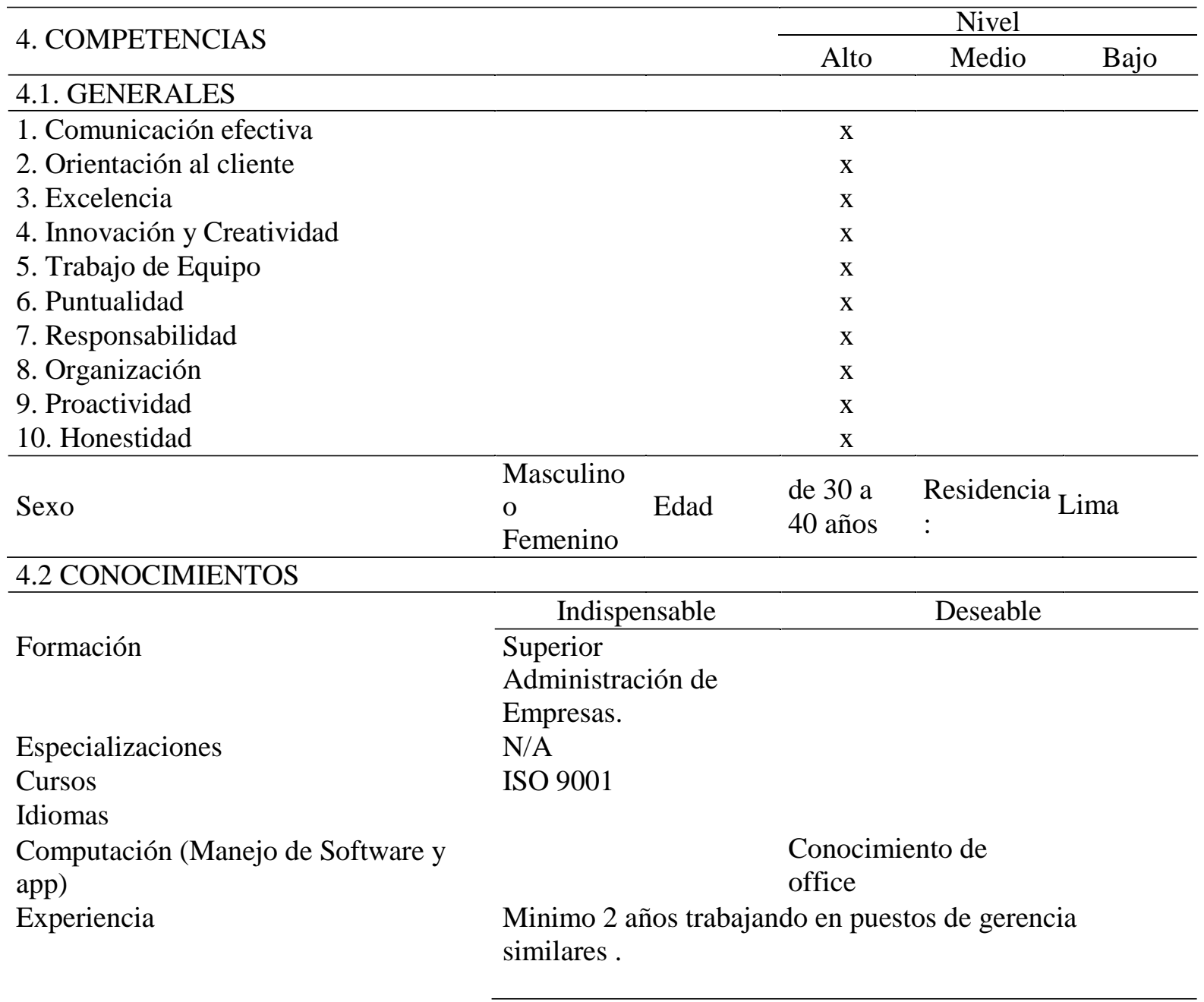


6. CONDICIONES

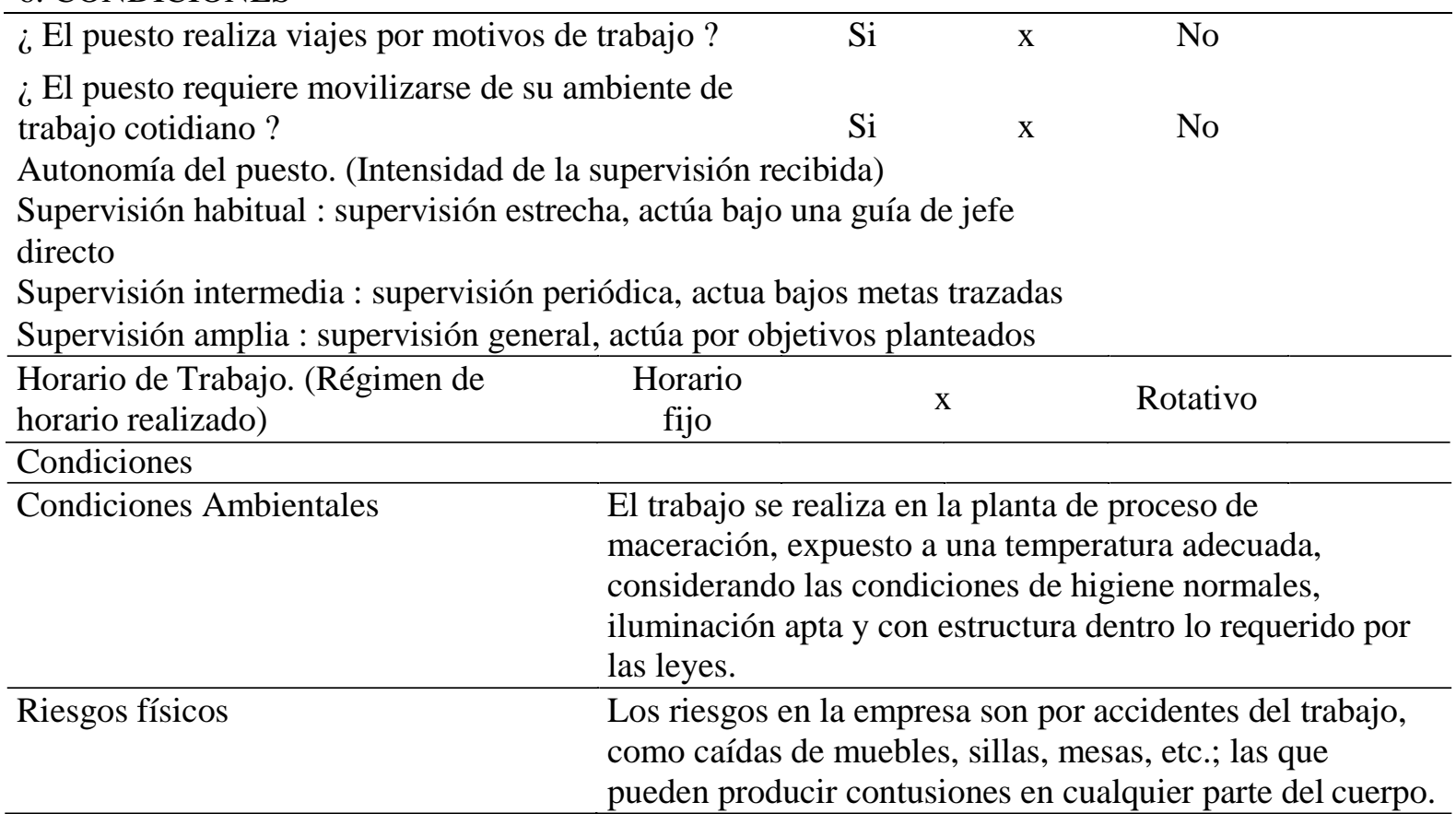


Fecha : $\quad 2 / 11 / 17$

\begin{tabular}{ll}
\hline & PERFIL DE PUESTO \\
\hline 1. IDENTIFICACION DEL PUESTO & Gerente Marketing \\
\hline Nombre del Puesto & Administración \\
Unidad & Gerencia Comecial \\
Gerencia & Gerente General \\
Reporta & Community Manager, Personal de ventas, asistente \\
Supervisa a & admnistrativo. \\
\hline 2. OBJETO GENERAL DEL CARGO
\end{tabular}

Garantizar que el funcionamiento comercial, las ventas, las relaciones con los clientes sean las mejores para obtener rentabilidad.

3. FUNCIONES PRINCIPALES

Realizar el presupuesto anual.

Planificar las tareas y acciones de los comerciales.

Alinear la política dictada y buscar la manera de que se alcancen las metas y objetivos propuestos. Supervisar las tareas de trabajo del personal de ventas, implementar sistemas de indicadores que reflejen total de ventas y metas.

Medir el potencial de los clientes

Fijar precios, definir políticas de descuentos y bonificaciones.

Hacer caso y ejecutar todas las tareas adicionales que sean asignadas por su superior o por la compañía.

\begin{tabular}{|c|c|c|c|}
\hline \multirow{2}{*}{ 4. COMPETENCIAS } & & \multicolumn{2}{|r|}{ Nivel } \\
\hline & & Alto & Medio \\
\hline \multicolumn{4}{|l|}{ 4.1. GENERALES } \\
\hline 1. Comunicación efectiva & & $\mathrm{x}$ & \\
\hline 2. Orientación al cliente & & $\mathrm{x}$ & \\
\hline 3. Excelencia & & $\mathrm{x}$ & \\
\hline 4. Innovación y Creatividad & & $\mathrm{x}$ & \\
\hline 5. Trabajo de Equipo & & $\mathrm{x}$ & \\
\hline 6. Puntualidad & & $\mathrm{x}$ & \\
\hline 7. Responsabilidad & & $\mathrm{x}$ & \\
\hline 8. Organización & & $\mathrm{x}$ & \\
\hline 9. Proactividad & & $\mathrm{x}$ & \\
\hline 10. Honestidad & & $\mathrm{x}$ & \\
\hline Sexo & $\begin{array}{ll}\text { Masculino } & \\
\text { o } & \text { Edad } \\
\text { Femenino } & \\
\end{array}$ & $\begin{array}{l}\text { de } 30 \text { a } 40 \\
\text { años }\end{array}$ & $\begin{array}{l}\text { Residencia Lima } \\
:\end{array}$ \\
\hline \multicolumn{4}{|l|}{ 4.2 CONOCIMIENTOS } \\
\hline \multirow[b]{2}{*}{ Formación } & Indispensable & \multirow{4}{*}{\multicolumn{2}{|c|}{ Conocimiento de office }} \\
\hline & $\begin{array}{l}\text { Superior } \\
\text { Marketing }\end{array}$ & & \\
\hline $\begin{array}{l}\text { Especializaciones } \\
\text { Cursos }\end{array}$ & & & \\
\hline $\begin{array}{l}\text { Idiomas } \\
\text { Computación (Manejo de Software } \\
\text { y app) }\end{array}$ & $\begin{array}{l}\text { Inglés intermedio } \\
\text { Manejo de SAP }\end{array}$ & & \\
\hline
\end{tabular}


Minimo 2 años trabajando en puestos de gerencia similares .

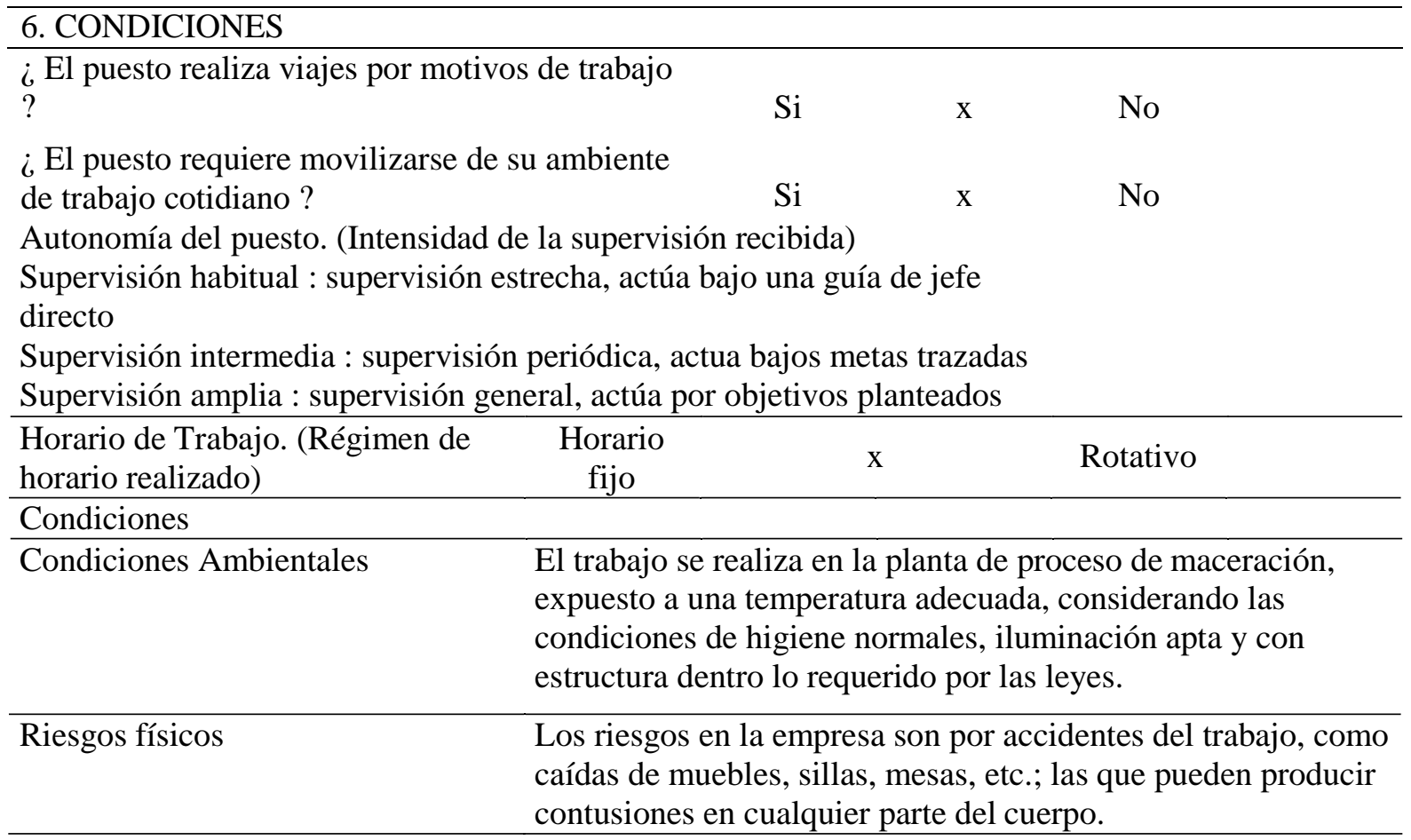


Fecha : $\quad 2 / 11 / 17$

PERFIL DE PUESTO

\begin{tabular}{ll}
\hline 1. IDENTIFICACION DEL PUESTO & \\
\hline Nombre del Puesto & Jefe de Producción y Logística \\
Unidad & Operaciones \\
Gerencia & Gerencia Administración y \\
& Finanzas \\
Reporta & $\begin{array}{l}\text { Gerente de Administración y } \\
\text { Sinanzas }\end{array}$ \\
\hline 2. OBJETO GENERAL DEL CARGO & Almacenero, Operarios de Maquinas, de etiquetado y \\
\hline
\end{tabular}

Garantizar y supervisar todo el proceso productivo para lograr eficiencia y productos que cumplan con los estándares de calidad requeridos.

3. FUNCIONES PRINCIPALES

Supervisar la transformación de los insumos y material de empaque del producto terminado.

Coordinar las tareas del personal que maneja la maquinaria.

Velar por que la maquinaria y equipos funcionen

correctamente.

Ser responsable de los inventarios de insumos, material de empaque y de los productos en proceso .

Supervisar que los colaboradores a su cargo cumplan con sus tareas asignadas.

Ejecutar planes de mejora y procesos.

Realizar controles a la maquinaria y ejecutar planes de mantenimiento y contingencia.

Aplicar y supervisar el cumplimiento de estandares de calidad requeridos.

Hacer caso y ejecutar todas las tareas adicionales que sean asignadas por su superior o por la compañía.

\begin{tabular}{|c|c|c|c|c|}
\hline \multirow{2}{*}{ 4. COMPETENCIAS } & & \multicolumn{3}{|c|}{ Nivel } \\
\hline & & Alto & Medio & Bajo \\
\hline \multicolumn{5}{|l|}{ 4.1. GENERALES } \\
\hline 1. Comunicación efectiva & & $\mathrm{x}$ & & \\
\hline 2. Orientación al cliente & & $\mathrm{x}$ & & \\
\hline 3. Excelencia & & $\mathrm{x}$ & & \\
\hline 4. Innovación y Creatividad & & $\mathrm{x}$ & & \\
\hline 5. Trabajo de Equipo & & $\mathrm{x}$ & & \\
\hline 6. Puntualidad & & $\mathrm{x}$ & & \\
\hline 7. Responsabilidad & & $\mathrm{x}$ & & \\
\hline 8. Organización & & $\mathrm{x}$ & & \\
\hline 9. Proactividad & & $\mathrm{x}$ & & \\
\hline 10. Honestidad & & $\mathrm{x}$ & & \\
\hline Sexo & Masculino Edad & $\begin{array}{l}\text { de } 30 \text { a } 38 \\
\text { años }\end{array}$ & $\begin{array}{l}\text { Residenci } \\
\text { a: }\end{array}$ & Lima \\
\hline \multicolumn{5}{|l|}{ 4.2 CONOCIMIENTOS } \\
\hline \multirow{2}{*}{ Formación } & Indispensable & & Deseable & \\
\hline & Ingeniería Industrial. & & & \\
\hline Especializaciones & Marketing & & & \\
\hline Cursos & ISO 9001, HACCP & & & \\
\hline
\end{tabular}


Idiomas

Computación (Manejo de Software y

app)

Experiencia
Inglés intermedio

Manejo de SAP

Conocimiento de

office

De cinco (2) años, en plantas de alimentos, con capacidad para planificar, organizar y supervisar el personal.

\section{CONDICIONES}

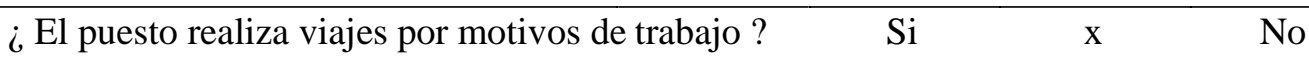

¿El puesto requiere movilizarse de su ambiente de trabajo cotidiano?

$\mathrm{Si} \quad \mathrm{X} \quad \mathrm{No}$

Autonomía del puesto. (Intensidad de la supervisión recibida)

Supervisión habitual : supervisión estrecha, actúa bajo una guía de jefe directo

X

Supervisión intermedia : supervisión periódica, actua bajos metas trazadas

Supervisión amplia : supervisión general, actúa por objetivos planteados

$\begin{array}{lccc}\text { Horario de Trabajo. (Régimen de } & \text { Horario } & \text { fijo } & \text { Rotativo } \\ \text { horario realizado) } & \text { fijo } & \text {. }\end{array}$

Condiciones

Condiciones Ambientales

El trabajo se realiza en la planta de proceso de maceración, expuesto a una temperatura adecuada, considerando las condiciones de higiene normales, iluminación apta y con estructura dentro lo requerido por las leyes.

Riesgos físicos

Los riesgos en la empresa son por accidentes del trabajo, como caídas de muebles, sillas, mesas, etc.; las que pueden producir contusiones en cualquier parte del cuerpo. 
Fecha :

\begin{tabular}{ll}
\hline & PERFIL DE PUESTO \\
\hline 1. IDENTIFICACION DEL PUESTO & \\
\hline Nombre del Puesto & Community manager \\
Unidad & Comercial \\
Gerencia & Gerencia Comercial \\
Reporta & Gerente Comercial \\
Supervisa a & Motorizado \\
\hline 2. OBJETO GENERAL DEL CARGO &
\end{tabular}

Administrar, gestionar y moderar la web, usando los canales necesarios para lograr los objetivos de la compañía.

\section{FUNCIONES PRINCIPALES}

Ser creativo y saber cómo plantear acciones novedosas.

Controlar la web para atender la ventas.

Responder con asertividad las comunicaciones de los clientes en la web, no importa la índole que sean.

Organizar y tomar las mejores decisiones para mantener la imagen de la empresa en la redes sociales.

Manejar herramientas digitales para la gestión de la web.

Identificar los problemas e inconvenientes que se presenten en la web.

Hacer caso y ejecutar todas las tareas adicionales que sean asignadas por su superior o por la compañía.

\begin{tabular}{|c|c|c|c|c|}
\hline \multirow{2}{*}{ 4. COMPETENCIAS } & & \multicolumn{3}{|c|}{ Nivel } \\
\hline & & Alto & Medio & Bajo \\
\hline \multicolumn{5}{|l|}{ 4.1. GENERALES } \\
\hline 1. Comunicación efectiva & & $\mathrm{x}$ & & \\
\hline 2. Orientación al cliente & & $\mathrm{x}$ & & \\
\hline 3. Excelencia & & $\mathrm{x}$ & & \\
\hline 4. Innovación y Creatividad & & $\mathrm{x}$ & & \\
\hline 5. Trabajo de Equipo & & $\mathrm{x}$ & & \\
\hline 6. Puntualidad & & $\mathrm{x}$ & & \\
\hline 7. Responsabilidad & & $\mathrm{x}$ & & \\
\hline 8. Organización & & $\mathrm{x}$ & & \\
\hline 9. Proactividad & & $\mathrm{x}$ & & \\
\hline 10. Honestidad & & $\mathrm{x}$ & & \\
\hline Sexo & Masculino Edad & $\begin{array}{l}\text { de } 30 \text { a } 38 \\
\text { años }\end{array}$ & Residenci & ima \\
\hline
\end{tabular}

4.2 CONOCIMIENTOS

Formación

Especializaciones

Cursos

Idiomas

Computación (Manejo de Software y

app)

Experiencia
Indispensable

Comunicador Social y

Periodismo.

Deseable

Marketing

ISO 9001, HACCP

Inglés intermedio

Manejo de SAP

Conocimiento de office

De uno (1) años manejando webs o plataformas similares. 
¿El puesto requiere movilizarse de su ambiente de trabajo cotidiano?

$\mathrm{x}$

No

Autonomía del puesto. (Intensidad de la supervisión recibida)

Supervisión habitual : supervisión estrecha, actúa bajo una guía de jefe directo

Supervisión intermedia : supervisión periódica, actua bajos metas trazadas

Supervisión amplia : supervisión general, actúa por objetivos planteados

\begin{tabular}{llll}
\hline $\begin{array}{l}\text { Horario de Trabajo. (Régimen de horario } \\
\text { realizado) }\end{array}$ & Horario fijo & $\mathrm{x}$ & Rotativo \\
\hline
\end{tabular}

Condiciones

Condiciones Ambientales

El trabajo se realiza en la planta de proceso de maceración, expuesto a una temperatura adecuada, considerando las condiciones de higiene normales, iluminación apta y con estructura dentro lo requerido por las leyes.

Riesgos físicos

Los riesgos en la empresa son por accidentes del trabajo, como caídas de muebles, sillas, mesas, etc.; las que pueden producir contusiones en cualquier parte del cuerpo. 
Fecha : $2 / 11 / 17$

\section{PERFIL DE PUESTO}

\begin{tabular}{ll}
\hline 1. IDENTIFICACION DEL PUESTO & \\
\hline Nombre del Puesto & Operario de Máquinaria \\
Unidad & Operaciones \\
Gerencia & Finanzas y \\
Reporta & Administración \\
Supervisa a & Jefe de Produccón y logística \\
\hline 2. OBJETO GENERAL DEL CARGO & N/a \\
\hline
\end{tabular}

Controlar que el proceso de producción y mantenimiento de maquinaria se realice de manera eficiente y así asegurar el nivel de producción esperado. Operadores de la maquinaria para maceración, filtrado y embotellado del producto.

Manejo de equipos y materiales con cierta complejidad y bajo su responsabilidad directa. 3. FUNCIONES PRINCIPALES

Solicitar a almacén la cantidad necesaria de fruta y pisco para el llenado de los tanques de maceración.

Operar los tanques de maceración llenado al inicio, vaceado para filtración y lavado para dejarlos listos para el siguiento proceso de maceración.

Llenar la máquina de filtrado con el macerado para que inicie el proceso de filtrado y luego el embotellado.

Controlar la descarga de materia prima

Verificar que el llenado se está realizando adecuadamente.

Entregar a los operarios de tapado y etiquetado el producto listo para que inicien su proceso.

Hacer caso y ejecutar todas las tareas adicionales que sean asignadas por su superior o por la compañía.

\begin{tabular}{|c|c|c|c|c|c|}
\hline \multirow{2}{*}{ 4. COMPETENCIAS } & & & \multicolumn{3}{|c|}{ Nivel } \\
\hline & & & Alto & Medio & Bajo \\
\hline \multicolumn{6}{|l|}{ 4.1. GENERALES } \\
\hline 1. Comunicación efectiva & & & & $\mathrm{x}$ & \\
\hline 2. Orientación al cliente & & & & $\mathrm{x}$ & $\mathrm{x}$ \\
\hline 3. Excelencia & & & & $\mathrm{x}$ & \\
\hline 4. Innovación y Creatividad & & & & & $\mathrm{x}$ \\
\hline 5. Trabajo de Equipo & & & & $\mathrm{x}$ & \\
\hline 6. Puntualidad & & & $\mathrm{x}$ & & \\
\hline 7. Responsabilidad & & & $\mathrm{x}$ & & \\
\hline 8. Organización & & & $\mathrm{x}$ & & \\
\hline 9. Proactividad & & & & $\mathrm{x}$ & \\
\hline 10. Honestidad & & & $\mathrm{x}$ & & \\
\hline Sexo & Masculino & Edad & $\begin{array}{l}\text { Entre: } 19 \text { a } \\
23 \text { años }\end{array}$ & $\begin{array}{l}\text { Residen } \\
\text { cia: }\end{array}$ & Lima \\
\hline \multicolumn{6}{|l|}{ 4.2 CONOCIMIENTOS } \\
\hline & \multicolumn{2}{|c|}{ Indispensable } & \multicolumn{3}{|c|}{ Deseable } \\
\hline $\begin{array}{l}\text { Formación } \\
\text { Especializaciones }\end{array}$ & \multicolumn{2}{|c|}{$\begin{array}{l}\text { Secundaria } \\
\text { Completa } \\
\text { Técnico }\end{array}$} & \multicolumn{3}{|c|}{$\begin{array}{l}\text { Conocimiento de Electricidad } \\
\text { Conocimiento en el manejo de } \\
\text { maquinaria }\end{array}$} \\
\hline
\end{tabular}


Cursos

Idiomas

Computación (Manejo de Software y

app)

Experiencia
N/A

N/A

Minimo 6 meses

trabajando en una

empresa similar

\section{CONDICIONES}

$¿$ El puesto realiza viajes por motivos de trabajo ?

$¿$ El puesto requiere movilizarse de su ambiente de trabajo cotidiano?

$\mathrm{Si}$

Conocimiento de

office

Autonomía del puesto. (Intensidad de la supervisión recibida)

Supervisión habitual : supervisión estrecha, actúa bajo una guía de jefe directo

No $\quad \mathrm{x}$

Supervisión intermedia : supervisión periódica, actpua bajos metas trazadas

Supervisión amplia : supervisión general, actúa por objetivos planteados

\begin{tabular}{llc}
\hline $\begin{array}{l}\text { Horario de Trabajo. (Régimen de } \\
\text { horario realizado) }\end{array}$ & Horario fijo & Rotativ \\
Condiciones & & 0 \\
\hline Condion
\end{tabular}

Condiciones Ambientales $\quad$ El trabajo se realiza en la planta de proceso de maceración, expuesto a una temperatura adecuada, considerando las condiciones de higiene normales, iluminación apta y con estructura dentro lo requerido por las leyes.

Riesgos físicos

Los riesgos en la empresa son por accidentes del trabajo, en el momento de hacer sus tareas. Estos riesgos estan cubiertos por el seguro complementario de trabajos de riesgo. 
PERFIL DE PUESTO

\section{IDENTIFICACION DEL PUESTO}

Nombre del Puesto

Unidad

Gerencia

Reporta

Supervisa a

2. OBJETO GENERAL DEL CARGO
Almacenero

Operaciones

Finanzas y Administración

Jefe de Producción y Logística

N/a

Es responsabilidad del almacenero custodiar, recepcionar, organizar y despachar todos los productos e insumos a ser utilizados para ser utilizados en los distintos procesos y áreas, cumpliendo con las normas y estándares establecidos por la compañía.

3. FUNCIONES PRINCIPALES

Efectuar la carga y descarga de la unidad que abastece de mercadería, de acuerdo a los procedimientos vigentes.

Organizar, distribuir y registrar la mercadería para los distintos procesos.

Realizar el control de ingreso y salidas de mercadería según de acuerdo lo establecido por los procedimientos.

Hacer caso y ejecutar todas las tareas adicionales que sean asignadas por su superior o por la compañía.

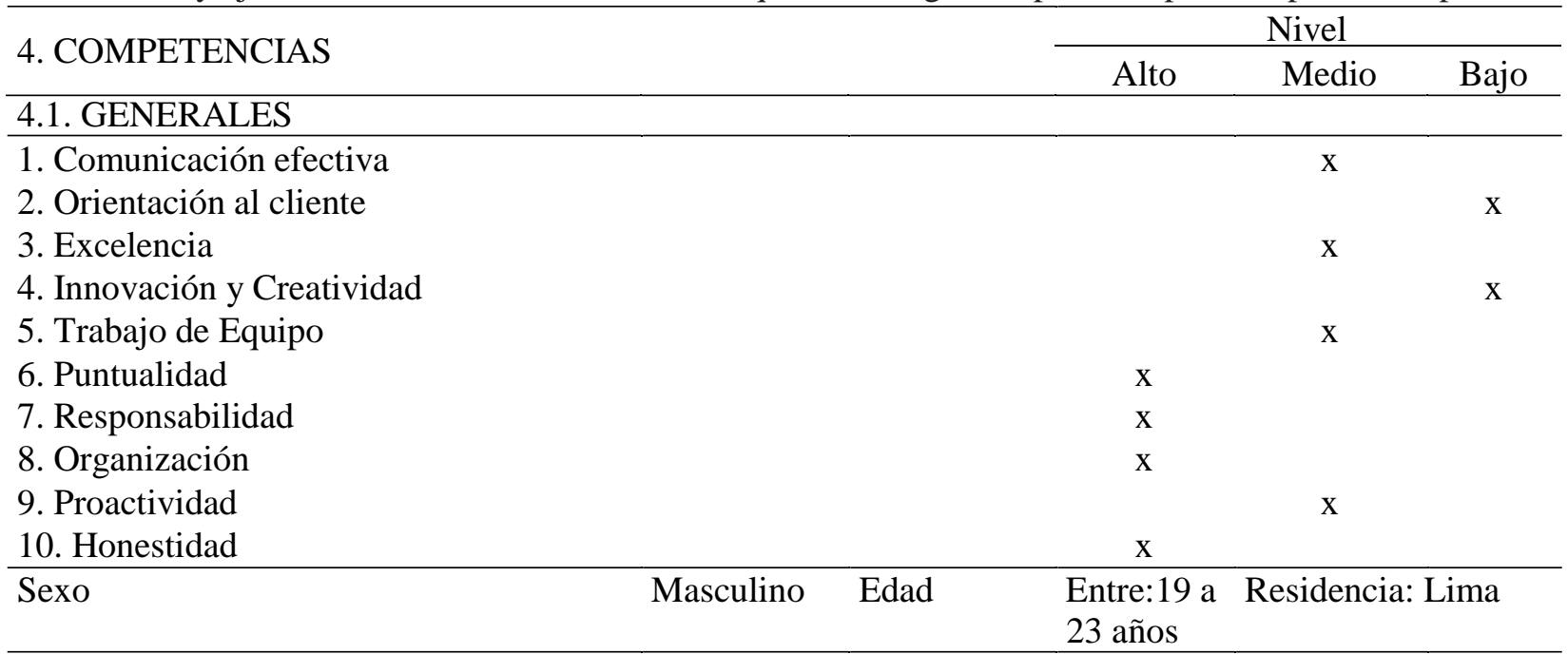

4.2 CONOCIMIENTOS

Formación

Especializaciones

Cursos

Idiomas

Computación (Manejo de Software y

app)

Experiencia

\begin{tabular}{l}
\multicolumn{2}{c}{ Indispensable } \\
\hline Secundaria Completa \\
N/A \\
N/A \\
N/A
\end{tabular}

Conocimiento de office

1-2 años

\section{Deseable}

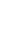

\section{CONDICIONES}

¿ El puesto realiza viajes por motivos de trabajo ?

$\mathrm{Si}$

$\mathrm{Si}$

trabajo cotidiano?

Autonomía del puesto. (Intensidsad de la supervisión recibida)

Supervisión habitual : supervisión estrecha, actúa bajo una guía de jefe directo

¿El puesto requiere movilizarse de su ambiente de 
Supervisión intermedia : supervisión periódica, actpua bajos metas trazadas

Supervisión amplia : supervisión general, actúa por objetivos planteados

\begin{tabular}{lll}
\hline $\begin{array}{l}\text { Horario de Trabajo. (Régimen de horario } \\
\text { realizado) }\end{array}$ & Horario fijo & Rotativo \\
\hline Condiciones & & El trabajo se realiza en la planta de proceso de maceración, \\
Condiciones Ambientales & $\begin{array}{l}\text { expesto a una temperatura adecuada, considerando las } \\
\text { estructura dentro lo requerido por las leyes. }\end{array}$ \\
\hline Riesgos físicos & $\begin{array}{l}\text { Los riesgos en la empresa son por accidentes del trabajo, en } \\
\text { el momento de hacer sus tareas. Estos riesgos estan cubiertos } \\
\text { por el seguro complementario de trabajos de riesgo. }\end{array}$ \\
\hline
\end{tabular}

\subsection{Remuneraciones, compensaciones e incentivos}

Según Chiavenato (2011), las remuneraciones con los pagos que perciben los

trabajadores por parte de la empresa y estos pagos pueden ser salarios, bonos, comisiones e incentivos, siendo el salario la retribución más importante porque refleja el intercambio entre a prestación de servicios por parte del trabajador y la remuneración por parte de la empresa.

La estructura salarial de la empresa se muestra en la tabla 121. 
Tabla 121

Estructura Salarial por Puesto

POR TRABAJADOR

\begin{tabular}{|c|c|c|c|c|c|c|c|c|c|c|c|c|c|}
\hline CARGO & AREA & $\begin{array}{l}\text { TIPO DE } \\
\text { COSTO Y } \\
\text { GASTO }\end{array}$ & $\begin{array}{l}\text { CAN } \\
\text { T. }\end{array}$ & $\begin{array}{l}\text { SUELDO } \\
\text { MENSUAL }\end{array}$ & Bono & $\begin{array}{c}\text { SCTR } \\
\text { MENSU } \\
\text { AL }\end{array}$ & $\begin{array}{c}\text { SUB- } \\
\text { TOTAL } \\
\text { MENSUAL }\end{array}$ & $\begin{array}{l}\text { SUB-TOTAL } \\
\text { ANUAL }\end{array}$ & $\begin{array}{c}\text { GRATIFICA } \\
\text { CION } \\
\text { (JUL-DIC) }\end{array}$ & ESSALUD & CTS & $\begin{array}{c}\text { Remuneració } \\
\text { n Anual } \\
\text { por } \\
\text { trabajador }\end{array}$ & $\begin{array}{c}\text { Total S/. } \\
\text { Planilla Anual }\end{array}$ \\
\hline Gerente General & Adm. & $\begin{array}{l}\text { G. } \\
\text { Administ. }\end{array}$ & 1 & S/. 5,000.00 & S/. 0.00 & S/. 0.00 & S/. 5,000.00 & S/. $60,000.00$ & S/. 5,000.00 & S/. 5,850.00 & S/. 2,708.33 & S/. 73,558.33 & S/. 73,558.33 \\
\hline $\begin{array}{l}\text { Asistente } \\
\text { Administrativo }\end{array}$ & Adm. & $\begin{array}{l}\text { G. } \\
\text { Administ. }\end{array}$ & 1 & S/. $1,200.00$ & S/. 0.00 & S/. 0.00 & S/. 1,200.00 & S/. $14,400.00$ & S/. $1,200.00$ & S/. $1,404.00$ & S/. 650.00 & S/. $17,654.00$ & S/. $17,654.00$ \\
\hline Jefe de Ventas & Ventas & G. Ventas & 1 & S/. 2,000.00 & S/. 500.00 & S/. 0.00 & S/. 2,500.00 & S/. $30,000.00$ & S/. 2,500.00 & S/. 2,925.00 & S/. 1,354.17 & S/. $36,779.17$ & S/. 36,779.17 \\
\hline Ejecutivo de Ventas & Ventas & G. Ventas & 1 & S/. $1,200.00$ & S/. 300.00 & S/. 0.00 & S/. 1,500.00 & S/. $18,000.00$ & S/. $1,500.00$ & S/. 1,755.00 & S/. 812.50 & S/. $22,067.50$ & S/. 22,067.50 \\
\hline $\begin{array}{l}\text { Community } \\
\text { Manager }\end{array}$ & Ventas & G. Ventas & 1 & S/. 1,200.00 & S/. 300.00 & S/. 0.00 & S/. $1,500.00$ & S/. $18,000.00$ & S/. $1,500.00$ & S/. 1,755.00 & S/. 812.50 & S/. 22,067.50 & S/. 22,067.50 \\
\hline $\begin{array}{l}\text { Jefe de Producción y } \\
\text { Logística }\end{array}$ & Prod. & MOI & 1 & S/. 3,000.00 & S/. 0.00 & S/. 60.00 & S/. 3,060.00 & S/. 36,720.00 & S/. 3,060.00 & S/. 3,580.20 & S/. $1,657.50$ & S/. $45,017.70$ & S/. $45,017.70$ \\
\hline Operario & Prod. & MOD & 3 & S/. 850.00 & S/. 0.00 & S/. 17.00 & S/. 867.00 & S/. $10,404.00$ & S/. 867.00 & S/. $1,014.39$ & S/. 469.63 & S/. $12,755.02$ & S/. 38,265.05 \\
\hline
\end{tabular}

Total 
Para la estructura salarial, ver tabla 121, se establecieron los siguientes requisitos:

- Jornadas laborales de ocho horas de lunes a viernes.

- Jornada laboral de medio día los sábados de ocho a doce.

- Se pagará el sueldo mínimo más el ajuste de mercado dependiendo del puesto requerido.

- Se considera el ingreso a planilla desde el primer día de trabajo.

- Los beneficios son los mínimos requeridos por ley, CTS, ESSALUD y 2 gratificaciones al año.

Como se mencionó en el capítulo anterior, dentro de las características que establece este régimen tenemos:

- $\quad$ La modalidad de contratación de los empleados será bajo el contrato de necesidades de mercado que da como máximo la contratación hasta de 5 años del trabajador.

- $\quad$ El trabajador está sujeto a 3 meses de prueba pudiendo el empleador rescindir el contrato durante estos meses. En esta modalidad de contrato esta versado el decreto legislativo $\mathrm{N}^{\mathrm{o}} 728$ aprobado por D.S N 003-97-TR-ley de la productividad y la competitividad laboral. Dicho contrato será por un periodo de 6 meses, el cual será renovado si la empresa lo desea o en caso contrario prescindir de los servicios si es que el trabajador no cumple con los requerimientos exigidos por la empresa en cuanto al desempeño.

- $\quad$ En este caso la legislación laboral vigente establece que los trabajadores percibirán adicionalmente a la remuneración mensual establecida por contrato las siguientes partidas: 
De la empresa

Aportes:

- Gratificaciones legales: establecida en Julio y Diciembre, cuyo monto es una remuneración mensual cada uno de estos meses.

- $\quad$ Compensación por tiempo de servicios (CTS): Equivalente a un dozavo de la remuneración computable por cada mes de servicios y a un treintavo de dicho dozavo por cada fracción de mes.

- Seguro Social de Salud: Monto correspondiente al empleador el cual asciende al 9\% sobre la remuneración mensual desembolsada cada mes.

- Descanso vacacional será de 30 días calendario por año de servicio.

- $\quad$ Seguro Complementario de trabajo de riesgo.

Del Trabajador

Aportes:

AFP (Administradora de Fondo de Pensiones), aportará lo siguiente:

- $\quad 10.00 \%$ aporte obligatorio

- $\quad 1.33 \%$ prima de seguro (promedio entre las AFPs)

- $\quad 1.55 \%$ comisión variable (promedio entre las AFPs)

- $\quad$ SNP (Sistema Nacional de Pensiones).

Aquellos empleados que prefieran el SNP tendrán que hacer una aportación del 13\% de su remuneración asegurable.

El pago de utilidades a los trabajadores. El monto a repartir entre los trabajadores será equivalente al $10 \%$ de las utilidades de la empresa y se dividirá el 50\% entre la cantidad total de trabajadores en planilla y el otro 50\% será pagado en proporción al sueldo que perciban y a las horas trabajadas cada uno de los trabajadores en planilla. 


\subsection{Política de recursos humanos}

Según Chiavenato (2009), las políticas de recursos humanos emergen en base al juicio, filosofía y la cultura organizacional impuesta por la organización. Estas políticas son reglamentos que se establecen para dirigir funciones y poder asegurar el desarrollo hacia el logro de los objetivos deseados. En resumen las políticas son pautas que las organizaciones establecen para lidiar con los trabajadores y a su vez encaminarlos para el logro de los objetivos.

Entre las políticas que manejará la empresa se consideran las siguientes:

- Política reclutamiento y selección.

Define todos los pasos, métodos y formas para realizar un adecuado reclutamiento y selección de personal.

Cómo política se entregará un kit de Bienvenida de acuerdo al siguiente detalle en tabla 122 .

Tabla 122

Kit de bienvenida

\begin{tabular}{lll}
\hline Práctica & Objetivo & Descripción \\
\hline Entrega de Kit: & Evidenciar la cercanía y & Estará compuesto por \\
Bienvenido a la familia & compromiso de HECHIZO, & información de HECHIZO, \\
HECHIZO & con el nuevo colaborador & reglamento, visión, misión y \\
& desde el primer día. & $\begin{array}{l}\text { valores. Además de un } \\
\text { cuadernos y lápiz con el logo. }\end{array}$ \\
\hline
\end{tabular}

- Política de perfil de puesto y ascensos.

Se establecen los requisitos básicos para la elaboración de los perfiles de puesto en conjunto con los gerentes y jefes de cada área (Ver tabla 123). 
Tabla 123

Política de mejora de clima laboral

\begin{tabular}{lll}
\hline Práctica & Objetivo & Descripción \\
\hline Escuchándonos & Establecer diálogo directo y & Desayunos quincenales con \\
& $\begin{array}{l}\text { cercano con los líderes y } \\
\text { colaboradores para que la } \\
\text { toma de decisiones sea } \\
\text { eficiente. }\end{array}$ & líderes y colaboradores. \\
& & \\
\hline
\end{tabular}

- Política de evaluación y retención del talento

Se programa la debida evaluación del personal para obtener información valiosa para tomar acción. Con los resultados obtenidos se decide si el trabajador necesita capacitación o está en condiciones de mejorar su situación laboral, ver tabla 124.

Tabla 124

Clima laboral

\begin{tabular}{lll}
\hline Práctica & Objetivo & Descripción \\
\hline Red de buen clima & Identificar, valorar y replicar & Ampliar la capacidad de \\
& buenas prácticas internas. & seguimiento y evaluación del \\
& Convertirlos en socios & impacto de las prácticas \\
& estratégicos. & aplicadas. \\
\hline
\end{tabular}

- Política de capacitación y desarrollo

Elaboración del calendario de capacitaciones de acuerdo al perfil de cada trabajador para ayudar en su desarrollo profesional en la empresa, ayudando de esta forma a potenciar sus conocimientos en beneficio del mismo trabajador y de la empresa. 


\section{Capítulo VII. Plan de marketing}

Según Kotler y Keller (2012), es un documento escrito en el que se escogen los objetivos, las estrategias y los planes de acción relativos a los elementos del marketing mix.

El principal objetivo del plan de marketing está orientado a darle notoriedad y fortalecer la imagen del producto, a través de la planificación para activación y reconocimiento de la marca del macerado de frutas en pisco. Estas acciones están ligadas a la obtención de rentabilidad para el proyecto.

Para el plan de marketing, el mix, la distribución, precio y nombre se utilizó la información recabada de las entrevistas de profundidad hechas a los dueños y Gerentes de bodegas de Pisco Sarcay y Bailetti (Ver tabla 23), productores artesanales de macerados de pisco en fruta Eddu's y Foodies (Ver tabla 21), sommelier para la mezcla de sabores (Ver tabla 24), de esa manera se logró tomar las decisiones que más convenían para la realización del proyecto. Para mayor información ver transcripciones de las entrevistas a profunidad en los Anexos \# 6, 7, 9, 10 y 11.

\subsection{Estrategias de marketing}

Según Kotler y Keller (2012), es el proceso social y administrativo pro el cual los grupos e individuos satisfacen sus necesidades al crear e intercambiar bienes y servicios.

La estrategia de Marketing elegida para el plan de negocios fue la de diferenciación, por que se ofrece un producto que es percibido en el mercado como único e innovador, con una participación de mercado conservadora, ya que se busca una percepción de exclusividad.

\subsubsection{Estrategia de Producto.}

Según Kotler y Keller (2012), la estrategia de producto es lo que se ofrezca en un mercado para su atención, adquisición, uso o consumo, y que pudiera satisfacer una necesidad o deseo. Los productos que se comercializan incluyen bienes físicos, servicios, personas, lugares, organizaciones e ideas. 
El nombre del producto es "Hechizo", este nombre significa una atracción misteriosa e irresistible que produce sobre alguien los encantos de algo, en este caso los macerados de frutas en pisco. Lo que se busca es que el público se quede hechizado con el producto, que le cause la sensación de atracción y les encante. El posicionamiento que se quiere lograr, propone que los macerados de frutas en pisco sean considerados como una alternativa de licor que se puede tomar en cualquier ocasión y en gratos momentos que serán recordados por los clientes, se quiere ofrecer una experiencia al tomar esta bebida espirituosa.

Según la matriz de estrategias de Michael Porter, se utilizará la estrategia de Diferenciación, ya que se ofrece un producto que ya existe, sin embargo, los sabores que se ofrecen son completamente nuevos y hace que Hechizo se distinga de la competencia.

Con este plan el enfoque está orientado a un segmento A y B, de las zonas 6 y 7 de Lima Metropolitana.

Este segmento de personas busca un producto que sea de alta calidad, excelente sabor y sea diferente al resto. Por lo que se busca ofrecer nuevos sabores, los cuales no se puedan encontrar en otros lugares ni empresas.

Asimismo, los ingredientes serán de la más alta calidad, con un pisco quebranta que tenga la denominación de origen, acompañado de frutas de alta calidad y sabor.

Es importante mencionar que el proceso de elaboración de alimentos también es de criterio importante para ofrecer los mejores productos, por lo que este proceso de maceración será estandarizado y se cuidará la higiene y manipulación de alimentos. Se observa el detalle de productos por sabores en la tabla 125 . 
Tabla 125

Macerados de frutas en pisco

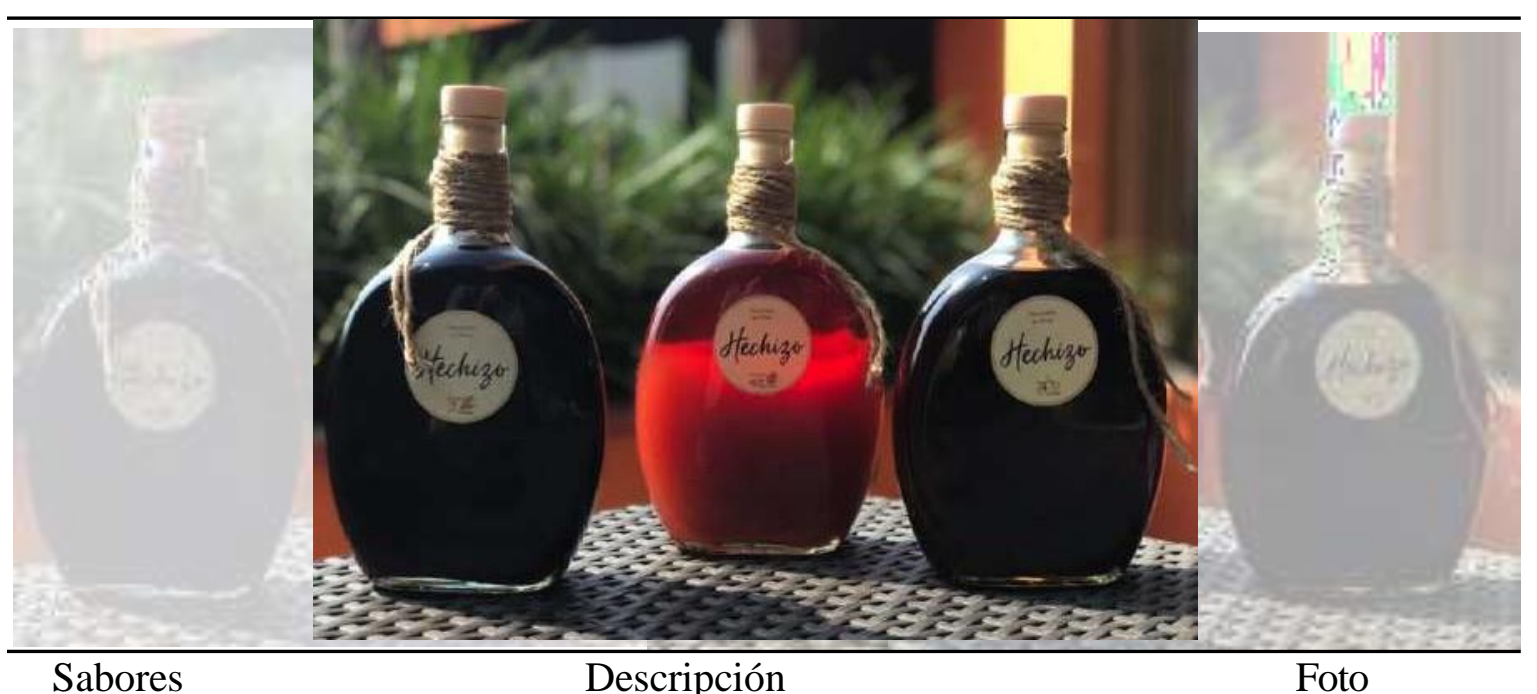

Delicioso, saludable, tropical, exótico, con un color y olor espectacular que podría cautivar a cualquiera. Es una mezcla de dos frutas sensacionales: la maracuyá, Maracuyá y mas conocida como el fruto de la pasión y la Frambuesa frambuesa conocida como fruto del bosque. Probarlo es un amor al primer sorbo, que no se puede olvidar. Se disfruta el equilibrio perfecto de ese sabor dulce que acaba por dejar un regusto de ácido. Sublime sensación para el paladar.

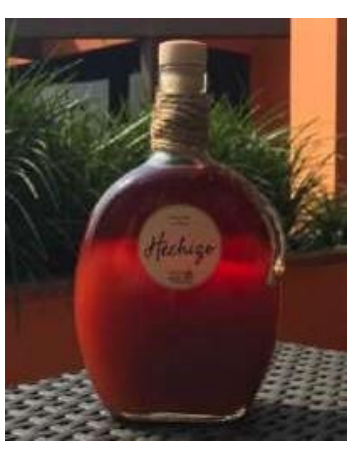

Unir generaciones y revivir las tradiciones mediante esta mezcla de dos frutos dulces, de aroma intenso y contundente color rojo. La guinda, que dejó un

Fresa y importantísimo legado en la historia y que se quiere

Guinda preservar este emblemático fruto y la fresa, esta delicia que destaca por su dulce sabor y sus propiedades nutricionales. Es un manjar de los dioses, con el toque perfecto de dulzor para disfrutarlo en cualquier ocasión.

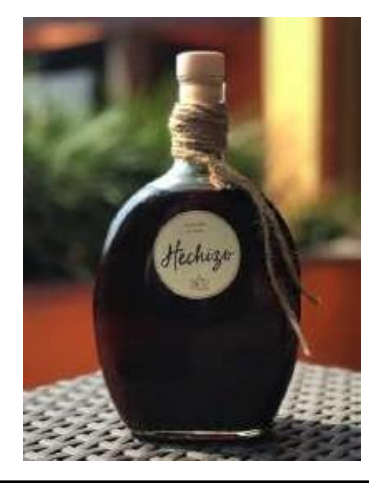

Chicha (maíz morado, membrillo y canela)
Refrescante, aroma intenso, color predominante y sabor exquisito. Es una bebida tradicional de la gastronomía peruana, que no podía faltar. Con propiedades medicinales y antioxidante. Esta maravillosa mezcla de sabores logra el extracto natural y así poder disfrutar cada sorbo de este elixir.

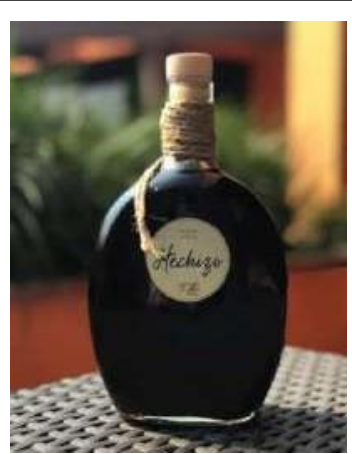




\subsubsection{Estrategia de Precio.}

Según Kotler y Keller (2012), la estrategia de precio se utiliza para obtener rentabilidad. Está orientada a la utilidad, volumen, imagen, competencia y supervisión.

A la empresa que lanza un producto nuevo al mercado se le ofrecen dos opciones estratégicas relacionadas con el precio: la estrategia de descremación, también llamada de desnatación, y la estrategia de penetración.

Descremación.

Mediante la estrategia de descremación la empresa orienta su producto a los consumidores menos sensibles al precio, que constituyen la "crema" del mercado. Fija un precio alto de partida esperando que estos consumidores, más innovadores, adquieran el producto. Con ella se pretende que el producto sea percibido como un bien o un servicio de prestigio altamente valorado

Se utilizó esta estrategia para Hechizo, ya que se enfoca a un segmento de mercado que está dispuesto a pagar un precio alto por productos de alta calidad, priorizando el sabor y la experiencia.

Por lo que Hechizo, se venderá en cualquiera de los tres sabores a un precio único, que tendrá el valor de S/ 55.00, incluyendo IGV.

Tanto el macerado de Frambuesa y Maracuyá, Fresa y Guinda y Chicha, tienen diferentes costos unitarios. Sin embargo, el costo promedio fue de S/ 30 a S/ 35, por lo que se determinó poner un precio estándar. Esto porque el consumidor al comprar, se puede dejar llevar por el precio más accesible, dejando de lado la posibilidad de comprar las otras alternativas.

\subsubsection{Estrategia de distribución.}

Según Ferrell O, y Hartline M, (2012), la distribución y la cadena de suministro son muy importantes porque a lo largo del tiempo ofrecen beneficios a los consumidores, como optimizar el uso del tiempo y facilidad en el lugar y posesión de los productos. El objetivo es que los clientes puedan reducir sus costos totales al poder adquirir los bienes y servicios cuando y donde sea necesario. Si la empresa ejecuta una buena distribución puede equilibrar problemas en la fijación de precios, en productos y promoción. 
La estrategia de distribución será selectiva. Para la distribución vía web se aplicó la distribución directa, ya que un motorizado se encargará de entregar el producto directamente a los compradores finales. En cuanto a distribución para licorerías y estaciones de servicios, la distribución será indirecta ya que se contratará los servicios de terceros, para reducir gastos y enfocarse en mejorar el negocio mediante la diferenciación de los productos para lograr afianzar las ventajas competitivas.

Los productos serán colocados en licorerías y estaciones de servicio, también se elaborarán contratos con estos minoristas para poder definir cantidades, precios y garantizar el buen funcionamiento de la cadena de suministro.

Para la distribución se han considerado los puntos de venta en los cuales se abastecerá el producto, entre los más importantes figuran las licorerías y estaciones de servicio. Además de las ventas directas por internet en donde el cliente es quien la ejecuta y luego de esta operación se procede con la entrega.

\subsubsection{Estrategia de Promoción y Publicidad.}

Como mencionan Ferrell O, y Hartline M, (2012), las diversas acciones de promoción son vitales dar a conocer las características y beneficios de los productos al mercado meta. El uso de la comunicación integrada de marketing tiene como significado el desarrollo estratégico de la promoción para poder elaborar un mensaje sólido que vaya expandiéndose por cada uno de los diversos canales con la finalidad de afianzar un impacto decisivo sobre los clientes vigentes y potenciales.

La publicidad es muy importante para lograr alcanzar al mercado objetivo. Se utilizará la internet para poder tener un mayor alcance debido a su gran y fácil expansión ligado a un menor costo de los medios tradicionales. El tipo de publicidad utilizada será la publicidad de producto, mediante la cual se mostrarán los beneficios, características y diversos sabores los 
macerados de frutas en pisco. Lo que se busca es captar la atención del público para luego despertar el interés.

La empresa optará por la estrategia de pull (jalar), por lo tanto, los esfuerzos de promoción estarán dirigidos a estimular la demanda entre los clientes finales, para que luego ellos realicen presión sobre la cadena de suministro para poder obtener el producto. La administración combinada de una fuerte publicidad, sumado a relaciones públicas y promoción de ventas al consumidor tiene como resultado el efecto de jalar (pull).

Los macerados de frutas en pisco requieren mayor publicidad, promoción de ventas y relaciones públicas y esto se considera a través de las etapas del ciclo de vida del producto. Por tal motivo inicio del ciclo, inclusive antes de la etapa de introducción del producto, los gastos en las actividades de promoción son elevados y representan unporcentaje significativo de los recursos de la empresa. Todos los gastos considerados en esta etapa serán considerados como inversiones a largo plazo debido a que el resultado de la promoción tomará algún tiempo en reflejar resultados. Es, recién en la etapa de madurez cuando la empresa puede experimentar una disminución en gastos promocionales, obteniendo como resultado menores costos y mayores utilidades.

Estrategia below the line (debajo de la línea)

Se implementará la estrategia below the line, que se harán uso de las redes sociales para dar a conocer el producto, obteniendo menores gastos en promoción debido al no uso de los canales tradicionales como televisión, radio o revistas. Además, se han programado ofrecer degustaciones del producto en los principales puntos de venta, entre los cuales están las licorerías y estaciones de servicio dentro de las zonas seis y siete para captar al público que gusta del pisco y sus derivados dando a ofrecer una nueva opción combinando nuestra bebida bandera con una gama de frutos logrando un producto de gran calidad. Campaña en redes sociales 
El primer paso será captar la atención del público mediante una campaña de misterio en las principales redes sociales como Facebook y Twitter.

Para el caso de Facebook se mostrarán imágenes relacionadas con el producto, pero sin evidenciar el macerado de frutas en pisco para poder lograr captar la atención del público en general. Un ejemplo será mostrar 2 frutas que al juntarse generan una explosión de sabor que culminan en personas felices y disfrutando.

En Twitter se mostrarán mensajes secretos (post) que den pistas al público en general sobre la existencia de este nuevo producto. El Community manager será el encargado de postear los mensajes generando la intriga entre el público.

Página web

La empresa contará con una página web que incluirá información acerca de los productos, como breves historias creadas para cada uno de los tres sabores de macerados de frutas. La web también expondrá información sobre la misión, visión y objetivos de la empresa, los cuales estarán enfocados a la satisfacción del cliente.

Otra información importante estará ubicada en la sección contáctenos, en la cual el público podrá encontrar un número telefónico y un correo de contacto. En ambos las personas podrán recibir información o resolver dudas.

Degustaciones en licorerías y estaciones de servicio

Luego del estudio de mercado en donde se definieron los sectores en los cuales se dirigirá el producto, se seleccionarán las principales licorerías y estaciones de servicio en los cuales se ofrecerán degustaciones del producto, se designarán cantidades mínimas de los tres sabores y se exhibirán banners con el logo y slogan de los macerados de frutas en pisco.

\subsection{Estrategia de ventas}

Para Kotler y Keller (2012), antes de decidir por la compra de un producto el consumidor pasa por diversas fases. Tres de estas se dan antes de que decida y la cuarta 
después de que decide. Estas fases son el reconocimiento de necesidades, evaluación de opciones, resolución de temores, decisión de compra y por último la implementación. Entonces, se puede determinar que el consumidor pasa por fases psicológicas al tomar una decisión de compra, ver tabla 126.

Tabla 126

Proceso de toma de decisión

\begin{tabular}{ll}
\hline 1. Reconocimiento de & $\begin{array}{l}\text { Ayudar a que el consumidor identifique la } \\
\text { necesidad implícita y cree un sentimiento de } \\
\text { urgencia. }\end{array}$ \\
$\begin{array}{l}\text { 2. Evaluación de opciones } \\
\text { 3. Resolución de temores }\end{array}$ & $\begin{array}{l}\text { Criterios de decisión. } \\
\text { Resuelve temores por la decisión de compra y } \\
\text { evitar arrepentimientos. }\end{array}$ \\
$\begin{array}{l}\text { 4. Decisión de Compra } \\
\text { 5. Implementación }\end{array}$ & $\begin{array}{l}\text { Que el proceso de compra sea fácil. } \\
\text { Promocionar información sobre el producto. }\end{array}$ \\
\hline
\end{tabular}

Siguiendo lo que sostienen ambos autores, la estrategia de ventas iniciaría entendiendo cómo es que compran las personas, aplicando todas estas etapas, pero considerando que la venta será vía la web y los otros canales.

1. Reconocimiento de necesidades

Hacer que el consumidor identifique la propuesta de valor de la marca. Aprovechar la ventaja de que el macerado de fruta está hecho de pisco y las nuevas propuestas de la mezcla de sabores que no hay en el mercado como:

Guinda y fresa - Regresando la guinda, haciendo que las generaciones como babyboomers recuerde sus épocas cuando eran jóvenes. Una propuesta con un sabor agradable.

Maracuyá y frambuesa - Una propuesta de sabor tropical, fresco.

Chicha - una mezcla de frescura con la chicha y aventura con el pisco. Para lograr que elijan HECHIZO, se realizará las siguientes estrategias, ver tabla 126:

- Estrategia 1: Promocionar la marca. 
Objetivo: Comunicar la aparición del nuevo producto, describirlo, informar al consumidor sobre la nueva propuesta (Ver tabla 127).

Tabla 127

Acciones para la estrategia 1

\begin{tabular}{cl}
\hline \multicolumn{1}{c}{ Página Web } & \multicolumn{1}{c}{ Otros Canales } \\
\hline $\begin{array}{c}\text { Acción 1 Realizar sorteos semanales para regalar 2 } \\
\text { botellas de macerados. }\end{array}$ & $\begin{array}{l}\text { Degustaciones en Licorerías y estaciones de } \\
\text { servicio de los tres sabores para que prueben } \\
\text { el macerado, impulsar la compra y recoger } \\
\text { comentarios. }\end{array}$ \\
Acción 2 Realizar oferta de martes 2 x 1, para & $\begin{array}{l}\text { Entrega de flyers con información sobre } \\
\text { sabores y forma de como consumir. }\end{array}$ \\
\hline
\end{tabular}

- Estrategia 2: Promocionar la marca, ver tabla 128.

Objetivo: Promocionar la nueva marca de macerados e informar y recoger

información y aprovecharla para generar ventas.

Tabla 128

Acciones para la estratega 2

\begin{tabular}{lll}
\hline \multicolumn{1}{c}{ Página Web } & \multicolumn{1}{c}{ Otros Canales } \\
\hline Acción 1 & $\begin{array}{l}\text { Marketing de referencia, utilizar los } \\
\text { comentarios de los consumidores para } \\
\text { generar tráfico en las ventas. }\end{array}$ & $\begin{array}{l}\text { Regalar muestras pequeñas de los } \\
\text { macerados de sabores distintos a los que } \\
\text { compra el cliente para que prueben. }\end{array}$ \\
Acción 2 & $\begin{array}{l}\text { Contactar bloggers para promocionar la } \\
\text { marca. }\end{array}$ & $\begin{array}{l}\text { Exhibidores de los productos en los } \\
\text { puntos de venta. }\end{array}$ \\
\hline
\end{tabular}

2. Evaluación de opciones

La propuesta de HECHIZO, macerados que atraen por la presentación del producto, la forma de la botella simula la forma de una de perfume. Los colores vivos de los macerados como el de frambuesa con maracuyá o el de la chicha, ver tabla 129.

- Estrategia 1: Hacer que los consumidores prueben HECHIZO.

Objetivo: Informar a los consumidores acerca de la calidad de HECHIZO y los beneficios de adquirirlo. 
Tabla 129

Acciones para el logro de objetivos de estrategia 1

\begin{tabular}{lll}
\hline \multicolumn{1}{c}{ Página Web } & \multicolumn{1}{c}{ Otros Canales } \\
\hline Acción 1 & $\begin{array}{l}\text { Hacer publicaciones diarias acerca del } \\
\text { producto en donde se destaca que se usa } \\
\text { productos de calidad. }\end{array}$ & $\begin{array}{l}\text { Entrega de volantes incluyendo } \\
\text { información sobre los insumos } \\
\text { describiendo que son de calidad. }\end{array}$ \\
Acción 2 & $\begin{array}{l}\text { Publicar recetas de cómo consumir los } \\
\text { macerados y dar ideas sobre } \\
\text { presentaciones. }\end{array}$ & $\begin{array}{l}\text { Participar en ferias haciendo } \\
\text { degustaciones del producto y } \\
\text { mostrando las presentaciones. }\end{array}$ \\
\hline
\end{tabular}

- Estrategia 2: Dar a conocer a los consumidores la mejor opción de compra.

Objetivo: Lograr que los consumidores compren HECHIZO a través de la web y la comodidad de su casa para incrementar las ventas (Ver tabla 130).

Tabla 130

Acciones para el logro de objtivos de estrategia 2

\begin{tabular}{lll}
\hline & \multicolumn{1}{c}{ Página Web } & \multicolumn{1}{c}{ Otros Canales } \\
\hline Acción 1 & $\begin{array}{l}\text { Hacer publicaciones en donde se } \\
\text { informe a los consumidores que } \\
\text { pueden hacer la compra vía web. }\end{array}$ & $\begin{array}{l}\text { Tener impulsadoras los fines de semanas en los } \\
\text { puntos de venta, para que informen sobre el } \\
\text { producto. } \\
\text { Acción 2 }\end{array}$ \\
$\begin{array}{l}\text { Informar sobre el servicio de } \\
\text { entrega a domicilio (delivery). }\end{array}$ & Informar que pueden comprar vía la web. \\
\hline
\end{tabular}

3. Resolución de temores

Cuando el consumidor hace la compra de HECHIZO, la hace convencido que tiene asegurado un producto que ofrece calidad, que va directamente relacionado con el precio.

- Estrategia 1: Demostrar la calidad de HECHIZO.

Objetivo: A través de la demostración de videos en vivo los potenciales clientes podrán verificar que estarían adquiriendo un producto que cubre sus expectativas (Ver tabla 131).

Tabla 131

Acciones para resolución de temores de estrategia 1

\begin{tabular}{lll}
\hline \multicolumn{1}{c}{ Página Web } & \multicolumn{1}{c}{ Otros Canales } \\
\hline Acción 1 & $\begin{array}{l}\text { Crear programa de afiliados y } \\
\text { programas de puntos. }\end{array}$ & $\begin{array}{l}\text { Incluir una tarjeta adicional en la que se informe } \\
\text { sobre el tiempo de vida del producto. }\end{array}$ \\
Acción 2 & $\begin{array}{l}\text { Colgar videos en vivo con } \\
\text { testimonios de consumidores. }\end{array}$ & $\begin{array}{l}\text { Informar que el pisco utilizado es ganador de } \\
\text { medallas y concursos. }\end{array}$ \\
\hline
\end{tabular}


- Estrategia 2: Crear ambientes para crear experiencias al consumidor.

Objetivo: Aumentar las ventas a través de historias o experiencias creadas para atraer a los clientes (Ver tabla 132).

Tabla 132

Acciones de resolución de temores de estrategia 2

\begin{tabular}{lll}
\hline \multicolumn{1}{c}{ Página Web } & \multicolumn{1}{c}{ Otros Canales } \\
\hline Acción 1 & $\begin{array}{l}\text { Aparecer en internet en listas de } \\
\text { guías de regalos para impulsar las } \\
\text { ventas. }\end{array}$ & $\begin{array}{l}\text { En épocas de estacionalidad alta hacer } \\
\text { degustaciones tematizadas para atraer la } \\
\text { atención de los clientes. }\end{array}$ \\
Acción 2 & $\begin{array}{l}\text { Manejar los comentarios buenos } \\
\text { y malos de los clientes y dejar } \\
\text { que se expresen. }\end{array}$ & Ofrecer a los canales bonos por ventas. \\
\hline
\end{tabular}

4. Decisión de compra

Los canales de venta son los indicados, el consumidor puede comprar HECHIZO macerados de fruta en pisco a través de la página web y se lo entregan en su casa o puede comprarlo en una licorería o grifo. Puede hacer la compra de forma sencilla.

- Estrategia 1: Persuadir al consumidor a la compra.

Objetivo: Hacer que los consumidores compren HECHIZO, persuadiendo al decisor de la compra (Ver tabla 133).

Tabla 133

Decisión de compra estrategia 1

\begin{tabular}{lll}
\hline & \multicolumn{1}{c}{ Página Web } & \multicolumn{1}{c}{ Otros Canales } \\
\hline Acción 1 & $\begin{array}{l}\text { Realizar concursos en las épocas } \\
\text { de mayor estacionalidad. }\end{array}$ & $\begin{array}{l}\text { Tener packs especiales para épocas en } \\
\text { estacionales. }\end{array}$ \\
Acción 2 & $\begin{array}{l}\text { Hacer ofertas aprovechando día } \\
\text { de la madre, padre, Fiestas } \\
\text { Patrias, fin de año. }\end{array}$ & $\begin{array}{l}\text { Negociar con los canales margen de } \\
\text { precio con margen de ventas. }\end{array}$ \\
\hline
\end{tabular}

- Estrategia 2: Posicionar la marca.

Objetivo: A través de la fidelización de los clientes posicionar la marca para que suban las ventas (Ver tabla 134). 
Tabla 134

Decisión de compra estrategia 2

\begin{tabular}{lll}
\hline & \multicolumn{1}{c}{ Página Web } & \multicolumn{1}{c}{ Otros Canales } \\
\hline Acción 1 & $\begin{array}{l}\text { Registro de clientes con datos, en } \\
\text { cumpleaños enviar saludo. }\end{array}$ & $\begin{array}{l}\text { Hacer que los consumidores finales } \\
\text { dejen su información para poder } \\
\text { contactarlos a través de la web. }\end{array}$ \\
Acción 2 & $\begin{array}{l}\text { Hacer publicaciones para } \\
\text { consumidores frecuentes con } \\
\text { promociones exclusivas. }\end{array}$ & $\begin{array}{l}\text { Temporalmente hacer regalos con la } \\
\text { compra. }\end{array}$ \\
\hline
\end{tabular}

5. Implementación,

Esta fase es muy importante, pues en la promoción y en la misma presentación de HECHIZO, se informará sobre como consumir, como almacenar, tiempo de vida de HECHIZO como fin para el aseguramiento de la calidad del mismo.

- Estrategia 1: Persuadir al consumidor para que compre HECHIZO.

Objetivo: Lograr que los consumidores compren HECHIZO a través de la información proporcionada (Ver tabla 135).

Tabla 135

Implementaciòn estrategia 1

\begin{tabular}{cl}
\hline \multicolumn{1}{c}{ Página Web } & \multicolumn{1}{c}{ Otros Canales } \\
\hline $\begin{array}{c}\text { Acción 1 Hacer concursos con los } \\
\text { consumidores sobre propuestas de } \\
\text { nuevas formas de presentación de } \\
\text { macerado. }\end{array}$ & $\begin{array}{l}\text { En los Canales de venta entregar volantes } \\
\text { con información de las ofertas y } \\
\text { presentaciones. }\end{array}$ \\
$\begin{array}{c}\text { Acción 2 } \\
\text { Utilizar testimonios de clientes } \\
\text { satisfechos para lograr más } \\
\text { compras. }\end{array}$ & $\begin{array}{l}\text { Ofrecer a los canales de venta descuento } \\
\text { por llegar a metas de ventas. }\end{array}$ \\
\hline
\end{tabular}

- Estrategia 2: Persuadir al consumidor para que compre HECHIZO.

Objetivo: Lograr que los consumidores compren HECHIZO a través de la información proporcionada (Ver tabla 136). 
Tabla 136

Implementaciòn estrategia 2

\begin{tabular}{lll}
\hline & \multicolumn{1}{c}{ Página Web } & \multicolumn{1}{c}{ Otros Canales } \\
\hline $\begin{array}{l}\text { Acción } \\
1\end{array}$ & Envío de actualizaciones a clientes. & $\begin{array}{l}\text { Tener el producto en sitios visibles con } \\
\text { banners atrayentes. }\end{array}$ \\
$\begin{array}{ll}\text { Acción } \\
2\end{array}$ & $\begin{array}{l}\text { Fomentar los foros con participación } \\
\text { de consumidores. }\end{array}$ & $\begin{array}{l}\text { Participar en eventos y hacer } \\
\text { demostraciones. }\end{array}$ \\
\hline
\end{tabular}

\subsubsection{Plan de ventas.}

De acuerdo a la demanda que arrojó el estudio de mercado, se determinó que se vendería HECHIZO por web y otros canales. En el estudio cuantitativo de mercado, usando la encuesta, se hizo la pregunta, en que época del año compraría HECHIZO para poder determinar la estacionalidad de la compra obteniendo el siguiente resultado en la tabla 137.

Tabla 137

Plan de ventas estrategia 1

\begin{tabular}{lccc}
\hline \multicolumn{1}{c}{ Estacionalidad } & $\%$ & $\%$ & Estacionalidad llevada al 100\% \\
\hline Primavera & $3 \%$ & $83 \%$ & $24.41 \%$ \\
Verano & $10 \%$ & $90 \%$ & $26.47 \%$ \\
Otoño & $1 \%$ & $81 \%$ & $23.82 \%$ \\
Invierno & $6 \%$ & $86 \%$ & $25.29 \%$ \\
Todo el año & $80 \%$ & & \\
\hline & $100 \%$ & & $100.00 \%$ \\
\hline
\end{tabular}

De esa forma se obtuvo una estacional mensual con la que se calculó las ventas, de acuerdo a la siguiente tabla 138 .

Tabla 138

Estacionalidad

\begin{tabular}{ccccccccccccc}
\hline Ene & Feb & Mar & Apr & May & Jun & Jul & Aug & Sep & Oct & Nov & Dec & \\
\hline $8.8 \%$ & $8.8 \%$ & $8.8 \%$ & $7.9 \%$ & $7.9 \%$ & $7.9 \%$ & $8.4 \%$ & $8.4 \%$ & $8.4 \%$ & $8.1 \%$ & $8.1 \%$ & $8.1 \%$ & $100.0 \%$ \\
\hline
\end{tabular}

Aprovechando las épocas especiales como día de la Madre, día del Padre, Fiestas Patrias, Navidades, festividades de fin de año y Año nuevo y aplicando las estrategias de ventas es que se espera llegar a las metas, ver tabla 139. 
Tabla 139

Programa de Ventas en unidades 2018-2022

\begin{tabular}{lccccc}
\hline Programa ventas botellas & 2018 & 2019 & 2020 & 2021 & 2022 \\
\hline WEB & 8,309 & 9,370 & 10,554 & 11,876 & 13,350 \\
Maracuyá y frambuesa & 2,991 & 3,373 & 3,800 & 4,275 & 4,806 \\
Fresa y guinda & 2,991 & 3,373 & 3,800 & 4,275 & 4,806 \\
Chicha & 2,326 & 2,624 & 2,955 & 3,325 & 3,738 \\
\hline OTROS CANALES & 26,919 & 30,356 & 34,193 & 38,475 & 43,252 \\
Maracuyá y frambuesa & 9,691 & 10,928 & 12,310 & 13,851 & 15,571 \\
Fresa y guinda & 9,691 & 10,928 & 12,310 & 13,851 & 15,571 \\
Chicha & 7,537 & 8,500 & 9,574 & 10,773 & 12,110 \\
\hline Total unidades & 35,228 & 39,726 & 44,748 & 50,351 & 56,602 \\
\hline
\end{tabular}

La venta en Soles se consideró igual para los dos canales, teniendo en cuenta los siguientes precios y márgenes (Ver tabla 140)

Tabla 140

Precios de venta

\begin{tabular}{|c|c|c|c|c|c|c|c|}
\hline Producto & $\begin{array}{l}\text { Precio de } \\
\text { venta } \\
\text { sugerido al } \\
\text { público }\end{array}$ & $\begin{array}{l}\text { Margen del } \\
\text { canal }\end{array}$ & \multicolumn{2}{|c|}{$\begin{array}{l}\text { Precio de venta } \\
\text { al canal }\end{array}$} & IGV & \multicolumn{2}{|c|}{ Valor venta } \\
\hline $\begin{array}{l}\text { Maracuyá y } \\
\text { frambuesa }\end{array}$ & 55.00 & $0 \%$ & $\mathrm{~S} /$. & 55.00 & $\begin{array}{c}\mathrm{S} / . \\
8.39\end{array}$ & $\mathrm{~S} /$. & 46.61 \\
\hline Fresa y guinda & 55.00 & $0 \%$ & $\mathrm{~S} /$. & 55.00 & 8.39 & $\mathrm{~S} /$. & 46.61 \\
\hline Chicha & 55.00 & $0 \%$ & $\mathrm{~S} /$. & 55.00 & $\begin{array}{c}\mathrm{S} / \\
8.39\end{array}$ & $\mathrm{~S} /$. & 46.61 \\
\hline $\begin{array}{l}\text { OTROS CANALES } \\
\text { Maracuyá y } \\
\text { frambuesa }\end{array}$ & 55.00 & $25 \%$ & $\mathrm{~S} /$. & 41.25 & $\begin{array}{c}\text { S/. } \\
6.29\end{array}$ & $\mathrm{~S} /$. & 34.96 \\
\hline Fresa y guinda & 55.00 & $25 \%$ & $\mathrm{~S} /$. & 41.25 & $\begin{array}{c}\sim \\
6.29\end{array}$ & $\mathrm{~S} /$. & 34.96 \\
\hline Chicha & 55.00 & $25 \%$ & $\mathrm{~S} /$. & 41.25 & $\begin{array}{c}\text { S/ } \\
6.29\end{array}$ & $\mathrm{~S} /$. & 34.96 \\
\hline
\end{tabular}

Considerando los precios mencionados arriba la proyección de ventas para los cinco años sería la siguiente: 
Tabla 141

Resumen de Ventas en Soles 2018-2022

\begin{tabular}{|c|c|c|c|c|c|}
\hline Programa ventas (soles) & 2018 & 2019 & 2020 & 2021 & 2022 \\
\hline WEB & S/. 387,278 & S/. 436,728 & S/. 491,932 & S/. 553,535 & S/. 622,250 \\
\hline Maracuyá y frambuesa & S/. 139,420 & S/. 157,222 & S/. 177,096 & S/. 199,272 & S/. 224,010 \\
\hline Fresa y guinda & S/. 139,420 & S/. 157,222 & S/. 177,096 & S/. 199,272 & S/. 224,010 \\
\hline Chicha & S/. 108,438 & S/. 122,284 & S/. 137,741 & S/. 154,990 & S/. 174,230 \\
\hline OTROS CANALES & S/. 941,028 & S/. $1,061,184$ & S/. 1,195,322 & S/. 1,345,007 & S/. 1,511,974 \\
\hline Maracuyá y frambuesa & S/. 338,770 & S/. 382,026 & S/. 430,316 & S/. 484,202 & S/. 544,311 \\
\hline Fresa y guinda & S/. 338,770 & S/. 382,026 & S/. 430,316 & S/. 484,202 & S/. 544,311 \\
\hline Chicha & S/. 263,488 & S/. 297,131 & S/. 334,690 & S/. 376,602 & S/. 423,353 \\
\hline Ventas (sin IGV) & S/. 1,328,306 & S/. 1,497,912 & S/. $1,687,254$ & S/. $1,898,541$ & S/. 2,134,224 \\
\hline IGV & S/. 239,095 & S/. 269,624 & S/. 303,706 & S/. 341,737 & S/. 384,160 \\
\hline Ventas (con IGV) & S/. 1,567,401 & S/. $1,767,536$ & S/. $1,990,960$ & S/. 2,240,279 & S/. 2,518,384 \\
\hline & & $12.77 \%$ & $12.64 \%$ & $12.52 \%$ & $12.41 \%$ \\
\hline
\end{tabular}

De acuerdo a la tabla 141, se puede observar un crecimiento en las ventas en los siguientes 4 años de $8.93 \%$ en el año 2019, 8.95\% en el año 2020, 8.97\% en el año 2021 y $8.99 \%$ en el año 2022.

\subsubsection{Políticas de servicios y garantías.}

La política de servicio y garantía que ofrecerá HECHIZO se basó en los estándares de calidad que aseguran la satisfacción total de cliente. Esta política se aplicará tanto para la compra por web como para la compra vía los canales: estaciones de servicio, licorerías u otros.

En cuanto a la web, HECHIZO, dará información sobre los productos para que sean adquiridos vía web. La compra se podrá hacer previo registro convirtiéndose en usuarios y en donde aceptaran los términos y condiciones que la empresa pública.

- Precios

Los precios publicados incluyen el I.G.V. Cabe resaltar que no incluyen los gastos correspondientes al envío, los mismos que son detallados en separados y deberán ser aceptados por el Cliente.

- Disponibilidad 
HECHIZO, informará al cliente de la disponibilidad de unidades para cada una de las promociones que publique. El objetivo es complacer a los clientes con relación a la demanda. En caso hubiera hecho el pedido el cliente y no haya disponibilidad del producto, se informará sobre la anulación del pedido.

-Pago

Al realizar el pedido el cliente se compromete a pagarlo. Al precio se le sumará el monto por gastos de envíos. La boleta correspondiente, se enviará en la confirmación de la compra. Ya que el cliente hará el pago vía tarjeta de débito o de crédito (Visa, MasterCard, Visa Electrón).

- Seguridad

La web asegura que las transacciones son seguras.

- Formalización de pedidos

Se da con la aceptación de condiciones y con la confirmación del proceso de compra.

La formalización se enviará con la confirmación de la compra.

- Cancelación de pedidos

Solo se aceptarán cuando sean solicitadas antes del envío del mismo y debe ser echar enviando un e-mail.

- Plazos, Lugar de entrega y extravíos

Para la entrega de producto, HECHIZO se compromete hacer la entrega del pedido en perfecto estado a la dirección dada por el cliente, en el horario laboral.

Plazo de entrega, la entrega se hará por medio de una empresa tercerizada, y será dentro de un plazo máximo de 3 días laborables, contando desde la confirmación del pedido. Se considerará entregado desde el momento en que se pone a disposición del cliente el producto. Se notificará al cliente sobre la entrega de su pedido vía mensaje e- mail al momento en que el producto salga de los almacenes. 
En caso no se encontrar el cliente se dejará una notificación para coordinar una nueva entrega.

Igualmente, al recibir el producto el cliente detecta que está roto, abierto, o algún problema con el embalaje. Deberá comunicarse vía e-mail o por teléfono para informar el incidente.

- Devolución

Se procederá a la devolución o reembolso, cuando el cliente comunique su intención dentro de 10 días laborable y siempre y cuando cumplan con las siguientes condiciones:

El producto se encuentre en el mismo estado en que se entregó y con el embalaje y etiquetado original.

- Adjuntar la copia del recibo de entrega.

Solo si el pedido está defectuoso, no es el que había pedido el cliente se procederá al reembolso. Sin embargo, si fuera porque no es del agrado del cliente, los costos de devolución serán por cuenta del mismo. 


\section{Capítulo VIII. Planificación financiera}

Se presentó y analizó todos los aspectos económicos y financieros en relación al proyecto. Para que esto sea factible, se determinaron todos los costos relacionados al proyecto y los flujos económicos y financieros.

Para la planificación financiera se utilizó la información recabada de las entrevistas de profundidad hechas a los dueños y Gerentes de bodegas de Pisco Sarcay y Bailetti (Ver tabla 23), productores artesanales de macerados de pisco en fruta Eddu's y Foodies (Ver tabla 21), sommelier para la mezcla de sabores (Ver tabla 24), de esa manera se logró tomar las decisiones que más convenían para la realización del proyecto.

\subsection{La Inversión}

Según Sapag y Sapag (2008), la Inversión pre-operativa corresponde a cuantificar la información obtenida en los estudios de mercado, técnico y organizacional. Esta información es muy importante porque se debe utilizar como referencia para poder proyectar el flujo de caja, el cual será materia de evaluación.

La Inversión se divide en activos fijo, activos intangibles, capital de trabajo y gastos pre-operativos, entre los montos estimados como Inversión, se consideraron los gastos preoperativos como los más relevantes, representando el 53\% de la Inversión total. Estos gastos consideran las inversiones más relevantes del proyecto, las cuales fueron obtenidas como resultado del estudio realizado en el capítulo tres. Se puede observar la distribución detallada de la Inversión en la tabla 142, tabla 143 y figura 14. 
Tabla 142

Distribución de la Inversión

\begin{tabular}{|c|c|c|c|c|}
\hline \multicolumn{5}{|c|}{ INVERSIÓN AÑO 0} \\
\hline Inversión & $\begin{array}{l}\text { Inversión sin } \\
\text { IGV }\end{array}$ & IGV & $\begin{array}{c}\text { Inversión con } \\
\text { IGV }\end{array}$ & $\%$ \\
\hline Activos Fijos & 106,163 & 19,109 & 125,273 & $30 \%$ \\
\hline Activos Intangibles & 4,988 & 730 & 5,719 & $1 \%$ \\
\hline Gastos pre-operativos & 190,460 & 18,627 & 209,087 & $51 \%$ \\
\hline Capital de Trabajo & 71,275 & & 71,275 & $17 \%$ \\
\hline Total & 372,887 & 38,467 & 411,354 & $100 \%$ \\
\hline
\end{tabular}

Tabla 143

Distribución de la Inversión en porcentaje

\begin{tabular}{lr}
\hline \multicolumn{2}{c}{ Inversión } \\
\hline Activo Fijo y bienes no depreciables \\
Activo Intangibles & $30 \%$ \\
Gastos pre-operativos & $1 \%$ \\
\hline Capital de Trabajo & $51 \%$ \\
\hline
\end{tabular}

\section{Estructura de Inversiones}

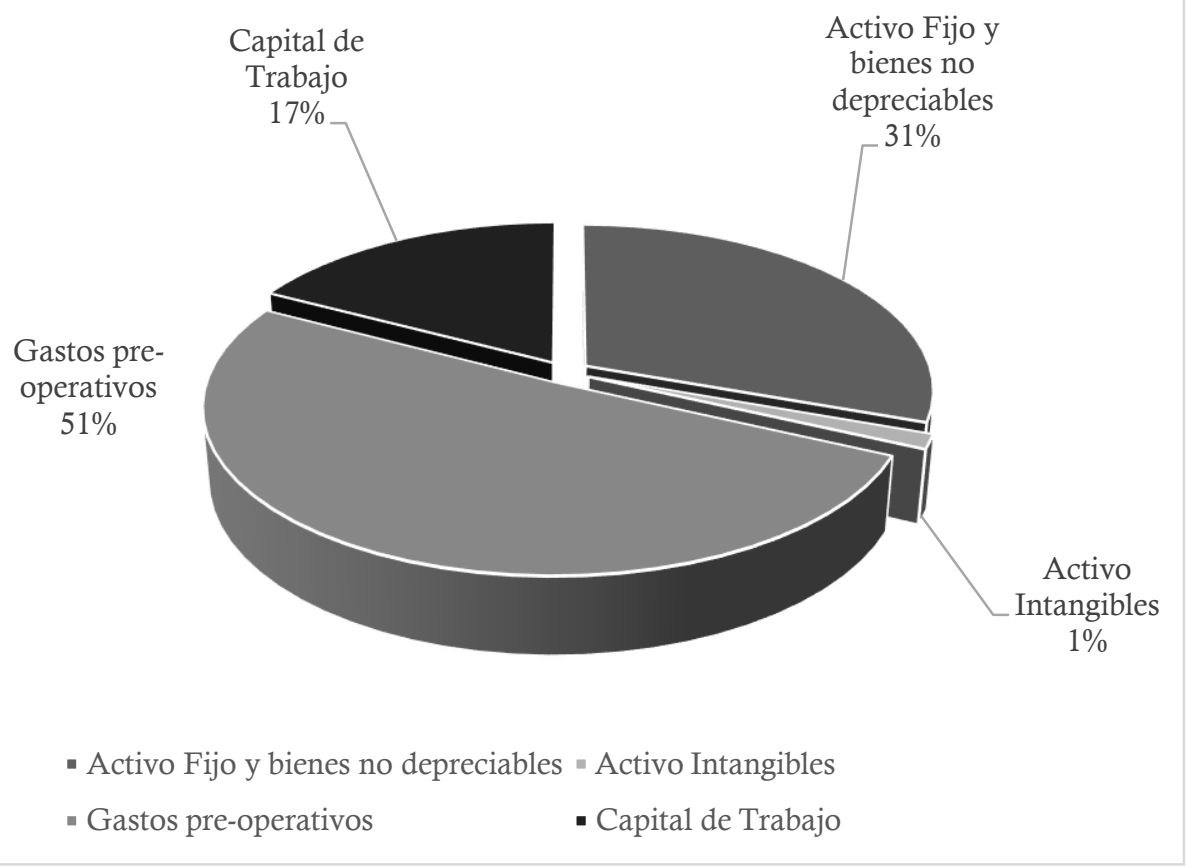

Figura 13. Estructura de Inversiones. 


\subsubsection{Inversión pre-operativa.}

Como indica Sapag y Sapag (2008), antes que la empresa inicie operaciones, se pueden considerar hasta tres clases de inversiones, activos intangibles, activos fijos y capital de trabajo. Las inversiones en activos fijos representan la adquisición de bienes tangibles utilizados en la transformación de insumos o en la operación regular de la empresa. Los activos intangibles representan la adquisición de servicios y derechos adquiridos que sirvan como soporte para el inicio de operaciones de la empresa.

La tabla 144, presenta la Inversión en gastos pre-operativos que se consideró antes de que la empresa inicie sus operaciones. Se decidió hacer la Inversión pre-operativa, luego de la valiosa información que se obtuvo de las entrevistas a profundidad con cada uno de los especialistas (Anexos 19). Se determinó que el tiempo de maceración del producto debería estimar dos meses para que el producto pueda obtener el sabor y aroma deseados. En resumen, para ofrecer el producto final, se necesitaba iniciar la producción con dos meses de anticipación. Toda la información vertida en este cuadro fue obtenida en el capítulo tres, debido a las cotizaciones y estimaciones realizadas en dicho capítulo. El total en gastos preoperativos asciende a S/ 209,087.16 incluido IGV. En el anexo 19 ver cuadro de amortización de los Gastos Pre Operativos.

La tabla 145 muestra la Inversión pre-operativa en bienes no depreciables, los cuales consideran diversos utensilios para acondicionar las oficinas. Esta información fue obtenida según cotizaciones con proveedor y se muestran al detalle durante el capítulo tres. En esta tabla se muestra el total que asciende a S/ 9,948.

En la tabla 146 se detalla la Inversión en activos fijos durante el año cero, aquí se consideró la compra de la maquinaria y equipos, pero divididas por cada área de la empresa, producción, ventas y administración, esto para poder tener la información más detallada. El 
total de esta Inversión asciende a S/ 125,273. En el anexo \# 19 se puede apreciar la depreciación de los activos fijos.

Para las tablas 147 y 148 se muestra la Inversión en activos intangibles, los cuales están representados en gran parte por las actividades de registro de la empresa, además de la marca y patentes. El total en gastos intangibles a S/ 5,718.84. Toda la información fue obtenida durante la elaboración del capítulo cinco. En el anexo \# 20 se puede ver el cálculo de la amortización de intangibles. 
Tabla 144

Inversión en Pre-Operativos (Nov-Dic)

Total Precio de Descripción

Cant. Costo unitario S/. Total Valor Venta IGV $18 \%$ Venta

\section{ACONDICIONAMIENTO LOCAL}

Acondicionamiento de planta de

operaciones y oficina administrativa ALQUILER PRE OPERATIVO

\begin{tabular}{|c|c|c|c|c|c|c|c|c|c|}
\hline Garantia de alquiler & 2 & $\mathrm{~S} /$. & $12,882.00$ & $\mathrm{~S} /$. & $25,764.00$ & & & $\mathrm{~S} /$. & $25,764.00$ \\
\hline Alquiler pre-operativo & 2 & $\mathrm{~S} /$. & $12,882.00$ & $\mathrm{~S} /$. & $25,764.00$ & & & $\mathrm{~S} /$. & $25,764.00$ \\
\hline \multicolumn{10}{|l|}{ MARKETING } \\
\hline Campañas de difusión & 1 & $\mathrm{~S} /$. & $7,474.58$ & $\mathrm{~S} /$. & $7,474.58$ & S/. & $1,345.42$ & $\mathrm{~S} /$. & $8,820.00$ \\
\hline \multicolumn{10}{|l|}{ BIENES NO DEPRECIABLES } \\
\hline Produccion & 1 & $\mathrm{~S} /$. & $5,110.46$ & $\mathrm{~S} /$. & $5,110.46$ & $\mathrm{~S} /$. & 919.88 & $\mathrm{~S} /$. & $6,030.34$ \\
\hline Administracion & 1 & $\mathrm{~S} /$. & $1,498.90$ & $\mathrm{~S} /$. & $1,498.90$ & $\mathrm{~S} /$. & 269.80 & $\mathrm{~S} /$. & $1,768.70$ \\
\hline Ventas & 1 & $\mathrm{~S} /$. & $1,821.53$ & $\mathrm{~S} /$. & $1,821.53$ & $\mathrm{~S} /$. & 327.87 & $\mathrm{~S} /$. & $2,149.40$ \\
\hline \multicolumn{10}{|l|}{ MATERIALES } \\
\hline Materia prima & 1 & $\mathrm{~S} /$. & $54,126.27$ & $\mathrm{~S} /$. & $54,126.27$ & $\mathrm{~S} /$. & $9,742.73$ & $\mathrm{~S} /$. & $63,869.00$ \\
\hline Material de empaque & 1 & $\mathrm{~S} /$. & $1,576.27$ & $\mathrm{~S} /$. & $1,576.27$ & $\mathrm{~S} /$. & 283.73 & $\mathrm{~S} /$. & $1,860.00$ \\
\hline Utensilios de producción & 1 & $\mathrm{~S} /$. & 642.15 & $\mathrm{~S} /$. & 642.15 & $\mathrm{~S} /$. & 115.59 & $\mathrm{~S} /$. & 757.74 \\
\hline Uniformes & 1 & $\mathrm{~S} /$. & 307.63 & $\mathrm{~S} /$. & 307.63 & $\mathrm{~S} /$. & 55.37 & $\mathrm{~S} /$. & 363.00 \\
\hline
\end{tabular}

\section{OTROS GASTOS PRE-OPERATIVOS}

\begin{tabular}{|c|c|c|c|c|c|c|c|c|c|}
\hline Personal (planilla pre - operativa) & 1 & S/. & $35,448.98$ & $\mathrm{~S} /$. & $35,448.98$ & & & $\mathrm{~S} /$. & $35,448.98$ \\
\hline Servicios (pre-operativo) & 1 & $\mathrm{~S} /$. & $11,525.42$ & $\mathrm{~S} /$. & $11,525.42$ & $\mathrm{~S} / \mathrm{.}$ & $2,074.58$ & S/. & $13,600.00$ \\
\hline TOTAL GASTOS PRE-OPERATIVOS & & & & $\mathrm{S} / \mathrm{.}$ & $190,460.19$ & $\mathrm{~S} /$. & $18,626.98$ & S/. & $209,087.16$ \\
\hline
\end{tabular}


Tabla 145

InversiónPre Operativa - Bienes no Depreciables

\begin{tabular}{|c|c|c|c|c|c|}
\hline Descripcion & Cantidad & Costo unitario $\mathrm{S} /$. & $\begin{array}{r}\text { Total Valor } \\
\text { (Sin IGV) }\end{array}$ & IGV $18 \%$ & $\begin{array}{l}\text { Total Valor } \\
\text { (Con IGV) }\end{array}$ \\
\hline \multicolumn{6}{|l|}{ PRODUCCION } \\
\hline Balanza electrónica & 1 & 349 & 349 & $\mathrm{~S} /$. & 412 \\
\hline Mesas de acero con lavadero & 2 & 720 & 1,440 & 259 & 1,699 \\
\hline Máquina de encapsulado & 2 & 228 & 456 & $\mathrm{~S} /$. & 538 \\
\hline Sillas & 2 & 153 & 305 & $\mathrm{~S} /$. & 360 \\
\hline Casilleros & 3 & 237 & 712 & 128 & 840 \\
\hline Escritorio básico & 1 & 330 & 330 & $\mathrm{~S} /$. & 390 \\
\hline Botiquin & 1 & $\mathrm{~S} /$. & S/. & $\mathrm{S} /$. & $\mathrm{S} /$. \\
\hline Extintores & 3 & $\mathrm{~S} /$. & 173 & $\mathrm{~S} /$. & 204 \\
\hline \multirow[t]{2}{*}{ Cámara de seguridad } & 4 & 190 & 762 & 137 & 899 \\
\hline & 1 & 550 & 550 & $\mathrm{~S} /$. & 649 \\
\hline TOTAL & & & S/. 5,110 & S/. 920 & S/. 6,030 \\
\hline \multicolumn{6}{|l|}{ VENTAS } \\
\hline Escritorio básico & 3 & 330 & 991 & 178 & 1,170 \\
\hline Estantes/Libreros & 1 & 322 & 322 & $\mathrm{~S} /$. & 380 \\
\hline Sillas & 3 & 169 & 508 & $\mathrm{~S} /$. & 600 \\
\hline TOTAL & & & $\mathrm{S} / .1,822$ & S/. 328 & $\mathrm{~S} / .2,149$ \\
\hline \multicolumn{6}{|l|}{ ADMINISTRATIVO } \\
\hline Escritorio Ejecutivo & 1 & 508 & 508 & S/. & 599 \\
\hline Escritorio básico & 1 & 330 & 330 & $\mathrm{~S} /$. & 390 \\
\hline Estantes/Libreros & 1 & 322 & 322 & $\mathrm{~S} /$. & 380 \\
\hline Sillas & 2 & 169 & 339 & 61 & 400 \\
\hline TOTAL & & & S/. 1,499 & S/. 270 & S/. 1,769 \\
\hline TOTAL BIENES NO DEPRECIABLES & & & $\mathrm{S} / .8,431$ & $\mathrm{~S} / .1,518$ & S/. 9,948 \\
\hline
\end{tabular}


Tabla 146

InversiónActivos fijos - Año Cero

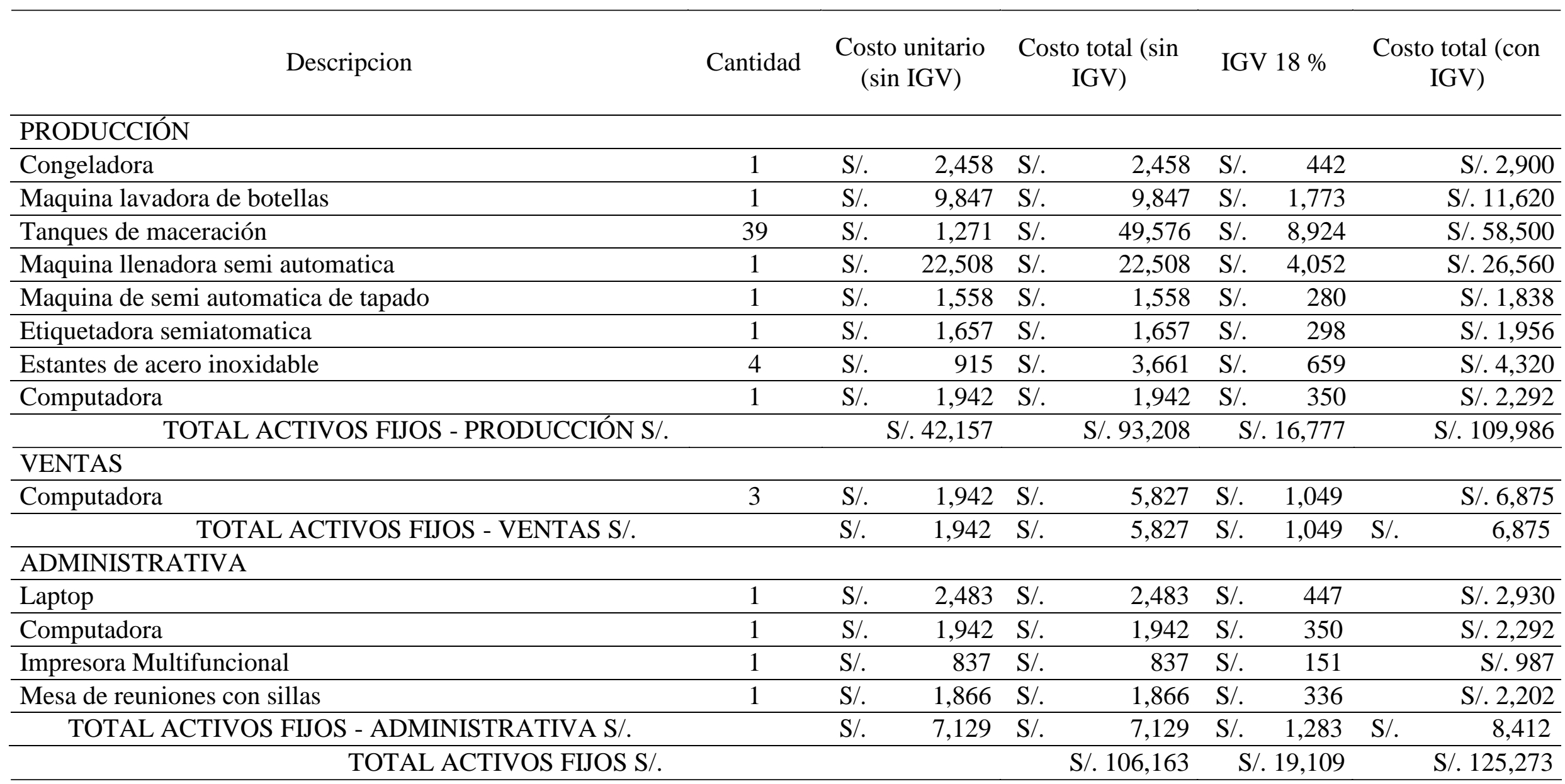


Tabla 147

InversiónIntangibles

\begin{tabular}{|c|c|c|c|c|c|c|c|c|}
\hline \multirow[t]{2}{*}{ DESCRIPCION } & \multirow[t]{2}{*}{ Cant. } & $\begin{array}{l}\text { Costo } \\
\text { unitario } \mathrm{S} / .\end{array}$ & \multicolumn{2}{|c|}{$\begin{array}{l}\text { Total Valor } \\
\text { Venta }\end{array}$} & \multicolumn{2}{|c|}{ IGV $18 \%$} & \multicolumn{2}{|c|}{$\begin{array}{l}\text { Total Precio de } \\
\text { Venta }\end{array}$} \\
\hline & & \multicolumn{7}{|c|}{ CONSTITUCION DE LA EMPRESA } \\
\hline Búsqueda de índices ante la SUNARP & & S/. $\quad 5.00$ & $\mathrm{~S} /$. & 5.00 & & & $\mathrm{~S} /$. & 5.00 \\
\hline Reserva de nombre ante la SUNARP & & S/. $\quad 18.00$ & $\mathrm{~S} /$. & 18.00 & & & $\mathrm{~S} /$. & 18.00 \\
\hline Elaboración de minuta & & S/. 450.00 & $\mathrm{~S} /$. & 450.00 & $\mathrm{~S} /$. & 81.00 & $\mathrm{~S} /$. & 531.00 \\
\hline Escritura Pública ante notario público & & S/. $\quad 90.00$ & $\mathrm{~S} /$. & 90.00 & $\mathrm{~S} /$. & 16.20 & $\mathrm{~S} /$. & 106.20 \\
\hline Gastos Administrativos Notaria & & 75.20 & $\mathrm{~S} /$. & 75.20 & $\mathrm{~S} /$. & 13.54 & $\mathrm{~S} /$. & 88.74 \\
\hline Elevar la escritura pública a SUNARP & & 90.00 & $\mathrm{~S} /$. & 90.00 & & & $\mathrm{~S} /$. & 90.00 \\
\hline $\begin{array}{l}\text { Costo de Libros contables (4) Resolución de } \\
\text { Superintendencia 226-2013/SUNAT }\end{array}$ & & S/. $\quad 80.00$ & $\mathrm{~S} /$. & 80.00 & $\mathrm{~S} /$. & 14.40 & $\mathrm{~S} /$. & 94.40 \\
\hline Legalización libros contables & & S/. 120.00 & $\mathrm{~S} /$. & 120.00 & $\mathrm{~S} /$. & 21.60 & $\mathrm{~S} /$. & 141.60 \\
\hline
\end{tabular}

\begin{tabular}{|c|c|c|c|c|c|c|c|c|c|}
\hline TOTAL CONSTITUCION DE LA EMPRESA & & & & $\mathrm{S} /$. & 928.20 & $\mathrm{~S} /$. & 146.74 & \multicolumn{2}{|c|}{ S/. $1,074.94$} \\
\hline \multicolumn{10}{|c|}{ REGISTRO DE MARCAS O PATENTES } \\
\hline Búsqueda fonética - figurativa & 3 & $\mathrm{~S} /$. & 31.00 & $\mathrm{~S} /$. & 93.00 & $\mathrm{~S} /$. & 16.74 & S/. & 109.74 \\
\hline Registro de marca y Logo (13.90\% de la UIT) & 1 & $\mathrm{~S} /$. & 549.05 & $\mathrm{~S} /$. & 549.05 & $\mathrm{~S} /$. & 98.83 & $\mathrm{~S} /$. & 647.88 \\
\hline Registro de Nombre Comercial (13.90\% de la UIT) & 1 & $\mathrm{~S} /$. & 549.05 & $\mathrm{~S} / \mathrm{s}$ & 549.05 & S/. & 98.83 & S/. & 647.88 \\
\hline Registro de Código de barras & 1 & $\mathrm{~S} /$. & 423.73 & $\mathrm{~S} /$. & 423.73 & $\mathrm{~S} /$. & 76.27 & $\mathrm{~S} /$. & 500.00 \\
\hline Publicación en Diario El Peruano & 1 & $\mathrm{~S} /$. & 200.00 & $\mathrm{~S} /$. & 200.00 & $\mathrm{~S} /$. & 36.00 & S/. & 236.00 \\
\hline
\end{tabular}


Tabla 148

Inversiónen Otros Intangibles

\begin{tabular}{lcccc}
\hline DESCRIPCION & Cant. & $\begin{array}{c}\text { Costo unitario } \\
\text { S/. }\end{array}$ & $\begin{array}{c}\text { Total Valor } \\
\text { Venta }\end{array}$ & IGV $18 \%$ \\
\hline LICENCIAS Y AUTORIZACIONES & $\begin{array}{c}\text { Total Precio de } \\
\text { Venta }\end{array}$ \\
\hline
\end{tabular}

Local: Distrito de San Luis

\begin{tabular}{|c|c|c|c|c|c|c|c|c|}
\hline Licencia de Funcionamiento & 1 & S/. 188.00 & $\mathrm{~S} /$. & 188.00 & & & $\mathrm{~S} /$. & 188.00 \\
\hline Inscripción de seguridad en Defensa Civil & 1 & S/. 76.00 & S/. & 76.00 & & & $\mathrm{~S} /$. & 76.00 \\
\hline Registro Sanitario & 1 & S/. 390.00 & $\mathrm{~S} /$. & 390.00 & & & $\mathrm{~S} /$. & 390.00 \\
\hline Habilitación sanitaria y HACCP & 1 & S/. 985.30 & $\mathrm{~S} /$. & 985.30 & $\mathrm{~S} /$. & 177.35 & $\mathrm{~S} /$. & $1,162.65$ \\
\hline Defensa Civil & 1 & S/. 115.00 & $\mathrm{~S} /$. & 115.00 & & & $\mathrm{~S} /$. & 115.00 \\
\hline
\end{tabular}

Defensa Civil S/. $\quad 1,802.90$

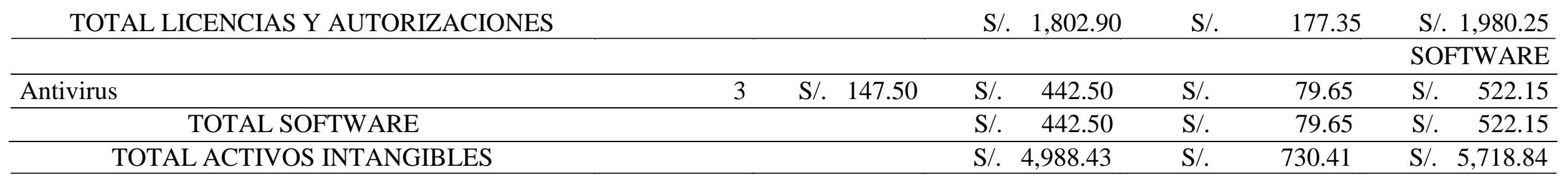

S/. 1,980.25 


\subsubsection{Inversión en Capital de Trabajo.}

Según Sapag y Sapag (2008), el invertir en capital de trabajo representa el acumulado de recursos que la empresa necesitaría para que opere de manera normal dentro de un ciclo productivo considerando la capacidad y tamaño de planta. Para el caso de empresas dedicadas a la producción, la Inversión en capital de trabajo se verá representada por el aseguramiento de recursos para la adquisición de materia prima y la cobertura de costos asociados con la operación.

Para la Inversión en capital de trabajo se consideraron las ventas anuales totales para poder calcular el capital de trabajo necesario para el desarrollo de la operación. La tabla 149 demuestra el resumen del capital de trabajo necesario durante los 5 años del proyecto. Se observar que el capital de trabajo necesario aumenta cada año, debido al crecimiento en las ventas. Para más detalle ver los anexos del21 al 24. 
Tabla 149

Inversión en Capital de Trabajo Anual

\begin{tabular}{lllll}
\hline Año 0 & Año 1 & Año 2 & Año 3 & Año 4
\end{tabular}

\begin{tabular}{|c|c|c|c|c|c|c|c|c|c|c|}
\hline Ventas & & & $\mathrm{S} /$. & $1,328,306$ & $\mathrm{~S} /$. & ,497,912 & $\mathrm{S} /$. & 687,254 & S/. $1,898,541$ & S/. 2,134,224 \\
\hline Capital de trabajo necesario & & & $\mathrm{S} /$. & 71,275 & $\mathrm{~S} /$. & 80,376 & $\mathrm{~S} /$. & 90,536 & S/. $\quad 101,874$ & S/. $\quad 114,520$ \\
\hline Inversión capital de trabajo & $\mathrm{S} /$. & $-71,275$ & $\mathrm{~S} /$. & $-9,101$ & $\mathrm{~S} /$. & $-10,160$ & $\mathrm{~S} /$. & $-11,337$ & $-12,646$ & \\
\hline Recuperación de capital de trabajo & & & & & & & & & & S/. $\quad 114,520$ \\
\hline
\end{tabular}




\subsubsection{Costo del proyecto.}

Para Sapag y Sapag (2008), los costos del proyecto son deducidos en base a los estudios técnicos y de mercado, se deben estimar y considerar todos los costos obtenidos como resultado de dichos estudios. El proyecto será analizado según la estimación de los costos en el flujo de caja. Es importante este análisis porque influyen de manera directa en la rentabilidad futura del proyecto.

Luego de terminados los estudios relacionados al proyecto se procedió a cuantificar todos los gastos incurridos en el proyecto de manera detallada. Los costos de producción fueron considerados como los más relevantes dentro del proyecto debido al negocio que consiste en la fabricación de macerados de frutas en pisco. Se detallaron los costos para cada uno de los tres sabores que ofrecerá la empresa a todo el público. Los costos fueron divididos entre fijos y variables para poder ser identificados de manera eficiente y tomar acción.

La tabla 150 muestra los costos unitarios de producción, se presenta el resumen de dichos costos unitarios teniendo como referencia cada uno de los tres sabores de macerados de frutas en pisco que ofrece la empresa durante los cinco años del proyecto. Se puede observar el costo de materia prima, mano de obra directa, costos indirectos de fabricación, gastos administrativos y de ventas. 
Tabla 150

Costos de Producción Unitarios

\begin{tabular}{|c|c|c|c|c|c|c|c|c|c|c|}
\hline \multirow{2}{*}{$\begin{array}{l}\text { Resumen de costos unitarios } \\
\text { Maracuyá y frambuesa }\end{array}$} & \multicolumn{2}{|c|}{ Año 1} & \multicolumn{2}{|c|}{ Año 2} & \multicolumn{2}{|c|}{ Año 3} & \multicolumn{2}{|c|}{ Año 4} & \multicolumn{2}{|c|}{ Año 5} \\
\hline & $\mathrm{S} /$. & 33.14 & $\mathrm{~S} /$. & 32.83 & $\mathrm{~S} /$. & 31.19 & $\mathrm{~S} /$. & 29.52 & $\mathrm{~S} /$. & 31.10 \\
\hline Materia prima & $\mathrm{S} /$. & 17.03 & $\mathrm{~S} /$. & 17.39 & $\mathrm{~S} /$. & 17.39 & S/. & 17.39 & $\mathrm{~S} /$. & 17.38 \\
\hline Mano de obra directa & $\mathrm{S} /$. & 0.83 & $\mathrm{~S} /$. & 1.04 & $\mathrm{~S} /$. & 0.94 & S/. & 0.84 & $\mathrm{~S} /$. & 0.94 \\
\hline $\mathrm{CIF}$ & $\mathrm{S} /$. & 5.60 & $\mathrm{~S} /$. & 5.39 & $\mathrm{~S} /$. & 4.92 & S/. & 4.50 & $\mathrm{~S} /$. & 5.06 \\
\hline Gastos administrativos & $\mathrm{S} /$. & 3.72 & $\mathrm{~S} /$. & 3.52 & $\mathrm{~S} /$. & 3.16 & $\mathrm{~S} /$. & 2.83 & $\mathrm{~S} /$. & 3.15 \\
\hline Gastos de ventas & $\mathrm{S} /$. & 5.96 & S/. & 5.49 & $\mathrm{~S} /$. & 4.80 & S/. & 3.96 & S/. & 4.57 \\
\hline Fresa y guinda & $\mathrm{S} /$. & 27.82 & $\mathrm{~S} /$. & 27.39 & $\mathrm{~S} /$. & 25.72 & S/. & 24.02 & $\mathrm{~S} /$. & 25.64 \\
\hline Materia prima & $\mathrm{S} /$. & 11.30 & $\mathrm{~S} /$. & 11.54 & $\mathrm{~S} /$. & 11.54 & S/. & 11.54 & $\mathrm{~S} /$. & 11.54 \\
\hline Mano de obra directa & $\mathrm{S} /$. & 0.88 & $\mathrm{~S} /$. & 1.11 & $\mathrm{~S} /$. & 0.99 & S/. & 0.89 & $\mathrm{~S} /$. & 1.00 \\
\hline $\mathrm{CIF}$ & $\mathrm{S} /$. & 5.96 & $\mathrm{~S} /$. & 5.73 & $\mathrm{~S} /$. & 5.23 & $\mathrm{~S} /$. & 4.79 & $\mathrm{~S} /$. & 5.38 \\
\hline Gastos administrativos & $\mathrm{S} /$. & 3.72 & $\mathrm{~S} /$. & 3.52 & $\mathrm{~S} /$. & 3.16 & $\mathrm{~S} /$. & 2.83 & $\mathrm{~S} /$. & 3.15 \\
\hline Gastos de ventas & $\mathrm{S} /$. & 5.96 & $\mathrm{~S} /$. & 5.49 & $\mathrm{~S} /$. & 4.80 & S/. & 3.96 & $\mathrm{~S} /$. & 4.57 \\
\hline Chicha & $\mathrm{S} /$. & 30.15 & $\mathrm{~S} /$. & 29.72 & $\mathrm{~S} /$. & 27.88 & $\mathrm{~S} /$. & 26.02 & $\mathrm{~S} /$. & 27.84 \\
\hline Materia prima & $\mathrm{S} /$. & 11.66 & $\mathrm{~S} /$. & 11.90 & $\mathrm{~S} /$. & 11.90 & S/. & 11.90 & $\mathrm{~S} /$. & 11.90 \\
\hline Mano de obra directa & $\mathrm{S} /$. & 1.13 & $\mathrm{~S} /$. & 1.43 & $\mathrm{~S} /$. & 1.28 & S/. & 1.15 & $\mathrm{~S} /$. & 1.29 \\
\hline CIF & $\mathrm{S} /$. & 7.67 & $\mathrm{~S} /$. & 7.38 & $\mathrm{~S} /$. & 6.74 & $\mathrm{~S} /$. & 6.17 & $\mathrm{~S} /$. & 6.93 \\
\hline Gastos administrativos & $\mathrm{S} /$. & 3.72 & $\mathrm{~S} /$. & 3.52 & $\mathrm{~S} /$. & 3.16 & $\mathrm{~S} /$. & 2.83 & $\mathrm{~S} /$. & 3.15 \\
\hline Gastos de ventas & $\mathrm{S} /$. & 5.96 & $\mathrm{~S} /$. & 5.49 & $\mathrm{~S} /$. & 4.80 & S/. & 3.96 & $\mathrm{~S} /$. & 4.57 \\
\hline
\end{tabular}

En la tabla 151 se detalla el margen unitario obtenido para cada uno de los tres sabores de macerados de frutas en pisco que ofrece la empresa durante los cinco años del proyecto. Cada margen esta expresado en porcentajes y para obtenerlos se consideró el valor de venta promedio, costo y margen unitario. 
Tabla 151

Margen Unitario

\begin{tabular}{|c|c|c|c|c|c|c|c|c|}
\hline MARGEN UNITARIO & & io 1 & & 102 & Año 3 & & o 4 & Año 5 \\
\hline \multicolumn{9}{|l|}{ Maracuyá y frambuesa } \\
\hline Valor venta promedio & $\mathrm{S} /$. & 32.30 & $\mathrm{~S} /$. & 34.51 & 34.84 & $\mathrm{~S} /$. & 35.18 & 44.35 \\
\hline Costo unitario & $\mathrm{S} /$. & 33.14 & $\mathrm{~S} /$. & 32.83 & 31.19 & $\mathrm{~S} /$. & 29.52 & 31.10 \\
\hline Marge unitario & $\mathrm{S} /$. & -0.83 & $\mathrm{~S} /$. & 1.68 & 3.65 & $\mathrm{~S} /$. & 5.66 & $\mathrm{~S} / . \quad 13.24$ \\
\hline Margen $\%$ & \multicolumn{2}{|c|}{$-3 \%$} & \multicolumn{2}{|c|}{$5 \%$} & $10 \%$ & \multicolumn{2}{|c|}{$16 \%$} & $30 \%$ \\
\hline \multicolumn{9}{|l|}{ Fresa y guinda } \\
\hline Valor venta promedio & $\mathrm{S} /$. & 32.30 & $\mathrm{~S} /$. & 34.51 & 34.84 & $\mathrm{~S} /$. & 35.18 & 44.35 \\
\hline Costo unitario & $\mathrm{S} /$. & 27.82 & $\mathrm{~S} /$. & 27.39 & 25.72 & $\mathrm{~S} /$. & 24.02 & 25.64 \\
\hline Marge unitario & $\mathrm{S} /$. & 4.48 & $\mathrm{~S} /$. & 7.12 & S/. $\quad 9.12$ & $\mathrm{~S} /$. & 11.16 & S/. 18.71 \\
\hline Margen $\%$ & \multicolumn{2}{|c|}{$14 \%$} & \multicolumn{2}{|c|}{$21 \%$} & $26 \%$ & \multicolumn{2}{|c|}{$32 \%$} & $42 \%$ \\
\hline \multicolumn{9}{|l|}{ Chicha } \\
\hline Valor venta promedio & $\mathrm{S} /$. & 32.30 & $\mathrm{~S} /$. & 34.51 & S/. 34.84 & $\mathrm{~S} /$. & 35.18 & 44.35 \\
\hline Costo unitario & $\mathrm{S} /$. & 30.15 & $\mathrm{~S} /$. & 29.72 & 27.88 & $\mathrm{~S} /$. & 26.02 & 27.84 \\
\hline Marge unitario & S/. & 2.16 & $\mathrm{~S} /$. & 4.79 & S/. $\quad 6.97$ & $\mathrm{~S} /$. & 9.16 & S/. 16.51 \\
\hline Margen \% & \multicolumn{2}{|c|}{$7 \%$} & \multicolumn{2}{|c|}{$14 \%$} & $20 \%$ & \multicolumn{2}{|c|}{$26 \%$} & $37 \%$ \\
\hline
\end{tabular}

La tabla 152 evidencia los costos fijos y variables unitarios para cada uno de los tres sabores de macerados de frutas en pisco. Para más detalle sobre los costos fijos y variables ver el anexo 25, en donde se detallan los costos fijos y variables. Los costos de material de empaque, utensilios de producción, uniformes y material de limpieza.

Tabla 152

Costos Fijos y Variables

\begin{tabular}{crrrrr}
\hline Resumen de costos unitarios & \multicolumn{1}{c}{ Año 1 } & \multicolumn{1}{c}{ Año 2} & Año 3 & Año 4 & \multicolumn{1}{c}{ Año 5 } \\
\hline Maracuya y frambuesa & S/. 33.14 & S/. 32.83 & S/. 31.19 & S/. 29.52 & S/. 31.10 \\
Costo variable unitario & S/.18.92 & S/.19.39 & S/.19.41 & S/.19.42 & S/.19.87 \\
Costo fijo unitario & S/.14.21 & S/.13.44 & S/.11.79 & S/.10.10 & S/.11.23 \\
Fresa y guinda & S/. 27.82 & S/. 27.39 & S/. 25.72 & S/. 24.02 & S/. 25.64 \\
\hline Costo variable unitario & S/.13.24 & S/.13.59 & S/.13.60 & S/.13.62 & S/.14.07 \\
\hline Costo fijo unitario & S/.14.58 & S/.13.80 & S/.12.11 & S/.10.39 & S/.11.56 \\
\hline Chicha & S/. 30.15 & S/. 29.72 & S/. 27.88 & S/. 26.02 & S/. 27.84 \\
\hline Costo variable unitario & S/.13.81 & S/.14.18 & S/.14.19 & S/.14.21 & S/.14.70 \\
\hline Costo fijo unitario & S/.16.33 & S/.15.55 & S/.13.68 & S/.11.81 & S/.13.14 \\
\hline
\end{tabular}


La tabla 153, muestra el margen de contribución unitario.

Tabla 153

Costos Fijos y Variables - Margen de contribución

\begin{tabular}{cccccc}
\hline Margen de Contribución & Año 1 & Año 2 & Año 3 & Año 4 & Año 5 \\
\hline Maracuyá y frambuesa & & & & & \\
Valor venta unitario promedio & S/.32.30 & S/.34.51 & S/.34.84 & S/.35.18 & S/.44.35 \\
Costo variable unitario & S/.18.92 & S/.19.39 & S/.19.41 & S/.19.42 & S/.19.87 \\
Margen de contribución unitario & $\mathrm{S} / .13 .38$ & $\mathrm{~S} / .15 .12$ & $\mathrm{~S} / .15 .44$ & $\mathrm{~S} / .15 .76$ & $\mathrm{~S} / .24 .48$ \\
\hline Fresa y guinda & & & & & \\
Valor venta unitario promedio & $\mathrm{S} / .32 .30$ & $\mathrm{~S} / .34 .51$ & $\mathrm{~S} / .34 .84$ & $\mathrm{~S} / .35 .18$ & $\mathrm{~S} / .44 .35$ \\
Costo variable unitario & $\mathrm{S} / .13 .24$ & $\mathrm{~S} / .13 .59$ & $\mathrm{~S} / .13 .60$ & $\mathrm{~S} / .13 .62$ & $\mathrm{~S} / .14 .07$ \\
Margen de contribución unitario & $\mathrm{S} / .19 .06$ & $\mathrm{~S} / .20 .92$ & $\mathrm{~S} / .21 .24$ & $\mathrm{~S} / .21 .56$ & $\mathrm{~S} / .30 .27$ \\
\hline Chicha & & & & & \\
Valor venta unitario promedio & $\mathrm{S} / .32 .30$ & $\mathrm{~S} / .34 .51$ & $\mathrm{~S} / .34 .84$ & $\mathrm{~S} / .35 .18$ & $\mathrm{~S} / .44 .35$ \\
Costo variable unitario & $\mathrm{S} / .13 .81$ & $\mathrm{~S} / .14 .18$ & $\mathrm{~S} / .14 .19$ & $\mathrm{~S} / .14 .21$ & $\mathrm{~S} / .14 .70$ \\
Margen de contribución unitario & $\mathrm{S} / .18 .49$ & $\mathrm{~S} / .20 .33$ & $\mathrm{~S} / .20 .65$ & $\mathrm{~S} / .20 .97$ & $\mathrm{~S} / .29 .65$ \\
\hline
\end{tabular}

\subsubsection{Inversiones futuras.}

Según Sapag y Sapag (2008), se deben proyectar las inversiones futuras en activos de reemplazo y ampliación de planta según se tenga considerado. Las inversiones en reemplazo de los activos se estiman en base a la vida útil de cada uno de ellos. Toda Inversión estará condicionada a la capacidad de producción, tamaño de la planta y a la adquisición o mantenimiento de equipos.

Las inversiones futuras están representadas por todas las inversiones realizadas desde el primer año de operación de la empresa, para el caso del proyecto se consideró la Inversión en activos fijos y capital de trabajo durante los tres primeros años del proyecto, mientras que solo se realizará una Inversión en capital de trabajo para el desarrollo del cuarto año. Se programó que de acuerdo a cómo el proyecto va creciendo por la necesidad de producción se comprarían más tanques de maceración y se comprarían más tanques de maceración cada año para poder responder a la demanda estimada. Debido a eso el capital de trabajo aumentaría cada año, ver tabla 154. 
Tabla 154

Inversiones Futuras

\begin{tabular}{|c|c|c|c|c|}
\hline \multicolumn{5}{|c|}{ INVERSIÓN AÑO 1} \\
\hline Inversión & $\begin{array}{c}\text { Inversión } \\
\text { sinIGV }\end{array}$ & IGV & $\begin{array}{c}\text { Inversión con } \\
\text { IGV }\end{array}$ & $\%$ \\
\hline Activos Fijos & 2,542 & 458 & 3,000 & $25 \%$ \\
\hline Capital de Trabajo & 9,101 & & 9,101 & $75 \%$ \\
\hline Total & 11,643 & 458 & 12,101 & $100 \%$ \\
\hline \multicolumn{5}{|c|}{ INVERSIÓN AÑO 2} \\
\hline Inversión & $\begin{array}{c}\text { Inversión sin } \\
\text { IGV }\end{array}$ & IGV & $\begin{array}{c}\text { Inversión con } \\
\text { IGV }\end{array}$ & $\%$ \\
\hline Activos Fijos & 6,356 & 1,144 & 7,500 & $42 \%$ \\
\hline Capital de Trabajo & 10,160 & & 10,160 & $58 \%$ \\
\hline Total & 16,516 & 1,144 & 17,660 & $100 \%$ \\
\hline \multicolumn{5}{|c|}{ INVERSIÓN AÑO 3} \\
\hline Inversión & $\begin{array}{c}\text { Inversión sin } \\
\text { IGV }\end{array}$ & IGV & $\begin{array}{c}\text { Inversión con } \\
\text { IGV }\end{array}$ & $\%$ \\
\hline Activos Fijos & 6,356 & 1,144 & 7,500 & $40 \%$ \\
\hline Capital de Trabajo & 11,337 & & 11,337 & $60 \%$ \\
\hline Total & 17,693 & 1,144 & 18,837 & $100 \%$ \\
\hline \multicolumn{5}{|c|}{ INVERSIÓN AÑO 4} \\
\hline Inversión & $\begin{array}{c}\text { Inversión sin } \\
\text { IGV }\end{array}$ & IGV & $\begin{array}{c}\text { Inversión con } \\
\text { IGV }\end{array}$ & $\%$ \\
\hline Capital de Trabajo & 12,646 & & 12,646 & $100 \%$ \\
\hline Total & 12,646 & - & 12,646 & $100 \%$ \\
\hline
\end{tabular}

\subsection{Financiamiento}

Para Sapag y Sapag (2008), los fondos para que una empresa inicie operaciones, pueden ser propios o de terceros. Para eso es necesario que se analicen los plazos, tasas de interés, forma de cómo amortizará la deuda, las garantías que le solicite la entidad, el tiempo del préstamo, si fuera a largo o a corto plazo. Cuando hay financiamientos los riesgos son mayores, pero la idea es obtener un recurso que permita el mejor funcionamiento para la empresa. Debería prestarse los fondos a una tasa en la que no afecte el rendimiento de la Inversión. Indica también que la forma de pago que escoja la empresa dependerá mucho de la ganancia de la tasa de rendimiento. 


\subsubsection{Endeudamiento y condiciones.}

Para la realización de este estudio se determinó que la estructura de Financiamiento sería basada en $53.81 \%$ de capital propio y $46.19 \%$ de deuda.

El requerimiento de Inversión para poder establecer el financiamiento se mostró en la tabla 155 y en la tabla 156 la estructura del mismo.

Tabla 155

Estructura de Inversión

\begin{tabular}{|c|c|c|c|c|c|c|c|}
\hline Inversión & $\begin{array}{l}\text { Inversión } \\
\text { SIN IGV }\end{array}$ & & IGV & $\begin{array}{l}\text { Inversión } \\
\text { CON IGV }\end{array}$ & $\begin{array}{l}\text { Capital } \\
\text { propio }\end{array}$ & & Deuda \\
\hline Activo Fijo & S/ 106,163 & S/ & 19,109 & S/ 125,273 & 5,273 & $\mathrm{~S} /$ & 120,000 \\
\hline Activo Intangibles & S/ $\quad 4,988$ & S/ & 730 & S/ $\quad 5,719$ & S/ $\quad 5,719$ & $\mathrm{~S} /$ & - \\
\hline Gastos pre-operativos & S/ 190,460 & S/ & 18,627 & S/ 209,087 & S/ 209,087 & $\mathrm{S} /$ & - \\
\hline Capital de Trabajo & S/ 71,275 & S/ & - & $\mathrm{S} / 71,275$ & $\mathrm{~S} / \quad 1,275$ & $\mathrm{~S} /$ & 70,000 \\
\hline TOTAL & S/ 372,887 & $\mathrm{S} /$ & 38,467 & $\mathrm{~S} / 411,354$ & S/ 221,354 & $\mathrm{S} /$ & 190,000 \\
\hline
\end{tabular}

Tabla 156

Estructura de Financiamiento

\begin{tabular}{cc}
\hline Capital Propio & Deuda \\
\hline S/ 221,354 & S/ 190,000 \\
\hline $53.81 \%$ & $46.19 \%$ \\
\hline
\end{tabular}

De acuerdo a eso se decidió que cada socio aporte S/. 73,785, dando un total de S/.221,354 y así financiar la diferencia (Ver tabla 157).

Tabla 157

Aporte de cada socio

\begin{tabular}{lc} 
& APORTE DE CADA SOCIO \\
\hline Guiselle & S/ 73,785 \\
Joselyn & S/ 73,785 \\
Carlos & S/ 73,785 \\
\hline TOTAL & S/ 221,354 \\
\hline
\end{tabular}

Para poder iniciar operaciones se pidió un préstamo para Activo Fijo por 4 años, a la Caja Municipal de Crédito de Lima, con una TEA 25\%, el pago de la cuota mensual sería S/.3,924.27. Por ser una empresa nueva solicitaron una garantíahipotecaria, se decidió poner en garantía un inmueble, que en este caso fue el departamento propio el mismo que está a 
nombre de uno de los inversionistas. Este tipo de préstamo es para Medianas empresas y es un promedio de tasa según la SBS, ver tabla 158.

Tabla 158

Porcentaje Tasas de interés anuales

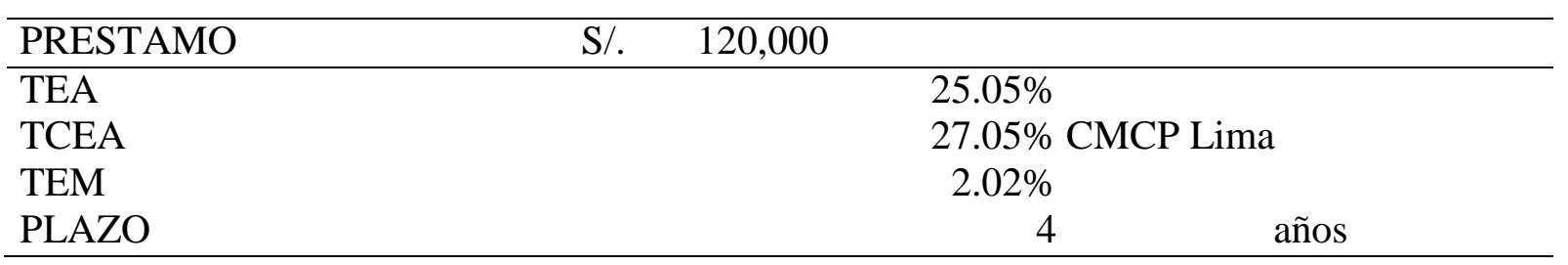

En la tabla 159 se aprecia el cronograma de pagos para los 4 años.

Tabla 159

Cronograma de pagos préstamo de Activos Fijos

\begin{tabular}{|c|c|c|c|c|c|c|c|c|}
\hline \multirow{2}{*}{$\frac{\text { Periodo }}{1}$} & \multicolumn{2}{|r|}{ Deuda } & \multicolumn{2}{|c|}{ Interés } & \multicolumn{2}{|c|}{ Amortización } & \multicolumn{2}{|c|}{ Cuota } \\
\hline & S/ & 120,000 & S/ & 2,418 & $\mathrm{~S} /$ & 1,506 & S/ & 3,924 \\
\hline 2 & S/ & 118,494 & S/ & 2,388 & S/ & 1,536 & S/ & 3,924 \\
\hline 3 & S/ & 116,957 & S/ & 2,357 & S/ & 1,567 & S/ & 3,924 \\
\hline 4 & S/ & 115,390 & S/ & 2,325 & S/ & 1,599 & S/ & 3,924 \\
\hline 5 & S/ & 113,791 & S/ & 2,293 & S/ & 1,631 & S/ & 3,924 \\
\hline 6 & S/ & 112,160 & S/ & 2,260 & S/ & 1,664 & S/ & 3,924 \\
\hline 7 & S/ & 110,496 & S/ & 2,227 & S/ & 1,698 & S/ & 3,924 \\
\hline 8 & S/ & 108,798 & S/ & 2,192 & S/ & 1,732 & S/ & 3,924 \\
\hline 9 & S/ & 107,066 & S/ & 2,158 & S/ & 1,767 & S/ & 3,924 \\
\hline 10 & S/ & 105,299 & S/ & 2,122 & $\mathrm{~S} /$ & 1,802 & S/ & 3,924 \\
\hline 11 & S/ & 103,497 & S/ & 2,086 & S/ & 1,839 & S/ & 3,924 \\
\hline 12 & S/ & 101,658 & S/ & 2,049 & S/ & 1,876 & S/ & 3,924 \\
\hline 13 & S/ & 99,783 & S/ & 2,011 & S/ & 1,914 & S/ & 3,924 \\
\hline 14 & S/ & 97,869 & S/ & 1,972 & S/ & 1,952 & S/ & 3,924 \\
\hline 15 & S/ & 95,917 & S/ & 1,933 & S/ & 1,991 & S/ & 3,924 \\
\hline 16 & S/ & 93,926 & S/ & 1,893 & S/ & 2,032 & S/ & 3,924 \\
\hline 17 & S/ & 91,894 & S/ & 1,852 & S/ & 2,072 & S/ & 3,924 \\
\hline 18 & S/ & 89,821 & S/ & 1,810 & S/ & 2,114 & S/ & 3,924 \\
\hline 19 & S/ & 87,707 & S/ & 1,767 & S/ & 2,157 & S/ & 3,924 \\
\hline 20 & S/ & 85,550 & S/ & 1,724 & S/ & 2,200 & S/ & 3,924 \\
\hline 21 & S/ & 83,350 & S/ & 1,680 & S/ & 2,245 & S/ & 3,924 \\
\hline 22 & S/ & 81,105 & S/ & 1,634 & S/ & 2,290 & S/ & 3,924 \\
\hline 23 & S/ & 78,815 & S/ & 1,588 & S/ & 2,336 & S/ & 3,924 \\
\hline 24 & S/ & 76,479 & S/ & 1,541 & S/ & 2,383 & S/ & 3,924 \\
\hline 25 & S/ & 74,096 & S/ & 1,493 & S/ & 2,431 & S/ & 3,924 \\
\hline 26 & S/ & 71,665 & S/ & 1,444 & S/ & 2,480 & S/ & 3,924 \\
\hline 27 & S/ & 69,185 & S/ & 1,394 & S/ & 2,530 & S/ & 3,924 \\
\hline 28 & S/ & 66,655 & S/ & 1,343 & S/ & 2,581 & S/ & 3,924 \\
\hline 29 & S/ & 64,074 & S/ & 1,291 & S/ & 2,633 & S/ & 3,924 \\
\hline
\end{tabular}




\begin{tabular}{crrrrrrrr}
\hline Periodo & \multicolumn{2}{c}{ Deuda } & \multicolumn{2}{c}{ Interés } & \multicolumn{2}{c}{ Amortización } & \multicolumn{2}{c}{ Cuota } \\
\hline 30 & S/ & 61,441 & S/ & 1,238 & S/ & 2,686 & S/ & 3,924 \\
31 & S/ & 58,755 & S/ & 1,184 & S/ & 2,740 & S/ & 3,924 \\
32 & S/ & 56,014 & S/ & 1,129 & S/ & 2,796 & S/ & 3,924 \\
33 & S/ & 53,219 & S/ & 1,072 & S/ & 2,852 & S/ & 3,924 \\
34 & S/ & 50,367 & S/ & 1,015 & S/ & 2,909 & S/ & 3,924 \\
35 & S/ & 47,458 & S/ & 956 & S/ & 2,968 & S/ & 3,924 \\
36 & S/ & 44,490 & S/ & 897 & S/ & 3,028 & S/ & 3,924 \\
37 & S/ & 41,462 & S/ & 836 & S/ & 3,089 & S/ & 3,924 \\
38 & S/ & 38,373 & S/ & 773 & S/ & 3,151 & S/ & 3,924 \\
39 & S/ & 35,222 & S/ & 710 & S/ & 3,214 & S/ & 3,924 \\
40 & S/ & 32,008 & S/ & 645 & S/ & 3,279 & S/ & 3,924 \\
41 & S/ & 28,728 & S/ & 579 & S/ & 3,345 & S/ & 3,924 \\
42 & S/ & 25,383 & S/ & 512 & S/ & 3,413 & S/ & 3,924 \\
43 & S/ & 21,970 & S/ & 443 & S/ & 3,482 & S/ & 3,924 \\
44 & S/ & 18,489 & S/ & 373 & S/ & 3,552 & S/ & 3,924 \\
45 & S/ & 14,937 & S/ & 301 & S/ & 3,623 & S/ & 3,924 \\
46 & S/ & 11,314 & S/ & 228 & S/ & 3,696 & S/ & 3,924 \\
47 & S/ & 7,618 & S/ & 154 & S/ & 3,771 & S/ & 3,924 \\
48 & S/ & 3,847 & S/ & 78 & S/ & 3,847 & S/ & 3,924 \\
\hline TOTAL & & & S/ & 68,365 & S/ & 120,000 & S/ & 188,365 \\
\hline
\end{tabular}
fijo.

En la tabla 160, se aprecia el resumen de los pagos por el financiamiento para Activo

Tabla 160

Resumen de amortización para Activo fijo

\begin{tabular}{rrrrrrrrr} 
& & \multicolumn{1}{c}{ Deuda } & & \multicolumn{1}{c}{ Interés } & \multicolumn{2}{c}{ Amortización } & \multicolumn{2}{c}{ Cuota } \\
\hline Año 1 & S/ & 120,000 & S/ & 26,874 & S/ & 20,217 & S/ & 47,091 \\
Año 2 & S/ & 99,783 & S/ & 21,405 & S/ & 25,686 & S/ & 47,091 \\
Año 3 & S/ & 74,096 & S/ & 14,457 & S/ & 32,634 & S/ & 47,091 \\
Año 4 & S/ & 41,462 & S/ & 5,629 & S/ & 41,462 & S/ & 47,091 \\
\hline TOTAL & & & S/ & 68,365 & S/ & 120,000 & S/ & 188,365 \\
\hline
\end{tabular}

También se determinó que se necesitará un financiamiento para capital trabajo (Vertabla 161), para eso se solicitó un préstamo a la CMAC Arequipa por S/.70,000 con una TEA $25.61 \%$, con una cuota mensual de S/.3,764.15, por el tiempo de dos años.

Tabla 161

Tasas de interés anual

\begin{tabular}{lccc}
\hline PRESTAMO & S/. & 70,000 & \\
\hline TEA & & & $25.61 \%$ \\
TCEA & & $29.08 \%$ & CMAC Arequipa \\
TEM & & $2.15 \%$ & años \\
\hline PLAZO & & 2 & \\
\hline
\end{tabular}


El pago del capital de trabajo se haría de acuerdo al siguiente cronograma de acurdo a la tabla 162 .

Tabla 162

Cronograma de pagos préstamo Capital de Trabajo

\begin{tabular}{|c|c|c|c|c|c|c|c|c|}
\hline \multirow{2}{*}{$\frac{\text { Periodo }}{1}$} & \multicolumn{2}{|c|}{ Deuda } & \multicolumn{2}{|c|}{ Interés } & \multicolumn{2}{|c|}{ Amortización } & \multicolumn{2}{|c|}{ Cuota } \\
\hline & $\mathrm{S} /$ & 70,000 & S/ & 1,505 & $\mathrm{~S} /$ & 2,259 & $\mathrm{~S} /$ & 3,764 \\
\hline 2 & $\mathrm{~S} /$ & 67,741 & S/ & 1,456 & $\mathrm{~S} /$ & 2,308 & $\mathrm{~S} /$ & 3,764 \\
\hline 3 & $\mathrm{~S} /$ & 65,433 & S/ & 1,407 & $\mathrm{~S} /$ & 2,357 & $\mathrm{~S} /$ & 3,764 \\
\hline 4 & $\mathrm{~S} /$ & 63,076 & S/ & 1,356 & $\mathrm{~S} /$ & 2,408 & $\mathrm{~S} /$ & 3,764 \\
\hline 5 & $\mathrm{~S} /$ & 60,668 & S/ & 1,304 & $\mathrm{~S} /$ & 2,460 & $\mathrm{~S} /$ & 3,764 \\
\hline 6 & $\mathrm{~S} /$ & 58,208 & S/ & 1,251 & $\mathrm{~S} /$ & 2,513 & $\mathrm{~S} /$ & 3,764 \\
\hline 7 & $\mathrm{~S} /$ & 55,695 & S/ & 1,197 & $\mathrm{~S} /$ & 2,567 & $\mathrm{~S} /$ & 3,764 \\
\hline 8 & $\mathrm{~S} /$ & 53,128 & S/ & 1,142 & $\mathrm{~S} /$ & 2,622 & $\mathrm{~S} /$ & 3,764 \\
\hline 9 & $\mathrm{~S} /$ & 50,507 & $\mathrm{~S} /$ & 1,086 & $\mathrm{~S} /$ & 2,678 & $\mathrm{~S} /$ & 3,764 \\
\hline 10 & S/ & 47,828 & $\mathrm{~S} /$ & 1,028 & $\mathrm{~S} /$ & 2,736 & $\mathrm{~S} /$ & 3,764 \\
\hline 11 & $\mathrm{~S} /$ & 45,092 & S/ & 969 & S/ & 2,795 & $\mathrm{~S} /$ & 3,764 \\
\hline 12 & $\mathrm{~S} /$ & 42,298 & S/ & 909 & $\mathrm{~S} /$ & 2,855 & $\mathrm{~S} /$ & 3,764 \\
\hline 13 & S/ & 39,443 & S/ & 848 & $\mathrm{~S} /$ & 2,916 & $\mathrm{~S} /$ & 3,764 \\
\hline 14 & $\mathrm{~S} /$ & 36,527 & S/ & 785 & S/ & 2,979 & $\mathrm{~S} /$ & 3,764 \\
\hline 15 & $\mathrm{~S} /$ & 33,548 & S/ & 721 & $\mathrm{~S} /$ & 3,043 & $\mathrm{~S} /$ & 3,764 \\
\hline 16 & $\mathrm{~S} /$ & 30,505 & S/ & 656 & S/ & 3,108 & $\mathrm{~S} /$ & 3,764 \\
\hline 17 & S/ & 27,397 & S/ & 589 & $\mathrm{~S} /$ & 3,175 & $\mathrm{~S} /$ & 3,764 \\
\hline 18 & S/ & 24,222 & S/ & 521 & S/ & 3,243 & $\mathrm{~S} /$ & 3,764 \\
\hline 19 & $\mathrm{~S} /$ & 20,978 & $\mathrm{~S} /$ & 451 & $\mathrm{~S} /$ & 3,313 & $\mathrm{~S} /$ & 3,764 \\
\hline 20 & $\mathrm{~S} /$ & 17,665 & $\mathrm{~S} /$ & 380 & $\mathrm{~S} /$ & 3,384 & $\mathrm{~S} /$ & 3,764 \\
\hline 21 & S/ & 14,281 & S/ & 307 & S/ & 3,457 & $\mathrm{~S} /$ & 3,764 \\
\hline 22 & $\mathrm{~S} /$ & 10,824 & S/ & 233 & $\mathrm{~S} /$ & 3,531 & $\mathrm{~S} /$ & 3,764 \\
\hline 23 & $\mathrm{~S} /$ & 7,292 & $\mathrm{~S} /$ & 157 & $\mathrm{~S} /$ & 3,607 & $\mathrm{~S} /$ & 3,764 \\
\hline 24 & $\mathrm{~S} /$ & 3,685 & $\mathrm{~S} /$ & 79 & S/ & 3,685 & $\mathrm{~S} /$ & 3,764 \\
\hline TOTAL & & & $\mathrm{S} /$ & 20,340 & $\mathrm{~S} /$ & 70,000 & $\mathrm{~S} /$ & 90,340 \\
\hline
\end{tabular}

En la tabla 163, se puede ver el resumen del pago de 1 financiamiento por capital de trabajo.

Tabla 163

Resumen de pago de Capital de Trabajo

\begin{tabular}{ccrrrrrrc}
\hline Periodo & \multicolumn{2}{c}{ Deuda } & & \multicolumn{2}{c}{ Interés } & \multicolumn{2}{c}{ Amortización } & \multicolumn{2}{c}{ Cuota } \\
\hline Año 1 & S/ & 70,000 & S/ & 14,613 & S/ & 30,557 & S/ & 45,170 \\
Año 2 & S/ & 39,443 & S/ & 5,727 & S/ & 39,443 & S/ & 45,170 \\
Año 3 & S/ & - & S/ & - & S/ & - & S/ & - \\
Año 4 & S/ & - & S/ & - & S/ & - & S/ & - \\
\hline TOTAL & & & S/ & 20,340 & S/ & 70,000 & S/ & 90,340 \\
\hline
\end{tabular}




\subsubsection{Capital y costo de oportunidad.}

Se definió que para poder llevar a cabo el proyecto, se necesitaba un capital de S/372,887, el costo de oportunidad es la rentabilidad que tendría el inversionista al utilizar el dinero para una mejor opción. Es decir que es la rentabilidad a la que renuncia al invertir en un proyecto de riesgo similar. Para determinar el costo de oportunidad del presente estudio, se utilizó el modelo Capital AssetPricingModel (CAPM), con este modelo se puede estimar el costo de capital de los inversionistas, tabla 164, el mismo que se usó como tasa de descuento en los flujos de caja para calcular el VPN. Para poder medirlo se necesitan los siguientes parámetros: la tasa libre de riesgo, la prima de riesgo del mercado, el horizonte de evaluación y el Beta del sector. La fórmula fue $R e=R f+B(R m-R f)+$ Spread Riesgo País.

Tabla 164 COK-Modelo CAPM

COSTO DE OPORTUNIDAD COK (MODELO CAPM)

\begin{tabular}{lc}
\hline Rendimiento del mercado USA & $8.64 \%$ \\
\hline Tasa libre de riesgo USA (T-Bonds) & $5.03 \%$ \\
\hline Beta desapalancada & 0.63 \\
\hline$\% \mathrm{D}$ & $46 \%$ \\
\hline$\% \mathrm{E}$ & $54 \%$ \\
\hline Riesgo país & $1.15 \%$ \\
\hline Impuesto a la renta & $29.5 \%$ \\
\hline Beta Apalancado & 1.01 \\
\hline COK (Modelo CAPM) & $9.84 \%$ \\
\hline Tasa de deuda & $27.05 \%$ \\
\hline Costo de Oportunidad (COK) & $36.89 \%$ \\
\hline
\end{tabular}

Para poder determinar el beta se usó la información de Damodarán en el Sector de bebidas alcohólicas y el riesgo país a Noviembre de 2017, obteniéndose un COK de 9.84\%.

Como el COK es la tasa de descuento mínima que debe obtener el inversionista sin contar con deuda. El costo de oportunidad del accionista debe ser mayor al costo de la deuda. Por eso al resultado obtenido de $9.84 \%$, se le sumó el costo promedio de la deuda obteniendo un nuevo COK de 36.89\%, ver tabla 164. 
Para poder obtener el costo promedio de la deuda se calculó cuánto era el peso de cada uno de los préstamos y la TCEA (tasa activa), luego se promedió. El COK normalmente se haya con el modelo CAPM. Ese modelo no es buena referencia para una pequeña empresa. Por lo tanto, se determinó un COK que se adecue más al tipo de negocio ya que tiene un riesgo más alto.

\subsubsection{Costo de capital promedio ponderado.}

Este método se utiliza para determinar la ganancia total del inversionista, dando un valor al capital propio y al capital prestado dando como resultado una tasa promedio. Para obtener el costo de capital promedio ponderado o WACC (Weightedaveragecost of capital), se utiliza la siguiente fórmula:WACC $=\mathrm{D} / \mathrm{D}+\mathrm{C} * \mathrm{~K}_{\mathrm{D}} *(1-\mathrm{T})+\mathrm{C} / \mathrm{D}+\mathrm{C} * \mathrm{~K}_{\mathrm{E}}$

Por lo tanto es una tasa de descuento y es lo mínimo que debe tener. Para determinar el costo de capital, ver tabla 165,se sacó un costo promedio de la deuda obteniendo un promedio de las tasas de los préstamos por activo fijo y capital de trabajo por $19.55 \%$.

Tabla 165

Costo de la deuda

\begin{tabular}{lcc}
\hline Deuda Activos Fijos & $63 \%$ & $27.05 \%$ \\
Deuda Capital de trabajo & $37 \%$ & $29.08 \%$ \\
\hline Costo promedio de la deuda & & $27.80 \%$ \\
\hline Costo neto de la deuda (menos los impuestos) & & $19.60 \%$ \\
\hline
\end{tabular}

Entonces, al utilizar el nuevo COK de $19.60 \%$, como se observa en la tabla 166 se obtuvo como costo promedio ponderado de capital (WACC) de $27.93 \%$.Este valor de $28.90 \%$ es la valla de rentabilidad que el proyecto debe superar para crear valor para los socios. 
Tabla 166

Costo Promedio Ponderado de Capital (WACC)

\begin{tabular}{llll}
\hline Capital & Monto & \multicolumn{1}{c}{$\%$} & Costo de capital \\
\hline Deuda & S/. & $190,00046 \%$ & $19.60 \%$ \\
Capital propio & S/. & $221,35454 \%$ & $36.89 \%$ \\
& S/. & $411,354100 \%$ & \\
& & & \\
Costo promedio ponderado capital & & \multicolumn{2}{|c}{$28.90 \%$} \\
(WACC) & & & \\
\hline
\end{tabular}

\subsection{Presupuestos Base}

Según Sapag y Sapag (2008), un presupuesto base es el plan de acción que está dirigido a cumplir una meta prevista, está expresada en valores y en términos financieros, que debe cumplirse en un determinado tiempo y bajo ciertas condiciones previstas.

\subsubsection{Presupuesto de ventas.}

Según Sapag y Sapag (2008), el presupuesto de ventas es el primer paso para realizar un presupuesto maestro, que contiene toda la planificación. El plan de ventas debe ser realista y los pronósticos deben ser preparados cuidadosamente y con exactitud, para que sean confiables, y puedan suministrar los datos para elaborar los otros presupuestos.Para estimar las ventas se tiene en cuenta los distintos sabores de macerados de frutas en pisco y los canales: web y otros canales. En la tabla 167 se muestra el programa de ventas de botellas de macerados de frutas en pisco en un periodo de 5 años. Para calcular las unidades vendidas se multiplica la demanda por la estacionalidad obteniendo las unidades de botellas por meses y sumándolas para obtener el total por año. 
Tabla 167

Programa de venta de botellas

\begin{tabular}{cccccc}
\hline Programa ventas botellas & 2018 & 2019 & 2020 & 2021 & 2022 \\
\hline WEB & 8,309 & 9,370 & 10,554 & 11,876 & 13,350 \\
Maracuyá y frambuesa & 2,991 & 3,373 & 3,800 & 4,275 & 4,806 \\
Fresa y guinda & 2,991 & 3,373 & 3,800 & 4,275 & 4,806 \\
Chicha & 2,326 & 2,624 & 2,955 & 3,325 & 3,738 \\
\hline OTROS CANALES & 26,919 & 30,356 & 34,193 & 38,475 & 43,252 \\
Maracuyá y frambuesa & 9,691 & 10,928 & 12,310 & 13,851 & 15,571 \\
Fresa y guinda & 9,691 & 10,928 & 12,310 & 13,851 & 15,571 \\
Chicha & 7,537 & 8,500 & 9,574 & 10,773 & 12,110 \\
\hline Total unidades & 35,228 & 39,726 & 44,748 & 50,351 & 56,602 \\
\hline
\end{tabular}

En la tabla 168 se mostró los precios por canal, en este caso, todas los sabores de macerados de frutas en pisco tendrán un precio de S/.55, sin embargo, al venderlo por web y por medio de otros canalaes hay una diferencia, ya que otros canales se queda con un margen del $25 \%$, mientras que por web es el $0 \%$. En definitiva a la empresa le conviene vender por web ya que recibe el $100 \%$ del precio, no obstante, al ser una nueva empresa es un margen más accesible en comparación de los retails.

Tabla 168

Precio por canal

\begin{tabular}{|c|c|c|c|c|c|c|c|c|}
\hline \multirow[t]{2}{*}{ Producto } & \multirow[t]{2}{*}{$\begin{array}{l}\text { Precio de } \\
\text { venta } \\
\text { sugerido al } \\
\text { público } \\
\end{array}$} & \multirow[t]{2}{*}{$\begin{array}{l}\text { Margen } \\
\text { del canal }\end{array}$} & \multicolumn{2}{|c|}{$\begin{array}{c}\text { Precio de } \\
\text { venta al canal }\end{array}$} & \multicolumn{2}{|c|}{ IGV } & \multicolumn{2}{|c|}{ Valor venta } \\
\hline & & & & & & & & \\
\hline Maracuyá y frambuesa & 55.00 & $0 \%$ & $\mathrm{~S} /$. & 55.00 & $\mathrm{~S} /$. & 8.39 & $\mathrm{~S} /$. & 46.61 \\
\hline Fresa y guinda & 55.00 & $0 \%$ & $\mathrm{~S} /$. & 55.00 & $\mathrm{~S} /$. & 8.39 & $\mathrm{~S} /$. & 46.61 \\
\hline Chicha & 55.00 & $0 \%$ & $\mathrm{~S} /$. & 55.00 & $\mathrm{~S} /$. & 8.39 & S/. & 46.61 \\
\hline \multicolumn{9}{|l|}{ OTROS CANALES } \\
\hline Maracuyá y frambuesa & 55.00 & $25 \%$ & $\mathrm{~S} /$. & 41.25 & $\mathrm{~S} /$. & 6.29 & $\mathrm{~S} /$. & 34.96 \\
\hline Fresa y guinda & 55.00 & $25 \%$ & $\mathrm{~S} /$. & 41.25 & $\mathrm{~S} /$. & 6.29 & $\mathrm{~S} /$. & 34.96 \\
\hline Chicha & 55.00 & $25 \%$ & $\mathrm{~S} /$. & 41.25 & $\mathrm{~S} /$. & 6.29 & $\mathrm{~S} /$. & 34.96 \\
\hline
\end{tabular}

Considerando la demanda de botellas y los precios establecidos, en la tabla 169, se mostró el programa de ventas en soles anuales. 
Tabla 169

Programa de ventas en Soles

\begin{tabular}{|c|c|c|c|c|c|}
\hline Programa ventas (soles) & 2018 & 2019 & 2020 & 2021 & 2022 \\
\hline WEB & S/. 387,278 & S/. 436,728 & S/. 491,932 & S/. 553,535 & S/. 622,250 \\
\hline Maracuyá y frambuesa & S/. 139,420 & S/. 157,222 & S/. 177,096 & S/. 199,272 & S/. 224,010 \\
\hline Fresa y guinda & S/. 139,420 & S/. 157,222 & S/. 177,096 & S/. 199,272 & S/. 224,010 \\
\hline Chicha & S/. 108,438 & S/. 122,284 & S/. 137,741 & S/. 154,990 & S/. 174,230 \\
\hline OTROS CANALES & S/. 941,028 & S/. $1,061,184$ & S/. $1,195,322$ & S/. $1,345,007$ & S/. $1,511,974$ \\
\hline Maracuyá y frambuesa & S/. 338,770 & S/. 382,026 & S/. 430,316 & S/. 484,202 & S/. 544,311 \\
\hline Fresa y guinda & S/. 338,770 & S/. 382,026 & S/. 430,316 & S/. 484,202 & S/. 544,311 \\
\hline Chicha & S/. 263,488 & S/. 297,131 & S/. 334,690 & S/. 376,602 & S/. 423,353 \\
\hline Ventas (sin IGV) & S/. $1,328,306$ & S/. $1,497,912$ & S/. 1,687,254 & S/. $1,898,541$ & S/. 2,134,224 \\
\hline IGV & S/. 239,095 & S/. 269,624 & S/. 303,706 & S/. 341,737 & S/. 384,160 \\
\hline Ventas (con IGV) & S/. $1,567,401$ & S/. $1,767,536$ & S/. $1,990,960$ & S/. 2,240,279 & S/. 2,518,384 \\
\hline
\end{tabular}

\subsubsection{Presupuesto de costo de producción.}

Según Sapag y Sapag (2008), el presupuesto de producción determina el número de unidades por cada producto a fabricarse para satisfacer las ventas planeadas a través de niveles de inventarios apropiados y a los costos que permitan obtener beneficios esperados.

En cuanto a la producción, el producto fue lanzado en 2018, sin embargo al ser macerados de frutas en pisco, la producción se comienza con 2 meses de anticipación ya que es el tiempo estimado que necesita el producto. Se debe tomar en cuenta que el producto necesita dos meses de maceración por lo tanto, se consideró para el plan de producción anual durante un periodo de cinco años, ver tabla 170.

Tabla 170

Proyección de producción en botellas

\begin{tabular}{lccccccc}
\hline PRODUCCIÓN botellas) & Nov-17 & Dic-17 & 2018 & 2019 & 2020 & 2021 & 2022 \\
\hline Maracuyá y Frambuesa & 764 & 823 & 14,804 & 15,626 & 17,433 & 19,428 & 17,326 \\
Fresa y Guinda & 764 & 823 & 14,804 & 15,626 & 17,433 & 19,428 & 17,326 \\
Chicha & 594 & 640 & 11,514 & 12,154 & 13,560 & 15,110 & 13,476 \\
\hline Total botellas al año & 2,123 & 2,287 & 41,121 & 43,407 & 48,426 & 53,965 & 48,128 \\
\hline Total botellas al mes & 2,123 & 2,287 & 3,427 & 3,617 & 4,035 & 4,497 & 4,011 \\
\hline Total botellas al dia & & & 143 & 151 & 168 & 187 & 167 \\
\hline Total botellas por hora & & & 18 & 19 & 21 & 23 & 21 \\
\hline
\end{tabular}


En la tabla 171, se consideró las siguientes variables para la proyección como es el \% de sampling, ya que al ser un producto nuevo debe haber degustaciones. Por otra parte, la merma de las frutas también se considera, son mínimos sin embargo, representan un porcentaje de $3 \%$, ya que al macerar las frutas van enteras.

Tabla 171

Variables para la proyección

\begin{tabular}{cccccc}
\cline { 2 - 5 } & 2018 & 2019 & 2020 & 2021 & 2022 \\
\hline \% de sampling & $4.0 \%$ & $4.0 \%$ & $3.0 \%$ & $2.0 \%$ & $1.0 \%$ \\
\% de merma & $3.0 \%$ & $3.0 \%$ & $3.0 \%$ & $3.0 \%$ & $3.0 \%$ \\
Stock de PT & $7.0 \%$ & $7.0 \%$ & $7.0 \%$ & $7.0 \%$ & $7.0 \%$ \\
\hline
\end{tabular}

Se consideró en la tabla 172 el presupuesto de compra de materia prima, considerando un periodo de dos meses anticipados debido al tiempo de maceración que requiere. En el último año, 2022, se observa una disminución en soles, esto sucede debido a que se comenzó dos meses anticipados por lo tanto, hay dos meses en los que ya no se produce y eso implica que no se comprará materia prima y la producción termina en octubre, por lo que se ve reflejado en el presupuesto de compras del año 2022.

Tabla 172

Presupuesto de compra de Materia prima por año

\begin{tabular}{|c|c|c|c|c|c|c|}
\hline & $\begin{array}{l}\text { Costo unitario } \\
\text { (sin IGV) por } \\
\text { unidad de compra }\end{array}$ & 2018 & 2019 & 2020 & 2021 & 2022 \\
\hline Pisco & S/. 33.90 & S/. 173,763 & S/. 187,695 & S/. 209,424 & S/. 233,356 & S/. 208,136 \\
\hline Maracuyá & S/. 127.12 & S/. 17,669 & S/. 18,686 & S/. 20,847 & S/. 23,263 & S/. 20,720 \\
\hline Frambuesa & S/. 203.39 & S/. 127,932 & S/. 135,254 & S/. 150,915 & S/. 168,203 & S/. 149,898 \\
\hline Fresa & S/. 21.19 & S/. 19,852 & S/. 20,975 & S/. 23,390 & S/. 26,059 & S/. 23,242 \\
\hline Guinda & $\mathrm{S} / .84 .75$ & S/. 38,475 & S/. 40,678 & S/. 45,339 & S/. 50,593 & S/. 45,085 \\
\hline Maíz morado & S/. 59.32 & S/. 8,186 & S/. 9,432 & S/. 10,500 & S/. 11,686 & S/. 10,441 \\
\hline Membrillo & S/. 169.49 & S/. 12,203 & S/. 14,068 & S/. 15,763 & S/. 17,458 & S/. 15,593 \\
\hline Piña golden & S/. 21.19 & S/. 6,737 & S/. 7,733 & S/. 8,623 & S/. 9,619 & S/. 8,581 \\
\hline Canela & S/. 135.59 & S/. 14,780 & S/. 17,085 & S/. 18,983 & S/. 21,153 & S/. 18,847 \\
\hline Clavo & S/. 101.69 & S/. 3,254 & S/. 3,864 & S/. 4,271 & S/. 4,780 & S/. 4,271 \\
\hline Botella & S/. 44.07 & S/. 89,458 & S/. 96,641 & S/. 107,790 & S/. 120,129 & S/. 107,129 \\
\hline Soguilla & S/. 6.78 & S/. 27,525 & S/. 29,729 & S/. 33,166 & S/. 36,963 & S/. 32,963 \\
\hline Tapon & S/. 33.90 & S/. 13,763 & S/. 14,881 & S/. 16,610 & S/. 18,508 & S/. 16,508 \\
\hline $\begin{array}{l}\text { Total materia } \\
\text { prima (sin IGV) }\end{array}$ & & S/. 553,597 & S/. 596,721 & S/. 665,621 & S/. 741,769 & S/.661,414 \\
\hline $\mathrm{IGV}$ & & S/. 99,648 & S/. 107,410 & S/. 119,812 & S/. 133,519 & S/.119,054 \\
\hline $\begin{array}{l}\text { Total materia } \\
\text { prima (con IGV) }\end{array}$ & & S/. 653,245 & S/. 704,131 & S/. 785,433 & S/. 875,288 & S/. 780,468 \\
\hline
\end{tabular}


En la tabla 173 se observa al detalle las cantidades de compra de materia prima por año, considerando los dos meses anticipados y se mostró la cantidad de materia prima que disminuirá en el año 2022 ya que dos meses no se compró materia prima.

Tabla 173

Presupuesto de compra de Materia prima por año (Unidades)

\begin{tabular}{|c|c|c|c|c|c|c|c|c|}
\hline & Unidad & $\begin{array}{c}\text { Nov- } \\
17\end{array}$ & $\begin{array}{c}\text { Dic- } \\
17\end{array}$ & $\begin{array}{l}\text { Total } \\
2018\end{array}$ & $\begin{array}{l}\text { Total } \\
2019\end{array}$ & $\begin{array}{l}\text { Total } \\
2020\end{array}$ & $\begin{array}{l}\text { Total } \\
2021\end{array}$ & $\begin{array}{l}\text { Total } \\
2022\end{array}$ \\
\hline Pisco & $\begin{array}{c}\text { Dama Juanas } 4 \\
\text { litros }\end{array}$ & 271 & 217 & 5,126 & 5,537 & 6,178 & 6,884 & 6,140 \\
\hline Maracuyá & Saco $50 \mathrm{~kg}$ & 8 & 7 & 139 & 147 & 164 & 183 & 163 \\
\hline Frambuesa & Caja de $6 \mathrm{~kg}$ & 33 & 35 & 629 & 665 & 742 & 827 & 737 \\
\hline Fresa & Caja $10 \mathrm{~kg}$ & 49 & 52 & 937 & 990 & 1,104 & 1,230 & 1,097 \\
\hline Guinda & Bolsa $5 \mathrm{~kg}$ & 24 & 25 & 454 & 480 & 535 & 597 & 532 \\
\hline $\begin{array}{l}\text { Maíz } \\
\text { morado }\end{array}$ & Saco $50 \mathrm{~kg}$ & 8 & 1 & 138 & 159 & 177 & 197 & 176 \\
\hline $\begin{array}{l}\text { Membrillo } \\
\text { Piña }\end{array}$ & Saco $50 \mathrm{~kg}$ & 5 & - & 72 & 83 & 93 & 103 & 92 \\
\hline Golden & Caja de $12 \mathrm{~kg}$ & 18 & 2 & 318 & 365 & 407 & 454 & 405 \\
\hline Canela & Caja de $2 \mathrm{~kg}$ & 7 & - & 109 & 126 & 140 & 156 & 139 \\
\hline Clavo & $\begin{array}{c}\text { Bolsa de } 5 \mathrm{~kg} \\
\text { Jaba de } 20\end{array}$ & 2 & 1 & 32 & 38 & 42 & 47 & 42 \\
\hline Botella & botellas & 108 & 86 & 2,030 & 2,193 & 2,446 & 2,726 & 2,431 \\
\hline Soguilla & Rollo 10 metros & 215 & 172 & 4,060 & 4,385 & 4,892 & 5,452 & 4,862 \\
\hline Tapon & Ciento & 22 & 17 & 406 & 439 & 490 & 546 & 487 \\
\hline
\end{tabular}

En la tabla 174 se mostró el costo total de materia prima al detalle por sabores. 
Tabla 174

Costo de Materia Prima (Soles) por Producto

\begin{tabular}{cccccc}
\hline MATERIA PRIMA & Año 1 & Año 2 & Año 3 & Año 4 & Año 5 \\
\hline Maracuyá y frambuesa & S/. 252,080 & S/. 271,716 & S/. 303,089 & S/. 337,763 & S/. 301,174 \\
Fresa y guinda & S/. 167,286 & S/. 180,317 & S/. 201,137 & S/. 224,148 & S/. 199,866 \\
Chicha & S/. 134,232 & S/. 144,688 & S/. 161,395 & S/. 179,858 & S/. 160,374 \\
$\begin{array}{c}\text { Total materia prima (sin } \\
\text { IGV) }\end{array}$ & S/. 553,597 & S/. 596,721 & S/. 665,621 & S/. 741,769 & S/. 661,414 \\
IGV & S/. 99,648 & S/. 107,410 & S/. 119,812 & S/. 133,519 & S/. 119,054 \\
$\begin{array}{c}\text { Total materia prima (con } \\
\text { IGV) }\end{array}$ & S/. 653,245 & S/. 704,131 & S/. 785,433 & S/. 875,288 & S/. 780,468 \\
\hline
\end{tabular}

En la tablas 175 y 176 se mostró el detalle de los gastos de producción promedio y los gastos de mano de obra necesarias para la producción de macerados de frutas en pisco durante el periodo de cinco años. También se mostró tomando en cuenta la materia prima, costos indirectos de fabricación y mano de obra directa, el costo promedio de los macerados de frutas en pisco y en base a ese costo se establecio el precio final de venta del producto. 
Tabla 175

Costo de Producción Promedio

\begin{tabular}{|c|c|c|c|c|c|}
\hline & \\
\hline & Año 1 & Año 2 & Año 3 & Año 4 & Año 5 \\
\hline Unidades & 41,121 & 43,407 & 48,426 & 53,965 & 48,128 \\
\hline Horas MOD & 5,752 & 6,072 & 6,774 & 7,549 & 6,732 \\
\hline Ingresos & S/. 1,328,306 & S/. 1,497,912 & $\begin{array}{c}\mathrm{S} / . \\
1,687,254 \\
\end{array}$ & $\begin{array}{c}\mathrm{S} / . \\
1,898,541 \\
\end{array}$ & $\begin{array}{c}\mathrm{S} / . \\
2,134,224 \\
\end{array}$ \\
\hline $\begin{array}{c}\text { COSTOS DE } \\
\text { PRODUCCION }\end{array}$ & & & & & \\
\hline MATERIA PRIMA & S/. 553,597 & S/. 596,721 & S/. 665,621 & S/. 741,769 & S/. 661,414 \\
\hline $\begin{array}{l}\text { MANO DE OBRA } \\
\text { DIRECTA }\end{array}$ & S/. 38,265 & S/. 51,020 & S/. 51,020 & S/. 51,020 & S/. 51,020 \\
\hline $\mathrm{CIF}$ & S/. 259,502 & S/. 263,335 & S/. 268,275 & S/. 273,694 & S/. 274,249 \\
\hline $\begin{array}{l}\text { TOTAL COSTOS } \\
\text { PRODUCCION } \\
\end{array}$ & S/. 851,364 & S/. 911,076 & S/. 984,916 & $\begin{array}{c}\mathrm{S} / . \\
1,066,483 \\
\end{array}$ & S/. 986,682 \\
\hline $\begin{array}{l}\text { COSTOS PRODUCCION } \\
\text { UNITARIO PROMEDIO }\end{array}$ & S/.20.70 & S/.20.99 & S/.20.34 & S/.19.76 & $\mathrm{S} / .20 .50$ \\
\hline
\end{tabular}

\section{COSTO TOTAL UNITARIO PROMEDIO}

\begin{tabular}{cccccc}
\cline { 2 - 5 } & Año 1 & Año 2 & Año 3 & Año 4 & Año 5 \\
\hline Unidades & 41,121 & 43,407 & 48,426 & 53,965 & 48,128 \\
\hline
\end{tabular}

\begin{tabular}{|c|c|c|c|c|c|}
\hline COSTOS TOTALES & & & & & \\
\hline MATERIA PRIMA & S/. 553,597 & S/. 596,721 & S/. 665,621 & S/. 741,769 & S/. 661,414 \\
\hline $\begin{array}{l}\text { MANO DE OBRA } \\
\text { DIRECTA }\end{array}$ & S/. 38,265 & S/. 51,020 & S/. 51,020 & S/. 51,020 & S/. 51,020 \\
\hline $\mathrm{CIF}$ & S/. 259,502 & S/. 263,335 & S/. 268,275 & S/. 273,694 & S/. 274,249 \\
\hline $\begin{array}{c}\text { GASTOS } \\
\text { ADMINISTRACION }\end{array}$ & S/. 152,935 & S/. 152,935 & S/. 152,935 & S/. 152,935 & S/. 151,620 \\
\hline GASTOS VENTAS & S/. 245,164 & S/. 238,209 & S/. 232,322 & S/. 213,859 & S/. 219,892 \\
\hline TOTAL COSTOS & S/. $1,249,464$ & S/. 1,302,220 & $\begin{array}{c}\mathrm{S} / . \\
1,370,173 \\
\end{array}$ & $\begin{array}{c}\mathrm{S} / . \\
1,433,277 \\
\end{array}$ & $\begin{array}{c}\mathrm{S} / . \\
1,358,194\end{array}$ \\
\hline $\begin{array}{c}\text { COSTO TOTAL } \\
\text { UNITARIO PROMEDIO }\end{array}$ & S/.30.39 & S/.30.00 & S/.28.29 & S/.26.56 & S/.28.22 \\
\hline
\end{tabular}


Tabla 176

Mano de obra

\begin{tabular}{cccccc}
\cline { 2 - 5 } & Año 1 & Año 2 & Año 3 & Año 4 & Año 5 \\
\hline MANO DE OBRA DIRECTA & 3 & 3 & 3 & 3 & 3 \\
\hline MANO DE OBRA DIRECTA & S/. 38,265 & S/. 38,265 & S/. 38,265 & S/. 38,265 & S/. 38,265 \\
\hline
\end{tabular}

\begin{tabular}{|c|c|c|c|c|c|}
\hline CONCEPTO & 2016 & 2017 & 2018 & 2019 & 2020 \\
\hline Básico & S/. 30,600 & S/. 30,600 & S/. 30,600 & S/. 30,600 & S/. 30,600 \\
\hline Bono & S/. 0 & S/. 0 & $\mathrm{~S} / .0$ & S/. 0 & S/. 0 \\
\hline S.C.T.R & S/. 612 & S/. 612 & S/. 612 & S/. 612 & S/. 612 \\
\hline Gratificación & S/. 2,601 & S/. 2,601 & S/. 2,601 & S/. 2,601 & S/. 2,601 \\
\hline CTS & S/. 1,409 & S/. 1,409 & S/. 1,409 & S/. 1,409 & S/. 1,409 \\
\hline ESSALUD & S/. 3,043 & S/. 3,043 & S/. 3,043 & S/. 3,043 & S/. 3,043 \\
\hline TOTAL MOD & S/. 38,265 & S/. 38,265 & S/. 38,265 & S/. 38,265 & S/. 38,265 \\
\hline
\end{tabular}

\subsubsection{Presupuesto de compras.}

Según Sapag y Sapag (2008), el presupuesto de compras es uno de los primeros presupuestos de costos que debe prepararse, ya que las cantidades por compras y los planes de entrega deben establecerse rápidamente, para que los materiales estén disponibles cuando se necesiten.

El presupuesto de compras, se considera desde el mes de noviembre, ver tabla 177. debido a que el producto se demora 2 meses en macerar, por lo que se debe realizar la producción 2 meses antes, noviembre y diciembre, para tener producción para inicio del año 2018 . 
Tabla 177

Resumen de compras

\begin{tabular}{|c|c|c|c|c|c|}
\hline MATERIAL INDIRECTO & Año 1 & Año 2 & Año 3 & Año 4 & Año 5 \\
\hline Material de Empaque & S/. 14,697 & S/. 15,513 & S/. 17,306 & S/. 19,286 & S/. 17,200 \\
\hline Utensilios de produccion & S/. 642 & S/. 642 & S/. 642 & S/. 642 & S/. 642 \\
\hline Uniformes de personal & S/. 308 & S/. 820 & S/. 820 & S/. 820 & S/. 820 \\
\hline Material de oficina & S/. 66 & S/. 66 & S/. 66 & S/. 66 & S/. 66 \\
\hline Material de limpieza & S/. 1,404 & S/. 1,404 & S/. 1,404 & S/. 1,404 & S/. 1,404 \\
\hline Total S/. (SIN IGV) & S/. 17,116 & S/. 18,445 & S/. 20,237 & S/. 22,218 & S/. 20,132 \\
\hline \multicolumn{6}{|l|}{ SERVICIOS } \\
\hline Energía Eléctrica & S/. 11,747 & S/. 13,247 & S/. 14,921 & S/. 16,790 & S/. 18,874 \\
\hline Agua & S/. 5,874 & S/. 6,623 & S/. 7,461 & S/. 8,395 & S/. 9,437 \\
\hline Arbitrios & $\mathrm{S} / .1,225$ & $\mathrm{~S} / .1,225$ & $\mathrm{~S} / .1,225$ & S/. 1,225 & $\mathrm{~S} / .1,225$ \\
\hline Servicio de teléfono - internet & S/. 336 & S/. 336 & S/. 336 & S/. 336 & S/. 336 \\
\hline Alquiler local & S/. 108,209 & S/. 108,209 & S/. 108,209 & S/. 108,209 & S/. 108,209 \\
\hline Servicio de contabilidad & S/. 0 & S/. 0 & S/. 0 & S/. 0 & S/. 0 \\
\hline $\begin{array}{l}\text { Servicio de limpieza } \\
\text { (honorarios) }\end{array}$ & S/. 8,400 & S/. 8,400 & S/. 8,400 & S/. 8,400 & $S / .8,400$ \\
\hline Servicio de seguridad & S/. 18,508 & S/. 18,508 & S/. 18,508 & S/. 18,508 & S/. 18,508 \\
\hline Recarga de extintores & S/. 140 & S/. 140 & S/. 140 & S/. 140 & S/. 140 \\
\hline $\begin{array}{l}\text { Mantenimiento de } \\
\text { maquinarias y equipos }\end{array}$ & S/. 4,068 & S/. 4,068 & S/. 4,068 & S/. 4,068 & S/. 4,068 \\
\hline $\begin{array}{l}\text { Poliza de seguro contra robo } \\
\text { y otros }\end{array}$ & S/. 2,441 & S/. 2,441 & S/. 2,441 & S/. 2,441 & S/. 2,441 \\
\hline $\begin{array}{l}\text { Servicio de motorizado } \\
\text { (honorarios) }\end{array}$ & S/. 0 & S/. 0 & S/. 0 & S/. 0 & S/. 0 \\
\hline $\begin{array}{l}\text { Servicio transporte } \\
\text { distribución }\end{array}$ & S/. 0 & S/. 0 & $\mathrm{~S} / .0$ & $\mathrm{~S} / .0$ & S/. 0 \\
\hline $\begin{array}{l}\text { Total Costo Servicios (sin } \\
\text { IGV) }\end{array}$ & S/. 160,947 & S/. 163,197 & S/. 165,709 & S/. 168,511 & S/. 171,638 \\
\hline \multicolumn{6}{|l|}{$\begin{array}{l}\text { MANO DE OBRA } \\
\text { INDIRECTA }\end{array}$} \\
\hline Basico & S/. 36,000 & S/. 36,000 & S/. 36,000 & S/. 36,000 & S/. 36,000 \\
\hline Bono & S/. 0 & S/. 0 & S/. 0 & S/. 0 & S/. 0 \\
\hline S.C.T.R & S/. 720 & S/. 720 & S/. 720 & S/. 720 & S/. 720 \\
\hline Gratificación & S/. 3,060 & S/. 3,060 & S/. 3,060 & $\mathrm{S} / .3,060$ & S/. 3,060 \\
\hline CTS & S/. 1,658 & S/. 1,658 & S/. 1,658 & S/. 1,658 & S/. 1,658 \\
\hline ESSALUD & S/. 3,580 & S/. 3,580 & S/. 3,580 & S/. 3,580 & S/. 3,580 \\
\hline Total MOI & S/. 45,018 & S/. 45,018 & S/. 45,018 & S/. 45,018 & S/. 45,018 \\
\hline TOTAL CIF (SIN IGV) & $\mathrm{S} / .223,080$ & S/. 226,659 & S/. 230,964 & S/. 235,747 & S/. 236,788 \\
\hline IGV & S/. 10,841 & S/. 11,485 & $\mathrm{~S} / .12,260$ & $\mathrm{~S} / .13,121$ & S/. 13,309 \\
\hline TOTAL CIF (CON IGV) & S/. 233,922 & S/. 238,145 & S/. 243,224 & S/. 248,868 & S/. 250,096 \\
\hline
\end{tabular}




\subsubsection{Presupuesto de costo de ventas.}

Según Sapag y Sapag (2008), el presupuesto de costo de ventas presenta una visión completa de todo el proceso completo, desde las materias primas, elaboración de las mismas y concluyendo en el almacén de productos terminados. Permite una apreciación general de la actividad fabril en términos de unidades monetarias.

Para evidenciar el costo de ventas, se presenta la tabla 178 donde se detalla el costo de materia prima para cada uno de los tres sabores durante los cinco años del proyecto. Los costos de ventas contemplan el costo de materia prima, mano de obra directa y los costos indirectos de fabricación. En el caso de materia prima inicialmente tiene un costo de S/ 553,597 (sin IGV) aumentando al año 5 con S/ 661,414, ya que habrá mayor demanda, por lo tanto, mayor compra de insumo.

Tabla 178

Costo de materia prima (Soles)

\begin{tabular}{lccccc}
\hline & Año 1 & Año 2 & Año 3 & Año 4 & Año 5 \\
\hline Maracuya y frambuesa & S/. 252,080 & S/. 271,716 & S/. 303,089 & S/. 337,763 & S/. 301,174 \\
Fresa y guinda & S/. 167,286 & S/. 180,317 & S/. 201,137 & S/. 224,148 & S/. 199,866 \\
Chicha & S/. 134,232 & S/. 144,688 & S/. 161,395 & S/. 179,858 & S/. 160,374 \\
\hline Total materia prima (sin & & & & & \\
IGV) & S/. 553,597 & S/. 596,721 & S/. 665,621 & S/. 741,769 & S/. 661,414 \\
IGV & S/. 99,648 & S/. 107,410 & S/. 119,812 & S/. 133,519 & S/. 119,054 \\
Total materia prima (con & & & & & \\
IGV) & S/. 653,245 & S/. 704,131 & S/. 785,433 & S/. 875,288 & S/. 780,468 \\
\hline
\end{tabular}

Sin embargo, como se puede observar en la tabla 179 el costo de la mano de obra directa se mantiene

Tabla 179

Costo de mano de obra directa

\begin{tabular}{lccccc} 
& Año 1 & Año 2 & Año 3 & Año 4 & Año 5 \\
\hline $\begin{array}{l}\text { MANO DE OBRA } \\
\text { DIRECTA }\end{array}$ & 3 & 4 & 4 & 4 & 4 \\
\hline $\begin{array}{l}\text { MANO DE OBRA } \\
\text { DIRECTA }\end{array}$ & S/. 38,265 & S/. 51,020 & S/. 51,020 & S/. 51,020 & S/. 51,020 \\
\hline
\end{tabular}




\subsubsection{Presupuesto de costo de gastos administrativos.}

Según Sapag y Sapag (2008), el presupuesto administrativo incluye la función de la alta gerencia, así como ciertas actividades de servicios tales como financiera, legales y de contabilidad.

En la tabla 180 se muestra el resumen de los gastos administrativos considerando la planilla (bono, s.c.t.r, gratificación, CTS, Essalud) con un monto total de S/. 91,212, servicios (energía eléctrica, agua, arbitrios, teléfono, internet, alquiler, servicio de contabilidad, servicio de limpieza, )con un total de S/. 52,962 y los materiales (materiales de oficina y materiales de limpieza, servicio de seguridad, extintores, mantenimiento de maquinarias y equipos, póliza de seguros contra robos, servicio de motorizado y servicio de transporte) con un total de S/. 1,537 asciende a S/ 145,711 (sin IGV) y será el mismo durante los cinco años del proyecto. En el anexo \# 26 se puede ver el detalle del presupuesto de gastos administrativos. 
Tabla 180

Resumen de gastos administrativos

\begin{tabular}{|c|c|c|c|c|c|}
\hline \multirow[t]{2}{*}{ PLANILLA } & \multirow{2}{*}{$\begin{array}{cr}\begin{array}{c}\text { Año } \\
1\end{array} & \text { Año 2 } \\
& \text { S/. 74,400 }\end{array}$} & Año 3 & Año 4 & \multicolumn{2}{|c|}{ Año 5} \\
\hline & & S/. 74,400 & S/. 74,400 & S/. 74,400 & S/. 74,400 \\
\hline Bono & S/. 0 & $\mathrm{~S} / .0$ & $\mathrm{~S} / .0$ & $\mathrm{~S} / .0$ & $\mathrm{~S} / .0$ \\
\hline S.C.T.R & S/. 0 & $\mathrm{~S} / .0$ & S/. 0 & S/. 0 & $\mathrm{~S} / .0$ \\
\hline Gratificación & S/. 6,200 & S/. 6,200 & S/. 6,200 & S/. 6,200 & S/. 6,200 \\
\hline CTS & S/. 3,358 & S/. 3,358 & S/. 3,358 & S/. 3,358 & S/. 3,358 \\
\hline ESSALUD & S/. 7,254 & S/. 7,254 & S/. 7,254 & S/. 7,254 & S/. 7,254 \\
\hline TOTAL PLANILLA & S/. 91,212 & S/. 91,212 & S/. 91,212 & S/. 91,212 & S/. 91,212 \\
\hline \multicolumn{6}{|l|}{ MATERIALES } \\
\hline Material de oficina & S/. 1,237 & S/. 1,237 & S/. 1,237 & S/. 1,237 & S/. 1,237 \\
\hline Material de limpieza & S/. 301 & S/. 301 & S/. 301 & S/. 301 & S/. 301 \\
\hline Total S/. (SIN IGV) & S/. 1,537 & S/. 1,537 & S/. 1,537 & S/. 1,537 & S/. 1,537 \\
\hline \multicolumn{6}{|l|}{ SERVICIOS } \\
\hline Energía Eléctrica & S/. 1,525 & S/. 1,525 & S/. 1,525 & S/. 1,525 & S/. 1,525 \\
\hline Agua & S/. 763 & S/. 763 & S/. 763 & S/. 763 & S/. 763 \\
\hline Arbitrios & S/. 263 & S/. 263 & S/. 263 & S/. 263 & S/. 263 \\
\hline Servicio de teléfono - internet & S/. 783 & S/. 783 & S/. 783 & S/. 783 & S/. 783 \\
\hline Alquiler local & S/. 30,917 & S/. 30,917 & S/. 30,917 & S/. 30,917 & S/. 30,917 \\
\hline Servicio de contabilidad & S/. 10,169 & S/. 10,169 & S/. 10,169 & S/. 10,169 & S/. 10,169 \\
\hline Servicio de limpieza (honorarios) & S/. 2,400 & S/. 2,400 & S/. 2,400 & S/. 2,400 & S/. 2,400 \\
\hline Servicio de seguridad & S/. 5,288 & S/. 5,288 & S/. 5,288 & S/. 5,288 & S/. 5,288 \\
\hline Recarga de extintores & S/. 40 & S/. 40 & S/. 40 & S/. 40 & S/. 40 \\
\hline $\begin{array}{l}\text { Mantenimiento de maquinarias y } \\
\text { equipos }\end{array}$ & S/. 508 & S/. 508 & S/. 508 & S/. 508 & S/. 508 \\
\hline $\begin{array}{l}\text { Póliza de seguro contra robo y } \\
\text { otros }\end{array}$ & S/. 305 & S/. 305 & S/. 305 & S/. 305 & S/. 305 \\
\hline $\begin{array}{l}\text { Servicio de motorizado } \\
\text { (honorarios) }\end{array}$ & S/. 0 & $\mathrm{~S} / .0$ & $\mathrm{~S} / .0$ & $\mathrm{~S} / .0$ & $\mathrm{~S} / .0$ \\
\hline Servicio transporte distribución & S/. 0 & S/. 0 & S/. 0 & S/. 0 & S/. 0 \\
\hline Total Costo Servicios (sin IGV) & S/. 52,962 & S/. 52,962 & S/. 52,962 & S/. 52,962 & S/. 52,962 \\
\hline $\begin{array}{l}\text { TOTAL GASTOS } \\
\text { ADMINISTRATIVOS (SIN IGV) }\end{array}$ & S/. 145,711 & S/. 145,711 & S/. 145,711 & S/. 145,711 & S/. 145,711 \\
\hline IGV & S/. 3,766 & S/. 3,766 & S/. 3,766 & S/. 3,766 & S/. 3,766 \\
\hline $\begin{array}{l}\text { TOTAL GASTOS } \\
\text { ADMINISTRATIVOS (CON } \\
\text { IGV) }\end{array}$ & S/. 149,477 & S/. 149,477 & S/. 149,477 & S/. 149,477 & S/. 149,477 \\
\hline
\end{tabular}

\subsubsection{Presupuesto de marketing y ventas..}

Según Sapag y Sapag (2008), el presupuesto de marketing y ventas comprende las actividades del área comercial, siendo una estimación anticipada de los ingresos y egresos ocasionados por dicha dependencia. Según la tabla 181, el total de gastos administrativos 
considerando la planilla, los servicios y los materiales asciende a S/ 149,477 y será el mismo en los 5 años.

Tabla 181

Resumen de marketing y ventas

\begin{tabular}{|c|c|c|c|c|c|}
\hline PLANILLA & Año 1 & Año 2 & Año 3 & Año 4 & Año 5 \\
\hline Basico & S/. 52,800 & S/. 52,800 & S/. 52,800 & S/. 52,800 & S/. 52,800 \\
\hline Bono & S/. 13,200 & S/. 13,200 & S/. 13,200 & S/. 13,200 & S/. 13,200 \\
\hline S.C.T.R & S/. 0 & S/. 0 & S/. 0 & S/. 0 & S/. 0 \\
\hline Gratificación & S/. 5,500 & S/. 5,500 & S/. 5,500 & S/. 5,500 & S/. 5,500 \\
\hline CTS & S/. 2,979 & S/. 2,979 & S/. 2,979 & S/. 2,979 & S/. 2,979 \\
\hline ESSALUD & S/. 6,435 & S/. 6,435 & S/. 6,435 & S/. 6,435 & S/. 6,435 \\
\hline Total Planilla & S/. 80,914 & S/. 80,914 & S/. 80,914 & S/. 80,914 & S/. 80,914 \\
\hline \multicolumn{6}{|l|}{ MATERIALES } \\
\hline Material de oficina & S/. 335 & S/. 335 & S/. 335 & S/. 335 & S/. 335 \\
\hline Material de limpieza & S/. 301 & S/. 301 & S/. 301 & S/. 301 & S/. 301 \\
\hline Total S/. (SIN IGV) & S/. 636 & S/. 636 & S/. 636 & S/. 636 & S/. 636 \\
\hline \multicolumn{6}{|l|}{ PUBLICIDAD } \\
\hline Facebook Ads & S/. 1,017 & S/. 1,017 & S/. 1,017 & S/. 1,017 & S/. 1,017 \\
\hline Tripticos & S/. 3,254 & S/. 1,627 & S/. 1,085 & S/. 542 & S/. 542 \\
\hline Degustaciones por 4 horas & S/. 73,220 & S/. 61,017 & S/. 48,814 & S/. 24,407 & S/. 24,407 \\
\hline Uniformes (Polos) & S/. 1,271 & S/. 2,360 & S/. 2,360 & S/. 2,360 & S/. 1,271 \\
\hline Permisos de Volantes/Tripticos & S/. 1,017 & S/. 508 & S/. 339 & S/. 339 & S/. 169 \\
\hline Banner & S/. 2,712 & S/. 2,712 & S/. 2,712 & S/. 1,356 & S/. 1,356 \\
\hline Total Costo Publicidad y Marketing (sin IGV) & S/. 82,492 & S/. 69,241 & S/. 56,326 & S/. 30,021 & S/. 28,763 \\
\hline
\end{tabular}

\begin{tabular}{|c|c|c|c|c|c|}
\hline SERVICIOS & & & & & \\
\hline Energía Eléctrica & S/. 1,525 & S/. 1,525 & S/. 1,525 & S/. 1,525 & S/. 1,525 \\
\hline Agua & S/. 763 & S/. 763 & S/. 763 & S/. 763 & S/. 763 \\
\hline Arbitrios & S/. 263 & S/. 263 & S/. 263 & S/. 263 & S/. 263 \\
\hline Servicio de teléfono - internet & S/. 1,119 & S/. 1,119 & S/. 1,119 & S/. 1,119 & S/. 1,119 \\
\hline Alquiler local & S/. 15,458 & S/. 15,458 & S/. 15,458 & S/. 15,458 & S/. 15,458 \\
\hline Servicio de contabilidad & S/. 0 & S/. 0 & S/. 0 & S/. 0 & $\mathrm{~S} / .0$ \\
\hline Servicio de limpieza (honorarios) & S/. 1,200 & S/. 1,200 & S/. 1,200 & S/. 1,200 & S/. 1,200 \\
\hline Servicio de seguridad & S/. 2,644 & S/. 2,644 & S/. 2,644 & S/. 2,644 & S/. 2,644 \\
\hline Recarga de extintores & $\mathrm{S} / .20$ & $\mathrm{~S} / .20$ & S/. 20 & $\mathrm{~S} / .20$ & S/. 20 \\
\hline Mantenimiento de maquinarias y equipos & S/. 508 & S/. 508 & S/. 508 & S/. 508 & S/. 508 \\
\hline Poliza de seguro contra robo y otros & S/. 305 & S/. 305 & S/. 305 & S/. 305 & S/. 305 \\
\hline Servicio de motorizado (honorarios) & S/. 13,200 & S/. 14,885 & S/. 16,767 & S/. 18,867 & S/. 21,209 \\
\hline Servicio transporte distribución & S/. 36,102 & S/. 40,711 & S/. 45,857 & S/. 51,600 & S/. 58,006 \\
\hline Total Costo Servicios (sin IGV) & S/. 73,107 & S/. 79,402 & S/. 86,430 & S/. 94,272 & S/. 103,020 \\
\hline TOTAL GASTOS DE VENTAS (SIN IGV) & S/. 237,149 & S/. 230,194 & S/. 224,306 & S/. 205,843 & S/. 213,333 \\
\hline IGV & S/. 22,700 & S/. 21,145 & S/. 19,747 & S/. 16,045 & S/. 16,972 \\
\hline TOTAL GASTOS DE VENTAS (CON IGV) & S/. 259,849 & S/. 251,339 & S/. 244,053 & S/. 221,889 & S/. 230,304 \\
\hline
\end{tabular}


El costo de marketing y ventas disminuye en los 5 años, debido a que el primer año la Inversión es fuerte, debido a que es un producto nuevo y debe introducirse al mercado, pero el objetivo es lograr hacerse conocidos por el boca a boca y ya no por publicidad, sino por consumo, ver tabla 181.

\subsubsection{Presupuesto de gastos financieros.}

Según Sapag y Sapag (2008), el presupuesto de gastos financieros es el presupuesto que se hace al final. Es de carácter aleatorio y depende siempre de las necesidades financieras planteadas por los plazos de cobro y los plazos de pago.

Para poder llevar a cabo el proyecto se decidió que se debía solicitar un un préstamo por S/120,000 para adquirir activo fijo, el mismo que deberá ser pagado en cuatro años los intereses y la amortización anual se puede apreciar en la tabla 182.

Tabla 182

Cronograma de financiamiento Prestamos Activos

\begin{tabular}{crrcr} 
& Deuda & Interés & Amortización & Cuota \\
\cline { 2 - 5 } Año 1 & 120,000 & 26,874 & 20,217 & 47,091 \\
Año 2 & 99,783 & 21,405 & 25,686 & 47,091 \\
Año 3 & 74,096 & 14,457 & 32,634 & 47,091 \\
Año 4 & 41,462 & 5,629 & 41,462 & 47,091 \\
\hline TOTAL & & 68,365 & 120,000 & 188,365 \\
\hline
\end{tabular}

Para poder operar se calculó que era necesario solicitar un préstamo por $\mathrm{S} / .70,000$ para Capital de Trabajo, el cual sería pagado en dos años, el cálculo y la amortización anual se puede ver en la tabla 183.

Tabla 183

Cronograma de financiamiento Capital de trabajo

\begin{tabular}{ccccc} 
& Deuda & Interés & Amortización & Cuota \\
\hline Año 1 & 70,000 & 14,613 & 30,557 & 45,170 \\
Año 2 & 39,443 & 5,727 & 39,443 & 45,170 \\
Año 3 & - & - & - & - \\
Año 4 & - & - & - & - \\
\hline TOTAL & & 20,340 & 70,000 & 90,340 \\
\hline
\end{tabular}


Por lo tanto el total de la deuda calculada por adquisición de activos fijos y capital de trabajo fue de S/190,000 y en la tabla 184 que el cronograma de financiamiento se puede apreciar el pago proyectada por intereses y amortización anuales.

Tabla 184

Cronograma de financiamiento Deuda Total

\begin{tabular}{rrrcr} 
& Deuda & Interés & Amortización & Cuota \\
\cline { 2 - 5 } Año 1 & 190,000 & 41,487 & 50,774 & 92,261 \\
Año 2 & 139,226 & 27,132 & 65,129 & 92,261 \\
Año 3 & 74,096 & 14,457 & 32,634 & 47,091 \\
Año 4 & 41,462 & 5,629 & 41,462 & 47,091 \\
\hline TOTAL & & 88,705 & 190,000 & 278,705 \\
\hline
\end{tabular}

\subsection{Presupuestos de Resultados.}

\subsubsection{Estado de ganancias y pérdidas proyectado.}

Es un estado financiero, el primero que debe elaborarse. En este se muestra la gestión económica de una organización en un tiempo determinado. En este informe se resume todos los ingresos y gastos en que se ha incurrido en el ciclo contable. En este se puede comparar los ingresos con los egresos, para ver la rentabilidad contable de la organización (Beltrán \& Cueva, 2009).

En el estado de Ganancia y pérdidas se dividió el funcionamiento en tres áreas : producción, ventas y administración, no está consideradas la amortización y depreciación. Se puede observar que Mano de obra directa no tiene IGV. Las compras activas y por ley se deprecian durante los 5 años, estas tienen un valor contable al final del proyecto el valor de los equipos en menor y es el valor del mercado, ocasionando una pérdida de capital.En el quinto año hay una disminución de S/. 79,316 en el costo de ventas, debido a que ya no se invierte porque ya no hay un pre operativo, ver tabla 185 . 
Tabla 185

Estado de Resultados Integrados

\begin{tabular}{lrrrrr}
\hline \multicolumn{7}{c}{ (NO INCLUYE GASTOS FINANCIEROS) } & & \\
\hline & 2018 & 2019 & 2020 & 2021 & 2022 \\
\hline VENTAS & $1,328,306$ & $1,497,912$ & $1,687,254$ & $1,898,541$ & $2,134,224$ \\
COSTO DE VENTAS & $(814,943)$ & $(874,400)$ & $(947,605)$ & $(1,028,537)$ & $(949,221)$ \\
$\quad(-)$ Materia Prima & $(553,597)$ & $(596,721)$ & $(665,621)$ & $(741,769)$ & $(661,414)$ \\
$\quad(-)$ Mano de obra directa & $(38,265)$ & $(51,020)$ & $(51,020)$ & $(51,020)$ & $(51,020)$ \\
$\quad(-)$ CIF & $(223,080)$ & $(226,659)$ & $(230,964)$ & $(235,747)$ & $(236,788)$ \\
\hline UTILIDAD BRUTA & 513,363 & 623,511 & 739,649 & 870,005 & $1,185,002$ \\
GASTOS OPERATIVOS & $(459,896)$ & $(456,435)$ & $(454,801)$ & $(441,010)$ & $(449,743)$ \\
(-) GASTOS & & & & & \\
ADMINISTRATIVOS & $(145,711)$ & $(145,711)$ & $(145,711)$ & $(145,711)$ & $(145,711)$ \\
$(-)$ GASTOS VENTAS & $(237,149)$ & $(230,194)$ & $(224,306)$ & $(205,843)$ & $(213,333)$ \\
$(-)$ DEPRECIACION & $(12,571)$ & $(12,825)$ & $(13,461)$ & $(14,096)$ & $(10,839)$ \\
$(-)$ AMORTIZACION & & & & & \\
INTANGIBLES & $(39,090)$ & $(39,090)$ & $(39,090)$ & $(39,090)$ & $(39,090)$ \\
(-) PROVISION DE & & & & & \\
INCOBRABLES & $(25,375)$ & $(28,615)$ & $(32,232)$ & $(36,269)$ & $(40,771)$ \\
\hline EBIT O UTILIDAD & 53,467 & 167,076 & 284,849 & 428,995 & 735,259 \\
OPERATIVA & & & & & \\
$(-)$ IMPUESTO A LA & $(5,347)$ & $(37,441)$ & $(72,184)$ & $(114,707)$ & $(205,055)$ \\
RENTA & & & & & \\
\hline UTILIDAD OPERATIVA & & & & & \\
DESPUES DE & 48,120 & 129,635 & 212,665 & 314,288 & 530,204 \\
IMPUESTOS & & & &
\end{tabular}

Para calcular el importe del impuesto a la renta se utilizó un tasa del 10\% cuando el monto es menor a 5 UIT (Unidad Impositiva Tributaria), cuando pasó las 5 UIT la tasa del impuesto a la renta es de $29.50 \%$, en la tabla 186se puede apreciar cómo se hizo el cálculo para aplicar las tasas.

Tabla 186

Cálculo de impuesto a la renta

\begin{tabular}{lrrrrr} 
& 2018 & 2019 & 2020 & 2021 & 2022 \\
\hline EBIT O UTILIDAD & & & & & \\
OPERATIVA & 53,467 & 167,076 & 284,849 & 428,995 & 735,259 \\
Hasta 15UIT & 53,467 & 60,750 & 60,750 & 60,750 & 60,750 \\
\hline
\end{tabular}

Mas de 15UIT

$\begin{array}{lllll}0 & 106,326 & 224,099 & 368,245 & 674,509\end{array}$


En la tabla 187 se puede apreciar el Estado de Resultados Integrados incluyendo

gastos financieros, quiere decir mostrando el costo de la deuda.

Tabla 187

Estado de Resultados Integrados- Incluye gastos Financieros (INCLUYE GASTOS FINANCIEROS)

\begin{tabular}{lrrrrr}
\hline & 2018 & 2019 & 2020 & 2021 & 2022 \\
\hline VENTAS & $1,328,306$ & $1,497,912$ & $1,687,254$ & $1,898,541$ & $2,134,224$ \\
COSTO DE VENTAS & $(814,943)$ & $(874,400)$ & $(947,605)$ & $(1,028,537)$ & $(949,221)$ \\
$\quad(-)$ Material directo & $(553,597)$ & $(596,721)$ & $(665,621)$ & $(741,769)$ & $(661,414)$ \\
$\quad(-)$ Mano de obra directa & $(38,265)$ & $(51,020)$ & $(51,020)$ & $(51,020)$ & $(51,020)$ \\
$\quad(-)$ CIF & $(223,080)$ & $(226,659)$ & $(230,964)$ & $(235,747)$ & $(236,788)$ \\
\hline UTILIDAD BRUTA & 513,363 & 623,511 & 739,649 & 870,005 & $1,185,002$ \\
(-) GASTOS ADMINISTRATIVOS & $(145,711)$ & $(145,711)$ & $(145,711)$ & $(145,711)$ & $(145,711)$ \\
(-) GASTOS VENTAS & $(237,149)$ & $(230,194)$ & $(224,306)$ & $(205,843)$ & $(213,333)$ \\
(-) DEPRECIACION & $(12,571)$ & $(12,825)$ & $(13,461)$ & $(14,096)$ & $(10,839)$ \\
(-) AMORTIZACION INTANGIBLES & $(39,090)$ & $(39,090)$ & $(39,090)$ & $(39,090)$ & $(39,090)$ \\
(-) PROVISIÓN DE INCOBRABLES & $(25,375)$ & $(28,615)$ & $(32,232)$ & $(36,269)$ & $(40,771)$ \\
\hline EBIT O UTILIDAD OPERATIVA & 53,467 & 167,076 & 284,849 & 428,995 & 735,259 \\
VENTA ACTIVOS FIJOS & & & & & 28,747 \\
(-) VALOR LIBROS & & & & & $(57,625)$ \\
GASTOS FINANCIEROS & $(41,487)$ & $(27,132)$ & $(14,457)$ & $(5,629)$ & \\
\hline UTILIDAD ANTES IMPUESTOS & 11,980 & 139,944 & 270,392 & 423,366 & 706,380 \\
(-) IMPUESTO A LA RENTA & $(1,198)$ & $(29,437)$ & $(67,919)$ & $(113,047)$ & $(196,536)$ \\
UTILIDAD NETA & 10,782 & 110,507 & 202,472 & 310,319 & 509,844 \\
\hline
\end{tabular}

Para aplicar el monto a pagar de impuesto a la renta como se obseva en la tabla 188 se hizo el siguiente cálculo :

Tabla 188

Cálculo del impuesto a la renta

\begin{tabular}{lrrrrr}
\cline { 2 - 6 } & 2018 & 2019 & 2020 & 2021 & 2022 \\
\hline UTILIDAD ANTES & 11,980 & 139,944 & 270,392 & 423,366 & 706,380 \\
IMPUESTOS & 11,980 & 60,750 & 60,750 & 60,750 & 60,750 \\
Hasta 15UIT & 0 & 79,194 & 209,642 & 362,616 & 645,630 \\
\hline Mas de 15UIT & & & &
\end{tabular}




\subsubsection{Balance proyectado.}

Como menciona Sapag y Sapag (2008), el balance representa el valor contable de la empresa y es tomado en una fecha determinada. Este balance está conformado por los lados que son equiparados por una igualdad, en el izquierdo se ubican los activos y en el derecho los pasivos más el capital. El balance es utilizado para mostrar los activos de la empresa y también la forma de financiamiento.

En el balance proyectado se pueden identificar los montos referentes a los activos, pasivos y patrimonio que presenta la empresa en el transcurso de los cinco años que estima el proyecto. En la tabla 189 se puede observar el aumento en los tres elementos del balance general debido a la adquisición de maquinaria, capital de trabajo y demás elementos. El total de los activos, pasivos y patrimonio asciende a S/ 411,354 en el año cero y culmina con S/ $1 ’ 365,279$ en el año 5. 
Tabla 189

Balance de Situación Financiera Proyectado

\begin{tabular}{|c|c|c|c|c|c|c|}
\hline & Año 0 & Año 1 & Año 2 & Año 3 & Año 4 & Año 5 \\
\hline \multicolumn{7}{|l|}{ Activos } \\
\hline \multicolumn{7}{|l|}{ Activo corriente } \\
\hline Caja & & 38,492 & 119,269 & 323,964 & 633,361 & $1,365,279$ \\
\hline Capital de trabajo & 71,275 & 80,376 & 90,536 & 101,874 & 114,520 & \\
\hline Crédito fiscal (igv) & 38,467 & & & & & \\
\hline Total activo corriente & 109,742 & 118,869 & 209,805 & 425,838 & 747,881 & $1,365,279$ \\
\hline \multicolumn{7}{|l|}{ Activo no corriente } \\
\hline Activo tangible & 106,163 & 108,706 & 115,062 & 121,418 & 121,418 & \\
\hline (-) Depreciación acumulada & & $-12,571$ & $-25,396$ & $-38,857$ & $-52,953$ & \\
\hline activo intangible & 195,449 & 195,449 & 195,449 & 195,449 & 195,449 & 195,449 \\
\hline (-) Amortización acumulada & & $-39,090$ & $-78,179$ & $-117,269$ & $-156,359$ & $-195,449$ \\
\hline Total activo no corriente & 301,612 & 252,494 & 206,935 & 160,740 & 107,554 & 0 \\
\hline Total activos & 411,354 & 371,362 & 416,740 & 586,578 & 855,435 & $1,365,279$ \\
\hline \multicolumn{7}{|l|}{ Pasivos } \\
\hline Deuda & 190,000 & 139,226 & 74,096 & 41,462 & 0 & \\
\hline Total pasivos & 190,000 & 139,226 & 74,096 & 41,462 & 0 & 0 \\
\hline \multicolumn{7}{|l|}{ Patrimonio } \\
\hline Capital & 221,354 & 221,354 & 221,354 & 221,354 & 221,354 & 221,354 \\
\hline Utilidad acumulada & & & 10,782 & 121,289 & 323,762 & 634,081 \\
\hline Utilidad del ejercicio & & 10,782 & 110,507 & 202,472 & 310,319 & 509,844 \\
\hline Total patrimonio & 221,354 & 232,137 & 342,643 & 545,116 & 855,435 & $1,365,279$ \\
\hline Total pasivos y patrimonio & 411,354 & 371,362 & 416,740 & 586,578 & 855,435 & $1,365,279$ \\
\hline
\end{tabular}




\subsubsection{Flujo de caja proyectado.}

Según Sapag y Sapag (2008), el flujo de caja tiene por finalidad ordenar la investigación recibida por las inversiones anteriores al inicio de las operaciones de la empresa, además de incluir las inversiones durante la operación, ingresos, egresos, el valor de auxilio y el valor de recupero del capital de trabajo.

En la tabla 190 se muestra el flujo de caja proyectado, en el cual se consideraron tres grandes indicadores, el primero es el flujo de caja operativo, que inicia en el año uno con 138,705 Soles y cierra al año cinco con547,958 nuevos soles, demostrando una tendencia creciente que beneficia al proyecto. El segundo es el flujo de caja de libre disponibilidad o el flujo de caja económico que a diferencia del flujo operativo, este inicia en el año cero con un monto negativo, sin embargo al término del quinto año cierra en positivo. El ultimo es el flujo de caja del accionista o el flujo de caja financiero, en este flujo se puede observar que el proyecto es rentable para el inversionista, cerrando al quinto año con un monto de 731,918 nuevos soles.

Cabe recalcar, que en el quinto año hay una dismunición de S/. 79,316 en el costo de materia prima, como se mencionó anteriormente esto se da debido a que ya no se invierte en comprar materia prima los dos últimos meses, es decir solo se compró hasta octubre, por el periodo de dos meses que hubo un pre operativo ya que se necesitan dos meses de maceración.

En la tabla 191 se detalla el módulo de IGV e indica el monto que se pagará anualmente durante el periodo de cinco años. En resumen, se puede concluir que el proyecto presenta un flujo de caja proyectado positivo en el periodo de cinco años, lo cual es favorable tanto para la empresa como para los inversionistas. En tabla 190, no se reporta utilidades porque se evalúa solamente la rentabilidad del proyecto. 
Tabla 190

Flujo de Caja Proyectado

\begin{tabular}{|c|c|c|c|c|c|c|}
\hline & \multirow[b]{2}{*}{ Año 0} & & & & \\
\hline & & Año 1 & Año 2 & Año 3 & Año 4 & Año 5 \\
\hline VENTAS (descontado incobrables) & & $1,542,026$ & $1,738,920$ & $1,958,727$ & $2,204,010$ & $2,477,613$ \\
\hline (-) MATERIAL DIRECTO O MATERIA PRIMA & & $(653,245)$ & $(704,131)$ & $(785,433)$ & $(875,288)$ & $(780,468)$ \\
\hline (-) MANO DE OBRA DIRECTA & & $(38,265)$ & $(51,020)$ & $(51,020)$ & $(51,020)$ & $(51,020)$ \\
\hline (-) $\mathrm{CIF}$ & & $(233,922)$ & $(238,145)$ & $(243,224)$ & $(248,868)$ & $(250,096)$ \\
\hline (-) GASTOS ADMINISTRATIVOS & & $(149,477)$ & $(149,477)$ & $(149,477)$ & $(149,477)$ & $(149,477)$ \\
\hline (-) GASTOS VENTAS & & $(259,849)$ & $(251,339)$ & $(244,053)$ & $(221,889)$ & $(230,304)$ \\
\hline (-) IMPUESTOS A LA RENTA & & $(5,347)$ & $(37,441)$ & $(72,184)$ & $(114,707)$ & $(205,055)$ \\
\hline (-) PAGO IGV (Estado) & & $(63,216)$ & $(124,674)$ & $(146,977)$ & $(175,287)$ & $(236,234)$ \\
\hline \multirow{2}{*}{ FLUJO DE CAJA OPERATIVO } & & 138,705 & 182,694 & 266,359 & 367,474 & 574,958 \\
\hline & Año 0 & Año 1 & Año 2 & Año 3 & Año 4 & Año 5 \\
\hline (-) INVERSION ACTIVOS TANGIBLES & $(125,273)$ & $(3,000)$ & $(7,500)$ & $(7,500)$ & & \\
\hline (-) INVERSION ACTIVOS INTANGIBLES & $(5,719)$ & & & & & \\
\hline (-) GASTOS PRE-OPERATIVOS & $(209,087)$ & & & & & \\
\hline (-) INVERSION CAPITAL DE TRABAJO & $(71,275)$ & $(9,101)$ & $(10,160)$ & $(11,337)$ & $(12,646)$ & \\
\hline (+) VALOR DE DESECHO ACTIVOS FIJOS & & & & & & 42,440 \\
\hline (+) VALOR DE RECUPERO CAPITAL DE TRABAJO & & & & & & 114,520 \\
\hline FLUJO DE CAPITAL O INVERSION TOTAL & $(411,354)$ & $(12,101)$ & $(17,660)$ & $(18,837)$ & $(12,646)$ & 156,960 \\
\hline \multirow[t]{2}{*}{$\begin{array}{l}\text { FLUJO DE CAJA DE LIBRE DISPONIBILIDAD } \\
\text { (ECONOMICO) }\end{array}$} & $(411,354)$ & 126,605 & 165,034 & 247,522 & 354,828 & 731,918 \\
\hline & Año 0 & Año 1 & Año 2 & Año 3 & Año 4 & Año 5 \\
\hline PRESTAMO & 190,000 & & & & & \\
\hline (-) CUOTAS (Amortización + Intereses) & & $(92,261)$ & $(92,261)$ & $(47,091)$ & $(47,091)$ & \\
\hline (+) ESCUDO FISCAL & & 4,149 & 8,004 & 4,265 & 1,661 & 0 \\
\hline FLUJO DE CAJA DE LA DEUDA & 190,000 & $(88,112)$ & $(84,257)$ & $(42,826)$ & $(45,431)$ & 0 \\
\hline
\end{tabular}

FLUJO DE CAJA DEL ACCIONISTA (FINANCIERO)

$(221,354)$

38,492

$80,777 \quad 204,695$

309,397

731,918 
Tabla 191

Módulo de IGV

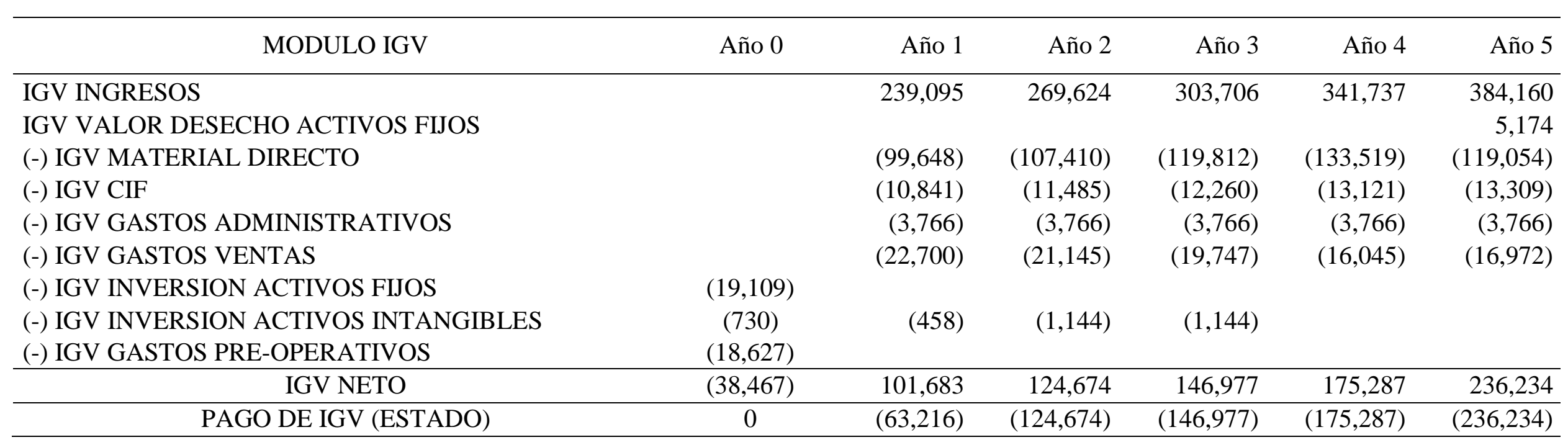




\section{Capítulo IX. Evaluación económica financiera}

En este capítulo se presentó la viabilidad y rentabilidad del negocio mediante la evaluación de una serie de los indicadores económicos y financieros.

\subsection{Evaluación Financiera}

Según Sapag y Sapag (2008), esta evaluación brinda información para comparar y poder evaluar con las herramientas técnicas la rentabilidad del proyecto y seguir con el proceso de Inversión.

\subsubsection{TIR.}

Para Sapag y Sapag (2008), la tasa interna de retorno (TIR) es utilizada para la evaluación del proyecto tomando como referencia una tasa única de rendimiento por periodo, en donde las sumas de todos los beneficios se expresan técnicamente iguales a los abonos enumerados en moneda actual. En resumen, el TIR demuestra la tasa de interés más elevada que el inversionista está dispuesto a pagar sin perder dinero.

Luego de los resultados obtenidos en el proyecto, se mostró en la tabla 192que el TIR económico es mayor al WACC, con lo cual se demuestró que el rendimiento del proyecto es superior a la rentabilidad mínima esperada. El TIR económico representó el 48.34\% sobre el WACC que es $28.90 \%$. En el caso del TIR financiero, tabla 193, este también es superior al COK, se observó que el rendimiento del proyecto es superior al costo mínimo de oportunidad del inversionista, siendo el TIR financiero $60.26 \%$ sobre el COK que representa un $36.89 \%$. 
Tabla 192

TIR Económico

FLUJO DE CAJA DE LIBRE DISPONIBILIDAD (ECONÓMICO)
Año 0 Año $1 \quad$ Año 2 Año 3 Año 4 Año 5

$\begin{array}{llllll}(411,354) & 126,605 & 165,034 & 247,522 & 354,828 & 731,918\end{array}$

\begin{tabular}{lc} 
WACC & $28.90 \%$ \\
TIR Economico & $48.34 \%$ \\
Beneficio/Costo & 1.57 \\
\hline
\end{tabular}

PERIODO DE RECUPERACIÓN DESCONTADO

Año 0 Año 1 Año 2 Año 3 Año 4 Año 5

Flujo de caja descontado \begin{tabular}{llllll}
$-411,354$ & 98,219 & 99,326 & 115,572 & 128,529 & 205,680 \\
\hline
\end{tabular}

Flujo de caja acumulado $\begin{array}{llllll}-411,354 & 313,135 & 213,809 & -98,237 & 30,292 & 235,972\end{array}$

Periodo de recuperación descontado

3.76 años

Tabla 193

TIR Financiero

FLUJO DE CAJA FINANCIERO DEL ACCIONISTA

\begin{tabular}{|c|c|c|c|c|}
\hline Año 0 & Año 1 & Año 2 & Año 4 & Año 5 \\
\hline$(221,354)$ & 38,492 & 80,777 & $204,695309,397$ & 731,918 \\
\hline $36.89 \%$ & & & & \\
\hline 170,096 & & & & \\
\hline $60.26 \%$ & & & & \\
\hline 1.77 & & & & \\
\hline
\end{tabular}

Beneficio/Costo

Año 0 Año 1 Año 2 Año 3 Año 4 Año 5 DESCONTADO

Flujo de caja descontado $\begin{array}{llllll}-221,354 & 28,120 & 43,109 & 79,806 & 88,123 & 152,292\end{array}$

Flujo de caja acumulado $\begin{array}{llllll}-221,354 & 193,234 & 150,125 & -70,318 & 17,804 & 170,096\end{array}$

Periodo de recuperación descontado 3.80 años 


\subsubsection{VAN.}

Según Sapag y Sapag (2008), el criterio del proyecto debe aceptarse si el valor actual neto es igual o superior a cero, debido a que el VAN es la diferencia entre todos los ingresos y egresos expresados en la moneda actual, ver detalle en tabla 194 y tabla 195.

Tabla 194

Van Económico

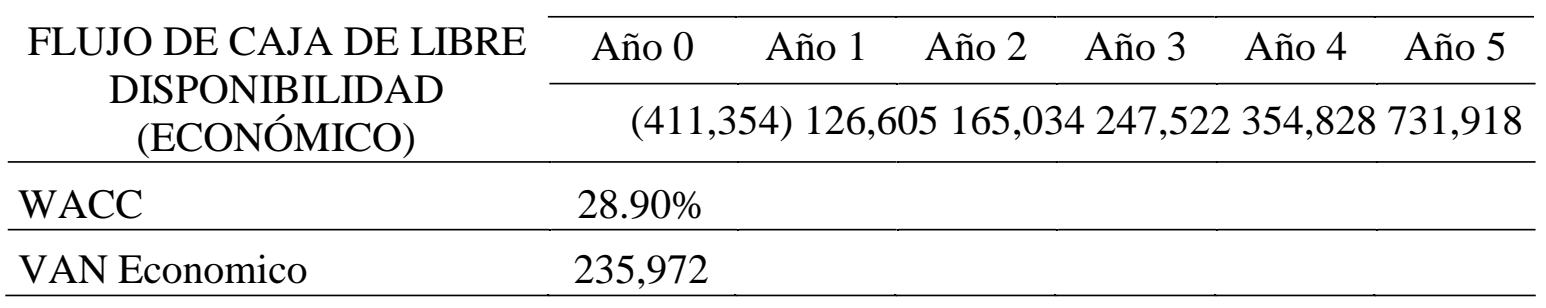

Tabla 195

Van Financiero

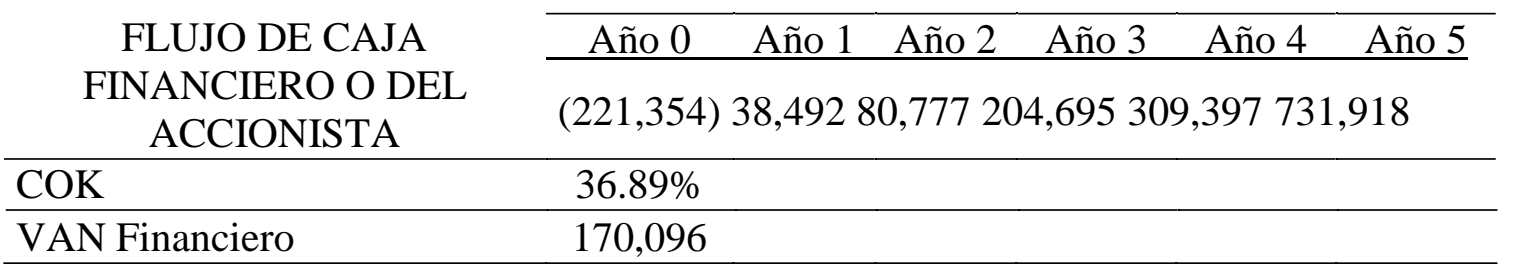

Los resultados arrojaron que el VAN es positivo, demostrando que este proyecto es rentable y siendo atractivos para la empresa, ya que al descontar la invesión inicial para ambos indica que el resultado es viable, ver en tabla 196.

\subsubsection{ROE.}

Para Beltrán y Cueva (2009), este es un ratio de rentabilidad que demuestra la rentabilidad patrimonial neta. Con este ratio se puede obtener el rendimiento de los capitales propios aportados, los que comúnmente se comparan con el costo de oportunidad de la empresa.

La fórmula utilizada para hacer el cálculo fue la siguiente:

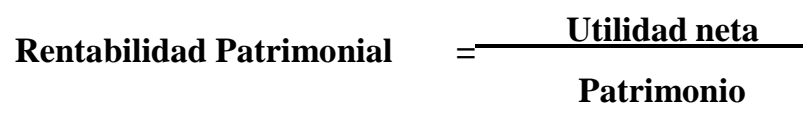


Como se puede ver en la tabla 196, la rentabilidad sobre el patrimonio a partir del segundo año fuepositivo y representa la tasa de descuento o rentabilidad mínima que se obtiene del proyecto.

Tabla 196

Resultados ROE

\begin{tabular}{lccccc}
\hline RATIOS RENTABILIDAD & Año 1 & Año 2 & Año 3 & Año 4 & Año 5 \\
\hline ROE & $5 \%$ & $48 \%$ & $59 \%$ & $57 \%$ & $60 \%$ \\
\hline
\end{tabular}

\subsubsection{Ratios.}

Según Sapag y Sapag (2008), los ratios o indicadores financieros son factores o razones que facilitan elementos contables y financieros para evaluar y contrastar la relación que existe entre dos representacionesfinancieras directas con el objetivo de examinar el estado de una organización en un periodo determinado. Estos ratios son indispensables al momento de evaluar la conducta de la empresa en términos financieros.

El margen operativo representa la relación entre los ingresos divididos entre las ventas netas y permite expresar la capacidad que tiene la empresa para generar ganancias. En este caso se puede observar que el margen operativo aumenta cada año iniciando con el $5 \%$ y culminando con un 33\%. Para el margen neto, lo representa la utilidad bruta entre los gastos e impuestos. Para el caso de la empresa este margen se mostró en aumento durante los cinco años. El ROA, es el beneficio entre los activos de la empresa (EBIT/Activos totales), permite mostrar el rendimiento de los activos. Por lo tanto, en la tabla 197 se muestran los ratios de rentabilidad margen operativo, margen neto y ROA, se puede observar que todos estos ratios aumentan durante los cinco años de proyecto.

Se mostró la diferencia que existe entre los activos y pasivos de la empresa con el objetivo de analizar la cantidad de deuda utilizada por la empresa para financiar los activos. El apalancamiento de la empresa será menor si el grado de propiedad se muestra mayor y en el caso de la empresa esta ratio va en aumento iniciando en el año uno con $63 \%$ y alcanzando 
el 100\% en el año cuatro. La cobertura de gastos financieros se utilizó como indicador económico para evaluar la capacidad de una empresa para crear resultados capaces para sustentar sus deberes financieros. Los porcentajes se pueden evidenciar en la tabla 198, donde se muestran ratios de endeudamiento, deuda entre capital, grado de propiedad y cobertura de gastos financieros.

Tabla 197

Ratios de Rentabilidad

\begin{tabular}{lccccc}
\hline & Año 1 & Año 2 & Año 3 & Año 4 & Año 5 \\
\hline MARGEN OPERATIVO & $4 \%$ & $11 \%$ & $17 \%$ & $23 \%$ & $34 \%$ \\
MARGEN NETO & $1 \%$ & $7 \%$ & $12 \%$ & $16 \%$ & $24 \%$ \\
ROA & $3 \%$ & $27 \%$ & $35 \%$ & $36 \%$ & $37 \%$ \\
\hline
\end{tabular}

Tabla 198

Ratios de Endeudamiento

\begin{tabular}{lccccc}
\hline & Año 1 & Año 2 & Año 3 & Año 4 & Año 5 \\
\hline DEUDA/CAPITAL & 0.60 & 0.22 & 0.08 & 0.00 & 0.00 \\
GRADO DE PROPIEDAD & $63 \%$ & $82 \%$ & $93 \%$ & $100 \%$ & $100 \%$ \\
COBERTURA DE GASTOS & & & & & \\
FINANCIEROS & 0.78 & 0.16 & 0.05 & 0.01 & \\
\hline
\end{tabular}

\subsection{Análisis de Riesgo}

Sapag y Sapag (2008), indica que los análisis de riesgo en los proyectos tienen la propiedad de reducir la incertidumbre de los resultados. Se analizó el problema de la medición del riesgo en los proyectos y distintos criterios de inclusión y análisis para la evaluación.

\subsubsection{Análisis de punto de equilibrio.}

Como menciona Sapag y Sapag (2008), el análisis de punto de equilibrio se enfoca en explicar la relación entre diversos factores como costos fijos, variables, volumen de ventas y utilidades obtenidas por la operación.En resumen, el punto de equilibrio representa el nivel de producción y ventas que una empresa o negocio alcanza para lograr cubrir los costos con sus ingresos obtenidos. En otras palabras, a este nivel de producción y ventas la utilidad operacional es cero, es decir, que los ingresos son iguales a la sumatoria de los costos y 
gastos operacionales. También el punto de equilibrio se considera como una herramienta útil para determinar el apalancamiento operativo que puede tener una empresa en un momento determinado.

Para poder obtener el punto de equilibrio se tomaron en cuenta algunas variables como el porcentaje de venta, valor de venta unitario y el costo unitario para poder deducir el margen de contribución, toda esta información fue obtenida del capítulo ocho. El proyecto consideró tres tipos de sabores de macerados de frutas en pisco, por lo tanto, se obtuvieron tres márgenes de contribución por cada sabor y lo que se realizó fue ponderar los resultados para generar un solo margen. Luego con esta información se puedo obtener las unidades promedio de equilibrio como se puede observar en la siguiente tabla199, donde se muestra la distribución porcentual para cada sabor, maracuyá y frambuesa 36\%, fresa y guinda $36 \%$ y chicha morada $28 \%$.

La tabla 200 muestra el punto de equilibrio, teniendo como referencia cada uno de los tres sabores y además se detalla para cada uno de los cinco años del proyecto.

En la tabla 201 se muestra el Estado de Resultados con el punto de equililbrio.

Tabla 199

Distribución por sabor

PRODUCTO

Maracuyá y frambuesa

Fresa y guinda

Chicha

\section{MEZCLA}

$36.0 \%$

$36.0 \%$

$28.0 \%$ 
Tabla 200

Punto de Equilibrio

\begin{tabular}{|c|c|c|c|c|c|c|c|c|c|c|c|c|c|}
\hline \multicolumn{3}{|c|}{ AÑO 1} & \multicolumn{3}{|c|}{ AÑO 2} & \multicolumn{3}{|c|}{ AÑO 3} & \multicolumn{2}{|r|}{ AÑO 4} & \multicolumn{3}{|c|}{ AÑO 5} \\
\hline $\begin{array}{c}\text { Maracuya } \\
y \\
\text { frambuesa }\end{array}$ & $\begin{array}{l}\text { Fresa y } \\
\text { guinda }\end{array}$ & Chicha & $\begin{array}{c}\text { Maracuya } \\
y \\
\text { frambuesa }\end{array}$ & $\begin{array}{l}\text { Fresa y } \\
\text { guinda }\end{array}$ & Chicha & $\begin{array}{c}\text { Maracuya } \\
\text { y } \\
\text { frambuesa }\end{array}$ & $\begin{array}{l}\text { Fresa y } \\
\text { guinda }\end{array}$ & Chicha & $\begin{array}{c}\text { Maracuya } \\
\text { y } \\
\text { frambuesa }\end{array}$ & $\begin{array}{l}\text { Fresa y } \\
\text { guinda }\end{array}$ & $\begin{array}{c}\text { Maracuya } \\
\text { y } \\
\text { frambuesa }\end{array}$ & $\begin{array}{c}\text { Fresa } \\
\text { y } \\
\text { guinda }\end{array}$ & Chicha \\
\hline
\end{tabular}

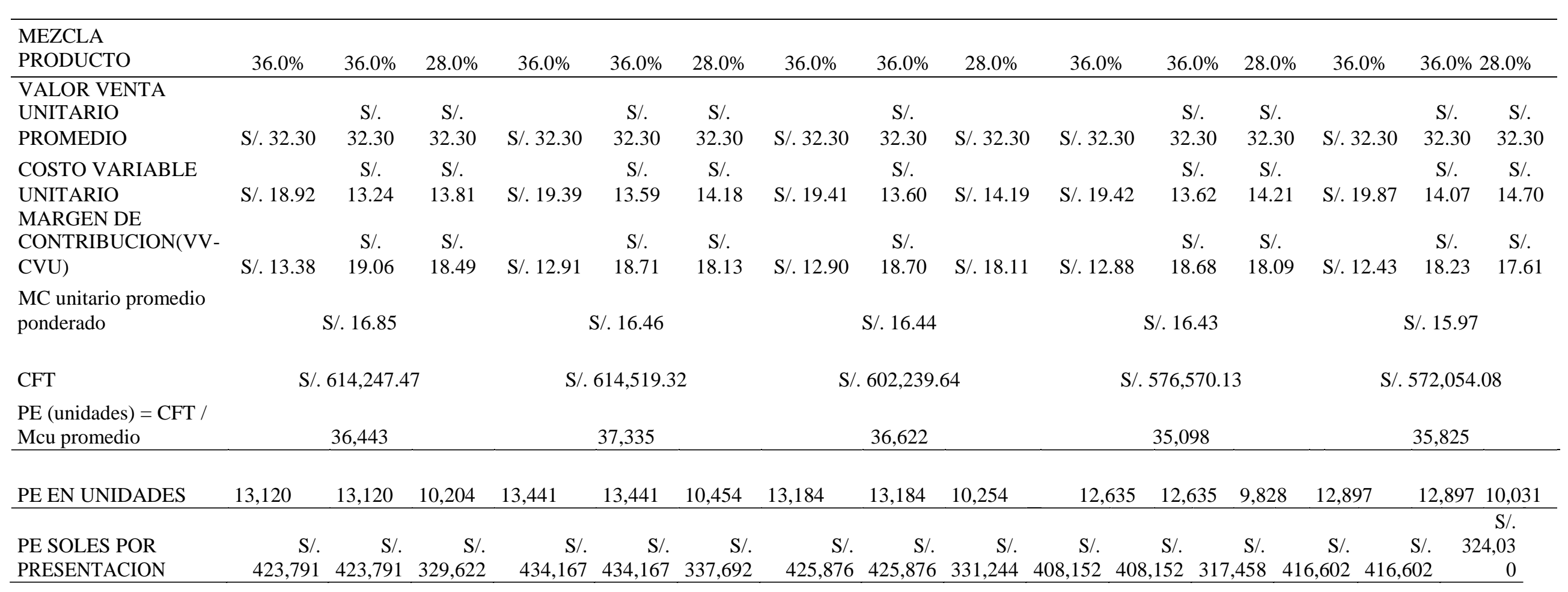


Tabla 201

Estado de Resultados (Punto de Equilibrio)

\begin{tabular}{|c|c|c|c|c|c|}
\hline VENTAS & S/. 1,177,204 & S/. 1,206,026 & S/. $1,182,996$ & S/. $1,133,762$ & S/. $1,157,234$ \\
\hline (-) COSTOS VARIABLES & $-S / .562,957$ & $-S / .591,506$ & $-S / .580,757$ & $-S / .557,192$ & $-\mathrm{S} / .585,180$ \\
\hline (-) COSTOS FIJOS & $-S / .614,247$ & $-S / .614,519$ & $-S / .602,240$ & $-S / .576,570$ & $-S / .572,054$ \\
\hline UTILIDAD OPERATIVA & $\mathrm{S} / .0$ & $\mathrm{~S} / .0$ & $\mathrm{~S} / .0$ & $\mathrm{~S} / .0$ & $\mathrm{~S} / .0$ \\
\hline
\end{tabular}




\subsubsection{Análisis de sensibilidad}

Según Sapag y Sapag (2008), el análisis de sensibilidad permite medir cuán sensible es la evaluación realizada a variaciones en uno o más parámetros decisorios. Existen distintos modelos de sensibilización que se pueden aplicar directamente a las mediciones del valor actual neto, la tasa interna de retorno y la utilidad.

Se hizo el análisis para determinar la baja de precios y para que el VAN se igual a cero, el proyecto resiste una baja de precios de hasta $7.03 \%$ y el TIRE sería $29.29 \%$ y el WACC 29.29\%, como se puede ver en la tabla 202.

Tabla 202

Análisis de Sensibilidad Unidimensional - Precios

\begin{tabular}{|c|c|c|c|c|}
\hline & \multicolumn{2}{|c|}{ Normal } & \multicolumn{2}{|c|}{$\mathrm{VANE}=0$} \\
\hline Disminución máxima de precios & & & & $-7.03 \%$ \\
\hline Maracuyá y frambuesa & $\mathrm{S} /$. & 55.00 & $\mathrm{~S} /$. & 51.13 \\
\hline Fresa y guinda & S/. & 55.00 & $\mathrm{~S} /$. & 51.13 \\
\hline Chicha & $\mathrm{S} /$. & 55.00 & $\mathrm{~S} /$. & 51.13 \\
\hline \multicolumn{5}{|c|}{ Variables de salida } \\
\hline VANE & S/. & 235,972 & $\mathrm{~S} /$. & - \\
\hline TIRE & \multicolumn{3}{|c|}{$48.34 \%$} & $29.29 \%$ \\
\hline WACC & \multicolumn{3}{|c|}{$28.90 \%$} & $29.29 \%$ \\
\hline
\end{tabular}

Luego se hizo el análisis de sensibilidad con la variable demanda, el proyecto resiste una bajada en la demanda de máximo $14.07 \%$ y el VAN sería 0, el TIRE sería de $29 \%$ y el WACC 29\%, el cálculo se puede aprecia en la tabla 203.

Tabla 203

Análisis de Sensibilidad Unidimensional - Cantidad

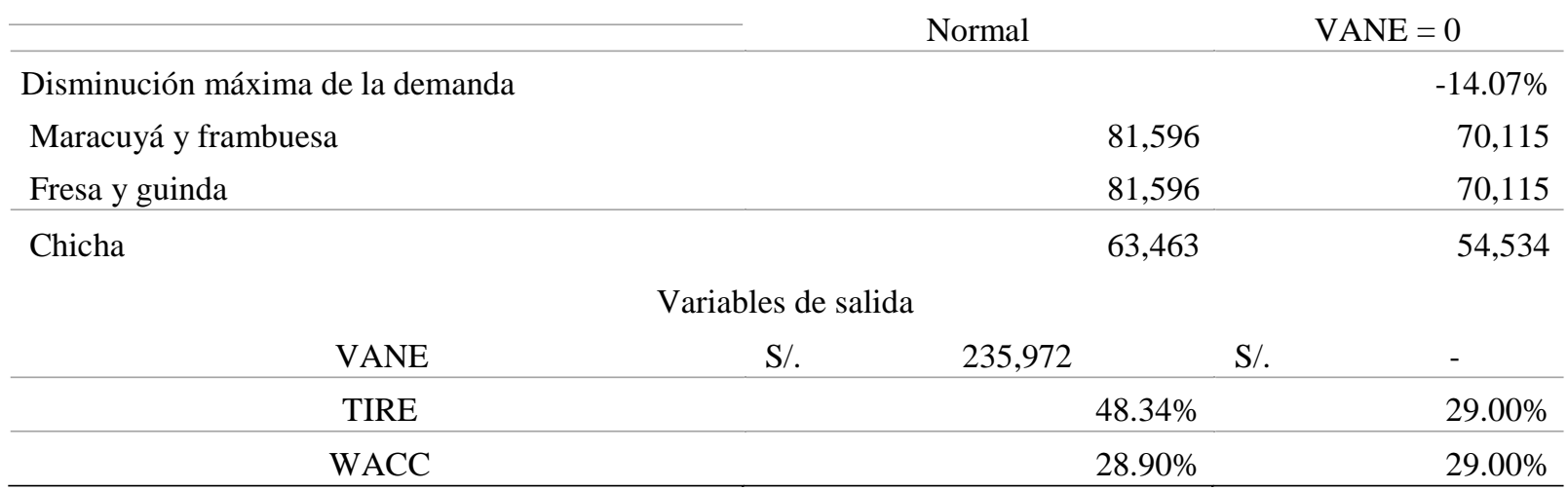


De la misma forma se analizó la variable sobre la subida de precios para materia prima y se determinó que el proyecto resiste que el costo suba en $16.34 \%$ y el VAN seguiría siendo 0, igualando el TIRE y el WACC en 29.50\%. Se puede ver el cálculo en la tabla 204.

Tabla 204

Análisis de Sensibilidad Unidimensional - Materia Prima

Normal

$\mathrm{VANE}=0$

\begin{tabular}{|c|c|c|c|c|c|}
\hline \multicolumn{5}{|c|}{ Aumento máximo del costo de la materia prima } & \multirow[t]{2}{*}{$16.34 \%$} \\
\hline Pisco & $\mathrm{S} /$. & 40.00 & S/. & 46.54 & \\
\hline Maracuyá & $\mathrm{S} /$. & 150.00 & S/. & 174.51 & \\
\hline Frambuesa & S/. & 240.00 & S/. & 279.22 & \\
\hline Fresa & $\mathrm{S} /$. & 25.00 & $\mathrm{~S} /$. & 29.09 & \\
\hline Guinda & $\mathrm{S} / \mathrm{s}$ & 100.00 & $\mathrm{~S} / \mathrm{s}$ & 116.34 & \\
\hline Maíz morado & S/. & 70.00 & $\mathrm{~S} /$. & 81.44 & \\
\hline Membrillo & S/. & 200.00 & S/. & 232.68 & \\
\hline Piña golden & $\mathrm{S} /$. & 25.00 & $\mathrm{~S} / \mathrm{s}$ & 29.09 & \\
\hline Canela & $\mathrm{S} /$. & 160.00 & $\mathrm{~S} /$. & 186.15 & \\
\hline Clavo & $\mathrm{S} /$. & 120.00 & $\mathrm{~S} /$. & 139.61 & \\
\hline Botella & $\mathrm{S} / \mathrm{s}$ & 52.00 & $\mathrm{~S} / \mathrm{s}$ & 60.50 & \\
\hline Soguilla & S/. & 8.00 & S/. & 9.31 & \\
\hline Tapon & $\mathrm{S} /$. & 40.00 & $\mathrm{~S} /$. & 46.54 & \\
\hline \multicolumn{6}{|c|}{ Variables de salida } \\
\hline VANE & S/. & 235,972 & S/. & - & \\
\hline TIRE & & \multicolumn{3}{|c|}{$48.34 \%$} & $29.50 \%$ \\
\hline WACC & & \multicolumn{3}{|c|}{$28.90 \%$} & $29.50 \%$ \\
\hline
\end{tabular}

También se analizó la variable de costo de personal y se detectó que el proyecto resiste si el costo de personal subiera hasta $40.23 \%$, el VAN sería 0 y el TIRE Y WACC serían $29.53 \%$. El cálculo se puede ver en la tabla 205. 
Tabla 205

Análisis de Sensibilidad Unidimensional - Costos de personal

\begin{tabular}{|c|c|c|c|c|}
\hline & \multicolumn{2}{|c|}{ Normal } & \multicolumn{2}{|c|}{$\mathrm{VANE}=0$} \\
\hline & & & \multicolumn{2}{|c|}{$40.23 \%$} \\
\hline Gerente General & $\mathrm{S} /$. & 5,000 & $\mathrm{~S} /$. & 7,012 \\
\hline Asistente Administrativo & $\mathrm{S} /$. & 1,200 & $\mathrm{~S} /$. & 1,683 \\
\hline Jefe de Ventas & $\mathrm{S} / \mathrm{s}$ & 2,000 & $\mathrm{~S} /$. & 2,805 \\
\hline Ejecutivo de Ventas & $\mathrm{S} /$. & 1,200 & $\mathrm{~S} /$. & 1,683 \\
\hline Community Manager & $\mathrm{S} /$. & 1,200 & $\mathrm{~S} /$. & 1,683 \\
\hline Jefe de Producción y Logística & $\mathrm{S} /$. & 3,000 & $\mathrm{~S} /$. & 4,207 \\
\hline Operario & $\mathrm{S} /$. & 850 & $\mathrm{~S} /$. & 1,192 \\
\hline \multicolumn{5}{|c|}{ Variables de salida } \\
\hline VANE & $\mathrm{S} / \mathrm{.}$ & 235,972 & $\mathrm{~S} /$. & - \\
\hline TIRE & \multicolumn{3}{|c|}{$48.34 \%$} & $29.53 \%$ \\
\hline WACC & \multicolumn{3}{|c|}{$28.90 \%$} & $29.53 \%$ \\
\hline
\end{tabular}

Después de haber realizado el análisis de sensibilidad unidimnsional tomando en cuenta los precios, cantidad, materia prima, costo del personal, queda demostrado que el negocio sigue siendo viable y nos permite conocer a cuánto más puede bajar el precio, cuántas botellas menos puede producir para seguir siendo rentable y no perder, cuánta materia prima se puede comprar extra sin afectar gastos y el costo de personal.

\subsubsection{Análisis de escenarios.}

El modelo de simulación de Monte Carlo, es un análisis de contextos inciertos en donde se pueden precisar valores esperados en variables que no se pueden controlar, seleccionando valores aleatorios con la probabilidad de seleccionar en todos los escenarios posible relación entre la distribución de probabilidades (Sapag y Sapag,2008).

Como se puede observar en el cuadro de abajo, en el escenario pesimista, aunque los precios bajen en $\% 5$, la demanda en $5 \%$ y los costos de materia prima y personal suban en 5\% el VANE sale negativo, el TIRE es menor al COK y el WACC es menor. En cuanto a un escenario normal, en todo queda en estatus quo todo es positivo y se iguala el TIRE al COK y el WACC es igual. En un escenario en que los precios suban en 5\%, la demanda suba en 5\% los costos de personal y de materia prima se mantengan, el VANE sigue siendo positivo, el TIRE es mayor que el COK ( Ver tabla 206). 
Tabla 206

Análisis de sensibilidad multidimensional

\begin{tabular}{|c|c|c|c|}
\hline & PESIMISTA & NORMAL & OPTIMISTA \\
\hline \multicolumn{4}{|l|}{ VARIABLES ENTRADA } \\
\hline PRECIOS & $-5 \%$ & $0 \%$ & $5 \%$ \\
\hline DEMANDA & $-5 \%$ & $0 \%$ & $5 \%$ \\
\hline COSTOS MATERIA & & & \\
\hline PRIMA & $5 \%$ & $0 \%$ & $0 \%$ \\
\hline COSTOS PERSONAL & $5 \%$ & $0 \%$ & $0 \%$ \\
\hline \multicolumn{4}{|l|}{ VARIABLES DE SALIDA } \\
\hline & $\mathrm{S} /$. & $\mathrm{S} /$ & $\mathrm{S} /$ \\
\hline VANE & 111,042 & 235,972 & 455,725 \\
\hline TIRE & $21.13 \%$ & $48.34 \%$ & $66.27 \%$ \\
\hline WACC & $29.50 \%$ & $28.90 \%$ & $28.84 \%$ \\
\hline
\end{tabular}

En un análisis multidimensional de todos los escenarios en donde se tiene un VANE promedio de S/.204,156.98 . Se puede apreciar que la probabilidad de éxito del estudio es de $84.28 \%$, y de fracaso un $15.72 \%$. Ver detalle en tabla 207.

Tabla 207

Análisis de escenarios

ESCENARIOS

PROBABILIDADES

$25 \%$

$50 \%$

$25 \%$

VAN ECONOMICO

ESPERADO

S/.

$204,156.98$

\begin{tabular}{lcrr}
\hline & & \multicolumn{2}{c}{ Prob (VANE - } \\
ESCENARIO & PROBABILIDAD & \multicolumn{1}{c}{ VAN E } & \multicolumn{2}{c}{ VANE)^2 } \\
\hline PESIMISTA & $25 \%$ & $-111,042$ & $24,837,652,233$ \\
BASE & $50 \%$ & 235,972 & $506,113,750$ \\
OPTIMISTA & $25 \%$ & 455,725 & $15,821,648,660$ \\
\hline
\end{tabular}

\begin{tabular}{|c|c|}
\hline VAN E ESPERADO = & $204,156.98$ \\
\hline VARIANZA = & $41,165,414,643$ \\
\hline
\end{tabular}

PROBABILIDAD DE NO EXITO (VAN E <0)

$15.72 \%$

PROBABILIDAD DE EXITO (VAN E $>=0)$

$\mathbf{8 4 . 2 8 \%}$ 
Matriz de Riesgo

Según el Project Management Institute, Inc(2013), la Matriz de Riesgo sirve para

disminuir la incertidumbre y su impacto minimizando la oportunidad de ocurrencia. Ver tabla 208.

Tabla 208

Matriz de probabilidad e impacto para riesgos negativos o amenazas

\begin{tabular}{|c|c|c|c|}
\hline \multirow{2}{*}{ Objetivo del proyecto } & Bajo & Moderado & Alto \\
\hline & 0.1 & 0.2 & 0.4 \\
\hline $\begin{array}{l}\text { Cambio en las leyes peruanas } \\
\text { (baja de precios) }\end{array}$ & $\begin{array}{l}\text { No afecta de manera } \\
\text { significativa el proyecto en } \\
-1 \%\end{array}$ & $\begin{array}{l}\text { Afecta procesos } \\
\text { estratégicos del } \\
\text { proyecto hasta }-7.52 \%\end{array}$ & $\begin{array}{l}\text { Requiere cambios } \\
\text { significativos del } \\
\text { proyecto en más de - } \\
7.52 \%\end{array}$ \\
\hline $\begin{array}{c}\text { Entrada de productos } \\
\text { sustitutos (baja en demanda) }\end{array}$ & $\begin{array}{l}\text { La demanda del proyecto es } \\
\text { afectada en }-5 \%\end{array}$ & $\begin{array}{l}\text { La demanda del } \\
\text { proyecto es afectada } \\
\text { hasta }-13.33 \%\end{array}$ & $\begin{array}{l}\text { La demanda del proyecto } \\
\text { es afectada en más de } \\
-13.33 \%\end{array}$ \\
\hline $\begin{array}{l}\text { Subida de los precios de } \\
\text { materia prima }\end{array}$ & $\begin{array}{l}\text { El costo del proyecto es } \\
\text { afectado en } 5 \%\end{array}$ & $\begin{array}{l}\text { El costo del proyecto es } \\
\text { afectado hasta } 20.37 \%\end{array}$ & $\begin{array}{l}\text { El costo del proyecto es } \\
\text { afectado en más de } \\
20.37 \%\end{array}$ \\
\hline $\begin{array}{l}\text { Subida de los costos de } \\
\text { personal }\end{array}$ & $\begin{array}{l}\text { Se ven afectadas algunas } \\
\text { áreas de la empresa en } 10 \%\end{array}$ & $\begin{array}{l}\text { Se afectan áreas claves } \\
\text { de la empresa hasta } \\
37.96 \%\end{array}$ & $\begin{array}{l}\text { Se requiere disminuir } \\
\text { personal en más de } \\
37.96 \%\end{array}$ \\
\hline
\end{tabular}

En la tabla 208 se observa las probabilidades de ocurrencia para eventos negativos o amenazas en caso se presentaran. Ante cualquiera de estos escenarios la empresa podría tomar acciones para mitigar estos riesgos.

En la tabla 209, se detalla la probabilidad de riesgos positivos y cómo afectaría a la empresa. De esa forma, la empresa estaría preparada para afrontar cualquier variación que se presentara. 
Tabla 209

Matriz de probabilidad e impacto para riesgos positivos $u$ oportunidades

\begin{tabular}{|c|c|c|c|}
\hline \multirow{2}{*}{ Objetivo del proyecto } & Bajo & Moderado & Alto \\
\hline & 0.1 & 0.2 & 0.4 \\
\hline $\begin{array}{l}\text { Cambio en las leyes peruanas } \\
\text { (sube de precios) }\end{array}$ & $\begin{array}{l}\text { No afecta de manera } \\
\text { significativa el proyecto en } \\
-5 \%\end{array}$ & $\begin{array}{l}\text { Afecta procesos } \\
\text { estratégicos del proyecto } \\
\text { hasta } 0 \%\end{array}$ & $\begin{array}{l}\text { Requiere cambios } \\
\text { significativos del } \\
\text { proyecto en más de 5\% }\end{array}$ \\
\hline $\begin{array}{c}\text { No entrada de productos } \\
\text { sustitutos (sube en demanda) }\end{array}$ & $\begin{array}{l}\text { La demanda del proyecto es } \\
\text { afectada en }-5 \%\end{array}$ & $\begin{array}{l}\text { La demanda del } \\
\text { proyecto es afectada } \\
\text { hasta } 0 \%\end{array}$ & $\begin{array}{l}\text { La demanda del proyecto } \\
\text { es afectada en más de } \\
5 \%\end{array}$ \\
\hline $\begin{array}{l}\text { Baja de precios en materia } \\
\text { prima }\end{array}$ & $\begin{array}{l}\text { El costo del proyecto es } \\
\text { afectado en } 5 \%\end{array}$ & $\begin{array}{l}\text { El costo del proyecto es } \\
\text { afectado hasta } 0 \%\end{array}$ & $\begin{array}{l}\text { El costo del proyecto es } \\
\text { afectado en más de } 0 \%\end{array}$ \\
\hline Baja en los costos de personal & $\begin{array}{l}\text { Se ven afectadas algunas } \\
\text { áreas de la empresa en 5\% }\end{array}$ & $\begin{array}{l}\text { Se afectan áreas claves } \\
\text { de la empresa hasta } 0 \%\end{array}$ & $\begin{array}{l}\text { Se requiere disminuir } \\
\text { personal en más de } 0 \%\end{array}$ \\
\hline
\end{tabular}




\section{Conclusiones y Recomendaciones}

\section{Conclusiones}

Se demuestra que el estudio realizado es viable, ya que dio como resultado un VAN igual a S/. 235,972, siendo mayor a cero. Además la TIRF fue $48.34 \%$ que era mayor al COK que dio $28.90 \%$.

Existe una oportunidad de negocio debido al constante crecimiento en el consumo del pisco que data desde el 2012 hasta la fecha y las nuevas tendencias en la distintas formas de consumo que conllevan a las personas a probar nuevas mezclas y sabores.

- El sampling ayudará de manera significativa a que el producto se haga conocido mediante la degustación orientada a los clientes potenciales que ayudará a captar el mercado objetivo.

. Incremento de inversiones para apoyar a las pequeñas empresas en el país y se pueda poner en marcha el negocio.

- Se puede aprovechar la demanda insatisfecha para poner en marcha Plan de Negociospara la producción de macerados de frutas en pisco y brindar más opciones de consumo de pisco en sus derivados.

Se hicieron las comparaciones de la sensibilidad del proyecto en cuanto a precio se obtuvo que con un VAN igual a cero podría resistir una baja del 7.42\%, en cuanto a demanda una baja de $13.18 \%$, costo de materia prima una subida de hasta $20.11 \%$ y costo de personal una subida de hasta $37.41 \%$.

- El producto se elaboró y se realizaron mejoras a lo largo del proyecto, logrando una receta única obteniendo el equilibrio perfecto y se logra percibir cada insumo por su sabor, aroma y color. 
El proceso de producción contemplado en el estudio, comprende una gestión eficiente para ofrecer un producto de calidad (sobre todo los tiempos considerados para maceración) logran que se use adecuadamente la capacidad instalada, aplicando estándares de calidad como HACCP.

Se concluyó que el plan de operaciones se concentraba en el proceso de producción, siendo este el core del negocio. Luego de haber hecho las pruebas y conversado con los expertos se concluyó que el tiempo de maceración ideal para asegurar la calidad de producto era de dos meses. Por lo tanto se hicieron los cálculos pre operativos que representaban gran parte de la Inversión.

\section{Recomendaciones}

Es vital realizar una campaña de promoción que le permita al público poder degustar el producto, porque una bebida como los macerados impacta de manera directa en el paladar por su calidad y sabor especial al combinar la bebida bandera del Perú con una gama de frutos que se encuentran en el territorio nacional.

Aprovechar los días festivos del pisco y sus derivados para darse a conocer al publico. Participar en ferias y eventos en donde se pueda ofrecer el producto y al degustarlo queden hechizados con el sabor, ya que el boca a boca es muy importante.

Encontrar proveedores de frutos deshidratados ya que implicaría un menor costo a la larga en materia prima, para evitar reposiciones.

Es recomendable realizar alianzas estratégicas con los proveedores de insumos para poder obtener mejores precios y con ello lograr costos competitivos que permitan ingresar al mercado y además obtener rentabilidad.

Se debe indagar en técnicas innovadoras en el proceso de maceración, que permitan ahorrar en costos y optimizar procesos, evitando el doble trabajo o reproceso. Esto permitirá 
elevar la producción y aumentar la capacidad de respuesta sobre un posible aumento en la demanda.

Durante los primeros dos años, se recomienda mantener y posicionarse con los tres sabores ofrecidos, sin embargo, a partir del tercer año se podría evaluar la opción de buscar nuevas mezclas de sabores que no existan en el mercado, previamente evaluando las preferencias del consumidor, para estar innovando con los sabores y no quedarse con lo mismo.

Se recomienda que CONAPISCO, PROMPERU, PRODUCE y demás organismos involucrados en la industria de pisco y derivados hagan mayor difusión sobre los beneficios que ofrecen a los productores tanto en técnicas y desarrollo de tecnologías para que puedan acceder a estas y formalizarse como empresa ya que esto ayudaría a que exista mayor información y estudios sobre este tipo de producto.

Se recomienda finalmente que este plan de negocios se ejecute dentro del plazo de cinco años, caso contrario se recomienda actualizar las cifras. $\}$

Al cabo de los primeros cinco años, demostrando ser un proyecto viable el siguiente paso sería la exportación, ya que se sabe que hay un gran porcentaje de peruanos en el mundo, los cuales extrañan su país y mediante esta deliciosa opción se puede cubrir esa demanda insatisfecha en el extranjero y a la vez, servirá como promoción para el Perú mediante este derivado del producto bandera. Se sabe que cuando se organizan eventos o ferias gastronómicas en las comunidades peruanas en el mundo, siempre logran convocar un gran número de personas y son un éxito. 


\section{Referencias}

Alonso, V.H (2010). Factores críticos de éxito y evaluación de la competitividad de destinos turísticos. Estudio de perspectiva turística. Universidad de Las Palmas de Gran Canaria. Ciudad Autónoma de Buenos Aires; Vol.19 (2). Recuperado en http://www.scielo.org.ar/scielo.php?script=sci_arttext\&pid=S185117322010000200003

America TV (2017, julio 23). Día del pisco. Recuperado de http://www.americatv.com.pe/noticias/actualidad/semana-chilcano-conoce-4-tipospisco-n261867

Arias, F. G. (2012). El Proyecto de Investigación: Introducción a la metodología científica. (6ta. Ed.) Venezuela: Editorial Episteme., C.A.

Banco Mundial (2017, Abril, 18) Perú Panorama general Recuperado de: http://www.bancomundial.org/es/country/peru/overview

Beltrán, A., \& Cueva, H. (2009). Evaluación privada de proyectos (2da ed.). Lima, Perú : Centro de Investigación de Universidad del Pacífico.

Benassini, M. (2009). Introducción a la investigación de mercados (14 ed.). México: Pearson Educación.

Cojal M. \& Rojas K. (2016). Asociatividad de pequeños productores de aguardiente para la elaboración y comercialización de un licor macerado con frutas exóticas a Baltimore EE.UU. Recuperado de http://repositorio.upn.edu.pe/bitstream/handle/11537/9985/Cojal\%20Mendoza\%20Jes sica\%20del\%20Roc\%C3\%ADo\%20Rojas\%20D\%C3\%ADaz\%20Kevinn\%20Andre\% C3\%A9.pdf?sequence $=1$

Conapisco (2017) Estadísticas. Recuperado de http://www.conapisco.org.pe/estadisticas.html Courtney, H. (2009). Pisco por la Razón o la Fuerza El Debate Entre Perú y Chile Sobre la 
Denominación de Origen del Pisco y sus Implicaciones. Independent Study Project (ISP) Collection. Recuperado de: http://digitalcollections.sit.edu/isp_collection/712 D'Alessio, (2012). Administración de las operaciones productivas Un enfoque en procesos para la gerencia.(1ra. Ed.) México. Pearson Educación de México, S.A. de C.V.

David, F. R. (2013). Conceptos de administración estratégica (14 ed.). México: Pearson Educación.

Diario Correo (2017, febrero 04). El pisco peruano llegó a 44 países. Recuperado de http://diariocorreo.pe/economia/el-pisco-peruano-llego-a-44-paises-en-el-2016728963

El Comercio (2014, enero 07). ¡Salud! El consumo interno de pisco crece $15 \%$ cada año. Recuperado de http://archivo.elcomercio.pe/economia/negocios/salud-consumointernopisco-crece-15-cada-ano-noticia-1683453

El Comercio (2015, julio 27), Productos bandera: cómo les ha ido en la última década. Recuperado de http://elcomercio.pe/economia/peru/productos-bandera-les-ido-ultimadecada-195195

Ferrell C, \&Hartline M, (2012). Estrategia de Marketing. (5ta ed.). México, México DF: CengageLearning Editores, S.A.

Garay, S. (2017, junio 28). Las rutas del pisco: experiencias que trascienden las visitas a bodegas. Gestión. Recuperado de http://gestion.pe/tendencias/rutas-piscoexperiencias-que-trascienden-visitas-bodegas-2193710

Gestión (2015, julio 26). Peruanos alcanzan un consumo anual de alcohol de 8.1 litros per cápita. Recuperado de http://gestion.pe/tendencias/peruanos-alcanzan-consumoanualalcohol-81-litros-per-capita-2138281 
Gestión (2015, julio 28). Los productos bandera de Perú, ¿cuánto han crecido?. Recuperado de http://gestion.pe/economia/productos-bandera-peru-cuanto-han-crecido$2138432 / 13$

Gestión (2016, febrero 19) Macerados de pisco: una alternativa. Recuperado de http://gestion.pe/empresas/macerados-pisco-alternativa-que-gana-presencia-segmentogourmet-2154860

Gestión (2017, febrero 04). Pisco: Producción alcanzó récord 10.5 millones de litros durante el 2016. Recuperado de http://gestion.pe/economia/pisco-produccion-alcanzo-105millones-litros-durante-2016-2181361

Gestión (2017, agosto 17). El congreso eleva al rango de ley declaración al pisco.

Recuperado de http://gestion.pe/tendencias/congreso-eleva-rango-ley-declaracion-alpisco-como-patrimonio-cultural-nacion-2197972

Guía Informativa Productos Bandera del Peru (2013), Indecopi. Recuperado de http://www.indecopi.gob.pe/documents/20182/143803/prodbandera_jun13.pdf History (2017). Las rutas del Pisco Peruano y/o chileno. Recuperado de https://pe.tuhistory.com/travel/CHILE/NOTICIA

INDECOPI (2016). Observatorio de mercados. Recuperado de https://www.INDECOPI.gob.pe/documents/474320/633971/N\%C2\%B0+33++Setiembre+2016+Pisco.pdf/c61abd40-6d20-4e57-9ef6-7b916fbee86d?version=1.0

Koo, W. (2016, setiembre 18). Pisco Perú Exportación 2016. Recuperado de https://www.agrodataperu.com/2016/09/pisco-peru-exportacion-2016.html/00pisco320

KotlerKeller. (2012). Identificación de segmentos de mercado y mercados meta. En K. Keller, Dirección de marketing ( Cap 8). México: Pearson Educación. 
La Información (2015, enero 16). El chilcano reclama su carácter genuino como cóctel clásico de Perú. Recuperado de http://www.lainformacion.com/economia-negocios-yfinanzas/bebidas-no-alcoholicas/el-chilcano-reclama-su-caracter-genuino-comococtel-clasico-de-peru_41DlasLfDCT99861ZONHp6/

La República (2010, abril 07). La controversia por origen del pisco la decide el consumidor. Recuperado de http://larepublica.pe/20-04-2010/la-controversia-por-origen-del-piscoladecide-el-consumidor

La Republica (2017, junio 20). Pisco peruano gana concurso en Europa. Recuperado de http://larepublica.pe/economia/887724-pisco-peruano-gana-cuatro-medallas-enconcurso-de-licores-en-europa

Ley No. 28681 (2006, febrero 10). Lima, Perú: Congreso de la República. Recuperado de ww2.congreso.gob.pe/Sicr/RelatAgenda/proapro.nsf/ProyectosAprobadosPortal/1E78 7D2DBBA8C3060525711200054551/\$FILE/2108Comercializaciondebebidasalcoholi cas.pdf

Ley No 30460 (2016, junio 15). Lima, Perú: Congreso de la República. Recuperado de http://busquedas.elperuano.com.pe/normaslegales/ley-que-declara-de-interesnacional-la-promocion-y-difusion-ley-n-30460-1392947-2/

Mendoza, W. (2011). Asociatividad como estrategia para desarrollar las exportaciones de pisco del valle de Cañete. Recuperado de http://www.repositorioacademico.usmp.edu.pe/bitstream/usmp/1602/1/sme_v2n1_art 3.pdf

Ministerio de la Producción (2018, febrero 2) Noticias. Ministra Schol: En el 2017 el consumo nacional de pisco alcanzó su pico más alto en los último diez años. Recuperado de http://www.produce.gob.pe/index.php/k2/noticias/item/776-ministra- 
schol-en-el-2017-el-consumo-nacional-de-pisco-alcanzo-su-pico-mas-alto-en-losultimos-diez-anos

Moyano, L. E. (2016). Plan de Negocios. Lima, Perú: Empresa Editora Macro EIRL. Recuperado de https://books.google.com.pe/books?id=j7wtDwAAQBAJ\&pg=PT50\&lpg=PT50\&dq= quien+creo+las+definiciones+de+mercado+objetivo,+potencial,+disponible+y+efectu vo\&source=bl\&ots=_9r1pHoCEt\&sig=xnKeqvVEeUmtX-s1pLSyBUAmvU\&hl=es\&sa=X\&ved=0ahUKEwiP3pqp2InXAhUIC5AKHVkRCesQ6AEIPTAE\#v $=$ onepage $\& q \& \mathrm{f}=$ false

Normativa Histórica n.d, Consejo Regulador Denominación de Origen Pisco. Recuperado de http://www.consejoreguladordelpisco.pe/normativa-historica/

Olabuénaga, J. (2012). Metodología de la investigación cualitativa, 5ta Ed., Bilbao. España. Editorial Universidad de Deusto

Paan, C. (2017, junio 05) El Comercio. Esta es la situación real del pisco. Recuperado de http://elcomercio.pe/economia/negocios/situacion-real-pisco-peru-analisis-428825

Perú Retail (2017, agosto 28). Pisco ya se vende en supermercados de Rusia. Recuperado de http://www.peru-retail.com/pisco-supermercados-de-rusia/

Ramos E. (2017), Perú importa el 98\% de canela entera de Sri Lanka. Recuperado de http://agraria.pe/noticias/de-sri-lanka-proviene-el-98-de-la-canela-entera-que-peruimp- 14220

Redacción EC (2015, febrero 07). Día del Pisco Sour se celebra con festivales y tours en Cercado. El Comercio. Recuperado de http://elcomercio.pe/lima/dia-pisco-sourcelebra-festivales-tours-cercado-331920? foto $=2$

Redacción Peru21 (2017, Mayo 26). “Concurso de Bruselas” llegó a un acuerdo y peruanos podrán usar la denominación “agua ardiente de Perú”. Perú21. Recuperado de 
https://peru21.pe/lima/concurso-bruselas-llego-acuerdo-peruanos-podrandenominacion-aguardiente-peru-77813

Reporte de Producción Manufacturera (2017, Mayo) Ministerio de la Producción. Peru Recuperado de:

http://demi.produce.gob.pe/images/publicaciones/publieb494f7047e46459c_11.pdf

Robles, B. (2011). La entrevista en profundidad: una técnica útil dentro del campo antropofísico. Cuicuilco, 18(52), 39-49. Recuperado de :http://www.scielo.org.mx/scielo.php?script=sci_arttext\&pid=S018516592011000300004

Rojas, A. (2017, julio 23). Hoy se celebra el Día Nacional del Pisco y Roberto Meléndez brimda una receta para festejarlo. El Comercio. Recuperado de http://elcomercio.pe/gastronomia/celebrar-dia-nacional-pisco-buen-pisco-sour-444158

Semana económica (2017, febrero 03) Producción de pisco registró record en 2016. Recuperado de http://semanaeconomica.com/article/sectores-yempresas/industria/213151-produccion-de-pisco-registro-record-en-el-2016/

Semana económica (2017, mayo 30) Producción del Pisco crecerá 4\% en el 2017.

Recuperado de http://semanaeconomica.com/article/sectores-yempresas/industria/229496-produccion-del-pisco-crecera-4-en-el-2017-estimoproduce/?ref=fh

Semana económica (2017, agosto 17). Produce: reconocimiento de pisco como patrimonio cultural permitirá desarrollo de la industria. Recuperado de http://semanaeconomica.com/article/sectores-y-empresas/industria/240261-producereconocimiento-de-pisco-como-patrimonio-cultural-permitira-desarrollo-de-laindustria/ 


\section{Anexos}

Anexo 1 - Presentación HECHIZO (macerados de frutas en pisco)
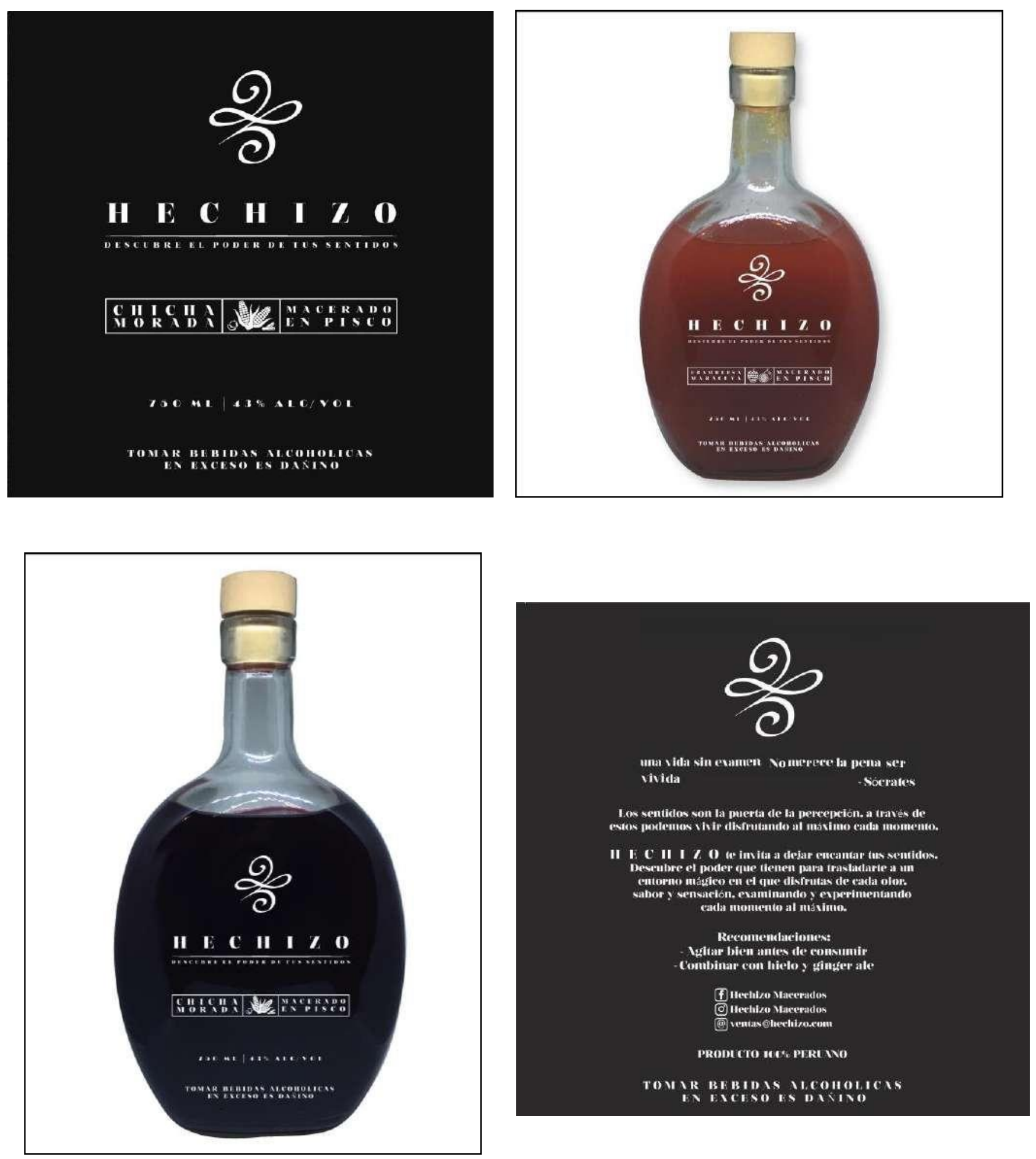


\section{Anexo 2 - Cuestionario de Entrevista a Profundidad - Sarcay y Bailetti}

Objetivo : Obtener información Administrativa, Operativa, Comercial y Logística.

Calentamiento

Buenas tardes,

Somos un grupo de la Universidad San Ignacio de Loyola, de la Maestría en Ciencias Empresariales y estamos desarrollando un estudio de investigación de mercado para un Plan de Negocios. El estudio es sobre la producción de macerados de frutas con pisco, por este motivo lo hemos vamos a realizar algunas preguntas.

Asimismo, pedimos la autorización para que la entrevista sea grabada durante la sesión, solo revelaremos su información si lo aprueba, de lo contrario cuando hagamos el informe no lo identificaremos. Todas las respuestas son aceptables, no hay correctas ni incorrectas, lo único que necesitamos es sinceridad para que nuestro estudio sea veraz.

\section{Cuestionario}

\begin{tabular}{|c|c|}
\hline $\begin{array}{l}\text { Información de } \\
\text { la Empresa }\end{array}$ & $\begin{array}{l}\text { No hemos encontrado información sobre cómo operan su empresa, queríamos saber } \\
\text { cómo la procesan y si pertenecen a alguna asociación. } \\
\text { ¿Puede Ud. Identificar su competencia directa e indirecta? }\end{array}$ \\
\hline Administración & $\begin{array}{l}\text { ¿Conoce empresas que elaboren macerados de fruta en pisco } \\
\text { ¿En este rubro que leyes importantes se deben tener en cuenta? } \\
\text { Adicional a estas leyes, ¿Qué tipo de licencias o autorizaciones se necesitan para } \\
\text { operar? } \\
\text { ¿Qué otros aspectos legales considera importante? }\end{array}$ \\
\hline Operaciones & $\begin{array}{l}\text { Ustedes ya han trabajado con macerados de pisco? } \\
\text { Cuál debería ser el nombre correcto para describir el producto? } \\
\text { Qué tipo de pisco se utiliza para la elaboración de macerado? } \\
\text { Es realmente importante el tipo de pisco que se debe utilizar? } \\
\text { Cuál sería el óptimo grado de alcohol } \\
\text { Qué tipo de insumos utilizan para la producción? } \\
\text { Algún tipo de preservante“? } \\
\text { ¿Cómo es el proceso o el flujo de producción y cuáles son los procesos que } \\
\text { consideran críticos que afecten al producto? } \\
\text { ¿Qué es lo más difícil? } \\
\text { ¿Cumplen con controles de calidad? } \\
\text { ¿Cuentan con alguna certificación? Cuáles }\end{array}$ \\
\hline Comercial & $\begin{array}{l}\text { ¿Qué aspecto es realmente importante para poder captar mercado? } \\
\text { Cómo promocionaría su producto? Cómo diferencia los gustos por género? } \\
\text { ¿Cómo se diferencia de la competencia? }\end{array}$ \\
\hline Logística & $\begin{array}{l}\text { ¿Con qué frutas ha probado en la producción de macerados } \\
\text { Sería posible que Sarcay de Azpitia pueda ser nuestro proveedor de pisco }\end{array}$ \\
\hline
\end{tabular}




\section{Anexo 3 - Cuestionario de Entrevista a profundidad -Juan Carlos Mathews}

Objetivo: Obtener información sobre el mercado de Pisco y macerados

Calentamiento

Buenas tardes,

Somos un grupo de la Universidad San Ignacio de Loyola, de la Maestría en Ciencias Empresariales y estamos desarrollando un estudio de investigación de mercado para un Plan de Negocios. El estudio es sobre la producción de macerados de frutas con pisco, por este motivo lo hemos vamos a realizar algunas preguntas.

Asimismo, pedimos la autorización para que la entrevista sea grabada durante la sesión, solo revelaremos su información si lo aprueba, de lo contrario cuando hagamos el informe no lo identificaremos. Todas las respuestas son aceptables, no hay correctas ni incorrectas, lo único que necesitamos es sinceridad para que nuestro estudio sea veraz.

\section{Cuestionario}

\begin{tabular}{|c|c|}
\hline $\begin{array}{l}\text { Información del } \\
\text { mercado }\end{array}$ & $\begin{array}{l}\text { ¿En dónde podemos encontrar información sobre la situación del pisco en el mercado } \\
\text { nacional e internacional? } \\
\text { ¿Cree que el pisco tiene mucha demanda tanto local como internacionalmente? } \\
\text { Piensa que los derivados del pisco también son demandados? } \\
\text { ¿Considera que se cubre la demanda? } \\
\text { En su experiencia como Vice Ministro de MYPE e Industria cómo ve el desarrollo de la } \\
\text { pequeña empresa y mediana empresa en el sector de pisco y sobre todo de macerados } \\
\text { ¿Cómo cree que se pueda manejar el tema de la producción artesanal para que se } \\
\text { formalicen? } \\
\text { ¿Hay algunas políticas de promoción para la pequeña empresa que se dedica a la } \\
\text { producción de un derivado de pisco, en este caso macerados de fruta en pisco? } \\
\text { ¿En dónde se puede conseguir información sobre las empresas que están en el mismo } \\
\text { rubro? } \\
\text { ¿Tiene idea de qué porcentaje de empresas formales e informales de macerados de frutas } \\
\text { en pisco hay en el mercado? } \\
\text { Si en algún momento se pensaría en exportar, los macerados piensan que serían } \\
\text { aceptados en el mercado internacional? } \\
\text { ¿Qué tipos de créditos hay para la MyPE’s? } \\
\text { ¿Cómo ve el mercado interno? } \\
\text { ¿Ha participado o hecho promoción de pisco en ferias : en qué presentaciones lo ha } \\
\text { visto, se puede proponer los macerados de fruta en pisco? }\end{array}$ \\
\hline
\end{tabular}




\title{
Anexo 4 - Cuestionario de Entrevista a profundidad - Productores artesanales
}

Objetivo : Obtener información sobre temas operativos, comercial y logístico

Calentamiento

Buenas tardes,

Somos un grupo de la Universidad San Ignacio de Loyola, de la Maestría en Ciencias Empresariales y estamos desarrollando un estudio de investigación de mercado para un Plan de Negocios. El estudio es sobre la producción de macerados de frutas con pisco, por este motivo lo hemos vamos a realizar algunas preguntas.

Asimismo, pedimos la autorización para que la entrevista sea grabada durante la sesión, solo revelaremos su información si lo aprueba, de lo contrario cuando hagamos el informe no lo identificaremos. Todas las respuestas son aceptables, no hay correctas ni incorrectas, lo único que necesitamos es sinceridad para que nuestro estudio sea veraz.

\section{Cuestionario}

\author{
¿Qué tipo de insumos cree que es el ideal para macerar: fruta fresca ? Qué tipo de pisco? \\ ¿En el proceso se puede mezclar la fruta con agua? \\ ¿Cuáles son los tiempos para macerar? \\ Operaciones ¿Cuál creen que el momento más crítico de la producción, por qué? \\ ¿Cómo almacenan el producto durante el tiempo de maceración? \\ ¿Utilizan algún insumo para que alargar la vida del macerado de fruta? \\ ¿Cree que poner la fruta en el producto final se la causa que haga que se acorte su vida?
}

¿Cómo se inician el proceso de ventas?

¿Cuál es la forma en la que llegan al consumidor final por supermercados u otras opciones?

¿Cuáles son los términos y condiciones que establecen estas ventas?

¿El producto resistiría un tiempo de recolocación de 90 días?

Comercial

¿Qué rango de precios tienen sus productos?

¿Cuál es su problema más recurrente con sus clientes?

¿Cuál es la estrategia para promocionar su producto?

¿Cómo se diferencia de la competencia?

\footnotetext{
¿Cómo realizan la distribución?

$\begin{array}{ll} & \text { Logística ¿Cuál es su política de abastecimiento? } \\ \text { ¿Cómo almacenan el producto final? }\end{array}$
} 


\title{
Anexo 5 - Cuestionario de Entrevista a profundidad - Sommelier
}

\author{
Objetivo: Obtener Estratégico Comercial - Sommelier
}

Calentamiento

Buenas tardes,

Somos un grupo de la Universidad San Ignacio de Loyola, de la Maestría en Ciencias Empresariales y estamos desarrollando un estudio de investigación de mercado para un Plan de Negocios. El estudio es sobre la producción de macerados de frutas con pisco, por este motivo lo hemos citado a fin de realizarle algunas preguntas.

Asimismo, pedimos la autorización para que la entrevista sea grabada durante la sesión, solo revelaremos su información si lo aprueba, de lo contrario cuando hagamos el informe no lo identificaremos. Todas las respuestas son aceptables, no hay correctas ni incorrectas, lo único que necesitamos es sinceridad para que nuestro estudio sea veraz.

\section{Cuestionario}

¿Qué nuevas estrategias se usan para promocionar el pisco?

Se podría decir que una nueva tendencia de consumo de pisco puede ser en macerados de fruta

En su experiencia cree que hay muchos consumidores de macerados de fruta en pisco?

Consideras que va creciendo la aceptación

Si se ofreciera un producto de calidad, sin connotación de artesanal habría proyección de aceptación?

Cree que el pisco quebranta es el ideal para la preparación de los macerados?

Podríamos mezclarlo con cualquier tipo de pisco?

Comercial / ¿Qué sabores son los preferidos?

Estratégico ¿Opina que es una buena mezcla la frambuesa con maracuyá?

¿y la fresa con guinda?

Qué opina de la combinación de canela con arándanos?

Cree que los macerados de fruta en pisco son más aceptados por mujeres que por hombres?

Cree que los macerados de fruta en pisco serían más consumidos por las mujeres?

Servirlo tipo chilcano es un opción más suave?

En su experiencia en qué ocasiones se consumen los macerados de fruta en pisco?

Sabe cuál es la frecuencia de consumo?

Podría considerarse una la rutas de pisco la experiencia de probar macerados de frutas

Qué nombre le pondrías al macerado de fruta en pisco? 


\section{Anexo 6 - Transcripción de Entrevista a profundidad a Sarcay}

\begin{tabular}{|c|c|}
\hline Día & $\begin{array}{rr} & 12: 00 \\
\text { Hora } & \text { p.m. }\end{array}$ \\
\hline Lugar & $\begin{array}{lll}\text { Entrevista } & \text { Jorge Marimon } \\
\text { do } & \text { Pizarro }\end{array}$ \\
\hline Tema & Obtener información administrativa, operativa, comercial y logística \\
\hline $\begin{array}{l}\text { Pregunta } \\
1\end{array}$ & ¿Ustedes ya han trabajado con macerados de pisco? \\
\hline Apuntes & $\begin{array}{l}\text { En estos momentos estamos implementando una linea de macerados, es un consorcio con un grupo } \\
\text { de jovenes emprendedores. }\end{array}$ \\
\hline $\begin{array}{l}\text { Pregunta } \\
2\end{array}$ & ¿Cuál debería ser el nombre correcto para describir el producto? \\
\hline Apuntes & $\begin{array}{l}\text { Para describir el producto se debe utilizar una correcta descripción y es "macerados de frutas en } \\
\text { pisco". Esto debe ser claro para que el público está informado del producto que puede adquirir. }\end{array}$ \\
\hline $\begin{array}{l}\text { Pregunta } \\
3\end{array}$ & ¿Qué tipo de pisco se utiliza para la elaboración de macerados? \\
\hline Apuntes & $\begin{array}{l}\text { El pisco quebranta es menos aromático y privilegia la fruta, pero el uso del tipo de pisco depende } \\
\text { del productor, del segmento y del tipo de mezcla que se quiere mostrar. }\end{array}$ \\
\hline Pregunta & ¿Es realmente importante el tipo de pisco que se debe utilizar? \\
\hline Apuntes & $\begin{array}{l}\text { No existe una regla, para algunos sabores se puede utilizar endulzantes o jarabe de goma, depende } \\
\text { mucho de la fruta o hierba que se use. }\end{array}$ \\
\hline $\begin{array}{l}\text { Pregunta } \\
5\end{array}$ & ¿Qué aspecto es realmente importante para poder captar mercado? \\
\hline Apuntes & $\begin{array}{l}\text { Lo principal es definir en segmento, en el caso de las edades no se puede abarcar un universo muy } \\
\text { extenso debído a que los gustos son muy diferentes entre rangos de edades. }\end{array}$ \\
\hline $\begin{array}{l}\text { Pregunta } \\
6\end{array}$ & ¿Con qué frutas han probado para producir macerados? \\
\hline Apuntes & $\begin{array}{l}\text { En nuestro caso estamos testeando con aguaymanto, maracuyá y cascara de lima. Estamos } \\
\text { probando para poder lograr la calidad en el producto. }\end{array}$ \\
\hline $\begin{array}{l}\text { Pregunta } \\
7\end{array}$ & ¿Cómo se podría diferenciar los gustos por género? \\
\hline Apuntes & $\begin{array}{l}\text { En el caso de las mujeres, ellas prefieren un licor mas aromático pero en el caso de loshombres, } \\
\text { ellos priorizan en sabor antes que el aroma. }\end{array}$ \\
\hline $\begin{array}{l}\text { Pregunta } \\
8\end{array}$ & ¿Conoce empresas que elaboren macerados? \\
\hline Apuntes & \\
\hline
\end{tabular}




\begin{tabular}{|c|c|}
\hline & $\begin{array}{l}\text { No existe información sobre empresas que elaboren macerados debido a que estas son artesanales y } \\
\text { en muchos de los casos no están registradas. }\end{array}$ \\
\hline $\begin{array}{l}\text { Pregunta } \\
9\end{array}$ & ¿Cómo especifican el venciminento del producto? \\
\hline Apuntes & $\begin{array}{l}\text { Para este caso de macerados de frutas en pisco, es el mismo alcohol del pisco el que preserva la } \\
\text { mezcla y le otorga una larga duración al producto. }\end{array}$ \\
\hline $\begin{array}{l}\text { Pregunta } \\
10\end{array}$ & ¿Cuál sería el óptimo grado de alcohol? \\
\hline Apuntes & $\begin{array}{l}\text { Todo depende del grado de alcohol que tenga el pisco que utilices, en nuestro caso se manejan } \\
\text { grados entre } 43 \text { y } 45 .\end{array}$ \\
\hline $\begin{array}{l}\text { Pregunta } \\
11\end{array}$ & ¿Qué tan difícil es acceder a la certificación HACCP? \\
\hline Apuntes & $\begin{array}{l}\text { Los costos para acceder a la certificación HACCP son muy elevados y además debemos sumarle el } \\
\text { mantener esta certificación. }\end{array}$ \\
\hline $\begin{array}{l}\text { Pregunta } \\
12\end{array}$ & ¿La empresa piensa implementar HACCP? \\
\hline Apuntes & $\begin{array}{l}\text { La bodega viene haciendo esfuerzos para acceder a la certificación HACCP, la cual es muy } \\
\text { importante en estos días ya que muchos mercados la tienen como requisito indispensable para } \\
\text { acceder. }\end{array}$ \\
\hline $\begin{array}{l}\text { Pregunta } \\
13\end{array}$ & ¿Sería posible que Sarcay de Aspitia pueda ser nuestro proveedor de pisco? \\
\hline Apuntes & $\begin{array}{l}\text { La bodega Sarcay de Aspitia puede ser un posible proveedor de pisco puro, teniendo muy presente } \\
\text { la calidad de producto final que se quiere ofrecer. }\end{array}$ \\
\hline $\begin{array}{l}\text { Pregunta } \\
14\end{array}$ & ¿Cuánto influye el tiempo de maceración del producto? \\
\hline Apuntes & $\begin{array}{l}\text { El Tiempo de maceración es muy importante y se debe probar cada sabor para obtener el tiempo de } \\
\text { maceración óptimo y lograr un producto de calidad. }\end{array}$ \\
\hline $\begin{array}{l}\text { Pregunta } \\
15\end{array}$ & ¿Existen programas de apoyo a los productores de pisco? \\
\hline Apuntes & $\begin{array}{l}\text { Existen programas de Inversión como Innovate Perú, el cual ayuda a los emprendedores para } \\
\text { financiar sus proyectos y hacerlos realidad, esa sería una buena opción para obtener capital. }\end{array}$ \\
\hline $\begin{array}{l}\text { Pregunta } \\
16\end{array}$ & ¿Quién es el encargado de otorgar la denominación de origen? \\
\hline Apuntes & $\begin{array}{l}\text { El Estado es el dueño de las denominaciones de origen, Indecopi declara pero el quien otorga es el } \\
\text { Consejo Regulador del Pisco. }\end{array}$ \\
\hline $\begin{array}{l}\text { Pregunta } \\
17\end{array}$ & ¿Qué papel juega el aplicar buenas prácticas? \\
\hline Apuntes & $\begin{array}{l}\text { El uso de buenas prácticas es muy importante para luego acceder a alguna certificación } \\
\text { internacional que avale la calidad del producto. }\end{array}$ \\
\hline $\begin{array}{l}\text { Pregunta } \\
18\end{array}$ & ¿Qué importancia tiene la denominación de origen? \\
\hline Apuntes & $\begin{array}{l}\text { Denominación de origen es muy importante si se quiere comercializar los macerados de frutas en } \\
\text { pisco, porque esta distinción es la que permite al pisco llevar ese nombre. }\end{array}$ \\
\hline $\begin{array}{l}\text { Pregunta } \\
19\end{array}$ & ¿Existe apoyo del sector público para incentivar la producción de pisco? \\
\hline Apuntes & $\begin{array}{l}\text { El apoyo del sector público es muy pobre porque no se enfoca a nivel empresarial sino a un nivel } \\
\text { muy macro. No se enfocan en lo que realmente se necesita. }\end{array}$ \\
\hline $\begin{array}{l}\text { Pregunta } \\
20\end{array}$ & ¿Sería factible para nuestra empresa aplicar a una certificación HACCP? \\
\hline Apuntes & $\begin{array}{l}\text { El certificado HACCP es muy costos, pero la tendencia lo estaría convirtiendo en obligatorio, en su } \\
\text { caso pueden aplicar a un consorcio con una empresa que tenga el soporte financiero. }\end{array}$ \\
\hline
\end{tabular}




\section{Anexo 7 - Transcripción de Entrevista a profundidad a Gerente de Bodega Bailetti}

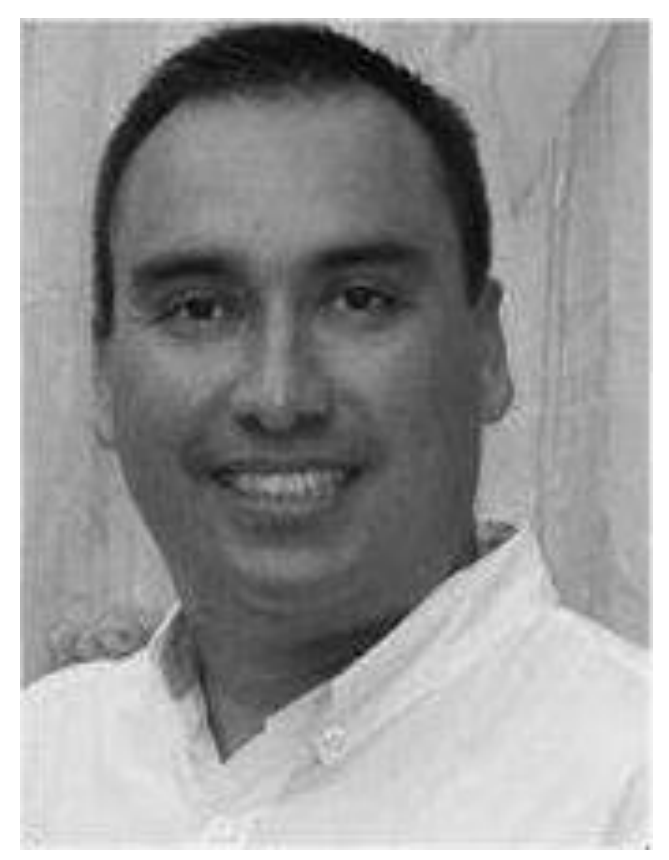

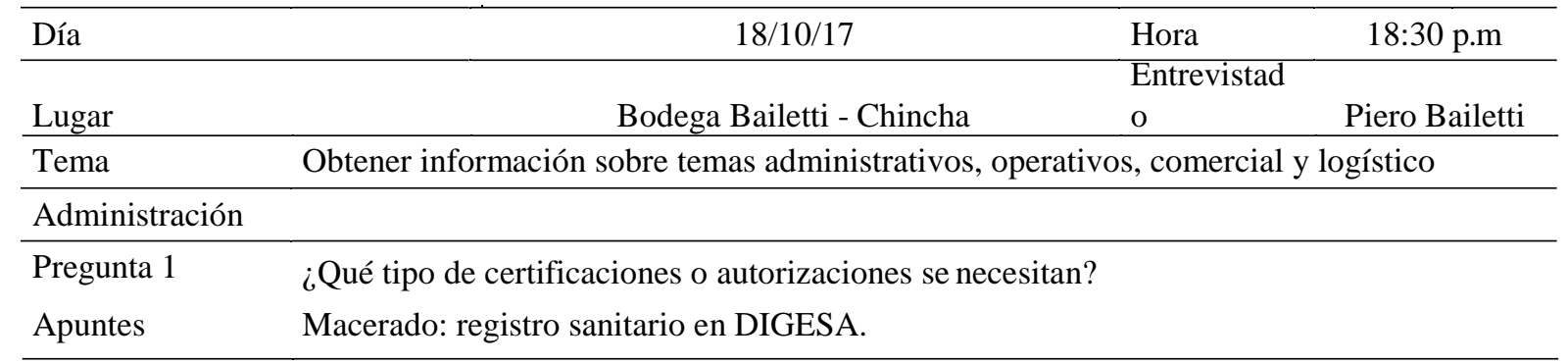

Pregunta $2 \quad$ ¿Qué otros aspectos legales considera importantes?

Denominación de origen del pisco, Indecopi hace inspección en planta. Cada 5 años se renueva. En caso el producto salga para exportación, debe demostrar que se está usando pisco con su denominación.

\begin{tabular}{ll}
\hline Operaciones & \\
\hline Pregunta 3 & $\begin{array}{l}\text { Sabemos que producen pisco ¿Han producido macerados de frutas en pisco? } \\
\text { Apuntes }\end{array}$ \\
$\begin{array}{ll}\text { bajan hecho pruebas y han usado pisco quebranta. Es un proyecto. La norma técnica es } \\
\text { luisa, hoja de coca, aguaymanto y uva borgoña. }\end{array}$ \\
\hline Pregunta 4 & ¿Qué tipo de maquinaria han usado para macerar? \\
Apuntes & Lo han realizado casero, en dama juanas y filtros. \\
\hline Pregunta 5 & ¿Qué tipo de preservante utilizan para la producción? \\
Apuntes & Un preservante natural de CapsuCork, pisco quebranta y frutas \\
\hline Pregunta 6 & ¿Cuál es el principal problema para la producción del macerado? \\
Apuntes & Encontrar los insumos de calidad. Comprar insumos de Lima. \\
\hline Pregunta 7 & ¿Qué tipo de insumos cree que es ideal para macerar? \\
Apuntes & Fruta fresca y también nuevos productos como kion, rocoto, lima, cítricos. \\
\hline Pregunta 8 & ¿En el proceso se puede mezclar la fruta con agua? \\
Apuntes & $\begin{array}{l}\text { Ellos no lo mezclan, sólo ponen la fruta, el preservante y pisco. Bajaría el grado de } \\
\text { alcohol. }\end{array}$ \\
\hline
\end{tabular}




\begin{tabular}{|c|c|}
\hline \multirow[b]{2}{*}{ Pregunta 9} & \multirow[b]{2}{*}{ ¿Cuáles son los tiempos para macerar? } \\
\hline & \\
\hline Apuntes & Mínimo 30 días, dependiendo de la fruta. \\
\hline Pregunta 10 & ¿Cuál creen que es el momento más critico de la producción? \\
\hline Apuntes & $\begin{array}{l}\text { Insumos y preservantes. La confianza de que sea un pisco chinchano, hay que mentalizar } \\
\text { al consumidor que es de buena calidad. }\end{array}$ \\
\hline Pregunta 11 & ¿Creen que poner la fruta en el producto final acorte su tiempo de vida? \\
\hline Apuntes & Sí, pero es más atractivo. \\
\hline \multicolumn{2}{|l|}{ Comercial } \\
\hline Pregunta 12 & ¿Cómo se inicia el proceso de ventas? \\
\hline Apuntes & Venderlo en la bodega. Meterse con una distribuidora. \\
\hline Pregunta 13 & ¿Qué rango de precios tienen sus productos? \\
\hline Apuntes & Accesibles y más baratos que la competencia. \\
\hline Pregunta 14 & ¿Cuál es la estrategia para promocionar su producto? \\
\hline Apuntes & El boca a boca, buscar una experiencia en el cliente. \\
\hline Pregunta 15 & ¿Cómo promocionan el pisco? \\
\hline Apuntes & Han sido invitados a Mistura, con stand gratis. \\
\hline Pregunta 16 & ¿Qué nombre recomendaría ponerle? \\
\hline Apuntes & Un nombre corto y que suene a quechua. \\
\hline Pregunta 17 & ¿Qué premios han ganado? \\
\hline Apuntes & $\begin{array}{l}\text { Don Salvatore, la gran medalla de oro. } \\
\text { Medallas de oro. }\end{array}$ \\
\hline Pregunta 18 & ¿Cómo llegan al consumidor final? \\
\hline Apuntes & $\begin{array}{l}\text { El único punto de venta es la bodega en Chincha. Este año recién tendrán un punto de } \\
\text { venta en Lima. }\end{array}$ \\
\hline \multicolumn{2}{|l|}{ Logística } \\
\hline Pregunta 19 & ¿Cómo almacenan el producto final? \\
\hline Apuntes & En la bodega Bailetti. \\
\hline Pregunta 20 & ¿Cómo realizan la distribución? \\
\hline Apuntes & Por el momento sólo se vende en la bodega, pero este año se distribuirá en Lima. \\
\hline Recomendacione & $\begin{array}{l}\text { Se refresca la fruta y hierbas. La distribución debe ser rápida y especificar que tiene un } \\
\text { tiempo de vida limitado. }\end{array}$ \\
\hline
\end{tabular}




\section{Anexo 8 - Transcripción de Entrevista a profundidad a Ex Viceministro de Mype}

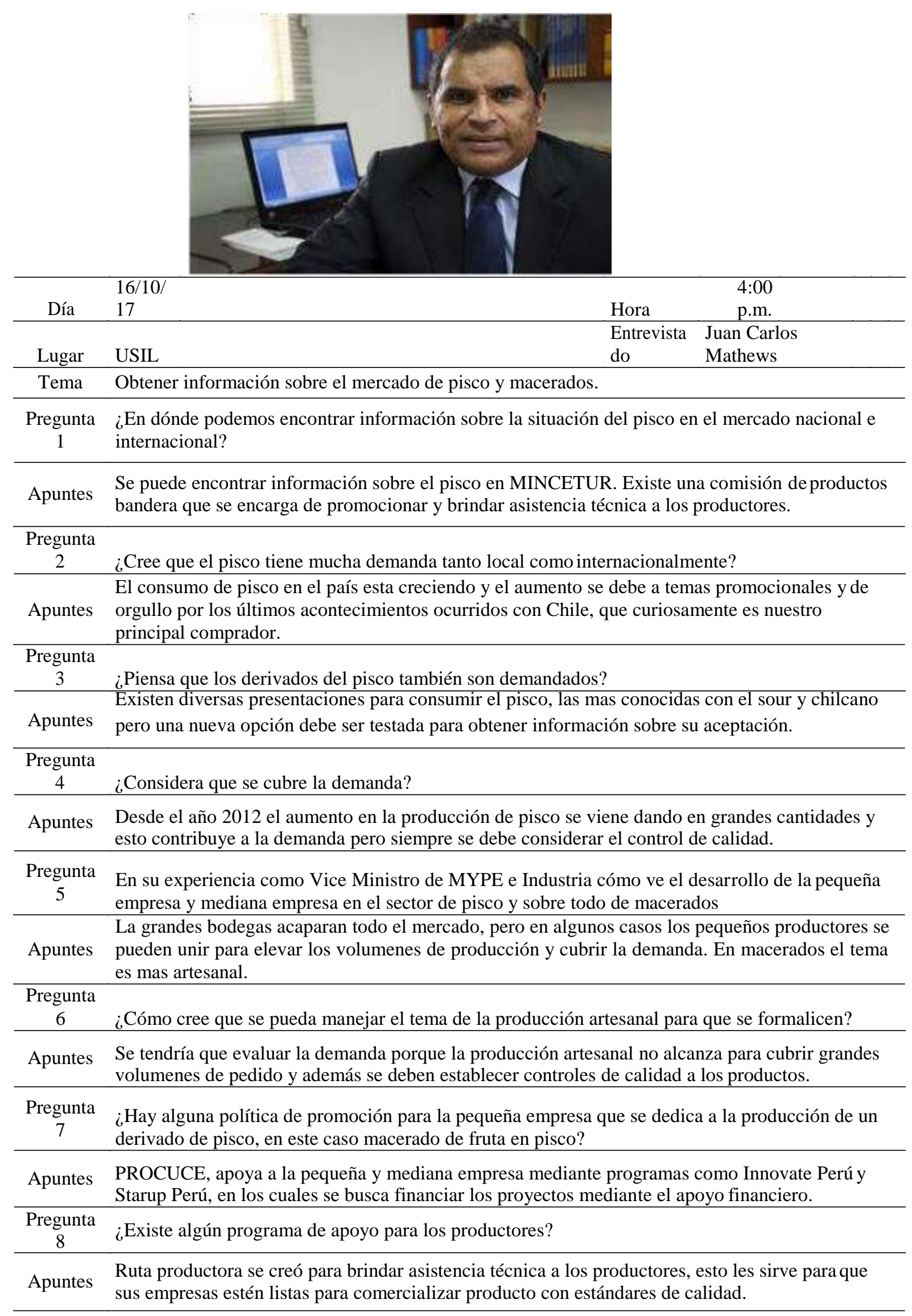




\begin{tabular}{|c|c|}
\hline $\begin{array}{l}\text { Pregunta } \\
9 \\
\end{array}$ & ¿En dónde se puede conseguir información sobre las empresas que están en el mismo rubro? \\
\hline Apuntes & $\begin{array}{l}\text { Conapisco congrega información sobre productores, catadores, además de incluir información } \\
\text { sobre la Sociedad Nacional de Industria, PROMPEX. Todo esto bajo la supervisión del } \\
\text { PRODUCE. }\end{array}$ \\
\hline $\begin{array}{l}\text { Pregunta } \\
10\end{array}$ & $\begin{array}{l}\text { ¿Tiene idea de qué porcentaje de empresas formales e informales de macerados de frutas en pisco } \\
\text { hay en el mercado? }\end{array}$ \\
\hline Apuntes & $\begin{array}{l}\text { No existe mucha información de estas empresas porque en su gran mayoría son informales pero en } \\
\text { el caso de las grandes bodegas algunas pueden tener entre sus líneas de productos algo sobre } \\
\text { macerados. }\end{array}$ \\
\hline $\begin{array}{l}\text { Pregunta } \\
\quad 11\end{array}$ & $\begin{array}{l}\text { Si en algún momento se pensaría en exportar, cree que los macerados serían aceptados en el } \\
\text { mercado internacional? }\end{array}$ \\
\hline Apuntes & $\begin{array}{l}\text { Se tendría que testear el producto en el exterior, una buena opción es aprovechar las ferias para } \\
\text { poder ofrecer el producto y obtener información sobre si el producto es aceptado. }\end{array}$ \\
\hline $\begin{array}{l}\text { Pregunta } \\
12\end{array}$ & ¿Qué aspectos se deben tomar en cuenta para elegir un mercado internacional? \\
\hline Apuntes & $\begin{array}{l}\text { Se debe tener presente tres aspectos para elegir el mercado y estos son, tamaño, barreras de acceso } \\
\text { y rentabilidad. Una buena opción es aprovechar los beneficios de convenios como los TLC. }\end{array}$ \\
\hline $\begin{array}{l}\text { Pregunta } \\
13 \\
\end{array}$ & ¿Cúal podría ser una estrategia para introducir el producto en el mercado internacional? \\
\hline Apuntes & $\begin{array}{l}\text { Debido a la producción en menor escala, una opción sería posicionar el producto en cadenas } \\
\text { especializadas que otorguen un mayor margen pero que demanden menor volumen. }\end{array}$ \\
\hline $\begin{array}{l}\text { Pregunta } \\
14 \\
\end{array}$ & ¿Qué otra estrategia se puede utilizar? \\
\hline Apuntes & $\begin{array}{l}\text { Se pude aprovechar el "branding" llegando a cadenas con marca propia que estén fuertemente } \\
\text { posicionadas en el mercado para evitar los costos de promoción e introducción de mercado. }\end{array}$ \\
\hline $\begin{array}{l}\text { Pregunta } \\
15\end{array}$ & ¿Cómo se puede promocionar el producto en el exterior? \\
\hline Apuntes & $\begin{array}{l}\text { Como estrategia de promoción se puede introducir el producto en el exterior dirigiéndolo a la } \\
\text { comunidad peruana en otros países, evitando de esta manera los costos de marketing internacional. }\end{array}$ \\
\hline $\begin{array}{l}\text { Pregunta } \\
16\end{array}$ & ¿Qué requisitos son importantes para exportar? \\
\hline Apuntes & $\begin{array}{l}\text { Uno de los requisitos muy importantes son los certificados de calidad, los cuales son de suma } \\
\text { importancia para los mercados en el exterior. }\end{array}$ \\
\hline $\begin{array}{l}\text { Pregunta } \\
17 \\
\end{array}$ & ¿Cuál es la importancia de las certificaciones? \\
\hline Apuntes & $\begin{array}{l}\text { En el mercado global sin certificaciones los productos no ingresan a los mercados internacionales. } \\
\text { Tanto los exportadores como sus proveedores deben estar certificados. }\end{array}$ \\
\hline $\begin{array}{l}\text { Pregunta } \\
18\end{array}$ & ¿Las alianzas estratégicas son válidad en este negocio? \\
\hline Apuntes & $\begin{array}{l}\text { Claro, para aprovechar los beneficios de las empresas consolidadas se puede acceder a una doble } \\
\text { articulación, juntarse con productores para lograr volumenes y vender por intermedio de empresas } \\
\text { grandes. }\end{array}$ \\
\hline $\begin{array}{l}\text { Pregunta } \\
19\end{array}$ & $\begin{array}{l}\text { ¿Cuál es la diferencia entre productos perecibles y no perecibles en cuanto a los temas } \\
\text { comerciales? }\end{array}$ \\
\hline Apuntes & $\begin{array}{l}\text { Los perecibles sulen ser entregados a consignación en cambio los productos no perecibles se } \\
\text { deben vender contra carta de crédito para asegurar la transacción comercial. }\end{array}$ \\
\hline $\begin{array}{l}\text { Pregunta } \\
\text { 20: }\end{array}$ & ¿Se pueden utilizar brockers para comercializar este producto? \\
\hline Apuntes & $\begin{array}{l}\text { No es muy probable porque los brockers comercializan productos que manejan grandes volumenes } \\
\text { de exportación y este producto debería buscar nichos de mercados. }\end{array}$ \\
\hline
\end{tabular}




\section{Anexo 9 - Transcripción de Entrevista a profundidad a Productor de Macerados}

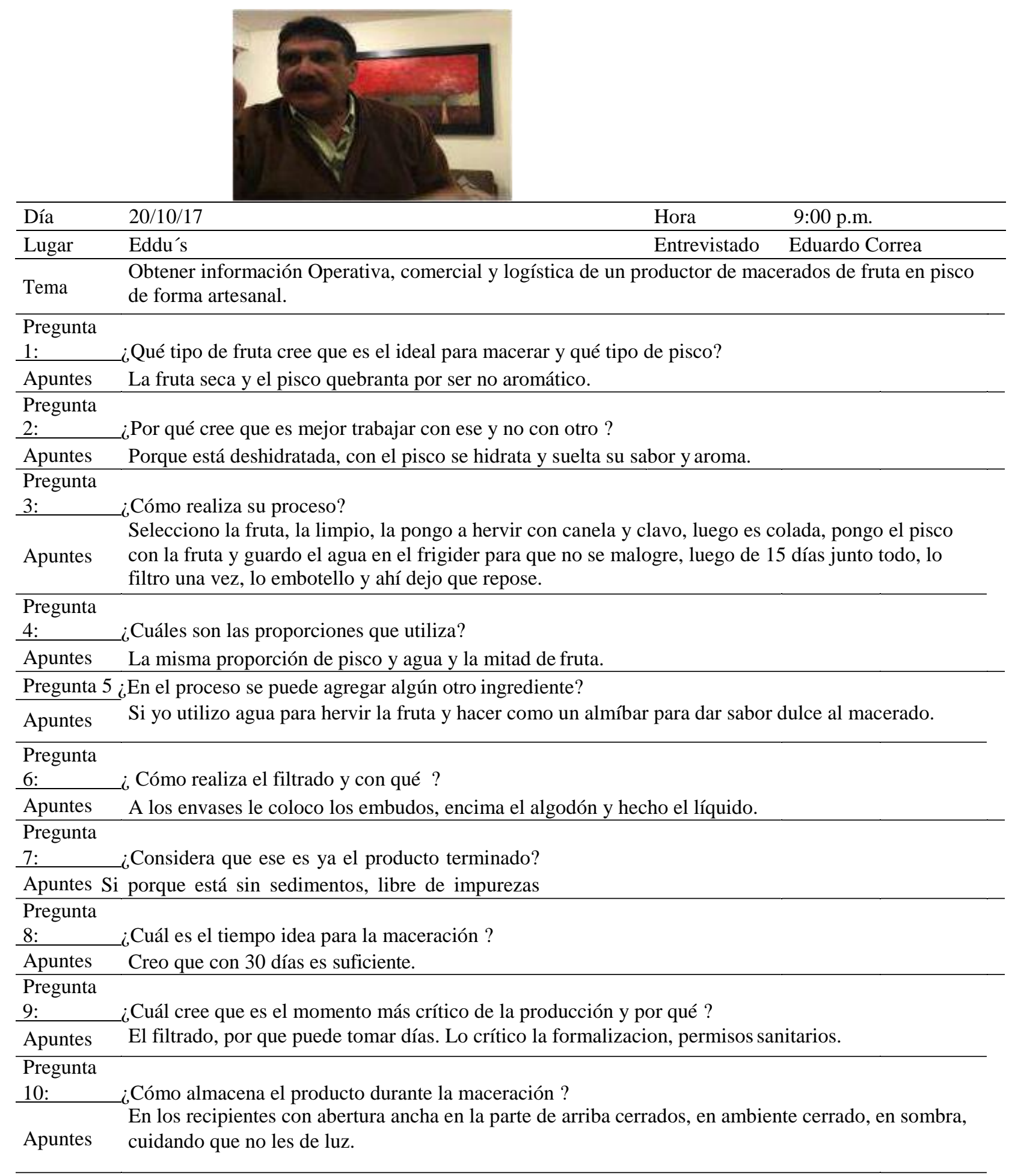

\section{Pregunta}

11: ¿Utiliza algún tipo de insumo para alargar la vida del macerado ?

Apuntes No, no utilizo, no es necesario, el pisco lo mantiene, por

eso uso fruta seca.

Pregunta

12: ¿Cree que poner la fruta en el producto final sea la causante de que acorte la vida útil? 
No para nada, es más dejar la fruta hace que siga macerando. No se malogran los macerados y lo he probado, duran más de 3 años sin nigún problema dependiendo de la fruta. He trabajado con higo y

Apuntes sí le salió como una telita blanca en la parte de arriba. En los que he trabajado con damascos y guinda no he tenido ese problema.

\begin{tabular}{ll}
\hline $\begin{array}{l}\text { Pregunta } \\
\text { 13: }\end{array}$ & ¿Cómo inician el proceso de ventas de tu producto ? \\
Apuntes & $\begin{array}{l}\text { A los amigos, conocidos, por facebook, me han pedido restaurantes y otros establecimientos pero } \\
\text { ellos si me piden registro sanitario. }\end{array}$ \\
\hline $\begin{array}{l}\text { Pregunta } \\
14:\end{array}$ & ¿Considera que llegar al consumidor final por supermercados u otras opciones ? \\
\hline Apuntes & $\begin{array}{l}\text { Como te comento, vendo a conocidos y referidos. No puedo entrar a supermercados porque no tengo } \\
\text { la capidad financiera y porque no cuento con Registro Sanitario. La mejor opcion es llegar a través } \\
\text { de otros establecimientos, restaurantes y bares. }\end{array}$
\end{tabular}
Pregunta
15: ¿Cree que su producto resistiría un tiempo de recolocación de 90 días?
Como te digo el macerado no se malogra, porque el pisco lo mantiene y si está cerrado no hay
Apuntes problema

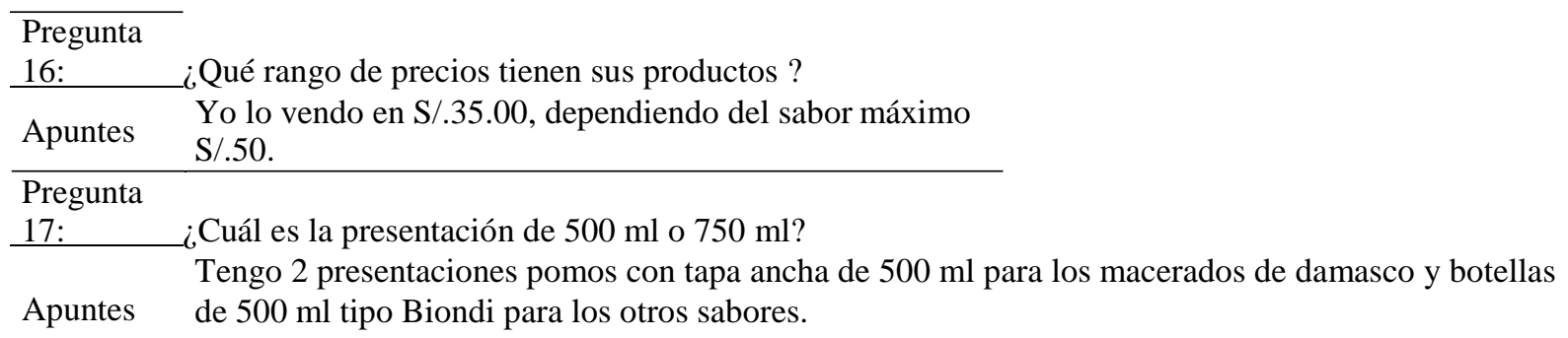

\begin{tabular}{ll}
\hline $\begin{array}{l}\text { Pregunta } \\
18:\end{array}$ & ¿Tiene algún problema recurrente con sus clientes o reclamo ? \\
\hline Apuntes & No de ningún tipo, es más les gusta mi producto, siempre me piden, tengo años preparándolo. \\
\hline $\begin{array}{ll}\text { Pregunta } \\
20:\end{array}$ & ¿Cuál es la estrategia de promoción del macerado ? \\
& $\begin{array}{l}\text { Mi estrategia es el mismo macerado, lo llevo a reuniones, y siempre me piden. Hice una producción } \\
\text { para una fiesta de re-encuentro de colegio por ejemplo. Así me conocen, me recomiendan y voy } \\
\text { teniendo más clientes. }\end{array}$ \\
Apuntes & ¿Cómo se diferencias de la competencia ? \\
Pregunta & La diferencia es la calidad, la receta, tengo años y \\
Apuntes & siempre me piden . \\
\hline $\begin{array}{l}\text { Pregunta } \\
22:\end{array}$ & ¿Cómo realiza la distribución ? \\
Apuntes & $\begin{array}{l}\text { Como te comento la distribución la hago yo mismo, yo los entrego, lo vendo amigos y conocidos. Por } \\
\text { ahín tipo de bar, restaurante. }\end{array}$
\end{tabular}

\begin{tabular}{|c|c|}
\hline $\begin{array}{l}\text { Pregunta } \\
23 \text { : }\end{array}$ & ¿Cuál es su política de abastecimiento? \\
\hline Apuntes & Compro el pisco quebranta de Bailetti y la fruta seca en el Mercado de Lince. \\
\hline $\begin{array}{l}\text { Pregunta } \\
24:\end{array}$ & Algún comentario adicional \\
\hline Apuntes & $\begin{array}{l}\text { No he trabajado con Maracuyá, pero habría que hervirla, licuarla, o comprar en algún tipo de polvo. } \\
\text { Creo que la receta que vas usar es importante, para que puedas guardar la armonía entre los } \\
\text { ingredientes y ninguno opaque al otro. El control y cuidado es imporante., }\end{array}$ \\
\hline
\end{tabular}




\section{Anexo 10 - Transcripción de Entrevista a profundidad a Productor de Macerados}

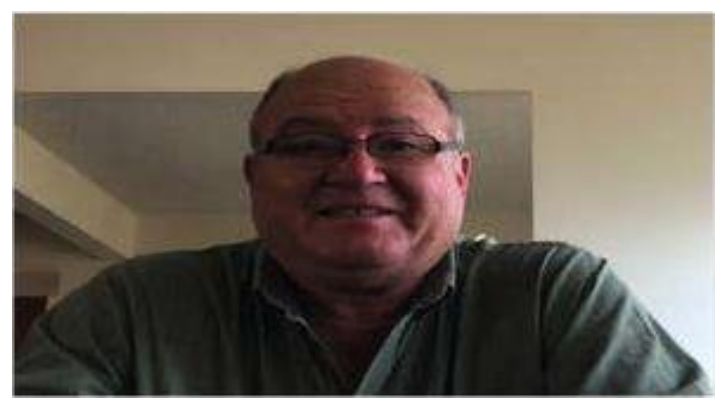

\begin{tabular}{|c|c|c|}
\hline Día & $21 / 10 / 17$ & 11:00 a.m. \\
\hline Lugar & Foodies $\quad$ Entre & Manuel Pardo Figueroa \\
\hline Tema & \multicolumn{2}{|c|}{$\begin{array}{l}\text { Obtener información Operativa, comercial y logística de un productor de macerados de fruta en } \\
\text { pisco de forma artesanal. }\end{array}$} \\
\hline
\end{tabular}

Pregunta 1: ¿Qué tipo de fruta cree que es el ideal para macerar y qué tipo de pisco?

La fruta seca y el pisco puro o quebranta por ser no aromático. No recomiendo usar un mosto

Apuntes verde, porque tus costos serian altos. Además la fruta seca se va hidratar con el pisco y va a soltar su aroma y sabor.

Pregunta 2: ¿Por qué cree que es mejor trabajar con ese y no con otro ?

Apuntes Porque está deshidratada, con el pisco se hidrata y suelta su sabor y aroma.

Pregunta 3: ¿Cómo realiza su proceso?

Selecciono la fruta, la limpio, la pongo a macerar con el pisco por 90 días. Antes de

Apuntes embotellarlo realizar un proceso de filtrado en tres etapas.

Pregunta 4: ¿Cuáles son las proporciones que utiliza?

Apuntes La proporción de pisco y fruta varía.

Pregunta 5 ¿En el proceso se puede agregar algún otro ingrediente?

No utilizo agua. Ni azucar, pero si se puede usar jarabe de goma. O algún tipo de almíbar. No

Apuntes utilizo saborizantes especiales.

Pregunta 6: ¿Cómo realiza el filtrado y con qué ?

Lo realizo con papel filtro, que lo compro en farmacias, ferreterias como Piamontesa. Limpio de impurezas. Producto transparente, atrayente para tu cliente. Hago un proceso de filtrado en

Apuntes recipientes puestos en cascada, encima de cada recipiente un colador y encima el papel filtro y se va echando el líquido en el primer colador y pasa al segundo recipiente y cae por gravedad, de gota y así pasa del segundo al tercer envase.

Pregunta 7: ¿Considera que ese es ya el producto terminado?

Si porque está limpio, toma tiempo, pero ya no necesita reposar el producto, porque en el triple

Apuntes filtrado se saca todas las impurezas que puedan aparecer. El producto debe estar transparente sin sedimentos.

Pregunta 8: ¿Cuál es el tiempo idea para la maceración ?

El tiempo de maceración debe ser de 90 días, para que la fruta se haya hinchado, liberado su

Apuntes sabor, impregnado el olor, el líquido haya reposado.

Pregunta 9: ¿Cuál cree que es el momento más crítico de la producción y por qué ?

El tiempo esperar por la primera producción despues de 90 días. Hacer producciones semanales

Apuntes $\quad$ y no cortar el proceso de produccion va ser importante.

Pregunta 10: ¿Cómo almacena el producto durante la maceración ?

Apuntes En ambiente fresco, seco y con poca luz.

Pregunta 11: ¿Utiliza algún tipo de insumo para alargar la vida del macerado ? No es necesario el pisco tiene el grado de alcohol suficiente para esterilizar, y la fruta seca está

Apuntes libre de bacterias. No usar preservantes naturales, cambian el sabor. No hay problema. 
Pregunta 12: ¿Cree que poner la fruta en el producto final sea la causante de que acorte la vida útil?

Apuntes No para nada se pone la fruta seca, nueva como adorno una muestra no lo malogra.

Pregunta 13: ¿Cómo inician el proceso de ventas de tu producto ?

Apuntes Ofreciendo a conocidos y por pedido

Pregunta 14: ¿Considera que llegar al consumidor final por supermercados u otras opciones?

Antes de llegar hay que analizar la capacidad de producción y financiera. Tomar en cuenta la estructura de precio que incluya todos lo márgenes.

Pregunta 15: ¿Cree que su producto resistiría un tiempo de recolocación de 90 días ?

Apuntes Como te digo el macerado no se malogra, porque el pisco lo mantiene y si está cerrado no hay problema

Pregunta 16: ¿Qué rango de precios tienen sus productos?

Apuntes Yo lo vendo en S/.50.00.

Pregunta 17: ¿Cuál es la presentación de $500 \mathrm{ml} \mathrm{o} 750 \mathrm{ml}$ ?

Tengo 2 presentaciones pomos con tapa ancha de $500 \mathrm{ml}$ para los macerados de damasco y

Apuntes botellas de $500 \mathrm{ml}$ tipo Biondi para los otros sabores.

Pregunta 18: ¿Tiene algún problema recurrente con sus clientes o reclamo ?

No para nada el proceso es artesanal, pero siempre lo piden, la calidad .

Apuntes $\quad$ El filtrado es importante, un producto de calidad.

Pregunta 20: ¿Cuál es la estrategia de promoción del macerado?

Apuntes En el precio que se va a poner considerar lo que se va a gastar en rebates, promoción,

Pregunta 21: ¿Cómo se diferencias de la competencia?

Apuntes Calidad del producto.

Pregunta 22: ¿ Cómo realiza la distribución?

Apuntes Entre amigos, en licorerías, restaurantes.

Pregunta 23: ¿Cuál es su política de abastecimiento?

Apuntes Compro el pisco quebranta y la fruta seca en el Mercado de Surquillo.

Pregunta 24: Algún comentario adicional

Mantener en el tiempo el sabor, controlar la receta, la calidad del producto, un buen proveedor de pisco, de la cantidad y calidad del mismo pisco para poder conseguir lo que quieres. Trabajar

Apuntes con sabores que hay en el mercado. Hacer un pareto para determinar qué sabor representaría el $80 \%$ de las ventas. El programa de producción controlado. 


\section{Anexo 11 - Transcripción de Entrevista a profundidad a Sommelier}

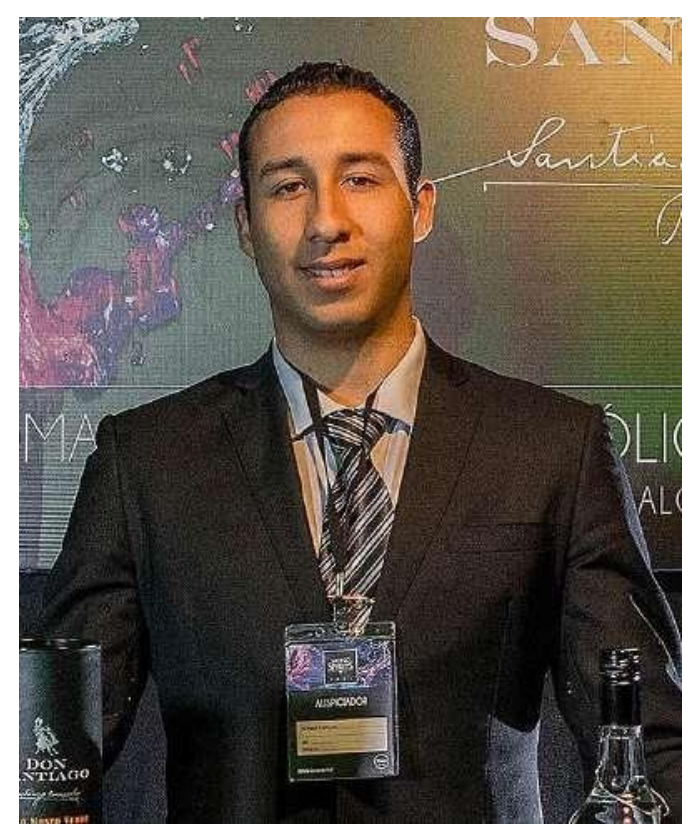

\begin{tabular}{|c|c|c|c|}
\hline Día & $22 / 10 / 17$ & Hora & 18:00 p.m \\
\hline Lugar & Oficina & Entrevistado & Héctor Tuesta \\
\hline Tema & \multicolumn{3}{|c|}{ Obtener información Estratégico y Comercial } \\
\hline Pregunta 1 & \multicolumn{3}{|c|}{ ¿Qué nuevas estrategias se usan para promocionar el pisco? } \\
\hline Apuntes & \multicolumn{3}{|c|}{$\begin{array}{l}\text { Maridar el pisco con distintos tipos de postres, habanos hasta con café. Repercuta en dos } \\
\text { puntos: poder apreciar el destilado bandera y que el consumo de pisco se eleva. Recomienda } \\
\text { un sistema de organización, hacer el pisco más cercano al consumidor. }\end{array}$} \\
\hline
\end{tabular}

Pregunta 2 ¿Se podría decir que una nueva tendencia de consumo de pisco puede ser en macerados de fruta en pisco? Apuntes tiempo. Pero en estos últimos años, el tema de macerados ha agarrado fuerza e incentiva al consumidor a tomar el pisco en distinas presentaciones.

Pregunta 3 En su experiencia, ¿Cree que hay muchos consumidores de macerados de fruta en pisco?

Apuntes El consumidor a veces no lo aprecia tanto, sí hay pero hay que buscarlo. Hay personas que sólo buscan tomar, otros buscan experiencia de consumir alcohol.

\begin{tabular}{|c|c|}
\hline Pregunta 4 & ¿Considera que la aceptación va creciendo? \\
\hline Apuntes & Sí, hay marcas que venden mezclas. Incluso hay bares que lo están implementando. \\
\hline Pregunta 5 & $\begin{array}{l}\text { Si se ofrece un producto de calidad, sin connotación de artesanal ¿Habría proyección de } \\
\text { aceptación? }\end{array}$ \\
\hline Apuntes & $\begin{array}{l}\text { La palabra artesanal está muy manoseada. Efectos de percepción del consumidor. El } \\
\text { mercado está abierto a un producto de calidad. }\end{array}$ \\
\hline Pregunta 6 & ¿Cree que el pisco quebranta es ideal para la preparación de los macerados? \\
\hline Apuntes & $\begin{array}{l}\text { Pisco quebranta es el más neutro que hay. Tiene mucho peso en boca. Es el más estándar y } \\
\text { ayuda con tema de costeos. }\end{array}$ \\
\hline Pregunta 7 & ¿Se puede mezclar con cualquier tipo de pisco? \\
\hline Apuntes & Sí, depende de las características del destilado combina mejor con distintas frutas. \\
\hline Pregunta 8 & ¿Qué sabores son los preferidos? \\
\hline Apuntes & Aguaymanto deshidratado, piña, maracuyá y mango. \\
\hline
\end{tabular}




\begin{tabular}{|c|c|}
\hline \multirow{2}{*}{ Pregunta 9} & \multirow[b]{2}{*}{ ¿Opina que frambu } \\
\hline & \\
\hline Apuntes & Sí \\
\hline Pregunta 10 & ¿Opina que fresa y guinda es una buena mezcla? \\
\hline Apuntes & Sí \\
\hline Pregunta 11 & ¿Opina que arándanos y canela es una buena mezcla? \\
\hline Apuntes & Sí \\
\hline Pregunta 12 & ¿Opina que piña y hierba luisa es una buena mezcla? \\
\hline Apuntes & Sí \\
\hline Pregunta 13 & ¿Opina que chicha (maíz morado, membrillo y canela) es una buena mezcla? \\
\hline Apuntes & Sí \\
\hline Pregunta 14 & ¿Qué opina de los sabores que ofrecemos? \\
\hline Apuntes & $\begin{array}{l}\text { Hacia un público específico la idea es buena. El pisco está de moda. Las combinaciones son } \\
\text { atractivas. }\end{array}$ \\
\hline Pregunta 15 & $\begin{array}{l}\text { ¿Cree que los macerados de frutas en pisco son más aceptados por mujeres que por } \\
\text { hombres? }\end{array}$ \\
\hline Apuntes & $\begin{array}{l}\text { Segmentarlo por género, no funciona. Hay mujeres que toman bebidas amargas, hay } \\
\text { hombres que le encanta bebidas dulces. Hoy en día, no es una limitación, verlo más por } \\
\text { tendencias y gustos. }\end{array}$ \\
\hline Pregunta 16 & Servirlo tipo chilcano ¿es una opción más suave? \\
\hline Apuntes & $\begin{array}{l}\text { Sí, depende del macerado. Hay ginger que son más gasificados y menos dulce para que se } \\
\text { aprecie el macerado. }\end{array}$ \\
\hline Pregunta 17 & En su experiencia, ¿en qué ocasiones consumen los macerados de frutas en pisco? \\
\hline Apuntes & $\begin{array}{l}\text { Depende del consumidor y el lugar donde vayas. Hay bares como Huaringas y Pitahaya que } \\
\text { se conocen por la coctelería con macerados. }\end{array}$ \\
\hline Pregunta 18 & ¿Sabe cuál es la frecuencia de consumo? \\
\hline Apuntes & $\begin{array}{l}\text { Personas lo toman en almuerzos, cenas, depende del sabor del macerado y de la preferencia } \\
\text { del cliente. }\end{array}$ \\
\hline Pregunta 19 & ¿Podría considerarse en las rutas de pisco la experiencia de probar los macerados de frutas? \\
\hline Apuntes & $\begin{array}{l}\text { Sí, hay bodegas que producen macerados y lo ofrecen. Es una buena idea porque le ofreces } \\
\text { otra forma de tomar su producto. }\end{array}$ \\
\hline Pregunta 20 & ¿Qué nombre le pondría al macerado de frutas en pisco? \\
\hline Apuntes & Nombre que se recuerde y tenga un significado. Depende del mercado. \\
\hline $\begin{array}{l}\text { Recomendacion } \\
\text { es }\end{array}$ & $\begin{array}{l}\text { Poner la misma cantidad de frutas en la presentación final, para mantener la estandarización } \\
\text { del sabor del producto. El alcohol es un preservante natural, el dulce también es un } \\
\text { preservante, dura aproximadamente dos años. La fruta expuesta llama la atención. } \\
\text { Estandarizar el precio. Deshidratar la fruta para botar el agua de la fruta y que tenga mayor } \\
\text { sabor y se realice el proceso de maceración en menor tiempo. } \\
\text { Necesitas estar en Sunat y en Indecopi. Registro sanitario por sabor. La ley va a cambiar } \\
\text { porque ya no se necesitará registro sanitario, sino HACCP. } \\
\text { Mantener en un lugar fresco, oscuro, para que no se malogren. }\end{array}$ \\
\hline
\end{tabular}




\section{Anexo 12 - Guía de pautas para FocusGroup}

\section{Objetivo general de la investigación}

- Identificar el nivel de aceptación de los macerados de frutas en pisco de varios sabores.

\section{Objetivos específicos}

- Determinar las características del producto que el cliente espera.

- Conocer la frecuencia de consumo.

- Identificar las variables determinantes al momento de compra.

- Conocer si la presentación tiene mayor aceptación.

- Determinar el nombre más adecuado para el producto.

- Conocer si los sabores son los adecuados.

\section{Contenido}

- Aspectos generales sobre las bebidas alcohólicas.

- Frecuencia de consumo de bebidas alcohólicas y cocteles.

- Presentación del producto de Macerados de frutas en pisco.

- Degustación de los Macerados de frutas en pisco.

- Posicionamiento y teste del nombre.

\section{Perfil del participante}

Hombres y mujeres de 21 a 65 años, que pertenezcan a los niveles socioeconómicos A y B y que residan en la zona 6 (Jesús María, Lince, Pueblo Libre, Magdalena y San Miguel) y zona 7 (Miraflores, San Isidro, San Borja, Santiago de Surco, La Molina) de Lima Metropolitana; y que tengan preferencia o gustos por el pisco y sus derivados.

\section{Determinación del número de focusgroup}

Se realizarán cuatro sesiones de focusgroup conformados entre 6 a 12 personas cada uno entre los rangos de 21 a 65 años de edad. 
Esta división se determinó para poder analizar las distintas opiniones de las personas de distintas edades y que se expresen libremente.

\section{Guía de pautas}

\section{Presentación y calentamiento}

Buenos/as días/tardes/noches, primero que nada quisiera agradecerles por haber aceptado la invitación al focusgroup, mi nombre es Joselyn/Guiselle/Carlos.

Somos estudiantes de maestría de la Universidad San Ignacio de Loyola, el motivo de la presente reunión es para conversar acerca de una idea de negocio para la producción de macerados de frutas en pisco.

La reunión será grabada con fines de recopilación de información. Todo lo que ustedes digan u opinen es importante. Siéntanse en la libertad de discutir y defender sus ideas con confianza. No hay respuestas buenas, ni respuestas malas, sólo respuestas sinceras.

Antes que nada queremos conocernos por lo que les pido que se presenten indicando su nombre, edad y distrito. Empezamos por la derecha.

\section{Reglas del juego}

- Relájese

- Opinión propia

- No temer con estar en desacuerdo

- Dinámica de romper el hielo (presentación de cada uno)

\section{Listado de preguntas}

I. ASPECTOS GENERALES SOBRE BEBIDAS ALCOHÓLICAS (Preguntas exploratorias).

- ¿Toman bebidas alcohólicas?

- ¿Cuál prefieren?

- ¿Qué tipo de cocteles consumen habitualmente? 


\section{FRECUENCIA DE CONSUMO DE BEBIDAS ALCOHÓLICAS.}

- ¿Con que frecuencia consumen bebidas alcohólicas?

\section{PRESENTACIÓN DEL MACERADO DE FRUTAS CON PISCO.}

- ¿Han escuchado o probado macerados de frutas en pisco?

- ¿Cuál ha sido su experiencia?

- ¿Qué diferencias encuentran respecto a los macerados de frutas en pisco que han probado anteriormente? Sabor, color, aroma, entre otros.

- ¿Qué expectativas tienen cuando van a tomar algún macerado de fruta en pisco?

- ¿Consumirían los macerados de frutas en pisco en eventos sociales, familiares, corporativos?

- ¿Reemplazarían tragos a base de ron, vodka, entre otros, por macerados de frutas en pisco en sus distintos sabores?

- ¿Cuál sería el principal atractivo del producto?

- ¿Cuánto están dispuestos a pagar por la botella de 750 ml?

- ¿Les gustaría poder comprar el macerado de frutas en pisco por redes sociales: Facebook o Instagram o prefieren encontrarlos en establecimientos?

- ¿Cuál es la característica que creen que se debería aprovechar para impulsar el posicionamiento del producto?

\section{DEGUSTACIÓN DE LOS MACERADOS DE FRUTAS EN PISCO.}

- De todos los sabores que probaron podrían clasificarlos del 1 al 5 (en orden de su mayor agrado).

- ¿Qué características creen que podría tener el macerado de frutas en pisco o en qué debería mejorar?

- ¿Qué otros sabores les gustaría encontrar?

V. POSICIONAMIENTO Y TEST DE NOMBRE. 
- De estos nombres: Qispi-Kay, KimsaPisqu o Nuna. ¿Cuál creen que suena mejor para el macerado de frutas en pisco?

- ¿Les parece que el nombre y logo es de fácil recordación?

\section{Despedida y Agradecimiento}

Finalizará el focusgroup y se les agradecerá a los participantes por su asistencia. Se les entregará una botella de 50ml de macerado de frutas en pisco, además de ofrecerles bocaditos y bebidas en agradecimiento por su participación. 


\section{Anexo 13 - Focus Group \#1}

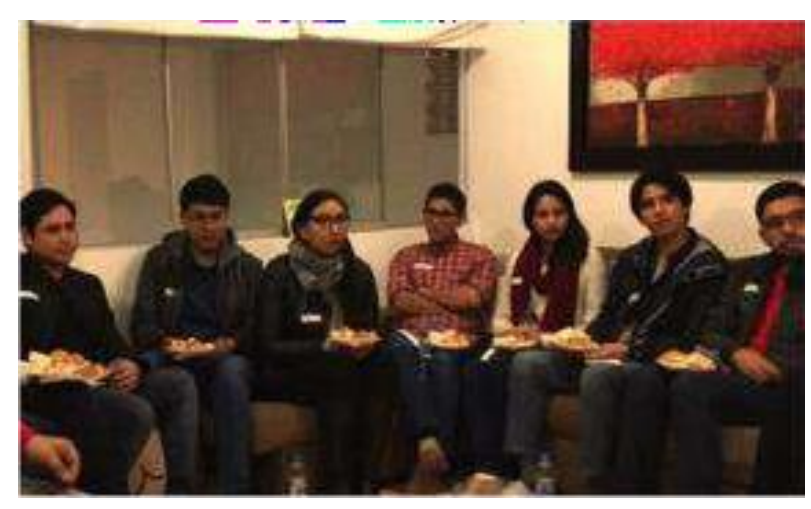

\begin{tabular}{lccc}
\hline Día & $20 / 10 / 17$ & Hora & $20: 00 \mathrm{pm}$ \\
\hline Lugar & Departamento & \# Participantes & 7 \\
\hline NSE & A \& B & & Zona 6 y Zona 7 \\
\hline
\end{tabular}

\section{Presentación}

Pregunta 1

Por favor, presentarse indicando nombre y distrito.

\begin{tabular}{|c|c|c|c|c|c|}
\hline \multicolumn{6}{|l|}{ Respuestas } \\
\hline $\begin{array}{l}\text { Participan } \\
\text { te \#1 }\end{array}$ & Rafael, La Molina & Participante \#4 & David, Surco & $\begin{array}{l}\text { Participante } \\
\# 7\end{array}$ & $\begin{array}{c}\text { Giancarlo, } \\
\text { Lince }\end{array}$ \\
\hline $\begin{array}{l}\text { Participan } \\
\text { te \#2 }\end{array}$ & Tommy, San Borja & Participante \#5 & $\begin{array}{c}\text { Estefany, } \\
\text { Pueblo Libre }\end{array}$ & & \\
\hline $\begin{array}{l}\text { Participan } \\
\text { te \#3 }\end{array}$ & Fiorella, San Borja & Participante \#6 & $\begin{array}{l}\text { Diego, San } \\
\text { Isidro }\end{array}$ & & \\
\hline
\end{tabular}

Aspectos generales sobre bebidas alcohólicas (Preguntas exploratorias)

Pregunta 2

¿Toma bebidas alcohólicas?

\begin{tabular}{lcccc}
\hline Respuestas & & & & \\
$\begin{array}{l}\text { Participan } \\
\text { te \#1 }\end{array}$ & Sí & Participante \#4 & Sí & \#7 \\
$\begin{array}{l}\text { Participan } \\
\text { te \#2 }\end{array}$ & Sí & Participante \#5 & Sí & \\
\hline $\begin{array}{l}\text { Participan } \\
\text { te \#3 }\end{array}$ & Sí & Participante \#6 & Sí & \\
\hline
\end{tabular}

Pregunta 3

¿Cuál prefiere?

\begin{tabular}{|c|c|c|c|c|c|}
\hline \multicolumn{6}{|l|}{ Respuestas } \\
\hline $\begin{array}{l}\text { Participan } \\
\text { te \#1 }\end{array}$ & Cerveza & Participante \#4 & Cerveza & $\begin{array}{l}\text { Participante } \\
\# 7\end{array}$ & Pisco \\
\hline $\begin{array}{l}\text { Participan } \\
\text { te \#2 }\end{array}$ & Pisco & Participante \#5 & Pisco & & \\
\hline $\begin{array}{l}\text { Participan } \\
\text { te \#3 }\end{array}$ & Pisco y Cerveza & Participante \#6 & Cerveza & & \\
\hline
\end{tabular}

Frecuencia de consumo de bebidas alcohólicas

Pregunta 5 
¿Con que frecuencia consumen bebidas alcohólicas?

\begin{tabular}{|c|c|c|c|c|c|}
\hline \multicolumn{6}{|l|}{ Respuestas } \\
\hline $\begin{array}{l}\text { Participan } \\
\text { te \#1 }\end{array}$ & $1 \mathrm{vez}$ a la semana & Participante \#4 & $\begin{array}{c}2 \text { veces a la } \\
\text { semana }\end{array}$ & $\begin{array}{l}\text { Participante } \\
\text { \#7 }\end{array}$ & $\begin{array}{l}1 \text { vez a la } \\
\text { semana }\end{array}$ \\
\hline $\begin{array}{l}\text { Participan } \\
\text { te } \# 2\end{array}$ & 2 veces por semana & Participante \#5 & $\begin{array}{l}1 \text { vez a la } \\
\text { semana }\end{array}$ & & \\
\hline $\begin{array}{l}\text { Participan } \\
\text { te \#3 }\end{array}$ & $1 \mathrm{vez}$ a la semana & Participante \#6 & $\begin{array}{l}1 \text { vez a la } \\
\text { semana }\end{array}$ & & \\
\hline \multicolumn{6}{|c|}{ Presentación del macerado de frutas con pisco } \\
\hline \multicolumn{6}{|c|}{$\begin{array}{l}\text { Pregunta } 6 \\
¿ \text { ¿Ha escuchado o probado macerados de frutas en pisco? }\end{array}$} \\
\hline \multicolumn{6}{|l|}{ Respuestas } \\
\hline $\begin{array}{l}\text { Participan } \\
\text { te \#1 }\end{array}$ & No & Participante \#4 & Sí & $\begin{array}{l}\text { Participante } \\
\# 7\end{array}$ & No \\
\hline $\begin{array}{l}\text { Participan } \\
\text { te \#2 }\end{array}$ & Sí & Participante \#5 & Sí & & \\
\hline $\begin{array}{l}\text { Participan } \\
\text { te \#3 }\end{array}$ & No & Participante \#6 & No & & \\
\hline
\end{tabular}

Pregunta 7

¿Cuál ha sido su experiencia?

\begin{tabular}{|c|c|c|c|c|c|}
\hline \multicolumn{6}{|l|}{ Respuestas } \\
\hline $\begin{array}{l}\text { Participan } \\
\text { te \#1 }\end{array}$ & Ninguna & Participante \#4 & $\begin{array}{l}\text { Macerado } \\
\text { casero }\end{array}$ & $\begin{array}{l}\text { Participante } \\
\# 7\end{array}$ & Ninguna \\
\hline $\begin{array}{l}\text { Participan } \\
\text { te } \# 2\end{array}$ & Canela y damasco & Participante \#5 & Coca y raíces & & \\
\hline $\begin{array}{l}\text { Participan } \\
\text { te \#3 }\end{array}$ & Ninguna & Participante \#6 & Ninguna & & \\
\hline \multicolumn{6}{|c|}{$\begin{array}{l}\text { Pregunta } 8 \\
\text { ¿Qué diferencias encuentra respecto a los macerados de frutas en pisco que han probado anteriormente? Sabor, } \\
\text { color, aroma, entre otros. }\end{array}$} \\
\hline \multicolumn{6}{|l|}{ Respuestas } \\
\hline $\begin{array}{l}\text { Participan } \\
\text { te \#1 }\end{array}$ & Sólo un sabor & Participante \#4 & $\begin{array}{l}\text { Macerados } \\
\text { con rocoto }\end{array}$ & $\begin{array}{l}\text { Participante } \\
\# 7\end{array}$ & Un solo sabor \\
\hline $\begin{array}{l}\text { Participan } \\
\text { te \#2 }\end{array}$ & Sólo un sabor & Participante \#5 & $\begin{array}{c}\text { Presencia de } \\
\text { fruta }\end{array}$ & & \\
\hline $\begin{array}{l}\text { Participan } \\
\text { te \#3 }\end{array}$ & Sólo un sabor & Participante \#6 & Un solo sabor & & \\
\hline
\end{tabular}

Pregunta 9

¿Qué expectativas tienen cuando van a tomar algún macerado de fruta en pisco?

Respuestas

\begin{tabular}{|c|c|c|c|c|c|}
\hline $\begin{array}{l}\text { Participan } \\
\text { te \#1 }\end{array}$ & Buena & Participante \#4 & $\begin{array}{l}\text { Llamó la } \\
\text { atención } \\
\text { nuevos } \\
\text { sabores }\end{array}$ & $\begin{array}{l}\text { Participante } \\
\text { \#7 }\end{array}$ & $\begin{array}{l}\text { Opción con } \\
\text { frutas, más } \\
\text { llamativo }\end{array}$ \\
\hline
\end{tabular}

\begin{tabular}{lccc}
\hline $\begin{array}{l}\text { Participan } \\
\text { te \#2 }\end{array}$ & Buena & Participante \#5 & Mezclas \\
\hline $\begin{array}{l}\text { Participan } \\
\text { te \#3 }\end{array}$ & Presencia de fruta & Participante \#6 & Le gustó \\
\hline
\end{tabular}

Pregunta 10

¿Consumirían los macerados de frutas en pisco en eventos sociales, familiares, corporativos?

\begin{tabular}{|c|c|c|c|c|c|}
\hline Respuestas & & & & & \\
\hline $\begin{array}{l}\text { Participan } \\
\text { te \#1 }\end{array}$ & Sí, es novedoso & Participante \#4 & Sí, eventos & $\begin{array}{l}\text { Participante } \\
\# 7\end{array}$ & Sí \\
\hline
\end{tabular}




\begin{tabular}{|c|c|c|c|c|c|}
\hline $\begin{array}{l}\text { Participan } \\
\text { te \#2 }\end{array}$ & Sí & Participante \#5 & Sí & & \\
\hline $\begin{array}{l}\text { Participan } \\
\text { te \#3 }\end{array}$ & Sí & Participante \#6 & Sí & & \\
\hline \multicolumn{6}{|c|}{$\begin{array}{l}\text { Pregunta } 11 \\
\text { ¿Reemplazarían tragos a base de ron, vodka, entre otros, por macerados de frutas en pisco en sus distintos } \\
\text { sabores? }\end{array}$} \\
\hline \multicolumn{6}{|l|}{ Respuestas } \\
\hline $\begin{array}{l}\text { Participan } \\
\text { te \#1 }\end{array}$ & Sí & Participante \#4 & Sí & $\begin{array}{l}\text { Participante } \\
\# 7\end{array}$ & Sí \\
\hline $\begin{array}{l}\text { Participan } \\
\text { te } \# 2\end{array}$ & Sí & Participante \#5 & $\mathrm{Si}$ & & \\
\hline $\begin{array}{l}\text { Participan } \\
\text { te \#3 }\end{array}$ & Sí & Participante \#6 & Sí & & \\
\hline
\end{tabular}

Pregunta 12

¿Cuál sería el principal atractivo del producto?

\begin{tabular}{|c|c|c|c|c|c|}
\hline \multicolumn{6}{|l|}{ Respuestas } \\
\hline $\begin{array}{l}\text { Participan } \\
\text { te \#1 }\end{array}$ & $\begin{array}{c}\text { Presentación } \\
\text { artesanal }\end{array}$ & Participante \#4 & Color & $\begin{array}{l}\text { Participante } \\
\text { \#7 }\end{array}$ & Color \\
\hline $\begin{array}{l}\text { Participan } \\
\text { te \#2 }\end{array}$ & Color & Participante \#5 & Macerado & & \\
\hline $\begin{array}{l}\text { Participan } \\
\text { te \#3 }\end{array}$ & Color & Participante \#6 & Artesanal & & \\
\hline
\end{tabular}

Pregunta 13

¿Cuánto están dispuestos a pagar por la botella de $750 \mathrm{ml}$ ?

Respuestas

\begin{tabular}{|c|c|c|c|c|c|}
\hline $\begin{array}{l}\text { Participan } \\
\text { te \#1 }\end{array}$ & $\mathrm{S} / 50$ & Participante \#4 & $\mathrm{S} / 50-\mathrm{S} / 60$ & $\begin{array}{l}\text { Participante } \\
\# 7\end{array}$ & $\mathrm{~S} / 50-\mathrm{S} / 70$ \\
\hline $\begin{array}{l}\text { Participan } \\
\text { te \#2 }\end{array}$ & $\mathrm{S} / 70-\mathrm{S} / 80$ & Participante \#5 & $\mathrm{S} / 50-\mathrm{S} / 100$ & & \\
\hline $\begin{array}{l}\text { Participan } \\
\text { te \#3 }\end{array}$ & Más de S/ 50 & Participante \#6 & $\mathrm{S} / 50-\mathrm{S} / 60$ & & \\
\hline
\end{tabular}

Pregunta 14

¿Les gustaría poder comprar el macerado de frutas en pisco por redes sociales: Facebook o Instagram o prefieren encontrarlos en establecimientos?

\begin{tabular}{|c|c|c|c|c|c|}
\hline \multicolumn{6}{|l|}{ Respuestas } \\
\hline $\begin{array}{l}\text { Participan } \\
\text { te \#1 }\end{array}$ & $\begin{array}{c}\text { Redes y } \\
\text { Establecimientos }\end{array}$ & Participante \#4 & $\begin{array}{c}\text { Licorería, } \\
\text { Establecimient } \\
\text { os }\end{array}$ & $\begin{array}{l}\text { Participante } \\
\# 7\end{array}$ & $\begin{array}{c}\text { Establecimien } \\
\text { tos }\end{array}$ \\
\hline $\begin{array}{l}\text { Participan } \\
\text { te \#2 }\end{array}$ & $\begin{array}{c}\text { Licorería, } \\
\text { establecimientos }\end{array}$ & Participante \#5 & $\begin{array}{c}\text { Establecimient } \\
\text { os }\end{array}$ & & \\
\hline $\begin{array}{l}\text { Participan } \\
\text { te \#3 }\end{array}$ & Establecimiento & Participante \#6 & $\begin{array}{c}\text { Licorería, } \\
\text { Establecimient } \\
\text { os }\end{array}$ & & \\
\hline
\end{tabular}

Pregunta 15

¿Cuál es la característica que creen que se debería aprovechar para impulsar el posicionamiento del producto?

Respuestas

\begin{tabular}{|c|c|c|c|c|c|}
\hline $\begin{array}{l}\text { Participan } \\
\text { te \#1 }\end{array}$ & Color & Participante \#4 & $\begin{array}{l}\text { Combinación } \\
\text { de sabores }\end{array}$ & $\begin{array}{l}\text { Participante } \\
\# 7\end{array}$ & $\begin{array}{c}\text { Combinación } \\
\text { de sabores }\end{array}$ \\
\hline $\begin{array}{l}\text { Participan } \\
\text { te \#2 }\end{array}$ & Sabores & Participante \#5 & $\begin{array}{c}\text { Productos } \\
\text { naturales }\end{array}$ & & \\
\hline $\begin{array}{l}\text { Participan } \\
\text { te \#3 }\end{array}$ & Envase, artesanal & Participante \#6 & $\begin{array}{l}\text { Macerado, } \\
\text { novedoso }\end{array}$ & & \\
\hline
\end{tabular}




\begin{tabular}{|c|c|c|c|c|c|}
\hline \multicolumn{6}{|c|}{ Degustación de los macerados de frutas en pisco } \\
\hline \multicolumn{6}{|c|}{ Pregunta 16} \\
\hline \multicolumn{6}{|c|}{ De todos los sabores que probaron podrían clasificarlos del 1 al 5 (en orden de su mayor agrado). } \\
\hline \multicolumn{6}{|l|}{ Respuestas } \\
\hline $\begin{array}{l}\text { Participan } \\
\text { te \#1 }\end{array}$ & $\begin{array}{l}\text { 1: Maracuyá y } \\
\text { Frambuesa } \\
\text { 2: Fresa con } \\
\text { Guinda } \\
\text { 3: Chicha } \\
\text { 4: Arándanos y } \\
\text { Canela } \\
\text { 5: Piña y Hierba } \\
\text { Luisa }\end{array}$ & Participante \#4 & $\begin{array}{l}\text { 1: Maracuyá y } \\
\text { Frambuesa } \\
\text { 2: Fresa y } \\
\text { Guinda } \\
\text { 3: Chicha } \\
\text { 4: Arándanos } \\
\text { y Canela } \\
\text { 5: Piña y } \\
\text { Hierba Luisa } \\
\end{array}$ & $\begin{array}{l}\text { Participante } \\
\# 7\end{array}$ & $\begin{array}{l}\text { 1: Fresa y } \\
\text { Guinda } \\
\text { 2: Maracuyá y } \\
\text { Frambuesa } \\
\text { 3: Chicha } \\
\text { 4: Arándanos } \\
\text { y Canela } \\
\text { 5: Piña y } \\
\text { Hierba luisa } \\
\end{array}$ \\
\hline $\begin{array}{l}\text { Participan } \\
\text { te \#2 }\end{array}$ & $\begin{array}{l}\text { 1: Maracuyá y } \\
\text { Frambuesa } \\
\text { 2: Fresa y Guinda } \\
\text { 3: Chicha } \\
\text { 4: Arándanos y } \\
\text { Canela } \\
\text { 5: Piña y Hierba } \\
\text { Luisa }\end{array}$ & Participante \#5 & $\begin{array}{l}\text { 1: Maracuyá y } \\
\text { Frambuesa } \\
\text { 2: Fresa y } \\
\text { Guinda } \\
\text { 3: Chicha } \\
\text { 4: Arándanos } \\
\text { y Canela } \\
\text { 5: Piña y } \\
\text { Hierba Luisa }\end{array}$ & & \\
\hline $\begin{array}{l}\text { Participan } \\
\text { te \#3 }\end{array}$ & $\begin{array}{l}\text { 1: Fresa y Guinda } \\
\text { 2: Chicha } \\
\text { 3: Maracuyá y } \\
\text { Frambuesa } \\
\text { 4: Piña y Hierba } \\
\text { Luisa } \\
\text { 5: Arándanos y } \\
\text { Canela }\end{array}$ & Participante \#6 & $\begin{array}{l}\text { 1: Fresa y } \\
\text { Guinda } \\
\text { 2: Maracuyá y } \\
\text { frambuesa } \\
\text { 3: Chicha } \\
\text { 4: Arándanos } \\
\text { y Canela } \\
\text { 5: Piña y } \\
\text { Hierba Luisa }\end{array}$ & & \\
\hline
\end{tabular}

Pregunta 17

¿Qué características creen que podría tener el macerado de frutas en pisco o en qué debería mejorar?

\begin{tabular}{|c|c|c|c|c|c|}
\hline \multicolumn{6}{|l|}{ Respuestas } \\
\hline $\begin{array}{l}\text { Participan } \\
\text { te \#1 }\end{array}$ & $\begin{array}{l}\text { Balance, } \\
\text { predominio de } \\
\text { frutas }\end{array}$ & Participante \#4 & $\begin{array}{l}\text { Variar tipo o } \\
\text { marca de pisco }\end{array}$ & $\begin{array}{l}\text { Participante } \\
\text { \#7 }\end{array}$ & $\begin{array}{l}\text { Tiempo de } \\
\text { maceración }\end{array}$ \\
\hline $\begin{array}{l}\text { Participan } \\
\text { te \#2 }\end{array}$ & $\begin{array}{l}\text { Buscar otro pisco } \\
\text { más suave }\end{array}$ & Participante \#5 & $\begin{array}{c}\text { Balance pisco } \\
\text { y frutas }\end{array}$ & & \\
\hline $\begin{array}{l}\text { Participan } \\
\text { te \#3 }\end{array}$ & $\begin{array}{c}\text { Tiempo de } \\
\text { maceración } \\
\text { correcto }\end{array}$ & Participante \#6 & $\begin{array}{c}\text { Balance } \\
\text { alcohol y fruta }\end{array}$ & & \\
\hline
\end{tabular}

Pregunta 18

¿Qué otros sabores les gustaría encontrar?

\begin{tabular}{|c|c|c|c|c|c|}
\hline \multicolumn{6}{|l|}{ Respuestas } \\
\hline $\begin{array}{l}\text { Participan } \\
\text { te \#1 }\end{array}$ & $\begin{array}{c}\text { Cereza y frutos } \\
\text { rojos }\end{array}$ & Participante \#4 & $\begin{array}{l}\text { Carambola y } \\
\text { frutos rojos }\end{array}$ & $\begin{array}{l}\text { Participante } \\
\# 7\end{array}$ & $\begin{array}{l}\text { Kiwi, camu } \\
\text { camu o fruto } \\
\text { de la selva }\end{array}$ \\
\hline $\begin{array}{l}\text { Participan } \\
\text { te \#2 }\end{array}$ & Frutos rojos & Participante \#5 & Pimienta & & \\
\hline $\begin{array}{l}\text { Participan } \\
\text { te \#3 }\end{array}$ & $\begin{array}{l}\text { Más opciones con } \\
\text { guinda }\end{array}$ & Participante \#6 & Ácidos & & \\
\hline
\end{tabular}

Posicionamiento y test de nombre 
Pregunta 19

De estos nombres: Qispi-Kay, Kimsa Pisqu o Nuna. ¿Cuál creen que suena mejor para el macerado de frutas en pisco?

\begin{tabular}{|c|c|c|c|c|c|}
\hline \multicolumn{6}{|l|}{ Respuestas } \\
\hline $\begin{array}{l}\text { Participan } \\
\text { te \#1 }\end{array}$ & Nuna & Participante \#4 & Nuna & $\begin{array}{l}\text { Participante } \\
\# 7\end{array}$ & Nuna \\
\hline $\begin{array}{l}\text { Participan } \\
\text { te \#2 }\end{array}$ & Kimsa & Participante \#5 & Nuna & & \\
\hline $\begin{array}{l}\text { Participan } \\
\text { te \#3 }\end{array}$ & Nuna & Participante \#6 & Nuna & & \\
\hline
\end{tabular}

Pregunta 20

¿Les parece que el nombre y logo es de fácil recordación?

Respuestas

\begin{tabular}{lccc}
\hline $\begin{array}{l}\text { Participan } \\
\text { te \#1 }\end{array}$ & Sí & Participante \#4 & Sí \\
\hline $\begin{array}{l}\text { Participan } \\
\text { te \#2 }\end{array}$ & Sí & Participante \#5 & Sí \\
\hline $\begin{array}{l}\text { Participan } \\
\text { te \#3 }\end{array}$ & Sí & Participante \#6 & Sí \\
\hline
\end{tabular}

Participante

\#7

Sí 


\section{Anexo 14 - Focus Group \# 2}

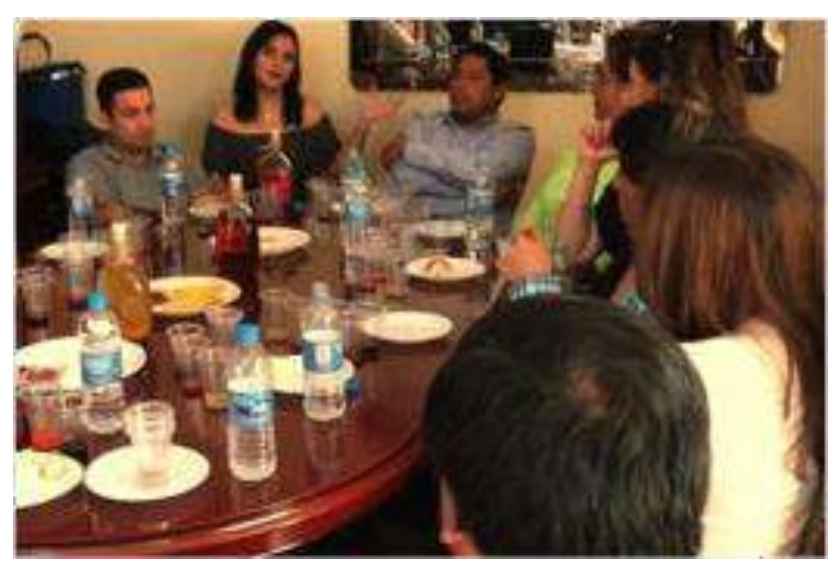

\begin{tabular}{lccc}
\hline Día & $29 / 10 / 17$ & Hora & $12: 00$ p.m. \\
\hline Lugar & Casa & \# Participantes & 7 \\
\hline NSE & A \& B & & Zona 6 y Zona 7 \\
\hline
\end{tabular}

Presentación

Pregunta 1

Por favor, presentarse indicando nombre y distrito.

\begin{tabular}{|c|c|c|c|c|c|}
\hline \multicolumn{6}{|l|}{ Respuestas } \\
\hline $\begin{array}{l}\text { Participante } \\
\# 1\end{array}$ & David, Lince & Participante \#4 & $\begin{array}{c}\text { Elodie, } \\
\text { Miraflores }\end{array}$ & $\begin{array}{l}\text { Participante } \\
\# 7\end{array}$ & $\begin{array}{c}\text { Germán, La } \\
\text { Molina }\end{array}$ \\
\hline $\begin{array}{l}\text { Participante } \\
\# 2\end{array}$ & $\begin{array}{c}\text { Omar, } \\
\text { Miraflores }\end{array}$ & Participante \#5 & Gustavo, Surco & & \\
\hline $\begin{array}{l}\text { Participante } \\
\text { \#3 }\end{array}$ & Ana, Lince & Participante \#6 & Judith, Surco & & \\
\hline
\end{tabular}

Aspectos generales sobre bebidas alcohólicas (Preguntas exploratorias)

Pregunta 2

¿Toma bebidas alcohólicas?

\begin{tabular}{lcccc}
\hline Respuestas & & & & \\
$\begin{array}{l}\text { Participante } \\
\# 1\end{array}$ & Sí & Participante \#4 & Sí & A7
\end{tabular}

\section{Pregunta 3}

¿Cuál prefiere?

\begin{tabular}{|c|c|c|c|c|c|}
\hline Respuestas & & & & & \\
\hline $\begin{array}{l}\text { Participante } \\
\# 1\end{array}$ & Ron & Participante \#4 & Vino y Pisco & $\begin{array}{l}\text { Participante } \\
\# 7\end{array}$ & Whisky, Vino \\
\hline $\begin{array}{l}\text { Participante } \\
\# 2\end{array}$ & $\begin{array}{c}\text { Pisco, Vino y } \\
\text { Cerveza }\end{array}$ & Participante \#5 & Whisky, Vino & & \\
\hline $\begin{array}{l}\text { Participante } \\
\# 3\end{array}$ & Pisco y Ron & Participante \#6 & Whisky, Vodka & & \\
\hline
\end{tabular}

\section{Frecuencia de consumo de bebidas alcohólicas}

Pregunta 5

¿Con que frecuencia consumen bebidas alcohólicas? 


\begin{tabular}{|c|c|c|c|c|c|}
\hline \multicolumn{6}{|l|}{ Respuestas } \\
\hline $\begin{array}{l}\text { Participante } \\
\# 1\end{array}$ & $1 \mathrm{vez}$ al mes & Participante \#4 & 2 veces al mes & $\begin{array}{l}\text { Participante } \\
\# 7\end{array}$ & 2 veces al mes \\
\hline $\begin{array}{l}\text { Participante } \\
\# 2\end{array}$ & $\begin{array}{c}2 \text { veces por } \\
\text { semana }\end{array}$ & Participante \#5 & 2 veces al mes & & \\
\hline $\begin{array}{l}\text { Participante } \\
\# 3\end{array}$ & $1 \mathrm{vez}$ al mes & Participante \#6 & 2 veces al mes & & \\
\hline
\end{tabular}

\section{Presentación del macerado de frutas con pisco}

\section{Pregunta 6}

¿Ha escuchado o probado macerados de frutas en pisco?

\begin{tabular}{lcccc}
\hline Respuestas & & & & \\
$\begin{array}{l}\text { Participante } \\
\# 1\end{array}$ & Sí & Participante \#4 & Sí & \#7 \\
\hline $\begin{array}{l}\text { Participante } \\
\# 2\end{array}$ & Sí & Participante \#5 & Sí \\
\hline $\begin{array}{l}\text { Participante } \\
\# 3\end{array}$ & Sí & Participante \#6 & No \\
\hline
\end{tabular}

\section{Pregunta 7}

¿Cuál ha sido su experiencia?

\begin{tabular}{|c|c|c|c|c|c|}
\hline \multicolumn{6}{|l|}{ Respuestas } \\
\hline $\begin{array}{l}\text { Participante } \\
\# 1\end{array}$ & $\begin{array}{c}\text { Buena, frutos } \\
\text { secos }\end{array}$ & Participante \#4 & Buena & $\begin{array}{l}\text { Participante } \\
\text { \#7 }\end{array}$ & De otros sabores \\
\hline $\begin{array}{l}\text { Participante } \\
\# 2\end{array}$ & Buena & Participante \#5 & $\begin{array}{l}\text { Damasco, } \\
\text { Eucalipto }\end{array}$ & & \\
\hline $\begin{array}{l}\text { Participante } \\
\text { \#3 }\end{array}$ & $\begin{array}{c}\text { Canela, } \\
\text { aguaymanto }\end{array}$ & Participante \#6 & Buena & & \\
\hline
\end{tabular}

Pregunta 8

¿Qué diferencias encuentra respecto a los macerados de frutas en pisco que han probado anteriormente? Sabor, color, aroma, entre otros.

\begin{tabular}{|c|c|c|c|c|c|}
\hline \multicolumn{6}{|l|}{ Respuestas } \\
\hline $\begin{array}{l}\text { Participante } \\
\# 1\end{array}$ & Sabor & Participante \#4 & Sabor & $\begin{array}{l}\text { Participante } \\
\# 7\end{array}$ & Color \\
\hline $\begin{array}{l}\text { Participante } \\
\# 2\end{array}$ & Color & Participante \#5 & Color & & \\
\hline $\begin{array}{l}\text { Participante } \\
\# 3\end{array}$ & Color & Participante \#6 & Color & & \\
\hline
\end{tabular}

Pregunta 9

¿Qué expectativas tienen cuando van a tomar algún macerado de fruta en pisco?

\begin{tabular}{|c|c|c|c|c|c|}
\hline \multicolumn{6}{|l|}{ Respuestas } \\
\hline $\begin{array}{l}\text { Participante } \\
\# 1\end{array}$ & Buena & Participante \#4 & Innovador & $\begin{array}{l}\text { Participante } \\
\# 7\end{array}$ & Interesante \\
\hline $\begin{array}{l}\text { Participante } \\
\# 2\end{array}$ & Interesante & Participante \#5 & Nuevo & & \\
\hline $\begin{array}{l}\text { Participante } \\
\text { \#3 }\end{array}$ & Buena & Participante \#6 & Buena & & \\
\hline
\end{tabular}

Pregunta 10

¿Consumirían los macerados de frutas en pisco en eventos sociales, familiares, corporativos?

\begin{tabular}{lcclll}
\hline Respuestas & & & & & \\
Participante & $\begin{array}{c}\text { Sí, buena } \\
\text { alternativa }\end{array}$ & Participante \#4 & Sí & $\begin{array}{l}\text { Participante } \\
\text { 1 }\end{array}$ & Innovador \\
\hline $\begin{array}{l}\text { Participante } \\
\text { Siferentes }\end{array}$ & $\begin{array}{c}\text { Sabores } \\
\text { difen }\end{array}$ & Participante \#5 & Sí & \\
\hline
\end{tabular}




\begin{tabular}{|c|c|c|c|c|c|}
\hline $\begin{array}{l}\text { Participante } \\
\# 3\end{array}$ & Sí & Participante \#6 & Sí & & \\
\hline \multicolumn{6}{|c|}{$\begin{array}{l}\text { Pregunta } 11 \\
\text { ¿Reemplazarían tragos a base de ron, vodka, entre otros, por macerados de frutas en pisco en sus distintos } \\
\text { sabores? }\end{array}$} \\
\hline \multicolumn{6}{|l|}{ Respuestas } \\
\hline $\begin{array}{l}\text { Participante } \\
\# 1\end{array}$ & Sí & Participante \#4 & Sí & $\begin{array}{l}\text { Participante } \\
\# 7\end{array}$ & Sí \\
\hline $\begin{array}{l}\text { Participante } \\
\# 2\end{array}$ & Sí & Participante \#5 & Sí & & \\
\hline $\begin{array}{l}\text { Participante } \\
\# 3\end{array}$ & Sí & Participante \#6 & Sí & & \\
\hline
\end{tabular}

\section{Pregunta 12}

¿Cuál sería el principal atractivo del producto?

\begin{tabular}{|c|c|c|c|c|c|}
\hline \multicolumn{6}{|l|}{ Respuestas } \\
\hline $\begin{array}{l}\text { Participante } \\
\# 1\end{array}$ & Frutas & Participante \#4 & Mezcla & $\begin{array}{l}\text { Participante } \\
\# 7\end{array}$ & Frutas \\
\hline $\begin{array}{l}\text { Participante } \\
\# 2\end{array}$ & Botella & Participante \#5 & Mezcla & & \\
\hline $\begin{array}{l}\text { Participante } \\
\# 3\end{array}$ & Color & Participante \#6 & Botella & & \\
\hline
\end{tabular}

\section{Pregunta 13}

¿Cuánto están dispuestos a pagar por la botella de $750 \mathrm{ml}$ ?

\begin{tabular}{|c|c|c|c|c|c|}
\hline \multicolumn{6}{|l|}{ Respuestas } \\
\hline $\begin{array}{l}\text { Participante } \\
\# 1\end{array}$ & $\mathrm{~S} / 50$ & Participante \#4 & $\mathrm{S} / 50$ & $\begin{array}{l}\text { Participante } \\
\# 7\end{array}$ & $\mathrm{~S} / 50$ \\
\hline $\begin{array}{l}\text { Participante } \\
\# 2\end{array}$ & $\mathrm{~S} / 50$ & Participante \#5 & $\mathrm{S} / 50$ & & \\
\hline $\begin{array}{l}\text { Participante } \\
\# 3\end{array}$ & $\mathrm{~S} / 50$ & Participante \#6 & $\mathrm{S} / 50$ & & \\
\hline
\end{tabular}

Pregunta 14

¿Les gustaría poder comprar el macerado de frutas en pisco por redes sociales: Facebook o Instagram o prefieren encontrarlos en establecimientos?

\begin{tabular}{|c|c|c|c|c|c|}
\hline \multicolumn{6}{|l|}{ Respuestas } \\
\hline $\begin{array}{l}\text { Participante } \\
\# 1\end{array}$ & Establecimientos & Participante \#4 & $\begin{array}{c}\text { Establecimiento } \\
\mathrm{s}\end{array}$ & $\begin{array}{l}\text { Participante } \\
\# 7\end{array}$ & $\begin{array}{c}\text { Establecimiento } \\
\mathrm{s}\end{array}$ \\
\hline $\begin{array}{l}\text { Participante } \\
\# 2\end{array}$ & Establecimientos & Participante \#5 & $\begin{array}{l}\text { Establecimiento } \\
\mathrm{S}\end{array}$ & & \\
\hline $\begin{array}{l}\text { Participante } \\
\# 3\end{array}$ & Establecimientos & Participante \#6 & $\begin{array}{c}\text { Establecimiento } \\
\mathrm{s}\end{array}$ & & \\
\hline
\end{tabular}

\section{Pregunta 15}

¿Cuál es la característica que creen que se debería aprovechar para impulsar el posicionamiento del producto?

\begin{tabular}{|c|c|c|c|c|c|}
\hline \multicolumn{6}{|l|}{ Respuestas } \\
\hline $\begin{array}{l}\text { Participante } \\
\# 1\end{array}$ & Color & Participante \#4 & $\begin{array}{c}\text { Forma de } \\
\text { botella }\end{array}$ & $\begin{array}{l}\text { Participante } \\
\# 7\end{array}$ & Calidad \\
\hline $\begin{array}{l}\text { Participante } \\
\# 2\end{array}$ & Sabor & Participante \#5 & Color & & \\
\hline $\begin{array}{l}\text { Participante } \\
\# 3\end{array}$ & Presentación & Participante \#6 & Sabor & & \\
\hline
\end{tabular}

\section{Degustación de los macerados de frutas en pisco}

\section{Pregunta 16}

De todos los sabores que probaron podrían clasificarlos del 1 al 5 (en orden de su mayor agrado).

\section{Respuestas}




\begin{tabular}{|c|c|c|c|c|c|}
\hline & & & & & \\
\hline & 1: Maracuyá y & & 1: Maracuyá y & & 1: Fresa y \\
\hline & Frambuesa & & Frambuesa & & Guinda \\
\hline & 2: Fresa y & & 2: Fresa y & & 2: Maracuyá y \\
\hline & Guinda & & Guinda & & Frambuesa \\
\hline Participante & 3: Chicha & Participante \#4 & 3: Arándanos y & Participante & 3: Chicha \\
\hline & 4: Arándanos y & & Canela & & 4: Arándanos y \\
\hline & Canela & & 4: Piña y Hierba & & Canela \\
\hline & 5: Piña y Hierba & & Luisa & & 5: Piña y Hierba \\
\hline & Luisa & & 5: Chicha & & luisa \\
\hline & 1: Fresa y & & 1: Maracuyá y & & \\
\hline & Guinda & & Frambuesa & & \\
\hline & 2: Maracuyá y & & 2: Fresa y & & \\
\hline Darticisante & Frambuesa & & Guinda & & \\
\hline Participante & 3: Chicha & Participante \#5 & 3: Chicha & & \\
\hline & 4: Arándanos y & & 4: Arándanos y & & \\
\hline & Canela & & Canela & & \\
\hline & 5: Piña y Hierba & & 5: Piña y Hierba & & \\
\hline & Luisa & & Luisa & & \\
\hline & 1: Fresa y & & 1: Fresa y & & \\
\hline & Guinda & & Guinda & & \\
\hline & 2: Maracuyá y & & 2: Maracuyá y & & \\
\hline & Frambues & & frambuesa & & \\
\hline Participante & 3: Chicha & Participante \#6 & 3: Chicha & & \\
\hline & 4: Piña y Hierba & & 4: Arándanos y & & \\
\hline & Luisa & & Canela & & \\
\hline & 5: Arándanos y & & 5: Piña y Hierba & & \\
\hline & Canela & & Luisa & & \\
\hline
\end{tabular}

\section{Pregunta 17}

¿Qué características creen que podría tener el macerado de frutas en pisco o en qué debería mejorar?

\begin{tabular}{|c|c|c|c|c|c|}
\hline \multicolumn{6}{|l|}{ Respuestas } \\
\hline $\begin{array}{l}\text { Participante } \\
\text { \#1 }\end{array}$ & $\begin{array}{l}\text { Proceso de } \\
\text { maceración }\end{array}$ & Participante \#4 & $\begin{array}{l}\text { Proceso de } \\
\text { maceración }\end{array}$ & $\begin{array}{l}\text { Participante } \\
\# 7\end{array}$ & $\begin{array}{l}\text { Proceso de } \\
\text { maceración }\end{array}$ \\
\hline $\begin{array}{l}\text { Participante } \\
\# 2\end{array}$ & $\begin{array}{l}\text { Proceso de } \\
\text { maceración }\end{array}$ & Participante \#5 & $\begin{array}{l}\text { Proceso de } \\
\text { maceración }\end{array}$ & & \\
\hline $\begin{array}{l}\text { Participante } \\
\# 3\end{array}$ & $\begin{array}{l}\text { Proceso de } \\
\text { maceración }\end{array}$ & Participante \#6 & $\begin{array}{l}\text { Proceso de } \\
\text { maceración }\end{array}$ & & \\
\hline
\end{tabular}

\section{Pregunta 18}

¿Qué otros sabores les gustaría encontrar?

\begin{tabular}{|c|c|c|c|c|c|}
\hline \multicolumn{6}{|l|}{ Respuestas } \\
\hline $\begin{array}{l}\text { Participante } \\
\# 1\end{array}$ & Eucalipto & Participante \#4 & Tuna & $\begin{array}{l}\text { Participante } \\
\# 7\end{array}$ & Damasco \\
\hline $\begin{array}{l}\text { Participante } \\
\# 2\end{array}$ & Damasco & Participante \#5 & Kión & & \\
\hline $\begin{array}{l}\text { Participante } \\
\# 3\end{array}$ & Canela & Participante \#6 & Damasco & & \\
\hline
\end{tabular}

\section{Posicionamiento y test de nombre}

Pregunta 19

De estos nombres: Qispi-Kay, Kimsa Pisqu o Nuna. ¿Cuál creen que suena mejor para el macerado de frutas en pisco?

\begin{tabular}{|c|c|c|c|c|c|}
\hline \multicolumn{6}{|l|}{ Respuestas } \\
\hline $\begin{array}{l}\text { Participante } \\
\# 1\end{array}$ & Ninguno & Participante \#4 & Nuna & $\begin{array}{l}\text { Participante } \\
\# 7\end{array}$ & Nuna \\
\hline $\begin{array}{l}\text { Participante } \\
\# 2\end{array}$ & Nuna & Participante \#5 & Nuna & & \\
\hline
\end{tabular}


Participante

\#3

Pregunta 20

¿Les parece que el nombre y logo es de fácil recordación?

\section{Respuestas}

Participante

\#1

Participante

\#2

\#3

Nuna Participante \#6

tecion?

Participante \#4

Nuna

(

Sí

Participante
\#7

Sí

\begin{tabular}{ll} 
Participante \#5 & Sí \\
\hline Participante \#6 & Sí \\
\hline
\end{tabular}




\section{Anexo 15 - Focus Group \# 3}

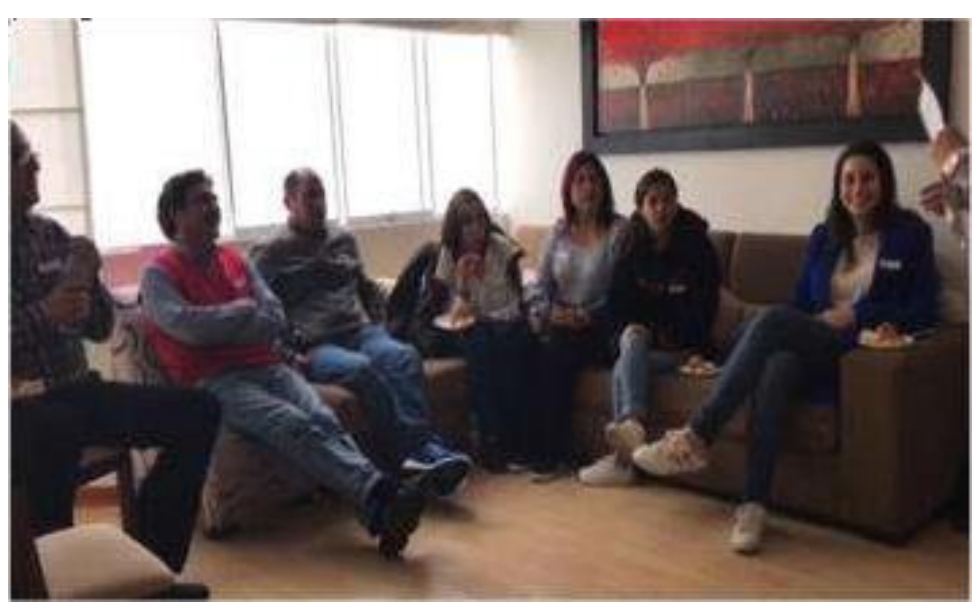

\begin{tabular}{|c|c|c|}
\hline Día & Hora & 11:30 a.m. NSE : A y B \\
\hline Lugar & \# Participantes & 7 Zona : 6 y 7 \\
\hline
\end{tabular}

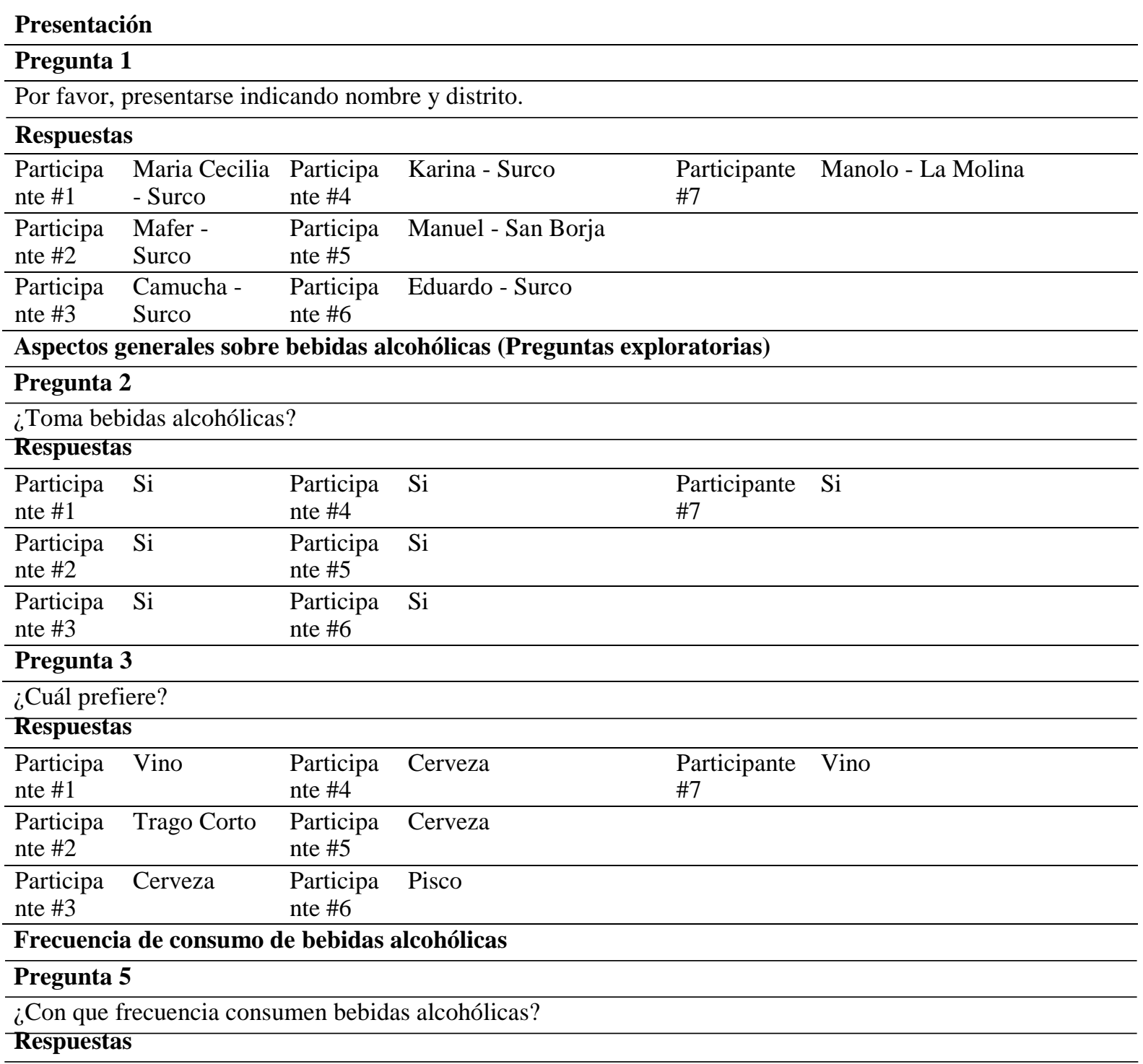




\begin{tabular}{|c|c|c|c|c|c|}
\hline $\begin{array}{l}\text { Participa } \\
\text { nte \#1 }\end{array}$ & Semanal & $\begin{array}{l}\text { Participa } \\
\text { nte \#4 }\end{array}$ & $1 \mathrm{vez}$ por semana & $\begin{array}{l}\text { Participante } \\
\# 7\end{array}$ & $\begin{array}{l}\text { Uno o dos días pero fines de } \\
\text { semana }\end{array}$ \\
\hline $\begin{array}{l}\text { Participa } \\
\text { nte \#2 }\end{array}$ & $\begin{array}{l}\text { Fines de } \\
\text { semana }\end{array}$ & $\begin{array}{l}\text { Participa } \\
\text { nte \#5 }\end{array}$ & Fines de semana & & \\
\hline $\begin{array}{l}\text { Participa } \\
\text { nte \#3 }\end{array}$ & $\begin{array}{l}\text { Fines de } \\
\text { semana }\end{array}$ & $\begin{array}{l}\text { Participa } \\
\text { nte \#6 }\end{array}$ & Fines de semana & & \\
\hline \multicolumn{6}{|c|}{ Presentación del macerado de frutas con pisco } \\
\hline \multicolumn{6}{|c|}{ Pregunta 6} \\
\hline \multicolumn{6}{|c|}{ ¿Ha escuchado o probado macerados de frutas en pisco? } \\
\hline \multicolumn{6}{|c|}{ Respuestas } \\
\hline $\begin{array}{l}\text { Participa } \\
\text { nte \#1 }\end{array}$ & $\begin{array}{l}\text { No ha } \\
\text { probado } \\
\text { muchos, pero } \\
\text { si ha } \\
\text { escuchado }\end{array}$ & $\begin{array}{l}\text { Participa } \\
\text { nte \#4 }\end{array}$ & No ha probado & $\begin{array}{l}\text { Participante } \\
\text { \#7 }\end{array}$ & $\begin{array}{l}\text { En restaurantes chilcanos } \\
\text { hechos con macerados, no } \\
\text { puro sino chilcano de varios } \\
\text { sabores hierbas y frutas. }\end{array}$ \\
\hline $\begin{array}{l}\text { Participa } \\
\text { nte \#2 }\end{array}$ & $\begin{array}{l}\text { Ha ido a dos } \\
\text { bares en } \\
\text { donde } \\
\text { preparan } \\
\text { macerados de } \\
\text { pisco en } \\
\text { Barranco y } \\
\text { Miraflores y } \\
\text { marcas en cc } \\
\text { y feria. }\end{array}$ & $\begin{array}{l}\text { Participa } \\
\text { nte \#5 }\end{array}$ & No ha probado. & & \\
\hline $\begin{array}{l}\text { Participa } \\
\text { nte \#3 }\end{array}$ & $\begin{array}{l}\text { En } \\
\text { restaurantes } \\
\text { campestres } \\
\text { en donde va a } \\
\text { almorzar en } \\
\text { los bares hay, } \\
\text { preparan su } \\
\text { pisco }\end{array}$ & $\begin{array}{l}\text { Participa } \\
\text { nte \#6 }\end{array}$ & $\begin{array}{l}\text { Siempre en su familia } \\
\text { siempre han preparado. }\end{array}$ & & \\
\hline \multicolumn{6}{|c|}{ Pregunta 7} \\
\hline \multicolumn{6}{|c|}{ ¿Cuál ha sido su experiencia? } \\
\hline \multicolumn{6}{|c|}{ Respuestas } \\
\hline $\begin{array}{l}\text { Participa } \\
\text { nte \#1 }\end{array}$ & Varias & $\begin{array}{l}\text { Participa } \\
\text { nte \#4 }\end{array}$ & $\begin{array}{l}\text { El dulce de la fruta } \\
\text { toque rico }\end{array}$ & $\begin{array}{l}\text { Participante } \\
\# 7\end{array}$ & Le gustó. \\
\hline $\begin{array}{l}\text { Participa } \\
\text { nte \#2 }\end{array}$ & $\begin{array}{l}\text { Si es rico, el } \\
\text { chilcano es } \\
\text { rico pero si le } \\
\text { agregas el } \\
\text { sabor de la } \\
\text { fruta es } \\
\text { mucho } \\
\text { coctail. }\end{array}$ & $\begin{array}{l}\text { Participa } \\
\text { nte \#5 }\end{array}$ & No ha probado & & \\
\hline $\begin{array}{l}\text { Participa } \\
\text { nte \#3 }\end{array}$ & Agradable & $\begin{array}{l}\text { Participa } \\
\text { nte \#6 }\end{array}$ & Le gustó & & \\
\hline \multicolumn{6}{|c|}{ Pregunta 8} \\
\hline \multicolumn{6}{|c|}{$\begin{array}{l}\text { ¿Qué diferencias encuentra respecto a los macerados de frutas en pisco que han probado anteriormente? Sabor, } \\
\text { color, aroma, entre otros. }\end{array}$} \\
\hline \multicolumn{6}{|c|}{ Respuestas } \\
\hline $\begin{array}{l}\text { Participa } \\
\text { nte \#1 }\end{array}$ & $\begin{array}{l}\text { Sabor más } \\
\text { intenso }\end{array}$ & $\begin{array}{l}\text { Participa } \\
\text { nte \#4 }\end{array}$ & No ha probado & $\begin{array}{l}\text { Participante } \\
\# 7\end{array}$ & i he probado antes \\
\hline $\begin{array}{l}\text { Participa } \\
\text { nte \#2 }\end{array}$ & Es rico & $\begin{array}{l}\text { Participa } \\
\text { nte \#5 }\end{array}$ & Aroma & & \\
\hline
\end{tabular}


Participa Es agradable Participa Le agrada

nte \#3

nte \#6

\begin{tabular}{|c|c|c|c|c|}
\hline \multicolumn{5}{|c|}{ Pregunta 9} \\
\hline \multicolumn{5}{|c|}{ ¿Qué expectativas tienen cuando van a tomar algún macerado de fruta en pisco? } \\
\hline \multicolumn{5}{|c|}{ Respuestas } \\
\hline $\begin{array}{l}\text { Participa } \\
\text { nte \#1 }\end{array}$ & Que le guste & $\begin{array}{l}\text { Participa } \\
\text { nte \#4 }\end{array}$ & el sabor & $\begin{array}{l}\text { Participante la calidad } \\
\# 7\end{array}$ \\
\hline $\begin{array}{l}\text { Participa } \\
\text { nte \#2 }\end{array}$ & $\begin{array}{l}\text { Que no sea } \\
\text { tan fuerte }\end{array}$ & $\begin{array}{l}\text { Participa } \\
\text { nte \#5 }\end{array}$ & El sabor & \\
\hline $\begin{array}{l}\text { Participa } \\
\text { nte \#3 }\end{array}$ & El sabor & $\begin{array}{l}\text { Participa } \\
\text { nte \#6 }\end{array}$ & La calidad & \\
\hline \multicolumn{5}{|c|}{ Pregunta 10} \\
\hline \multicolumn{5}{|c|}{ ¿Consumirían los macera } \\
\hline \multicolumn{5}{|c|}{ Respuestas } \\
\hline $\begin{array}{l}\text { Participa } \\
\text { nte \#1 }\end{array}$ & $\begin{array}{l}\text { Almuerzos, } \\
\text { reuniones } \\
\text { amigos }\end{array}$ & $\begin{array}{l}\text { Participa } \\
\text { nte \#4 }\end{array}$ & $\begin{array}{l}\text { Cuando le apetece, no } \\
\text { hay necesidad que sea } \\
\text { un día en especial }\end{array}$ & $\begin{array}{l}\text { Participante En cualquier ocación. } \\
\# 7\end{array}$ \\
\hline $\begin{array}{l}\text { Participa } \\
\text { nte \#2 }\end{array}$ & $\begin{array}{l}\text { Reuniones } \\
\text { familiares, } \\
\text { cumpleaños, } \\
\text { reuniones en } \\
\text { general }\end{array}$ & $\begin{array}{l}\text { Participa } \\
\text { nte \#5 }\end{array}$ & En cualquier ocasión. & \\
\hline $\begin{array}{l}\text { Participa } \\
\text { nte \#3 }\end{array}$ & $\begin{array}{l}\text { En invierno } \\
\text { cuando tengo } \\
\text { frío, } \\
\text { reuniones } \\
\text { familiares, un } \\
\text { shot me } \\
\text { encanta }\end{array}$ & $\begin{array}{l}\text { Participa } \\
\text { nte \#6 }\end{array}$ & $\begin{array}{l}\text { En cualquier momento } \\
\text { para poder tomar puro. }\end{array}$ & \\
\hline
\end{tabular}

\section{Pregunta 11}

¿Reemplazarían tragos a base de ron, vodka, entre otros, por macerados de frutas en pisco en sus distintos sabores?

\begin{tabular}{|c|c|c|c|c|c|}
\hline \multicolumn{6}{|c|}{ Respuestas } \\
\hline $\begin{array}{l}\text { Participa } \\
\text { nte \#1 }\end{array}$ & $\begin{array}{l}\text { Para variar de } \\
\text { vez en } \\
\text { cuando, para } \\
\text { no aburrirse. }\end{array}$ & $\begin{array}{l}\text { Participa } \\
\text { nte \#4 }\end{array}$ & Piensa que sí & $\begin{array}{l}\text { Participante } \\
\# 7\end{array}$ & $\begin{array}{l}\text { Ha reemplazdo a los tragos } \\
\text { tradicionales. }\end{array}$ \\
\hline $\begin{array}{l}\text { Participa } \\
\text { nte \#2 }\end{array}$ & $\begin{array}{l}\text { Chicalno por } \\
\text { vodka si. }\end{array}$ & $\begin{array}{l}\text { Participa } \\
\text { nte \#5 }\end{array}$ & $\begin{array}{l}\text { Cuestión de sabores, } \\
\text { prefiere macerado para } \\
\text { variar. }\end{array}$ & & \\
\hline $\begin{array}{l}\text { Participa } \\
\text { nte \#3 }\end{array}$ & $\begin{array}{l}\text { Si no hay } \\
\text { problema. }\end{array}$ & $\begin{array}{l}\text { Participa } \\
\text { nte \#6 }\end{array}$ & $\begin{array}{l}\text { Prefiere el pisco por } \\
\text { sobre todos. }\end{array}$ & & \\
\hline \multicolumn{6}{|c|}{ Pregunta 12} \\
\hline \multicolumn{6}{|c|}{ ¿Cuál sería el principal atractivo del producto? } \\
\hline \multicolumn{6}{|c|}{ Respuestas } \\
\hline $\begin{array}{l}\text { Participa } \\
\text { nte \#1 }\end{array}$ & $\begin{array}{l}\text { Equilibrio del } \\
\text { sabor }\end{array}$ & $\begin{array}{l}\text { Participa } \\
\text { nte \#4 }\end{array}$ & Que tenga la fruta & $\begin{array}{l}\text { Participante } \\
\# 7\end{array}$ & $\begin{array}{l}\text { Da credibilidad que el } \\
\text { producto es natural. }\end{array}$ \\
\hline $\begin{array}{l}\text { Participa } \\
\text { nte \#2 }\end{array}$ & $\begin{array}{l}\text { Que se vea la } \\
\text { fruta. }\end{array}$ & $\begin{array}{l}\text { Participa } \\
\text { nte \#5 }\end{array}$ & La fruta & & \\
\hline $\begin{array}{l}\text { Participa } \\
\text { nte \#3 }\end{array}$ & $\begin{array}{l}\text { La fruta que } \\
\text { tiene }\end{array}$ & $\begin{array}{l}\text { Participa } \\
\text { nte \#6 }\end{array}$ & Que no esté turbio & & \\
\hline \multicolumn{6}{|c|}{ Pregunta 13} \\
\hline \multicolumn{6}{|c|}{ ¿Cuánto están dispuestos a pagar por la botella de $750 \mathrm{ml}$ ? } \\
\hline \multicolumn{6}{|c|}{ Respuestas } \\
\hline
\end{tabular}




\begin{tabular}{|c|c|c|c|c|}
\hline $\begin{array}{l}\text { Participa } \\
\text { nte \#1 }\end{array}$ & $\begin{array}{l}\text { Máximo } 60 \\
\text { Soles }\end{array}$ & $\begin{array}{l}\text { Participa } \\
\text { nte \#4 }\end{array}$ & $\begin{array}{l}\text { Coincide entre } 50 \text { y } 60 \\
\text { Soles }\end{array}$ & $\begin{array}{l}\text { Participante } 55 \text { Soles } \\
\# 7\end{array}$ \\
\hline $\begin{array}{l}\text { Participa } \\
\text { nte \#2 }\end{array}$ & $\begin{array}{l}\text { Entre } 50 \text { y } 60 \\
\text { Soles }\end{array}$ & $\begin{array}{l}\text { Participa } \\
\text { nte \#5 }\end{array}$ & $\begin{array}{l}\text { Coincide entre } 50 \text { y } 60 \\
\text { Soles }\end{array}$ & \\
\hline $\begin{array}{l}\text { Participa } \\
\text { nte \#3 }\end{array}$ & $\begin{array}{l}\text { Entre } 50 \text { y } 60 \\
\text { Soles }\end{array}$ & $\begin{array}{l}\text { Participa } \\
\text { nte \#6 }\end{array}$ & $\begin{array}{l}\text { Coincide entre } 50 \text { y } 60 \\
\text { Soles }\end{array}$ & \\
\hline \multicolumn{5}{|c|}{ Pregunta 14} \\
\hline \multicolumn{5}{|c|}{$\begin{array}{l}\text { ¿Les gustaría poder comprar el macerado de frutas en pisco por redes sociales: Facebook o Instagram o } \\
\text { prefieren encontrarlos en establecimientos? }\end{array}$} \\
\hline \multicolumn{5}{|c|}{ Respuestas } \\
\hline $\begin{array}{l}\text { Participa } \\
\text { nte \#1 }\end{array}$ & $\begin{array}{l}\text { No fb, } \\
\text { autoservicio. }\end{array}$ & $\begin{array}{l}\text { Participa } \\
\text { nte \#4 }\end{array}$ & $\begin{array}{l}\text { Licorerias y } \\
\text { autoservicios. }\end{array}$ & $\begin{array}{l}\text { Participante Autoservicio o licorerías. } \\
\# 7\end{array}$ \\
\hline $\begin{array}{l}\text { Participa } \\
\text { nte \#2 }\end{array}$ & $\begin{array}{l}\text { Autoservicios } \\
\text { y estaciones } \\
\text { de servicio. }\end{array}$ & $\begin{array}{l}\text { Participa } \\
\text { nte \#5 }\end{array}$ & $\begin{array}{l}\text { Licorerias y } \\
\text { autoservicios. }\end{array}$ & \\
\hline $\begin{array}{l}\text { Participa } \\
\text { nte \#3 }\end{array}$ & $\begin{array}{l}\text { Autoservicio } \\
\text { y facebook } \\
\text { fabuloso y lo } \\
\text { lleven a tu } \\
\text { casa un } \\
\text { boom. }\end{array}$ & $\begin{array}{l}\text { Participa } \\
\text { nte \#6 }\end{array}$ & Autoservicio & \\
\hline \multicolumn{5}{|c|}{ Pregunta 15} \\
\hline \multirow{2}{*}{\multicolumn{5}{|c|}{$\begin{array}{l}\text { ¿Cuál es la característica } \\
\text { Respuestas }\end{array}$}} \\
\hline & & & & \\
\hline $\begin{array}{l}\text { Participa } \\
\text { nte \#1 }\end{array}$ & $\begin{array}{l}\text { La forma de } \\
\text { la botella }\end{array}$ & $\begin{array}{l}\text { Participa } \\
\text { nte \#4 }\end{array}$ & Que sea agradable. & $\begin{array}{ll}\text { Participante } & \text { Producto no turbio, equilibrio } \\
\# 7 & \text { perfecto de fruta con pisco. }\end{array}$ \\
\hline $\begin{array}{l}\text { Participa } \\
\text { nte \#2 }\end{array}$ & $\begin{array}{l}\text { Que se vea la } \\
\text { fruta y el } \\
\text { sabor. }\end{array}$ & $\begin{array}{l}\text { Participa } \\
\text { nte \#5 }\end{array}$ & Que tenga la fruta & \\
\hline $\begin{array}{l}\text { Participa } \\
\text { nte \#3 }\end{array}$ & $\begin{array}{l}\text { En lugar de } \\
\text { poner la } \\
\text { soguilla una } \\
\text { lazo con tela } \\
\text { tipo incaica. }\end{array}$ & $\begin{array}{l}\text { Participa } \\
\text { nte \#6 }\end{array}$ & $\begin{array}{l}\text { Que sea más dulce y } \\
\text { debe ser agradable y } \\
\text { poder tomar puro. Hacer } \\
\text { degustaciones. }\end{array}$ & \\
\hline \multicolumn{5}{|c|}{ Degustación de los macerados de frutas en pisco } \\
\hline \multicolumn{5}{|c|}{ Pregunta 16} \\
\hline \multicolumn{5}{|c|}{ De todos los sabores que probaron podrían clasificarlos del 1 al 5 (en orden de su mayor agrado). } \\
\hline \multicolumn{5}{|c|}{ Respuestas } \\
\hline $\begin{array}{l}\text { Participa } \\
\text { nte \#1 }\end{array}$ & $\begin{array}{l}\text { 1: Guinda } \\
\text { con fresa. } \\
\text { 2:Maracuyá } \\
\text { con } \\
\text { frambuesa } \\
\text { 3:Hierba } \\
\text { luisa con } \\
\text { piña. } \\
\text { 4:Arandanos } \\
\text { con canela } \\
\text { 5:Chicha } \\
\end{array}$ & $\begin{array}{l}\text { Participa } \\
\text { nte \#4 }\end{array}$ & $\begin{array}{l}\text { 1: Guinda con fresa } \\
\text { 2:Maracuyá con } \\
\text { frambuesa } \\
\text { 3:Arándanos } \\
\text { 4:Pina } \\
\text { 5:Chicha }\end{array}$ & $\begin{array}{ll}\text { Participante } & \text { 1: Guinda con fresa } \\
\# 7 & \text { 2:Arapandano } \\
& \text { 3:Maracuyá con frambuesa } \\
& \text { 4:Pina } \\
& \text { 5:Chicha }\end{array}$ \\
\hline $\begin{array}{l}\text { Participa } \\
\text { nte \#2 }\end{array}$ & $\begin{array}{l}\text { 1: Guinda } \\
\text { con fresa } \\
\text { 2:Arándonas } \\
\text { 3:Maracuyá } \\
\text { 4:Piña hierba } \\
\text { luisa } \\
\text { 5:Chicha }\end{array}$ & $\begin{array}{l}\text { Participa } \\
\text { nte \#5 }\end{array}$ & $\begin{array}{l}\text { 1: Guinda con fresa } \\
\text { 2:Maracuyá con } \\
\text { frambuesa } \\
\text { 3:Arándanos } \\
\text { 4:Pina } \\
\text { 5:Chicha }\end{array}$ & \\
\hline
\end{tabular}




$\begin{array}{llll}\text { Participa } & \text { 1: Guinda } & \text { Participa } & \text { 1: Guinda con fresa } \\ \text { nte \#3 } & \text { con fresa } & \text { nte \#6 } & \text { 2:Maracuyá con } \\ & \text { 2:Arándonas } & & \text { frambuesa } \\ & \text { 3:Maracuyá } & & \text { 3:Arándanos } \\ \text { 4:Piña hierba } & & \text { 4:Pina } \\ & \text { luisa } & & \text { 5:Chicha } \\ \text { 5:Chicha } & & \end{array}$

\begin{tabular}{|c|c|c|c|c|}
\hline \multicolumn{5}{|c|}{ Pregunta 17} \\
\hline \multicolumn{5}{|c|}{ ¿Qué características creen que podría tener el macerado de frutas en pisco o en qué debería mejorar? } \\
\hline \multicolumn{5}{|c|}{ Respuestas } \\
\hline $\begin{array}{l}\text { Participa } \\
\text { nte \#1 }\end{array}$ & $\begin{array}{l}\text { Equilibrio del } \\
\text { sabor }\end{array}$ & $\begin{array}{l}\text { Participa } \\
\text { nte \#4 }\end{array}$ & La botella es linda. & $\begin{array}{ll}\text { Participante } & \text { Mayor transparencia y fruta } \\
\# 7 & \text { seca y ponerla }\end{array}$ \\
\hline $\begin{array}{l}\text { Participa } \\
\text { nte \#2 }\end{array}$ & $\begin{array}{l}\text { El nombre en } \\
\text { el vidrio un } \\
\text { sticker } \\
\text { transparente. } \\
\text { Un nombre } \\
\text { artesanal. }\end{array}$ & $\begin{array}{l}\text { Participa } \\
\text { nte \#5 }\end{array}$ & Poner la fruta & \\
\hline $\begin{array}{l}\text { Participa } \\
\text { nte \#3 }\end{array}$ & $\begin{array}{l}\text { Poner frutas } \\
\text { que es lo que } \\
\text { atrae, la } \\
\text { cereza de la } \\
\text { torta. }\end{array}$ & $\begin{array}{l}\text { Participa } \\
\text { nte \#6 }\end{array}$ & $\begin{array}{l}\text { Tapones que dice Perú, } \\
\text { capuchón para la tapa. }\end{array}$ & \\
\hline \multicolumn{5}{|c|}{ Pregunta 18} \\
\hline \multicolumn{5}{|c|}{ ¿Qué otros sabores les gustaría encontrar? } \\
\hline \multicolumn{5}{|c|}{ Respuestas } \\
\hline $\begin{array}{l}\text { Participa } \\
\text { nte \#1 }\end{array}$ & $\begin{array}{l}\text { No tengo } \\
\text { idea }\end{array}$ & $\begin{array}{l}\text { Participa } \\
\text { nte \#4 }\end{array}$ & Sí guida & $\begin{array}{l}\text { Participante Jengibre } \\
\# 7\end{array}$ \\
\hline $\begin{array}{l}\text { Participa } \\
\text { nte \#2 }\end{array}$ & $\begin{array}{l}\text { Maracuyá } \\
\text { sola y } \\
\text { frambuesa } \\
\text { sola. }\end{array}$ & $\begin{array}{l}\text { Participa } \\
\text { nte \#5 }\end{array}$ & Han probado con ajíes. & \\
\hline $\begin{array}{l}\text { Participa } \\
\text { nte \#3 }\end{array}$ & Guinda sola & $\begin{array}{l}\text { Participa } \\
\text { nte \#6 }\end{array}$ & no se me ocurre & \\
\hline \multicolumn{5}{|c|}{ Posicionamiento y test de nombre } \\
\hline \multicolumn{5}{|c|}{ Pregunta 19} \\
\hline \multicolumn{5}{|c|}{$\begin{array}{l}\text { De estos nombres: Qispi-Kay, Kimsa Pisqu o Nuna. ¿Cuál creen que suena mejor para el macerado de frutas } \\
\text { en pisco? }\end{array}$} \\
\hline \multicolumn{5}{|c|}{ Respuestas } \\
\hline $\begin{array}{l}\text { Participa } \\
\text { nte \#1 }\end{array}$ & Kimsa Pisqu & $\begin{array}{l}\text { Participa } \\
\text { nte \#4 }\end{array}$ & Kimsa Pisqu & $\begin{array}{l}\text { Participante Kimsa Pisqu } \\
\# 7\end{array}$ \\
\hline $\begin{array}{l}\text { Participa } \\
\text { nte \#2 }\end{array}$ & Kimsa Pisqu & $\begin{array}{l}\text { Participa } \\
\text { nte \#5 }\end{array}$ & Kimsa Pisqu & \\
\hline $\begin{array}{l}\text { Participa } \\
\text { nte \#3 }\end{array}$ & Kimsa Pisqu & $\begin{array}{l}\text { Participa } \\
\text { nte \#6 }\end{array}$ & Kimsa Pisqu & \\
\hline \multicolumn{5}{|c|}{ Pregunta 20} \\
\hline \multicolumn{5}{|c|}{ ¿Les parece que el nombre y logo es de fácil recordación? } \\
\hline \multicolumn{5}{|c|}{ Respuestas } \\
\hline $\begin{array}{l}\text { Participa } \\
\text { nte \#1 }\end{array}$ & $\begin{array}{l}\text { No se } \\
\text { acuerda. }\end{array}$ & $\begin{array}{l}\text { Participa } \\
\text { nte \#4 }\end{array}$ & No lo recuerdan & $\begin{array}{l}\text { Participante No lo recuerdan } \\
\text { \#7 }\end{array}$ \\
\hline $\begin{array}{l}\text { Participa } \\
\text { nte \#2 }\end{array}$ & $\begin{array}{l}\text { No lo } \\
\text { recuerdan }\end{array}$ & $\begin{array}{l}\text { Participa } \\
\text { nte \#5 }\end{array}$ & No lo recuerdan & \\
\hline $\begin{array}{l}\text { Participa } \\
\text { nte \#3 }\end{array}$ & $\begin{array}{l}\text { No lo } \\
\text { recuardan }\end{array}$ & $\begin{array}{l}\text { Participa } \\
\text { nte \#6 }\end{array}$ & No lo recuerdan & \\
\hline
\end{tabular}




\section{Anexo 16 - Focus Group \# 4}

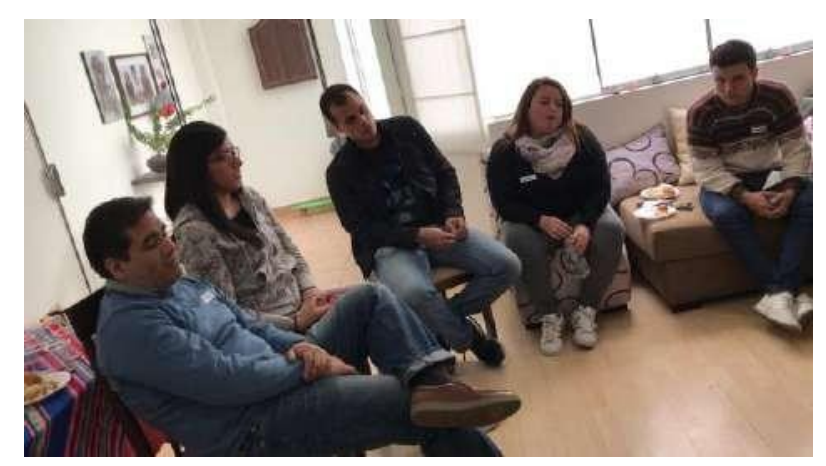

\begin{tabular}{|c|c|c|c|}
\hline Día: 07/10/2017 & \multicolumn{2}{|c|}{ Hora: 16:00 } & \\
\hline Lugar: Santiago de Surco & \multicolumn{2}{|c|}{$\begin{array}{l}\text { Participantes \# } \\
7\end{array}$} & \\
\hline NSE & $\mathrm{A} \& \mathrm{~B}$ & Zona 6 y 7 & \\
\hline \multicolumn{4}{|l|}{ Presentación } \\
\hline \multicolumn{4}{|c|}{ Pregunta 1} \\
\hline \multicolumn{4}{|c|}{ Por favor, presentarse indicando nombre y distrito. } \\
\hline \multicolumn{4}{|l|}{ Respuestas } \\
\hline $\begin{array}{l}\text { Particip } \\
\text { ante \#1 Alexandra, San Borja }\end{array}$ & Participante \#4 Sophia, & Participante \#7 & $\begin{array}{l}\text { Esteban, San } \\
\text { Borja }\end{array}$ \\
\hline $\begin{array}{l}\text { Particip } \\
\text { ante \#2 } \quad \text { Melissa, San Borja } \\
\end{array}$ & $\begin{array}{c}\text { Participante \#5 } \begin{array}{c}\text { Eloy, San } \\
\text { Borja }\end{array} \\
\end{array}$ & & \\
\hline Giovanni, San Borja & $\begin{array}{r}\text { Participante \#6 } \begin{array}{c}\text { Liliana, } \\
\text { Surco }\end{array} \\
\end{array}$ & & \\
\hline
\end{tabular}

\section{Aspectos generales sobre bebidas alcohólicas (Preguntas exploratorias)}

\section{Pregunta 2}

¿Toma bebidas alcohólicas?

\begin{tabular}{|c|c|c|c|c|c|}
\hline \multicolumn{6}{|c|}{ Respuestas } \\
\hline $\begin{array}{l}\text { Particip } \\
\text { ante \#1 }\end{array}$ & $\mathrm{Si}$ & Participante \#4 & $\mathrm{Si}$ & Participante \#7 & $\mathrm{Si}$ \\
\hline $\begin{array}{l}\text { Particip } \\
\text { ante \#2 }\end{array}$ & $\mathrm{Si}$ & Participante \#5 & $\mathrm{Si}$ & & \\
\hline $\begin{array}{l}\text { Particip } \\
\text { ante \#3 }\end{array}$ & $\mathrm{Si}$ & Participante \#6 & $\mathrm{Si}$ & & \\
\hline \multicolumn{6}{|c|}{ Pregunta 3} \\
\hline \multicolumn{6}{|c|}{ ¿Cuál prefiere? } \\
\hline \multicolumn{6}{|c|}{ Respuestas } \\
\hline $\begin{array}{l}\text { Particip } \\
\text { ante \#1 }\end{array}$ & Cerveza y ron & Participante \#4 & Pisco & Participante \#7 & $\begin{array}{l}\text { Cerveza, pisco y } \\
\text { vino }\end{array}$ \\
\hline $\begin{array}{l}\text { Particip } \\
\text { ante \#2 }\end{array}$ & Cerveza & Participante \#5 & $\begin{array}{l}\text { Cerveza y } \\
\text { pisco }\end{array}$ & & \\
\hline $\begin{array}{l}\text { Particip } \\
\text { ante \#3 }\end{array}$ & Pisco & Participante \#6 & Pisco & & \\
\hline
\end{tabular}

\section{Frecuencia de consumo de bebidas alcohólicas}

\section{Pregunta 5}

¿Con que frecuencia consumen bebidas alcohólicas?

\section{Respuestas}




\begin{tabular}{|c|c|c|c|c|}
\hline $\begin{array}{l}\text { Particip } \\
\text { ante \#1 }\end{array}$ & $1 \mathrm{vez}$ por semana & Participante \#4 $\begin{array}{c}\text { ॠvez por } \\
\text { semana }\end{array}$ & Participante \#7 & $\begin{array}{l}2 \text { veces por } \\
\text { semana }\end{array}$ \\
\hline $\begin{array}{l}\text { Particip } \\
\text { ante \#2 }\end{array}$ & $1 \mathrm{vez}$ por semana & 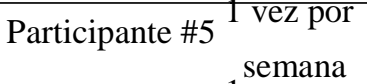 & & \\
\hline $\begin{array}{l}\text { Particip } \\
\text { ante \#3 }\end{array}$ & $1 \mathrm{vez}$ por semana & $\begin{array}{r}\text { Participante \#6 } \begin{array}{r}\text { vez por } \\
\text { semana }\end{array} \\
\end{array}$ & & \\
\hline
\end{tabular}

\section{Presentación del macerado de frutas con pisco}

\section{Pregunta 6}

\begin{tabular}{|c|c|c|c|c|c|}
\hline \multicolumn{6}{|c|}{ Respuestas } \\
\hline $\begin{array}{l}\text { Particip } \\
\text { ante \#1 }\end{array}$ & $\mathrm{Si}$ & Participante \#4 & $\mathrm{Si}$ & Participante \#7 & No \\
\hline $\begin{array}{l}\text { Particip } \\
\text { ante \#2 }\end{array}$ & $\mathrm{Si}$ & Participante \#5 & No & & \\
\hline $\begin{array}{l}\text { Particip } \\
\text { ante \#3 }\end{array}$ & $\mathrm{Si}$ & Participante \#6 & $\mathrm{Si}$ & & \\
\hline
\end{tabular}

Pregunta 7

¿Cuál ha sido su experiencia?

\begin{tabular}{|c|c|c|c|c|c|}
\hline \multicolumn{6}{|c|}{ Respuestas } \\
\hline $\begin{array}{l}\text { Particip } \\
\text { ante \#1 }\end{array}$ & Se siente la fruta & Participante \#4 & $\begin{array}{l}\text { En algunos el } \\
\text { pisco es muy } \\
\text { fuerte }\end{array}$ & Participante \#7 & $\begin{array}{l}\text { Me siento en la } \\
\text { playa }\end{array}$ \\
\hline $\begin{array}{l}\text { Particip } \\
\text { ante \#2 }\end{array}$ & $\begin{array}{l}\text { Un sabor es mas fuerte } \\
\text { que otro }\end{array}$ & Participante \#5 & $\begin{array}{l}\text { El sabor es } \\
\text { compartido }\end{array}$ & & \\
\hline $\begin{array}{l}\text { Particip } \\
\text { ante \#3 }\end{array}$ & No es muy fuerte & Participante \#6 & sabores & & \\
\hline
\end{tabular}

\section{Pregunta 8}

¿Qué diferencias encuentra respecto a los macerados de frutas en pisco que han probado anteriormente? Sabor, color, aroma, entre otros.

\begin{tabular}{|c|c|c|c|c|c|}
\hline \multicolumn{6}{|c|}{ Respuestas } \\
\hline $\begin{array}{l}\text { Particip } \\
\text { ante \#1 }\end{array}$ & La mezcla de sabores & Participante \#4 & $\begin{array}{l}\text { Los colores } \\
\text { son } \\
\text { particulares }\end{array}$ & Participante \#7 & $\begin{array}{l}\text { Mejor sabor en } \\
\text { ciertas frutas }\end{array}$ \\
\hline $\begin{array}{l}\text { Particip } \\
\text { ante \#2 }\end{array}$ & Sabores distintos & Participante \#5 & $\begin{array}{l}\text { Algunos } \\
\text { sabores solos } \\
\text { son mejores }\end{array}$ & & \\
\hline $\begin{array}{l}\text { Particip } \\
\text { ante \#3 }\end{array}$ & Los aromas son agradables & Participante \#6 & $\begin{array}{l}\text { Variedad de } \\
\text { sabores }\end{array}$ & & \\
\hline
\end{tabular}

\section{Pregunta 9}

¿Qué expectativas tienen cuando van a tomar algún macerado de fruta en pisco?

\begin{tabular}{|c|c|c|c|c|c|}
\hline \multicolumn{6}{|c|}{ Respuestas } \\
\hline $\begin{array}{l}\text { Particip } \\
\text { ante \#1 }\end{array}$ & Que se sientan los sabores & Participante \#4 & $\begin{array}{l}\text { Sentir el } \\
\text { sabor de la } \\
\text { fruta }\end{array}$ & Participante \#7 & $\begin{array}{l}\text { Poder diferenciar } \\
\text { los aromas }\end{array}$ \\
\hline $\begin{array}{l}\text { Particip } \\
\text { ante \#2 }\end{array}$ & $\begin{array}{l}\text { Debe predominar el sabor } \\
\text { de la fruta }\end{array}$ & Participante \#5 & $\begin{array}{l}\text { Que sea } \\
\text { agradable al } \\
\text { paladar }\end{array}$ & & \\
\hline $\begin{array}{l}\text { Particip } \\
\text { ante \#3 }\end{array}$ & Sentir todos los sabores & Participante \#6 & $\begin{array}{l}\text { Sentir aroma } \\
\text { y sabor de las } \\
\text { frutas }\end{array}$ & & \\
\hline
\end{tabular}

\section{Pregunta 10}

¿Consumirían los macerados de frutas en pisco en eventos sociales, familiares, corporativos?

\section{Respuestas}




\begin{tabular}{|c|c|c|c|c|}
\hline & & & & \\
\hline $\begin{array}{l}\text { Particip } \\
\text { ante \#1 }\end{array}$ & En almuerzos & Participante \#4 $\begin{array}{l}\mathrm{Si}, \text { en } \\
\text { matrimonios }\end{array}$ & Participante \#7 & $\begin{array}{l}\text { En cualquier } \\
\text { momento }\end{array}$ \\
\hline $\begin{array}{l}\text { Particip } \\
\text { ante \#2 }\end{array}$ & En cualquier lado & $\begin{array}{r}\text { Participante \#5 } \begin{array}{r}\text { En reuniones } \\
\text { con amigos }\end{array} \\
\end{array}$ & & \\
\hline $\begin{array}{l}\text { Particip } \\
\text { ante \#3 }\end{array}$ & En cualquier momento & $\begin{array}{r}\text { Participante \#6 En reuniones } \\
\text { con amigos }\end{array}$ & & \\
\hline \multicolumn{5}{|c|}{ Pregunta 11} \\
\hline \multicolumn{5}{|c|}{$\begin{array}{l}\text { ¿Reemplazarían tragos a base de ron, vodka, entre otros, por macerados de frutas en pisco en sus distintos } \\
\text { sabores? }\end{array}$} \\
\hline \multicolumn{5}{|c|}{ Respuestas } \\
\hline $\begin{array}{l}\text { Particip } \\
\text { ante \#1 }\end{array}$ & $\begin{array}{l}\text { Lo agregaría como nueva } \\
\text { opción }\end{array}$ & $\begin{array}{r}\text { Participante \#4 Lo incluyo } \\
\text { en mi lista }\end{array}$ & Participante \#7 & $\begin{array}{l}\text { Puedo } \\
\text { considerarlo como } \\
\text { opción }\end{array}$ \\
\hline $\begin{array}{l}\text { Particip } \\
\text { ante \#2 }\end{array}$ & Entraría a mi lista & $\begin{array}{ll} & \text { Lo pongo } \\
\text { Participante \#5 } & \begin{array}{l}\text { despúes de la } \\
\text { cerveza }\end{array} \\
\end{array}$ & & \\
\hline $\begin{array}{l}\text { Particip } \\
\text { ante \#3 }\end{array}$ & Sería una opción más & $\begin{array}{ll} & \text { Me gusta, si } \\
\text { Participante \#6 } & \begin{array}{l}\text { puedo } \\
\text { reemplazar } \\
\text { otro }\end{array}\end{array}$ & & \\
\hline
\end{tabular}

Pregunta 12

¿Cuál sería el principal atractivo del producto?

\begin{tabular}{|c|c|c|c|c|c|}
\hline \multicolumn{6}{|c|}{ Respuestas } \\
\hline $\begin{array}{l}\text { Particip } \\
\text { ante \#1 }\end{array}$ & La mezcla de sabores & Participante \#4 & $\begin{array}{l}\text { Los colores } \\
\text { son bonitos }\end{array}$ & Participante \#7 & $\begin{array}{l}\text { La mezcla de } \\
\text { sabores }\end{array}$ \\
\hline $\begin{array}{l}\text { Particip } \\
\text { ante \#2 }\end{array}$ & Poder encontrar 2 sabores & Participante \#5 & $\begin{array}{l}\text { El sabor debe } \\
\text { ser muy } \\
\text { bueno }\end{array}$ & & \\
\hline $\begin{array}{l}\text { Particip } \\
\text { ante \#3 }\end{array}$ & Que se vea la fruta & Participante \#6 & $\begin{array}{l}\text { Encontrar la } \\
\text { fruta dentro }\end{array}$ & & \\
\hline
\end{tabular}

\section{Pregunta 13}

¿Cuánto están dispuestos a pagar por la botella de $750 \mathrm{ml}$ ?

\begin{tabular}{|c|c|c|c|c|}
\hline \multicolumn{5}{|c|}{ Respuestas } \\
\hline $\begin{array}{l}\text { Particip } \\
\text { ante \#1 }\end{array}$ & 60 soles & $\begin{array}{c}\text { Participante \#4 } \begin{array}{c}\text { Entre } 50 \text { y } 60 \\
\text { soles }\end{array} \\
\end{array}$ & Participante \#7 & $\begin{array}{l}\text { Creo que } 60 \text { soles } \\
\text { esta bien }\end{array}$ \\
\hline $\begin{array}{l}\text { Particip } \\
\text { ante \#2 }\end{array}$ & 50 soles & Participante \#5 & & \\
\hline $\begin{array}{l}\text { Particip } \\
\text { ante \#3 }\end{array}$ & 69 soles & Participante \#6 & & \\
\hline
\end{tabular}

\section{Pregunta 14}

¿Les gustaría poder comprar el macerado de frutas en pisco por redes sociales: Facebook o Instagram o prefieren encontrarlos en establecimientos?

\begin{tabular}{|c|c|c|c|c|c|}
\hline \multicolumn{6}{|c|}{ Respuestas } \\
\hline $\begin{array}{l}\text { Particip } \\
\text { ante \#1 }\end{array}$ & $\begin{array}{l}\text { El primer contacto debe } \\
\text { ser físico }\end{array}$ & Participante \#4 & $\begin{array}{l}\text { Si puedo } \\
\text { comprarlo } \\
\text { online }\end{array}$ & Participante \#7 & $\begin{array}{l}\text { Primero debo } \\
\text { probarlo }\end{array}$ \\
\hline $\begin{array}{l}\text { Particip } \\
\text { ante \#2 }\end{array}$ & En supermercados & Participante \#5 & $\begin{array}{l}\text { Online y } \\
\text { físico }\end{array}$ & & \\
\hline $\begin{array}{l}\text { Particip } \\
\text { ante \#3 }\end{array}$ & $\begin{array}{l}\text { En estaciones de servicio } \\
\text { seria una buena opción }\end{array}$ & Participante \#6 & $\begin{array}{l}\text { En los } \\
\text { tambos } \\
\text { puede ser }\end{array}$ & & \\
\hline
\end{tabular}

\section{Pregunta 15}

¿Cuál es la característica que creen que se debería aprovechar para impulsar el posicionamiento del producto?

\section{Respuestas}




\begin{tabular}{|c|c|c|c|c|}
\hline $\begin{array}{l}\text { Particip } \\
\text { ante \#1 }\end{array}$ & $\begin{array}{l}\text { Usar una botella } 100 \% \\
\text { transparente }\end{array}$ & Participante \#4 Resaltar el & Participante \#7 & $\begin{array}{l}\text { Una botella que } \\
\text { resalte }\end{array}$ \\
\hline $\begin{array}{l}\text { Particip } \\
\text { ante } \# 2\end{array}$ & La mezcla de frutas & $\begin{array}{c}\text { Participante \#5 } \\
\text { frutas }\end{array}$ & & \\
\hline $\begin{array}{l}\text { Particip } \\
\text { ante \#3 }\end{array}$ & Colocar frutas dentro & Participante \#6 $\begin{array}{c}\text { La mezcla de } \\
\text { frutas }\end{array}$ & & \\
\hline
\end{tabular}

\section{Degustación de los macerados de frutas en pisco}

\section{Pregunta 16}

De todos los sabores que probaron podrían clasificarlos del 1 al 5 (en orden de su mayor agrado).

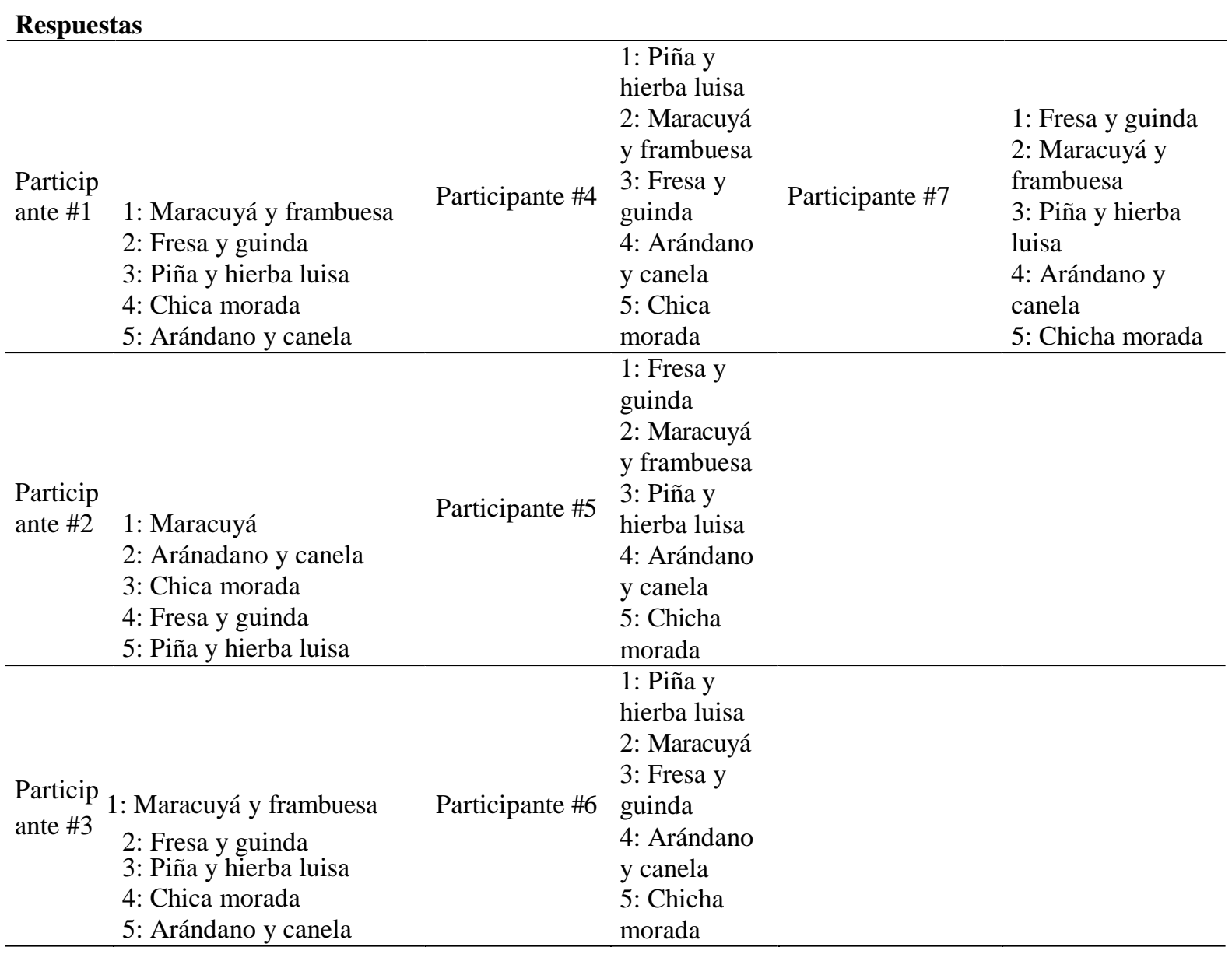

\section{Pregunta 17}

¿Qué características creen que podría tener el macerado de frutas en pisco o en qué debería mejorar?

\begin{tabular}{|c|c|c|c|c|c|}
\hline \multicolumn{6}{|c|}{ Respuestas } \\
\hline $\begin{array}{l}\text { Particip } \\
\text { ante \#1 }\end{array}$ & $\begin{array}{l}\text { Equilibrar los sabores para } \\
\text { sentirlos }\end{array}$ & Participante \#4 & $\begin{array}{l}\text { Mejorar el } \\
\text { equilibrio de } \\
\text { sabores }\end{array}$ & Participante \#7 & $\begin{array}{l}\text { Aumentar el dulce } \\
\text { en algunos }\end{array}$ \\
\hline $\begin{array}{l}\text { Particip } \\
\text { ante \#2 }\end{array}$ & $\begin{array}{l}\text { Aumentar la cantidad de } \\
\text { algunas frutas }\end{array}$ & Participante \#5 & $\begin{array}{l}\text { Que se sienta } \\
\text { más la fruta }\end{array}$ & & \\
\hline $\begin{array}{l}\text { Particip } \\
\text { ante \#3 }\end{array}$ & Que predomine la fruta & Participante \#6 & $\begin{array}{l}\text { Que tenga un } \\
\text { poco de } \\
\text { dulce }\end{array}$ & & \\
\hline
\end{tabular}

\section{Pregunta 18}

¿Qué otros sabores les gustaría encontrar?

\begin{tabular}{|c|c|c|c|c|c|}
\hline \multicolumn{6}{|c|}{ Respuestas } \\
\hline $\begin{array}{l}\text { Particip } \\
\text { ante \#1 }\end{array}$ & Otras mezclas de cítricos & Participante \#4 & $\begin{array}{l}\text { Mezclar } \\
\text { verduras con } \\
\text { frutas }\end{array}$ & Participante \#7 & Probar con kion \\
\hline
\end{tabular}




\begin{tabular}{|c|c|c|c|}
\hline $\begin{array}{l}\text { Particip } \\
\text { ante \#2 }\end{array}$ & Granadilla con mandarina & Participante \#5 Granadilla & \\
\hline $\begin{array}{l}\text { Particip } \\
\text { ante \#3 }\end{array}$ & Granada & $\begin{array}{r}\text { Participante \#6 Más sabores } \\
\text { de cítricos }\end{array}$ & \\
\hline \multicolumn{4}{|c|}{ Posicionamiento y test de nombre } \\
\hline \multicolumn{4}{|c|}{ Pregunta 19} \\
\hline \multicolumn{4}{|c|}{$\begin{array}{l}\text { De estos nombres: Qispi-Kay, Kimsa Pisqu o Nuna. ¿Cuál creen que suena mejor para el macerado de frutas } \\
\text { en pisco? }\end{array}$} \\
\hline \multicolumn{4}{|c|}{ Respuestas } \\
\hline $\begin{array}{l}\text { Particip } \\
\text { ante \#1 }\end{array}$ & Nuna & $\begin{array}{c}\text { Participante \#4 No encuentro } \\
\text { relación }\end{array}$ & No suena a pisco \\
\hline $\begin{array}{l}\text { Particip } \\
\text { ante \#2 }\end{array}$ & Nuna, pero no lo asocio & $\begin{array}{ll} & \text { Se debe } \\
\text { Participante \#5 } & \begin{array}{l}\text { asociar con la } \\
\text { costa }\end{array}\end{array}$ & \\
\hline $\begin{array}{l}\text { Particip } \\
\text { ante \#3 }\end{array}$ & Puede ser Nuna & $\begin{array}{c}\text { Participante \#6 } \begin{array}{c}\text { Puede ser } \\
\text { Nuna }\end{array} \\
\end{array}$ & \\
\hline
\end{tabular}

\section{Pregunta 20}

¿Les parece que el nombre y logo es de fácil recordación?

\begin{tabular}{|c|c|c|c|c|c|}
\hline \multicolumn{6}{|c|}{ Respuestas } \\
\hline $\begin{array}{l}\text { Particip } \\
\text { ante \#1 }\end{array}$ & Los nombres son difíciles & Participante \#4 & $\begin{array}{l}\text { No se } \\
\text { relaciona con } \\
\text { el producto }\end{array}$ & Participante \#7 & $\begin{array}{l}\text { Deben buscar otro } \\
\text { nombre }\end{array}$ \\
\hline $\begin{array}{l}\text { Particip } \\
\text { ante \#2 }\end{array}$ & $\begin{array}{l}\text { No logro recordar los } \\
\text { nombres }\end{array}$ & Participante \#5 & $\begin{array}{l}\text { Dificil de } \\
\text { recordar }\end{array}$ & & \\
\hline $\begin{array}{l}\text { Particip } \\
\text { ante \#3 }\end{array}$ & Nombres difíciles & Participante \#6 & $\begin{array}{l}\text { Un poco } \\
\text { difícil de } \\
\text { recordar }\end{array}$ & & \\
\hline
\end{tabular}




\section{Anexo 17 - Cuestionario de la Encuesta}

\section{Presentación de los investigadores}

Gracias por participar en nuestra encuesta. Somos alumnos de la universidad San Ignacio de Loyola y estamos realizando una investigación de mercado.

\section{Indicaciones sobre el llenado de la encuesta}

La presente encuesta es totalmente anónima. Le rogamos conteste con total sinceridad. Por favor coloque un aspa (X) o encierre en un círculo (O), en la alternativa que corresponda a su respuesta. Todas las respuestas son válidas y nos ayudaran en nuestro proyecto.

\section{Contenido de la encuesta}

1. Sexo
a) Femenino
b) Masculino

2. Edad
a) De 21 a 29 años
b) De 30 a 39 años
c) De 40 a 49 años
d) De 50 a 59 años
e) De 60 a 65 años
f) De 66 años a más

3. Distrito
a) Jesús María
b) Lince
c) Pueblo Libre
d) Magdalena
e) San Miguel
f) La Molina
g) Miraflores
h) San Borja
i) San Isidro
j) Santiago de Surco
k) Otros 
4. ¿Consume usted bebidas alcohólicas?
a) $\mathrm{Si}$
b) No
c) A veces

5. ¿Con qué frecuencia consume usted bebidas alcohólicas?
a) Siempre
b) De vez en cuando
c) Rara vez
d) Casi nunca
e) Nunca

6. ¿Consume pisco?
a) Siempre
b) De vez en cuando
c) Rara vez
d) Casi nunca
e) Nunca

7. ¿Ha probado los macerados de frutas en pisco?
a) Sí
b) No

8. ¿Qué marcas de macerados en frutas conoce?
a) RR Macerados
b) Malika
c) Sanka Macerados
d) Olaya Macerados
e) Golden Fruit Macerados
f) Ninguna
g) Otro

HECHIZO son macerados de frutas en pisco, el cual se elabora de manera $100 \%$ natural y utiliza productos de alta calidad ofreciendo mezclas innovadoras. Se presenta en botellas de $750 \mathrm{ml}$ en donde se puede apreciar las frutas. El objetivo es que el pisco quebranta adquiera los aromas y sabores de las frutas utilizadas dando como resultado una nueva opción para deleitar su paladar.

9. ¿Estaría dispuesto a comprar HECHIZO (macerados de frutas en pisco)?
a) Definitivamente si
b) $\mathrm{Si}$
c) Tal vez
d) No
e) Definitivamente no 
10. De los siguientes sabores, marque del 1 al 5 según su preferencia, siendo 1 el más importante y 5 el menos importante

\begin{tabular}{|l|l|l|l|l|l|}
\hline \multicolumn{1}{|c|}{ Sabores } & $\mathbf{1}$ & $\mathbf{2}$ & $\mathbf{3}$ & $\mathbf{4}$ & $\mathbf{5}$ \\
\hline Fresa y guinda & & & & & \\
\hline Hierba luisa y piña & & & & & \\
\hline Maracuyá y frambuesa & & & & & \\
\hline Chica morada (maíz morado, membrillo y canela) & & & & & \\
\hline Arándano y canela & & & & & \\
\hline
\end{tabular}

11. ¿Qué atributos considera usted que son los más importantes?
a) Precio
b) Calidad
c) Sabor
d) Versatilidad
e) Tradición

12. ¿Con qué frecuencia adquiriría usted $\mathrm{HECHIZO(macerado} \mathrm{de} \mathrm{frutas} \mathrm{en} \mathrm{pisco)?}$
a) Semanas
b) Mensual
c) Quincenal
d) Bimensual
e) Trimestral

13. ¿Cuántas botellas de $750 \mathrm{ml}$ adquiriría usted cada vez que realice una compra?
a) Una
b) Dos
c) Tres
d) Cuatro
e) Cinco o más

14. De las siguientes opciones elija usted el rango de precios que estaría dispuesto a pagar por HECHIZO (macerados de frutas en pisco)
a) $\mathrm{S} / 45$ a $\mathrm{S} / 49$
b) $\mathrm{S} / 50$ a $\mathrm{S} / 54$
c) $\mathrm{S} / 55$ a $\mathrm{S} / 59$
d) $S / 60$ a $S / 64$
e) De S/ 65 a más

15. ¿En qué ocasión consumiría usted HECHIZO (macerado de frutas en pisco? (Puede marcar más de una opción)
a) Fiestas
b) Eventos
c) Reuniones 

d) Almuerzos
e) Cenas

16. ¿En qué época del año consumiría usted HECHIZO (Macerados de frutas en pisco)?
a) Primavera
b) Verano
c) Otoño
d) Invierno
e) Todo el año

17. ¿Dónde le gustaría encontrar HECHIZO (macerados de frutas en pisco)? (Puede marcar mas de una opción)
a) $\mathrm{Si}$
b) $\mathrm{No}$ 
Anexo 18 - Cálculo Mercado Potencial - Proyección NSE

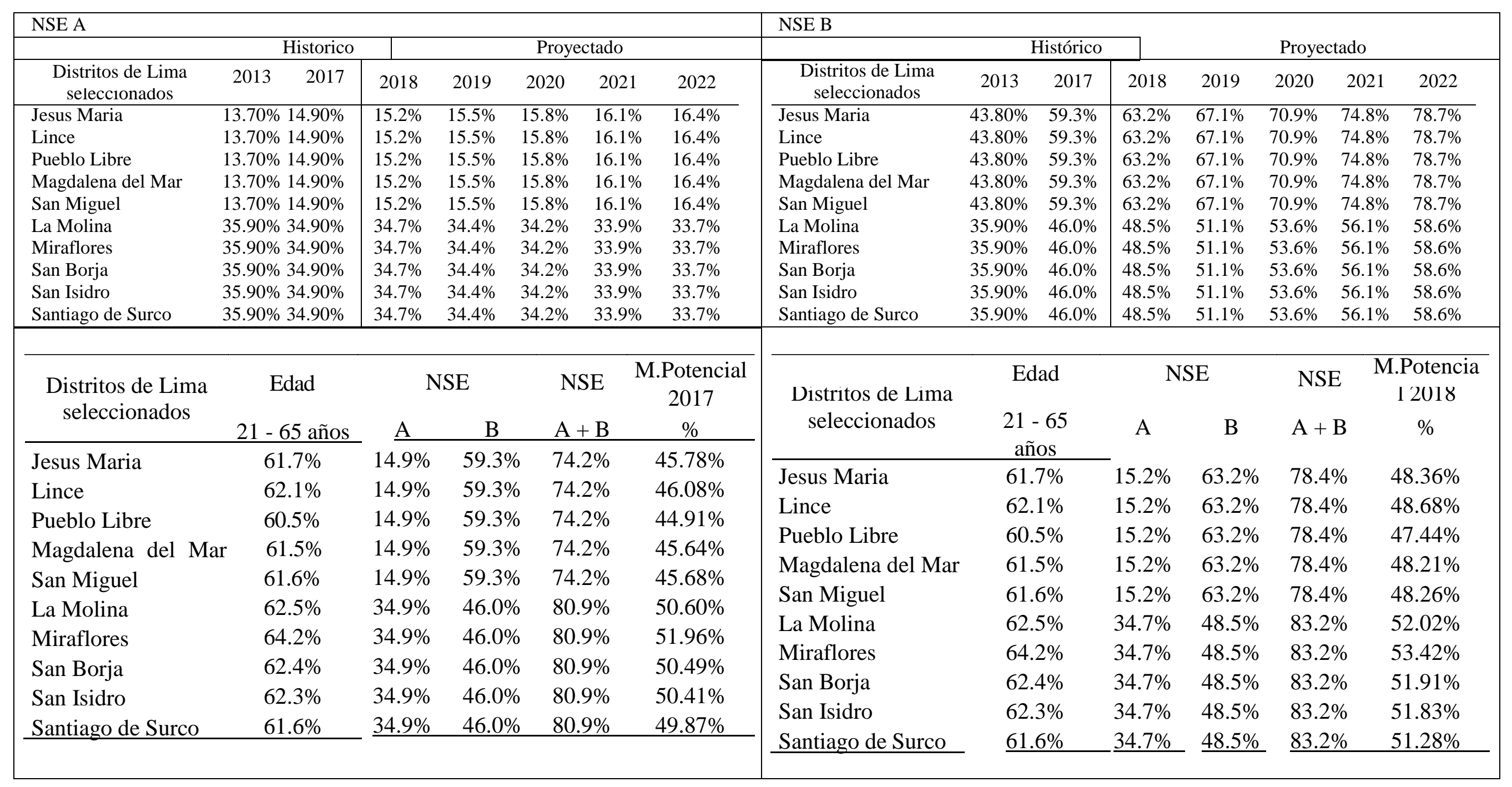




\begin{tabular}{|c|c|c|c|c|c|c|c|c|c|c|c|}
\hline \multirow{2}{*}{$\begin{array}{l}\text { Distritos de Lima } \\
\text { seleccionados }\end{array}$} & \multirow{2}{*}{$\begin{array}{c}\text { Edad } \\
21-65 \text { años }\end{array}$} & \multicolumn{2}{|c|}{ NSE } & \multirow{2}{*}{$\begin{array}{l}\text { NSE } \\
\mathrm{A}+\mathrm{B}\end{array}$} & \multirow{2}{*}{$\begin{array}{c}\text { M.Potencial } \\
2019 \\
\% \\
\end{array}$} & \multirow{2}{*}{$\begin{array}{l}\text { Distritos de Lima } \\
\text { seleccionados }\end{array}$} & \multirow{2}{*}{$\begin{array}{c}\text { Edad } \\
21-65 \text { años }\end{array}$} & \multicolumn{2}{|c|}{ NSE } & \multirow{2}{*}{$\begin{array}{l}\text { NSE } \\
\mathrm{A}+\mathrm{B} \\
\end{array}$} & \multirow{2}{*}{$\begin{array}{c}\text { M.Potencial } \\
2020 \\
\%\end{array}$} \\
\hline & & A & $\mathrm{B}$ & & & & & $\underline{\mathrm{A}}$ & B & & \\
\hline Jesus Maria & $61.7 \%$ & $15.5 \%$ & $67.1 \%$ & $82.6 \%$ & $50.9 \%$ & Jesus Maria & $61.7 \%$ & $15.8 \%$ & $70.9 \%$ & $86.7 \%$ & $53.5 \%$ \\
\hline Lince & $62.1 \%$ & $15.5 \%$ & $67.1 \%$ & $82.6 \%$ & $51.3 \%$ & Lince & $62.1 \%$ & $15.8 \%$ & $70.9 \%$ & $86.7 \%$ & $53.9 \%$ \\
\hline Pueblo Libre & $60.5 \%$ & $15.5 \%$ & $67.1 \%$ & $82.6 \%$ & $50.0 \%$ & Pueblo Libre & $60.5 \%$ & $15.8 \%$ & $70.9 \%$ & $86.7 \%$ & $52.5 \%$ \\
\hline Magdalena del Mar & $61.5 \%$ & $15.5 \%$ & $67.1 \%$ & $82.6 \%$ & $50.8 \%$ & Magdalena del Mar & $61.5 \%$ & $15.8 \%$ & $70.9 \%$ & $86.7 \%$ & $53.3 \%$ \\
\hline San Miguel & $61.6 \%$ & $15.5 \%$ & $67.1 \%$ & $82.6 \%$ & $50.8 \%$ & San Miguel & $61.6 \%$ & $15.8 \%$ & $70.9 \%$ & $86.7 \%$ & $53.4 \%$ \\
\hline La Molina & $62.5 \%$ & $34.4 \%$ & $51.1 \%$ & $85.5 \%$ & $53.4 \%$ & La Molina & $62.5 \%$ & $34.2 \%$ & $53.6 \%$ & $87.7 \%$ & $54.9 \%$ \\
\hline Miraflores & $64.2 \%$ & $34.4 \%$ & $51.1 \%$ & $85.5 \%$ & $54.9 \%$ & Miraflores & $64.2 \%$ & $34.2 \%$ & $53.6 \%$ & $87.7 \%$ & $56.3 \%$ \\
\hline San Borja & $62.4 \%$ & $34.4 \%$ & $51.1 \%$ & $855 \%$ & $53.3 \%$ & San Borja & $62.4 \%$ & $34.2 \%$ & $53.6 \%$ & $87.7 \%$ & $54.8 \%$ \\
\hline San Isidro & $62.3 \%$ & 34.40 & 51.10 & 002.50 & $\begin{array}{l}53.5 \% \\
52.20\end{array}$ & San Isidro & $62.3 \%$ & $34.2 \%$ & $53.6 \%$ & $87.7 \%$ & $54.7 \%$ \\
\hline Santiago de Surco & $61.6 \%$ & $34.4 \%$ & $51.1 \%$ & $85.5 \%$ & $\begin{array}{l}55.210 \\
52.7 \%\end{array}$ & Santiago de Surco & $61.6 \%$ & $34.2 \%$ & $53.6 \%$ & $\underline{87.7 \%}$ & $54.1 \%$ \\
\hline \multirow{2}{*}{$\begin{array}{l}\text { Distritos de Lima } \\
\text { seleccionados }\end{array}$} & Edad & \multicolumn{2}{|c|}{ NSE } & NSE & $\begin{array}{c}\text { M.Potencial } \\
2021\end{array}$ & Distritos de Lima & Edad & \multicolumn{2}{|c|}{ NSE } & NSE & M.Potencial \\
\hline & $21-65$ años & A & $\mathrm{B}$ & $A+B$ & $\%$ & & 21 - 65 años & A & B & $A+B$ & $\%$ \\
\hline Jesus Maria & $61.7 \%$ & $16.1 \%$ & $74.8 \%$ & $90.9 \%$ & $56.1 \%$ & Jesus Maria & $61.7 \%$ & $16.4 \%$ & $78.7 \%$ & $95.1 \%$ & $58.66 \%$ \\
\hline Lince & $62.1 \%$ & $16.1 \%$ & $74.8 \%$ & $90.9 \%$ & $56.5 \%$ & Lince & $62.1 \%$ & $16.4 \%$ & $78.7 \%$ & $95.1 \%$ & $59.05 \%$ \\
\hline Pueblo Libre & $60.5 \%$ & $16.1 \%$ & $74.8 \%$ & $90.9 \%$ & $55.0 \%$ & Pueblo Libre & $60.5 \%$ & $16.4 \%$ & $78.7 \%$ & $95.1 \%$ & $57.54 \%$ \\
\hline Magdalena del Mar & $61.5 \%$ & $16.1 \%$ & $74.8 \%$ & $90.9 \%$ & $55.9 \%$ & Magdalena del Mar & $61.5 \%$ & $16.4 \%$ & $78.7 \%$ & $95.1 \%$ & $58.49 \%$ \\
\hline San Miguel & $61.6 \%$ & $16.1 \%$ & $74.8 \%$ & $90.9 \%$ & $56.0 \%$ & San Miguel & $61.6 \%$ & $16.4 \%$ & $78.7 \%$ & $95.1 \%$ & $58.54 \%$ \\
\hline La Molina & $62.5 \%$ & $33.9 \%$ & $56.1 \%$ & $90.0 \%$ & $56.3 \%$ & La Molina & $62.5 \%$ & $33.7 \%$ & $58.6 \%$ & $92.3 \%$ & $57.71 \%$ \\
\hline Miraflores & $64.2 \%$ & $33.9 \%$ & $56.1 \%$ & $90.0 \%$ & $57.8 \%$ & Miraflores & $64.2 \%$ & $33.7 \%$ & $58.6 \%$ & $92.3 \%$ & $59.27 \%$ \\
\hline San Borja & $62.4 \%$ & $33.9 \%$ & $56.1 \%$ & $90.0 \%$ & $56.2 \%$ & San Borja & $62.4 \%$ & $33.7 \%$ & $58.6 \%$ & $92.3 \%$ & $57.59 \%$ \\
\hline San Isidro & $62.3 \%$ & $33.9 \%$ & $56.1 \%$ & $90.0 \%$ & $56.1 \%$ & San Isidro & $62.3 \%$ & $33.7 \%$ & $58.6 \%$ & $92.3 \%$ & $57.50 \%$ \\
\hline Santiago de Surco & $61.6 \%$ & $33.9 \%$ & $56.1 \%$ & $\underline{90.0 \%}$ & $55.5 \%$ & Santiago de Surco & $\underline{61.6 \%}$ & $33.7 \%$ & $58.6 \%$ & $92.3 \%$ & $56.89 \%$ \\
\hline
\end{tabular}




\section{Anexo 19- Amortización de Gasto Pre Operativo}

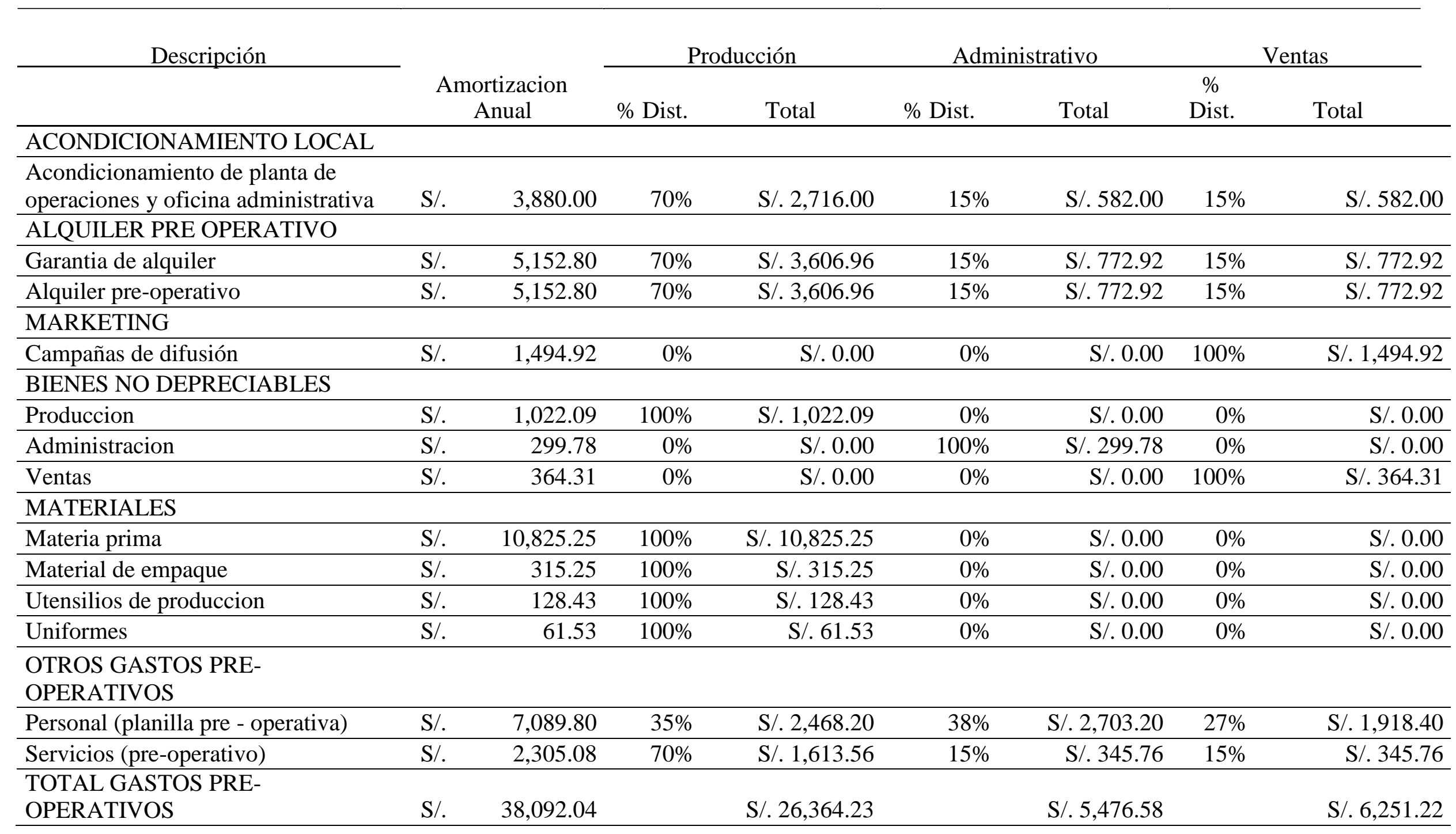




\section{Anexo 20- Depreciación Activos Fijos}

\begin{tabular}{|c|c|c|c|c|c|c|c|c|c|c|c|}
\hline Descripción & $\begin{array}{r}\text { Costo total } \\
(\sin I G V)\end{array}$ & $\begin{array}{l}\text { Vida Útil } \\
\text { contable } \\
\text { (años) }\end{array}$ & $\begin{array}{l}\text { Deprec. } \\
\text { Año } 1\end{array}$ & $\begin{array}{l}\text { Deprec. } \\
\text { Año } 2\end{array}$ & $\begin{array}{l}\text { Deprec. } \\
\text { Año } 3\end{array}$ & $\begin{array}{l}\text { Deprec. } \\
\text { Año } 4\end{array}$ & $\begin{array}{l}\text { Deprec. } \\
\text { Año } 5\end{array}$ & $\begin{array}{c}\text { Deprec } \\
\text { acumulada } \\
\text { (5 años) }\end{array}$ & $\begin{array}{l}\text { Valor en } \\
\text { libros } \\
\text { (5to año) }\end{array}$ & $\begin{array}{c}\text { Valor } \\
\text { mercado S/. }\end{array}$ & $\begin{array}{c}\text { Valor } \\
\text { residual al } \\
\text { 5to año } \\
\text { (Valor de } \\
\text { desecho } \\
\text { neto) }\end{array}$ \\
\hline \multicolumn{12}{|c|}{ PRODUCCIÓN } \\
\hline Congeladora & S/. 2,458 & 10 & S/. 246 & S/. 246 & S/. 246 & S/. 246 & S/. 246 & S/. 1,229 & S/. 1,229 & S/. 737 & S/. 882 \\
\hline Maquina lavadora de botellas & S/. 9,847 & 10 & S/. 985 & S/. 985 & S/. 985 & S/. 985 & S/. 985 & S/. 4,924 & S/. 4,924 & S/. 2,954 & S/. 3,535 \\
\hline $\begin{array}{l}\text { Maquina llenadora semi } \\
\text { automatica }\end{array}$ & S/. 22,508 & 10 & S/. 2,251 & S/. 2,251 & $\mathrm{S} / .2,251$ & S/. 2,251 & $\mathrm{S} / .2,251$ & S/. 11,254 & S/. 11,254 & S/. 6,753 & S/. 8,081 \\
\hline $\begin{array}{l}\text { Maquina de semi automatica de } \\
\text { tapado }\end{array}$ & S/. $\quad 1,558$ & 10 & S/. 156 & S/. 156 & S/. 156 & S/. 156 & S/. 156 & S/. 779 & S/. 779 & S/. 467 & S/. 559 \\
\hline Etiquetadora semiatomatica & S/. 1,657 & 10 & S/. 166 & S/. 166 & S/. 166 & S/. 166 & S/. 166 & S/. 829 & S/. 829 & S/. 331 & $\mathrm{~S} / .478$ \\
\hline Estantes de acero inoxidable & S/. 3,661 & 10 & S/. 366 & S/. 366 & S/. 366 & S/. 366 & S/. 366 & S/. 1,830 & S/. 1,830 & S/. 732 & S/. 1,056 \\
\hline Computadora & S/. 1,942 & 4 & $\mathrm{~S} / .486$ & S/. 486 & S/. 486 & S/. 486 & & S/. 1,942 & $\mathrm{~S} / .0$ & $\mathrm{~S} / .0$ & $\mathrm{~S} / .0$ \\
\hline TOTAL & & & S/. 9,612 & S/. 9,612 & $\mathrm{S} / .9,612$ & S/. 9,612 & S/. 9,127 & S/. 47,575 & S/. 45,633 & S/. 21,890 & S/. 28,894 \\
\hline Computadora & S/. 5,827 & 4 & S/. 1,457 & S/. 1,457 & S/. 1,457 & S/. 1,457 & & S/. 5,827 & S/. 0 & S/. 0 & S/. 0 \\
\hline TOTAL & & & S/. 1,457 & S/. 1,457 & S/. 1,457 & S/. 1,457 & S/. 0 & S/. 5,827 & S/. 0 & S/. 0 & S/. 0 \\
\hline \multicolumn{12}{|c|}{ ADMINISTRATIVA } \\
\hline Laptop & S/. 2,483 & 4 & S/. 621 & S/. 621 & S/. 621 & S/. 621 & & S/. 2,483 & S/. 0 & $\mathrm{~S} / .0$ & S/. 0 \\
\hline Computadora & S/. 1,942 & 4 & S/. 486 & S/. 486 & S/. 486 & S/. 486 & & S/. 1,942 & S/. 0 & S/. 0 & S/. 0 \\
\hline Impresora Multifuncional & S/. 837 & 4 & S/. 209 & S/. 209 & S/. 209 & S/. 209 & & S/. 837 & $\mathrm{~S} / .0$ & S/. 0 & S/. 0 \\
\hline Mesa de reuniones con sillas & S/. 1,866 & 10 & S/. 187 & S/. 187 & S/. 187 & S/. 187 & S/. 187 & S/. 933 & S/. 933 & S/. 373 & S/. 538 \\
\hline \multirow[t]{2}{*}{ TOTAL } & & & $\mathrm{S} / .1,502$ & S/. 1,502 & S/. 1,502 & $\mathrm{S} / .1,502$ & S/. 187 & S/. 6,195 & S/. 933 & S/. 373 & S/. 538 \\
\hline & & & S/. 12,571 & S/. 12,571 & S/. 12,571 & S/. 12,571 & S/. 9,313 & S/. 59,597 & S/. 46,566 & S/. 22,264 & S/. 29,433 \\
\hline
\end{tabular}




\section{Anexo 21- Amortización Intangibles}

\begin{tabular}{|c|c|c|c|c|c|c|c|c|c|c|c|}
\hline DESCRIPCION & \multirow{2}{*}{\multicolumn{2}{|c|}{$\begin{array}{l}\text { Amortización Anual } \\
\qquad \cup \mathrm{U} \%\end{array}$}} & \multicolumn{3}{|c|}{ Producción } & \multicolumn{3}{|c|}{ Adminstrativo } & \multicolumn{3}{|c|}{ Ventas } \\
\hline CONSTITUCION DE LA EMPRESA & & & \multirow{2}{*}{$\frac{\% \text { Dist. }}{0 \%}$} & \multicolumn{2}{|c|}{ Total } & \multirow{2}{*}{$\frac{\% \text { Dist. }}{100 \%}$} & \multicolumn{2}{|c|}{ Total } & \multirow{2}{*}{$\frac{\% \text { Dist. }}{0 \%}$} & \multicolumn{2}{|c|}{ Total } \\
\hline Búsqueda de índices ante la SUNARP & $\mathrm{S} /$. & 1.00 & & S/. & - & & $\mathrm{S} /$. & 1.00 & & $\mathrm{~S} /$. & - \\
\hline Elaboración de minuta & $\mathrm{S} /$. & 90.00 & $0 \%$ & $\mathrm{~S} /$. & - & $100 \%$ & $\mathrm{~S} /$. & 90.00 & $0 \%$ & $\mathrm{~S} /$. & - \\
\hline Escritura Pública ante notario público & $\mathrm{S} /$. & 18.00 & $0 \%$ & $\mathrm{~S} /$. & - & $100 \%$ & $\mathrm{~S} /$. & 18.00 & $0 \%$ & $\mathrm{~S} /$. & - \\
\hline Gastos Administrativos Notaria & $\mathrm{S} /$. & 15.04 & $0 \%$ & $\mathrm{~S} /$. & - & $100 \%$ & S/. & 15.04 & $0 \%$ & $\mathrm{~S} /$. & - \\
\hline Elevar la escritura pública a SUNARP & $\mathrm{S} /$. & 18.00 & $0 \%$ & $\mathrm{~S} /$. & - & $100 \%$ & $\mathrm{~S} /$. & 18.00 & $0 \%$ & $\mathrm{~S} /$. & - \\
\hline Costo de Libros contables (4) SUNAT & $\mathrm{S} /$. & 16.00 & $0 \%$ & $\mathrm{~S} /$. & - & $100 \%$ & $\mathrm{~S} /$. & 16.00 & $0 \%$ & $\mathrm{~S} /$. & - \\
\hline Legalización libros contables & $\mathrm{S} /$. & 24.00 & $0 \%$ & $\mathrm{~S} /$. & - & $100 \%$ & $\mathrm{~S} /$. & 24.00 & $0 \%$ & $\mathrm{~S} /$. & - \\
\hline TOTAL CONSTITUCION DE LA EMPRESA & $\mathrm{S} /$. & 185.64 & & $\mathrm{~S} /$. & - & & $\mathrm{S} / . \quad 18$ & 85.64 & & $\mathrm{~S} /$. & - \\
\hline \multicolumn{12}{|l|}{ REGISTRO DE MARCAS O PATENTES } \\
\hline Búsqueda fonética - figurativa & $\mathrm{S} /$. & 18.60 & $0 \%$ & $\mathrm{~S} /$. & - & $0 \%$ & S/. & - & $100 \%$ & $\mathrm{~S} /$. & 18.60 \\
\hline Registro de marca y Logo (13.90\% de la UIT) & $\mathrm{S} / \mathrm{.}$ & 109.81 & $0 \%$ & $\mathrm{~S} /$. & - & $0 \%$ & $\mathrm{~S} /$. & - & $100 \%$ & $\mathrm{~S} /$. & 109.81 \\
\hline Registro de Nombre Comercial (13.90\% de la UIT) & $\mathrm{S} /$. & 109.81 & $0 \%$ & $\mathrm{~S} /$. & - & $0 \%$ & $\mathrm{~S} /$. & - & $100 \%$ & $\mathrm{~S} /$. & 109.81 \\
\hline Registro de Código de barras & $\mathrm{S} /$. & 84.75 & $100 \%$ & S/. & 84.75 & $0 \%$ & $\mathrm{~S} /$. & - & $0 \%$ & $\mathrm{~S} /$. & - \\
\hline TOTAL REGISTRO DE MARCAS O PATENTES & $\mathrm{S} /$. & 362.97 & & $\mathrm{~S} /$. & 84.75 & & S/. & - & & S/. 278 & 8.22 \\
\hline \multicolumn{12}{|l|}{ LICENCIAS Y AUTORIZACIONES } \\
\hline \multicolumn{12}{|l|}{ Local: Distrito de San Luis } \\
\hline Licencia de Funcionamiento & $\mathrm{S} /$. & 37.60 & $70 \%$ & $\mathrm{~S} /$. & 26.32 & $20 \%$ & $\mathrm{~S} /$. & 7.52 & $10 \%$ & $\mathrm{~S} /$. & 3.76 \\
\hline Inscripción de seguridad en Defensa Civil & $\mathrm{S} / \mathrm{.}$ & 15.20 & $70 \%$ & $\mathrm{~S} / \mathrm{.}$ & 10.64 & $20 \%$ & $\mathrm{~S} /$. & 3.04 & $10 \%$ & $\mathrm{~S} /$. & 1.52 \\
\hline Registro Sanitario & $\mathrm{S} /$. & 78.00 & $100 \%$ & $\mathrm{~S} /$. & 78.00 & $0 \%$ & $\mathrm{~S} /$. & - & $0 \%$ & $\mathrm{~S} /$. & - \\
\hline Habilitación sanitaria y HACCP & $\mathrm{S} /$. & 197.06 & $100 \%$ & $\mathrm{~S} /$. & 197.06 & $0 \%$ & $\mathrm{~S} /$. & - & $0 \%$ & $\mathrm{~S} /$. & - \\
\hline Carnet de sanidad & $\mathrm{S} /$. & 9.72 & $100 \%$ & S/. & 9.72 & $0 \%$ & $\mathrm{~S} /$. & - & $0 \%$ & $\mathrm{~S} /$. & - \\
\hline Defensa Civil & $\mathrm{S} /$. & 23.00 & $70 \%$ & $\mathrm{~S} /$. & 16.10 & $20 \%$ & $\mathrm{~S} /$. & 4.60 & $10 \%$ & S/. & 2.30 \\
\hline TOTAL LICENCIAS Y AUTORIZACIONES & $\mathrm{S} /$. & 360.58 & & S/. 3 & 337.84 & & S/. & 15.16 & & $\mathrm{~S} /$. & 7.58 \\
\hline \multicolumn{12}{|l|}{ SOFTWARE } \\
\hline Antivirus & $\mathrm{S} /$. & 88.50 & $25 \%$ & $\mathrm{~S} /$. & 22.13 & $50 \%$ & $\mathrm{~S} /$. & 44.25 & $25 \%$ & $\mathrm{~S} /$. & 22.13 \\
\hline TOTAL SOFTWARE & $\mathrm{S} /$. & 88.50 & & S/. & 22.13 & & $\mathrm{~S} /$. & 44.25 & & $\mathrm{~S} / .2$ & 22.13 \\
\hline TOTAL ACTIVOS INTANGIBLES & $\mathrm{S} /$. & 997.69 & & $\mathrm{~S} /$. & 444.71 & & S/. 2 & 45.05 & & S/. 30 & 7.93 \\
\hline
\end{tabular}




\section{Anexo 22- Inversión de capital de trabajo (soles)}

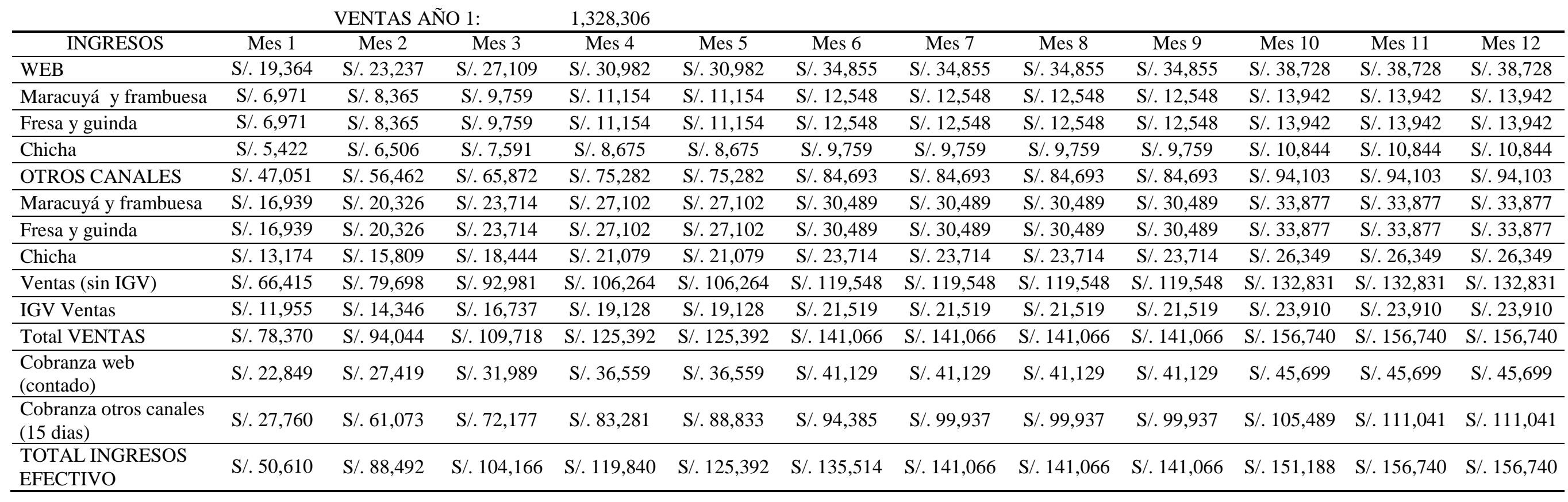




\section{Anexo 23- Inversión en Capital de Trabajo Egresos en Materiales y Personal}

\begin{tabular}{|c|c|c|c|c|c|c|c|c|c|c|c|c|}
\hline $\begin{array}{l}\text { EGRESOS } \\
\text { EFECTIVO }\end{array}$ & Mes 1 & Mes 2 & Mes 3 & Mes 4 & Mes 5 & Mes 6 & Mes 7 & Mes 8 & Mes 9 & Mes 10 & Mes 11 & Mes 12 \\
\hline Materiales & S/. 42,352 & S/. 46,862 & S/. 49,317 & S/. 55,332 & S/. 55,523 & S/. 56,797 & S/. 57,592 & S/. 61,171 & S/. 61,638 & S/. 63,670 & S/. 62,799 & S/. 62,954 \\
\hline $\begin{array}{l}\text { Material directo o } \\
\text { materia prima }\end{array}$ & S/. 34,269 & S/. 38,831 & S/. 40,431 & S/. 45,354 & S/. 45,543 & S/. 46,503 & S/. 46,789 & S/. 50,517 & S/. 50,579 & S/. 52,127 & S/. 51,415 & S/. 51,239 \\
\hline Material de empaque & S/. 735 & S/. 882 & S/. 1,029 & S/. 1,176 & S/. 1,176 & S/. 1,323 & S/. 1,323 & S/. 1,323 & S/. 1,323 & S/. 1,470 & S/. 1,470 & S/. 1,470 \\
\hline $\begin{array}{l}\text { Utensilios de } \\
\text { produccion }\end{array}$ & $\mathrm{S} / .0$ & $\mathrm{~S} / .0$ & S/. 0 & S/. 0 & S/. 0 & S/. 0 & S/. 0 & S/. 0 & S/. 0 & $\mathrm{~S} / .0$ & S/. 0 & S/. 642 \\
\hline Uniformes & & & & & & S/. 308 & & & & & & \\
\hline Material de oficina & S/. 554 & S/. 0 & $\mathrm{~S} / .0$ & S/. 361 & S/. 0 & S/. 0 & S/. 361 & S/. 0 & S/. 0 & S/. 361 & S/. 0 & $\mathrm{~S} / .0$ \\
\hline Material de limpieza & S/. 334 & $\mathrm{~S} / .0$ & S/. 334 & S/. 0 & S/. 334 & $\mathrm{~S} / .0$ & S/. 334 & $\mathrm{~S} / .0$ & S/. 334 & S/. 0 & S/. 334 & S/. 0 \\
\hline IGV Materiales & S/. 6,461 & S/. 7,148 & S/. 7,523 & S/. 8,440 & S/. 8,470 & S/. 8,664 & S/. 8,785 & S/. 9,331 & S/. 9,402 & S/. 9,712 & S/. 9,579 & S/. 9,603 \\
\hline Personal & S/. 18,923 & S/. 18,923 & S/. 18,923 & S/. 18,923 & S/. 23,625 & S/. 18,923 & S/. 27,604 & S/. 19,705 & S/. 18,923 & S/. 18,923 & $\mathrm{~S} / .23,625$ & S/. 27,604 \\
\hline Gerente General & S/. 5,000 & S/. 5,000 & S/. 5,000 & S/. 5,000 & S/. 5,000 & S/. 5,000 & S/. 5,000 & S/. 5,000 & S/. 5,000 & S/. 5,000 & S/. 5,000 & S/. 5,000 \\
\hline $\begin{array}{l}\text { Asistente } \\
\text { Administrativo }\end{array}$ & S/. 1,200 & S/. 1,200 & S/. 1,200 & S/. 1,200 & S/. 1,200 & S/. 1,200 & S/. 1,200 & S/. 1,200 & S/. 1,200 & S/. 1,200 & S/. 1,200 & S/. 1,200 \\
\hline Jefe de Ventas & S/. 2,000 & $\mathrm{S} / .2,000$ & S/. 2,000 & S/. 2,000 & S/. 2,000 & S/. 2,000 & S/. 2,000 & $\mathrm{S} / .2,000$ & S/. 2,000 & S/. 2,000 & S/. 2,000 & S/. 2,000 \\
\hline Ejecutivo de Ventas & S/. 1,200 & S/. 1,200 & S/. 1,200 & S/. 1,200 & S/. 1,200 & S/. 1,200 & S/. 1,200 & S/. 1,200 & S/. 1,200 & S/. 1,200 & S/. 1,200 & S/. 1,200 \\
\hline Community Manager & S/. 1,200 & S/. 1,200 & S/. 1,200 & S/. 1,200 & S/. 1,200 & S/. 1,200 & S/. 1,200 & S/. 1,200 & S/. 1,200 & S/. 1,200 & S/. 1,200 & S/. 1,200 \\
\hline $\begin{array}{l}\text { Jefe de Producción y } \\
\text { Logística }\end{array}$ & S/. 3,000 & S/. 3,000 & S/. 3,000 & S/. 3,000 & S/. 3,000 & S/. 3,000 & S/. 3,000 & S/. 3,000 & S/. 3,000 & S/. 3,000 & S/. 3,000 & S/. 3,000 \\
\hline Operario & S/. 2,550 & S/. 2,550 & $\mathrm{S} / .2,550$ & S/. 2,550 & S/. 2,550 & S/. 2,550 & S/. 2,550 & S/. 2,550 & S/. 2,550 & S/. 2,550 & S/. 2,550 & S/. 2,550 \\
\hline Bonos & S/. 1,100 & S/. 1,100 & S/. 1,100 & S/. 1,100 & S/. 1,100 & S/. 1,100 & S/. 1,100 & S/. 1,100 & S/. 1,100 & S/. 1,100 & S/. 1,100 & S/. 1,100 \\
\hline SCTR & S/. 111 & S/. 111 & S/. 111 & S/. 111 & S/. 111 & S/. 111 & S/. 111 & $\mathrm{~S} / .111$ & S/. 111 & S/. 111 & S/. 111 & S/. 111 \\
\hline Gratificación & & & & & & & S/. 8,681 & & & & & S/. 8,681 \\
\hline CTS & & & & & S/. 4,702 & & & & & & S/. 4,702 & \\
\hline ESSALUD & S/. 1,562 & S/. 1,562 & S/. 1,562 & S/. 1,562 & S/. 1,562 & S/. 1,562 & S/. 1,562 & S/. 2,344 & S/. 1,562 & S/. 1,562 & S/. 1,562 & S/. 1,562 \\
\hline
\end{tabular}




\section{Anexo 24 - Capital de Trabajo: Egresos en Servicios}

\begin{tabular}{|c|c|c|c|c|c|c|c|c|c|c|c|c|}
\hline Servicios & S/. 23,040 & S/. 23,439 & S/. 23,977 & S/. 24,938 & S/. 24,512 & S/. 28,337 & S/. 25,775 & S/. 25,337 & S/. 25,351 & S/. 26,312 & S/. 25,875 & S/. 29,111 \\
\hline Energía Eléctrica & S/. 847 & S/. 965 & S/. 1,082 & S/. 1,191 & S/. 1,198 & S/. 1,308 & S/. 1,308 & S/. 1,308 & S/. 1,316 & S/. 1,425 & S/. 1,425 & S/. 1,425 \\
\hline Agua & S/. 424 & S/. 482 & S/. 541 & S/. 595 & S/. 599 & S/. 654 & S/. 654 & S/. 654 & S/. 658 & S/. 713 & S/. 713 & S/. 713 \\
\hline Arbitrios & S/. 438 & S/. 0 & $\mathrm{~S} / .0$ & S/. 438 & S/. 0 & $\mathrm{~S} / .0$ & S/. 438 & $\mathrm{~S} / .0$ & S/. 0 & S/. 438 & S/. 0 & S/. 0 \\
\hline Servicio de teléfono - internet & S/. 186 & S/. 186 & S/. 186 & S/. 186 & S/. 186 & S/. 186 & S/. 186 & S/. 186 & S/. 186 & S/. 186 & S/. 186 & S/. 186 \\
\hline Alquiler local & S/. 12,882 & S/. 12,882 & S/. 12,882 & S/. 12,882 & S/. 12,882 & S/. 12,882 & S/. 12,882 & S/. 12,882 & S/. 12,882 & S/. 12,882 & S/. 12,882 & S/. 12,882 \\
\hline Servicio de contabilidad & S/. 847 & S/. 847 & S/. 847 & S/. 847 & S/. 847 & S/. 847 & S/. 847 & S/. 847 & S/. 847 & S/. 847 & S/. 847 & S/. 847 \\
\hline $\begin{array}{l}\text { Servicio de limpieza } \\
\text { (honorarios) }\end{array}$ & S/. 1,000 & S/. 1,000 & S/. 1,000 & S/. 1,000 & S/. 1,000 & S/. 1,000 & S/. 1,000 & S/. 1,000 & S/. 1,000 & S/. 1,000 & S/. 1,000 & S/. 1,000 \\
\hline Servicio de seguridad & S/. 2,203 & S/. 2,203 & S/. 2,203 & S/. 2,203 & S/. 2,203 & S/. 2,203 & S/. 2,203 & S/. 2,203 & S/. 2,203 & S/. 2,203 & S/. 2,203 & $\mathrm{S} / .2,203$ \\
\hline Recarga de extintores & $\mathrm{S} / .0$ & $\mathrm{~S} / .0$ & $\mathrm{~S} / .0$ & $\mathrm{~S} / .0$ & S/. 0 & S/. 0 & $\mathrm{~S} / .0$ & S/. 0 & $\mathrm{~S} / .0$ & S/. 0 & $\mathrm{~S} / .0$ & S/. 200 \\
\hline $\begin{array}{l}\text { Mantenimiento de maquinarias } \\
\text { y equipos }\end{array}$ & S/. 0 & S/. 0 & S/. 0 & $\mathrm{~S} / .0$ & S/. 0 & S/. 2,542 & S/. 0 & $\mathrm{~S} / .0$ & $\mathrm{~S} / .0$ & $\mathrm{~S} / .0$ & $\mathrm{~S} / .0$ & S/. 2,542 \\
\hline $\begin{array}{l}\text { Poliza de seguro contra robo y } \\
\text { otros }\end{array}$ & S/. 254 & S/. 254 & S/. 254 & S/. 254 & S/. 254 & S/. 254 & S/. 254 & S/. 254 & S/. 254 & S/. 254 & S/. 254 & S/. 254 \\
\hline $\begin{array}{l}\text { Servicio de motorizado } \\
\text { (honorarios) }\end{array}$ & S/. 1,000 & S/. 1,030 & S/. 1,060 & S/. 1,090 & S/. 1,090 & S/. 1,120 & S/. 1,120 & S/. 1,120 & S/. 1,120 & S/. 1,150 & S/. 1,150 & S/. 1,150 \\
\hline Servicio transporte distribución & S/. 1,780 & S/. 2,288 & S/. 2,542 & S/. 2,797 & S/. 2,797 & S/. 3,305 & S/. 3,305 & S/. 3,305 & S/. 3,305 & S/. 3,559 & S/. 3,559 & S/. 3,559 \\
\hline IGV Servicios & S/. 1,178 & S/. 1,301 & S/. 1,378 & S/. 1,453 & S/. 1,455 & S/. 2,034 & S/. 1,577 & S/. 1,577 & S/. 1,579 & S/. 1,654 & S/. 1,654 & $\mathrm{S} / .2,148$ \\
\hline Promocion y Publicidad & S/. 8,520 & S/. 7,720 & S/. 8,020 & S/. 8,520 & S/. 8,020 & S/. 7,720 & S/. 8,820 & S/. 7,720 & S/. 8,020 & S/. 8,520 & S/. 7,720 & S/. 8,020 \\
\hline Facebook Ads & S/. 85 & S/. 85 & S/. 85 & S/. 85 & S/. 85 & S/. 85 & S/. 85 & S/. 85 & S/. 85 & $\mathrm{~S} / .85$ & S/. 85 & S/. 85 \\
\hline Tripticos & S/. 271 & S/. 271 & S/. 271 & S/. 271 & S/.271 & S/. 271 & S/. 271 & S/.271 & S/. 271 & S/. 271 & S/. 271 & S/. 271 \\
\hline Degustaciones por 6 horas & S/. 6,102 & S/. 6,102 & S/. 6,102 & S/. 6,102 & S/. 6,102 & S/. 6,102 & S/. 6,102 & S/. 6,102 & S/. 6,102 & S/. 6,102 & S/. 6,102 & S/. 6,102 \\
\hline Uniformes (Polos) & S/. 0 & S/. 0 & S/. 254 & S/. 0 & S/. 254 & S/. 0 & S/. 254 & S/. 0 & S/. 254 & S/. 0 & S/. 0 & S/. 254 \\
\hline Permisos de Volantes/Tripticos & S/. 85 & S/. 85 & S/. 85 & S/. 85 & S/. 85 & $\mathrm{~S} / .85$ & $\mathrm{~S} / .85$ & S/. 85 & $\mathrm{~S} / .85$ & S/. 85 & $\mathrm{~S} / .85$ & S/. 85 \\
\hline Banner & S/. 678 & $\mathrm{~S} / .0$ & $\mathrm{~S} / .0$ & S/. 678 & $\mathrm{~S} / .0$ & $\mathrm{~S} / .0$ & S/. 678 & S/. 0 & $\mathrm{~S} / .0$ & S/. 678 & $\mathrm{~S} / .0$ & S/. 0 \\
\hline IGV Promocion y Publicidad & S/. 1,300 & S/. 1,178 & S/. 1,223 & S/. 1,300 & S/. 1,223 & S/. 1,178 & S/. 1,345 & S/. 1,178 & S/. 1,223 & $\mathrm{S} / .1,300$ & S/. 1,178 & $\mathrm{~S} / .1,223$ \\
\hline
\end{tabular}


Anexo 25 - Capital de Trabajo: Egresos en Impuestos y Préstamo

\begin{tabular}{|c|c|c|c|c|c|c|c|c|c|c|c|c|}
\hline \multicolumn{2}{|c|}{ EGRESOS EFECTIVO } & \multirow[t]{2}{*}{$\begin{array}{c}\text { Mes } \\
1 \\
\end{array}$} & \multirow{2}{*}{$\begin{array}{r}\text { Mes } 3 \\
\text { S/. } 701\end{array}$} & \multirow{2}{*}{$\begin{array}{r}\text { Mes } 4 \\
\text { S/. } 818\end{array}$} & \multirow{2}{*}{$\begin{array}{l}\text { Mes } \\
5 \\
\text { S/. } 935\end{array}$} & Mes 6 & Mes 7 & Mes 8 & Mes 10 & Mes 11 & \multicolumn{2}{|c|}{ Mes 12} \\
\hline Impuestos & S/. 0 & & & & & S/. 935 & S/. 6,792 & S/. 10,423 & S/. 10,148 & S/. 10,038 & S/. 11,995 & S/. 12,269 \\
\hline $\begin{array}{r}\text { Pago IGV (al } \\
\text { mc }\end{array}$ & $\begin{array}{l}\text { estado) - Del } \\
\text { dulo de IGV }\end{array}$ & S/. 0 & S/. 0 & $\mathrm{~S} / .0$ & S/. 0 & $\mathrm{~S} / .0$ & S/. 5,740 & S/. 9,371 & S/. 9,096 & S/. 8,986 & S/. 10,826 & S/. 11,101 \\
\hline $\begin{array}{r}\text { PAGO A CUENTA } \\
\mathrm{F}\end{array}$ & $\begin{array}{l}\text { IMPUESTO } \\
\text { ENTA }(1 \%)\end{array}$ & S/. 584 & S/. 701 & S/. 818 & S/. 935 & S/. 935 & S/. 1,051 & S/. 1,051 & S/. 1,051 & S/. 1,051 & S/. 1,168 & S/. 1,168 \\
\hline Prestamo & S/. 5,959 & S/. 5,959 & S/. 5,959 & S/. 5,959 & S/. 5,959 & S/. 5,959 & S/. 5,959 & S/. 5,959 & S/. 5,959 & S/. 5,959 & $\mathrm{S} / .5,959$ & S/. 5,959 \\
\hline Cuotas prestamos & S/. 5,959 & S/. 5,959 & S/. 5,959 & S/. 5,959 & S/. 5,959 & S/. 5,959 & S/. 5,959 & S/. 5,959 & S/. 5,959 & S/. 5,959 & S/. 5,959 & S/. 5,959 \\
\hline Total egresos efectivo & S/. 88,948 & S/. 92,065 & $\begin{array}{r}\text { S/. } \\
95,200\end{array}$ & $\begin{array}{r}\mathrm{S} / . \\
101,141\end{array}$ & $\begin{array}{r}\mathrm{S} / . \\
105,182\end{array}$ & S/. 105,002 & $\begin{array}{r}\text { S/. } \\
118,438\end{array}$ & $\begin{array}{r}\mathrm{S} / . \\
115,533\end{array}$ & S/. 115,198 & $\begin{array}{r}\mathrm{S} / . \\
117,281\end{array}$ & $\begin{array}{r}\mathrm{S} / . \\
121,700\end{array}$ & $\begin{array}{r}\mathrm{S} / . \\
129,627\end{array}$ \\
\hline $\begin{array}{l}\text { Saldo de caja (ingresos } \\
\text { - egresos) }\end{array}$ & $-\mathrm{S} / .44,887$ & $-\mathrm{S} / .14,321$ & $\begin{array}{r}-\mathrm{S} / \\
3,670 \\
\end{array}$ & $\mathrm{~S} / .4,175$ & S/. 5,108 & S/. 14,101 & S/. 5,639 & S/. 8,543 & S/. 8,878 & S/. 15,608 & S/. 16,163 & S/. 8,236 \\
\hline Saldo de caja inicial & S/. 0 & $-\mathrm{S} / .44,887$ & $\begin{array}{r}-\mathrm{S} / \\
59,208 \\
\end{array}$ & $\begin{array}{r}-\mathrm{S} / . \\
62,878 \\
\end{array}$ & $\begin{array}{r}-\mathrm{S} / . \\
58,702 \\
\end{array}$ & -S/. 53,594 & $-S / .39,494$ & $\begin{array}{r}-\mathrm{S} / . \\
33,855\end{array}$ & $-\mathrm{S} / .25,311$ & $-S / .16,433$ & $-S / .825$ & S/. 15,338 \\
\hline $\begin{array}{l}\text { Saldo de caja final } \\
\text { (acumulado) }\end{array}$ & $-\mathrm{S} / .44,887$ & $-\mathrm{S} / .59,208$ & $\begin{array}{r}-\mathrm{S} / \\
62,878\end{array}$ & $\begin{array}{r}-\mathrm{S} / . \\
58,702\end{array}$ & $\begin{array}{r}-\mathrm{S} / . \\
53,594\end{array}$ & -S/. 39,494 & $-\mathrm{S} / .33,855$ & $\begin{array}{r}-\mathrm{S} / . \\
25,311\end{array}$ & $-\mathrm{S} / .16,433$ & $-S / .825$ & S/. 15,338 & S/.23,574 \\
\hline
\end{tabular}




\begin{tabular}{|c|c|c|c|c|c|c|c|c|c|c|c|c|c|}
\hline $\begin{array}{l}\text { MODULO DE } \\
\text { IGV }\end{array}$ & Año 0 & Mes 1 & Mes 2 & Mes 3 & Mes 4 & Mes 5 & Mes 6 & Mes 7 & Mes 8 & Mes 9 & Mes 10 & Mes 11 & Mes 12 \\
\hline IGV Ventas & & S/. 11,955 & S/. 14,346 & S/. $\quad 16,737$ & S/. 19,128 & S/. 19,128 & S/. 21,519 & S/. 21,519 & S/. 21,519 & S/. 21,519 & S/. 23,910 & $\begin{array}{c}\mathrm{S} / . \\
23,910\end{array}$ & S/. 23,910 \\
\hline IGV Materiales & & S/. $\quad-6,461$ & S/. $\quad-7,148$ & S/. $\quad-7,523$ & S/. $\quad-8,440$ & S/. $\quad-8,470$ & S/. $\quad-8,664$ & S/. $\quad-8,785$ & S/. $\quad-9,331$ & S/. $\quad-9,402$ & S/. $\quad-9,712$ & $\begin{array}{r}\text { S/. - } \\
9,579\end{array}$ & S/. $\quad-9,603$ \\
\hline IGV Servicios & & S/. $-1,178$ & S/. $-1,301$ & S/. $\quad-1,378$ & S/. $-1,453$ & S/. $-1,455$ & S/. $-2,034$ & S/. $-1,577$ & S/. $-1,577$ & S/. $\quad-1,579$ & S/. $-1,654$ & $\begin{array}{c}\mathrm{S} / . \\
1,654\end{array}$ & S/. $-2,148$ \\
\hline IGV Promocion y & Publicidad & S/. $\quad-1,300$ & S/. $-1,178$ & S/. $-1,223$ & S/. $\quad-1,300$ & S/. $-1,223$ & S/. $-1,178$ & S/. $-1,345$ & S/. $\quad-1,178$ & S/. $-1,223$ & S/. $-1,300$ & $\begin{array}{c}\mathrm{S} / .- \\
1,178\end{array}$ & S/. $-1,223$ \\
\hline $\begin{array}{l}\text { IGV Activos } \\
\text { tangibles }\end{array}$ & S/. $-19,109$ & & & & & & & & & & & & \\
\hline $\begin{array}{l}\text { IGV Activos } \\
\text { intangibles }\end{array}$ & S/. $\quad-730$ & & & & & & & & & & & & \\
\hline $\begin{array}{l}\text { IGV Gastos } \\
\text { preoperativos }\end{array}$ & S/. $-18,627$ & & & & & & & & & & & & \\
\hline IGV Neto & -38.467 & 3,017 & 4,719 & 6,612 & 7,934 & 7,979 & 9,643 & 9,811 & 9,433 & 9,314 & 11,243 & 11,498 & 10,935 \\
\hline Credito fiscal & $-38,467$ & $-35,450$ & $-30,731$ & $-24,119$ & $-16,185$ & $-8,205$ & 0 & 0 & 0 & 0 & 0 & 0 & 0 \\
\hline Pago de IGV & 0 & - & - & - & - & - & 1,438 & 9,811 & 9,433 & 9,314 & 11,243 & 11,498 & 10,935 \\
\hline
\end{tabular}


Anexo 26 - Costos: Costo variable y fijos

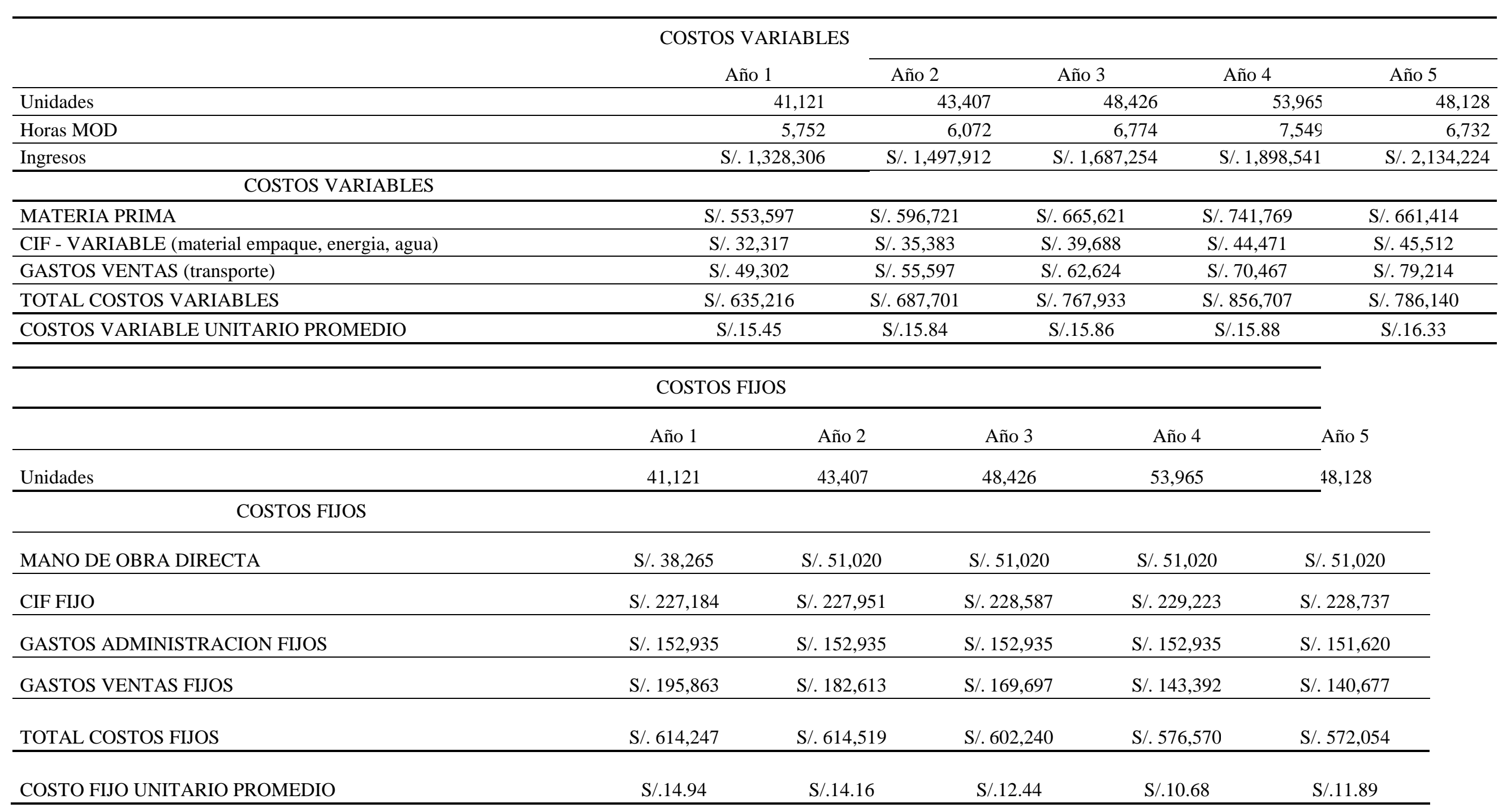


Material de Empaque

\begin{tabular}{|c|c|c|c|c|c|c|c|}
\hline Material empaque & $\begin{array}{l}\text { Costo } \\
\text { unitario }\end{array}$ & Nov - Dic & 2018 & 2019 & 2020 & 2021 & 2022 \\
\hline $\begin{array}{l}\text { Cajas de carton de embalaje (6 botellas por } \\
\text { caja) }\end{array}$ & S/. 2.12 & S/. $1,557.20$ & S/. $14,521.19$ & S/. 15,328.39 & S/. 17,099.58 & S/. $19,057.20$ & S/. 16,995.76 \\
\hline Cintas de embalaje (Rollo para 50 cajas) & S/. 1.27 & S/. 19.07 & S/. 175.42 & S/. 184.32 & S/. 205.93 & S/. 228.81 & S/. 204.66 \\
\hline Total material empaque (Sin IGV) & & S/. 1,576.27 & S/. 14,696.61 & S/. $15,512.71$ & S/. $17,305.51$ & S/. 19,286.02 & S/. $17,200.42$ \\
\hline IGV & $18 \%$ & S/. 283.73 & S/. 2,645.39 & S/. 2,792.29 & S/. 3,114.99 & S/. $3,471.48$ & S/. 3,096.08 \\
\hline Total material empaque (Con IGV) & & S/. $1,860.00$ & S/. $17,342.00$ & $\mathrm{~S} / .18,305.00$ & S/. $20,420.50$ & S/. 22,757.50 & $\mathrm{S} / .20,296.50$ \\
\hline
\end{tabular}

Utensilios de Producción

\begin{tabular}{|c|c|c|c|c|c|c|c|c|}
\hline Utensilios de producción & $\begin{array}{c}\text { Precio } \\
\text { unitario } \\
\text { (con IGV) }\end{array}$ & $\begin{array}{c}\text { Costo } \\
\text { unitario } \\
\text { (sin IGV) }\end{array}$ & Nov-Dic & 2018 & 2019 & 2020 & 2021 & 2022 \\
\hline Cuchillos & S/. 41.73 & $\mathrm{~S} / .35 .36$ & $\mathrm{~S} / .212 .19$ & S/. 212.19 & S/. 212.19 & S/. 212.19 & S/. 212.19 & S/. 212.19 \\
\hline Lupas & S/. 44.84 & S/. 38.00 & S/. 76.00 & $\mathrm{~S} / .76 .00$ & S/. 76.00 & $\mathrm{~S} / .76 .00$ & $\mathrm{~S} / .76 .00$ & S/. 76.00 \\
\hline Calibradores & S/. 103.84 & S/. 88.00 & S/. 176.00 & S/. 176.00 & S/. 176.00 & S/. 176.00 & S/. 176.00 & S/. 176.00 \\
\hline Tablas de cortar & S/. 25.00 & S/. 21.19 & S/. 42.37 & S/. 42.37 & S/. 42.37 & S/. 42.37 & S/. 42.37 & S/. 42.37 \\
\hline Tacho de 50 lts & S/. 80.00 & S/. 67.80 & S/. 135.59 & S/. 135.59 & S/. 135.59 & S/. 135.59 & S/. 135.59 & S/. 135.59 \\
\hline Total utensilios de produccion (Sin IGV) & & & S/. 642.15 & S/. 642.15 & S/. 642.15 & S/. 642.15 & S/. 642.15 & S/. 642.15 \\
\hline IGV & & $18 \%$ & S/. 115.59 & S/. 115.59 & S/. 115.59 & S/. 115.59 & S/. 115.59 & $\mathrm{~S} / .115 .59$ \\
\hline Total utensilios de produccion (Con IGV) & & & S/. 757.74 & S/. 757.74 & S/. 757.74 & S/. 757.74 & S/. 757.74 & S/. 757.74 \\
\hline
\end{tabular}


Uniformes

\begin{tabular}{|c|c|c|c|c|c|c|c|}
\hline Uniformes (soles) & $\begin{array}{l}\text { Costo unitario } \\
(\sin \mathrm{IGV})\end{array}$ & Nov-Dic & 2018 & 2019 & 2020 & 2021 & 2022 \\
\hline Mandiles & S/. 16.95 & S/. 50.85 & S/. 50.85 & S/. 135.59 & S/. 135.59 & S/. 135.59 & S/. 135.59 \\
\hline Botas & S/. 21.19 & S/. 63.56 & S/. 63.56 & S/. 169.49 & S/. 169.49 & S/. 169.49 & S/. 169.49 \\
\hline Mascarillas & $\mathrm{S} / .6 .78$ & S/. 20.34 & S/. 20.34 & S/. 54.24 & S/. 54.24 & S/. 54.24 & S/. 54.24 \\
\hline Gorros & $\mathrm{S} / .8 .47$ & $\mathrm{~S} / .25 .42$ & S/. 25.42 & S/. 67.80 & S/. 67.80 & S/. 67.80 & S/. 67.80 \\
\hline Guantes & S/. 15.25 & S/. 45.76 & S/. 45.76 & S/. 122.03 & S/. 122.03 & S/. 122.03 & $\mathrm{~S} / .122 .03$ \\
\hline Chaquetin & S/. 16.95 & S/. 50.85 & S/. 50.85 & S/. 135.59 & S/. 135.59 & S/. 135.59 & S/. 135.59 \\
\hline Pantalones & S/. 16.95 & S/. 50.85 & S/. 50.85 & S/. 135.59 & S/. 135.59 & S/. 135.59 & S/. 135.59 \\
\hline Total uniformes (Sin IGV) & & S/. 307.63 & S/. 307.63 & S/. 820.34 & S/. 820.34 & S/. 820.34 & S/. 820.34 \\
\hline IGV & & S/. 55.37 & S/. 55.37 & S/. 147.66 & S/. 147.66 & S/. 147.66 & S/. 147.66 \\
\hline Total uniformes (Con IGV) & & S/. 363.00 & S/. 363.00 & S/. 968.00 & S/. 968.00 & S/. 968.00 & S/. 968.00 \\
\hline
\end{tabular}

Materiales de limpieza

\begin{tabular}{|c|c|c|c|c|c|c|}
\hline MATERIALES DE LIMPIEZA & $\begin{array}{c}\% \\
\text { Asignación }\end{array}$ & 2018 & 2019 & 2020 & 2021 & 2022 \\
\hline MATERIALES DE LIMPIEZA - OPERACIONES & $70.0 \%$ & S/. $1,403.80$ & S/. $1,403.80$ & S/. $1,403.80$ & S/. $1,403.80$ & S/. $1,403.80$ \\
\hline MATERIALES DE LIMPIEZA - GASTOS DE VENTAS & $15.0 \%$ & S/. 300.81 & S/. 300.81 & S/. 300.81 & S/. 300.81 & S/. 300.81 \\
\hline MATERIALES DE LIMPIEZA - GASTOS ADMINISTRATIVOS & $15.0 \%$ & S/. 300.81 & S/. 300.81 & S/. 300.81 & S/. 300.81 & S/. 300.81 \\
\hline TOTAL COSTO DE MATERIALES DE LIMPIEZA (SIN IGV) & & S/. 2,005.42 & S/. 2,005.42 & S/. 2,005.42 & S/. 2,005.42 & S/. 2,005.42 \\
\hline IGV & & S/. 360.98 & S/. 360.98 & S/. 360.98 & S/. 360.98 & S/. 360.98 \\
\hline TOTAL COSTO DE MATERIALES DE LIMPIEZA (CON IGV) & & S/. 2,366.40 & S/. 2,366.40 & S/. 2,366.40 & S/. 2,366.40 & S/. 2,366.40 \\
\hline
\end{tabular}




\section{Anexo 27 - Detalle de Gastos Administrativos}

\begin{tabular}{|c|c|c|c|c|c|c|c|c|c|c|c|}
\hline & \multicolumn{10}{|c|}{ POR TRABAJADOR } & \multirow[t]{2}{*}{$\begin{array}{c}\text { Total } \\
\text { Planilla } \\
\text { Anual }\end{array}$} \\
\hline CARGO & $\begin{array}{c}\text { C } \\
\text { A } \\
\text { NT }\end{array}$ & $\begin{array}{c}\text { SUELDO } \\
\text { MENSUA } \\
\text { L }\end{array}$ & BONO & $\begin{array}{c}\text { SCTR } \\
\text { MENSU } \\
\text { AL }\end{array}$ & $\begin{array}{c}\text { SUB- } \\
\text { TOTAL } \\
\text { MENSU } \\
\text { AL }\end{array}$ & $\begin{array}{c}\text { SUB- } \\
\text { TOTAL } \\
\text { ANUAL }\end{array}$ & $\begin{array}{c}\text { GRAT. } \\
\text { (JUL- } \\
\text { DIC) }\end{array}$ & $\begin{array}{c}\text { ESSAL } \\
\text { UD }\end{array}$ & CTS & $\begin{array}{l}\text { Total Gasto } \\
\text { Remuneraci } \\
\text { ón Anual por } \\
\text { trabajador }\end{array}$ & \\
\hline Gerente & & $\mathrm{S} /$. & $\mathrm{S} /$. & $\mathrm{S} /$. & S/. & $\mathrm{S} /$. & S/. & S/. & S/. & $\mathrm{S} /$. & S/. \\
\hline $\begin{array}{l}\text { General } \\
\text { Asistente }\end{array}$ & 1 & 5,000 & - & - & 5,000 & 60,000 & 5,000 & 5,850 & 2,708 & 73,558 & 73,558 \\
\hline $\begin{array}{l}\text { Administrat } \\
\text { ivo } \\
\text { TOTAL }\end{array}$ & 1 & $\begin{array}{c}\text { S/. } \\
1,200\end{array}$ & S/. & S/. & $\begin{array}{c}\text { S/. } \\
1,200\end{array}$ & $\begin{array}{c}\text { S/. } \\
14,400\end{array}$ & $\begin{array}{c}\mathrm{S} / . \\
1,200\end{array}$ & $\begin{array}{c}\text { S/. } \\
1,404\end{array}$ & $\begin{array}{c}\text { S/. } \\
650\end{array}$ & $\begin{array}{c}\text { S/. } \\
17,654\end{array}$ & $\begin{array}{c}\text { S/. } \\
17,654 \\
\text { S/. } \\
91,212\end{array}$ \\
\hline
\end{tabular}

Planilla Administrativa

\begin{tabular}{|c|c|c|c|c|c|}
\hline PLANILLA ADMINISTRATIVA & Año 1 & Año 2 & Año 3 & Año 4 & Año 5 \\
\hline Basico & S/. 74,400 & S/. 74,400 & S/. 74,400 & S/. 74,400 & S/. 74,400 \\
\hline Bono & $\mathrm{S} / .0$ & $\mathrm{~S} / .0$ & $\mathrm{~S} / .0$ & $\mathrm{~S} / .0$ & $\mathrm{~S} / .0$ \\
\hline S.C.T.R & S/. 0 & S/. 0 & $\mathrm{~S} / .0$ & $\mathrm{~S} / .0$ & $\mathrm{~S} / .0$ \\
\hline Gratificación & S/. 6,200 & S/. 6,200 & S/. 6,200 & S/. 6,200 & S/. 6,200 \\
\hline CTS & S/. 3,358 & S/. 3,358 & S/. 3,358 & S/. 3,358 & S/. 3,358 \\
\hline ESSALUD & S/. 7,254 & S/. 7,254 & S/. 7,254 & S/. 7,254 & S/. 7,254 \\
\hline TOTAL PERSONAL & S/. 91,212 & S/. 91,212 & S/. 91,212 & S/. 91,212 & S/. 91,212 \\
\hline
\end{tabular}

Materiales

\begin{tabular}{|c|c|c|c|c|c|}
\hline MATERIALES & Año 1 & Año 2 & Año 3 & Año 4 & Año 5 \\
\hline Material de oficina & S/. 1,237 & S/. 1,237 & S/. 1,237 & S/. 1,237 & S/. 1,237 \\
\hline Material de limpieza & S/. 301 & S/. 301 & S/. 301 & S/. 301 & S/. 301 \\
\hline Total S/. (SIN IGV) & S/. 1,537 & S/. 1,537 & S/. 1,537 & S/. 1,537 & S/. 1,537 \\
\hline IGV & S/. 277 & S/. 277 & S/. 277 & S/. 277 & S/. 277 \\
\hline Total S/. (CON IGV) & S/. 1,814 & S/. 1,814 & S/. 1,814 & S/. 1,814 & S/. 1,814 \\
\hline
\end{tabular}


Servicios

\begin{tabular}{|c|c|c|c|c|c|}
\hline SERVICIOS & Año 1 & Año 2 & Año 3 & Año 4 & Año 5 \\
\hline Energía Eléctrica & $\mathrm{S} / .1,525$ & S/. 1,525 & S/. 1,525 & $\mathrm{~S} / .1,525$ & S/. 1,525 \\
\hline Agua & S/. 763 & S/. 763 & S/. 763 & S/. 763 & S/. 763 \\
\hline Arbitrios & S/. 263 & S/. 263 & S/. 263 & S/. 263 & S/. 263 \\
\hline Servicio de teléfono - internet & S/. 783 & $\mathrm{~S} / .783$ & $\mathrm{~S} / .783$ & S/. 783 & S/. 783 \\
\hline Alquiler local & S/. 30,917 & S/. 30,917 & S/. 30,917 & S/. 30,917 & S/. 30,917 \\
\hline Servicio de contabilidad & S/. 10,169 & S/. 10,169 & S/. 10,169 & S/. 10,169 & S/. 10,169 \\
\hline Servicio de limpieza (honorarios) & S/. 2,400 & $\mathrm{~S} / .2,400$ & S/. 2,400 & S/. 2,400 & S/. 2,400 \\
\hline Servicio de seguridad & S/. 5,288 & S/. 5,288 & S/. 5,288 & S/. 5,288 & S/. 5,288 \\
\hline Recarga de extintores & $\mathrm{S} / .40$ & $\mathrm{~S} / .40$ & $\mathrm{~S} / .40$ & $\mathrm{~S} / .40$ & $\mathrm{~S} / .40$ \\
\hline $\begin{array}{l}\text { Mantenimiento de maquinarias y } \\
\text { equipos }\end{array}$ & S/. 508 & S/. 508 & S/. 508 & S/. 508 & S/. 508 \\
\hline Poliza de seguro contra robo y otros & S/. 305 & S/. 305 & S/. 305 & S/. 305 & S/. 305 \\
\hline Servicio de motorizado (honorarios) & S/. 0 & S/. 0 & S/. 0 & S/. 0 & S/. 0 \\
\hline Servicio transporte distribución & $\mathrm{S} / .0$ & $\mathrm{~S} / .0$ & $\mathrm{~S} / .0$ & $\mathrm{~S} / .0$ & $\mathrm{~S} / .0$ \\
\hline Total Costo Servicios (sin IGV) & S/. 52,962 & S/. 52,962 & S/. 52,962 & S/. 52,962 & S/. 52,962 \\
\hline IGV & S/. 3,489 & $\mathrm{~S} / .3,489$ & S/. 3,489 & S/. 3,489 & S/. 3,489 \\
\hline Total Costo Servicios (con IGV) & S/. 56,451 & S/. 56,451 & S/. 56,451 & S/. 56,451 & S/. 56,451 \\
\hline
\end{tabular}




\section{Anexo 28 - Detalle de Gastos Ventas}

AÑO

POR TRABAJADOR

\begin{tabular}{|c|c|c|c|c|c|c|c|c|c|c|c|}
\hline CARGO & $\begin{array}{l}\text { CA } \\
\text { NT }\end{array}$ & $\begin{array}{c}\text { SUELD } \\
\text { O } \\
\text { MENSU } \\
\text { AL }\end{array}$ & $\begin{array}{c}\text { BON } \\
\text { O }\end{array}$ & $\begin{array}{l}\text { SCTR } \\
\text { MENS } \\
\text { UAL }\end{array}$ & $\begin{array}{c}\text { SUB- } \\
\text { TOTAL } \\
\text { MENSU } \\
\text { AL }\end{array}$ & $\begin{array}{c}\text { SUB- } \\
\text { TOTAL } \\
\text { ANUAL }\end{array}$ & $\begin{array}{c}\text { GRATI } \\
\text { FIC } \\
\text { (JUL- } \\
\text { DIC) }\end{array}$ & $\begin{array}{l}\text { ESSAL } \\
\text { UD }\end{array}$ & CTS & $\begin{array}{c}\text { Total } \\
\text { Gasto } \\
\text { Remunera } \\
\text { ción Anual } \\
\text { por } \\
\text { trabajador }\end{array}$ & $\begin{array}{c}\text { Total Planilla } \\
\text { Anual }\end{array}$ \\
\hline $\begin{array}{l}\text { Jefe de } \\
\text { Ventas }\end{array}$ & 1 & S/. 2,000 & $\begin{array}{l}\mathrm{S} / . \\
500\end{array}$ & S/. 0 & S/. 2,50C & S/. 30,000 & $\begin{array}{c}\mathrm{S} / . \\
2,500\end{array}$ & $\begin{array}{c}\mathrm{S} / . \\
2,925\end{array}$ & S/. 1,354 & S/. 36,779 & S/. 36,779 \\
\hline $\begin{array}{l}\text { Ejecutivo de } \\
\text { Ventas }\end{array}$ & 1 & S/. 1,200 & $\begin{array}{c}\text { S/. } \\
300\end{array}$ & S/. 0 & S/. $1,50 C$ & S/. 18,000 & $\begin{array}{c}\mathrm{S} / . \\
1,500\end{array}$ & $\begin{array}{c}\mathrm{S} / . \\
1,755\end{array}$ & S/. 813 & S/. 22,068 & S/. 22,068 \\
\hline $\begin{array}{l}\text { Community } \\
\text { Manager }\end{array}$ & 1 & S/. 1,200 & $\begin{array}{l}\mathrm{S} / . \\
300\end{array}$ & S/. 0 & S/ $1,50 \mathrm{C}$ & S/. 18,000 & $\begin{array}{c}\text { S/. } \\
1,500\end{array}$ & $\begin{array}{c}\mathrm{S} / . \\
1,755\end{array}$ & S/. 813 & S/. 22,068 & S/. 22,068 \\
\hline
\end{tabular}

Planillas Ventas

\begin{tabular}{lrrrrr}
\hline & Año 1 & \multicolumn{1}{l}{ Año 2 } & \multicolumn{1}{l}{ Año 3 } & \multicolumn{1}{l}{ Año 4 } & \multicolumn{1}{c}{ Año 5 } \\
\hline Basico & S/. 52,800 & S/. 52,800 & S/. 52,800 & S/. 52,800 & S/. 52,800 \\
\hline Bono & S/. 13,200 & S/. 13,200 & S/. 13,200 & S/. 13,200 & S/. 13,200 \\
\hline S.C.T.R & S/. 0 & S/. 0 & S/. 0 & S/. 0 & S/. 0 \\
\hline Gratificación & S/. 5,500 & S/. 5,500 & S/. 5,500 & S/. 5,500 & S/. 5,500 \\
\hline CTS & S/. 2,979 & S/. 2,979 & S/. 2,979 & S/. 2,979 & S/. 2,979 \\
\hline ESSALUD & S/. 6,435 & S/. 6,435 & S/. 6,435 & S/. 6,435 & S/. 6,435 \\
\hline TOTAL PERSONAL & S/. 80,914 & S/. 80,914 & S/. 80,914 & S/. 80,914 & S/. 80,914 \\
\hline
\end{tabular}

Materiales

$\begin{array}{lllll}\text { Año } 1 & \text { Año } 2 & \text { Año } 3 & \text { Año } 4\end{array}$

\begin{tabular}{llllll} 
Material de oficina & S/. 335 & S/. 335 & S/. 335 & S/. 335 & S/. 335 \\
\hline Material de limpieza & S/. 301 & S/. 301 & S/. 301 & S/. 301 & S/. 301 \\
\hline Total S/. (SIN IGV) & S/. 636 & S/. 636 & S/. 636 & S/. 636 & S/. 636 \\
\hline IGV & S/. 114 & S/. 114 & S/. 114 & S/. 114 & S/. 114 \\
\hline Total S/. (CON IGV) & S/.750 & S/. 750 & S/.750 & S/. 750 & S/. 750 \\
\hline
\end{tabular}


Servicios

\begin{tabular}{|c|c|c|c|c|c|}
\hline & Año 1 & Año 2 & Año 3 & Año 4 & Año 5 \\
\hline Energía Eléctrica & S/. 1,525 & S/. 1,525 & S/. 1,525 & S/. 1,525 & S/. 1,525 \\
\hline Agua & S/. 763 & S/. 763 & S/. 763 & S/. 763 & S/. 763 \\
\hline Arbitrios & S/. 263 & S/. 263 & S/. 263 & S/. 263 & S/. 263 \\
\hline Servicio de teléfono - internet & S/. 1,119 & S/. 1,119 & S/. 1,119 & S/. 1,119 & S/. 1,119 \\
\hline Alquiler local & S/. 15,458 & S/. 15,458 & S/. 15,458 & S/. 15,458 & S/. 15,458 \\
\hline Servicio de contabilidad & S/. 0 & S/. 0 & S/. 0 & S/. 0 & $\mathrm{~S} / .0$ \\
\hline Servicio de limpieza (honorarios) & S/. 1,200 & S/. 1,200 & S/. 1,200 & S/. 1,200 & S/. 1,200 \\
\hline Servicio de seguridad & S/. 2,644 & S/. 2,644 & S/. 2,644 & S/. 2,644 & S/. 2,644 \\
\hline Recarga de extintores & $\mathrm{S} / .20$ & S/. 20 & S/. 20 & S/. 20 & S/. 20 \\
\hline $\begin{array}{l}\text { Mantenimiento de maquinarias y } \\
\text { equipos }\end{array}$ & S/. 508 & S/. 508 & S/. 508 & S/. 508 & S/. 508 \\
\hline Poliza de seguro contra robo y otros & S/. 305 & S/. 305 & S/. 305 & S/. 305 & S/. 305 \\
\hline Servicio de motorizado (honorarios) & S/. 13,200 & S/. 14,378 & S/. 15,665 & S/. 17,070 & S/. 18,604 \\
\hline Servicio transporte distribución & S/. 28,475 & S/. 31,017 & S/. 33,792 & S/. 36,822 & S/. 40,132 \\
\hline Total Costo Servicios (sin IGV) & S/. 65,480 & S/. 69,200 & S/. 73,262 & S/. 77,697 & S/. 82,541 \\
\hline IGV & S/. 6,365 & S/. 6,822 & S/. 7,322 & S/. 7,867 & S/. 8,463 \\
\hline Total Costo Servicios (con IGV) & S/. 71,845 & S/. 76,023 & S/. 80,584 & S/. 85,565 & S/. 91,004 \\
\hline
\end{tabular}

Publicidad

\begin{tabular}{|c|c|c|c|c|c|}
\hline PUBLICIDAD & Año 1 & Año 2 & Año 3 & Año 4 & Año 5 \\
\hline Facebook Ads & S/. 1,017 & S/. 1,017 & S/. 1,017 & S/. 1,017 & S/. 1,017 \\
\hline Tripticos & S/. 3,254 & S/. 1,627 & S/. 1,085 & S/. 542 & S/. 542 \\
\hline Degustaciones por 4 horas & S/. 73,220 & S/. 61,017 & S/. 48,814 & S/. 24,407 & S/. 24,407 \\
\hline Uniformes (Polos) & S/. 1,271 & S/. 2,360 & S/. 2,360 & S/. 2,360 & S/. 1,271 \\
\hline Permisos de Volantes/Tripticos & S/. 1,017 & S/. 508 & S/. 339 & S/. 339 & S/. 169 \\
\hline Banner & S/. 2,712 & S/. 2,712 & S/. 2,712 & S/. 1,356 & S/. 1,356 \\
\hline Total Costo Servicios (sin IGV) & S/. 82,492 & S/. 69,241 & S/. 56,326 & S/. 30,021 & S/. 28,763 \\
\hline IGV & S/. 14,848 & S/. 12,463 & S/. 10,139 & S/. 5,404 & S/. 5,177 \\
\hline $\begin{array}{l}\text { Total Costo Servicios (con } \\
\text { IGV) }\end{array}$ & S/. 97,340 & S/. 81,705 & S/. 66,465 & S/. 35,425 & S/. 33,940 \\
\hline
\end{tabular}


Anexo 29 - Costos de Producción: Maracuyá y frambuesa

\begin{tabular}{|c|c|c|c|c|c|}
\hline & \\
\hline & Año 1 & Año 2 & Año 3 & Año 4 & Año 5 \\
\hline Unidades & 11,325 & 11,545 & 12,461 & 13,451 & 11,701 \\
\hline Horas MOD & 1,406 & 1,434 & 1,547 & 1,670 & 1,453 \\
\hline Ingresos & S/. 420,599 & S/. 458,147 & S/. 499,141 & S/. 543,903 & S/. 592,791 \\
\hline
\end{tabular}

COSTOS DE PRODUCCION

\begin{tabular}{lccccc}
\hline MATERIA PRIMA & $\mathrm{S} / .193,146$ & $\mathrm{~S} / .200,779$ & $\mathrm{~S} / .216,600$ & $\mathrm{~S} / .233,919$ & $\mathrm{~S} / .203,478$ \\
MANO DE OBRA DIRECTA & $\mathrm{S} / .12,228$ & $\mathrm{~S} / .12,228$ & $\mathrm{~S} / .12,228$ & $\mathrm{~S} / .12,228$ & $\mathrm{~S} / .12,228$ \\
CIF & $\mathrm{S} / .80,439$ & $\mathrm{~S} / .81,153$ & $\mathrm{~S} / .82,070$ & $\mathrm{~S} / .83,064$ & $\mathrm{~S} / .83,013$ \\
TOTAL COSTOS PRODUCCION & $\mathrm{S} / .285,813$ & $\mathrm{~S} / .294,160$ & $\mathrm{~S} / .310,898$ & $\mathrm{~S} / .329,211$ & $\mathrm{~S} / .298,719$ \\
\hline & & & & & \\
\hline COSTO PRODUCCION UNITARIO & $\mathrm{S} / .25 .24$ & $\mathrm{~S} / .25 .48$ & $\mathrm{~S} / .24 .95$ & $\mathrm{~S} / .24 .48$ & $\mathrm{~S} / .25 .53$ \\
\hline
\end{tabular}

\begin{tabular}{lllllll}
\hline & \multicolumn{3}{l}{ COSTO TOTAL UNITARIO } & & \\
\cline { 2 - 7 } & Año 1 & Año 2 & Año 3 & Año 4 & Año 5 \\
\hline Unidades & 11,325 & 11,545 & 12,461 & 13,451 & 11,701 \\
\hline
\end{tabular}

COSTOS TOTALES

\begin{tabular}{lccccc}
\hline MATERIA PRIMA & $\mathrm{S} / .193,146$ & $\mathrm{~S} / .200,779$ & $\mathrm{~S} / .216,600$ & $\mathrm{~S} / .223,919$ & $\mathrm{~S} / .203,478$ \\
MANO DE OBRA DIRECTA & $\mathrm{S} / .12,228$ & $\mathrm{~S} / .12,228$ & $\mathrm{~S} / .12,228$ & $\mathrm{~S} / .12,228$ & $\mathrm{~S} / .12,228$ \\
CIF & $\mathrm{S} / .80,439$ & $\mathrm{~S} / .81,153$ & $\mathrm{~S} / .82,070$ & $\mathrm{~S} / .83,064$ & $\mathrm{~S} / .83,013$ \\
GASTOS ADMINISTRACION & $\mathrm{S} / .55,057$ & $\mathrm{~S} / .55,057$ & $\mathrm{~S} / .55,057$ & $\mathrm{~S} / .55,057$ & $\mathrm{~S} / .54,583$ \\
GASTOS VENTAS & $\mathrm{S} / .85,513$ & $\mathrm{~S} / .82,083$ & $\mathrm{~S} / .78,896$ & $\mathrm{~S} / .71,022$ & $\mathrm{~S} / .71,789$ \\
\hline TOTAL COSTOS & $\mathrm{S} / .426,383$ & $\mathrm{~S} / .431,299$ & $\mathrm{~S} / .444,850$ & $\mathrm{~S} / .455,290$ & $\mathrm{~S} / .425,091$ \\
\hline & & & & \multicolumn{2}{c}{$\mathrm{S} / .33 .85$} \\
\hline COSTO TOTAL UNITARIO & $\mathrm{S} / .37 .65$ & $\mathrm{~S} / .37 .36$ & $\mathrm{~S} / .35 .70$ & & $\mathrm{~S} / .36 .33$ \\
\hline
\end{tabular}




\section{Anexo 30 - Costos de Producción: Fresa y Guinda}

\begin{tabular}{lrrrrr} 
& Año 1 & Año 2 & Año 3 & Año 4 & Año 5 \\
\cline { 2 - 6 } Unidades & 11,325 & 11,545 & 12,461 & 13,451 & 11,701 \\
Horas MOD & 1,496 & 1,525 & 1,646 & 1,777 & 1,546 \\
Ingresos & S/. 420,599 & S/. 458,147 & S/. 499,141 & S/. 543,903 & S/. 592,791 \\
\hline
\end{tabular}

COSTOS DE PRODUCCION

\begin{tabular}{|c|c|c|c|c|c|}
\hline MATERIA PRIMA & S/. 128,176 & S/. 133,241 & S/. 143,741 & S/. 155,234 & S/. 135,033 \\
\hline MANO DE OBRA DIRECTA & $\mathrm{S} / .13,009$ & S/.13,009 & $\mathrm{S} / .13,008$ & $\mathrm{~S} / .13,008$ & $\mathrm{~S} / .13,009$ \\
\hline CIF & S/. 85,574 & S/. 86,332 & S/. 87,309 & S/. 88,366 & S/. 88,311 \\
\hline TOTAL COSTOS PRODUCCION & S/. 226,758 & S/. 232,583 & S/. 244,058 & S/. 256,609 & S/. 236,353 \\
\hline COSTO PRODUCCION UNITARIO & $\mathrm{S} / .20 .02$ & S/.20.15 & S/.19.59 & S/.19.08 & S/.20.20 \\
\hline \multicolumn{6}{|c|}{ COSTO TOTAL UNITARIO } \\
\hline & Año 1 & Año 2 & Año 3 & Año 4 & Año 5 \\
\hline Unidades & 11,325 & 11,545 & 12,461 & 13,451 & 11,701 \\
\hline
\end{tabular}

COSTOS TOTALES

\begin{tabular}{|c|c|c|c|c|c|}
\hline MATERIA PRIMA & S/. 128,176 & S/. 133,241 & S/. 143,741 & S/. 155,234 & S/. 135,033 \\
\hline MANO DE OBRA DIRECTA & S/. 13,009 & S/. 13,009 & S/. 13,008 & S/. 13,008 & S/. 13,009 \\
\hline CIF & S/. 85,574 & S/. 86,332 & S/. 87,309 & S/. 88,366 & S/. 88,311 \\
\hline GASTOS ADMINISTRACION & S/.55,057 & S/.55,057 & S/.55,057 & S/.55,057 & S/.54,583 \\
\hline GASTOS VENTAS & $\mathrm{S} / .85,513$ & $\mathrm{~S} / .82,083$ & S/.78,896 & $\mathrm{S} / .71,022$ & S/.71,789 \\
\hline TOTAL COSTOS & S/. 367,328 & S/. 369,722 & S/. 378,010 & S/. 382,688 & S/. 362,725 \\
\hline COSTO TOTAL UNITARIO & S/.32.44 & $\mathrm{S} / .32 .02$ & S/.30.34 & $\mathrm{S} / .28 .45$ & $\mathrm{~S} / .31 .00$ \\
\hline
\end{tabular}




\section{Anexo 31 - Costos de Producción: Chicha}

\begin{tabular}{lrrrrr} 
& \multicolumn{1}{c}{ Año 1 } & Año 2 & Año 3 & Año 4 & Año 5 \\
\hline Unidades & 8,808 & 8,979 & 9,692 & 10,462 & 9,100 \\
Horas MOD & 1,498 & 1,527 & 1,649 & 1,780 & 1,548 \\
Ingresos & S/. 327,132 & S/. 356,337 & S/. 388,220 & S/. 423,036 & S/. 461,059 \\
\hline
\end{tabular}

\begin{tabular}{|c|c|c|c|c|c|}
\hline COSTOS DE PRODUCCION & & & & & \\
\hline MATERIA PRIMA & S/. 102,852 & S/. 106,916 & S/. 115,341 & S/. 124,564 & S/. 108,354 \\
\hline MANO DE OBRA DIRECTA & $\mathrm{S} / .13,028$ & $\mathrm{~S} / .13,028$ & $\mathrm{~S} / .13,029$ & $\mathrm{~S} / .13,029$ & $\mathrm{~S} / .13,028$ \\
\hline $\mathrm{CIF}$ & S/. 85,704 & S/. 86,457 & S/. 87,444 & S/. 88,505 & S/. 88,437 \\
\hline TOTAL COSTOS PRODUCCION & S/. 201,584 & S/. 206,401 & S/. 215,814 & S/. 226,098 & S/. 209,819 \\
\hline $\begin{array}{l}\text { COSTO PRODUCCION } \\
\text { UNITARIO }\end{array}$ & $\mathrm{S} / 22.89$ & $\mathrm{~S} / .22 .99$ & $\mathrm{~S} / .22 .27$ & $\mathrm{~S} / .21 .61$ & $\mathrm{~S} / .23 .06$ \\
\hline \multicolumn{6}{|c|}{ COSTO TOTAL UNITARIO } \\
\hline & Año 1 & Año 2 & Año 3 & Año 4 & Año 5 \\
\hline Unidades & 8,808 & 8,979 & 9,692 & 10,462 & 9,100 \\
\hline
\end{tabular}

COSTOS TOTALES

\begin{tabular}{lccccc}
\hline MATERIA PRIMA & $\mathrm{S} / .102,852$ & $\mathrm{~S} / .106,916$ & $\mathrm{~S} / .115,341$ & $\mathrm{~S} / .124,564$ & $\mathrm{~S} / .108,354$ \\
MANO DE OBRA DIRECTA & $\mathrm{S} / .13,028$ & $\mathrm{~S} / .13,028$ & $\mathrm{~S} / .13,029$ & $\mathrm{~S} / .13,029$ & $\mathrm{~S} / .13,028$ \\
CIF & $\mathrm{S} / .85,704$ & $\mathrm{~S} / .86,457$ & $\mathrm{~S} / .87,444$ & $\mathrm{~S} / .88,505$ & $\mathrm{~S} / .88,437$ \\
GASTOS ADMINISTRACION & $\mathrm{S} / .42,822$ & $\mathrm{~S} / .42,822$ & $\mathrm{~S} / 42,822$ & $\mathrm{~S} / .42,822$ & $\mathrm{~S} / .42,454$ \\
GASTOS VENTAS & $\mathrm{S} / .66,510$ & $\mathrm{~S} / .63,842$ & $\mathrm{~S} / .61,363$ & $\mathrm{~S} / .55,240$ & $\mathrm{~S} / 55,836$ \\
\hline TOTAL COSTOS & $\mathrm{S} / .310,916$ & $\mathrm{~S} / .313,066$ & $\mathrm{~S} / .319,999$ & $\mathrm{~S} / .324,160$ & $\mathrm{~S} / .308,108$ \\
\hline & & & & & \\
\hline COSTO TOTAL UNITARIO & $\mathrm{S} / .35 .30$ & $\mathrm{~S} / .34 .87$ & $\mathrm{~S} / .33 .02$ & $\mathrm{~S} / .30 .98$ & $\mathrm{~S} / .33 .86$ \\
\hline
\end{tabular}




\section{Anexo 32 - Cotizaciones}

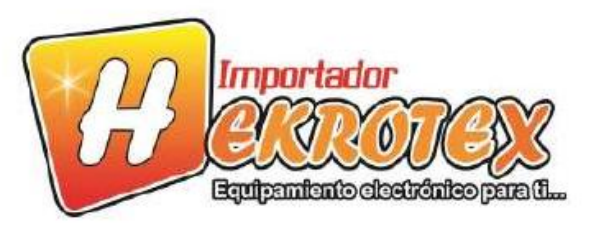

R.U.C. 20556951994

AV. LOS HEROES N 165 SAN JUAN DE MIRAFLORES LIMA
- LMAA (IRENIE A LA ESTACION ATOCONGO)

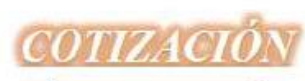

I-MAIZ: inuportailor ehekrotex.com / www.hekrotex.com

Tolófono: (O1) 2766836 RPM: 2995566739 RPC: 96930710

$N^{\circ} 000543$

$\begin{array}{ll}\text { FORMA DE PAGO } & \text { : Al contado, (Solo pago contra entrega) } \\ \text { ENTREGA } & \text { :24 horas despues del depósito, se realizara el despacho } \\ \text { GARANTIA } & : 12 \text { meses, por defecto de fabrica } \\ \text { SERVICIO TECNICO } & : \text { El traslado al centro autorizado por servicio técnico. } \\ \text { Emio hma } & : S / 30.00\end{array}$
COTIZADOA Guiselle Jimenez
LUGAR IIMA
PRODUCTO Balanza electrónica $300 \mathrm{Kg}$
VALIDEZ : 15 dias a partir de la fecha
FECHA : settembre, $02 \quad 2017$

Enrohotuo

$5 / 30.08$

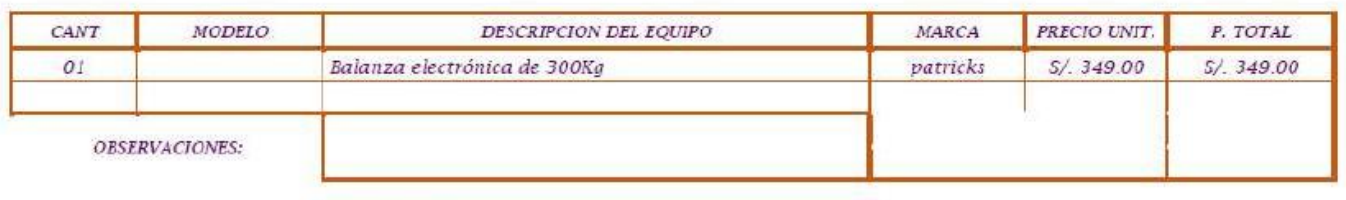

VALOR EN LETRAS

$-/ 100$ soles

COTIZADO POR :

RAQUEL SANCHE2

ACEPTADO POR:

ATENTAMENTE,

ASESORA CORPORATIVA

LADEN S.A.C.

BANCO DE CREDITO DEL PERU A NOMBRE DE LADEN S.A.C.

Cuenta comiente en soles: $\quad 194-2144423-0-37$
Cuenta comiente en ablares: $194-2294597-1-55$

Cuenta comiemte en ablar es: $194-2294597-1-55$
Ci. Cta. Imtb:
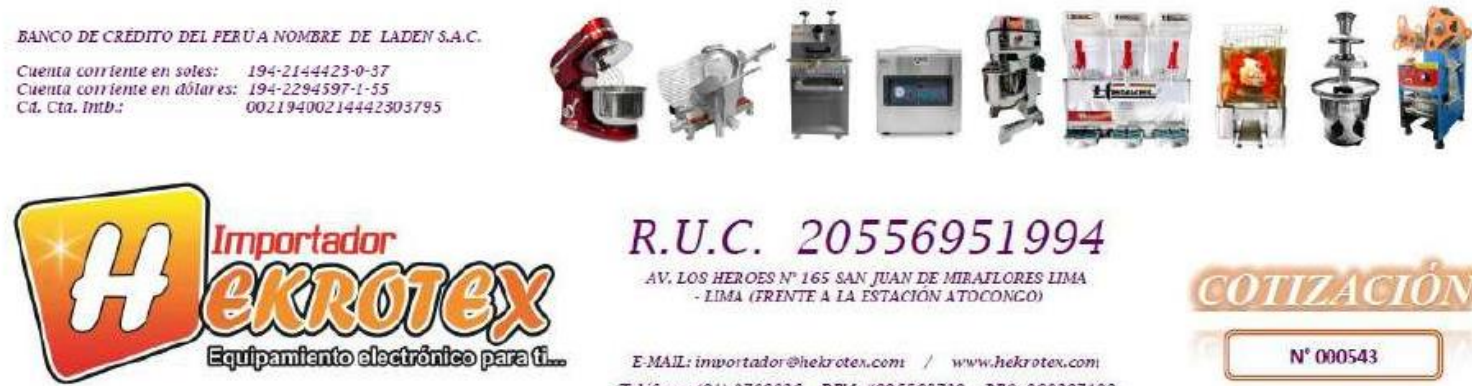

\section{R.U.C. 20556951994}

AV. LOS HEROES N 165 SAN JUAN DE MIRAALLORES LMMA

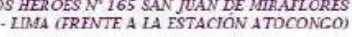

EMAIL: imvortador ehekr oter.cont / www.hekrotex.com Teléfono:(01) 2766836 RPM: \#995566739 RPC: 969307102
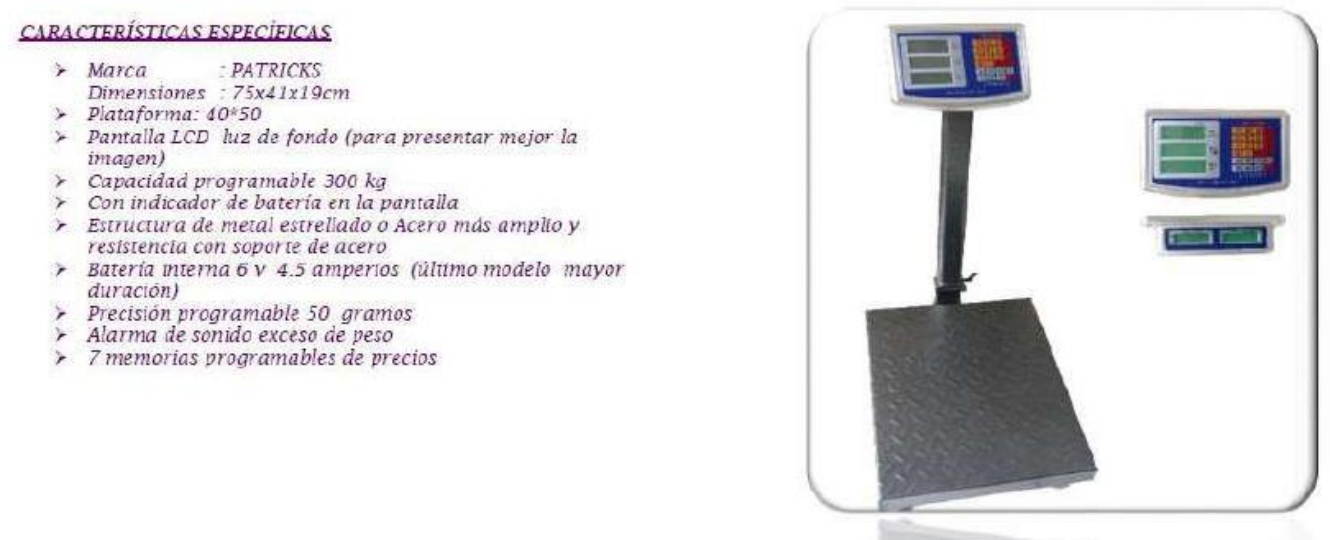

BANCO DE CREDITO DIL PERU A NOMBRE DE LADEN S.A.C

Cuenta corriente en soles: 194-2144423-0.37

cuenta comiente en dolares. 194.2294597 .1555
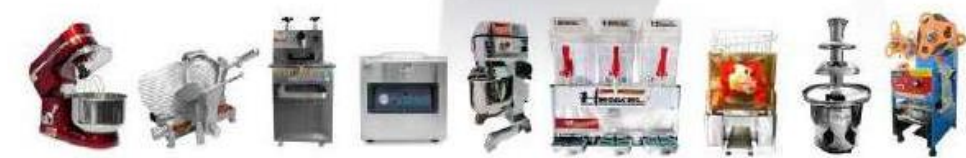


\section{-

Lima, 02 de Octubre del 2017

SEṄORES

Atención: Srta. Guiselle Jiménez requerimiento.

A través de la presente nos es grato saludarlo y extenderle nuestra cotización según su

\section{CONGELADORA DE $320 \mathrm{Lt}$.}

MEDIDAS: (exteriores) $1.00 \mathrm{mts}$ largo $\times 0.75 \mathrm{cms}$ fondo $\times 1.00 \mathrm{mts}$ alto.

\section{CARACTERISTICAS:}

- Doble sistema de enfriamiento, conservación o congelación.

- Construcción sólida en plancha de acero Satinado calidad 430 de 1/40 de espesor

- Aislamiento de poliuretano inyectado.

- Circuito refrigerante en tuberia de cobre de $3 / 8$ interns.

- 01 tapa

- 05 parades en tefirigeracior

- 04 ruedas de nylon

- Motor de $1 / 4 \mathrm{HP}$ con refrigerante ecológico.

- Puerta con manija y llave de seguridad.

PRECIO: S/ 2,900.00 incluido IGV, incluye transporte y 01 año de garantia.

FORMA DE PAGO:

- Deposito a la cuenta de la empresa o pago en efectivo

- CTA. En soles en SCOTIABANK: $043-7417215$

PLAZO DE ENTREGA: contamos con stock para entrega inmediata VALIDES DE COTIZACION: 07 dias útiles.

Sin nada más que informarle, quedo de usted.

Atentamente, 
Mensaje reenviado

De: Carlos Trujillo<ctrujillo@tramontina.com.pe>

Fecha: 22 de septiembre de 2017, 9:55

Asunto: COTIZACION CUCHILLOS

Para: Guiselle Jimenez <guiselle@kristal.group>

Estimada Guiselle

Abajo cotización requerida :

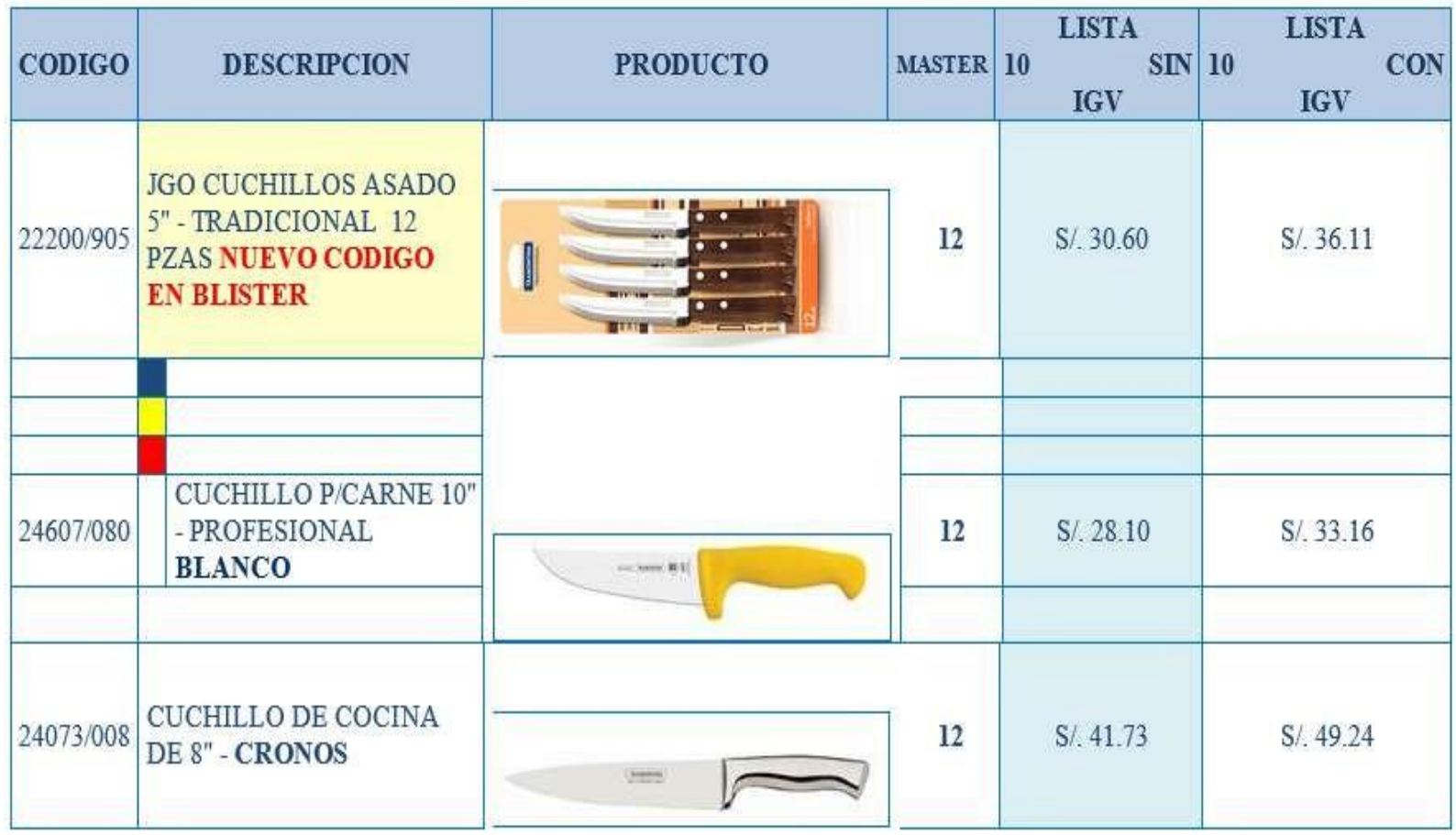

Saludos

Carlos Trujillo Martinez

Coordinador Comercial

TRAMONTINA DEL PERU S.A.C

$\underline{\text { Av. Javier Prado Este } 488 \text { Piso } 10}$

Torre Las Orquideas - San Isidro

Celular 986641588

Telf. 4212135 Anexo 205

\section{TRAMONTINA}




\section{Cork Perú S.A.}

E-mai: info@corkperu.com

Web: www.corkparu.com

RUC: 20506982465

COTZACIÓN

$N^{*}$ 111-2017110028

PERU

$$
\text { Wob: mwicorkpartcon }
$$

1170

Chomlios, 2 de Noviembre de: 2017

Setores:

TEUO SIERRA JOSEI W DEUA

Direccion : CALLOS EIECTRONICOS NRO 232 URB. RES LOS INGENEROS LIMA - LIMA - LA MOUNA

R.U.C. CALLOS EIECTRONICOS NRO 232 URB. RES LOS INGENIEROS LIMA - LIMA - LA MOUNA

Atencion

Telefono :954716341।

Referencla :

Procentamoc a uolci. Nuestra cotizaolon por lo cloulente:

\begin{tabular}{|c|c|c|c|c|c|c|}
\hline item & Codiligs & Deseripelent & Unie & Canbid & $\begin{array}{l}\text { V. Unitario } \\
\text { git }\end{array}$ & $\begin{array}{l}\text { Tolat } \\
\text { \&i }\end{array}$ \\
\hline & stoces! & 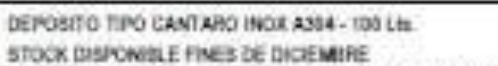 & UND & $1 \pm 000$ & 750.000300 & 5.300.04 \\
\hline & sxecte? & 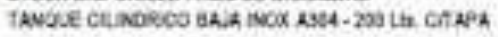 & UWD & 1000 & $1,5 x+000000$ & $1,500 \mathrm{in}$ \\
\hline
\end{tabular}

COnDECICNES CONERCULt:
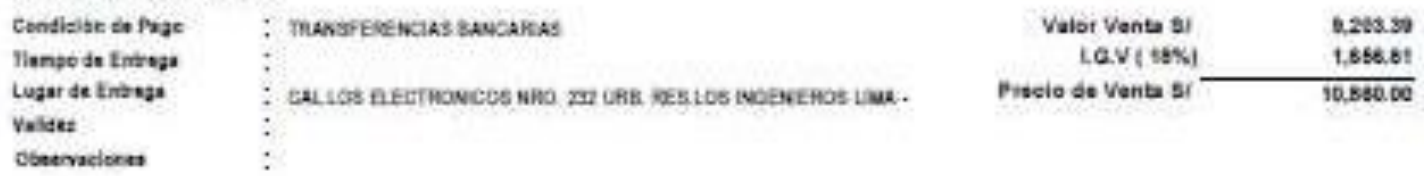

Muy Abentamente.

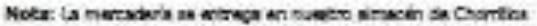

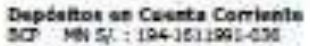

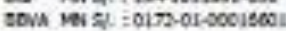

a.s: $10+1962025-10$ Nes : $0172-200000$ ic 205

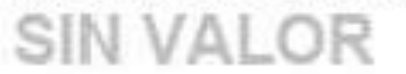

uno sobit

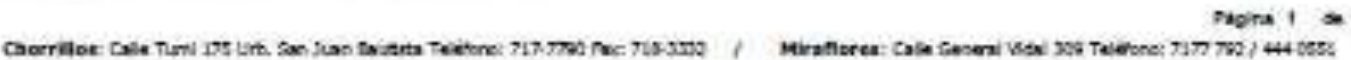


DONGGUAN XIANGBO ELECTROMECHANICAL EQUIPMENT CO,LTD

A5-B building, Waijing industrial zone, Xiansha beiwang road, Gaobu town, Dongguan city, Guangdong, China P.C 523000

TEL:+86+0769-38971477 MOB:+86-13580806509 Fax.86-0769-23156191 Email: cindy-hui@foxmail.com info@0769xb.com.cn

\section{Multi-Function Aluminum Capper}

\begin{tabular}{|c|c|c|c|c|}
\hline Item & Item Description & Product Photo & $\begin{array}{l}\text { UNIT PRICE } \\
\text { (EXW) }\end{array}$ & product function, feature \& specification \\
\hline DK-40 & $\begin{array}{l}\text { Technical Parameters: } \\
\text { Power supply } 220 \mathrm{~V} / 110 \mathrm{~V} \\
50 \mathrm{~Hz} / 60 \mathrm{~Hz} \\
\text { Capacity } 700 \text { - } \\
\text { 1000bottle/hour } \\
\text { Cap diameter: } 20-35 \mathrm{~mm} \\
\text { Bottle height } 20-300 \mathrm{~mm} \\
\text { G.W. } 70 \mathrm{kgs} \text { After } \\
\text { packing: } 85 \mathrm{~kg} \\
\text { Dimension } 700 \times 340 \times 1260 \mathrm{~mm}\end{array}$ & & USD360 & $\begin{array}{l}\text { This capper suitable for tightening metal } \\
\text { cap,alminium cap,screw metal cap for glass bottles, } \\
\text { plastic bottles, easy to operate, the machine use } \\
\text { stainless steel material, can be customized } \\
\text { according to ur size }\end{array}$ \\
\hline
\end{tabular}

1.Payment term: $\mathrm{T} / \mathrm{T} 100 \%$ before shipment)

2.Warranty: 1 year warranty, and offer maintenance forever.

3.MOQ: 1 sets

4.Delivery Date:We have machine in stock, Voltage: $110 \mathrm{~V}$ need production day 10 days

5.The price is valid within one month.

Messages Translation: - Disable $\bigcirc$ English $\bigcirc$ Espan̂ol

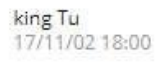


DONGGUAN XIANGBO ELECTROMECHANICAL EQUIPMENT CO,LTD

A5-B building, Waijing industrial zone,Xiansha beiwang road, Gaobu town, Dongguan city, Guangdong, China P.C 523000

TEL:+86+0769-38971477_MOB:+86-13580806509 Fax.86-0769-23156191 Email: cindy-hui@foxmail.com info@0769xb.com.cn

\begin{tabular}{|c|c|c|c|c|}
\hline Item & Item Description & Product Photo & \begin{tabular}{|c|} 
UNIT \\
PRICE \\
(EXW
\end{tabular} & product function, feature \& specification \\
\hline DGM-s80 & $\begin{array}{l}\text { Technical Parameters: } \\
\text { Voltage: } 220 \mathrm{~V} / 50 / 60 \mathrm{HZ} \\
\text { 100w } \\
\text { labeling speed: } 20- \\
\text { 40pcs/min } \\
\text { bottle dia: } 15-120 \mathrm{~mm} \\
\text { labeling width: } 26-160 \mathrm{~mm} \\
\text { labeling Lenth: } 25-\mathrm{L} 300 \\
\text { label roller size inner } \phi \\
75 \mathrm{~mm} \\
\text { label roller sizeoutter } \phi \\
275 \mathrm{~mm}\end{array}$ & & USD390 & $\begin{array}{l}\text { Purpose and introduction: } \\
\text { 1, Adhesive labeling for round bottle, round } \\
\text { jar and cylinder and so on } \\
\text { 2, Applicable for PET, Plastic, glass, metal } \\
\text { bottles and so on. } \\
\text { 3, Widely used in many industry such as } \\
\text { cosmetic, drink, food, and medicine and so } \\
\text { on, which can greatly improve productivity } \\
\text { and the quality of labeling. }\end{array}$ \\
\hline
\end{tabular}

Remark:

1.Payment term: $\mathrm{T} / \mathrm{T} 100 \%$ before shipment)

2.Warranty:ONE year warranty, and offer maintenance forever.

3.MOQ: 1sets

4.Delivery Date:3-5days

5.The price is valid within one month.

\section{DIGITAL COMPUTER SRV.}

Cotización001\#07-11-17

Lima, 07 de Noviembre de 2017

SEÑORES:

ATT:-

GUISELLE JIMENEZ 


\section{DIGITAL COMPUTER}

Lima, 07 de Noviembre de 2017

SENTORES:

ATT.-

GUISELLE JIMENEZ MEMORIA KINGSTON 8GB DDR4 2133MHZ, HDD SATA 1TB DVD-WRITER SATA LG, KIT MICROSOFT 600 TECLADO Y MOUSE CASE APEX.ADV. FUENTE REAL CERTIFICADA

Forma de Rage; CONTADO

Gacantía: Por Defectos de Fabricación Incluído IGV.

CTA BCP SOLES S/. : : : 191-31955029-0-05

CTA BCP DOLARES \$ : $\quad$ : $191-34109633-1-73$

CTA A SCOTDABANK \$ : : 009-386-213860149142-42

CTA A SCOTIABANK S/. : : 386-0149131

CTA BBVA SOLES S/. : : 0011-0921-0200189512

CTA BBVA DOLARES \$ : 0011-0921-0200189520

T/CAMBIO

: 5/ 3.29

Atentamente,

Rodolfo Justo F.

Soporte Tecnice.

RPC 992626515 - 987126581 rodolfojusto@outlook.com / roajusto@hotmail.com 


\section{DC \\ DIGITAL COMPUTER}

Lima, 07 de Noviembre de 2017

SEÑORES:

ATT.-

GUISELLE JIMENEZ

01 Multifuncional HP Laser]et Pro M127fn copia/Imprime/escanea

$\$ 252.00$

Forma de Rage: CONTADO

Garantía: Por Defectos de Fabricación

Entrega $;$ INMEDIATA

Induído IGV.

Atentamente,

Rodolfo Justo $F$.

DIGITAL COMPUTER 
TwEspacio, Twoficina CORPORACION OFFICE DECOR SAC

Av. Higuereta $N^{\circ} 414$ Surco | Lima | Perú

Teléfono: $267-8047$

RPC: 982509926 RPM\#9800-32430

ventas@officedecor.com.pe

Surco, 09 de Noviembre de 2017

\section{COTZACIÓN Nº12824}

Señor.

Presente-

Atención: Srta. Guiselle Jimenez

Estimados señores:

Mediante la presente tenemos el aqrado de diricirnos a Ustedes; en atendín a su solicitud de Cotización, para presentarle los predos de nuestros siguientes produdos:

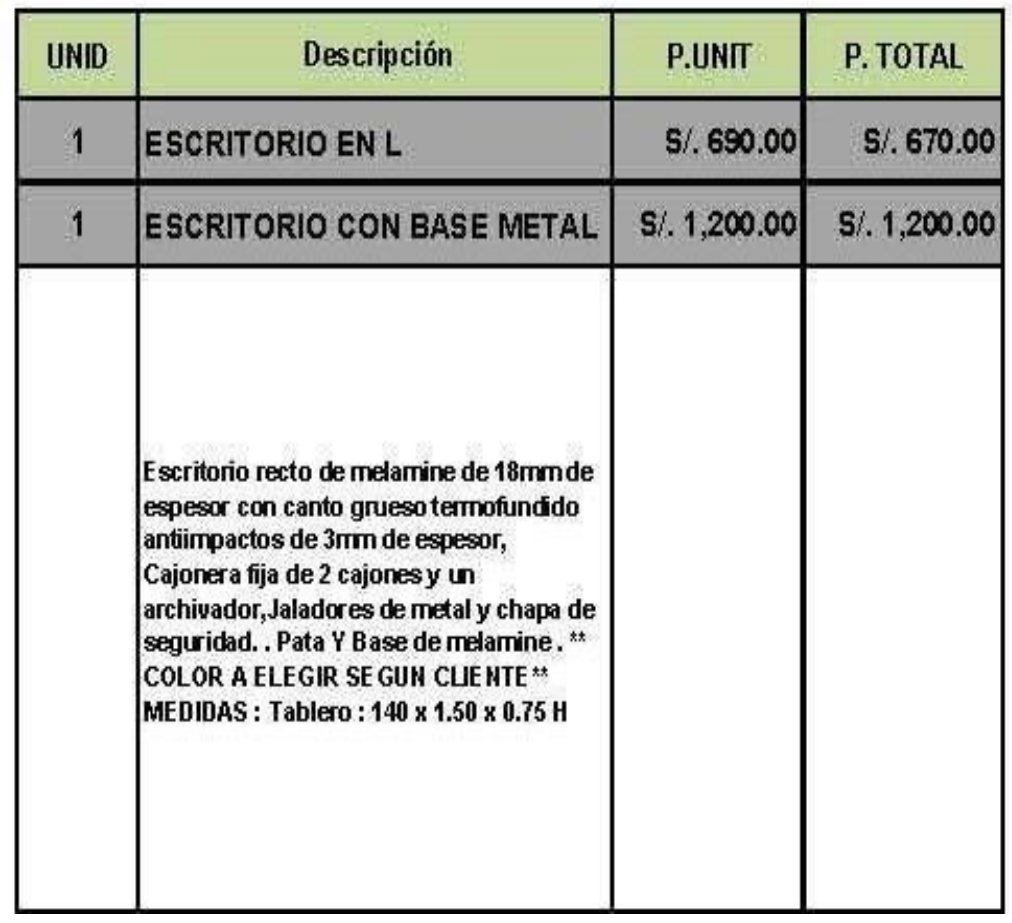

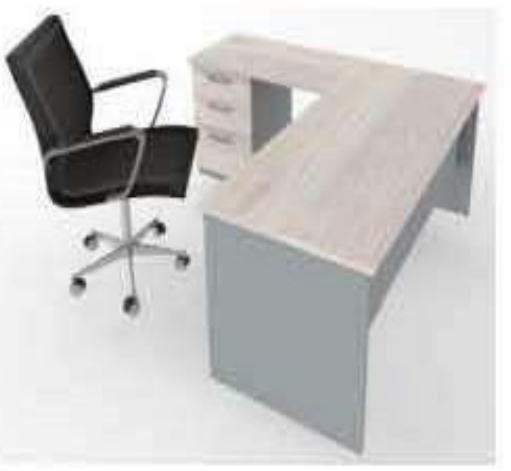




\begin{tabular}{|c|c|c|c|}
\hline 5 & $\begin{array}{l}\text { SILLA MODELO LEE RECLINABLE } \\
\text { DOBLE PALANCA }\end{array}$ & 5l. 220.00 & S. $1,100.00$ \\
\hline & $\begin{array}{l}\text { Silla de oficina giratoria económica } \\
\text { recomendable para uso doméstico. } \\
\text { Garruchas de nylon con ejes de acero de } \\
\text { alta resistencia. } \\
\text { Araña de nylon de } 5 \text { purtas. } \\
\text { Mecanismo neumático Reclinable } \\
\text { Telescopio decorativo en polipropileno. } \\
\text { Brazos de polipropileno. } \\
\text { Asierto y espaldar tapizados en tela. } \\
\text { La silla resiste un peso de } 100 \mathrm{~kg} \text {. } \\
\text { aproximadamente. } \\
\text { Medida de asierto: } 45 \times 49 \mathrm{~cm} \\
\text { Medida de espaldar: } 47 \times 43 \mathrm{~cm} \\
\text { Altura total: } 89 \text { - } 101 \mathrm{~cm} \text { (Regulable). } \\
\text { Garantiá } 1 \text { año }\end{array}$ & & \\
\hline 5 & SIL LAS NUVO & S). 300.00 & S). $1,500.00$ \\
\hline & $\begin{array}{l}\text { Silla operativa }\left(360^{\circ}\right) \text { de diseño } \\
\text { ergonómico } \\
\text { con respaldo alto con mecanismo de } \\
\text { contacto permanerte que permite regular } \\
\text { et } \\
\text { respaldo ala comodidad del ustario. } \\
\text { Base de mylon reforzada y garruchas de } \\
\text { mylon Sisterna neumático a gas que } \\
\text { permite } \\
\text { regular la altura. } \\
\text { Carcaza de polipropileno color negro. } \\
\text { Asiento muy confortable. } \\
\text { Tapizado en color a elegir por el clierte } \\
\text { ASIENTO Y RESPALD: } \\
\text { Espuma resistente, asierto con } \\
\text { bordesperimetrales redondeados. } \\
\text { Resisterte hasta } 120 \mathrm{k} \text { aprox. } \\
2 \text { AÑOS DE GARANTIA }\end{array}$ & & \\
\hline
\end{tabular}
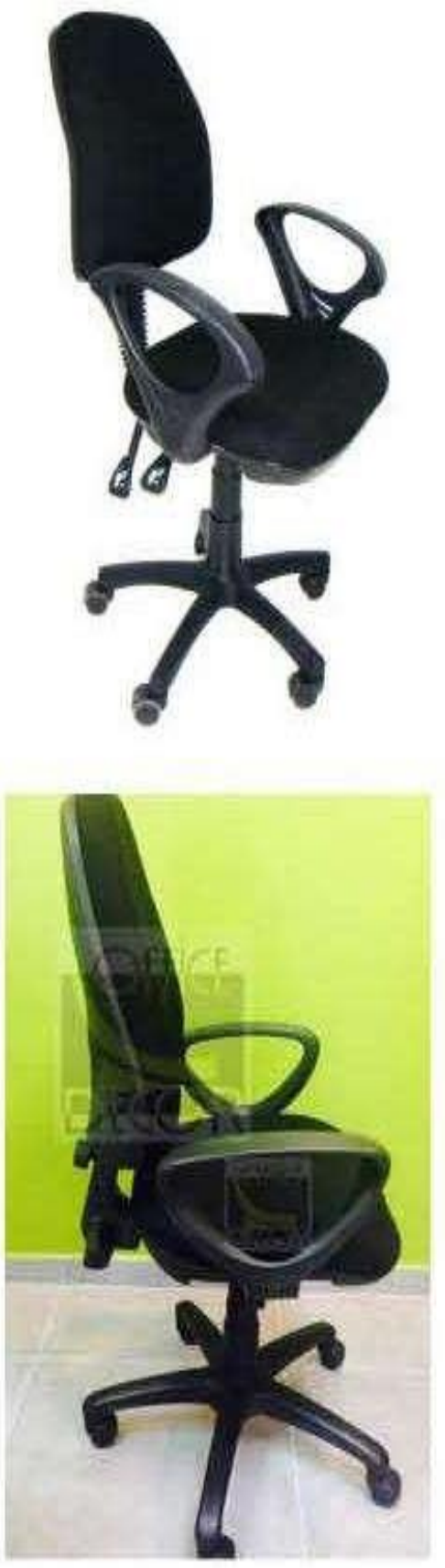

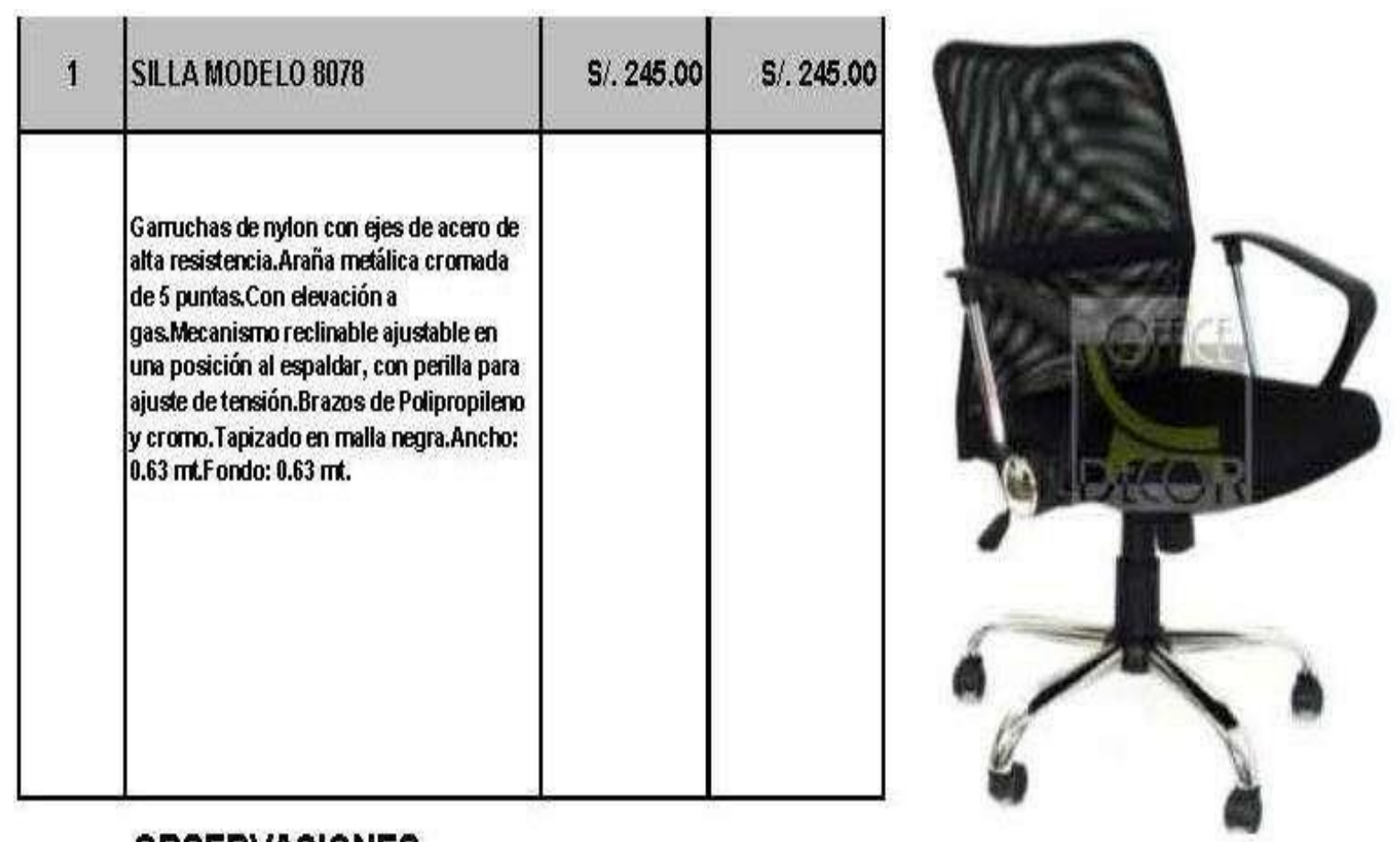

\section{OBSERVACIONES}

PRECIOS INC 18\% IGV

INCLUYE TRANSPORTE A SUS OFICINAS DENTRO DE LIMA METROPOLITANA A PARTR DE S/. 1500,00 SOLES. *SOLO EMERLADO CON PLASTICO*

\section{FORMA DE PAGO:}

PAG0 50\% ADELANTO Y SALDO CONTRA ENTREGA

Entrega de 3 a 5 dias utiles en sus oficinas (por las cantidades), apartir del día en que se recibe la OC y el adelanto. Validez de la cotizacion: Solo 5 dias ( por el incremento de variacion de dólar)

NUMERO DE CTA: 286-3000563914

MONEDA: Soles

CCl: 003-286-003000563914-28

BANCO: BANCO INTERBANKEN SOLES

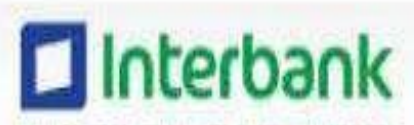

El tiempo yale más que el dinero

\section{CONDICIONES DE VENTA:}

Toda fecha de entrega se incia a partir de haber cumplido con:

1) Recepcion de la Orden de Compra

2) Conformidad del abono en cuenta o cheque por Adelanto correspondiente de ser el caso.

3) Definicion de colores de mobiliario ( definicion de color de melamine y bases metalicas LAF)

Alex andra Quinteros Erazo

RPC $\quad 982509926$

alexandra.quinteros@officedecor.com.pe

FIJ0 5606461

comporacion office Decer sac 


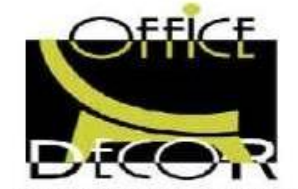

Www.officedecor.com.pe RUC: 20524869986
TuEspacio; Tu oficina CORPORACION OFFICE DECOR:

Av. Higuereta $N^{\circ} 414$ Surco

Telef. 560-6461

ventas@officedecor.com.pe RPC: +51 1982509926 RPM: 980-1

Surco, 10 de Noviembre del 2017

Atención: Srta. Jimenez

Presente-

Estimados señores:

Mediante la preserte tenemos el acrado de dirigimos a Ustedes,

en atención a su solicitud de Catizacoón, para presentarte los

precios de nuestros siguientes productos.

\begin{tabular}{|c|c|c|c|}
\hline CANT & Descripcion & р.имт & P. TOTAL \\
\hline 1 & MESA DE REUNIONES MODELO WHITE (UN SOLO COLOR) & S. $1,400.00$ & 5.. $1,400.00$ \\
\hline & 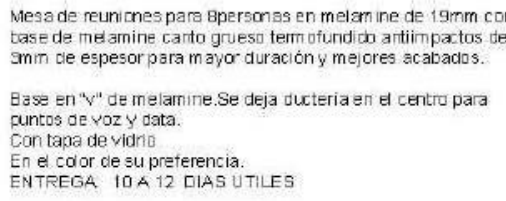 & & \\
\hline
\end{tabular}

\begin{tabular}{|c|c|c|c|}
\hline 8 & SILLA HODEL 08078 (SALA DE REUNIONES) & S/. 233.05 & S/. $1,864.40$ \\
\hline & \multicolumn{3}{|c|}{$\begin{array}{l}\text { Garruchas de rylon con ejes de acero de alta resistencia.Araŕa } \\
\text { metalica cromada de } 5 \text { puntas Con elevación a gas Mecarismo } \\
\text { recli nable ajustable en una posición al espal dar, con perilla para } \\
\text { aj uste de tensión Brazos de Polipropileno y cromo. Tapizado en } \\
\text { malla negra Ancho. } 0.63 \text { mt. Fondo. } 0.63 \mathrm{mt} \text {. }\end{array}$} \\
\hline & & SUB-TOTAL & Sl. $3,264.40$ \\
\hline & & IGV & Si. 587.59 \\
\hline & & TOTAL & S1. $3,851.99$ \\
\hline
\end{tabular}

\begin{tabular}{|l|l|}
\hline Si $1,926.00$ & ADELANTO $50 \%$ \\
\hline S $/ 1,540.80$ & SALDO $50 \%$ CONTRA ENTREGA \\
\hline
\end{tabular}




\section{OBSERVACIONES}

PRECIOS INCLUYEN IGV 18\% FINAL TOTAL

INCLUYE TRANSPORTE A SUS OFICINAS DENTRO DE LIMA METROPOLITANA
"SOLO EMBALADO CON PLASTICO*

GARANTIA 3 AÑOS MUEBLES

PRECIOS INCLUYEN MOVILIDAD + INSTALACION

FORMA DE PAGO:

ADELANTO 50\% Y SALDO 50\% CONTARRENTREGA.

Entrega: 7 a 10 dias Tema de mobiliario, para sillas de 3 a 5 dias

Validez delacotizacion: Sole 5 dias.

NUMERO DE CTA: 286-3000563914

MONEDA: Soles

CCl: 003-286-003000563914-28

BANCO: BANCO INTERBANKEN SOLFS

NUMERO DE CTA :194-2061381-0-29

MONEDA: Soles

CCl: 02-194-002061381029- 98

BANCO: BANCO DE CREDITO DEL PERU

\section{CONDICIONES DE VENTA:}

Toda fecha de entrega se incia a partir de haber cumplido con:

1) Recepcion de la Orden de Compra.

2) Conformidad del abono en cuenta o cheque por Adelanto correspondiente de ser el caso.

3) Definicion de colores de mobiliario (definicion de calor de melamine y bases metalicas LAF)

4) Visita en caso de ser necesario

ALEXANDRA QUINTEROS ERAZO

alexandra.quinteros@officedecor.com.pe Corporacion Office Decor Sac
RPC $\quad 982509926$

FIJO 267-8047

ventascoofficedecor.com.pe

\footnotetext{
PLESA

PLAN ENTERPRISE S.A.

articulos de seguridad industi

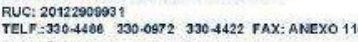

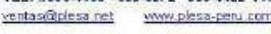

CLIENTE : Grisclle Jimenez

R.u.c.

DIRECCIÓN

ATENCION

Aimendros no, 221 La Molin

guiselle@kristal.group

TELÉPONO

981044382
}

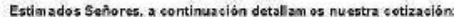

\begin{tabular}{|c|c|c|c|c|c|c|}
\hline COONKO PL.ESA & CANTENaD & LME. & ARTKELLO & CARACIERISTICKS & 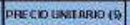 & DHEC 1 I OTAL (S) \\
\hline & & & & & no wourereice & Howna we uav \\
\hline & & & & & & \\
\hline & 1 & PZa & MAhDil OEPYCCC & 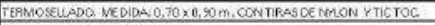 & & \\
\hline & & & & COLOR ANQRANHADO-EN STOCK & 6,23 & \\
\hline & - & (7) & 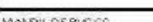 & 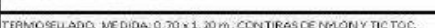 & - & \\
\hline & & & & 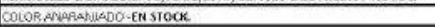 & 7,50 & \\
\hline & & & & & & \\
\hline & 1 & rea & MaroliLOEPCCCO & 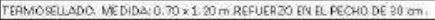 & & \\
\hline & & & & 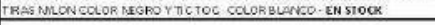 & 8,56 & \\
\hline & 1 & $P A R$ & GUSNIE PROTEXC $3524^{\prime \prime}$ & 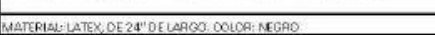 & & \\
\hline & & & & 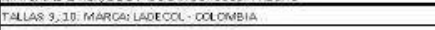 & 8,37 & \\
\hline & & & & ( & SUITOTOI & 5 \\
\hline & & & & & $16 \mathrm{~V}$ & 5 \\
\hline & & & & & TOTAL & s \\
\hline
\end{tabular}

La presente cotización esta sujeta a la aprobacion final de PLESA

OS PRECIOS ESTAN EXPRESADOS EN DOLARES AMERICANOS. NO INCLUYEN I.G.V

Valieez de lo oferta

Plisev de estregs

Lagar de entrega

Cansición de pas

Farma de Pagpo

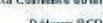

Dolares $8 \mathrm{cc}$

Tdiss

For Coordina

Agencia (napa destinol)/ Racogo en PLEA

Depositio en cuanta comerce a rambre de PLAN ENTERPRISE S.A 


\section{Innovación}

\section{PROFORMA}

\begin{tabular}{lll|}
\hline Cliente: Guiselle Jimenez & Teléfono: & 981044382 \\
Direcciónchincha & Responsable: & \\
Fecha: $22 / 11 / 2017$ & & \\
\hline
\end{tabular}

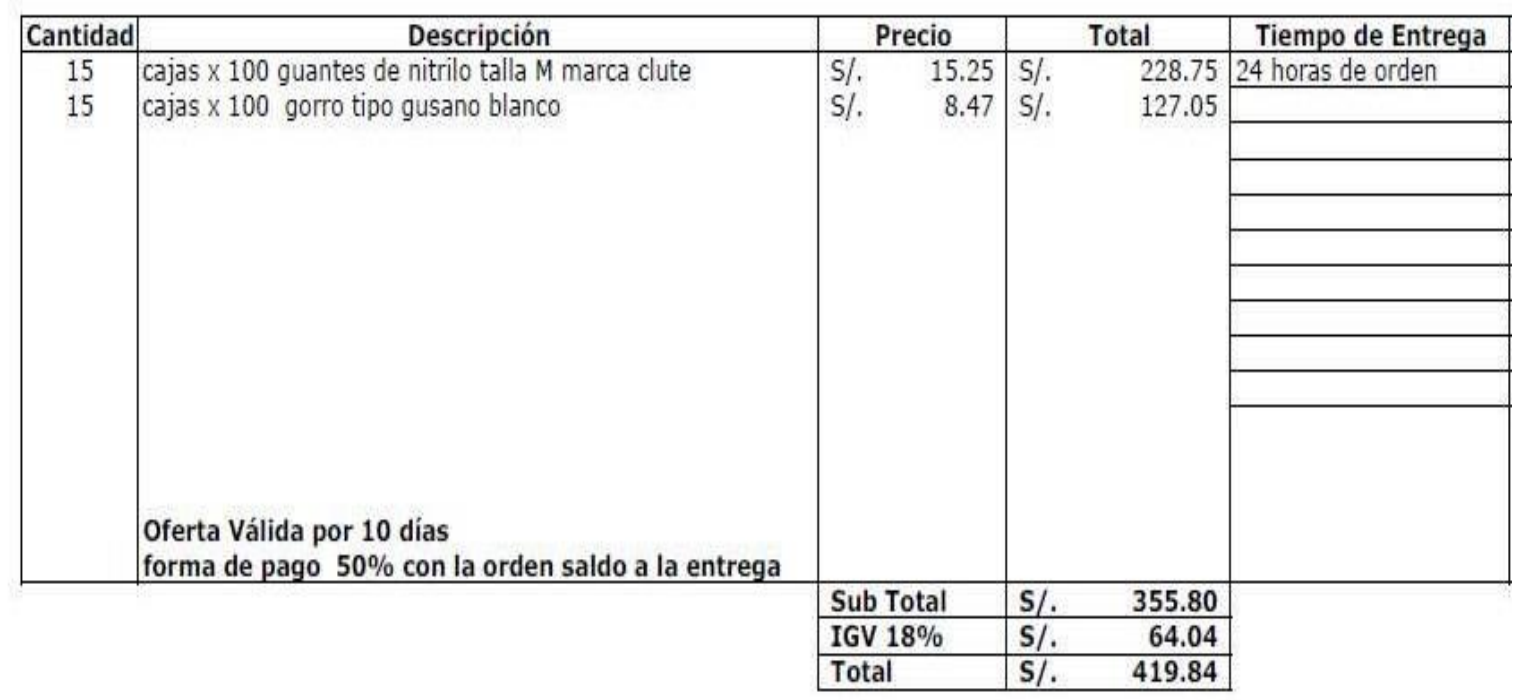

Nota: Los precios $\underline{\text { NO }}$ incluyen el IGV 


\section{evom}

S.R. C.

La Victoria, 22 de noviembre del 2017.

Sr::

Guiselle Jimenez

Ref: Cotización Productos

Presente

\section{Ref:: COTIZACIÓN BOTAS TERMICAS -20 C Y MANGAS DE POLIURETANO} TERMICO

De acuerdo a lo conversado, nos es grato ofrecerles nuestra mejor cotización por las botas térmicas de marca Dunlop (Holanda) y las mangas de poliuretano termoplástico certificado para industria de alimentos (Alemania).

\begin{tabular}{|c|c|l|c|c|c|r|}
\hline ITEM & CODIGO & \multicolumn{1}{|c|}{ DESCRIPCIÓN } & COLOR & $\begin{array}{c}\text { P.U. } \\
\text { (SOLES) }\end{array}$ & CANT & $\begin{array}{c}\text { TOTAL } \\
\text { (SOLES) }\end{array}$ \\
\hline $\mathbf{1}$ & 171 BV-39 & $\begin{array}{l}\text { BOTA DE SEGURIDAD IND. PUNTA DE } \\
\text { ACERO C/ BLANCO }\end{array}$ & blanco & 50.46 & $\mathbf{1}$ & 50.46 \\
\hline $\mathbf{2}$ & SCH1563 & MANGAS DE PROTECCION C/AZUL & azul & $\mathbf{3 1 . 5 4}$ & $\mathbf{1}$ & 31.54 \\
\hline $\mathbf{3}$ & SCH1562 & MANGAS DE PROTECCION C/ BLANCO & blanco & $\mathbf{2 1 . 1 9}$ & $\mathbf{1}$ & $\mathbf{2 1 . 1 9}$ \\
\hline
\end{tabular}

Tiempo de vida útil de la MANGA DE POLIURETANO es de 06 meses aproximadamente.

Los precios no incluyen el I.G.V.

A la espera de sus comentarios, nos despedimos.

Atentamente,

Luis Ñacari I.

FBK PERU SAC

RPC: 983481939

Fijo: $476-0101$

E-mail: ventas9@tbkperu.com

\section{DEVOM SAC}

RUC: 20537480077 - TEL/FAX: (511) 224-3668

CTA. Cte. Bco. De Crédito (SOLES): 191-1866053-0-19

\section{Calle Juan José Mostajo 241 Interior 104 Urb. Santa Catalina, La Victoria} Lima 13 -Teléfono Oficina: 224-3669 E-mail: ventas9@fbkperu.com 


\section{TEMPANO S.A.C.}

St (es) ; Guiselle Jimenez

Direcoên :

Aterición :

Presente :-

Le(s) hacomos lloga Nuestra Cotización de acuardo alo solictado

\begin{tabular}{|c|c|c|c|c|c|}
\hline IIEM & DESARIPCION & uner & CANT & $\begin{array}{l}\text { DUNIT } \\
\text { (S/) }\end{array}$ & $\begin{array}{l}\text { 口тоा } \\
\text { (s/.) }\end{array}$ \\
\hline 01 & GLANTESDE EXAVENPGEMDMTALAMO X LOOLD, (CR & Cl & 100 & 14.850 & 1485 \\
\hline 02 & 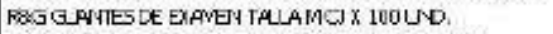 & UN: & 120 & 11.539 & \multirow[t]{2}{*}{11.74} \\
\hline 03 & MPOCARU RS DESCAFTAELES ELANCA CAIA X 50 UNO & 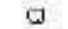 & 120 & 67797 & \\
\hline 04 & GORROS DEGCARTALLES ELANCA CAKAX LOOLND. & $\mathrm{c}$ & 100 & 8.219 & $8: 22$ \\
\hline 05 & 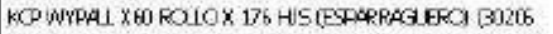 & tN. & 100 & 14,600 & $14 \$$ \\
\hline 06 & 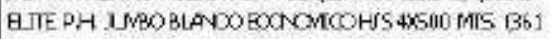 & $\rho Q$ & 100 & 33.350 & 333 \\
\hline 07 & 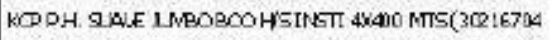 & $D Q$ & 100 & 26.312 & 26.7 \\
\hline \multirow[t]{5}{*}{ ws } & 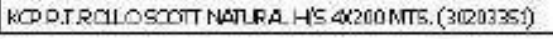 & $\mathrm{DQ}$ & 100 & 54.49 & 54.50 \\
\hline & & & & 98-TOIAL & 168.5 \\
\hline & & & & $19.2(18 \times)$ & 30,4 \\
\hline & & & & PERC $[5]$, & 0.00 \\
\hline & & & & TOTAL $(\$)$ & 199.3 \\
\hline
\end{tabular}

\section{CONDICIONES}

FOEMA DE PAGO

- Contado Efectivo

PLAZODEENTREGA.

VALIDEZ DE CFRTS

Sin ctro particular y a la apera de sus grdas órdenes quedamos de ustedes.

arentamente,

JERSSY MEVESES SANDOVIOL

930567232 
PIATTO PRONTO SAC

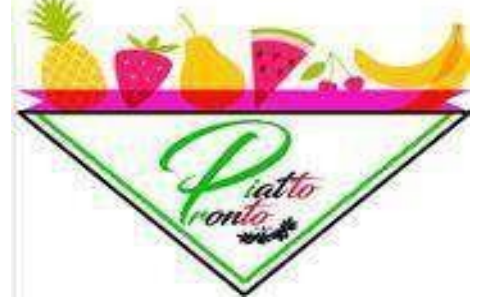

DIRECCION: JR. JORGE CHAVEZ, 424, BREÑA, LIMA CONTACTO: 934758918 / 973515267

E-MAIL:piattopronto2015@gmail.com RUC: 20602472389

Ventas al por Mayor y Menor de Frutas frescas, al granel y delicatesses

\begin{tabular}{llr|}
\hline $\begin{array}{l}\text { Cliente: } \\
\text { Dirección : }\end{array}$ & CARLOS BR ICEÑO & \\
Ciudad: & LIMA & \\
Teléfonos: & & Provin cia: \\
\hline
\end{tabular}

Descripción

Fresa selecta

Piña Golden

Maracuyá
Cant.

$1 \mathrm{~kg}$

$1 \mathrm{~kg}$

$1 \mathrm{~kg}$
Codi go:

Soli ci tud :

Atenci ón:
Sub Total S/ 9,00

Total IGV $18 \% \quad 1,26$

Total S/

$\mathbf{9 , 2 6}$ 
N.V. $003-2017$.

Propuesta de Productos de Estación.

Lima, 20 de noviembre del 2017.

Señor:

CARLOS ALBERTO BRICEÑO DIAZ

Presente.-

De nuestra consideración:

Pormediodelapresentelehacemosllegarlapropuestadenuestralíneadeproductosdeest acióna granel.

\section{ALCANCE.}

Nuestro trabajo iniciaría a partir de la aceptación de la presente propuesta.

\section{LÍNEA DE PRODUCTOS.}

] Fresasfrescascultivotradicionalporkilo.]

Frambuesa fresca seleccionada porkilo. $]$

Guinda nacional seleccionada por kilo. $]$

Membrillo criollo por kilo

] Maíz morado

Entregable:

] La presente línea de productos se entrega debidamente acondicionado para la conservación del frutofresco.

\section{LISTA DE PRECIOS:}

- FresasfrescascultivotradicionalporkiloS/2.50

- FrambuesafrescaseleccionadaporkiloS/40.00

- Guinda nacional seleccionada por kilo S/ 20.00

- Membrillo criollo por kilo S/ 4.00

- $\quad$ Maíz morado por kilo S/ 1.40 
DATOS:

] ElprimerdespachoporDeliverytendráuncostodeS/0.00;pordespachosposterioresse cargaráelmontodeDeliverypreviaevaluación.

\section{HORARIOS DE DESPACHOS:}

] CHANCAY -HUARAL.

De lunes a jueves de 10:00 am hasta las 06:00 pm.

] LIMA.

Los viernes de 02:00 pm hasta las 09:00 pm; y los sábados de 08:00 am hasta las 04:00 pm.

(Repartosenlossiguientesdistritos:SanMiguel,SanIsidro,Miraflores,SantiagodeSurco,S anBorja, LaMolina).

Agradecemos por anticipado la oportunidad que nos brinda de ofrecer nuestra línea de productos. Muy atentamente,

Jerussa Obando

Gerente General 